\title{
Síntesis de materiales reticulares metal- orgánicos para su aplicación como catalizadores heterogéneos con interés industrial y medioambiental.
}

TESIS DOCTORAL

Presentada por:

Andrea Santiago Portillo

Dirigida por:

Prof. Mercedes Álvaro Rodríguez

Dr. Sergio Navalón Oltra

Valencia, noviembre 2018 

Dạ MERCEDES ÁLVARO RODRÍGUEZ, profesora catedrática de la Universitat Politècnica de València y D. SERGIO NAVALÓN OLTRA, profesor titular de la Universitat Politècnica de València.

CERTIFICAN, que la presente tesis doctoral, titulada: "Síntesis de materiales reticulares metal-orgánicos para su aplicación como catalizadores heterogéneos con interés industrial $y$ medioambiental", ha sido desarrollada por ANDREA SANTIAGO PORTILLO, en el marco del Programa de Doctorado de Química Sostenible, bajo su dirección, en el Departamento de Química de la Universitat Politècnica de València. 

El ser humano nunca sabe de lo que es capaz hasta que lo intenta.

Charles Dickens 



\section{Agradecimientos}

Después de pasarte 5 años viviendo en el laboratorio de la universidad, que como dice mi padre, muchos días me hubiese sido más fácil dormir allí que llegar a casa para en unas horitas volver a estar allí, sólo me queda dar las gracias a todas las personas que de un modo u otro han hecho posible que esos días acaben con este buen sabor de boca.

Primero que nada, a Mercedes por confiar en mí desde el principio y darme la oportunidad de haber hecho esto posible, sus palabras de madre me han hecho falta muchas veces y siempre han estado ahí.

Y por supuesto a Sergio, por confiar siempre en mí, él es uno de los pilares de esto y aunque a veces se me olvide darle toda la importancia que debería, sabe que le estoy muy agradecida por todo. Pero también a Belén, por ayudarme siempre en todo lo posible y por qué tiene siempre palabras de ánimo y apoyo para darte, eres un amor.

También agradecer principalmente a Herme, al que admiro muchísimo, aún no entiendo como una persona tan inteligente puede expresarse de una forma tan clara. Gracias por todo el tiempo invertido en mí. Cuando trabajas con una persona tan importante como él, hay que agradecer cada minuto que te ofrece.

Pero no me puedo olvidar de agradecer a otro gran pilar en esto, mis compañeros de laboratorio, pero sobre todo a Juan Carlos, el que ha estado siempre a mi lado en esto. Aún no me explico como pude tener tanta suerte de que estuvieras conmigo en todo momento e incluso ahora, que tú ya has acabado, sigues estando ahí. Ahora que tenemos chicas empezando esto es cuando más cuenta me doy de todo el apoyo que me has dado, porque celebras todos mis éxitos y siempre has estado ahí para levantarme de cada derrota, gracias, te mereces todo lo bueno que te pase, que debe ser mucho porque eres de las mejores personas que conozco. Guapo, sabes que eres una de las personas más importantes de mi vida, te adoro.

Pero como he dicho, también agradecer a todos mis compañeros de laboratorio y todas las personas que han pasado por el laboratorio 2.5 del departamento de química, porque siempre hemos sabido montar una familia y ayudarnos unos a otros en cada momento. Soy muy afortunada de haber estado trabajando con gente tan excepcional.

A Juan Fran, por hacerme más fáciles los días, ¡Qué bien nos lo pasábamos con tus avances en el baile y escuchando Camela! Gracias por todo lo que me has ayudado y por lo bien que nos lo hemos pasado tanto dentro como fuera del lab.

A Adri, al que adoro, por tus abrazos y por siempre tener una frase de ánimo perfecta. Ojalá hubieses estado más tiempo aquí.

A Cris máster, loca, que sabes que te adoro, gracias por aparecer por aquí y alegrarnos los días, nos has hecho mucha falta. 
A Patricio, porque en solo 3 meses nos ganaste a todos, por tratarnos tan bien en Chile, sabes que aquí siempre tendremos un lugar para ti y tu familia.

A Paco, porque te hemos visto poco, pero intensamente. Gracias por hacernos más amenas las últimas horas de las tardes con tus mil historias, porque si hay cosas que no le pueden pasar a nadie, a ti te pasan todas. Eres un grande.

A Murthy, por intentar ayudarnos en todo, gracias por contar siempre con nosotros.

A Marina, que, aunque no hayas estado en el lab, has formado parte igualmente de esta familia. Gracias por hacernos más cómodas las comidas, por estar siempre ahí y por formar parte de nuestra familia.

Y bueno, a nuestra descendencia, las chicas nuevas del lab, espero que os vaya todo genial, estoy segura de que será así. Las 3 sabéis que estaré aquí para todo lo que necesitéis. Mucho ánimo y fuerza para lo que os viene.

A María, porque temí mucho tu llegada, pero fue verte y saber que seríamos amigas y espero que sea así para siempre. No te compares con nadie, todos, a nuestro modo, somos los mejores.

A Arianna, por hacernos parte de tu familia, por estar ahí para todo y contar siempre conmigo, espero que todo lo que deseas que ocurra en un futuro te pase, sé que será así.

A Cris, que mal me caías al principio y lo que te quiero ahora. Eres muy, muy válida, en todo. Porque no sabes de lo que eres capaz hasta que lo intentas, y tú lo estas intentando todo excelentemente. Mil gracias por todo lo que has hecho por mí y por apoyarme siempre. No te pongas el listón tan alto, que ni Juan Carlos ni yo fuimos perfectos y date tiempo para disfrutar de tu alrededor.

Como no, agradecer a toda la gente del ITQ, siempre nos han tratado genial, gracias por todo el apoyo y ayuda que nos dais, tanto los compañeros (amigos) del grupo de investigación, como a los técnicos, aunque especialmente a Adelina, a la que adoro. Ojalá tener más muestras para analizar en Raman y pasarme más horas contigo, jeres la mejor!

Principalmente a mi persona, Rocío, eres de 10, una persona inmejorable en todo. Gracias por estar siempre ahí y por poder contar siempre contigo. ¡Ah! Y no te olvides que a tu boda tengo que ir, y tú a la mía.

A Amparo, Esther, Sonia, Diego y Ivan, por ayudarnos en todo y siempre con una sonrisa, gracias por perder vuestro tiempo, que sé que es muy valioso, con nosotros.

Y a todos los demás, por formar parte de esta gran familia.

Pero por supuesto agradecer también a mis amigos, por tener tanta paciencia conmigo, por entender que pasara aquí tanto tiempo y siempre que podían venir a comer conmigo y por estar ahí siempre, porque están en todo lo que hago y lo que soy. 
Y como no a mis personas, a mis padres, mis hermanas y mis sobrinas, que os amo, gracias por estar ahí en cada paso, por ayudarme en todo y más, por alegrarme la vida, todo.

Y finalmente, al amor de mi vida, llegaste casi al final del camino, pero no has hecho nada más que hacerlo todo siempre más fácil, por entenderlo siempre todo y no hacer más que facilitarlo. Porque nadie confía en mi más que tú y por cuidarme siempre. Eres el mejor hombre del mundo, parece que naciste para mí, y no podía haber encontrado a nadie mejor con quien pasar el resto de mi vida. Te amo. Siempre. 



\section{Lista de símbolos y abreviaturas}




\begin{tabular}{ll}
${ }^{\circ} \mathbf{C}$ & Grados Celsius \\
$\mathbf{2 D}$ & 2 dimensiones \\
$\boldsymbol{\theta}$ & Ángulo de difracción \\
$\boldsymbol{\lambda}$ & Longitud de onda \\
$\boldsymbol{\sigma}_{\mathbf{m}}$ & Constante de Hammett en posición meta \\
$\Delta \mathbf{E}$ & Incremento de energía \\
$\boldsymbol{\mu} \mathbf{g}$ & Microgramos \\
$\mathbf{A E}$ & Análisis elemental \\
$\mathbf{C A}$ & Centro activo \\
$\mathbf{c m}$ & Centímetro \\
$\mathbf{D B T}$ & Dibenzotiofeno \\
$\mathbf{D B T}-\mathbf{S}$ & Dibenzotiofeno sulfona \\
$\mathbf{D M F}$ & Dimetilformamida \\
$\mathbf{D M S O}$ & Dimetilsulfóxido \\
$\mathbf{E D S}$ & Espectroscopía de rayos X de energía dispersada \\
$\mathbf{E D X}$ & Análisis por dispersión de energía de rayos X \\
$\mathbf{E P R}$ & Resonancia paramagnética electrónica \\
$\mathbf{E a}$ & Energía de activación \\
$\mathbf{F T I R}$ & Espectroscopía de infrarrojo por transformada de Fourier \\
$\mathbf{G C}$ & Cromatografía de gases \\
$\mathbf{G C - M S}$ & Cromatografía de gases con espectroscopía de masas \\
$\mathbf{G H z}$ & Gigahercio \\
$\mathbf{g}$ & Gramos \\
$\mathbf{H F T}$ & Test de filtración en caliente \\
$\mathbf{H K U S T}$ & Universidad de Ciencia y Tecnología de Hong Kong \\
$\mathbf{H z}$ & Hercio \\
$\mathbf{h}$ & Horas \\
$\mathbf{I C P - A E S}$ & Espectroscopía de emisión de plasma de acoplamiento inductivo \\
$\mathbf{I R}$ & Infrarrojo \\
\hline
\end{tabular}




J Julio

kJ Kilojulio

L Litros

m Metro

MCM Material de composición móvil

MIL Material del instituto de Lavoisier

mg Miligramos

mL Mililitros

MOF Metal organic framework

NU Universidad de Northwestern

nm Nanómetros

PBN fenil tert-butilnitrona

ppm Partes por millón

RMN Resonancia magnética nuclear

ROS Especies reactivas de oxígeno

ro Velocidad de reacción inicial

SEM Microscopía electrónica de barrido

s Segundos

TBHP Tert butil hidroperóxido

TEMPO 2,2,6,6-Tetramethyl-1-piperidinyloxy

TGA Análisis de termogravimetría

TON Número de ciclos catalíticos

TPP Trifenilfosfina

UiO Universidad de Oslo

UV-Vis Ultravioleta-Visible

u.a. Unidades arbitrarias

V Voltio

W Vatio

XPS Espectroscopía electrónica de rayos X 
XRD

Difracción de rayos $\mathrm{X}$

ZIF

Zeolitic Imidazolate Framework 


\section{Índice}

Capítulo 1. Introducción . .1

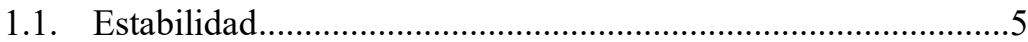

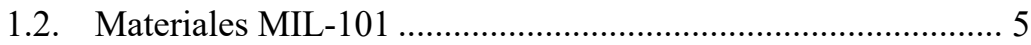

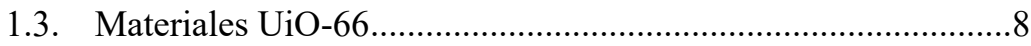

1.4. Propiedades de los materiales MOF .......................................

1.5. MOFs como catalizadores heterogéneos ...................................12

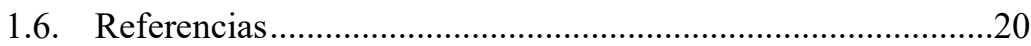

Capítulo 2. Objetivos ..................................................................................27

Capítulo 3. MIL-101 como promotor sólido reusable para la autooxidación de hidrocarburos bencílicos. ........................................31

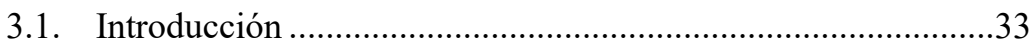

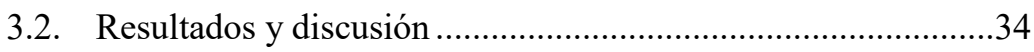

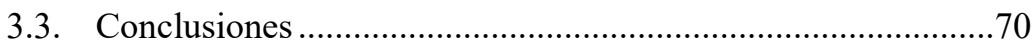

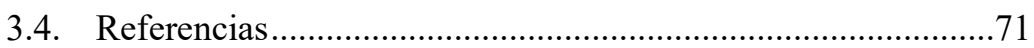

Capítulo 4. Actividad catalítica del MIL-101 para la desulfuración oxidativa de dibenzotiofenos ..................................................................73

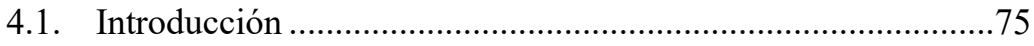

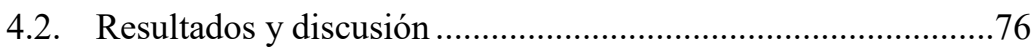

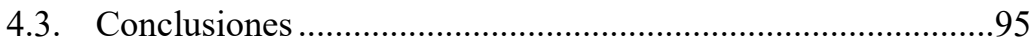

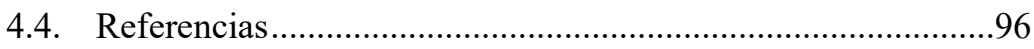


Capítulo 5. Influencia de los sustituyentes en el ligando del MIL$101(\mathrm{Cr})$ en la oxidación aeróbica de bencilaminas a iminas.........101

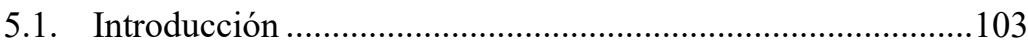

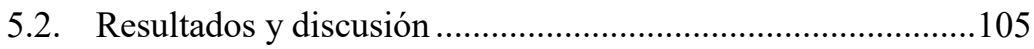

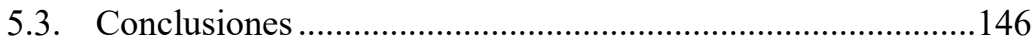

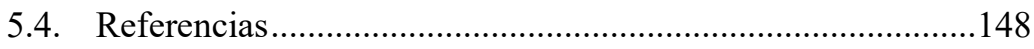

Capítulo 6. Influencia de los sustituyentes en el ligando del MIL$101(\mathrm{Cr})$ en tres reacciones característica de ácidos de Lewis.......153

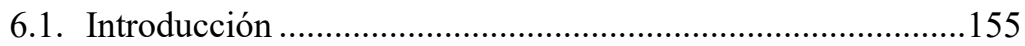

6.2. Resultados y discusión .........................................................157

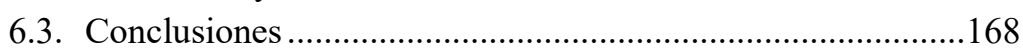

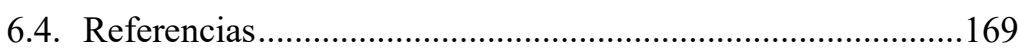

Capítulo 7. Oxidación de alquenos empleando UiO-66 con intercambio combinado de átomos de titanio y sustitución en los

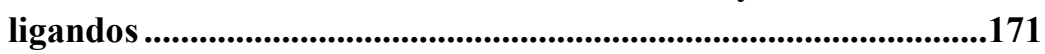

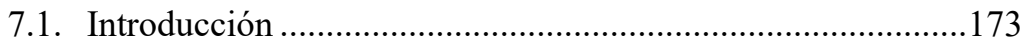

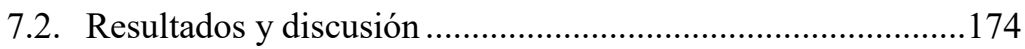

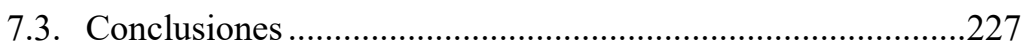

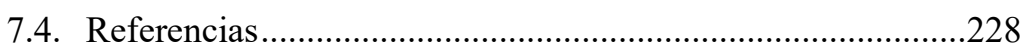

Capítulo 8. Sección experimental ........................................................233

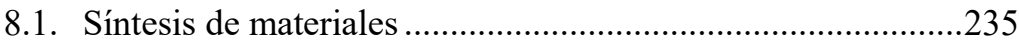

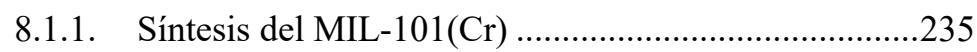

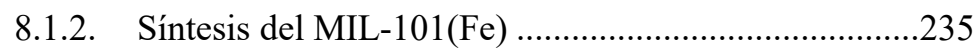

8.1.3. Síntesis de los materiales MIL-101(Cr)-X, X: $\mathrm{H}, \mathrm{NO}_{2}$,

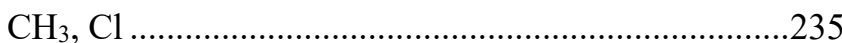

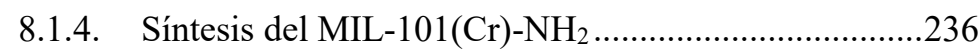

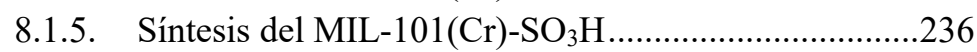

8.1.6. Síntesis de los materiales MIL-101(Cr)-X, X: $\mathrm{H}, \mathrm{NO}_{2}$,

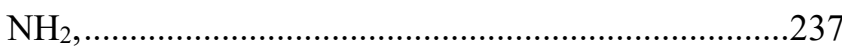

8.1.7. Intercambio post-sintético de $\mathrm{Zr}^{4+}$ por $\mathrm{Ti}^{4+}$ en la estructura

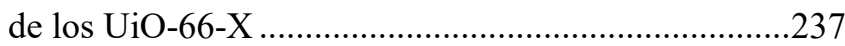

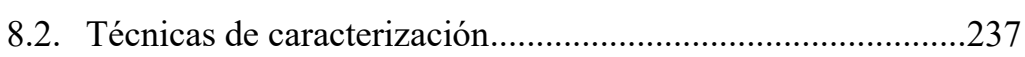

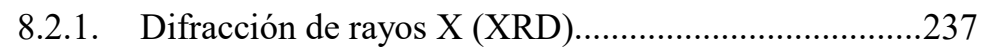


8.2.2. Espectroscopía de infrarrojo por Transformada de Fourier

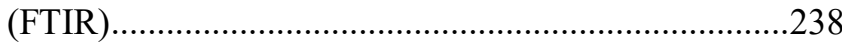

8.2.3. Análisis de termogravimetría (TGA)...........................238

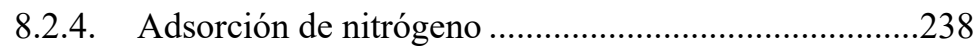

8.2.5. Espectroscopía de plasma ICP-OES ............................239

8.2.6. Espectroscopía raman..................................................239

8.2.7. Resonancia paramagnética electrónica (EPR)..............240

8.2.8. Análisis elemental por combustión (AE)......................240

8.2.9. Espectroscopía de infrarrojo por Transformada de Fourier de adsorción de $\mathrm{CO}$ (CO-FTIR)

8.2.10. Microscopía electrónica de barrido ...............................241

8.2.11. Espectrometría fotoelectrónica de rayos X (XPS) ......241

8.3. Procedimientos de reacción.....................................................242

8.3.1. Procedimiento general para la oxidación aeróbica de compuestos bencílicos ...................................................242

8.3.2. Procedimiento general para oxidación desulfurativa de dibenzotiofenos ............................................................242

8.3.3. Procedimiento de extracción líquido-líquido para eliminar completamente la sulfona del medio de reacción.........242

8.3.4. Procedimiento general para la oxidación de bencilaminas

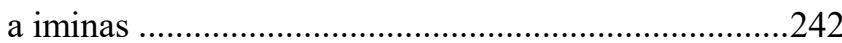

8.3.5. Procedimiento para la reacción de Prins.........................243

8.3.6. Procedimiento para la reacción de apertura de

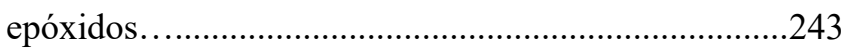

8.3.7. Procedimiento para la acetalización de benzaldehído .243

8.3.8. Procedimiento para la epoxidación de cicloalquenos..243

8.3.9. Reacciones para estudiar la energía de activación de la

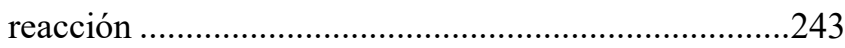

8.3.10. Experimentos de inhibición............................................244

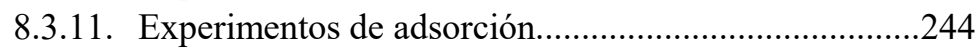

8.3.12. Experimentos de medida de lixiviado ..........................244

8.3.13. Experimentos de reusabilidad del material...................244

8.4. Procedimientos de análisis de las muestras de reacción..........245

8.4.1. Análisis de las muestras de reacción por cromatografía de

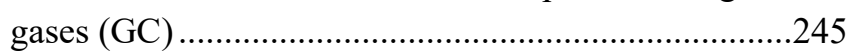

8.4.2. Análisis dela cantidad de agua oxigenada formada.....246

8.5. Referencias 
Capítulo 9. Conclusiones

Resúmenes de la tesis .................................................................253

Lista de publicaciones.......................................................259 


\section{Capítulo 1 \\ Introducción.}


Introducción. 
Capitulo 1.

Los materiales reticulares metal-orgánico (MOFs de sus siglas en inglés) se considera que fueron desarrollados casi simultáneamente por los grupos de investigación del profesor Omar Yaghi, ${ }^{1-5}$ en aquel momento en Arizona State University, el profesor Gerard Ferey, ${ }^{6-7}$ en la universidad de Versalles, y el profesor Kitagawa, ${ }^{8-9}$ de la universidad de Kyoto en Japón. Estos materiales que también han sido descritos como compuestos poliméricos de coordinación porosos (PCP de sus siglas en inglés) se caracterizan por cumplir tres condiciones simultáneamente; alta cristalinidad, porosidad y el hecho de que la red se deba a la presencia de enlaces de coordinación fuertes metal-ligando. ${ }^{10-11}$ De esta manera, quedan fuera de la consideración como MOFs otros materiales donde no existe porosidad, son amorfos o la interacción responsable de la creación de la estructura es más débil, como por ejemplo cuando está constituida por puentes de hidrógeno. ${ }^{4,11-13}$

La red cristalina de los materiales tipo MOF posee nodos donde están localizados átomos metálicos o agregados de unos pocos átomos metálicos con o sin átomos de oxígeno y ligandos orgánicos que mantienen la posición de los nodos metálicos. ${ }^{1,4,11}$ Estos ligandos orgánicos se caracterizan por presentar una estructura rígida con dos o más posiciones de coordinación (bi o multipodales). Típicos ligandos orgánicos son los compuestos aromáticos mono o policíclicos que poseen sustituyentes capaces de coordinarse con metales. El sustituyente más habitual es el carboxilato que interacciona con los átomos metálicos mediante enlaces de coordinación y además por interacción electrostática fuerte anión-catión. ${ }^{4,13-16}$ Estos grupos carboxilato pueden interaccionar con un átomo metálico o, más habitualmente, con dos del mismo nodo o incluso de diferentes nodos. Otros átomos donadores que forman parte de ligandos orgánicos son átomos básicos de nitrógeno como el imidazol y benzimidazol y átomos de fósforo. Se han descrito materiales MOFs de prácticamente todos los metales tri y tetrapositivos, lo que incluye todos los metales de transición y tierras raras, así como metales de los grupos principales 3a, 4a y 5 a tales como el aluminio, galio, indio, estaño, etc. ${ }^{13,16-18}$

La figura 1.1 ilustra los dos componentes que constituyen el MOF y el concepto en el que se basan estos materiales. 


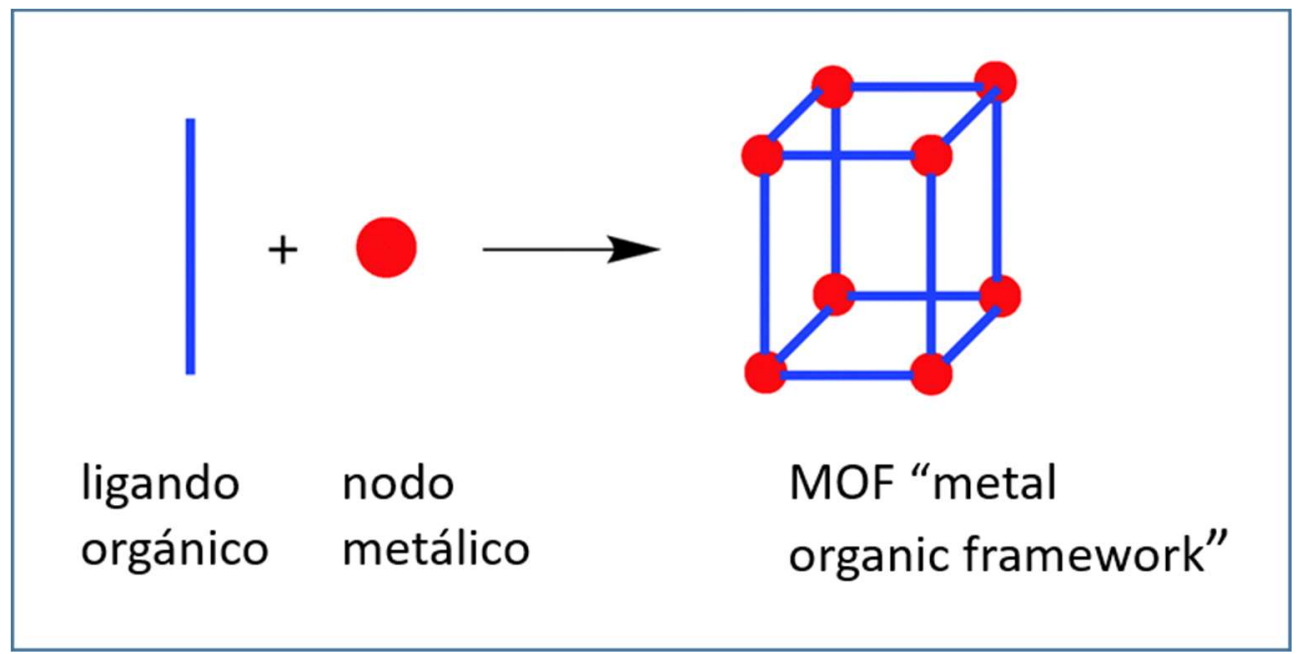

Figura 1.1. Esquema representativo de un MOF y de sus elementos constitutivos.

Entre las características estructurales por las que los MOFs han recibido gran atención se encuentran la gran área específica y la elevada porosidad que estos materiales pueden presentar. Así, se han descrito varias estructuras de MOFs con áreas superiores a los $1000 \mathrm{~m}^{2} \mathrm{~g}^{-1} \mathrm{e}$ incluso a los $2000 \mathrm{~m}^{2} \mathrm{~g}^{-1}$ siendo el valor más alto hasta ahora descrito el de $7140 \mathrm{~m}^{2} \mathrm{~g}^{-1}$ que corresponde al material NU-110. ${ }^{19}$ Esta elevada área superficial deriva de la estructura tan abierta que presentan estos materiales (ver figura 1.1) que da lugar a una alta porosidad y una pequeña proporción de espacio ocupada, que de acuerdo con programas de simulación, puede ser tan baja como el $20 \%$ de todo el espacio definido por la fórmula unidad. Relacionado con la alta porosidad, elevada área superficial y alta proporción de espacios vacíos, se encuentra la baja densidad reticular de los MOFs. ${ }^{4}$ Este parámetro se refiere a la masa contenida en el volumen de la celda unidad y para el caso de los MOFs, en cuanto a la densidad de red, se encuentran entre los materiales menos densos hasta ahora descritos. De hecho, comparado con otros materiales porosos tales como las zeolitas, materiales mesoporosos inorgánicos o híbridos e incluso carbones activos, los MOFs presentan las áreas superficiales específicas más elevadas hasta ahora descritas y las menores densidades reticulares. ${ }^{13,16-17,20-25}$

Uno de los hechos estructurales que han atraído gran atención en los MOFs es el elevado porcentaje metálico que contienen y el hecho de que, en alguna de estas estructuras, estos metales posean posiciones de coordinación no comprometidas con la estructura cristalina. Así, no es infrecuente que el contenido en metales de transición de los MOFs sea superior al 30\% y en algunos casos incluso superior al 50\%. Estos datos de composición contrastan con el bajo contenido en metales que se puede incorporar en otro tipo de materiales porosos o densos tales como zeolitas, MCM-41, carbones activos, etc. 
que generalmente está por debajo del $10 \% \mathrm{y}$, muy habitualmente, se encuentra en torno al $1 \%$ o próximo a este valor. ${ }^{20-25}$ La presencia de metales de transición en la estructura de los MOFs y su alto contenido hace que estos materiales sean especialmente adecuados como catalizadores, tal como se describirá en la siguiente sección, pero también adecuados para procesos de separación selectiva, como absorbentes de gases y líquidos y en propiedades optoelectrónicas..$^{26-37}$

\subsection{Estabilidad}

Puesto que la estructura de los MOFs, tal como se ha definido en la sección anterior, se basa en enlaces de coordinación metal-ligando, que a la vez puede tener contribuciones electroestáticas anión-catión, muchos de los MOFs poseen estructuras estables en un amplio rango de condiciones y temperaturas. ${ }^{38-45}$

Como regla general, la estabilidad de los MOFs aumenta con la carga de los nodos catiónicos y por ello los MOFs que presentan mayor estabilidad corresponden a estructuras que contienen metales tri y tetrapositivos, siendo considerablemente más lábiles las estructuras donde los cationes son dipositivos tales como los MOFs descritos para los metales $\mathrm{Cu}^{2+}$ (HKUST-1) o $\mathrm{Zn}^{2+}$ (MOF-5 y ZIF-8). Puesto que estos MOFs de cationes divalentes se encuentran entre los primeros MOFs descritos en la literatura y han sido ampliamente estudiados, existe una creencia general de que los MOFs son materiales sumamente lábiles y de una baja estabilidad frente a la temperatura y a agentes quími$\cos ^{1,38}$ Así, por ejemplo, se sabe que la estructura del MOF-5 cambia con la exposición prolongada de este material a la humedad, incluso a temperatura ambiente, transformándose en otro material, también cristalino, que es denominado MOF-5 ${ }^{\prime} \cdot{ }^{46-48}$ De la misma manera, el MOF de cobre, HKUST-1, no es estable cuando este material se suspende en disoluciones que contienen aminas, tioles $\mathrm{u}$ otros agentes complejantes del ion $\mathrm{Cu}^{2+}{ }^{28}$

Sin embargo, en contraste de esta creencia general, se han descrito materiales tipo MOFs que son extremadamente estables frente a tratamientos físicos o químicos. Entre ellos se encuentran los materiales MOFs que van a ser objeto de estudio en la presente tesis doctoral y cuya estructura cristalina y propiedades se describe a continuación. ${ }^{38,49-}$ 53

\subsection{Materiales MIL-101}

La mayoría de estructuras de MOFs se denotan por un código de tres letras seguidas de números, indicándose a veces la naturaleza del centro metálico. Un ejemplo de esta nomenclatura son los materiales MIL-XXX, donde las siglas MIL se refieren a Materiales del Instituto Lavoisier de sus siglas en francés. Entre estos materiales MIL-XXX, los que han resultado ser más estables son los MIL-101. ${ }^{54-55}$ En estos materiales los nodos están constituidos por tres iones metálicos trivalentes unidos a un átomo central de oxígeno. Ejemplos de estos nodos son los que derivan del $\mathrm{Cr}^{3+}\left(\mathrm{Cr}_{3}-\mu_{3} \mathrm{O}\right)^{7+}$ y los de $\mathrm{Fe}^{3+}$ 
$\left(\mathrm{Fe}_{3}-\mu_{3} \mathrm{O}\right)^{7+}$. El ligando orgánico de estos materiales MIL-101 es el di anión tereftalato. Fórmulas unidades para este material MIL-101 serían $\mathrm{Cr}_{3} \mathrm{~F}\left(\mathrm{H}_{2} \mathrm{O}\right)_{2} \mathrm{O}\left[\left(\mathrm{O}_{2} \mathrm{C}\right)-\mathrm{C}_{6} \mathrm{H}_{4-}\right.$ $\left.\left(\mathrm{CO}_{2}\right)\right]_{3}$ y $\mathrm{Fe}_{3} \mathrm{Cl}\left(\mathrm{H}_{2} \mathrm{O}\right)_{2} \mathrm{O}\left[\left(\mathrm{O}_{2} \mathrm{C}\right)-\mathrm{C}_{6} \mathrm{H}_{4}-\left(\mathrm{CO}_{2}\right)\right]_{3}$ donde se indica la composición de los nodos y la proporción entre estos nodos y los ligandos orgánicos. Cada uno de los nodos $\left(\mathrm{M}_{3}-\mu_{3} \mathrm{O}\right)^{7+}$ se encuentra coordinado con seis ligandos BTC donde los dos átomos del grupo carboxilato se unen a iones metálicos contiguos y a su vez, cada ion metálico se encuentra formando un octaedro donde las cuatro posiciones están ocupadas por dos ligandos BTC diferentes. La quinta es el átomo de oxígeno compartido con los otros tres iones metálicos y la sexta es bien una molécula de disolvente (DMF o agua) o bien una de cada tres posiciones es un anión para compensar la carga del nodo. Este anión puede ser un haluro, típicamente fluoruro o cloruro, pero también puede ser un ion hidróxido. Alrededor de los nodos se encuentran seis ligandos tereftalato (dos por cada átomo metálico tripositivo) definiendo una estructura con poros y ventanas de $1.2 \mathrm{~nm}$ y $1.6 \mathrm{~nm}$ y cajas más amplias de $2.9 \mathrm{~nm}$ y $3.4 \mathrm{~nm}$. La figura 1.2 muestra la estructura de este material MIL-101. ${ }^{49-52}$ 


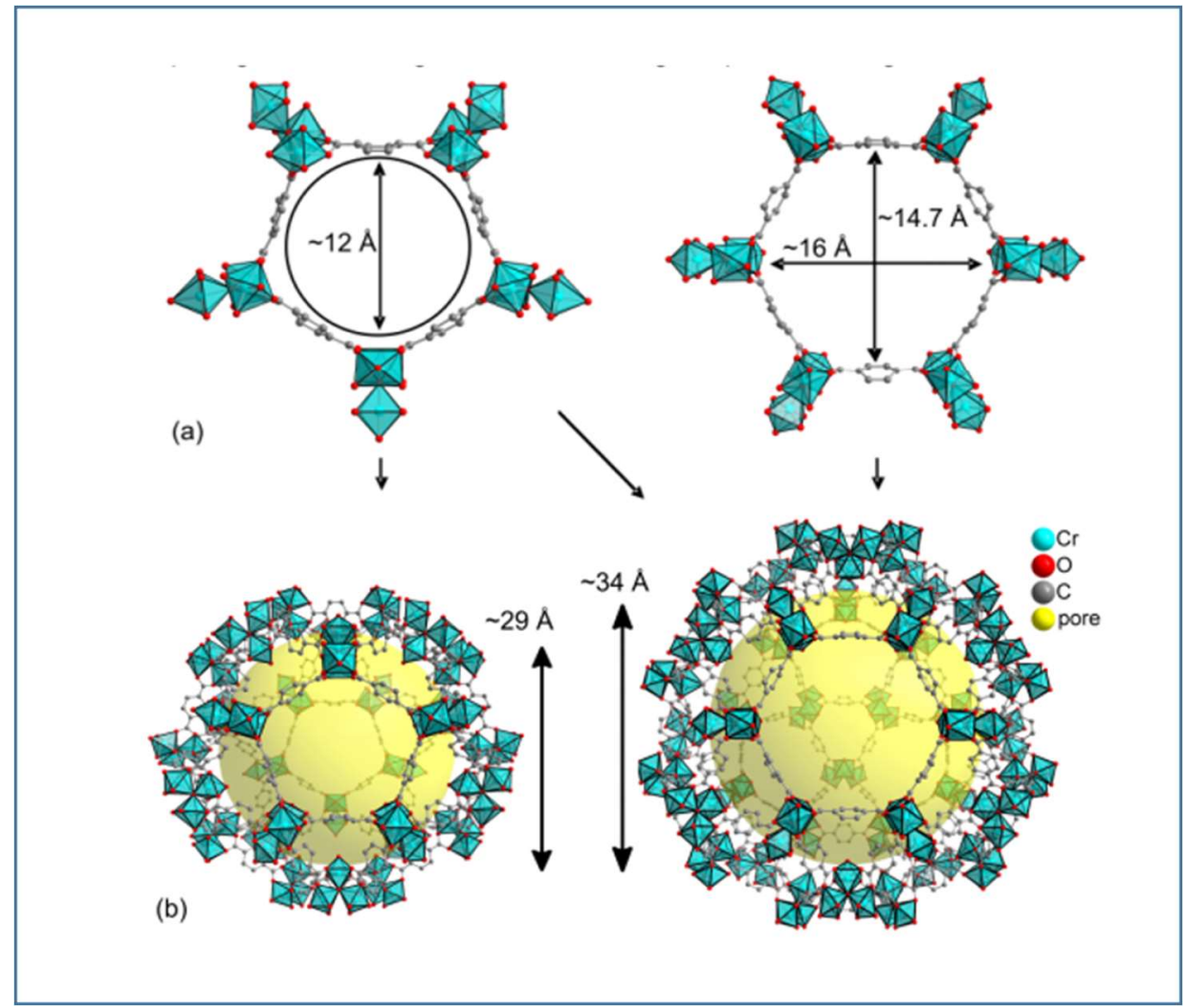

Figura 1.2. Estructura del MIL-101(Cr) donde se indican las aperturas de los poros de cinco y seis nodos (a) y se ilustra la geometría de las cajas correspondientes a las ventanas (b).

La estabilidad térmica del MIL-101 es notable, pudiéndose calentar en el caso del MIL-101(Cr) a temperaturas próximas a los $300^{\circ} \mathrm{C}$ sin que ocurra ningún cambio. Un fenómeno observado, pero no completamente comprendido, es el comportamiento térmico del material MIL-101(Fe) el cual por calentamiento a temperaturas superiores a $200{ }^{\circ} \mathrm{C}$ sufre una reducción del $\mathrm{Fe}^{3+}$ a Fe ${ }^{2+}$ sin que cambie la estructura del material. Esta reducción térmica es reversible, produciéndose la reoxidación cuando se disminuye la temperatura. El cambio $\mathrm{Fe}^{3+}$ a $\mathrm{Fe}^{2+}$ ha sido demostrado por una combinación de diferentes técnicas espectroscopias, incluyendo espectroscopia Mössbauer, espectros de EPR y espectroscopia vibracional de infrarrojo. ${ }^{56}$

El material MIL-101 es también estable frente a un gran número de disolventes orgánicos, reactivos químicos y rango de $\mathrm{pH}$. En general, valores extremos de $\mathrm{pH}$ en disolución acuosa producen la ruptura de la estructura de los MOFs debido bien a la protonación de los grupos carboxilato, o de los ligandos en general, a valores de $\mathrm{pH}$ 
ácidos, o bien a la transformación de los nodos metálicos en hidróxidos a valores de $\mathrm{pH}$ fuertemente básicos. En el caso de los materiales MIL-101 la estabilidad frente a ácidos es notable y así es posible incluso llevar a cabo reacciones orgánicas sobre ligandos que requieren la presencia de reactivos fuertemente ácidos, sin que ello conlleve la ruptura de la estructura del material MIL-101. ${ }^{51}$ En los capítulos 5 y 6 de la presente tesis doctoral haremos amplio uso de esta propiedad del material MIL-101 para la preparación de materiales análogos con grupos sulfónicos presentes como sustituyentes en los ligandos tereftalatos. ${ }^{51,52}$ Sin embargo, la estabilidad de los materiales MIL-101 frente a bases es menor y en general, estos materiales pierden su estructura por calentamiento en suspensiones acuosas a $\mathrm{pH}$ superiores a 10.57

\subsection{Materiales UiO-66}

Otro material que será ampliamente utilizado en la presente tesis doctoral es el conocido como UiO-66. ${ }^{53} \mathrm{La}$ fórmula unidad de este material es $\mathrm{Zr}_{6} \mathrm{O}_{4}(\mathrm{OH})_{4}\left(\mathrm{C}_{8} \mathrm{H}_{4} \mathrm{O}_{4}\right)_{6}$. $\mathrm{La}$ estructura del material UiO-66 está constituida por nodos metálicos conteniendo seis átomos de $\mathrm{Zr}^{4+}$ formando un octaedro en cuyas caras se sitúa con una coordinación $\mu_{3}$ alternativamente bien un átomo de oxígeno o bien un grupo $\mathrm{OH} .{ }^{58}$ Estos nodos metálicos se encuentran coordinados a seis ligandos tereftalatos definiendo cajas de dimensiones $1.2 \mathrm{~nm}$ a las cuales se accede por aperturas de $0.75 \mathrm{~nm}$ como se observa en la figura 1.3. Una de las características principales del material UiO-66 que deriva de la presencia de $\mathrm{Zr}^{4+}$ es su alta estabilidad térmica y química. Así se ha descrito que el calentamiento a temperaturas de $400{ }^{\circ} \mathrm{C}$ no produce el colapso de la red, aunque sí hay un cierto reordenamiento, produciéndose la eliminación de un porcentaje de ligandos tereftalatos. Solo temperaturas superiores a $500{ }^{\circ} \mathrm{C}$ producen la descomposición completa de la estructura del UiO-66.

Esta temperatura de descomposición es notable y es superior a la temperatura en la que la mayoría de los catalizadores homogéneos y heterogéneos de una forma u otra sufren cambios en la estructura, como por ejemplo, crecimiento de tamaños, aglomeraciones... ${ }^{59}$ La gran porosidad característica de los MOFs y su elevada área superficial también son características del material UiO-66, habiéndose descrito áreas superficiales de $1150 \mathrm{~m}^{2} \mathrm{~g}^{-1} \mathrm{y}$ volumen de poro de $0.43 \mathrm{~cm}^{3} \mathrm{~g}^{-1} .58,60$ En este sentido, una de las características del material UiO-66 que se está poniendo de manifiesto a través de estudios recientes es la presencia de defectos estructurales los cuales influyen en la estabilidad, en el área y también en las propiedades catalíticas que se discutirán más adelante. ${ }^{53,61-63}$

En el caso del material UiO-66, se ha estudiado procedimientos de síntesis utilizando ácido trifluoacético y otros aditivos, denominados moduladores de estructura, que favorecen el crecimiento controlado del cristal y que, al final de la síntesis, producen materiales sumamente cristalinos. ${ }^{61}$ La presencia de defectos en la estructura y su extensión se puede establecer de una forma simple mediante análisis elemental, que muchas veces no coincide con el teórico, indicando que existe un exceso o defecto de ligando 
tereftalato, respecto al contenido de zirconio. Esto determina que pueden existir posiciones de coordinación alrededor de átomos de zirconio no satisfechas y que pueden tener un papel en la actividad catalítica del material. ${ }^{62,63}$

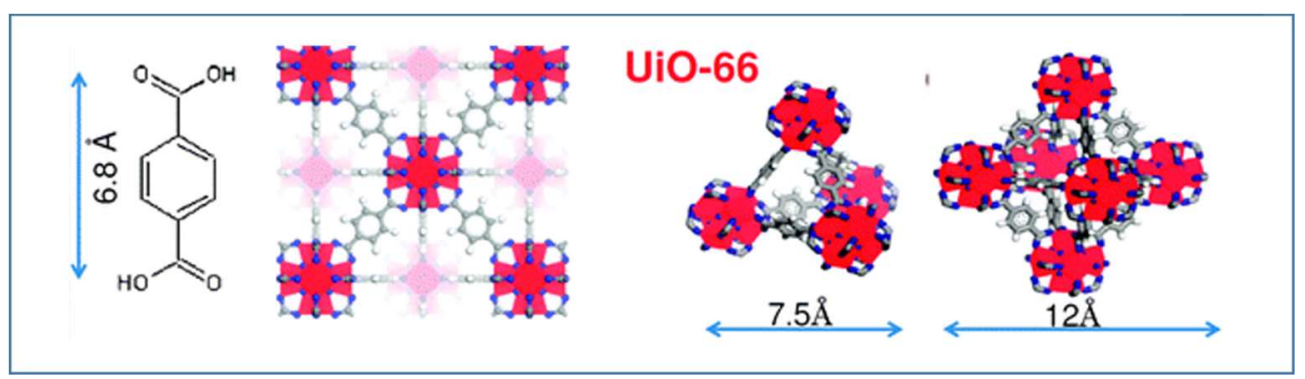

Figura 1.3. Estructura del UiO-66 donde se indican las dimensiones del tereftalato, la estructura cúbica de la celda unidad y la presencia en su estructura de supertetraedros y superoctaedros definidos por cuatro y seis nodos, respectivamente.

\subsection{Propiedades de los materiales MOF}

En las secciones anteriores ya se ha indicado que la cristalinidad, porosidad, contenido en metal, elevada área superficial y en algunos casos estabilidad, son algunas de las propiedades que caracterizan a los MOFs. Estas propiedades tienen relevancia en la mayoría de aplicaciones de estos materiales. ${ }^{1,4,13} \mathrm{La}$ elevada área superficial ha hecho que los MOFs sean materiales prometedores en procesos de adsorción de gases e incluso de hidrocarburos. ${ }^{19}$ Especial relevancia tienen los estudios de Yaghi y Ferey sobre las propiedades de adsorción de $\mathrm{H}_{2}$ y $\mathrm{CO}_{2}$ en ciertos MOFs. ${ }^{64-69}$ También los MOFs pueden adsorber de forma selectiva hidrocarburos aromáticos con 8 carbonos tales como paraxilenos, los cuales se empaquetan perfectamente en las cavidades del UiO-66. ${ }^{70}$

A parte de como adsorbentes, los MOFs también sirven para la separación de mezclas de gases. Una de las mezclas más importantes que hay que separar es el etileno y propileno en efluentes provenientes del cracking térmico de la nafta y que son procesos que consumen un porcentaje elevado de energía. ${ }^{71-73}$

Otra propiedad característica de los MOFs es la capacidad de predecir la estructura resultante en base a la consideración de la naturaleza de los nodos metálicos y de su coordinación, además de la direccionalidad de los ligandos orgánicos. Esta capacidad de diseño y predicción es única comparada con otros materiales porosos, particularmente zeolitas, donde en base a la estructura del agente director ("template") resulta prácticamente imposible determinar las dimensiones y geometría de los poros en estos materiales, incluso empleando los niveles de cálculo más avanzados. En contraste a esta situación, en una contribución seminal, Yaghi demostró que manteniendo la naturaleza del catión (por ejemplo, $\mathrm{Zn}^{2+}$ ) y la direccionalidad del ligando orgánico, pero variando la 
longitud de este, era posible preparar una serie de sólidos cristalinos tipo MOFs isoestructurales pero con dimensiones de cavidades crecientes en función de las dimensiones del ligando orgánico. La figura 1.4 ilustra el concepto en base al cual se puede predecir la estructura de los materiales MOF. En contraste, si se cambia la direccionalidad y la multipodalidad del ligando, se varia la estructura del MOF. ${ }^{74-75}$

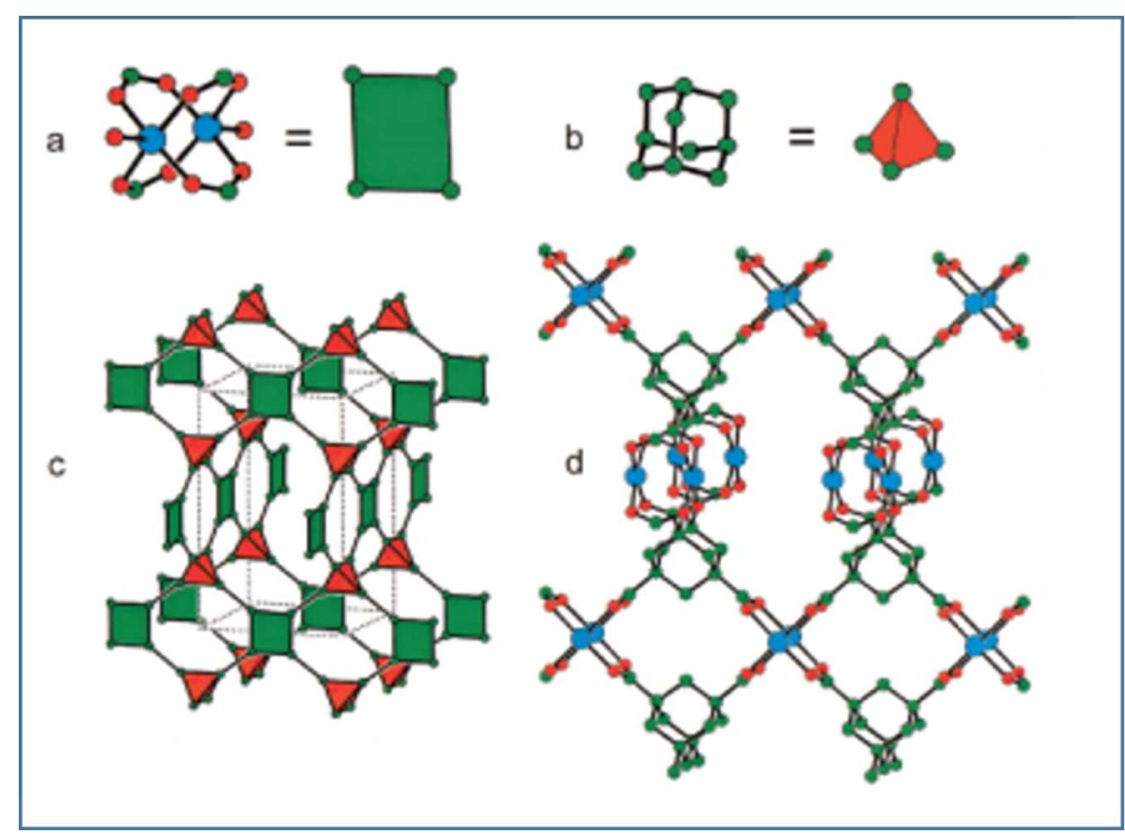

Figura 1.4. Predicción de la estructura de MOFs en base a la consideración de la dirección de coordinación de los nodos metálicos y la estructura de los ligandos orgánicos.

Otra característica de los MOFs es la reversibilidad, particularmente durante la síntesis, en la formación de enlaces metal-ligando. ${ }^{76,77}$ Esta reversibilidad determina que, especialmente en las condiciones de síntesis de temperatura y concentración de reactivos, se produzca la entrada y salida de ligandos.

Esta reversibilidad, ha dado lugar a dos líneas de investigación complementarias. La primera de ellas es la preparación de MOFs sumamente cristalinos empleando durante la síntesis ligandos monopodales que hacen cinéticamente más lento el proceso de crecimiento de la red y de esta manera mejoran la cristalinidad del material. Estos agentes se denominan en general moduladores y típicamente son ácidos carboxílicos monopodales, tales como el ácido benzoico o el ácido trifluoroacético que se ha mencionado anteriormente al describir la síntesis de materiales UiO-66 de alta cristalinidad. ${ }^{61} \mathrm{La}$ figura 
Capitulo 1 .

1.5 presenta un ejemplo de la estrategia basado en moduladores aplicado a la síntesis de MOFs. ${ }^{77}$

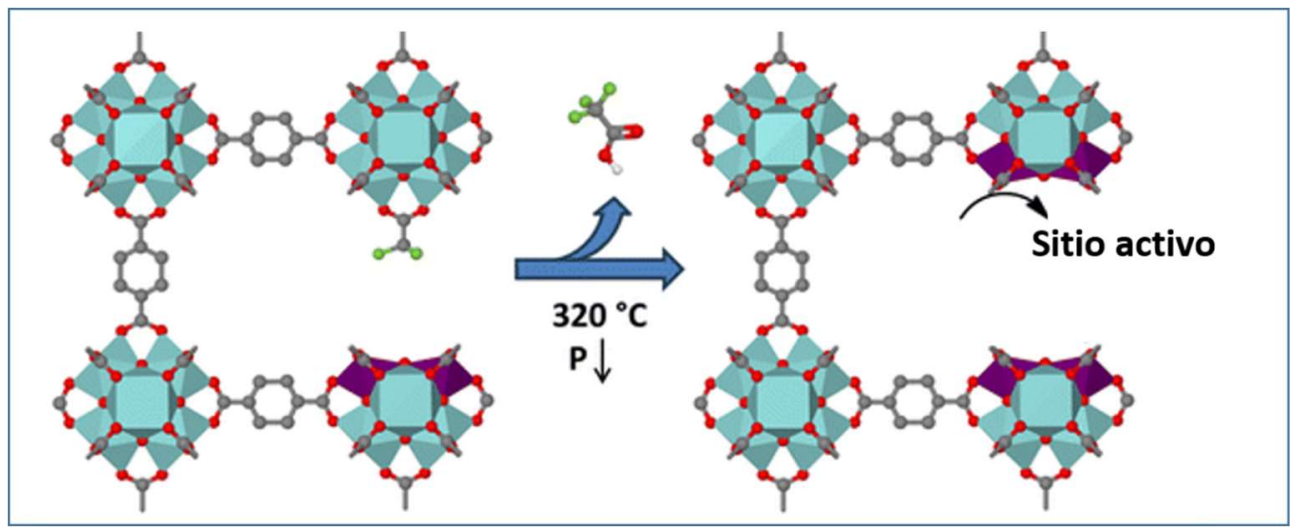

Figura 1.5. Estrategia del uso de moduladores para aumentar la actividad catalítica de los MOFs. La misma estrategia puede servir para la preparación de estructuras altamente cristalinas.

Otra aplicación de la reversibilidad del enlace metal-ligando de la cual se está haciendo uso recientemente es la posibilidad de proceder a un intercambio de ligando o metal tras la síntesis. De esta manera en el capítulo 7 se describirá que es posible intercambiar un cierto porcentaje de $\mathrm{Zr}^{4+}$ en la estructura del material UiO-66 por $\mathrm{Ti}^{4+}$ y que también se pueden intercambiar ligandos una vez el material ha sido sintetizado. ${ }^{53} \mathrm{La}$ figura 1.6 ilustra el proceso de intercambio de catión o ligando en un material MOF derivado de la reversibilidad del enlace metal-ligando. ${ }^{78-80}$ 


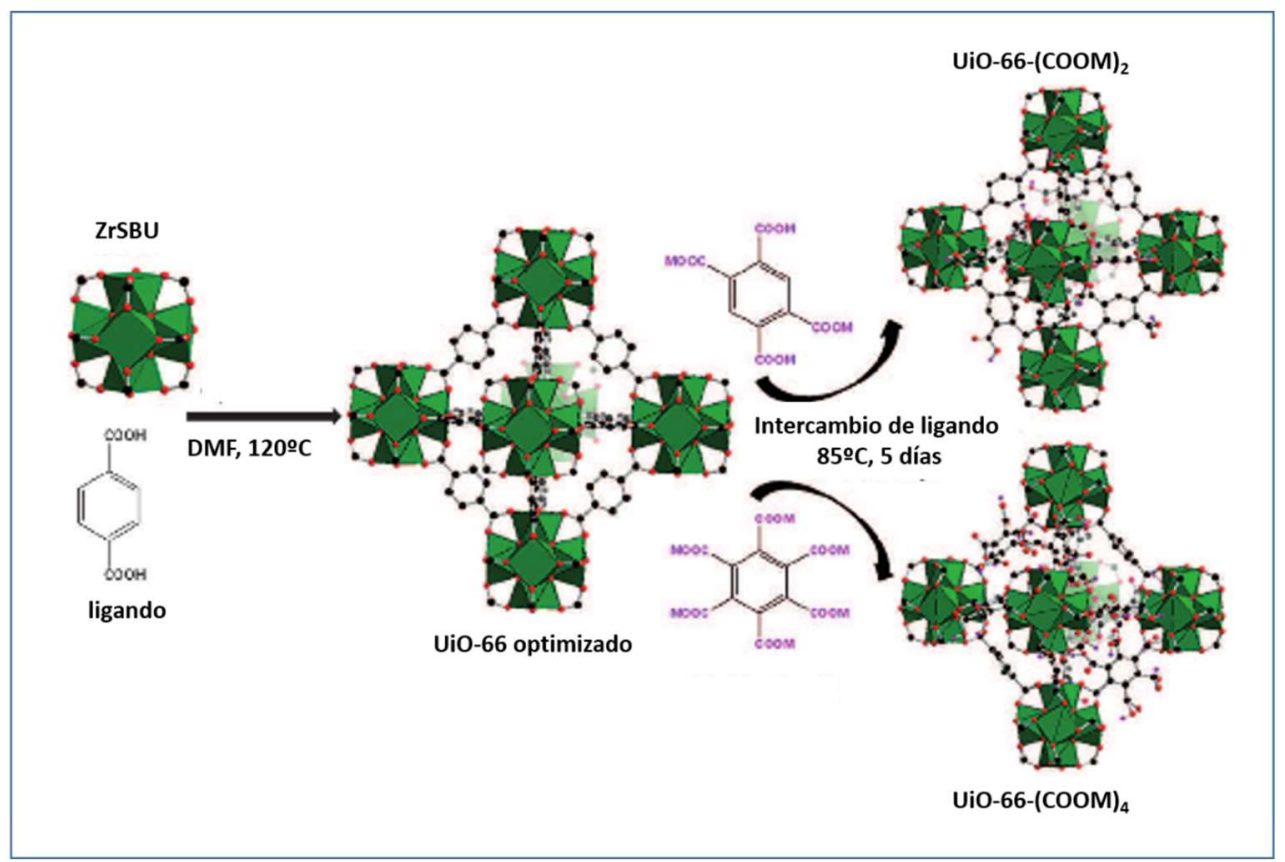

Figura 1.6. Proceso post-sintético de intercambio de ligando en el UiO-66 que permite obtener muestras de UiO-66 con mezclas de diferentes ligandos. ${ }^{80}$

Otra propiedad de los MOFs relacionada con el punto anterior es la posibilidad de preparar materiales que contengan más de un metal ("mixed metal") o más de un ligando ("mixed ligand"). Estos materiales con más de un metal o ligando en su estructura pueden obtenerse muchas veces directamente por síntesis al emplear en la preparación de los mismos, mezclas de ligandos o metales que poseen propiedades compatibles. ${ }^{81-84}$ Ejemplos de esta aproximación sería llevar a cabo la síntesis de un MOF empleando proporciones diferentes de tereftalato y tereftalatos sustituidos o, alternativamente, mezclas de cationes $\mathrm{Cr}^{3+}$ y $\mathrm{Fe}^{3+} .83$ A este respecto, conviene hacer notar que en materiales relacionados tales como las zeolitas, ha resultado sumamente difícil la introducción en la red de otros cationes diferentes del silicio y el aluminio, siendo por tanto el caso de los MOFs de una gran versatilidad respecto a la composición que pueden presentar.

\subsection{MOFs como catalizadores heterogéneos.}

El objeto de la presente tesis doctoral es avanzar en el empleo de MOFs con elevada estabilidad estructural como catalizadores heterogéneos en reacciones de oxidación aeróbica (capítulos 3, 4, 5 y 7) y aquellas que requieren ácidos de Lewis (capítulo 6). ${ }^{49-53}$ De hecho, una de las principales aplicaciones de los MOFs es su uso como catalizadores 
heterogéneos en condiciones compatibles con su estructura y, particularmente, para reacciones en fase líquida de sustratos que sean más voluminosos que las dimensiones de los poros de las zeolitas de poro grande que está en torno a $0.7 \mathrm{~nm} .{ }^{26-37,49-53}$ Existen en la literatura numerosas revisiones que describen el uso de los MOFs como catalizadores heterogéneos y en el presente capítulo de introducción solamente resumiremos los conceptos más relevantes que guardan relación con el objeto de la presente tesis doctoral. ${ }^{49-}$ 53

Como catalizadores heterogéneos, los centros activos en los MOFs pueden estar situados en una o varias de las tres posiciones indicadas en la figura 1.7. Como puede verse en ella, los centros metálicos, generalmente metales de transición, pueden tener posiciones de coordinación intercambiables que podrían interaccionar con sustratos..$^{85}$ En general los metales de transición pueden actuar como ácidos de Lewis, necesitando para ello la coordinación con el reactivo, o como oxidantes. ${ }^{52}$ En este último caso puede ocurrir la transferencia electrónica, característica del proceso redox, incluso sin que el reactivo se coordine con el metal.

Con respecto al uso de MOFs como catalizadores del tipo ácido de Lewis existen estructuras, tales como la del MIL-101, que se ha comentado anteriormente, donde de las seis posiciones de coordinación alrededor de cada metal, una de ellas está ocupada por un disolvente en dos de cada tres átomos metálicos. Estas moléculas de $\mathrm{DMF}$ o $\mathrm{H}_{2} \mathrm{O}$ se podrían intercambiar durante el mecanismo de reacción con un reactivo.

Para este tipo de mecanismos se asume generalmente que las posiciones que definen a la estructura del material no pueden participar en la reacción. ${ }^{85} \mathrm{Sin}$ embargo, esta asunción puede ser incorrecta puesto que tal como se ha comentado anteriormente, es posible producir el intercambio de ligandos en la estructura de muchos materiales $\mathrm{MOF}^{78-80} \mathrm{In}$ cluso en el caso de MOFs donde el catión metálico no posee posiciones intercambiables no asociadas con la estructura del material, tales como el UiO-66 o el MIL-53, se ha descrito su comportamiento como catalizadores ácidos de Lewis. ${ }^{58}$ En estos casos se cree que la presencia de defectos en la estructura ocasionaría la presencia de centros metálicos con una deficiencia de ligando y con capacidad de promover reacciones basadas en la acidez Lewis. ${ }^{86}$

Los defectos estructurales juegan un papel muy importante en catálisis heterogénea en gran número de materiales, como por ejemplo en zeolitas, donde la acidez Lewis se acepta que es debida exclusivamente al aluminio octaédrico fuera de la estructura cristalina ${ }^{87,88}$ En el caso de los MOFs, ya se ha comentado que el material UiO-66 se caracteriza por la presencia, según el procedimiento de síntesis, de un gran número de defectos. ${ }^{61-63}$ Estos defectos surgen durante la formación del cristal debido a la fuerte coordinación metal-ligando. Cuando el metal tiene una elevada densidad de carga positiva, hace difícil o imposible la generación de estos errores $\mathrm{y}$, por tanto, se produce la formación de la estructura termodinámicamente más estable que corresponde a la estructura cristalina perfecta y sin defectos del UiO-66. Estos defectos hacen que en determinadas posiciones la esfera de coordinación de los cationes $\mathrm{Zr}^{4+}$ sea incompleta. ${ }^{89}$ 
Posiciones de los centros activos en un MOF:

1. En el metal.

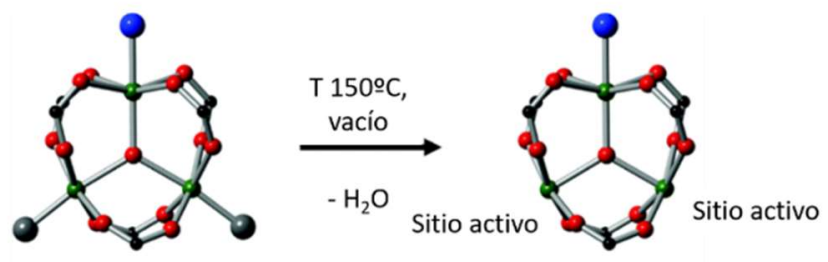
- $\mathrm{C}$
- $\mathrm{Cr}$
- $F$
- $\mathrm{H}_{2} \mathrm{O}$

2. Grupos funcionales en el ligando.

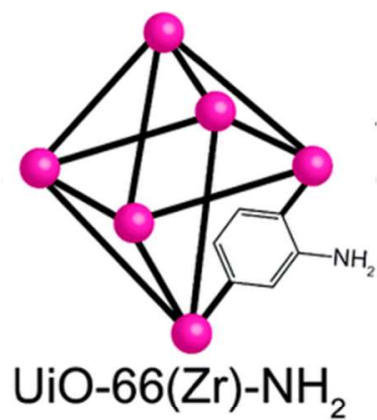

3. En los espacios intercristalinos. Complejos de base de Schift.

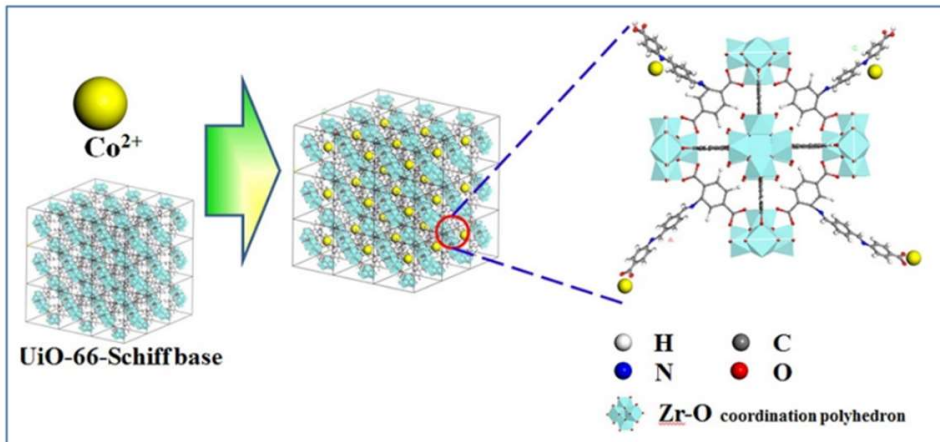

Figura 1.7. Posible localización de los centros activos en un MOF. 
Las reacciones orgánicas que han sido estudiadas empleando MOFs como catalizadores sólidos de Lewis incluyen reacciones de condensación aldohólica, esterificación, adiciones a enlaces múltiples, apertura de epóxidos, formación de heterociclos, etc. ${ }^{52,58}$ La figura 1.8 ilustra algunas de las reacciones promovidas por centros ácidos de Lewis catalizadas por los nodos metálicos en materiales MOFs. En la presente tesis doctoral, el capítulo 6 describe la influencia que la sustitución en el anillo aromático puede ejercer sobre la actividad de los nodos metálicos en reacciones que son catalizadas por centros ácidos. ${ }^{58}$

\section{Apertura de epóxidos}

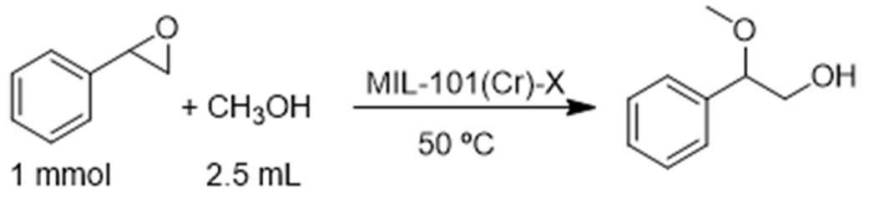

\section{Acetalización de aldehidos}

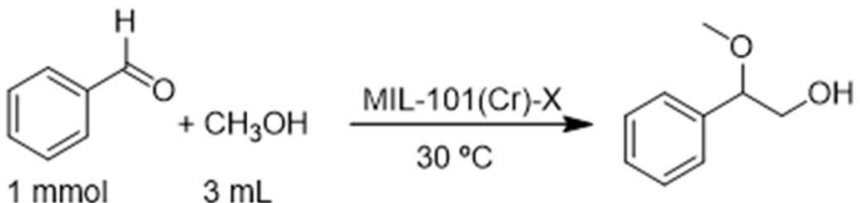

\section{Reacción de Prins}
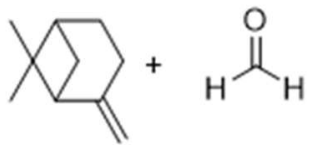

$\mathrm{CH}_{3} \mathrm{CN}(2.5 \mathrm{~mL}), 80^{\circ} \mathrm{C}$

$1 \mathrm{mmol} \quad 1 \mathrm{mmol}$

Figura 1.8. Reacciones catalizadas por centros ácido de Lewis que serán objeto de estudio en el capítulo 6.

Se ha comentado también, que los nodos metálicos pueden catalizar reacciones de oxidación empleando una gran variedad de agentes oxidantes tales como hidroperóxidos orgánicos, peróxido de hidrógeno, oxígeno, iodo hipervalente, etc. ${ }^{49-53,58,90}$ De entre ellas debido a su interés en química verde y a la dificultad de conseguir oxidaciones selectivas destaca la oxidación aeróbica. La figura 1.9 ilustra una de las reacciones de oxidación que han sido descritas empleando MOFs como catalizadores. ${ }^{50}$

Esta actividad catalítica de los MOFs para reacciones de oxidación es de alguna manera ampliamente utilizada en la industria, la cual, ha venido empleando masivamente 
en procesos de oxidación, carboxilatos y, particularmente, acetatos de metales de transición tales como acetato de manganeso, de cobalto, de cinc o de hierro que se emplean para llevar a cabo por ejemplo las oxidaciones bencílicas de metilbencenos y para-xileno.

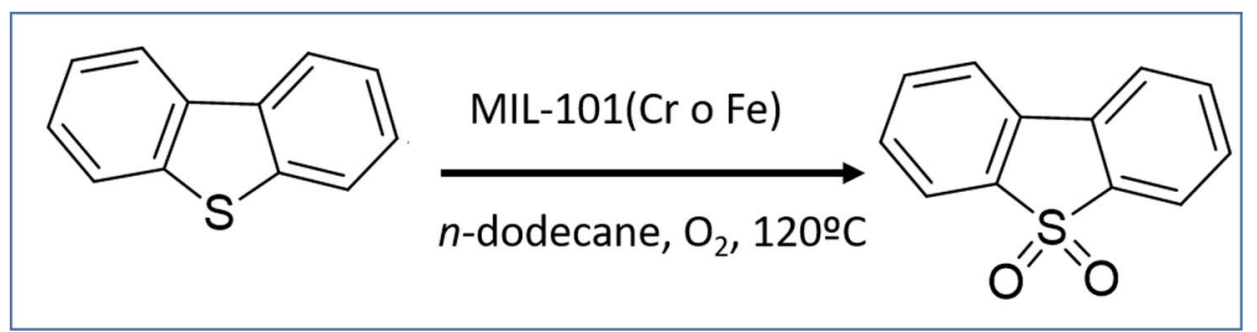

Figura 1.9. Esquema de la reacción de oxidación de dibenzotiofeno a su correspondiente sulfona que será objeto de estudio en el capítulo 4.

Existe otra posibilidad donde los ligandos poseen grupos funcionales que actúan como centros catalíticos. ${ }^{51-53}$ En este caso los nodos metálicos pueden estar perfectamente coordinados y solo cumplen la función de definir la estructura cristalina del material. ${ }^{53}$ Ejemplos típicos de grupos funcionales de un ligando con actividad catalítica son los grupos amino y ácido sulfónico en el ácido tereftálico. ${ }^{51-53}$ Aunque la basicidad del grupo amino en anilinas es muy débil, y, generalmente, mucho menor que la de aminas alifáticas, se han descrito numerosas reacciones de condensación catalizadas por los grupos amino de los ligandos tereftalatos en materiales MOFs. ${ }^{51-53,58,90}$

El grupo sulfónico aromático es un catalizador ampliamente utilizado en fase homogénea, por ejemplo, en el ácido paratoluensulfónico. ${ }^{91-93}$ También cuando se encuentra presente en MOFs, este grupo sulfónico actúa como ácido de Bronsted, promoviendo reacciones de esterificación y trans-esterificación de ácidos carboxílicos y transformaciones de biomasa como, por ejemplo, reacciones de deshidratación. La figura 1.10 resume algunas de las reacciones que han sido descritas para grupos funcionales presentes en el ligando orgánico..$^{51,53}$ 


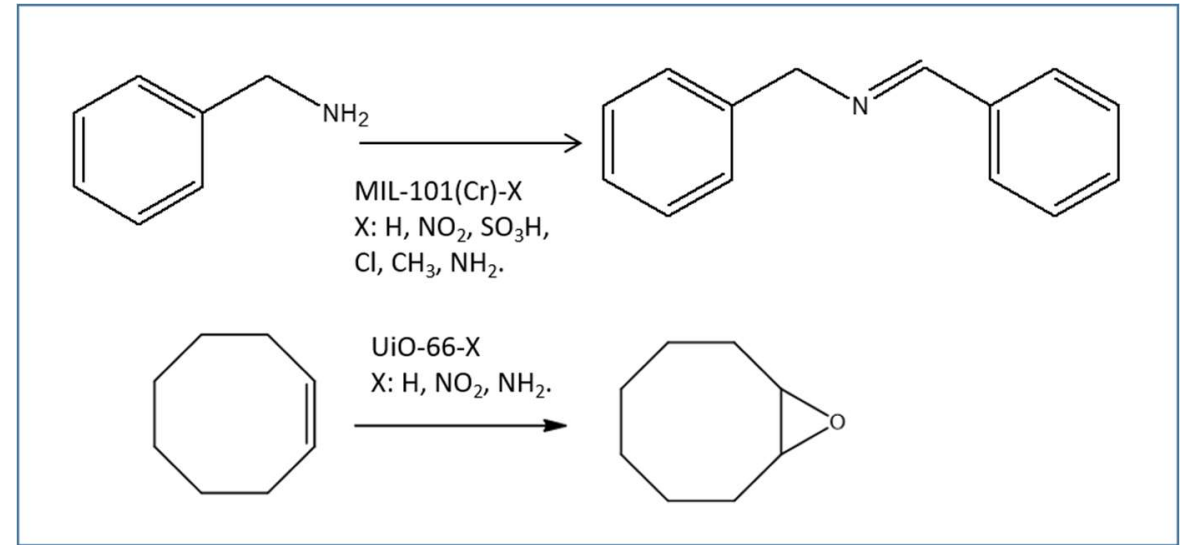

Figura 1.10. Ejemplos de reacciones que han sido descritas como catalizadas por diferentes sustituyentes en el ligando orgánico de MIL-101(Cr) y UiO-66.

La tercera posición donde pueden localizarse los centros activos en un MOF son los espacios intracristalinos y los poros donde puede alojarse un huésped que actúa como centro catalítico del proceso. Ejemplos destacados de esta estrategia incluyen la formación de complejos metálicos en posiciones satélite respecto a la estructura tales como complejos de polipiridilo, complejos de base de Schift, ftalocianimas metálicas y aquellos en los que se incorpora una nanopartícula metálica o óxidos metálicos. ${ }^{90}$ En el caso de complejos metálicos, se ha descrito que la inmovilización en la estructura evita mecanismos de desactivación habituales en fase homogénea, tales como los que derivan de la dimerización y oligomerización del complejo metálico. Además, la adsorción de sustratos y reactivos en el interior del MOF pueden cooperar con la actividad catalítica al producir una preconcentración de reactivos en proximidad al complejo metálico. ${ }^{94,95}$

En el caso de nanopartículas metálicas, se ha descrito la incorporación dentro de las cavidades de los MOFs de nanopartículas de metales nobles como oro y paladio. ${ }^{96-98}$ Entre las ventajas que presenta la incorporación de las nanopartículas metálicas en el interior del MOF, una de las principales derivada del confinamiento geométrico, pero también de la interacción con los componentes del MOF para dificultar el crecimiento en tamaño de las nanopartículas durante el curso de la reacción, así como estabilizar nanopartículas metálicas de tamaño pequeño. De esta manera se ha descrito que el MIL$101(\mathrm{Cr})$ con nanopartículas de paladio en el interior es uno de los catalizadores de paladio heterogéneos más activos para promover reacciones de acoplamiento carbono-carbono y carbono-nitrógeno, siendo además el catalizador estable y no sufriendo desactivación con su reuso..$^{97,98}$

También, nanopartículas de oro encapsuladas en el interior de MOFs, y, más específicamente, el material MIL-101, es uno de los catalizadores más estables y eficientes para promover la oxidación aeróbica de alcoholes siendo el catalizador reutilizable. ${ }^{96}$ 
En vista de lo anterior, la presente tesis doctoral ha ido encaminada a avanzar en el empleo de MOFs como catalizadores tanto en reacciones que requieren centros ácidos de Lewis como en reacciones de oxidación aeróbica. ${ }^{49-53}$ Así, por un lado, se pretende estudiar la oxidación aeróbica de hidrocarburos bencílicos determinando en este caso el posible papel que pueda jugar el MOF en la generación de especies reactivas de oxígeno (capítulo 3)..$^{49}$ Por otro lado, se pretende llevar a cabo la oxidación aeróbica de otros compuestos orgánicos que hasta ahora no han sido estudiados empleando MOFs como catalizadores. De particular interés, por la relevancia que tiene en el sector del refino y de combustibles, es la posibilidad de llevar a cabo la oxidación aeróbica de tiofenos y benzotiofenos (capítulo 4). ${ }^{50}$

Un aspecto importante que se pretende estudiar en la presente tesis doctoral es el posible papel que pueden jugar los sustituyentes sobre el anillo aromático sobre la actividad catalítica de los iones metálicos presentes en el nodo. ${ }^{51-53}$ Se pretende determinar en qué extensión la sustitución en el anillo aromático puede aumentar la eficiencia de los iones metálicos nodales tanto en la catálisis ácida, como en reacciones de oxidación aeróbica. El esquema 1.1 resume el concepto que se pretende desarrollar en los capítulos 5,6 y 7 . 
Capítulo 5:

MIL-101(Cr)-X. X: H, NO $\mathrm{SO}_{3} \mathrm{H}, \mathrm{Cl}, \mathrm{CH}_{3}$ y $\mathrm{NH}_{2}$.

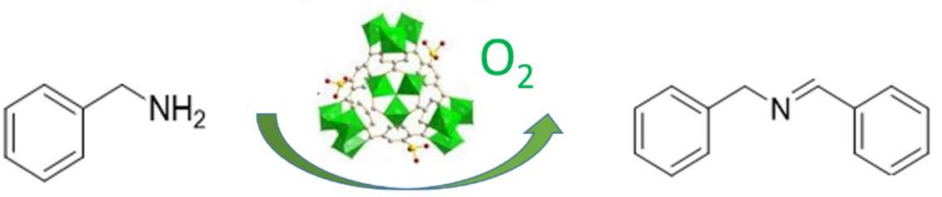

Capítulo 6:

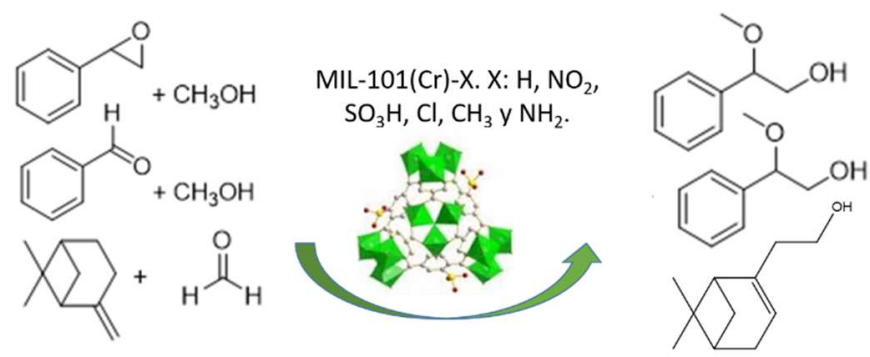

Capítulo 7:

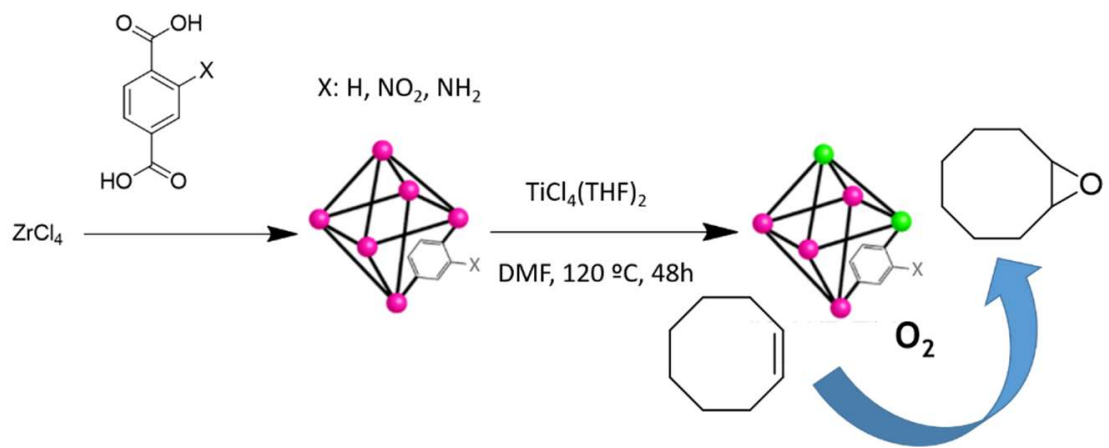

Esquema 1.1. Esquema de las reacciones objeto de estudio en los capítulos 5, 6 y 7 .

Finalmente, se busca introducir centros activos metálicos en materiales inactivos por intercambio post-sintético de metal en la red cristalina, combinando la presencia de estos centros metálicos con la influencia del sustituyente (capítulo 7). El objetivo es desarrollar materiales que, siendo estructuralmente robustos, presenten la máxima actividad catalítica. ${ }^{53}$ 


\subsection{Referencias}

1. H. Li, M. Eddaoudi, M. O'Keeffe y O. M. Yaghi, Nature, 1999, 402, 276-279.

2. M. Eddaoudi, J. Kim, N. Rosi, D. Vodak, J. Wachter, M. O'Keefe y O. M. Yaghi, Science, 2002, 295, 469-472.

3. H. K. Chae, D. Y. Siberio-Pe'rez, J. Kim, Y. B. Go, M. Eddaoudi, A. J. Matzger, M. O'Keeffe y O. M. Yaghi, Nature, 2004, 427, 523-527.

4. J. L. C. Rowsell y O.M. Yaghi, Microporous Mesoporous Mater., 2004, 73, 3-14.

5. J. L. C. Rowsell y O. M. Yaghi, Angew. Chem., 2005, 117, 4748-4758.

6. A. K. Cheetham, G. Férey, T. Loiseau, Angew. Chem. 1999, 111, 3466-3492.

7. G. Férey, Chem. Mater.,2001, 13, 3084-3098.

8. S. Kitagawa, R. Kitaura, Comments Inorg. Chem. 2002, 23, 101-126.

9. S. Kitagawa, R. Kitaura y S. Noro, Angew. Chem., Int. Ed., 2004, 43, 2334-2375.

10. U. Mueller, M. Schubert, F. Teich, H. Puetter, K. Schierle-Arndt y J. Pastre, J. Mater. Chem., 2006, 16, 626-636.

11. M. Eddaoudi, D. B. Moler, H. Li, B. Chen, T. M. Reineke, M. O'Keeffe, O. M. Yaghi, Acc. Chem. Res., 2001, 34, 319-330.

12. T. J. Barton, L. M. Bull, W. G. Klemperer, D. A. Loy, B. McEnaney, M. Misono, P. A. Monson, G. Pez, G. W. Scherer, J. C. Vartuli y O. M. Yaghi, Chem. Mater., 1999, 11, 2633-2656.

13. S. L. James, Chem. Soc. Rev., 2003, 32, 276-288.

14. H. Li, M. Eddaoudi, T.L. Groy y O.M. Yaghi, J. Am. Chem. Soc., 1998, 120, 85718572.

15. T.M. Reineke, M. Eddaoudi, M. O'Keeffe y O. M. Yaghi, Angew. Chem. Int. Ed., 1999, 38, 2590-2594.

16. O. K. Farha y J. T. Hupp, Acc. Chem. Res., 2010, 43, 1166-1175.

17. T Loiseau y G Férey, J. Fluorine Chem., 2007, 128, 413-422.

18. L. J. Wang, H. Deng, H. Furukawa, F. Gandara, K. E. Cordova, D. Peri y O. M. Yaghi, Inorg. Chem., 2014, 53, 5881-5883.

19. O. K. Farha, I. Eryazici, N. C. Jeong, B. G. Hauser, C. E. Wilmer, A. A. Sarjeant, R. Q. Snurr, S. T. Nguyen, A. Özgür Yazaydın y J. T. Hupp, J. Am. Chem. Soc., 2012, 134, 15016-15021.

20. G. Férey, Chem. Soc. Rev., 2008, 37, 191-214. 
21. S. Bordiga, F. Bonino, K. P. Lillerud and C. Lamberti Chem. Soc. Rev., 2010, 39, 4885-4927.

22. Y. J. Colon y R. Q. Snurr, Chem. Soc. Rev., 2014, 43, 5735-5749.

23. Q.L. Zhu y Q. Xu, Chem. Soc. Rev., 2014, 43, 5468-5512.

24. H. Furukawa, N. Ko, Y. B. Go, N. Aratani, S. B. Choi, E. Choi, A. OĖ. Yazaydin, R. Q. Snurr, M. O'Keeffe, J. Kim y O. M. Yaghi, Science, 2010, 329, 424-428.

25. J. J. Perry IV, J. A. Perman, M. J. Zaworotko, Chem. Soc. Rev., 2009, 38, 1400-1417.

26. A. Corma, H. Garcia y F. X. Llabrés i Xamena, Chem. Rev., 2010, 110, 4606-4655.

27. M. Yoon, R. Srirambalaji, y K. Kim, Chem. Rev., 2012, 112, 1196-1231.

28. H. Furukawa, K.E. Cordova, M. O'Keeffe y O. M. Yaghi, Science, 2013, 341, 1230444.

29. A, Dhakshinamoorthy y H, Garcia, Chem. Soc. Rev., 2012, 41, 5262-5284.

30. A. Dhakshinamoorthy, M. Opanasenko, J. Čejka, y H. Garcia, Catal. Sci. Technol. 2013, 3, 2509-2540.

31. M. Ranocchiari, y J.A.V Bokhoven, Phys. Chem. Chem. Phys., 2011, 13, 6388-6396.

32. C. Wang, M. Zheng, y W. J. Lin, Phys. Chem. Lett., 2011, 2, 1701-1709.

33. Z. Y. Gu, J. Park, A. Raiff, Z. Wei y H.C. Zhou, ChemCatChem, 2014, 6, 67-75.

34. J. Gascon, A. Corma, F. Kapteijn y F. X. Llabrés i Xamena, ACS Catal., 2014, 4, 361-378.

35. O. V. Zalomaeva, A. M. Chibiryaev, K. A. Kovalenko, O. A. Kholdeeva, B. S. Balzhinimaev y V.P. Fedin, J. Catal., 2013, 298, 179-185.

36. I. D. Ivanchikova, J. S. Lee, N. V. Maksimchuk, A. N. Shmakov, Y. A. Chesalov, A. B. Ayupov, Y. K. Hwang, C.-H. Jun, J.-S. Chang y O. A. Kholdeeva, Eur. J. Inorg. Chem., 2014, 1, 132-139.

37. N. V. Maksimchuk, O. A. Kholdeeva, K. A. Kovalenko, V. P. Fedin, Isr. J. Chem., 2011, 51, 281-289.

38. S. Yuan, L. Feng, K. Wang, J. Pang, M. Bosch, C. Lollar, Y. Sun, J. Qin, X. Yang, P. Zhang, Q. Wang, L. Zou, Y. Zhang, L. Zhang, Y. Fang J. Li y H.-C. Zhou, Adv. Mater., 2018, 30, 1704303.

39. S. S.-Y. Chui, S. M.-F. Lo, J. P. H. Charmant, A. G. Orpen y I. D. Williams, Science, 1999, 283, 1148-1150.

40. C. Wang, X. Liu, N. Keser Demir, J. P. Chen y K. Li, Chem. Soc. Rev., 2016, 45, $5107-5134$ 
41. T. Devic y C. Serre, Chem. Soc. Rev., 2014, 43, 6097-6115.

42. Y. Bai, Y. Dou, L.-H. Xie, W. Rutledge, J.-R. Li y H.-C. Zhou, Chem. Soc. Rev., 2016, 45, 2327-2367.

43. J. Canivet, A. Fateeva, Y. Guo, B. Coasne y D. Farrusseng, Chem. Soc. Rev., 2014, 43, 5594-5617.

44. N. C. Burtch, H. Jasuja y K. S. Walton, Chem. Rev., 2014, 114, 10575-10612.

45. A. J. Howarth, Y. Liu, P. Li, Z. Li, T. C. Wang, J. T. Hupp y O. K. Farha, Nat. Rev. Mater., 2016, 1, 15018-15032.

46. Y. Ming, N. Kumar y D. J. Siege, ACS Omega, 2017, 2, 4921-4928.

47. N. C. Burtch, H. Jasuja y K. S. Walton, Chem. Rev., 2014, 114, 10575-10612.

48. V. V. Butova, M. A. Soldatov, A. A. Guda, K. A. Lomachenko y C. Lamberti, Russian Chem. Rev., 2016, 85, 280-307.

49. A. Santiago-Portillo, S. Navalon, F. Cirujano, F. Llabrés i Xamena, M. Alvaro y H. Garcia, ACS Catal., 2015, 5, 3216-3224.

50. A. Gómez-Paricio, A. Santiago-Portillo, S. Navalón, P. Concepción, M. Alvaro y H. Garcia, Green Chem., 2016, 18, 508-515.

51. A. Santiago-Portillo, J. F. Blandez, S. Navalón, M. Álvaro, y H. García, Catal. Sci. Technol., 2017, 7, 1351-1362.

52. A. Santiago-Portillo, S. Navalón, P. Concepción, M. Álvaro y H. García, ChemCatChem, 2017, 9, 2506-2511.

53. A. Santiago-Portillo, S. Navalón, M. Álvaro, y H. García, J. Catal., 2018, 365, 450463.

54. G. Férey, C. Mellot-Draznieks, C. Serre, F. Millange, J. Dutour, S. Surblé y I. Margiolaki, Science, 2005, 309, 2040-2042.

55. N. V. Maksimchuk, O. V. zalomaeva, I. Y. Skobelev, K. A. Kovalenko, V. P. Fedin y O. A. Kholdeeva, Proc. R. Soc. A, 2012, 468, 2017-2034.

56. X. Li, L. Lachmanski, S. Saf, S. Sene, C. Serre, J. M. Grenèche, J. Zhang y R. Gref, Scientific Reports, 2017, 7, 13142-13153.

57. N. C. Burtch, H. Jasuja y K. S. Walton, Chem. Rev., 2014, 114, 10575-10612.

58. J. F. Blandez, A. Santiago-Portillo, S. Navalón, M. Gimenez-Marques, M. Alvaro, P. Horcajada y H. García, J. Mol. Catal. A Chem., 2016, 425, 332-339.

59. J. H. Cavka, S. Jakobsen, U. Olsbye, N. Guillou, C. Lamberti, S. Bordiga y K. P. Lillerud, J. Am. Chem. Soc., 2008, 130, 13850-13851. 
Capítulo 1.

60. L. Valenzano, B. Civalleri, S. Chavan, S. Bordiga, M. H. Nilsen, S. Jakobsen, K. P. Lillerud y C. Lamberti, Chem. Mater., 2011, 23, 1700-1718.

61. Z. Fang, B. Bueken, D. E. de Vos y R. A. Fischer, Angew. Chem. Int. Ed., 2015, 54, $7234-7254$.

62. Y. Jiao, Y. Liu, G. Zhu, J. T. Hungerford, S. Bhattacharyya, R. P. Lively, D. S. Sholl y K. S. Walton, J. Phys. Chem. C, 2017, 121, 23471-23479.

63. A. W. Thornton, R. Babarao, A. Jain, F. Trousseletc y F.-X. Coudert, Dalton Trans., 2016, 45, 4352-4359.

64. B. Chen, N. W. Ockwig, A. R. Millward, D. S. Contreras y O. M. Yaghi, Angew. Chem. Int. Ed., 2005, 44, 4745-4749.

65. J. L. C. Rowsell, A. R. Millward, K. S. Park y O. M. Yaghi, J. Am. Chem. Soc., 2004, 126, $5666-5667$.

66. A. R. Millward, O. M. Yagui, J. Am. Chem. Soc., 2005, 127, 17998-17999.

67. P. L. Llewellyn, S. Bourrelly, C. Serre, A. Vimont, M. Daturi, L. Hamon, G. de Weireld, J.-S. Chang, D.-Y. Hong, Y. K. Hwang, S. H. Jhung y G. Férey, Langmuir 2008, 24, 7245-7250.

68. G. Férey, M. Latroche, C. Serre, F. Millange, T. Loiseau y A. Percheron-Guégan, Chem. Commun., 2003, 0, 2976-2977.

69. P. L. Llewellyn, S. Bourrelly, C. Serre, A. Vimont, M. Daturi, L. Hamon, G. de Weireld, J.-S. Chang, D.-Y. Hong, Y. K. Hwang, S. H. Jhung y G. Férey, Langmuir, 2008, 24, 7245-7250.

70. P. S. Bárcia, D. Guimarães, P. A. P. Mendes, J. A. C. Silva, V. Guillerm, H. Chevreau, C. Serre y A. E. Rodrigues, Microporous and Mesoporous Mater., 2011, 139, 6773.

71. S.-C. Xiang, Z. Zhang, C.-G. Zhao, K. Hong, X. Zhao, D.-R. Ding, M.-H. Xie, C.D. Wu, M. C. Das, R. Gill, K. M. Thomas y B. Chen, Nature Comm., 2011, 2, 204-211.

72. J.-R. Li , R. J. Kuppler y H.-C. Zhou, Chem. Soc. Rev., 2009, 38, 1477-1504.

73. T. Rodenas, I. Luz, G. Prieto, B. Seoane, H. Miro, A. Corma, F. Kapteijn, F. X. Llabrés i Xamena y J. Gascon, Nature Mater., 2015, 14, 48-55.

74. B. Chen, M. Eddaoudi, T. M. Reineke, J. W. Kampf, M. O'Keeffe, y O. M. Yaghi, J. Am. Chem. Soc., 2000, 122, 11559-11560.

75. J. Kim, B. Chen, T. M. Reineke, H. Li, M. Eddaoudi, D. B. Moler, M. O'Keeffe y O. M. Yaghi, J. Am. Chem. Soc., 2001, 123, 8239-8247.

76. K. J. Gagnon, C. M. Beavers y A. Clearfield, J. Am. Chem. Soc., 2013, 135, 12521255. 
77. F. Vermoortele, B. Bueken, G. Le Bars, B. V. de Voorde, M. Vandichel, K. Houthoofd, A. Vimont, M. Daturi, M. Waroquier, V. Van Speybroeck, C. Kirschhock y D. E. de Vos, J. Am. Chem. Soc., 2013, 135, 11465-11468.

78. T. Li, M. T. Kozlowski, E. A. Doud, M. N. Blakely y N. L. Rosi, J. Am. Chem. Soc., 2013, 135, 11688-11691.

79. M. Kim, J. F. Cahill, Y. Su, K. A. Prather y S. M. Cohen, Chem. Sci., 2012, 3, 126130.

80. Z. Hu, S. Faucher, Y. Zhuo, Y. Sun, S. Wang y D. Zhao, Chem. Eur. J., 2015, 21, 17246-17255.

81. B.-Q. Ma, K. L. Mulfort y J. T. Hupp, Inorg. Chem., 2005, 44, 4912-4914.

82. S. M. Chavan, G. C. Shearer, S. Svelle, U. Olsbye, F. Bonino, J. Ethiraj, K. P. Lillerud y S. Bordiga, Inorg. Chem., 2014, 53, 9509-9515.

83. M. Lammert, S. Bernt, F. Vermoortele, D. E. de Vos y N. Stock, Inorg. Chem., 2013, 52, 8521-8528.

84. G.-T. Vuong, M.-H. Pham y T.-O. Do, Cryst. Eng. Comm., 2013, 15, 9694-9703.

85. S. M. J. Rogge, A. Bavykina, J. Hajek, H. Garcia, A. I. Olivos-Suarez, A. SepúlvedaEscribano, A. Vimont, G. Clet, P. Bazin, F. Kapteijn, M. Daturi, E. V. Ramos-Fernandez, F. X. Llabrés i Xamena, V. Van Speybroeck y J. Gascon, Chem. Soc. Rev., 2017, 46, 3134-3184.

86. M. Vandichel, J. Hajek, F. Vermoortele, M. Waroquier, D. E. de Vos y V. Van Speybroeck, Cryst. Eng. Comm., 2015, 17, 395-406.

87. A. Corma, M. E. Domine, S. Valencia, J. Catal., 2003, 215, 294-304.

88. H. Y. Luo, J. D. Lewis y Y. Roman-Leshkov, Annu. Rev. Chem. Biomol. Eng., 2016. 7, 663-692.

89. G. C. Shearer, S. Chavan, S. Bordiga, S. Svelle, U. Olsbye y K. P. Lillerud, Chem. Mater., 2016, 28, 3749-3761.

90. A. Santiago-Portillo, S. Daliran, S. Navalón, A. R. Oveisi, M. Álvaro, R. GhorbaniVaghei, D. Azarifar y H. García, J. Colloid Interface Sci., 2018, 532, 700-710.

91. C. S. Gill, B. A. Price y C. W. Jones, J. Catal., 2007, 251, 145-152.

92. R. Aafaqi, A. R. Mohamed y S. Bhatia, J. Chem. Technol. Biotechnol., 2004, 79, $1127-1134$.

93. M. C. de Jong, R. Feijt, E.Zondervan, T. A. Nijhuis y A. B. de Haan, Appl. Catal. A, 2009, 365, 141-147. 
Capitulo 1.

94. T. Bunchuay, R. Ketkaew, P. Chotmongkolsap, T. Chutimasakul, J. Kanarat, Y. Tantirungrotechaib y J. Tantirungrotechai, Catal. Sci. Technol., 2017, 7, 6069-6079.

95. M.-L. Wei, J.-J. Sun y X.-Y. Duan, Eur. J. Inorg. Chem., 2014, 345-351.

96. H. Liu, Y. Liu, Y. Li, Z. Tang y H. Jiang, J. Phys. Chem. C, 2010, 114, 13362-13369.

97. B. Yuan, Y. Pan, Y. Li, B. Yin y H. Jiang, Angew. Chem. Int. Ed., 2010, 49, 40544058.

98. F. Carson, V. Pascanu, A. Bermejo Gómez, Y. Zhang, A. E. Platero-Prats, X. Zou y B. Martín-Matute, Chem. Eur. J., 2015, 21, 10896-10902. 
Introducción. 


\section{Capítulo 2 Objetivos.}


Capitulo 2.

En vista del amplio uso de algunos materiales MOFs como catalizadores heterogéneos en reacciones en fase líquida, el objetivo general de la presente tesis doctoral es avanzar en el empleo de estos materiales en reacciones de oxidación de hidrocarburos, así como de compuestos conteniendo nitrógeno y azufre en reacciones de oxidación aeróbica. Es conocida la dificultad de llevar a cabo reacciones de oxidación aeróbica de compuestos orgánicos de forma selectiva, requiriendo, en general, estas reacciones el empleo de generadores de radicales que típicamente sufren de descomposición e inician mecanismos de oxidación en cadena. Se trata de estudiar si mediante el empleo de MOFs es posible conseguir selectividad en los procesos de oxidación, así como de establecer el papel que estos MOFs juegan en la reacción, bien como iniciadores, o bien como auténticos catalizadores donde la formación de cada molécula de producto requiere del centro activo. Además, se trata de estudiar los casos que puedan tener interés industrial, por llevarse a cabo en grandes cantidades, tales como reacciones de oxidación en posiciones bencílicas de hidrocarburos aromáticos, reacciones de epoxidación de alquenos y reacciones de oxidación de grupos funcionales obteniendo heteroátomos, tales como nitrógeno y azufre. También, se pretende establecer si la presencia de sustituyentes en el anillo aromático modifica la velocidad de oxidación de estos materiales MOFs.

Ya se ha comentado que la influencia de los sustituyentes se ha escrito recientemente para el caso de reacciones ácido-base empleando el MOF UiO-66 como catalizador, siendo de interés expandir estos resultados a otros tipos de MOFs de interés en catálisis y, particularmente, al MIL-101, así como a otras reacciones que impliquen los metales como centros activos y que no sean reacciones ácido-base, tales como las reacciones de oxidación.

Específicamente, los objetivos de cada capítulo experimental de la presente tesis doctoral son los siguientes:

(I) Estudiar la actividad del material MIL-101(Cr o Fe) en reacciones de oxidación aeróbica de hidrocarburos bencílicos. Se determinará la naturaleza de las especies reactivas de oxígeno responsables de la oxidación, así como el papel del MOF MIL-101(Cr o Fe) como promotor o catalizador de estas oxidaciones. Además, se determinará la estabilidad del material MIL$101(\mathrm{Cr}$ o $\mathrm{Fe}$ ) en las condiciones de reacción analizando el posible lixiviado de metales a la fase líquida y la cristalinidad de la muestra empleada como catalizador tras un uso exhaustivo del material.

(II) Se estudiará la posibilidad de emplear el material MIL-101(Cr o Fe) como catalizador o promotor de la oxidación aeróbica de dibenzotiofeno y derivados. Especial importancia tendrá la determinación de la cinética de la reacción y del papel que el disolvente pueda jugar en la reacción. En caso de resultados favorables, se establecerá la posibilidad de eliminar este tipo de compuestos de la fase líquida mediante extracción con agua y el empleo 
de combustibles reales en algún ensayo. También en este caso se determinará la naturaleza de las especies reactivas de oxígeno implicadas en la oxidación.

(III) Oxidación aeróbica de bencilaminas empleando MIL-101(Cr) como catalizador y donde el ligando tereftalato se encuentre sustituido con grupos electrón-dadores o aceptores en el anillo aromático. Se pretende buscar una correlación entre la actividad catalítica del material, que se supone debida a los átomos metálicos, y la naturaleza de los sustituyentes sobre el anillo aromático.

(IV) Estudio de la posible influencia de la naturaleza del sustituyente presente en los ligandos tereftálicos en la actividad catalítica como ácido de Lewis del material MIL-101(Cr)-X. Se pretende correlacionar la actividad catalítica para 3 reacciones características catalizadas por ácidos de Lewis con la constante de Hammett del sustituyente que indica la capacidad dadora y aceptora de electrones sobre el anillo aromático. Las reacciones que se pretenden estudiar, que son promovidas típicamente por ácidos de Lewis, son la reacción de apertura de epóxidos, la formación de acetales de aldehídos y compuestos carbonílicos y la reacción de Prins.

(V) Modificación post-síntesis de los nodos metálicos de un material UiO-66 (Zr)-X a fin de introducir en los nodos un cierto porcentaje de iones $\mathrm{Ti}^{4+}$ que puedan introducir centros activos en la reacción. Además del intercambio iónico de cationes $\mathrm{Zr}^{4+}$ por $\mathrm{Ti}^{4+}$ se estudiará la influencia que la presencia de sustituyentes dadores o aceptores de electrones sobre los anillos de tereftalato ejercen sobre la velocidad de la reacción. Se determinará también la naturaleza de las especies reactivas de oxígeno que intervienen en el proceso.

En caso de que estos resultados fueran positivos, se habría logrado expandir el empleo de materiales MOFs en catálisis heterogénea para reacciones de oxidación aeróbica de hidrocarburos bencílicos y alicíclicos, así como compuestos conteniendo heteroátomos. El papel del material MOF como promotor o como catalizador auténtico, permitirá en el futuro desarrollar nuevas vías para conseguir materiales más eficientes y estables que promuevan estas reacciones. Además, los resultados que se obtengan permitirán establecer y cuantificar en qué medida sustituyentes sobre el ligando orgánico afectan a reacciones de oxidación aeróbica en función del tipo de MOF. 
Capítulo 3

MIL-101 como promotor sólido reusable para la autooxidación de hidrocarburos bencílicos. 
MIL-101 como promotor sólido reusable para la autooxidación de hidrocarburos bencílicos. 


\subsection{Introducción}

Como se ha comentado en la introducción, los MOFs ofrecen muchas oportunidades cómo catalizadores heterogéneos cómo, particularmente, para promover reacciones orgánicas en fase líquida. ${ }^{1-12}$

Una de las reacciones orgánicas más complejas de llevar acabo con alta selectividad es la oxidación de hidrocarburos por oxígeno molecular. ${ }^{13-16}$ Estos tipos de reacciones se llevan a cabo en procesos industriales, a gran escala, empleando condiciones homogéneas utilizando, en ciertos casos, acetatos metálicos en los que el catión metálico podría presentar una esfera de coordinación análoga a la que se encuentra en ciertos MOFs basados en carboxilatos como ligandos. En una serie de estudios, tal como se ha detallado en la introducción, nuestro grupo ha descrito que muestras de Fe(BTC) (BTC: 1,3,5benceno tricarboxilato) comercialmente disponibles son incapaces de promover oxidaciones aeróbicas de alcoholes e hidrocarburos en ausencia de cocatalizadores. ${ }^{5} \mathrm{Sin}$ embargo, si el material $\mathrm{Fe}(\mathrm{BTC})$ contiene N-hidroxi-ftalimida (NHPI) ${ }^{17}$ o en el caso de $\mathrm{Cu}$ (BTC) incorpora 2,2,6,6-tetrametil-1-piperidiniloxil (TEMPO) ${ }^{18}$ entonces, los sólidos resultantes presentan actividad en varias oxidaciones aeróbicas de una manera similar a la combinación de $\mathrm{Co}^{2+}, \mathrm{Mn}^{2+}$ y otros metales de transición con NHPI en fase homogénea. ${ }^{19-21}$

Considerando la importancia de las reacciones de oxidación aeróbicas en la industria química y continuando con esta línea de investigación, es de interés desarrollar sistemas más eficientes en los que la oxidación aeróbica pueda tener lugar en ausencia de cualquier cocatalizador.

El presente capítulo describe que los materiales MIL-101(Cr) o MIL-101(Fe) (MIL101: Materiaux de l'Institute Lavoisier) son capaces de promover la oxidación bencílica de hidrocarburos con oxígeno molecular en ausencia de cualquier cocatalizador.

En la literatura, existen algunos precedentes describiendo el uso de MOFs para llevar a cabo la oxidación de cicloalcanos, ${ }^{22}$ alquenos, ${ }^{23-27}$ posiciones bencílicas ${ }^{28-31} \mathrm{o}$ epoxidación de estireno, ${ }^{32}$ pero hasta ahora esos estudios han empleado comúnmente hidroperóxidos tales como el peróxido de tertbutilo (TBHP) como agente oxidante. ${ }^{22-25,28,31-33}$ En otros precedentes, los peróxidos tales como $\mathrm{H}_{2} \mathrm{O}_{2}{ }^{26,32}$ o la combinación de trimetilacetaldehido con oxígeno para generar radicales acilperoxi ${ }^{27}$ han sido usados en lugar de hidroperóxidos orgánicos. De manera similar, la combinación de peróxidos orgánicos como iniciadores y MIL-100 o MIL-101 conteniendo Fe o Cr como catalizadores y oxígeno como reactivo han sido descritos para llevar a cabo la oxidación de ciclohexano 22 o alquenos (ciclohexeno, $\alpha$ - o $\beta$ - pineno y limoneno). ${ }^{24,34,35}$ Sin embargo, el uso de oxígeno molecular, $\mathrm{O}_{2}$, exclusivamente para promover la oxidación usando MOFs como iniciadores, ha permanecido hasta el presente estudio ignorado. ${ }^{14,15}$ En este contexto, sería importante que estos procesos pudieran llevarse a cabo en ausencia total de hidroperóxidos como reactivos o iniciadores, empleando sólo oxígeno molecular y MOFs. ${ }^{14,15,32}$ 
En el presente capítulo se describirá que los materiales MIL-101(Cr) o MIL101(Fe) en presencia de oxígeno son capaces de activar la autooxidación de hidrocarburos bencílicos con una selectividad que es más elevada que la que se consigue con iniciadores convencionales para los mismos niveles de conversión.

\subsection{Resultados y discusión}

En la primera fase de nuestro estudio se seleccionó indano como compuesto modelo para estudiar la actividad catalítica de MIL-101(Cr) y MIL-101(Fe) antes y después de activación a $120^{\circ} \mathrm{C}$ bajo vacío durante $6 \mathrm{~h}$. El propósito es determinar la influencia que DMF/etanol o agua adsorbidos en el material pueden tener en su actividad catalítica. Precedentes en la literatura han mostrado que es posible eliminar el agua del material MIL-101 por activación a $120^{\circ} \mathrm{C}$ a vacío..$^{22,35} \mathrm{La}$ tabla 3.1 muestra el área superficial BET y el valor del volumen de poro de las muestras de MIL-101(Cr) y MIL-101(Fe) en función de la temperatura de activación. Como puede verse en la tabla, el área superficial y la porosidad aumenta con la temperatura del pretratamiento en el rango entre 80 y $140^{\circ} \mathrm{C}$ para ambas muestras de MIL-101.

Tabla 3.1. Área superficial y volumen de poro del MIL-101(Cr) y MIL-101(Fe) usadas en el presente capitulo en función dela temperatura de activación

\begin{tabular}{|c|c|c|c|}
\hline & $\begin{array}{r}\text { Temperatura de activación } \\
\left({ }^{\circ} \mathrm{C}\right)\end{array}$ & $\begin{array}{c}\text { BET } \\
\left(\mathrm{m}^{2} / \mathrm{g}\right)\end{array}$ & poro $\left(\mathrm{cm}^{3} / \mathrm{g}\right)$ \\
\hline MIL-101(Cr) & 80 & 1765 & 1.14 \\
\cline { 2 - 4 } & 140 & 2014 & 1.18 \\
\hline MIL-101(Fe) & 80 & 1834 & 0.98 \\
\cline { 2 - 4 } & 140 & 2058 & 1.19 \\
\hline
\end{tabular}

En todos los casos, la conversión de indano dio lugar a la formación preferente de la mezcla de productos bencílicos ol/ona esperada. Un experimento de control en las condiciones de reacción, pero en ausencia de cualquier catalizador, muestra como máximo un $10 \%$ de conversión de indano. Esta conversión, en ausencia de catalizador, corresponde, de acuerdo con la literatura, ${ }^{36,37}$ a la existencia en un grado pequeño de un proceso de autooxidación térmico ineficiente en el cual el $\mathrm{O}_{2}$ forma complejos de transferencia de carga de colisión con el anillo aromático, generándose en el proceso el anión 
Capitulo 3.

superóxido $\mathrm{O}_{2}{ }^{-}$que promueve la oxidación aeróbica. En contraste, la autooxidación ocurre en un grado mucho mayor en presencia de MIL-101 como promotor (Figura 3.1) La posibilidad de que en los experimentos usando MIL-101 como iniciador la muestra de indano contuviera algún hidroperóxido presente, generado por envejecimiento del indano, en contacto con la atmósfera, fue considerada en un primer momento y descartada puesto que si se usa una muestra de indano recién destilada se observa igualmente un perfil temporal de reacción coincidente (la máxima diferencia entre la muestra sin destilar y destilada fue del $2 \%$ como se observa en la figura 3.2 ).

La comparación de la actividad catalítica de los materiales sin y tras activación ( $\mathrm{Fi}$ guras 3.3 y 3.1, respectivamente) muestran para el caso del MIL-101(Cr) unos gráficos de conversión-tiempo muy similares, aunque, en el caso del material MIL-101(Fe) se observó un aumento significativo de la actividad catalítica tras la activación. Estos ensayos preliminares conducen a la conclusión de que el catalizador MIL-101(Cr) sin ningún tratamiento térmico es un catalizador conveniente para promover autooxidaciones bencílicas, considerando su alta selectividad ol/ona a conversiones de indano inferiores al $50 \%$. Así, por consiguiente, en la mayoría de los experimentos siguientes se empleó la muestra de MIL-101(Cr) como catalizador. Es interesante hacer notar que mientras la selectividad ol/ona conjunta disminuye a medida que la conversión de indano aumenta para el material MIL-101(Cr), en el caso de la muestra MIL-101(Fe) el máximo en la selectividad se observa alrededor de una conversión del $50 \%$ (Ver figuras 3.1 y 3.3). Este aumento de la selectividad conjunta ol/ona a bajas conversiones se debe probablemente a la descomposición del hidroperóxido hacia mezclas de ol/ona en este rango de conversiones. 
a)

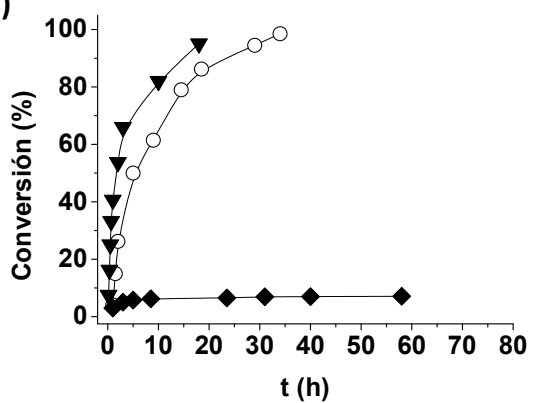

b) 100

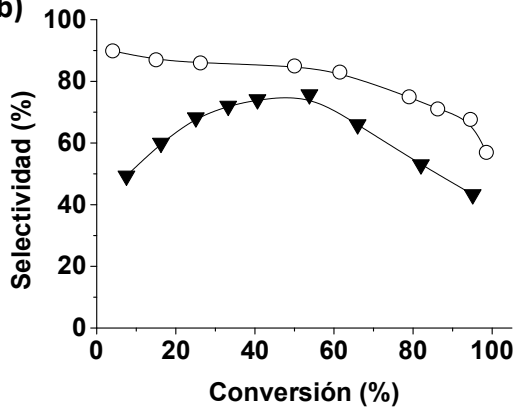

c)

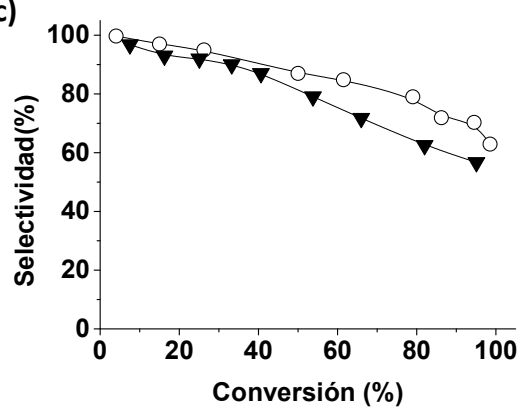

Figura 3.1. Gráfico de conversión frente a tiempo (a), selectividad ol/ona frente a conversión (b) y curva de conversión frente a selectividad ol/ona/hidroperóxido (c) para la oxidación aeróbica del indano usando MIL-101(Cr) o (Fe) activados cómo catalizadores. Leyenda: MIL-101(Fe) ( $\mathbf{\Delta})$, MIL-101(Cr) ( $)$ y control en ausencia de catalizador ( $\bullet$ ). Condiciones de reacción: $75 \mathrm{mg}$ de catalizador, 20 mmoles de sustratos, $120^{\circ} \mathrm{C}$, atmósfera de $\mathrm{O}_{2}$. 
Capitulo 3.

a)

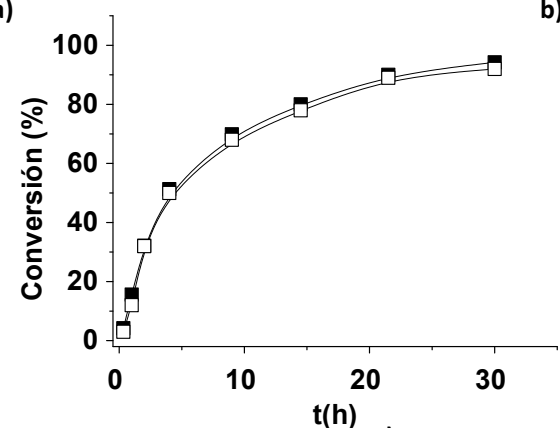

$\mathrm{t}(\mathrm{h})$
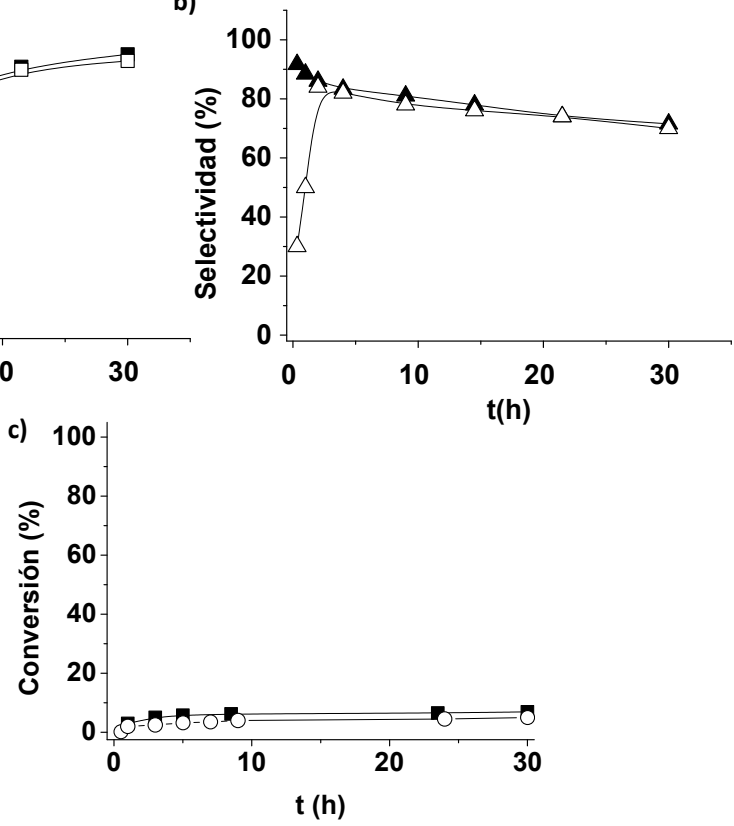

Figura 3.2. Gráfico de conversión frente a tiempo (a), selectividad ol/ona frente a conversión (b) para la oxidación aeróbica de indano sin destilar (símbolos rellenos) y destilado (símbolos vacíos) usando MIL-101(Cr) como catalizador. Condiciones de reacción: $75 \mathrm{mg}$ de catalizador, 20 mmoles de sustratos, $120^{\circ} \mathrm{C}$, atmósfera de $\mathrm{O}_{2}$. (c) Experimentos control en ausencia de catalizador con indano sin destilar (a) y destilado (०). Condiciones de reacción: 20 mmoles de sustratos, $120^{\circ} \mathrm{C}$, atmósfera de $\mathrm{O}_{2}$. 
a)

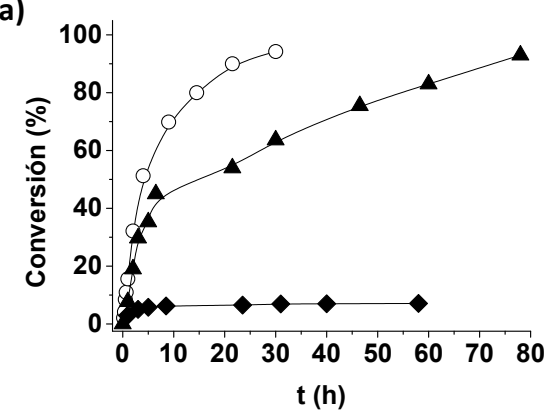

b) 100

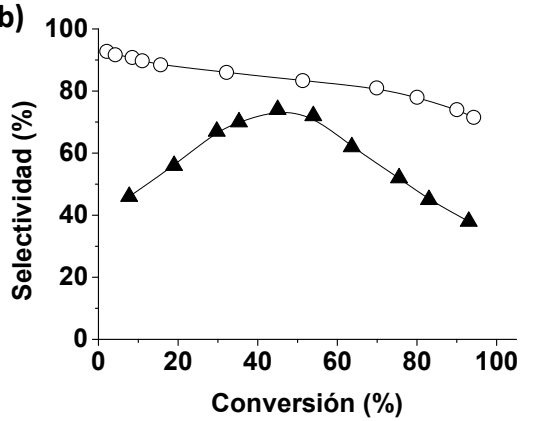

c)

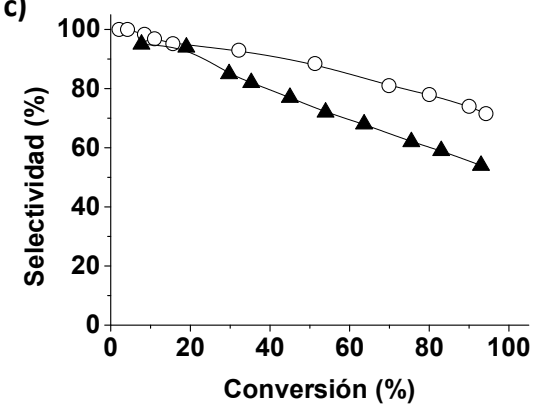

Figura 3.3. Gráfico de conversión frente a tiempo (a), selectividad ol/ona frente a conversión (b) y curva de conversión frente a selectividad ol/ona/hidroperóxido (c) para la oxidación aeróbica del indano usando MIL-101(Cr) o (Fe) sin activar cómo catalizadores. Leyenda: MIL-101(Fe) ( $\mathbf{\Delta})$, MIL-101(Cr) ( $)$ y control en ausencia de catalizador $(\bullet)$. Condiciones de reacción: $75 \mathrm{mg}$ de catalizador, $20 \mathrm{mmoles}$ de sustratos, $120^{\circ} \mathrm{C}$, atmósfera de $\mathrm{O}_{2}$.

El esquema 3.1 muestra los productos observados en la oxidación de indano y el mecanismo de reacción propuesto basado en la variación temporal de la distribución de productos que se observa (ver esquema 3.1b y figura 3.4). Como puede verse en el Esquema 3.1, el 1-indanol y la 1-indanona aparecen como productos inestables que sufren oxidación adicional a medida que el tiempo de reacción aumenta. La mezcla ol/ona derivaría del correspondiente hidroperóxido del 1-indanilo, el cual pudo ser caracterizado por cromatografía de gases tras su descomposición con trifenilfosfina ${ }^{38}$. Es conocido que los hidroperóxidos orgánicos pueden descomponer para dar la cetona y el alcohol correspondiente en cantidades variables dependiendo de las condiciones de reacción. ${ }^{37-39}$ Los balances de masas en la oxidación catalítica del indano usando tanto MIL-101(Cr) como MIL-101(Fe) basándose en los moles iniciales de indano fueron en todos los casos superiores al $95 \%$, aunque, los balances de masas tendieron a ser ligeramente menos completos con el aumento de la conversión. 
a) MIL-101 ( $\mathrm{CrOFe})+\mathrm{O}_{2} \rightarrow \mathrm{O}_{2}^{-}$

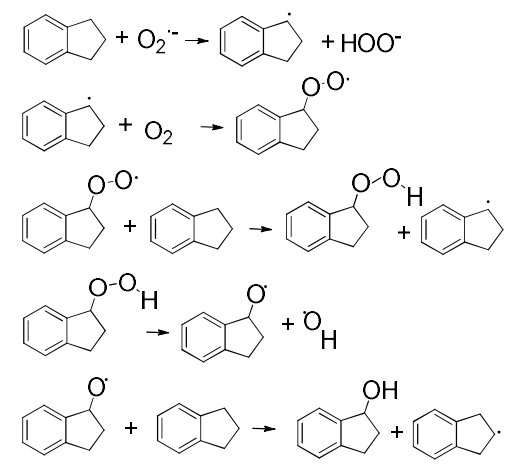

i<smiles>OC1Cc2ccccc2C1c1ccc2ccccc2c1</smiles>

Otros productos de oxidación

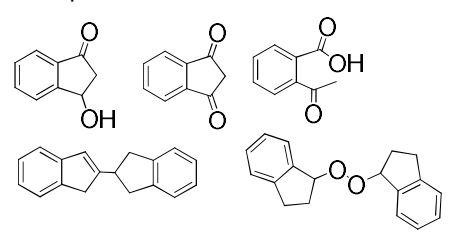

b)

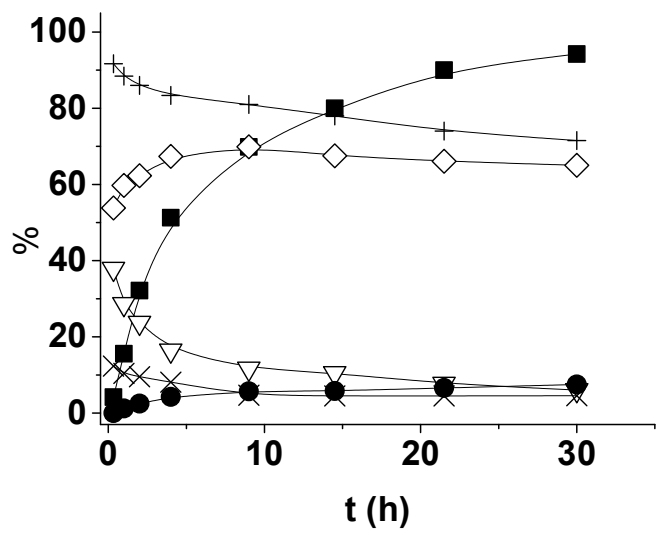

Esquema 3.1. (a) Mecanismo de reacción propuesto para la oxidación de indano empleando MIL101(Cr o $\mathrm{Fe}$ ) como catalizador y (b) Gráfico de conversión y selectividad frente a tiempo para la oxidación de indano usando MIL-101(Cr) sin activar. Leyenda: conversión de indano (- $\mathbf{a}$ y selectividad al hidroperóxido de 1-indanilo $(x)$, indanona $(\diamond)$, indanol $(\nabla)$ e indanol + indanona $(+)$. Condiciones de reacción: $75 \mathrm{mg}$ de catalizador, 20 mmoles de sustratos, $120^{\circ} \mathrm{C}$, atmósfera de $\mathrm{O}_{2}$. 
a)

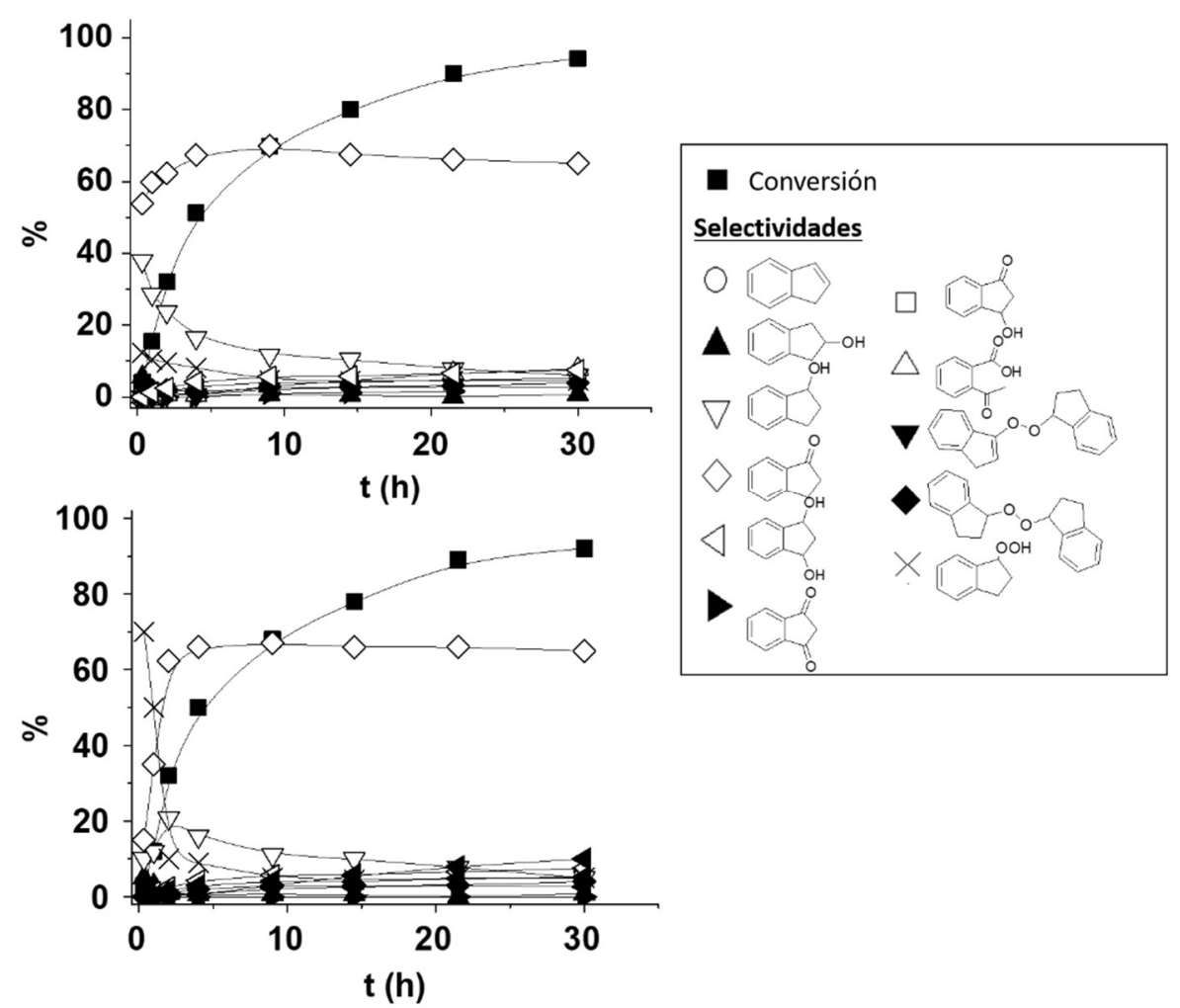

Figura 3.4. Gráfico de conversión y selectividad a los productos de reacción obtenidos en la oxidación aeróbica del indano sin destilar (a) y destilado (b) usando MIL-101(Cr) cómo catalizador. Condiciones de reacción: $75 \mathrm{mg}$ de catalizador, 20 mmoles de sustratos, $120^{\circ} \mathrm{C}$, atmósfera de $\mathrm{O}_{2}$.

Para poner en contexto los resultados de los ensayos catalíticos preliminares conviene hacer notar que estudios anteriores han mostrado que, aunque tratamientos de activación similares son capaces de reducir una cantidad significativa de iones $\mathrm{Fe}^{3+} \mathrm{a}$ ion $\mathrm{Fe}^{2+}, 40-42$ en el caso del MIL-101(Cr) no se han observado cambios en el estado de oxidación del $\mathrm{Cr}^{43}$ Indicar que cuando un ion $\mathrm{Fe}^{3+}$ se reduce a $\mathrm{Fe}^{2+}$ uno de los ligandos apicales $\mathrm{OH}$ inicialmente enlazado al ion metálico se debe perder para mantener neutralidad de cargas en el sistema, por lo que este ion estaría más expuesto y disponible a la activación del oxígeno. De acuerdo con esta interpretación, los datos catalíticos parecen indicar que la presencia de $\mathrm{Fe}^{2+}$ es en principio beneficiosa para la actividad del material MIL-101(Fe). Se volverá sobre este punto más adelante al discutir el mecanismo de oxidación. 
Capitulo 3.

Relacionado con la diferente reactividad de MIL-101(Cr) respecto MIL-101(Fe), la química de metales de transición muestra que incluso para un estado de oxidación dado, la reactividad de complejos metálicos depende de la naturaleza del catión. ${ }^{43,44}$ En el presente caso, se debe mencionar que debido a las diferentes condiciones de síntesis el material MIL-101 $(\mathrm{Cr})$ tiene iones $\mathrm{F}^{-}$mientras que MIL-101(Fe) tiene iones $\mathrm{Cl}^{-}$. Estas diferencias serían responsables de la mayor actividad catalítica observada para MIL-101(Cr) respecto a MIL-101(Fe).

Uno de los principales problemas de la oxidación aeróbica es la falta de selectividad hacia un producto determinado que además disminuye con la conversión. A partir del gráfico de selectividad frente a conversión para la oxidación de indano mostrado en la Figura 3.1, se puede concluir que MIL-101(Cr) exhibe, a pesar de tener la misma estructura, una mayor selectividad que el MIL-101(Fe). Más aún, para conversiones por debajo del $50 \%$, se alcanzan selectividades a la mezcla ol/ona superiores al $85 \%$ para MIL$101(\mathrm{Cr})$. Una posible racionalización para esta mayor selectividad se basa en la asunción de que la reacción está teniendo lugar dentro de los poros del MOF. Si eso fuera así, los poros del MIL-101(Cr) favorecerían la adsorción de indano y desorción de los productos ol/ona más polares. Así la adsorción preferente de indano dentro de los poros haría más favorable su oxidación con respecto a la oxidación de los productos ol/ona más polares.

A fin de proporcionar soporte experimental a la adsorción preferente de indano frente a indanol/indanona en MIL-101(Cr) respecto a MIL-101(Fe), se llevaron a cabo medidas de adsorción de indano, indanol e indanona, así como de mezclas de estos compuestos. La tabla 3.2 resume los resultados de adsorción. Se midió que las relaciones de adsorción indano/indanol, indano/indanol o indano/(indanol+indanona) son mayores en los experimentos de adsorción de MIL-101(Cr) con respecto a MIL-101(Fe), lo cual apoyaría la existencia de diferencias en las preferencias de adsorción y estas serían el posible origen de las diferencias de selectividad observadas para ambos MOFs. Además, podría ser que estas diferencias derivaran de las diferencias en la estabilidad del hidroperóxido de 1-indanilo en estos dos MOFs (comparar partes B y C en la Figura 3.1 y la Figura 3.3) como consecuencia de la mayor habilidad del $\mathrm{Cr}^{3+}$ a descomponer este intermedio comparado con la de los iones $\mathrm{Fe}^{2+} / 3+45,46$ 
Tabla 3.2. Medidas de adsorción isoterma de los sustratos individuales (indano, indanol o indanona) combinación de dos (indano y indanol o indanona) o los tres sustratos (indano, indanol y indanona) usando los sólidos MIL-101(Cr) o MIL-101(Fe).

\begin{tabular}{|c|c|c|c|c|c|}
\hline & \multicolumn{2}{|c|}{$\begin{array}{l}\text { Ratios de adsorción cal- } \\
\text { culados a partir de la ad- } \\
\text { sorción de los sustratos } \\
\text { individuales (indano, } \\
\text { indanol o indanona) }\end{array}$} & \multicolumn{2}{|c|}{$\begin{array}{l}\text { Ratios de adsorción cal- } \\
\text { culador a partir de la ad- } \\
\text { sorción competitiva de } \\
\text { los } 2 \text { componentes (in- } \\
\text { dano y indanol; indano y } \\
\text { indanone) }{ }^{\mathrm{b}}\end{array}$} & \multirow{2}{*}{$\begin{array}{l}\text { Ratios de adsor- } \\
\text { ción calculador a } \\
\text { partir de la adsor- } \\
\text { ción competitiva } \\
\text { de los } 3 \text { compo- } \\
\text { nentes (indano, in- } \\
\text { danol y indanone) }\end{array}$} \\
\hline & $\begin{array}{l}\text { Ratio molar } \\
\text { Indano/In- } \\
\text { danol }\end{array}$ & $\begin{array}{l}\text { Ratio } \\
\text { molar In- } \\
\text { dano/In- } \\
\text { danona }\end{array}$ & $\begin{array}{l}\text { Ratio molar } \\
\text { Indane/Inda- } \\
\text { nol }\end{array}$ & $\begin{array}{l}\text { Ratio } \\
\text { molar In- } \\
\text { dane/In- } \\
\text { danone }\end{array}$ & \\
\hline $\mathrm{Cr}$ & 2.72 & 1.17 & 2.56 & 1.5 & 2 \\
\hline $\mathrm{Fe}$ & 0.54 & 0. & 0.49 & 1.3 & 0.68 \\
\hline \multicolumn{6}{|c|}{$\begin{array}{l}{ }^{a} \text { Adsorción de los componentes solos: } 75 \mathrm{mg} \text { MIL-101, } 1 \mathrm{mmol} \text { sustrato (in- } \\
\text { dano, indanol o indanona), atmósfera de } \mathrm{O}_{2}, p \text {-xileno }(3 \mathrm{~mL}) \text {, temperatura am- } \\
\text { biente. }\end{array}$} \\
\hline \multicolumn{6}{|c|}{$\begin{array}{l}{ }^{\mathrm{b}} \text { Adsorción competitiva de los dos componentes: } 75 \mathrm{mg} \text { MIL-101, } 1 \mathrm{mmol} \\
\text { indano mezclada con } 0.1 \mathrm{mmol} \text { de indanol o } 0.1 \mathrm{mmol} \text { de indanona, atmósfera de } \\
\mathrm{O}_{2}, p \text {-xileno }(3 \mathrm{~mL}) \text {, temperatura ambiente. }\end{array}$} \\
\hline \multicolumn{6}{|c|}{$\begin{array}{l}{ }^{\mathrm{c}} \text { Medida de adsorción competitiva de los tres componentes: } 75 \mathrm{mg} \text { MIL-101, } \\
1 \mathrm{mmol} \text { indano mezclado con } 0.1 \mathrm{mmol} \text { de indanol y } 0.1 \mathrm{mmol} \text { de indanona, at- } \\
\text { mósfera de } \mathrm{O}_{2}, p \text {-xileno }(3 \mathrm{~mL}) \text {, temperatura ambiente. }\end{array}$} \\
\hline
\end{tabular}

La estabilidad del MIL-101(Cr) como catalizador fue estudiada midiendo su actividad catalítica tras reúsos consecutivos, así como, medidas analíticas de iones metálicos en disolución y de cristalinidad del sólido por difracción de rayos X. Se observó que en cuatro usos consecutivos los perfiles temporales de conversión (Figura 3.5) y las curvas de selectividad frente a conversión fueron coincidentes, confirmando que la actividad catalítica no disminuye con el reúso. Además, el análisis químico de Cr por ICP-AES en la fase líquida muestra que el contenido de este metal es inferior al $0.2 \%$ de la cantidad inicial de este elemento en el catalizador. También la difracción de rayos X del MIL101(Cr) muestra que la cristalinidad de este material se mantiene en 4 usos (Figura 3.5). Por consiguiente, estas 3 técnicas experimentales apoyan la estabilidad del MIL-101(Cr) como catalizador. De manera análoga se encontró que la difracción de rayos X de MIL- 
101(Fe) no cambia con su uso como catalizador (Figura 3.5) y que la cantidad de hierro lixiviado medida por ICP-AES fue del $1.6 \%$ en peso de la cantidad total inicial de $\mathrm{Fe}$ presente en MIL-101(Fe). Esta estabilidad no es sorprendente considerando que el material MIL-101 es uno de los MOFs más robustos que pueden soportar tratamientos en condiciones drásticas mucho más agresivas que las empleadas en el presente estudio. ${ }^{47}$ Además, la cantidad de Fe lixiviada algo superior comparada con la de $\mathrm{Cr}$, sugiere una mayor estabilidad de MIL-101(Cr) con respecto a MIL-101(Fe), tal como ha sido previamente observado por Kholdeeva y colaboradores cuando usaron estos materiales como catalizadores en la oxidación alílica de alquenos por $\mathrm{O}_{2}$ con pequeñas cantidades de TBHP como iniciador de radicales en ausencia de disolvente. ${ }^{24,35}$

a)

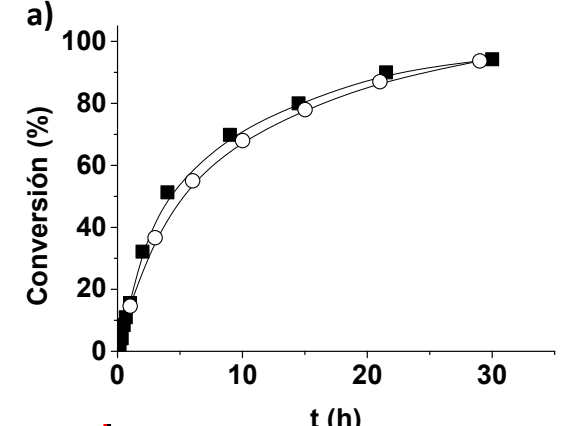

c)

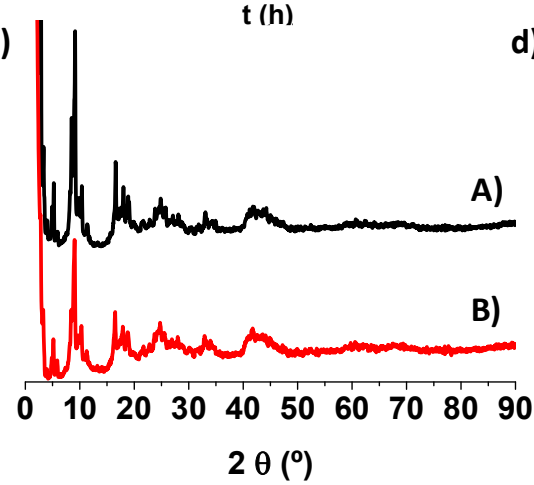

b)

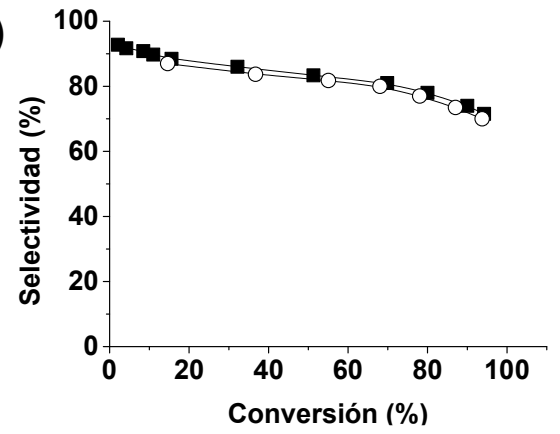

d)

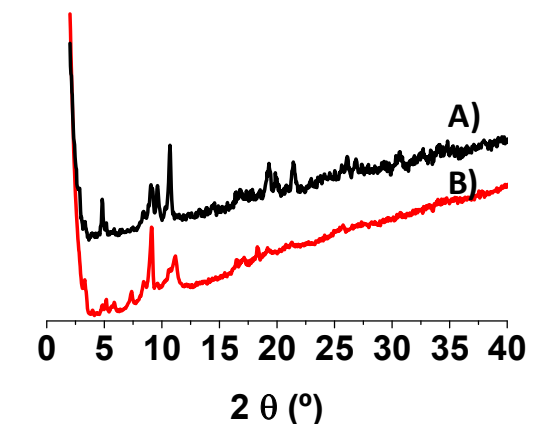

Figura 3.5. (a,b) reusabilidad de MIL-101(Cr) como catalizador para la oxidación aeróbica de indano, (c) cristalinidad de la muestra de MIL-101(Cr) fresca (A) y tras cuatro usos (B), y (d) difracción de rayos X de la muestra MIL-101(Fe) fresca (A) y tras su uso como catalizador en la oxidación aeróbica de indano (B). Leyenda: primer uso ( $\bullet$ cuarto uso (०). Condiciones de reacción: $75 \mathrm{mg}$ de catalizador, 20 mmoles de sustratos, $120^{\circ} \mathrm{C}$, atmósfera de $\mathrm{O}_{2}$. 
La heterogeneidad de la reacción fue estudiada llevando a cabo ensayos de filtración en caliente. Los resultados se presentan en la Figura 3.6. Como puede verse allí, el perfil temporal en la conversión de indano no se ve prácticamente afectado por la eliminación del sólido. Sin embargo, la selectividad ol/ona del filtrado es menor que para la reacción en presencia de MIL-101(Cr). Un resultado similar en el ensayo de filtración en caliente fue observado para la oxidación de tetralina a 1-tetralona usando TBHP como oxidante, MIL-101(Cr) como catalizador y clorobenceno como disolvente. ${ }^{29}$ En este precedente, el ligero aumento en la conversión de tetralina tras la filtración del catalizador sólido fue atribuido a la autooxidación térmica de la tetralina debido a la presencia de radicales intermedios activos en el filtrado y la cantidad muy pequeña de $\mathrm{Cr}$ lixiviado $(0.14 \mathrm{ppm})$ del material MIL-101(Cr). Además, un valor de selectividad más bajo hacia 1-tetralona tras la filtración del catalizador (73\%) respecto a la selectividad (83\%) en presencia del catalizador fue igualmente observado. ${ }^{29}$ Similarmente, en otro trabajo describiendo la oxidación anaeróbica sin disolvente de la tetralina usando un MOF de cobre se propuso que la evolución de la conversión tras la filtración del catalizador era debida principalmente a la presencia de hidroperóxidos orgánicos que están implicados en la autooxidación térmica de la tetralina. ${ }^{14} \mathrm{~A}$ fin de apoyar esta propuesta y considerando la cantidad muy pequeña de Cr lixiviado en el experimento usando MIL-101(Cr), se llevó a cabo un experimento control sobre la autooxidación de indano promovida por acetato de $\mathrm{Cr}$ en una concentración correspondiente a la cantidad determinada para el lixiviado de MIL-101(Cr). Los resultados se presentan en la Figura 3.7. Se observó que esta cantidad ínfima de $\mathrm{Cr}^{3+}(0.00058 \mathrm{mmol})$ era capaz de promover la autoxidación de indano en un porcentaje significativo de hasta un $78 \%$ en $30 \mathrm{~h}$, aunque la selectividad ol/ona para el control usando $\mathrm{Cr}\left(\mathrm{CH}_{3} \mathrm{COO}\right)_{3}$ fue significativamente menor que la conseguida en presencia de MIL-101(Cr) como iniciador.

En nuestro caso, la falta de influencia de la presencia del sólido una vez que la reacción ha empezado sería compatible con 2 posibilidades, la existencia de lixiviado de la especie catalíticamente activa presente en la fase líquida o con la operación de un mecanismo de autooxidación. Se ha comentado ya anteriormente que los análisis químicos muestran concluyentemente que el porcentaje de metal lixiviado en la disolución es despreciable y, por consiguiente, sugerimos que el papel de MIL-101(Cr) en la oxidación aeróbica de indano es el de actuar cómo un iniciador en un mecanismo radicalario en cadena con un ciclo de propagación de gran número de pasos. En otras palabras, una vez que se forman los radicales bencílicos en presencia de oxígeno tendría lugar una oxidación en cadena, no solo en el interior de los poros del sólido sino, también, en la fase líquida incluso en ausencia del material. Este mecanismo en cadena de autooxidación de indano ocurriendo incluso en ausencia de MIL-101 requiere la presencia de (hidro)peróxidos, los cuales son detectables por análisis de GC. A fin de proporcionar evidencia de la presencia de hidroperóxido de indanilo en la mezcla de reacción, se usó el procedimiento convencional en el que se añade un exceso de trifenilfosfina a la mezcla de reacción y se cuantifica por GC la formación de óxido de trifenilfosfina, generado por descomposición nucleofílica del hidroperóxido orgánico. ${ }^{38}$ La ecuación 3.1 indica el 
proceso a través del cual se lleva a cabo la cuantificación indirecta de hidroperóxidos inestables empleando trifenilfosfina. Los resultados obtenidos muestran, de hecho, que dependiendo del tiempo de reacción pueden estar presentes en la mezcla de reacción diferentes concentraciones de hidroperóxido que pueden llegar a representar hasta el $12 \%$ de selectividad a un valor de conversión de indano del $25 \%$ (ver gráfico en el esquema 3.1b).

$$
\mathrm{R}-\mathrm{OOH}+(\mathrm{Ph})_{3} \mathrm{P} \rightarrow \mathrm{R}-\mathrm{OH}+(\mathrm{Ph})_{3} \mathrm{PO}
$$

Ecuación 3.1. Proceso de cuantificación del hidroperóxido de 1-indanilo
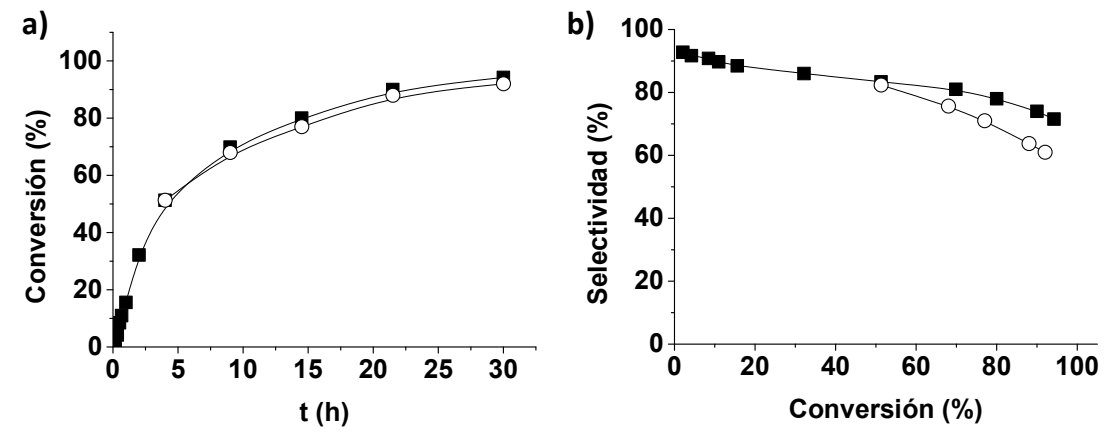

Figura 3.6. Perfil temporal de conversión (a) y gráfico de selectividad a la mezcla ol/ona frente a conversión (b) para la oxidación aeróbica del indano en presencia de MIL-101(Cr) (ש) y tras filtrar el catalizador a un valor de conversión del 50\% (०). Condiciones de reacción: $75 \mathrm{mg}$ de catalizador, 20 mmoles de sustratos, $120^{\circ} \mathrm{C}$, atmósfera de $\mathrm{O}_{2}$.

a)

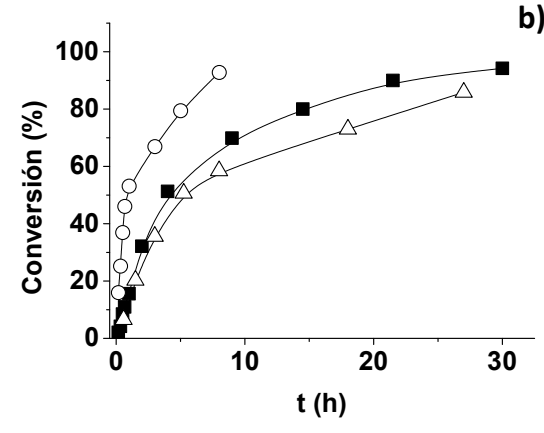

b) 100

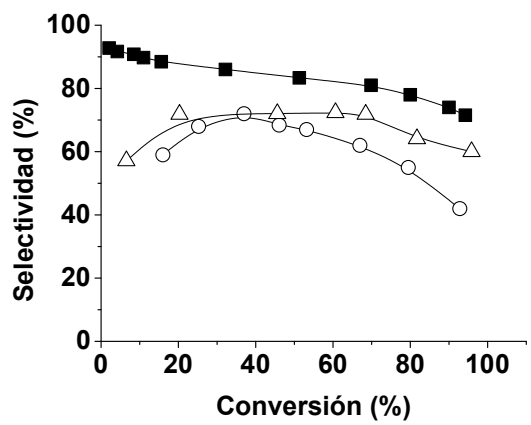

Figura 3.7. Gráficos de conversión frente a tiempo (a), selectividad ol/ona frente a conversión (b) para la oxidación aeróbica del indano usando acetato de $\mathrm{Cr}$ a dos concentraciones diferentes (símbolos vacíos) como catalizador homogéneo o MIL-101(Cr) (ש) como catalizador heterogéneo. Condiciones de reacción: MIL-101(Cr) $(75 \mathrm{mg}, 0.29 \mathrm{mmol} \mathrm{Cr}), \mathrm{Cr}\left(\mathrm{CH}_{3} \mathrm{COO}\right)_{3}(0.29(\mathrm{\circ})$ o $0.00058(\Delta)) \mathrm{mmol} \mathrm{de} \mathrm{Cr}$, 20 mmoles de sustratos, $120^{\circ} \mathrm{C}$, atmósfera de $\mathrm{O}_{2}$. La mínima cantidad de acetato de $\mathrm{Cr}$ corresponde con la cantidad de $\mathrm{Cr}$ lixiviada usando MIL-101(Cr) como catalizador. 
A fin de apoyar el papel de los sólidos con estructura MIL-101 como iniciadores del mecanismo de autooxidación de cadena larga, se llevó a cabo una serie de experimentos en los que se usó TBHP (Figuras 3.8 a, c y 3.9 a, c) o azobisisobutironitrilo (AIBN) (Figuras 3.8 b, d y 3.9 b, d) como iniciadores de radicales moleculares. Este último, el AIBN, debe promover la autooxidación en ausencia de cualquier material sólido. La cantidad de TBHP o AIBN fue la misma que la de moles de metal presentes en el material MIL-101(Cr) (0.29 mmoles) o los moles de hidroperóxido de 1-indanilo encontrados en la mezcla de reacción ( 0.6 mmoles) usando MIL-101(Cr) como catalizador. Usando estos iniciadores de radicales orgánicos, la conversión de indano es más alta que cuando se usa MIL-101(Cr), mientras que, se encontraron conversiones similares cuando se usó TBHP como iniciador de radicales. La principal diferencia, sin embargo, entre el uso de AIBN o TBHP y MIL-101(Cr) es la selectividad a productos, la cual en el rango de conversiones completas es siempre menor para los productos -ol/-ona con iniciadores radicalarios orgánicos que con MIL-101(Cr), que fue el sólido más selectivo, así como en el caso del MIL-101(Fe). Por ejemplo, en el caso de la oxidación de indano, al 30\% de conversión, la selectividad hacia la mezcla -ol/-ona usando AIBN como iniciador de radicales es del $66 \%$, usando TBHP es $74 \%$ y en presencia de MIL-101(Cr) es de $87 \%$. Conviene hacer notar que en oxidaciones aeróbicas la selectividad es el parámetro clave, más que las conversiones, debido a la complejidad en la mezcla de reacción. La purificación de los productos es un proceso complicado y se prefiere llevar a cabo las oxidaciones a conversiones menores a fin de conseguir selectividades hacía el producto de interés más elevadas. En este contexto, la eficiencia de MIL-101(Cr) es notablemente mejor que la de iniciadores radicales orgánicos. 
a)
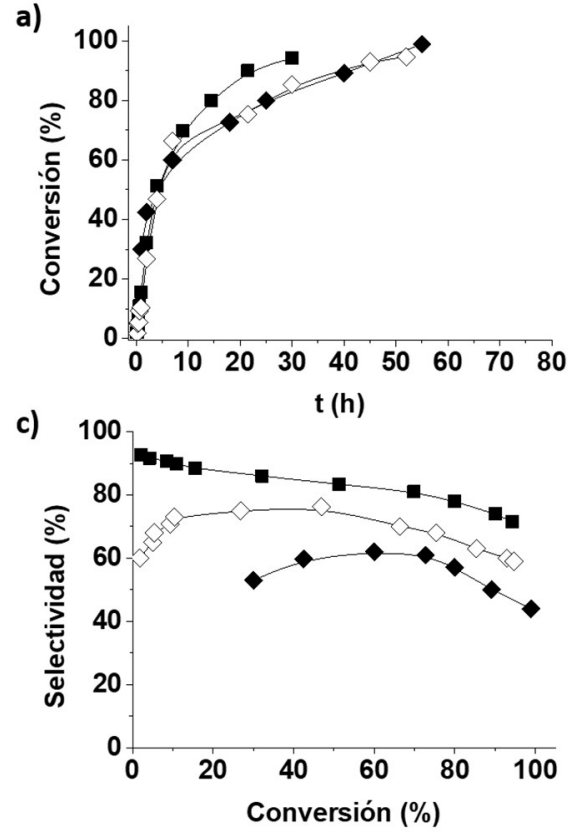

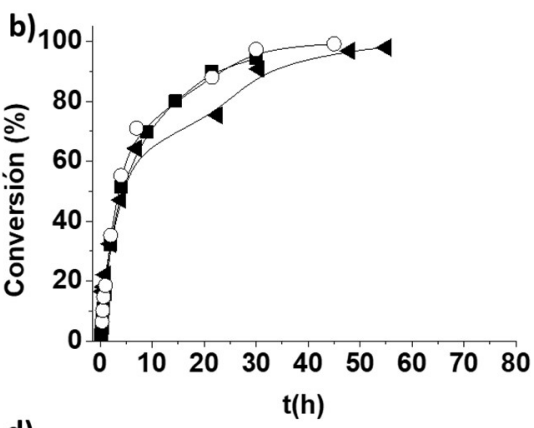

d) 100

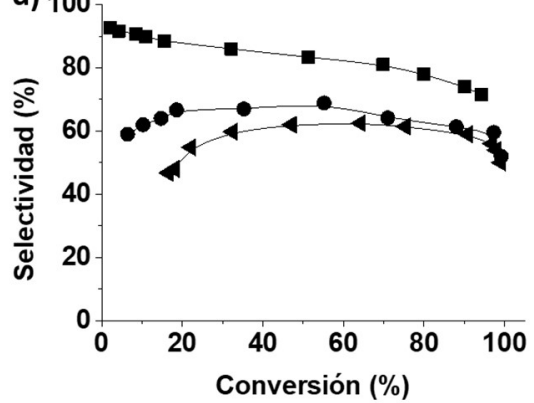

Figura 3.8. Gráfico de conversión frente a tiempo $(a, b)$, selectividad ol/ona frente a conversión (c,d) para la oxidación aeróbica del indano usando MIL-101(Cr) cómo catalizador heterogéneo. Leyenda: MIL-101(Cr) (75 mg, $0.29 \mathrm{mmol}$ de Cr) (ש) y los iniciadores de radicales homogéneos TBHP $(0.15$ mmol $(\diamond) ; 2 \mathrm{mmol}(\diamond))$ y AIBN $(0.15 \mathrm{mmol}(\circ) ; 2 \mathrm{mmol}(\boldsymbol{\Delta}))$. Condiciones de reacción: MIL-101(Cr) u oxidante como sea indicado, 20 mmoles de sustratos, $120^{\circ} \mathrm{C}$, atmósfera de $\mathrm{O}_{2}$. 
MIL-101(Cr) $/ \mathrm{O}_{2}$ vs TBHP $/ \mathrm{O}_{2}(\mathrm{a}, \mathrm{c})$

a)
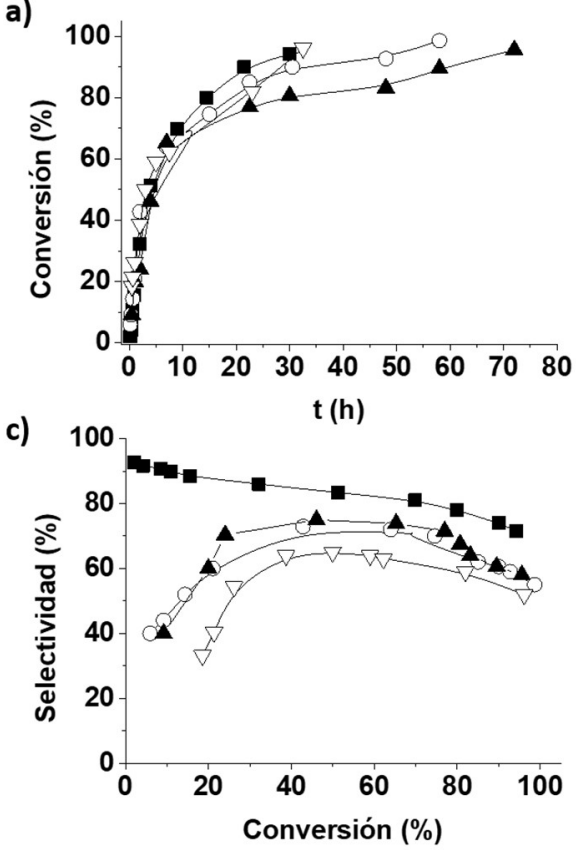

MIL-101(Cr) and $\mathrm{O}_{2}$ vs AIBN/ $\mathrm{O}_{2}(\mathrm{~b}, \mathrm{~d})$
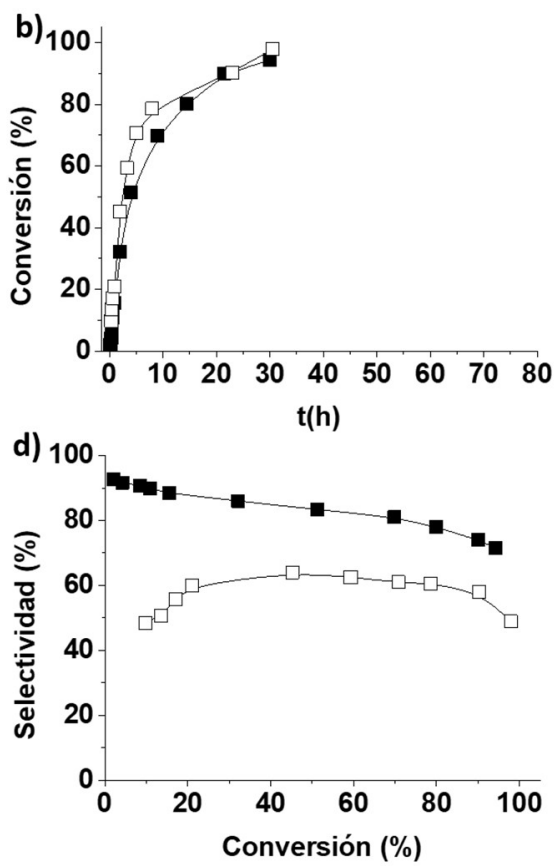

Figura 3.9. Gráfico de conversión frente a tiempo (a,b), selectividad ol/ona frente a conversión (c,d) para la oxidación aeróbica del indano usando MIL-101(Cr) cómo catalizador heterogéneo. Leyenda: MIL-101(Cr) (75 mg, $0.29 \mathrm{mmol}$ de Cr) (@) y los iniciadores de radicales homogéneos TBHP $(0.5$ $\mathrm{mmol}(\boldsymbol{\Delta}) ; 1 \mathrm{mmol}(\circ) ; 1.5 \mathrm{mmol}(\nabla))$ y AIBN $(0.3 \mathrm{mmol}(\square))$. Condiciones de reacción: MIL-101(Cr) u oxidante como sea indicado, 20 mmoles de sustratos, $120^{\circ} \mathrm{C}$, atmósfera de $\mathrm{O}_{2}$.

Usando acetato de $\mathrm{Cr}$ como catalizador homogéneo para la oxidación aeróbica de indano se consiguió una selectividad hacia la mezcla-ol/-ona de $69 \%$ al $30 \%$ de conversión (Figura 3.3). Estos valores confirman la superioridad del material MIL-101(Cr) en el control de la distribución de productos de la oxidación aeróbica de compuestos bencílicos como el indano.

Así, aparentemente, el principal papel del MIL-101 en presencia de oxígeno es el de actuar como iniciador de radicales y proporcionar cavidades de reacción con concentraciones de compuestos diferentes y polaridades diferentes que en la fase líquida. La actividad del MIL-101 como iniciador de radicales junto con la cadena de propagación larga en la autooxidación de indano explica que una vez los radicales han sido creados la filtración no afecta a la conversión, solo a la distribución de productos (Figura 3.6). El papel de estos materiales MIL-101 como iniciadores de radicales fue también demostrado por medidas cinéticas en las cuales la cantidad de sólido se varió en más de un 
orden de magnitud de 75 a 7.5 o $1.5 \mathrm{mg}$, sin que se observase variación en la velocidad inicial de reacción ni en el perfil temporal de desaparición del indano (Figura 3.10 a), aunque la selectividad en función de la cantidad de catalizador muestre variaciones importantes en la proporción relativa de los procesos que tienen lugar dentro y fuera de los poros (Figura 3.10 b). Las figuras 3.10 y 3.11 muestran una comparación de las gráficas de selectividad frente a conversión.
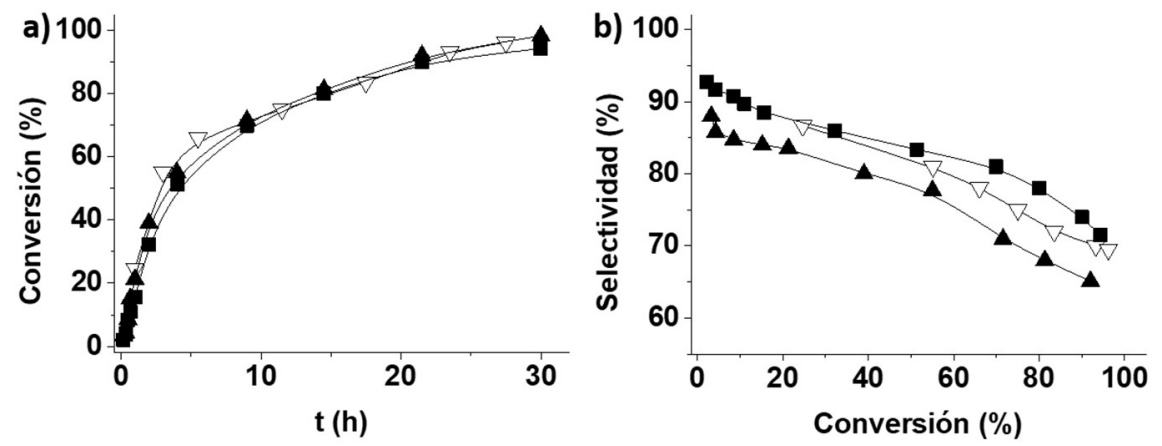

Figura 3.10. Perfil temporal de conversión (a) y gráfico de selectividad a la mezcla ol/ona frente a conversión (b) para la oxidación aeróbica del indano en presencia de diferentes cantidades de MIL101(Cr). Leyenda: $75 \mathrm{mg}$ de MIL-101(Cr) (®), $7.5 \mathrm{mg}(\nabla)$ y $1.5 \mathrm{mg}$ de catalizador $(\boldsymbol{\Delta})$. Condiciones de reacción: catalizador MIL-101(Cr), 20 mmoles de sustrato, $120^{\circ} \mathrm{C}$, atmósfera de $\mathrm{O}_{2}$.
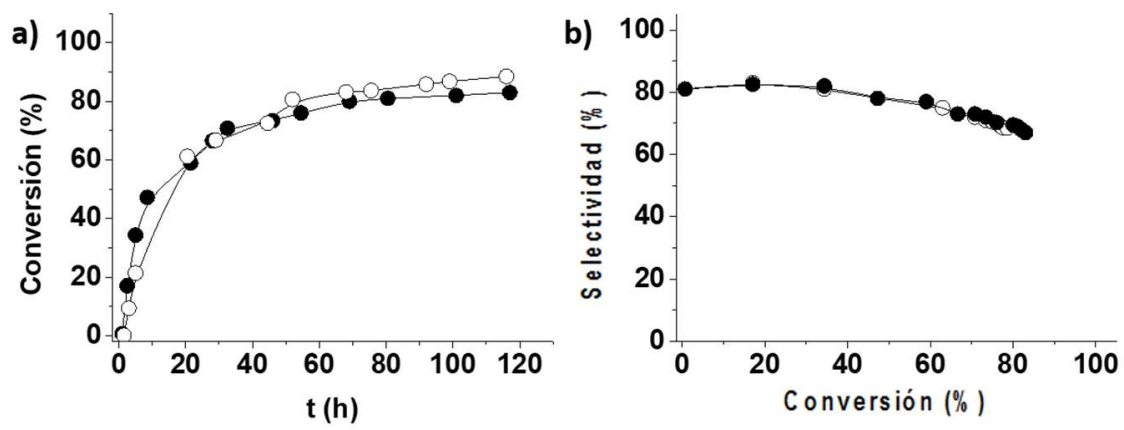

Figura 3.11. Perfil temporal de conversión (a) y gráfico de selectividad a la mezcla ol/ona frente a conversión (b) en presencia de catalizador fresco $(\circ)$ y reusado $(\bullet)$ para el test de productividad con 1.5 $\mathrm{mg}$ de MIL-101(Cr) en la oxidación aeróbica de indano. Condiciones de reacción: catalizador $1.5 \mathrm{mg}$ de MIL-101(Cr), 522 mmoles de sustrato, $120^{\circ} \mathrm{C}$, atmósfera de $\mathrm{O}_{2}$. 
La propuesta de que los sólidos MIL-101 actúan como iniciadores de radicales está de acuerdo también con el test de productividad en el cual grandes excesos de indano son oxidados (460 y 444 mmoles en el primer y segundo uso respectivamente, por MIL101(Cr) (1.5mg) Figura 3.11). En estas condiciones, en las cuales se usa un exceso grande de indano con respecto al MIL-101(Cr), la reacción para eventualmente a tiempos de reacción largos alcanzándose conversiones de entorno al 85\% sin conseguir conversiones completas. Este comportamiento seria consistente con una desactivación reversible del catalizador, en el presente caso debido a la falta de generación de radicales bencílicos. Sin embargo, si el catalizador sólido es recuperado por filtración y lavado exhaustivamente con etanol y usado de nuevo, se obtienen perfiles temporales de conversión muy similares a los que se determinan para muestras frescas del material. Por consiguiente, la aparente desactivación del catalizador es causada probablemente por el bloqueo de los sitios activos del catalizador por los productos de reacción en lugar de por una destrucción de los centros activos los cuales recuperan su actividad al eliminar los productos de reacción que actuaban como veneno.

Estos hechos indicarían que solo unos pocos radicales indanilo se forman por el catalizador sólido. Las conversiones de sustrato y, por consiguiente, la velocidad de reacción está controlada no solo por la etapa de iniciación, sino por la velocidad de propagación, la cual básicamente depende de la concentración de oxígeno y de la longitud de la cadena de propagación. Si en lugar de oxígeno se usa aire en el proceso, se observa una disminución significativa en la velocidad inicial de reacción, la cual sigue la tendencia esperada para una cinética de primer orden con respecto a la presión de oxígeno (Figura 3.12 y 3.13). Como se muestra en la figura 3.12, cuando el experimento se lleva a cabo en ausencia de oxígeno, no se observa conversión de indano, pero si la reacción se inicia bajo Ar y posteriormente se introduce oxígeno en el sistema, entonces la misma velocidad de reacción que cuando la reacción se inicia en oxígeno es observada.
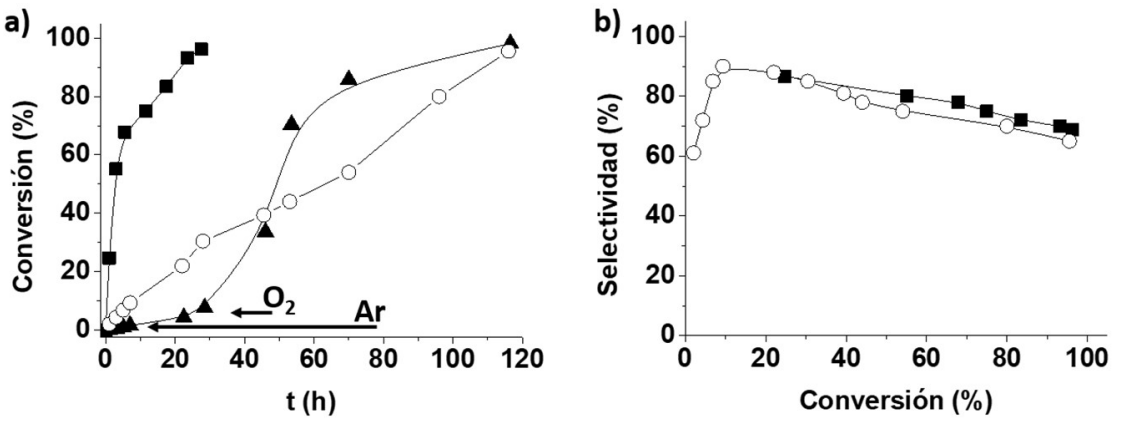

Figura 3.12. Influencia de la atmósfera de la reacción en el perfil temporal de conversión (a) y gráfico de selectividad a la mezcla ol/ona frente a conversión (b) en presencia de MIL-101(Cr). Leyenda: usando oxígeno (-), empleando aire (o) y empleando Ar como atmósfera hasta las $24 \mathrm{~h}$, a partir de ahí se cambia a atmósfera de oxígeno $(\boldsymbol{\Delta})$ en la oxidación aeróbica de indano. Condiciones de reacción: catalizador $7.5 \mathrm{mg}$ de MIL-101(Cr), 20 mmoles de sustrato y $120^{\circ} \mathrm{C}$. 


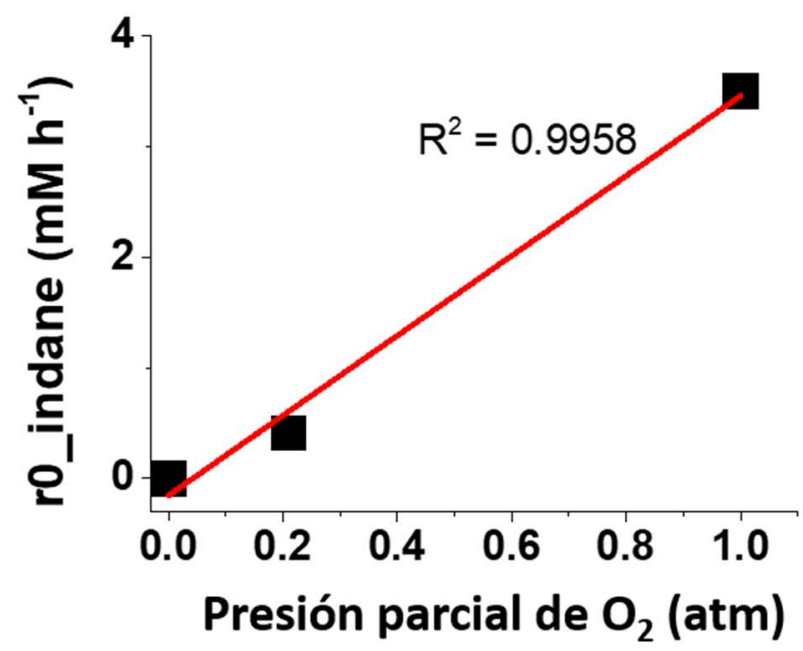

Figura 3.13. Influencia de la presión parcial de $\mathrm{O}_{2}$ en la velocidad inicial de la reacción de oxidación aeróbica de indano usando MIL-101(Cr) como catalizador. Condiciones de reacción: catalizador 7.5 mg de MIL-101(Cr), 20 mmoles de sustrato y $120^{\circ} \mathrm{C}$.

A fin de proporcionar información adicional sobre los mecanismos de reacción, se llevaron a cabo una serie de experimentos mostrados en la figura 3.14 en los cuales la oxidación de indano se llevó a cabo con MIL-101(Cr) en presencia de TEMPO, ácido benzoico y DMF. Se observó que mientras el TEMPO (bien añadido a tiempo inicial o añadido transcurridas 1.5 horas correspondientes a una conversión de indano del $28 \%$ ) inhibe eficientemente la reacción. Por otra parte, la presencia de ácido benzoico no posee influencia en la actividad catalítica. Y en el caso del DMF, este actúa como inhibidor de la oxidación aeróbica de indano. Estos resultados sobre la influencia de la presencia de inhibidores en la reacción indican que los centros ácido/base no están probablemente implicados en la oxidación, mientras que los intermedios de reacción más probables implican radicales bencílicos. De hecho, cuando el TEMPO está presente simultáneamente con $\mathrm{O}_{2}$ molecular, la distribución de productos cambia en alguna medida; los peróxidos simétricos y asimétricos de indanilo e indenilo, junto con algún éter 1-indanilo fueron caracterizados en la mezcla de reacción. TEMPO y DMF son capaces de inhibir la reacción bien sean añadidos a tiempo inicial (Figura 3.14) o sean añadidos una vez que la reacción ha sido iniciada (Figura 3.15). 


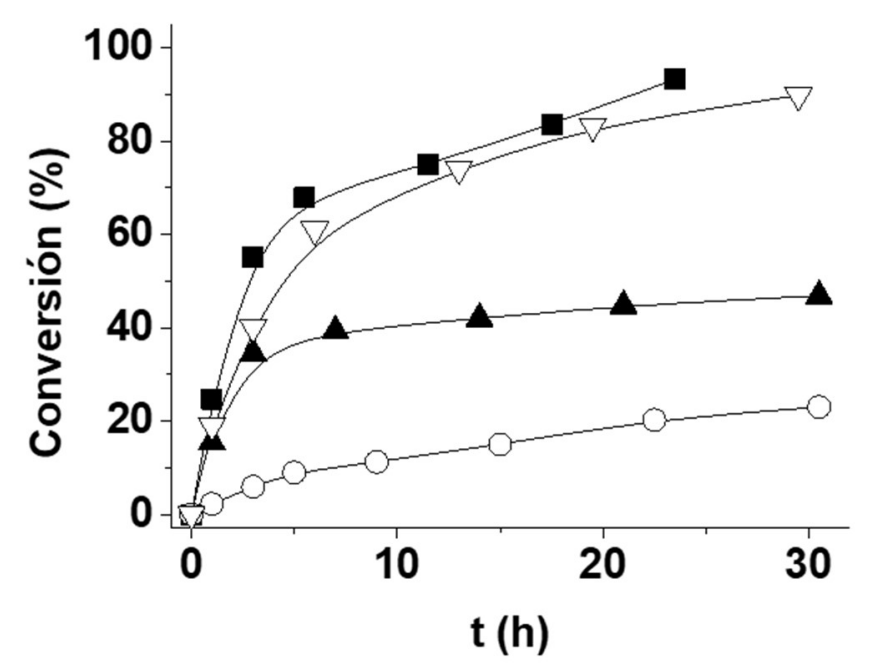

Figura 3.14. Oxidación aeróbica de indano usando MIL-101(Cr) como catalizador ( $\mathbf{a})$ en presencia de TEMPO (o), ácido benzoico $(\nabla)$ y DMF $(\Delta)$.Condiciones de reacción: $75 \mathrm{mg}$ de catalizador, $20 \mathrm{mmo-}$ les de indano, $120^{\circ} \mathrm{C}$, atmósfera de $\mathrm{O}_{2}$.

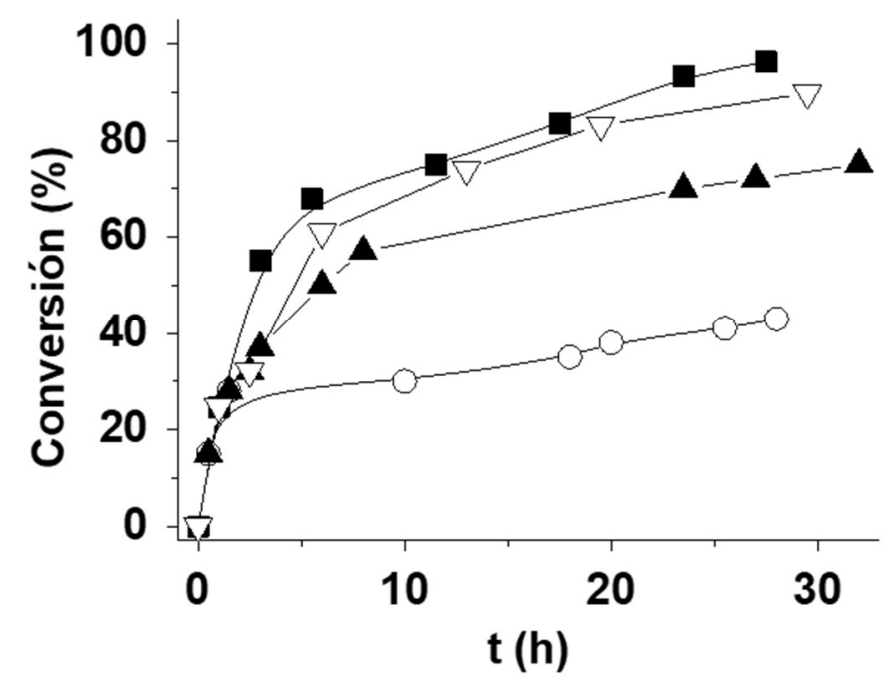

Figura 3.15. Oxidación aeróbica de indano usando MIL-101(Cr) como catalizador ( $\mathbf{\square})$ en presencia de TEMPO (०), ácido benzoico $(\nabla)$ y DMF $(\boldsymbol{\Delta})$.Condiciones de reacción: $75 \mathrm{mg}$ de catalizador, $20 \mathrm{mmo}-$ les de indano, $120^{\circ} \mathrm{C}$, atmósfera de $\mathrm{O}_{2}$. Los inhibidores TEMPO, ácido benzoico y DMF fueron añadidos a la $1.5 \mathrm{~h}$ de reacción cuando la conversión de indano era del $28 \%$. 
A fin de determinar la aplicabilidad del material MIL-101 como iniciador de radicales para promover la autooxidación de hidrocarburos bencílicos se llevó a cabo la oxidación de 6 compuestos diferentes, tales como, etilbenceno, $n$-butilbenceno, isobutilbenceno, cumeno, sec-butilbenceno y 1-bromo-4-butilbenceno. Estos experimentos (excepto el etilbenceno el cual fue siempre destilado) se llevaron a cabo usando sustratos comerciales sin destilar y recién destilados. El objeto de estos experimentos fue determinar si la posible presencia de cantidades ínfimas de hidroperóxido orgánico en muestras envejecidas influye o no en la actividad catalítica cuando se usa MIL-101(Cr) como catalizador (Figuras 3.16 a 3.26). Se observó que la actividad catalítica usando sustratos destilados es similar o ligeramente inferior (diferencias de menos del 5\%) que la observada usando sustratos sin destilar y, por tanto, la actividad catalítica observada se atribuye principalmente a las especies generadas por el cluster metálico en el material con $\mathrm{O}_{2}$ molecular (ver más adelante la discusión del mecanismo de reacción). En todos los casos, conversiones completas del material de partida fueron conseguidas empleando MIL-101(Cr) hacia una mezcla de productos, los cuales pueden fácilmente ser racionalizados como derivados de la autoxidación en las posiciones bencílicas. La tabla 3.2 proporciona un resumen de los resultados obtenidos, mientras que las figuras 3.16 a 3.26 ilustran las cinéticas de las oxidaciones. Como una tendencia general, el etilbenceno y el sec-butilbenceno dan lugar a la formación de acetofenona cuya selectividad se mantiene durante el aumento de la conversión. En contraste, el $n$-butil e isobutilbenceno forman como producto primario la correspondiente butirofenona que aparece como inestable durante el trascurso de la reacción sufriendo una oxidación a ácido benzoico. Esta inestabilidad con respecto a la acetofenona refleja la diferente habilidad a sufrir rotura oxidativa de enlace $\mathrm{C}-\mathrm{C}$ de un grupo metilo (etilbenceno y sec-butilbenceno) con respecto a la reactividad mayor de los grupos metileno (butirofenona). El hecho de que el intermedio de reacción se fuera al radical bencílico correspondiente se haya apoyado en que un sustituyente bromo en para disminuye la velocidad de reacción en torno a 1.2 lo cual está de acuerdo con la influencia esperada para un grupo $p$-bromo electrón atrayente como sustituyente. Los radicales bencílicos terciarios, como radicales cumilo, forman los hidroperóxidos más estables, los cuales pueden ser cuantificados en este caso por GC y GC-MS. Se encontró que la selectividad al hidroperóxido disminuye con la conversión de cumeno como ya era conocido para oxidaciones promovidas a través de radicales. 
MIL-101 como promotor sólido reusable para la autooxidación de hidrocarburos bencílicos.

Tabla 3.2. Oxidación aeróbica de hidrocarburos aromáticos bencílicos usando MIL-101(Cr) como catalizador heterogéneo.

\begin{tabular}{|c|c|c|c|}
\hline & $\begin{array}{l}\text { Conversión } \\
(\%)\end{array}$ & Productos de reacción & $\begin{array}{l}\text { Selectividad } \\
(\%)\end{array}$ \\
\hline Etilbenceno & 90 & Acetofenona & 80 \\
\hline$n$-Butilbenceno ${ }^{\mathrm{b}}$ & 100 & $\begin{array}{l}\text { Ácido Benzoico } \\
\text { Butirofenona }\end{array}$ & $\begin{array}{l}58 \\
40\end{array}$ \\
\hline Isobutilbenceno $^{c}$ & 100 & $\begin{array}{l}\text { Ácido Benzoico } \\
\text { Fenilisopropil cetona }\end{array}$ & $\begin{array}{l}78 \\
18\end{array}$ \\
\hline Cumeno & 100 & $\begin{array}{l}\text { Acetofenona } \\
\text { Cumil hidroperóxido }\end{array}$ & $\begin{array}{l}78 \\
18\end{array}$ \\
\hline sec-Butilbenceno & 100 & $\begin{array}{l}\text { Acetofenona } \\
\text { Propiofenona }\end{array}$ & $\begin{array}{l}79 \\
18\end{array}$ \\
\hline $\begin{array}{l}\text { 1-Bromo-4-butil- } \\
\text { benceno }\end{array}$ & 50 & 4-bromobutirofenona & 80 \\
\hline \multicolumn{4}{|c|}{$\begin{array}{l}{ }^{\text {a }} \text { Condiciones de reacción: } 7.5 \mathrm{mg} \text { de catalizador, } 20 \mathrm{mmol} \text { de sustrato, } \\
\text { atmósfera de } \mathrm{O}_{2}, 120^{\circ} \mathrm{C} \text { y tiempo de reacción indicado en las figuras de } 3.16 \\
\text { a } 3.26 \text {. }\end{array}$} \\
\hline \multicolumn{4}{|c|}{${ }^{b}$ Tiempo de reacción $96 \mathrm{~h}$} \\
\hline${ }^{\mathrm{c}}$ Tiempo de rea & ón $46 \mathrm{~h}$ & & \\
\hline
\end{tabular}


Capitulo 3.
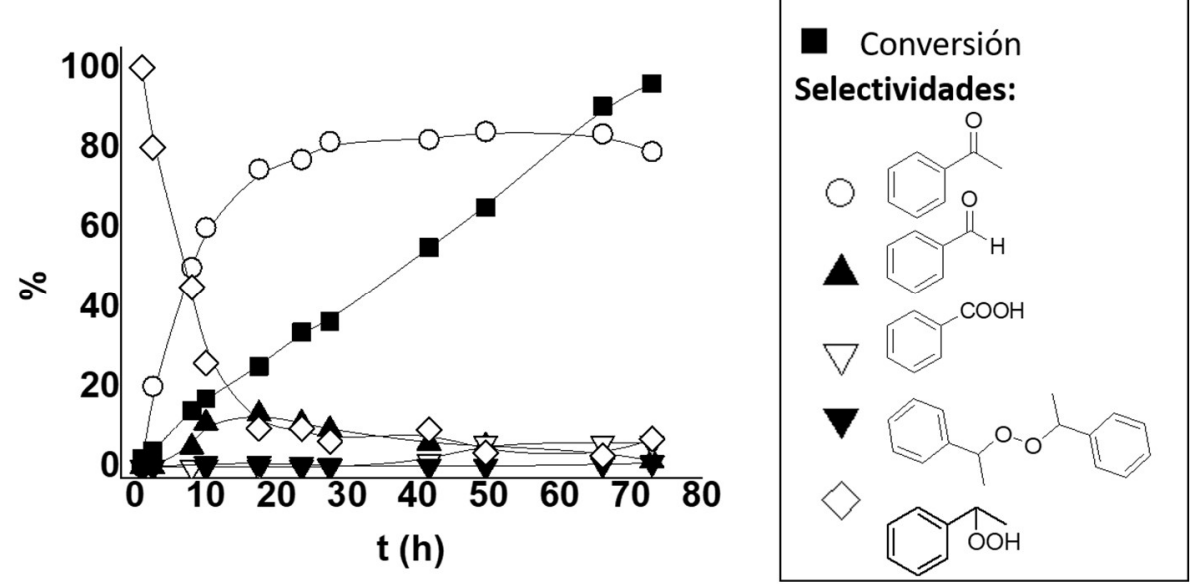

Figura 3.16. Gráfico de conversión y selectividad frente a tiempo para la oxidación aeróbica de etilbenceno usando MIL-101(Cr) como catalizador. Reacciones de reacción: $7.5 \mathrm{mg}$ de catalizador, 20 mmol de sustrato, atmósfera de $\mathrm{O}_{2}$ y $120^{\circ} \mathrm{C}$. 
a)

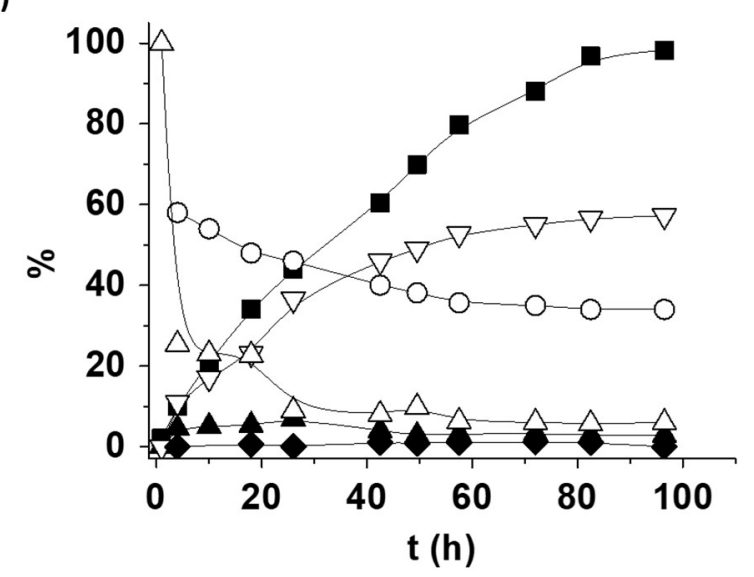

b)

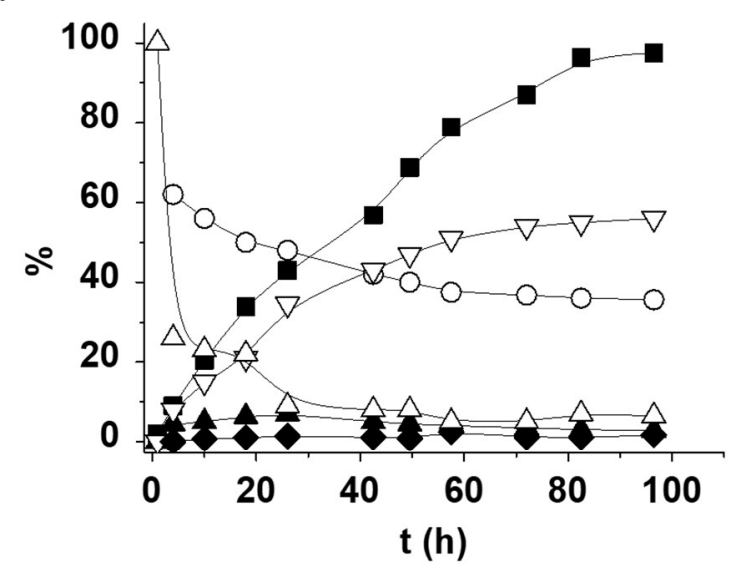

Conversión

Selectividades:

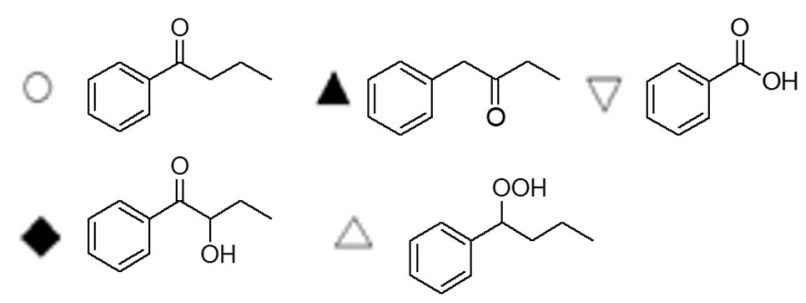

Figura 3.17. Gráficos de conversión y selectividad frente a tiempo para la oxidación aeróbica de $n$ butilbenceno sin destilar (a) y destilado (b) usando MIL-101(Cr) como catalizador. Reacciones de reacción: $7.5 \mathrm{mg}$ de catalizador, $20 \mathrm{mmol}$ de sustrato, atmósfera de $\mathrm{O}_{2}$ y $120{ }^{\circ} \mathrm{C}$. 
Capitulo 3.

a)

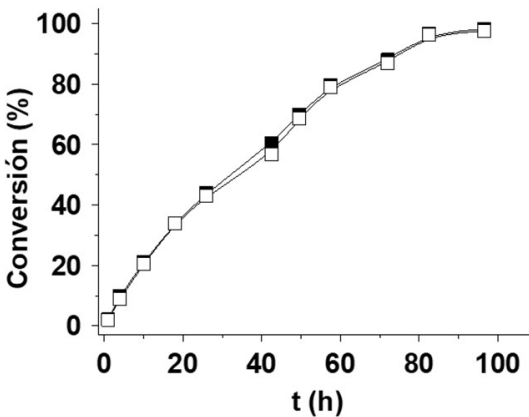

b)

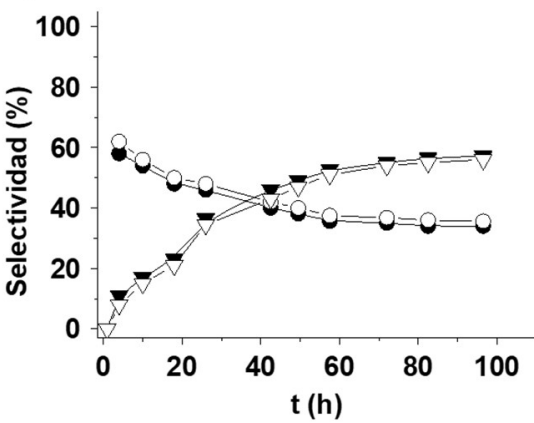

Figura 3.18. Comparación de los gráficos de conversión frente a tiempo (a) y selectividad frente a tiempo (b) de butirofenona (círculos) y ácido benzoico (triángulos) para la oxidación aeróbica de $n$ butilbenceno sin destilar (símbolos rellenos) y destilado (símbolos vacíos) usando MIL-101(Cr) como catalizador. Reacciones de reacción: $7.5 \mathrm{mg}$ de catalizador, $20 \mathrm{mmol}$ de sustrato, atmósfera de $\mathrm{O}_{2}$ y 120 ${ }^{\circ} \mathrm{C}$. 
a)

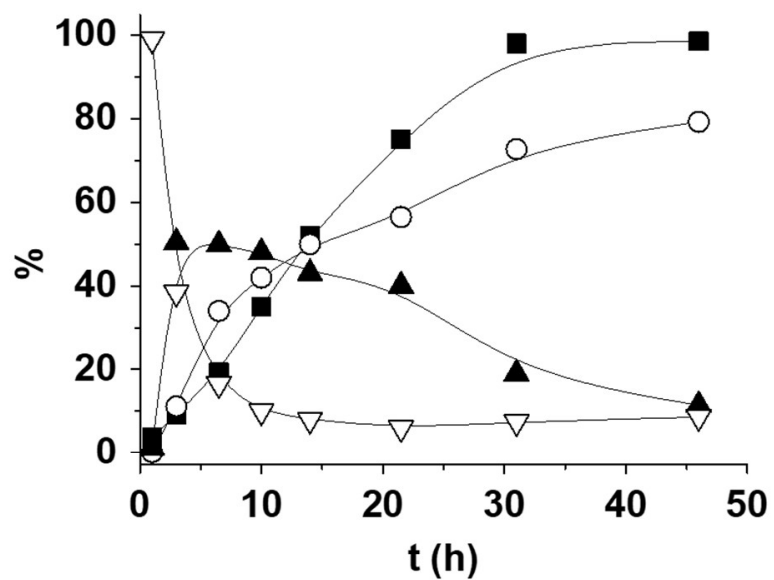

b)

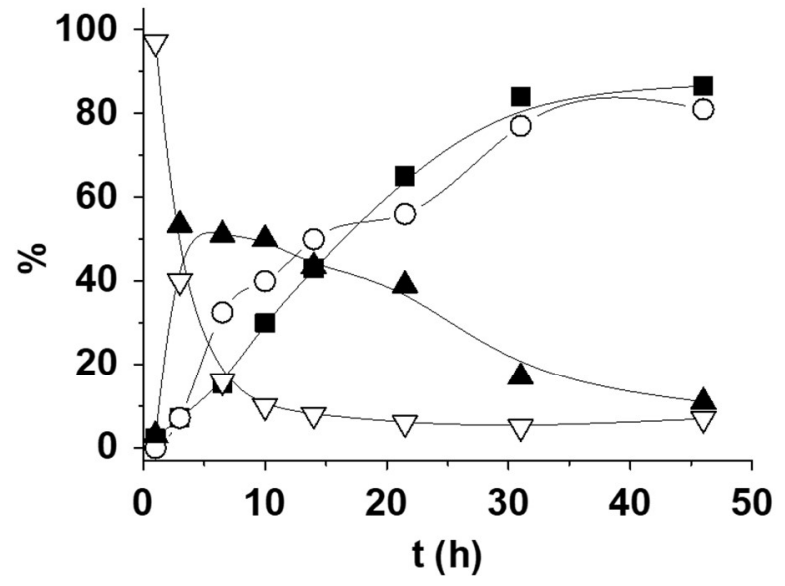

Conversión

Selectividades:<smiles>O=C1C=CC(C(=O)O)C=C1</smiles><smiles>CC(C)C(=O)c1ccccc1</smiles>

Figura 3.19. Gráficos de conversión y selectividad frente a tiempo para la oxidación aeróbica de isobutilbenceno sin destilar (a) y destilado (b) usando MIL-101(Cr) como catalizador. Reacciones de reacción: $7.5 \mathrm{mg}$ de catalizador, $20 \mathrm{mmol}$ de sustrato, atmósfera de $\mathrm{O}_{2}$ y $120{ }^{\circ} \mathrm{C}$. 
Capitulo 3.

a)

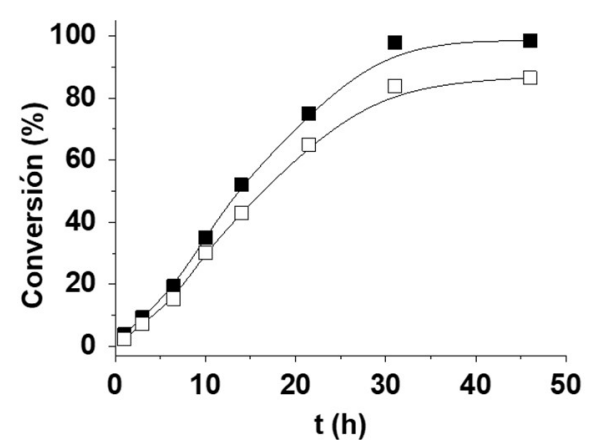

b)

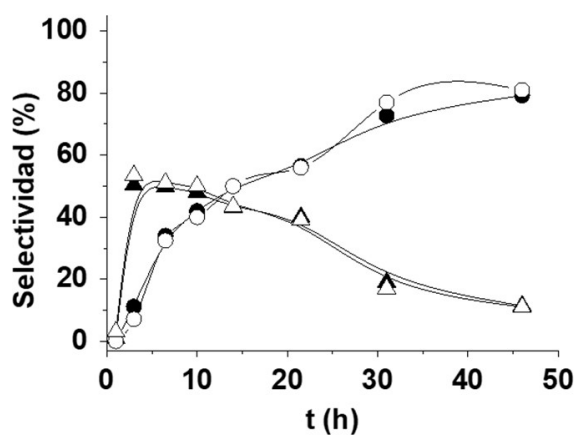

Figura 3.20. Comparación de los gráficos de conversión frente a tiempo (a) y selectividad frente a tiempo (b) de fenilisopropil cetona (triángulos) y ácido benzoico (círculos) para la oxidación aeróbica de isobutilbenceno sin destilar (símbolos rellenos) y destilado (símbolos vacíos) usando MIL-101(Cr) como catalizador. Reacciones de reacción: $7.5 \mathrm{mg}$ de catalizador, $20 \mathrm{mmol}$ de sustrato, atmósfera de $\mathrm{O}_{2}$ y $120^{\circ} \mathrm{C}$. 
a)

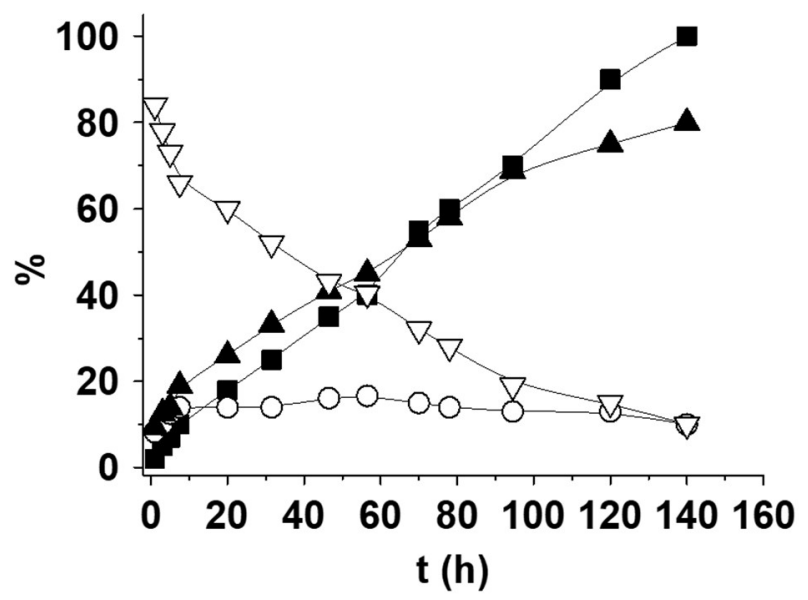

b) 100
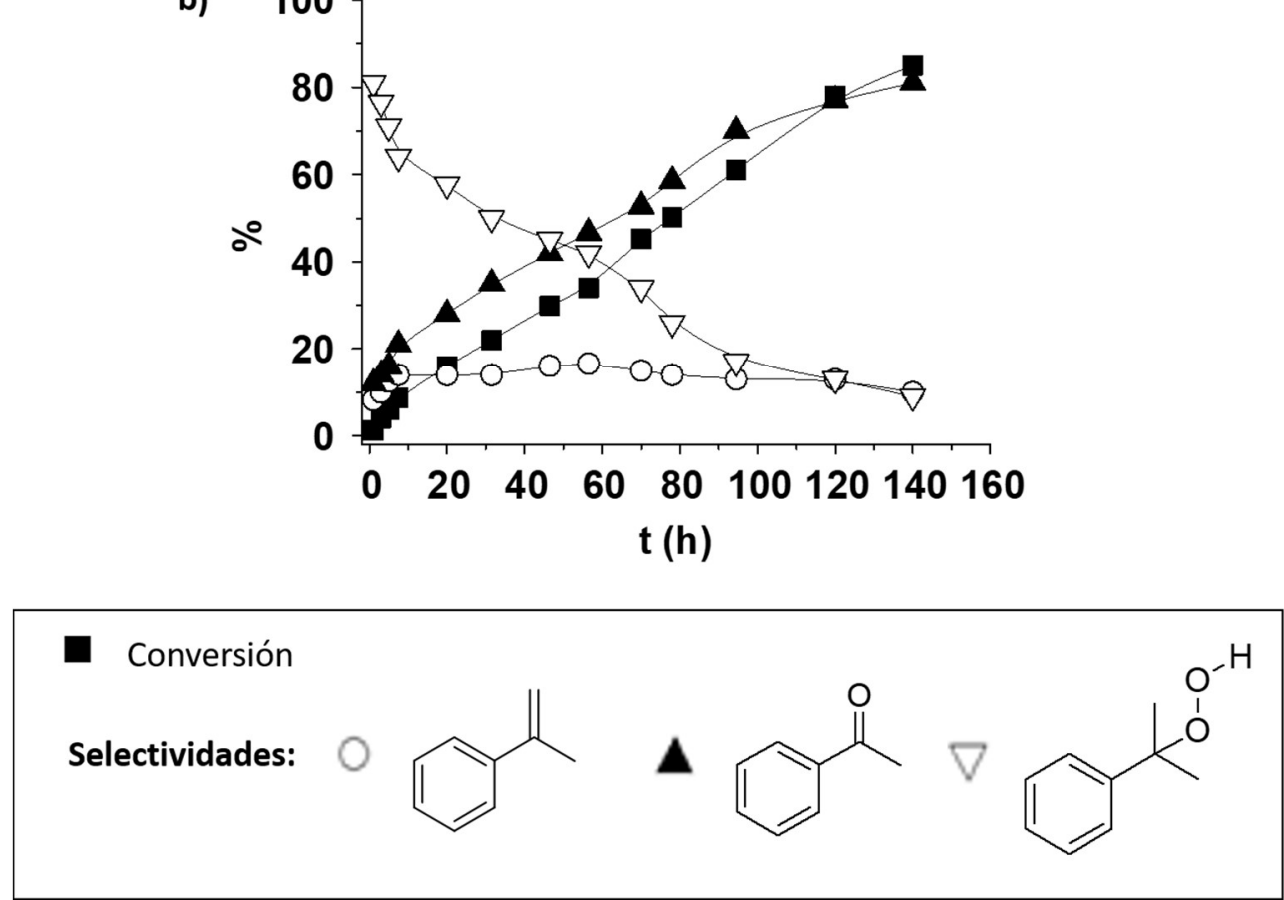

Figura 3.21. Gráficos de conversión y selectividad frente a tiempo para la oxidación aeróbica de cumeno sin destilar (a) y destilado (b) usando MIL-101(Cr) como catalizador. Reacciones de reacción: $7.5 \mathrm{mg}$ de catalizador, $20 \mathrm{mmol}$ de sustrato, atmósfera de $\mathrm{O}_{2}$ y $120{ }^{\circ} \mathrm{C}$. 
Capitulo 3.

a)

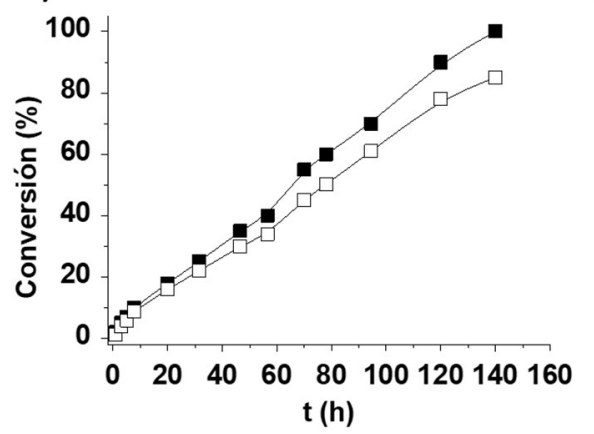

b)

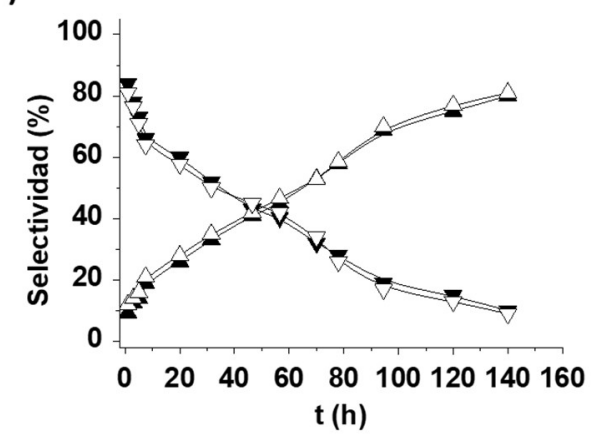

Figura 3.22. Comparación de los gráficos de conversión frente a tiempo (a) y selectividad frente a tiempo (b) de acetofena (círculos) e hidroperóxido de cumilo (triángulos) para la oxidación aeróbica de cumeno sin destilar (símbolos rellenos) y destilado (símbolos vacíos) usando MIL-101(Cr) como catalizador. Reacciones de reacción: $7.5 \mathrm{mg}$ de catalizador, $20 \mathrm{mmol}$ de sustrato, atmósfera de $\mathrm{O}_{2}$ y $120^{\circ} \mathrm{C}$. 
a)

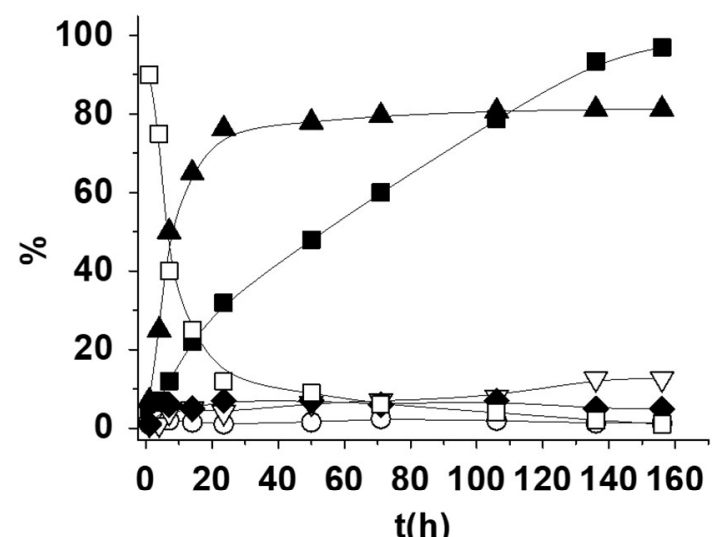

th)

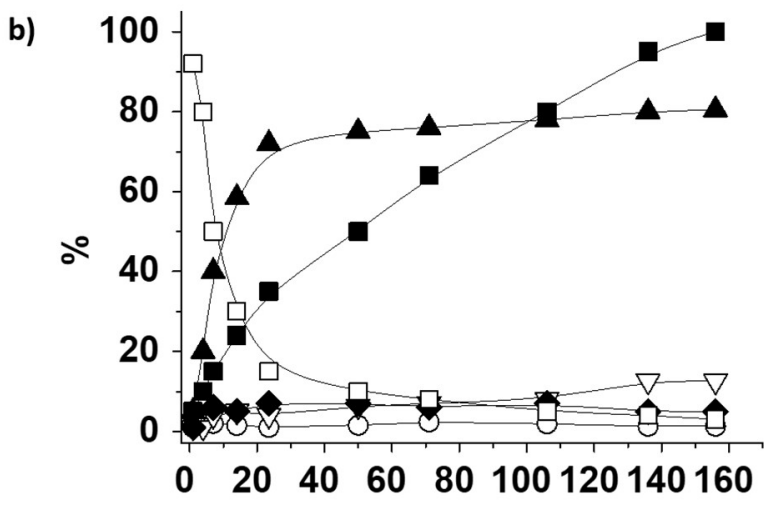

t (h)

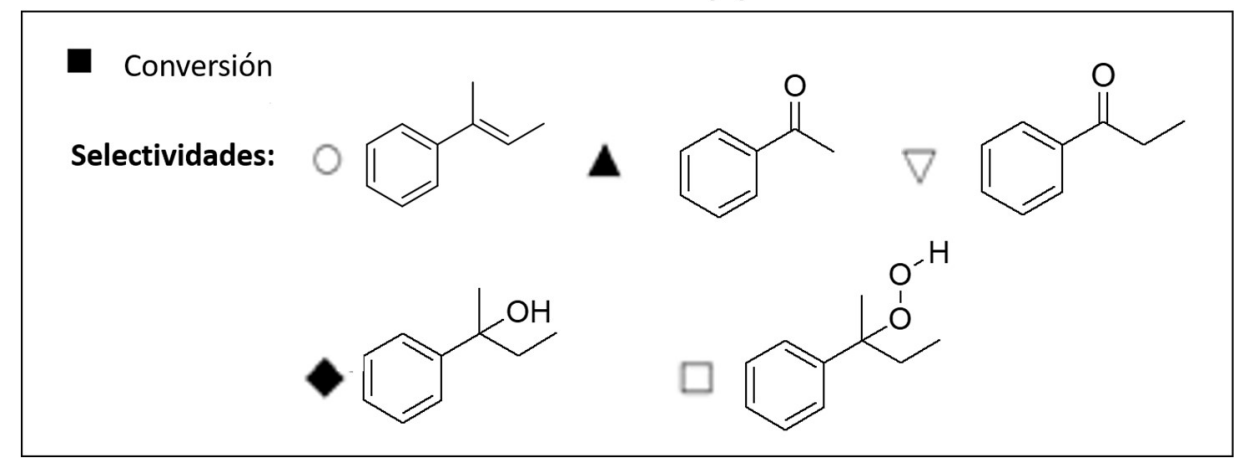

Figura 3.23. Gráficos de conversión y selectividad frente a tiempo para la oxidación aeróbica de secbutilbenceno sin destilar (a) y destilado (b) usando MIL-101(Cr) como catalizador. Reacciones de reacción: $7.5 \mathrm{mg}$ de catalizador, $20 \mathrm{mmol}$ de sustrato, atmósfera de $\mathrm{O}_{2}$ y $120{ }^{\circ} \mathrm{C}$. 
Capitulo 3.

a)

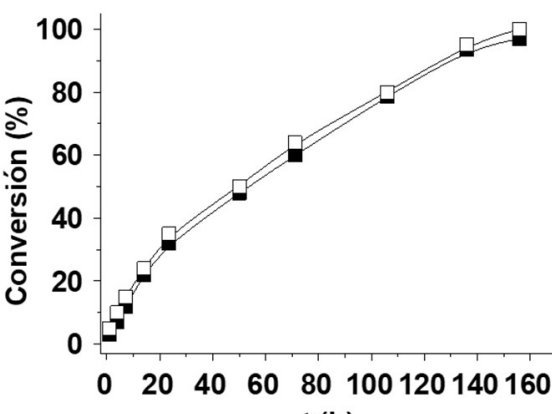

b)

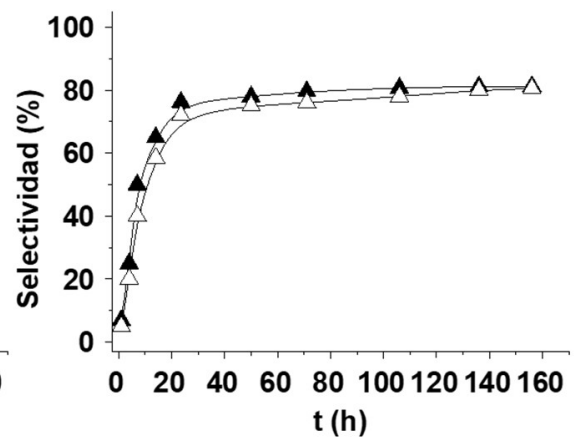

Figura 3.24. Comparación de los gráficos de conversión frente a tiempo (a) y selectividad frente a tiempo (b) de propiofenona (triángulos) para la oxidación aeróbica de sec-butilbenceno sin destilar (símbolos rellenos) y destilado (símbolos vacíos) usando MIL-101(Cr) como catalizador. Reacciones de reacción: $7.5 \mathrm{mg}$ de catalizador, $20 \mathrm{mmol}$ de sustrato, atmósfera de $\mathrm{O}_{2}$ y $120{ }^{\circ} \mathrm{C}$. 
a)

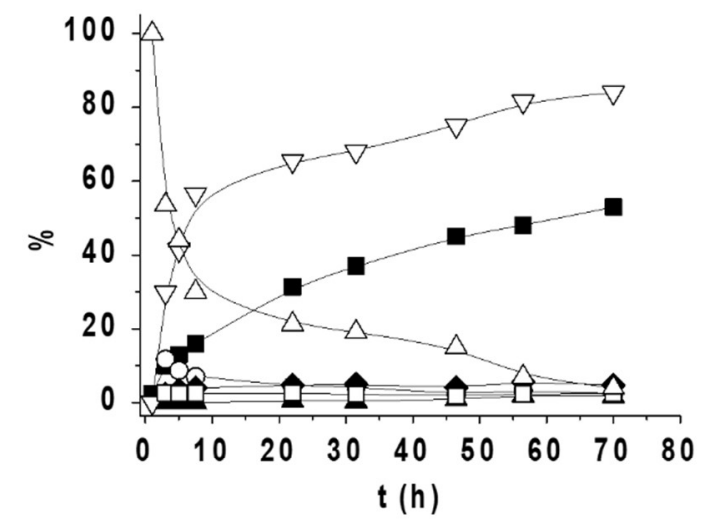

b)
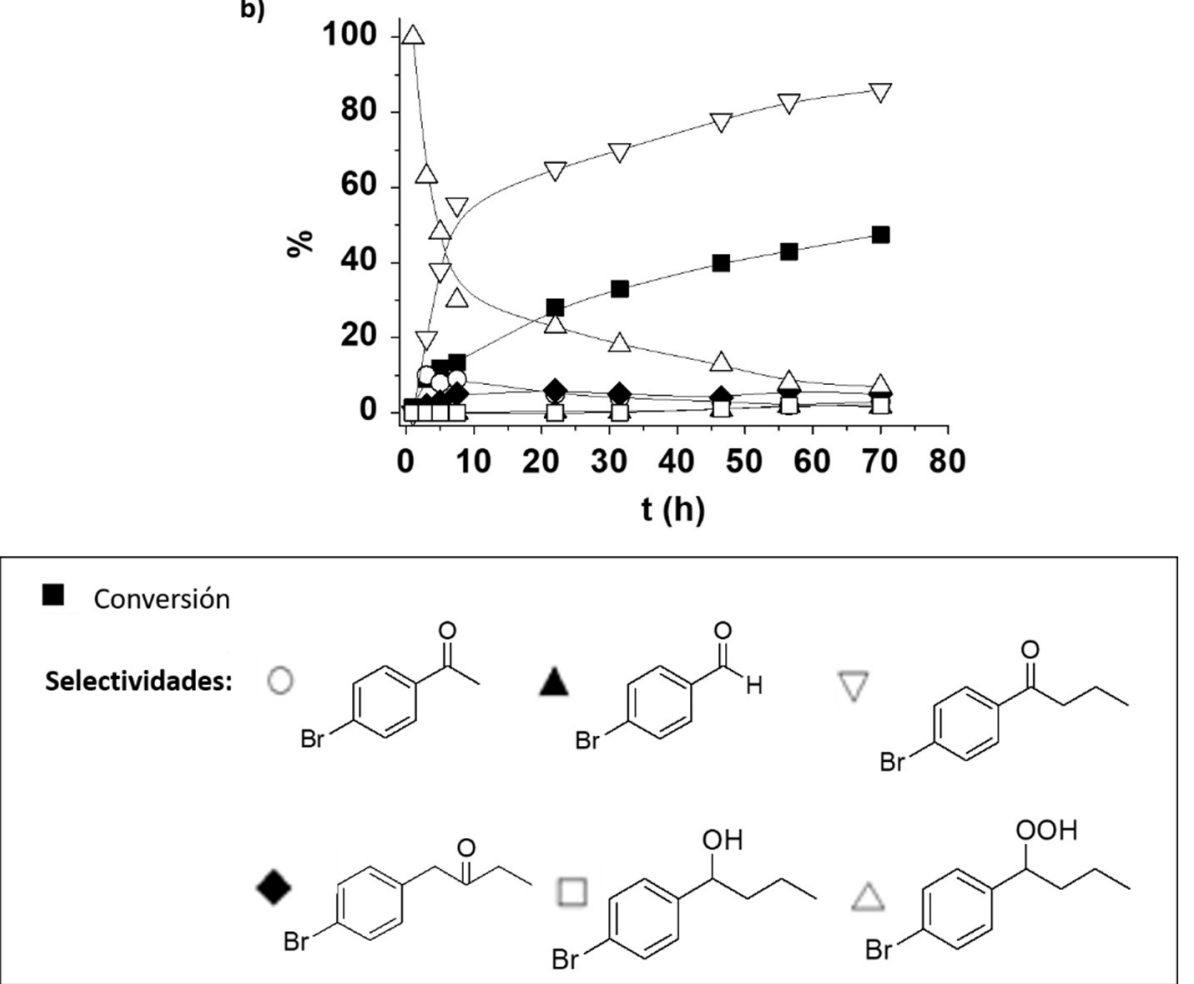

Figura 3.25. Gráficos de conversión y selectividad frente a tiempo para la oxidación aeróbica de 1bromo-4-butilbenceno sin destilar (a) y destilado (b) usando MIL-101(Cr) como catalizador. Reacciones de reacción: $7.5 \mathrm{mg}$ de catalizador, $20 \mathrm{mmol}$ de sustrato, atmósfera de $\mathrm{O}_{2}$ y $120{ }^{\circ} \mathrm{C}$. 
a)

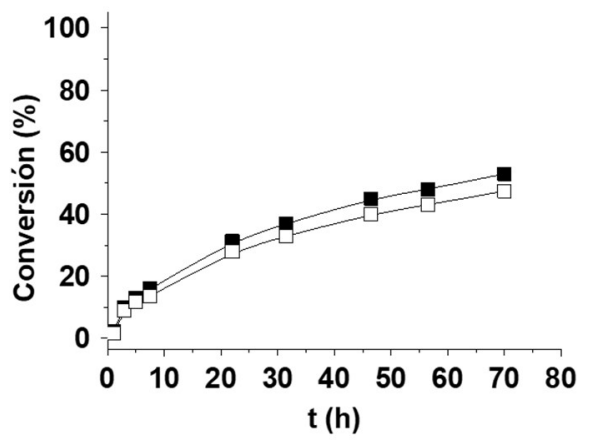

b)

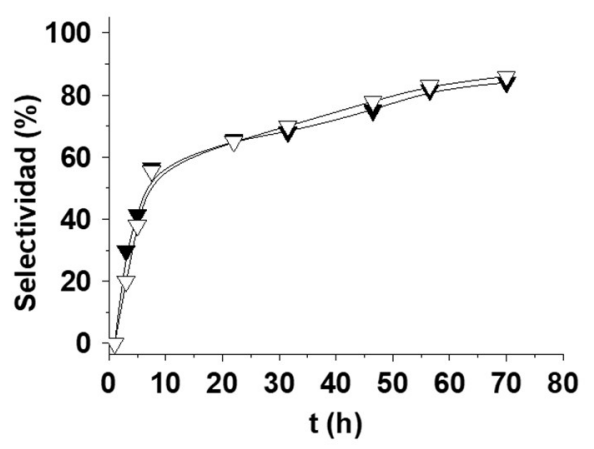

Figura 3.26. Comparación de los gráficos de conversión frente a tiempo (a) y selectividad frente a tiempo (b) de bromobutirofenona (triángulos) para la oxidación aeróbica de 1-bromo-4-butilbenceno sin destilar (símbolos rellenos) y destilado (símbolos vacíos) usando MIL-101(Cr) como catalizador. Reacciones de reacción: $7.5 \mathrm{mg}$ de catalizador, $20 \mathrm{mmol}$ de sustrato, atmósfera de $\mathrm{O}_{2}$ y $120^{\circ} \mathrm{C}$.

A fin de resaltar la influencia de la porosidad del material MIL-101(Cr) sobre el resultado de la reacción (es decir, la posible implicación de catálisis con selectividad de forma o de tamaño) la actividad catalítica del cumeno y del 1,3-diisopropilbenceno se compararon en la oxidación aeróbica. La figura 3.27 muestra la menor conversión del 1, 3 -diisopropilbenceno respecto del cumeno a pesar de que el primero contiene 2 grupos isopropilo. Esta menor reactividad del 1,3-diisopropilbenceno se puede atribuir a la difusión más dificultosa de este sustrato por los poros de MIL-101(Cr) debido a sus dimensiones moleculares mayores comparadas con el cumeno y que la reacción de oxidación radicalaria tiene lugar preferentemente dentro de los poros del MIL-101(Cr). Si el ion superóxido u otra especie reactiva de oxígeno fueran capaces de difundir fuera del sólido y la mayor parte de la oxidación tuviera lugar fuera de las partículas del material, entonces, no se debería esperar diferencias entre la reactividad del cumeno y el 1,3-diisopropilbenceno. El hecho de que la oxidación ocurra preferentemente dentro de los poros, es apoyado también llevando a cabo experimentos de adsorción isoterma observando una mayor adsorción preferente del cumeno $(0.077$ mmoles $/ 75 \mathrm{mg})$ en el material MIL$101(\mathrm{Cr})$ que la obtenida usando 1,3-diisopropilbenceno $(0.033 \mathrm{mmol} / 75 \mathrm{mg})$. Además, un estudio sobre la influencia de la temperatura de reacción en la conversión del cumeno y 1,3-diisopropilbenceno indica que los valores de energía de activación aparentes son de 18.6 y $19.5 \mathrm{kcal} \mathrm{mol}^{-1}$, que indica que estas reacciones están realmente bajo control cinético (Figura 3.28). Conviene hacer notar que, en general, las reacciones controladas por difusión presentan energías de activación bajas en torno a $5 \mathrm{kcal} \mathrm{mol}^{-1}$. 


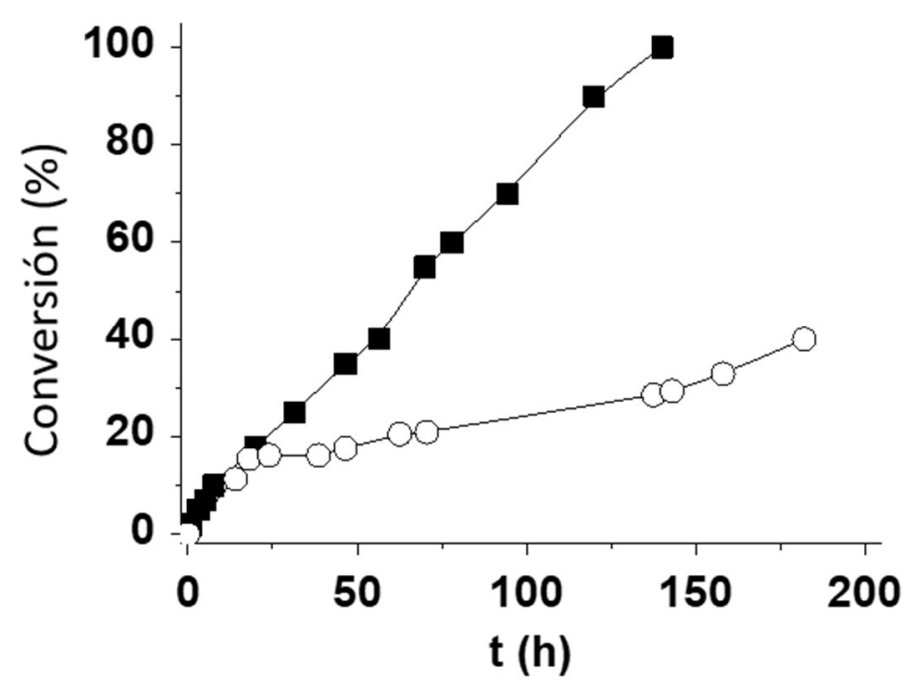

Figura 3.27. Gráfico de conversión frente a tiempo para la oxidación aeróbica de cumeno (匹) o 1,3diisopropilbenceno (०) usando MIL-101(Cr) como catalizador. Condiciones de reacción: $75 \mathrm{mg}$ de catalizador, 20 mmoles de indano, $120^{\circ} \mathrm{C}$, atmósfera de $\mathrm{O}_{2}$.

Los datos presentes sobre la actividad catalítica de MIL-101(Cr) y MIL-101(Fe) difiriendo en la adsorción relativa pueden ponerse en contexto con la falta de actividad del catalizador comercial $\mathrm{Fe}$ (BTC) para promover este tipo de oxidación en ausencia de N-hidroxiftalimida (NHPI de sus siglas en inglés) como iniciador de radicales. Se propone que la actividad de MIL-101 para generar radicales bencílicos por autooxidación deriva de la interacción del oxígeno con los nodos metálicos de la red, formando peróxidos metálicos de $\mathrm{Fe}$ o $\mathrm{Cr}$ con carácter de radical en el átomo de oxígeno que sería capaz de abstraer un átomo de hidrógeno de la posición bencílica. En apoyo de esta propuesta, conviene indicar que existen precedentes en la literatura describiendo para otros com-

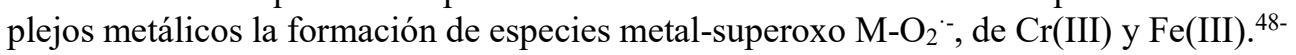
${ }^{50}$ Estas especies exhiben actividad en la activación de enlaces $\mathrm{C}-\mathrm{H}$ en hidrocarburos. ${ }^{48,50}$ Además, los grupos hemo conteniendo $\mathrm{Fe}^{2+}$ son los transportadores naturales de $\mathrm{O}_{2}$ en sangre y otros fluidos biológicos. ${ }^{51-53}$ En la literatura, hay también precedentes en los que se usa MIL-101(Cr) como catalizador para promover la oxidación bencílica de hidrocarburos usando siempre TBHP como reactivo oxidante. En el presente caso, se ha mostrado que esta oxidación puede ser promovida en ausencia de TBHP. Nuestro grupo ha mostrado anteriormente que la oxidación aeróbica en posiciones bencílicas puede llevarse a cabo en presencia de varios MOFs conteniendo $\mathrm{Cu} .{ }^{14,15} \mathrm{El}$ esquema 3.2 resume nuestra propuesta mecanística. Así, esta propuesta es en gran medida similar a la realizada anteriormente para la oxidación llevada a cabo por NHPI/Fe (BTC), excepto que 
Capitulo 3.

en este caso el iniciador de radicales se formaría espontáneamente por interacción de los clusters metálicos con oxígeno, un hecho que no ha sido observado para la muestra comercial de Fe(BTC).

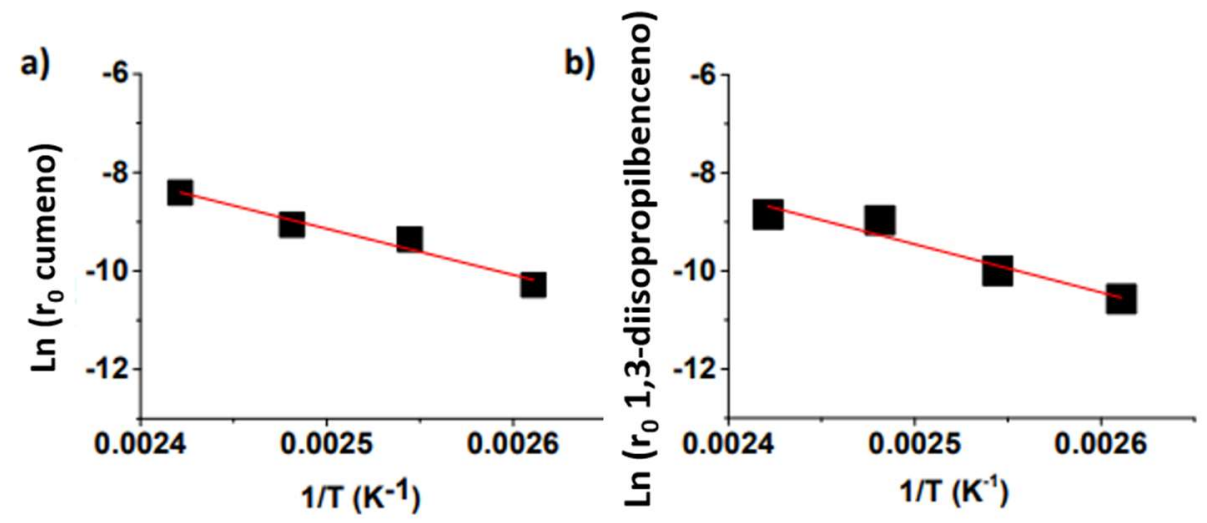

Figura 3.28. Gráficos de Arrhenius para la oxidación aeróbica de cumeno (a) y 1,3-diisopropilbeneno. Condiciones de reacción: $75 \mathrm{mg}$ de catalizador, 20 mmoles de indano, $120^{\circ} \mathrm{C}$, atmósfera de $\mathrm{O}_{2}$.

\section{INICIACIÓN}

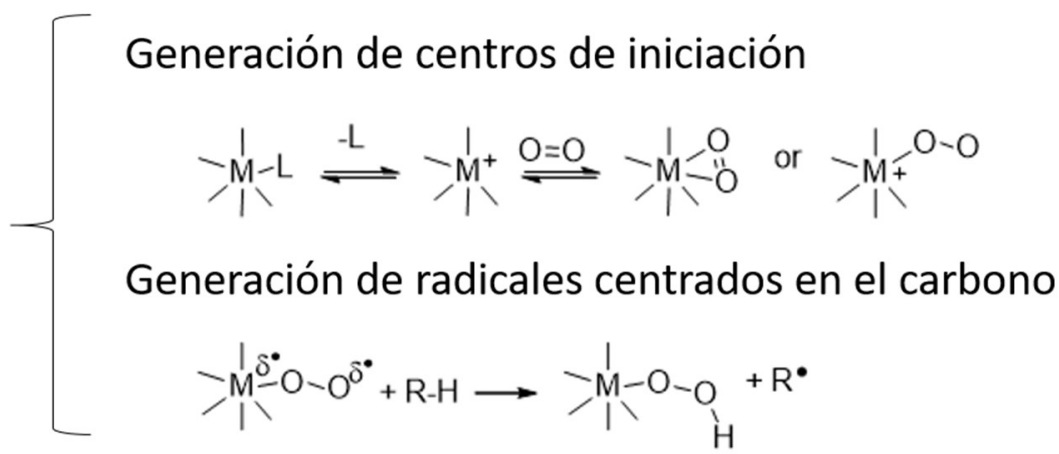

\section{PROPAGACIÓN}

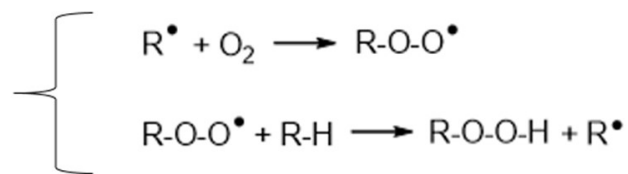

Esquema 3.2. Propuesta mecanística para la oxidación aeróbica de hidrocarburos bencílicos usando MIL-101(Cr) como catalizador. 
La influencia de la activación para MIL-101(Fe) aumentando su actividad catalítica sugiere que los iones Fe(II) son más eficientes que los Fe(III) para formar estas especies metal-peroxo, aunque podría ser también que la eliminación de algunas moléculas de agua actuando como ligandos de $\mathrm{Fe}(\mathrm{III})$ liberara posiciones de coordinación alrededor del $\mathrm{Fe}(\mathrm{III})$, las cuales estarían disponibles para la interacción con oxígeno.

Más aún, experimentos de inhibición selectivos para los radicales $\mathrm{O}_{2}{ }^{-} / \mathrm{HOO}$ fueron llevados a cabo usando $p$-benzoquinona, ${ }^{54}$ observándose una inhibición completa de la reacción (Figura 3.29). Este estudio de inhibición apoya que los radicales $\mathrm{O}_{2}{ }^{-} / \mathrm{HOO}$ son las especies radicalarias primarias que promueven las reacciones de autooxidación. En otros experimentos, el dimetilsulfóxido (DMSO) fue empleado como inhibidor selectivo de radicales $\mathrm{HO}^{55,56}$, observándose, en este caso, una inhibición parcial de la reacción (Figura 3.29). Este experimento indica que la ruptura homolítica de R-O-O-H para conducir a la formación de $\mathrm{R}-\mathrm{O}$ y $\mathrm{H}-\mathrm{O}$ tiene lugar en algún grado. Conviene hacer notar que la presencia de DMSO resulta en un aumento de la selectividad ol/ona respecto a experimentos similares en ausencia de DMSO, sugiriendo que la alta reactividad de los radicales $\mathrm{OH}^{*}$ contribuye a la falta de selectividad hacia los productos de interés. (Figura $3.29 b)$.

a)

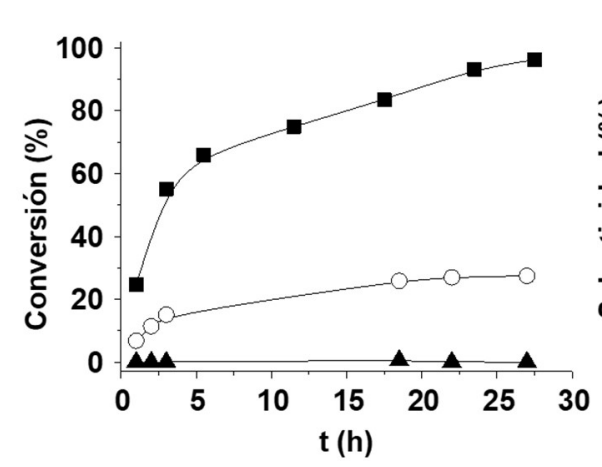

b)

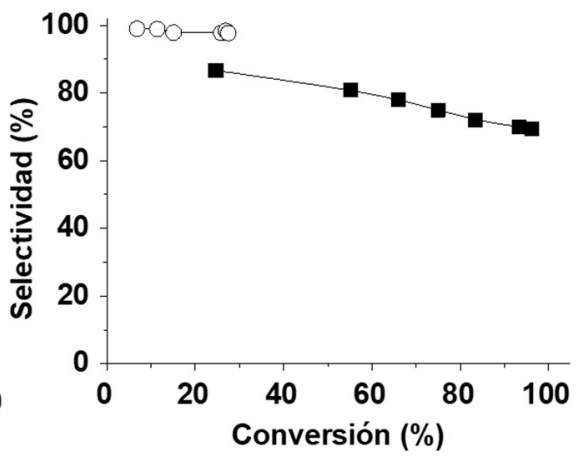

Figura 3.29. Gráficos de conversión frente a tiempo (a) y selectividad ol/ona frente a conversión (b) para la oxidación aeróbica de indano usando MIL-101(Cr) como catalizador ( $\mathbf{(})$ en presencia del $20 \%$ de DMSO (०) y $20 \%$ de $p$-benzoquinona ( $\Delta$ ). Condiciones de reacción: catalizador ( $7.5 \mathrm{mg}$ ), sustrato (20 mmoles), $120^{\circ} \mathrm{C}, 20 \mathrm{~mol} \%$ de $p$-benzoquinona o DMSO respecto al sustrato, $\mathrm{O}_{2}(1 \mathrm{~atm})$. 
Capitulo 3.

\subsection{Conclusiones}

Los datos del presente capítulo abren nuevas perspectivas en el uso de MOFs como catalizadores de oxidación mostrando que los materiales MIL-101 pueden generar radicales centrados en el C en presencia de oxígeno molecular y que la adsorción en el interior de los poros puede jugar un papel mejorando la selectividad del producto hacia la mezcla deseada ol/ona como consecuencia de llevar a cabo la oxidación en una cavidad de reacción restringida. Hay que comentar que los procesos industriales actuales basados en oxidaciones aeróbicas, por ejemplo, la oxidación del ciclohexano se llevan a cabo a conversiones inferiores al $5 \%$ a fin de obtener selectividades hacia ol/ona superiores al $90 \%$ simplificando de esta manera la purificación de la mezcla que resultaría muy complicada. En el área de oxidaciones aeróbicas, sería un avance significativo aumentar las conversiones sin que ello redujera la selectividad por debajo de valores del $90 \%$. 
MIL-101 como promotor sólido reusable para la autooxidación de hidrocarburos bencílicos.

\subsection{Referencias.}

1. A. Corma, H. García y F. X. Llabrés i Xamena, Chem. Rev., 2010, 110, 4606-4655.

2. M. Yoon, R. Srirambalaji, y K. Kim, Chem. Rev., 2012, 112, 1196-1231.

3. H. Furukawa, K. E, Cordova, M. O'Keeffe y O. M. Yaghi, Science, 2013, 341, 1230444.

4. A. Dhakshinamoorthy, y H. García, Chem. Soc. Rev., 2012, 41, 5262-5284.

5. A. Dhakshinamoorthy, M. Opanasenko, J. Čejka, y H. García, Catal. Sci. Technol., 2013, 3, 2509-2540.

6. M. Ranocchiari, y J. A. V Bokhoven, Phys. Chem. Chem. Phys., 2011, 13, 6388-6396.

7. C. Wang, M. Zheng, y W. Lin, J. Phys. Chem. Lett., 2011, 2, 1701-1709.

8. Z. -Y. Gu, J. Park, A. Raiff, Z. Wei, H.-C. Zhou, ChemCatChem, 2014, 6, 67-75.

9. J. Gascon, A. Corma, F. Kapteijn, y F. X. Llabrés i Xamena, ACS Catal., 2014, 4, 361-378.

10. O. V. Zalomaeva, A. M Chibiryaev, K. A. Kovalenko, O. A.; Kholdeeva, B. S. Balzhinimaev, y V. P. J. Fedin, Catal. 2013, 298, 179-185.

11. I. D. Ivanchikova, J. S. Lee, N. V. Maksimchuk, A. N. Shmakov, Y. A. Chesalov, A. B. Ayupov, Y. K. Hwang, C. -H. Jun J. -S. Chang y O. A. Kholdeeva, Eur. J. Inorg. Chem., 2014, 1, 132-139.

12. N. V. Maksimchuk, O. A. Kholdeeva, K. A. Kovalenko y V. P. Fedin, Isr. J. Chem., 2011, 51, 281-289.

13. A. Dhakshinamoorthy, M. Alvaro, y H. Garcia, Catal. Sci. Technol., 2011, 1, 856867.

14. F. X. Llabrés i Xamena, O. Casanova, R. G. Tailleur, H. García, y A. Corma, J. Catal., 2008, 255, 220-227.

15. I. Luz, A. León, M. Boronat, F. X. Llabrés i Xamena, y A. Corma, Catal. Sci. Technol., 2013, 3, 371-379.

16. O. A. Kholdeeva, Catal. Sci. Technol., 2014, 4, 1869-1889.

17. A. Dhakshinamoorthy, M. Alvaro, y H. García, J. Catal. 2012, 289, 259-265.

18. A. Dhakshinamoorthy, M. Alvaro, y H. García, ACS Catal., 2011, 1, 48-53.

19. Y. Ishii y S. Sakaguchi, Catal. Today, 2006, 117, 105-113.

20. T. Iwahama, S. Sakaguchi, Y. Nishiyama y Y. Ishii, Tetrahedron Lett., 1995, 36, 6923-6926. 
Capítulo 3.

21. T. Iwahama, Y. Yoshino, T. Keitoku, S. Y. Sakaguchi, I. J. Org. Chem., 2000, 65, 6502-6507.

22. N. V. Maksimchuk, K. A Kovalenko, V. P. Fedin y O. A. Kholdeeva, Chem. Commun., 2012, 48, 6812-6814.

23. K. Brown, S. Zolezzi, P. Aguirre, D. Venegas-Yazigi, V. Paredes-García, R. Baggio, M. Novak y E. Spodine, Dalton Trans., 2009, 8, 1422-1427.

24. O. A. Kholdeeva, I. Y. Skobelev, I. D. Ivanchikova, K. A. Kovalenko, V. P. Fedin, y A. B. Sorokin, Catal. Today, 2014, 238, 54-61.

25. N. V. Maksimchuk, K. A. Kovalenko, V. P. Fedin y O. A. Kholdeeva, Adv. Synth. Catal., 2010, 352, 2943-2948.

26. Z. Saedi, S. Tangestaninejad, M. Moghadam, V. Mirkhani y I. Mohammadpoor-Baltork, Catal. Comm., 2012, 17, 18-22.

27. Y. Qi, Y. Luan, J. Yu, X. Peng y G. Wang, Chem. - Eur. J., 2015, 21, 1589-1597.

28. A. Dhakshinamoorthy, M. Alvaro y H. García, J. Catal., 2009, 267, 1-4.

29. J. Kim, S. Bhattacharjee, K. -E. Jeong, S.-Y.; Jeong y W. S. Ahn, Chem. Commun., 2009, 0, 3904-3906.

30. E. -V. Ramos-Fernandez, M. Garcia-Domingos, J. Juan-Alcaniz, J. Gascon, y F. Kapteijn, Appl. Catal. A-Gen., 2011, 391, 261-267.

31. J. Sun, G. Yu, Q. Huo, Q. Kan, y J. Guan, RSC Adv., 2014, 4, 38048-38054.

32. I. Y. Skobelev, K. A. Kovalenko, V. P. Fedin, A. B. Sorokin y O. A. Kholdeeva, Kinet. Catal., 2013, 54, 607-614.

33. I. Y. Skobelev, A. B. Sorokin, K. A. Kovalenko, V. P. Fedin y O. A. Kholdeeva, J. Catal., 2013, 298, 61-69.

34. F. X, Llabrés i Xamena, O. Casanova, R. Galiasso Tailleur, H. Garcia, y A. Corma, J. Catal., 2008, 255, 220-227.

35 I. Luz, A. León, M. Boronat, F. X. Llabrés i Xamena y A. Corma, Catal. Sci. Technol., 2013, 3, 371-379.

36 N. A. Milas, Chem. Rev., 1932, 10, 295-364.

37. A. E. Shilov y G. B. Shul'pin, Chem. Rev., 1997, 97, 2879-2932.

38. M. M. Fares, M. El-Khateeb, K. J. Asali, J. Inorg. Organomet. Polym., 2003, 13, 143-155.

39. M. S. Kharasch, A. Fono, W. Nudenberg, J. Org. Chem., 1951, 16, 105-112. 
40. H. Leclerc, A. Vimont, J. C. Lavalley, M. Daturi, A. D. Wiersum, P. L. Llewellyn, P. Horcajada, G. Ferey y C. Serre, 2011, 13, 11748-11756.

41. J. W. Yoon, Y. -K. Seo, Y.K. Hwang, J. -S. Chang, H. Leclerc, S. Wuttke, P. Bazin, A. Vimont, M. Daturi, E. Bloch, P. L. Llewellyn, C. Serre, P. Horcajada, J. -M. Grenche, A. E. Rodrigues, G. Férey, Angew. Chem. Int. Ed., 2010, 49, 5949-5952.

42. A. Vimont, F. Thibault-Starzyk y M. Datur, Chem. Soc. Rev., 2010, 39, 4928-4950.

43. T. Devic, C. Serre, Chem.Soc.Rev., 2014, 43, 6097-6115.

44. L. Helm y A. E. Merbach, Chem. Rev., 2005, 105, 1923-1959.

45. T. C. Bruise, Acc. Chem. Res., 1991, 24, 243-249.

46. C. B. Hansen y W. Drenth, Catal. Lett., 1993, 20, 359-364.

47. G. Ferey, C. Mellot-Draznieks, C. Serre, F. Millange, J. Dutour, S. Surble y I. Margiolaki, Science, 2005, 309, 2040-2042.

48. A. Ansari, P. Jayapal y G. Rajaraman, Angew. Chem. Int. Ed., 2015, 54, 564 -568.

49. J. Cho, J. Woo y W. Nam, J. Am. Chem. Soc., 2010, 132, 5958-5959.

50. K.-B. Cho, H. Kang, J. Woo, J. Y. Park, M. S. Seo, J. Cho y W. Nam, Inorg. Chem., 2014, 53, 645-652.

51. D. F. Bocian, E. W. Findsen, J. A. Hofmann, G. A. Schick, D. R. English, D. N. Hendrickson y K. S. Suslick, Inorg. Chem., 1984, 23, 800-807.

52. K. B. Shumaev, A. A. Gubkin, V. A. Serezhenkov, I. I. Lobysheva, O. V. Kosmachevskaya, E. K. Ruuge, V. Z. Lankin, A. F. Topunov y A. F. Vanin, Nitric Oxide, 2008, 18, 37-46.

53. A. L. Silva, L. F. de Almeida, A. L. Marqués, H. R. Costa, A. B. da Silva y J. de Jesus Gomes Varela Jr., J. Mol. Model., 2014, 20, 2131.

54. A. Dhakshinamoorthy, S. Navalon, M. Alvaro y H. García, ChemSusChem, 2012, 5, 46-64.

55. M. J. Burkitt y R. P. Mason, Proc. Natl. Acad. Sci. USA 1991, 88, 8440-8444.

56. R. Martin, S. Navalon, J. J. Delgado, J. J. Calvino, M. Alvaro y H. García, Chem. Eur. J., 2011, 17, 9494-9502. 


\section{Capítulo 4}

\section{Actividad catalítica del \\ MIL-101 para la \\ desulfuración oxidativa \\ de dibenzotiofenos.}


Actividad catalítica del MIL-101 para la desulfuración oxidativa de dibenzotiofenos. 


\section{1 introducción}

Como se ha venido indicando, los MOFs están encontrando una aplicación creciente en catálisis heterogénea, particularmente, para llevar a cabo reacciones en fase líquida donde algunos MOFs poseen una estabilidad notable permitiendo su recuperación tras la reacción y su reuso en reacciones consecutivas. ${ }^{1-7}$ Entre los diferentes MOFs que han sido descritos en la literatura, el MIL-101 se encuentra entre los más ampliamente usados puesto que presenta una estabilidad considerable en condiciones catalíticas, se puede preparar de forma confiable en cantidades suficientes y posee un área superficial BET superior a $2000 \mathrm{~m}^{2} \mathrm{~g}^{-1}$ con un alto contenido en metal (alrededor del $20 \%){ }^{6-12}$ Como se ha visto en el capítulo anterior, este material puede promover reacciones de oxidación aeróbicas de hidrocarburos bencílicos incluso en ausencia de reactivos oxidantes tales como el TBPH ${ }^{13-19}$ y $\mathrm{H}_{2} \mathrm{O}_{2} \cdot{ }^{19,20}$ Existen antecedentes en la bibliografía, algunos de ellos de nuestro grupo, que han empleado el MIL-101 como iniciadores sólidos de reacciones de autooxidación. . $^{16,17,21,22}$ Además de promover la oxidación aeróbica de compuestos bencílicos ${ }^{23}$, los MOFs pueden oxidar tioles ${ }^{24} \mathrm{o}$, cuando se combinan con iniciadores de radicales tales como la N-hidroxiftalimida (NHPI) ${ }^{25-27} \mathrm{o}$ 2,2,6,6-tetrametil-1-1piperidiniloxi (TEMPO), ${ }^{28}$ promover la oxidación aeróbica de otros sustratos tales como hidrocarburos insaturados ${ }^{25,27}$ alcoholes $^{28}$ y aminas. ${ }^{26}$ En este contexto, en el presente capítulo se describe que los dibenzotiofenos (DBTs) pueden ser oxidados eficientemente por oxígeno molecular empleando MIL-101 como catalizador.

El DBT y sus derivados metil-sustituidos se encuentran entre los compuestos de azufre presentes en gasoil y destilados de petróleo de alto punto de ebullición. Estos compuestos del azufre son responsables de un gran porcentaje de la contaminación atmosférica por $\mathrm{SO}_{\mathrm{x}}$ de origen antropogénico. ${ }^{30} \mathrm{La}$ tendencia tras legislación en materia de calidad de combustibles es a disminuir el contenido en azufre de los mismos (en el momento presente por debajo del límite de $10 \mathrm{ppm}$ de azufre en peso) y los tratamientos convencionales de hidrodesulfuración en procesos de refinado necesitan ser suplementados con tratamientos adicionales que eliminen en mayor grado los compuestos conteniendo azufre presentes en los combustibles. ${ }^{30,31}$ Conviene hacer notar que los DBTs , en particular su derivado 4-metil y el 4,6-dimetil se encuentran entre los compuestos de azufre más difíciles de eliminar en el proceso de hidrodesulfuración. ${ }^{18,30,31}$ Una posibilidad de eliminar el DBT y sus derivados alquilados presentes en los destilados del petróleo es su oxidación a los sulfóxidos y/o sulfonas correspondientes, los cuales presentan una hidrofilicidad mayor y puntos de ebullición también mayores, haciendo posible su eliminación de estos combustibles..$^{30}$ Típicamente, estos tratamientos oxidativos utilizan hidroperóxidos orgánicos, reactivos de oxidación en combinación con metales de transición como catalizadores. ${ }^{18,30,32-37}$ En este contexto, sería ventajoso, considerando los volúmenes de combustible tan elevados que deben ser tratados, que los hidroperóxidos se reemplazaran por oxígeno molecular. Algunos intentos de usar oxígeno molecular descritos en la literatura han empleado polioxometalatos como catalizadores. Así, por ejemplo, un MOF nanocristalino (NENU-9N) impregnado con fosfovanadomolibdato ha sido empleado para conseguir la desulfuración oxidativa completa a $80^{\circ} \mathrm{C}$ durante $1.5 \mathrm{~h}$. El 
papel del MOF en este caso es el de facilitar la dispersión del polioxometalato hidrofílico en un diésel real o disolvente análogo. Es importante hacer notar, sin embargo, que la oxidación catalítica se lleva a cabo en presencia de un gran exceso de isobutiraldehido con respecto al DBT (relación molar 10:1). Se ha propuesto que el isobutiraldehido resulta oxidado al perácido correspondiente por el oxígeno molecular y, entonces, en un segundo paso el perácido promueve la oxidación del DBT a DBT-sulfona. En las condiciones estudiadas, se han alcanzado valores de frecuencia de ciclos (TOF) de $80 \mathrm{~h}^{-1}$. En otro estudio, un polioxometalato del tipo Anderson modificado con sales de amonio cuaternario fue empleado para promover la oxidación aeróbica de derivados del DBT usando $\mathrm{O}_{2}$ como oxidante. El papel de la sal de amonio cuaternaria es el de facilitar la dispersión del polioxometalato en decalina que es el medio de reacción, puesto que de otra forma la actividad catalítica del polioxometalato sería despreciable. Se consiguió una buena actividad catalítica, aunque el valor de TOF fue solo de $12.8 \mathrm{~h}^{-1}$. Sin embargo, no se describieron procedimientos de cómo recuperar la sal de amonio cuaternaria y, por tanto, la reusabilidad y estabilidad del catalizador no han podido ser conocidas, requiriéndose, por tanto, estudios adicionales para establecer la posible aplicación de estos materiales.

Además de la hidrodesulfuración o la desulfuración oxidativa, la eliminación de los derivados del DBT de los combustibles puede llevarse a cabo por métodos de adsorción. ${ }^{38}$ Los materiales carbonosos (carbón activo, aerogeles de carbón o incluso nanotubos de carbón), ${ }^{39,40}$ óxidos metálicos o metales ${ }^{40}$ zeolitas, ${ }^{40}$ arcillas, ${ }^{41-43}$ sílices, ${ }^{44}$ polímeros orgánico ${ }^{40}$ o polímeros de metales de coordinación ${ }^{31,45}$ han sido descritos como adsorbentes entre otros materiales. Además, la tecnología de imprinting molecular ha sido aplicada igualmente para la desulfuración selectiva de combustibles. ${ }^{3}$

En el presente capítulo describiremos que el MIL-101(Cr): $\left(\mathrm{Cr}_{3} \mathrm{~F}\left(\mathrm{H}_{2} \mathrm{O}\right)_{2} \mathrm{O}\left[\left(\mathrm{O}_{2} \mathrm{C}\right)-\right.\right.$ $\left.\left.\mathrm{C}_{6} \mathrm{H}_{4}-\left(\mathrm{CO}_{2}\right)\right]_{3} \cdot n \mathrm{H}_{2} \mathrm{O}\right)(n \leq 25)$ promueve la transformación del DBT y sus derivados metilados en las correspondientes sulfonas empleando solo oxígeno molecular sin la necesidad de aldehídos o sales de amonio. El MIL-101(Cr) puede ser recuperado y reusado sin una disminución en la actividad catalítica. Los resultados descritos en este capítulo son ventajosos respecto a aquellos procesos oxidativos de desulfuración que requieren hidroperóxidos como oxidantes o la adición de un exceso de aditivos.

\subsection{Resultados y discusión}

En el presente capítulo se emplearon 2 materiales MIL-101 que fueron el MIL101(Cr) y el MIL-101(Fe). Estos dos materiales son isoestructurales y difieren en la naturaleza del metal de transición y en la presencia de -F o - $\mathrm{Cl}$ como ligando en el caso de MIL-101 (Cr) y MIL-101(Fe), respectivamente. ${ }^{9,46}$ Los valores de área superficial BET y volumen de poro obtenidos tras la síntesis fueron de alrededor de $2015 \mathrm{~m}^{2} \mathrm{~g}^{-1}$ y 1.19 $\mathrm{cm}^{3} \mathrm{~g}^{-1} \mathrm{y}, 1850 \mathrm{~m}^{2} \mathrm{~g}^{-1}$ y $1.12 \mathrm{~cm}^{3} \mathrm{~g}^{-1}$, respetivamente. ${ }^{23}$ Estas diferencias pueden influir en la interacción del MOF con el oxígeno molecular y con sustratos y pueden modificar también la polaridad del espacio intracristalino del material. ${ }^{12,23,47}$ Se ha demostrado que 
Capitulo 4.

diferencias en la polaridad de compuestos de partida y de los productos resultantes de la oxidación determinan variaciones significativas en la afinidad por la superficie interna, lo cual resulta en cambios en la selectividad de los productos. ${ }^{23}$ Además, los sólidos MIL-101 poseen grandes poros (diámetros libres de 2.9 y $3.4 \mathrm{~nm}$ ) con ventanas microporosas de 1.2 y $1.6 \mathrm{~nm}$, respectivamente, permitiendo la adsorción de derivados de DBT en estas cavidades. ${ }^{48}$

En los estadios iniciales de nuestro trabajo, se llevó a cabo el tratamiento de DBT (200 mg L $\mathrm{m}^{-1}$ ) disuelto en $n$-dodecano a $120^{\circ} \mathrm{C}$ (punto de explosión y temperatura de autoignición de 71 y $203{ }^{\circ} \mathrm{C}$ respectivamente) con $\mathrm{O}_{2}$ en presencia de MIL-101 ( $\mathrm{Cr}$ o Fe) sin y con tratamiento de preactivación (Esquema 4.1). Las condiciones usadas están fuera del rango de explosión de la mezcla.

Se ha observado frecuentemente que, a fin de ser usado como catalizador, los MOFs tienen que ser sometidos a un proceso de activación donde se elimine el agua coadsorbida y moléculas de disolvente y se generen centros de coordinación insaturados alrededor de los iones metálicos. ${ }^{13,22,49,50}$ En el caso presente, los sólidos MIL-101 fueron activados a $150{ }^{\circ} \mathrm{C}$ a vacío durante $6 \mathrm{~h}$ y la eficiencia de estos materiales tras su preactivación fue comparada con la de muestras sin tratar. En todos los casos se observó que el único producto de reacción es lo correspondiente DBT-sulfona (DBT-S) y que el proceso va acompañado por la oxidación muy minoritaria del disolvente (aproximadamente 1\%). En ausencia de catalizador, el proceso de autooxidación en las condiciones y tiempos empleados ocurre en una extensión despreciable, incluso si la temperatura alcanza valores de $180^{\circ} \mathrm{C}$ (Figura 4.1). Se ha observado que este tratamiento de activación no influye en la actividad del MIL-101(Cr) mientras que la actividad del MIL-101(Fe) aumenta con la activación. Se ha descrito que bajo estas condiciones de activación los iones $\mathrm{Fe}^{3+}$ sufren reducción a $\mathrm{Fe}^{2+}$ en el material MIL-101(Fe) ${ }^{51-53}$ mientras que este proceso de reducción no ocurre en el caso de MIL-101(Cr). ${ }^{12}$ Además, el agua de coordinación se desorbe más fácilmente del material MIL-101(Fe) que del material MIL-101(Cr) ${ }^{12,47} \mathrm{La}$ comparación entre los dos MOFs indica que MIL-101(Fe) es menos activo que el MIL101(Cr), aunque la actividad de las dos muestras es similar (Figura 4.2). En uno de estos experimentos, la disolución de $n$-dodecano conteniendo DBT (200 mg L-1, correspondiente a alrededor de 267 ppm en peso de azufre ) se sometió a oxidación por MIL$101(\mathrm{Cr})$ a $120^{\circ} \mathrm{C}$ y tras la reacción el catalizador se filtró y la solución de $n$-dodecano transparente se extrajo con agua, observándose la completa eliminación de azufre de $n$ dodecano, por debajo del límite de detección de nuestro equipo $\left(4 \mathrm{mg} \mathrm{L}^{-1}\right.$, aproximadamente 5.3 ppm de peso en S), indicando que, por transformación del DBT en DBT-S este último compuesto puede ser eliminado completamente del agua. 


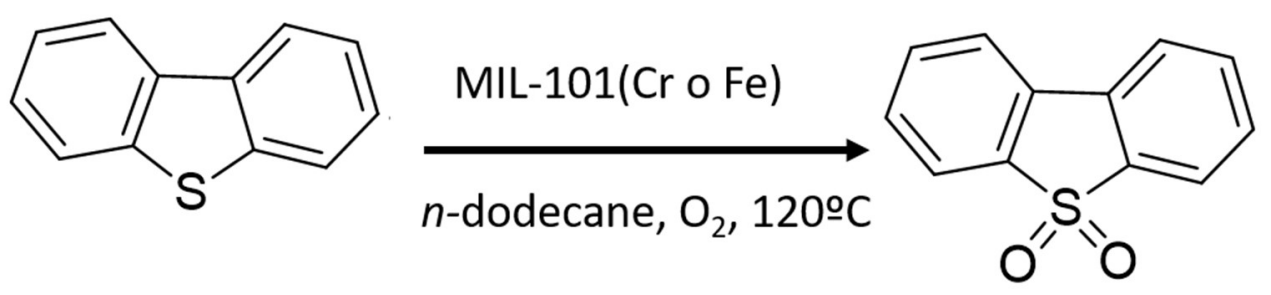

Esquema 4.1. Oxidación aeróbica del DBT a DBT-Sulfona usando MIL-101(Cr o Fe) como catalizador.
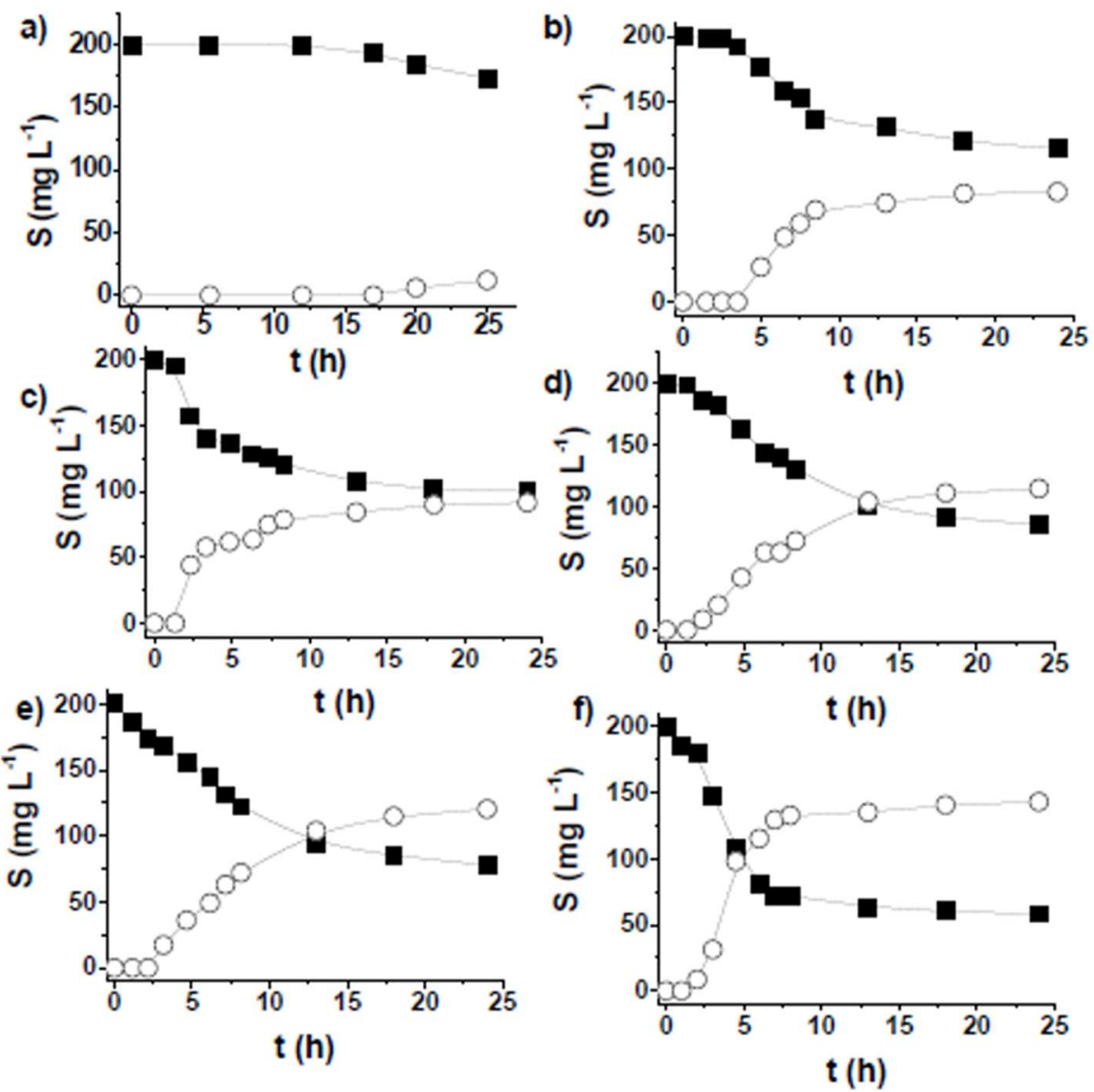

Figura 4.1. Experimentos de control para la oxidación aeróbica de DBT (匹) a DBT-Sulfona ( $\square$ ) en ausencia de catalizador a diferentes temperaturas de reacción. Leyenda: a) $120^{\circ} \mathrm{C}$, b) $140{ }^{\circ} \mathrm{C}$, c) $150^{\circ} \mathrm{C}$, d) $160{ }^{\circ} \mathrm{C}$, e) $170{ }^{\circ} \mathrm{C}$ y f) $180{ }^{\circ} \mathrm{C}$. Condiciones de reacción: DBT $\left(1,150 \mathrm{mg} \mathrm{L}^{-1}, n\right.$-dodecano $(10 \mathrm{~mL})$, $\mathrm{O}_{2}(1 \mathrm{~atm})$. 

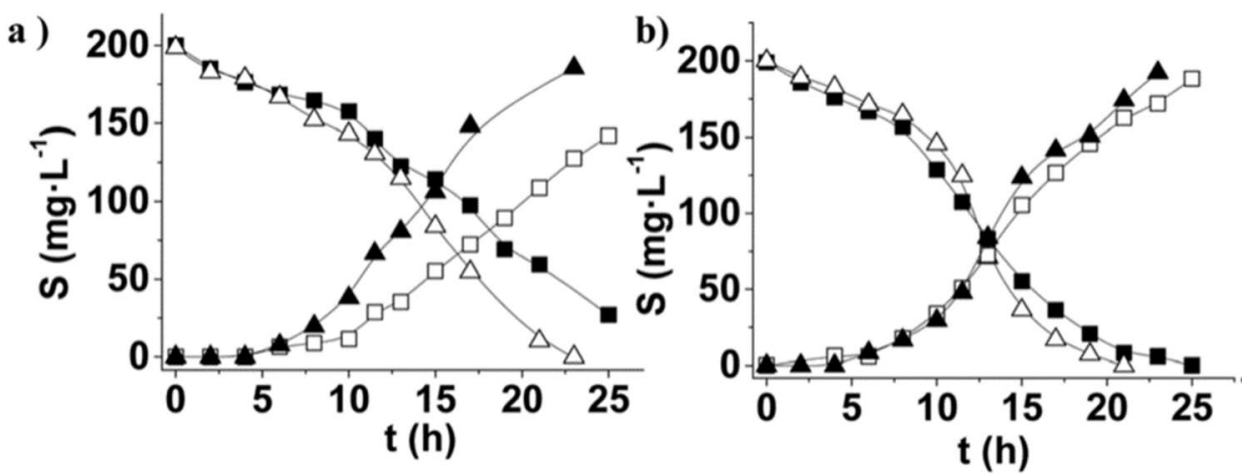

Figura 4.2. Oxidación aeróbica de DBT a DBT-Sulfona usando (a) MIL-101(Fe) o (b) MIL-101(Cr) con o sin activación. Condiciones de reacción: catalizador $\left(500 \mathrm{mg} \mathrm{L}^{-1}\right)$, DBT (1150 mg L-1, $1534 \mathrm{ppm}$ peso en azufre) $n$-dodecano $(10 \mathrm{~mL}), \mathrm{O}_{2}(1 \mathrm{~atm}), 120^{\circ} \mathrm{C}$. Leyenda: Catalizador no activado: DBT (๘) y DBT-Sulfona $(\square)$ o, catalizador activado, DBT $(\Delta)$ y DBT-Sulfona $(\boldsymbol{\Delta})$.

Una observación notable que resulta de la medida de la evolución temporal de la reacción fue la presencia de un período de inducción (Figura 4.2). A fin de comprender el origen de este período de inducción se llevaron a cabo varios ensayos que se pueden observar en la Figura 4.3, incluyendo: (1) calentamiento de una disolución de DBT en $n$-dodecano en presencia de MIL-101(Cr) bajo Ar durante $20 \mathrm{~h}$ y a continuación adición de $\mathrm{O}_{2}$, (2) calentamiento de MIL-101(Cr) en $n$-dodecano usando 1 atm de $\mathrm{O}_{2}$ durante 12 $\mathrm{h}$ y entonces añadiendo DBT, y (3) calentamiento de MIL101(Cr) en $n$-dodecano bajo atmósfera de argón durante $12 \mathrm{~h}$ y entonces adición rápida de DBT en atmósfera de oxígeno. En todos los casos, el período de inducción inicial que duraba alrededor de $6 \mathrm{~h}$ desapareció. Esto indica que la difusión del DBT y la activación de oxígeno no es responsable del período de inducción, sino que, más probablemente este período es causado por la difusión lenta del $n$-dodecano al interior de los poros de MIL-101. De esta manera, los resultados en los experimentos de control indican que el período de inducción puede evitarse calentando el material MIL-101 en $n$-dodecano a la temperatura de reacción antes de empezar. En un estudio sobre la adsorción de alcanos lineales, se observó un cambio en el régimen de adsorción con la longitud de la cadena a partir del $n$-nonano, cuya adsorción requiere un tiempo significativamente largo para alcanzar el equilibrio. ${ }^{54}$ Esta observación de una adsorción lenta a partir del $n$-nonano ha sido atribuida a la gran libertad conformacional que poseen estos alcanos lineales y a las dimensiones relativas con respecto al tamaño de los poros del material MIL-101. ${ }^{54}$ De manera similar, en el presente estudio, la difusión del $n$-dodecano en el interior de MIL-101 sería un proceso lento que influiría en la cinética de reacción. 

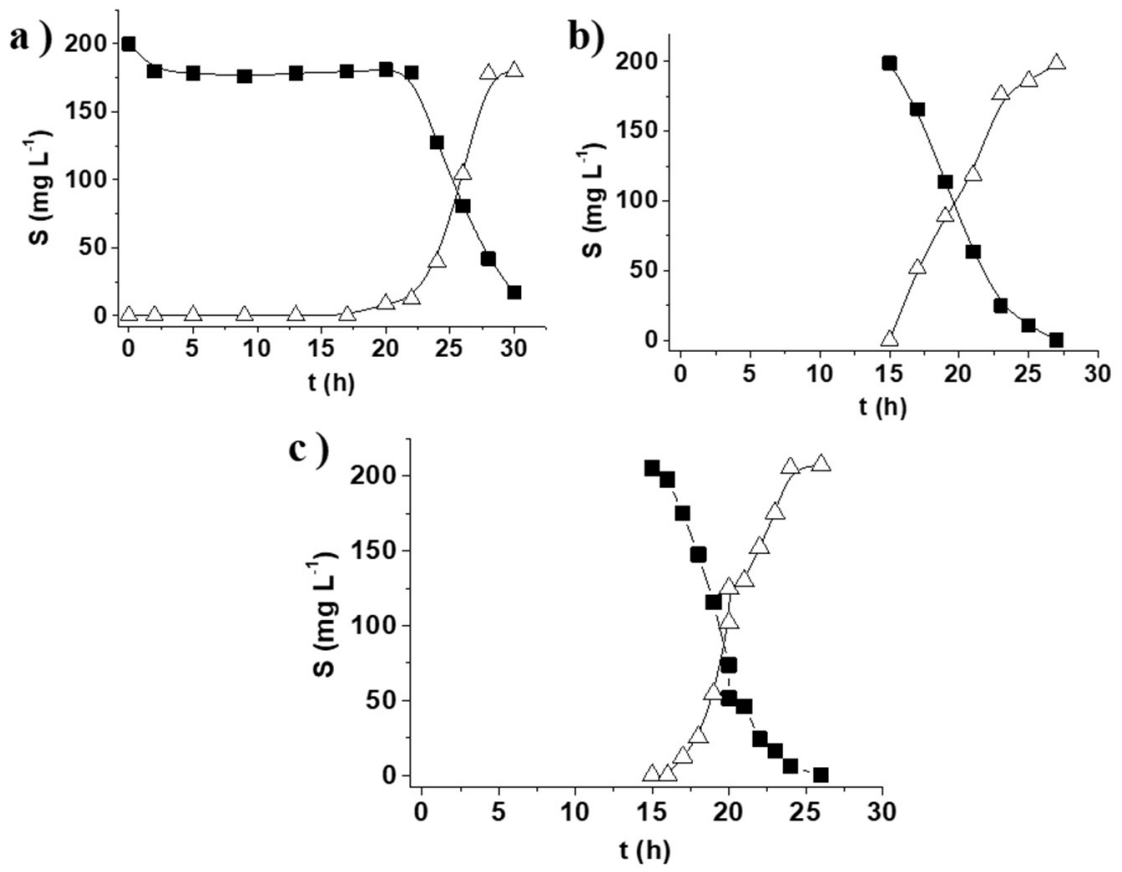

Figura 4.3. Influencia en la oxidación aeróbica de DBT (๘) a DBT-Sulfona $(\Delta)$ usando MIL-101(Cr) como catalizador en varios pretratamientos. Condiciones de reacción: catalizador $\left(500 \mathrm{mg} \mathrm{L}^{-1}\right)$, DBT (1150 mg L ${ }^{-1}, 1534 \mathrm{ppm}$ peso en azufre) $n$-dodecano $(10 \mathrm{~mL}), 120^{\circ} \mathrm{C}$, la atmósfera depende del experimento ( $\mathrm{a}, \mathrm{b}$ o c). Leyenda: (a) DBT en $n$-dodecano con MIL-101(Cr) bajo atmósfera de $\mathrm{Ar}$ a $120^{\circ} \mathrm{C}$ durante $20 \mathrm{~h}$ y luego se añade $\mathrm{O}_{2}$; (b) suspendiendo MIL-101(Cr) en $n$-dodecano bajo $\mathrm{O}_{2}$ a $120{ }^{\circ} \mathrm{C}$ durante $15 \mathrm{~h}$ y luego se añade DBT; (c) poniendo en contacto MIL-101(Cr) en $n$-dodecano bajo atmósfera de Ar durante $15 \mathrm{~h}$ a $120^{\circ} \mathrm{C}$ y luego se añade DBT bajo atmósfera de $\mathrm{O}_{2}$. 
a)

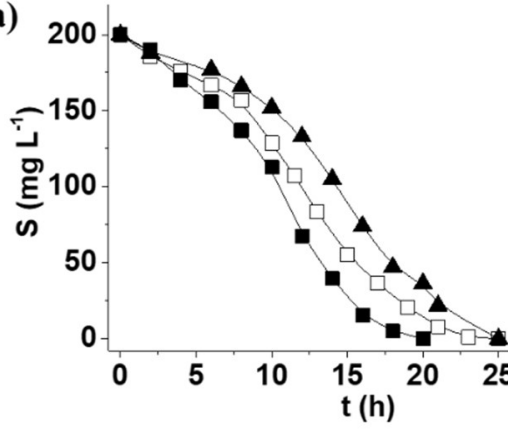

b)

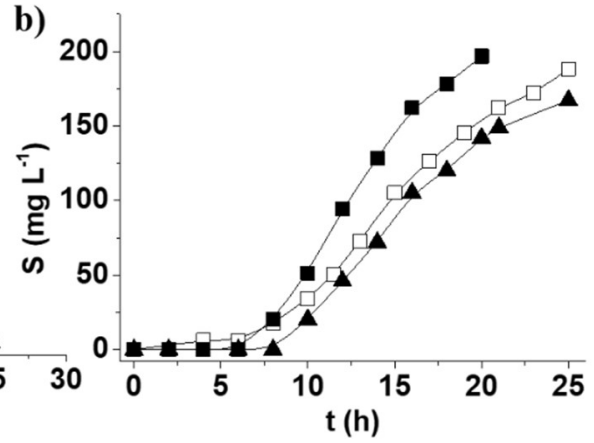

Figura 4.4. Influencia del disolvente en la oxidación aeróbica de DBT (a) a DBT-Sulfona (b) usando MIL-101(Cr) como catalizador. Condiciones de reacción: catalizador $\left(500 \mathrm{mg} \mathrm{L}^{-1}\right)$, DBT $(1150 \mathrm{mg} \mathrm{L}$ $\left.{ }^{1}\right) n$-dodecano $(10 \mathrm{~mL}), \mathrm{O}_{2}(1 \mathrm{~atm}), 120^{\circ} \mathrm{C}$. Leyenda: $n$-decano $(\mathbf{\square}), n$-dodecano $(\square), n$-tetradecano $(\mathbf{\Delta})$.

Aceptando la explicación anterior para justificar el período de inducción en la oxidación aeróbica de DBT y la conveniencia de poner en contacto antes de la reacción el material MIL-101 (Cr) con el disolvente, se pensó en la posibilidad de que la longitud de la cadena del disolvente juegue un papel en la cinética de la reacción. Como muestra la figura 4.4, el perfil temporal de la oxidación del DBT depende de forma evidente del disolvente, de acuerdo con la propuesta de que $n$-alcanos de cadena corta disminuyen el período de inducción.

La influencia de la presión de oxígeno y la temperatura de la reacción en la oxidación aeróbica de DBT promovida por MIL-101 se estudió igualmente (Figuras 4.5 y 4.6). Se comprobó que la concentración de oxígeno influye en el período de inducción, pero no en la velocidad de reacción tras la iniciación, así como, que la reacción puede llevarse a cabo empleando aire. Este hecho puede interpretarse considerando que además de la difusión de $n$-dodecano, la difusión de oxígeno también contribuye al período de inducción, que es el fenómeno que requiere el mayor tiempo para cualquiera de los 2 procesos. Cuando la presión de oxígeno aumenta, el oxígeno puede acceder a los centros metálicos mucho más rápidamente y formar el ion superióxido que reaccionara con el DBT fuera de los cristales del material MIL-101. Cualquier proceso que sea más rápido, bien el llenado de los microporos por $n$-dodecano o bien difundiendo las especies reactivas de oxígeno hacia fuera del MIL-101 iniciaría la oxidación del DBT. Como era de esperar, el período de inducción disminuye y la velocidad de reacción aumenta con la temperatura de reacción con el rango de temperaturas de 110 a $140^{\circ} \mathrm{C}$. El gráfico de Arrhenius representando el logaritmo de la velocidad tras el período de inducción sigue una relación lineal con la inversa de la temperatura absoluta permitiendo estimar la energía de activación aparente de $137 \mathrm{KJ} \mathrm{mol}^{-1}$. Este valor de $\mathrm{E}_{\mathrm{a}}$ es más alto que otros descritos en la literatura para la oxidación de DBT usando TBHP usando MIL-47(V) y MIL-125(Ti) 
que fueron estimados como 51 y $75 \mathrm{~kJ} \mathrm{~mol}^{-1} .{ }^{32}$ Considerando que los peróxidos orgánicos son más reactivos que el oxígeno molecular, el valor de $\mathrm{E}_{\mathrm{a}}$ más alto no es inesperado para la presente oxidación aeróbica. Un experimento adicional donde se aumentó la cantidad de catalizador resulta en una disminución del periodo de inducción y el tiempo final. Conversiones completas de DBT se pueden conseguir en 4h de tiempo de reacción (comparar fig 4.6d y 4.7).
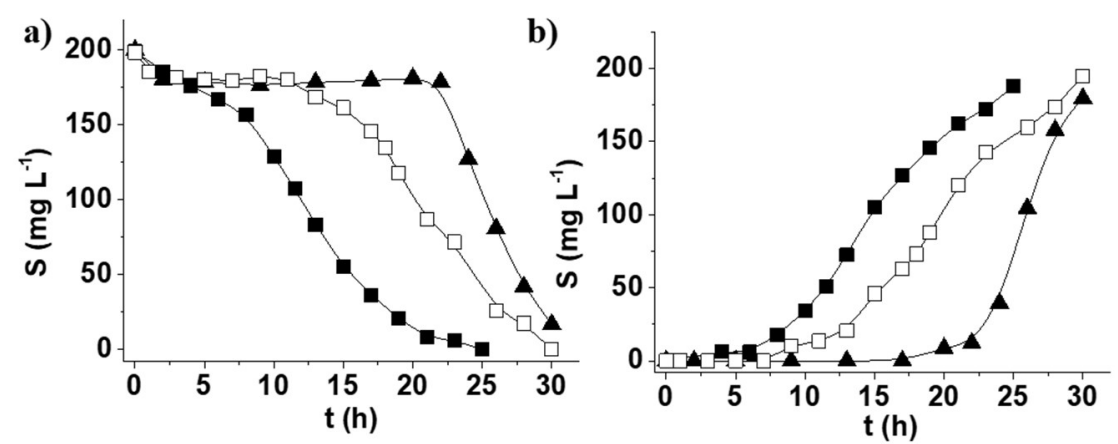

Figura 4.5. Influencia de la presión parcial de oxígeno en la oxidación aeróbica de DBT (a) a DBTSulfona (b) usando MIL-101(Cr) como catalizador. Condiciones de reacción: catalizador $\left(500 \mathrm{mg} \mathrm{L}^{-1}\right)$, DBT $\left(1150 \mathrm{mg} \mathrm{L}^{-1}\right) n$-dodecano $(10 \mathrm{~mL})$, atmósfera de reacción $(1 \mathrm{~atm}), 120^{\circ} \mathrm{C}$. Leyenda: $\mathrm{O}_{2}(\boldsymbol{\square})$, aire () y Ar durante $23 \mathrm{~h}$ y luego añadiendo $\mathrm{O}_{2}$ a $1 \mathrm{~atm}(\boldsymbol{\Delta})$. 

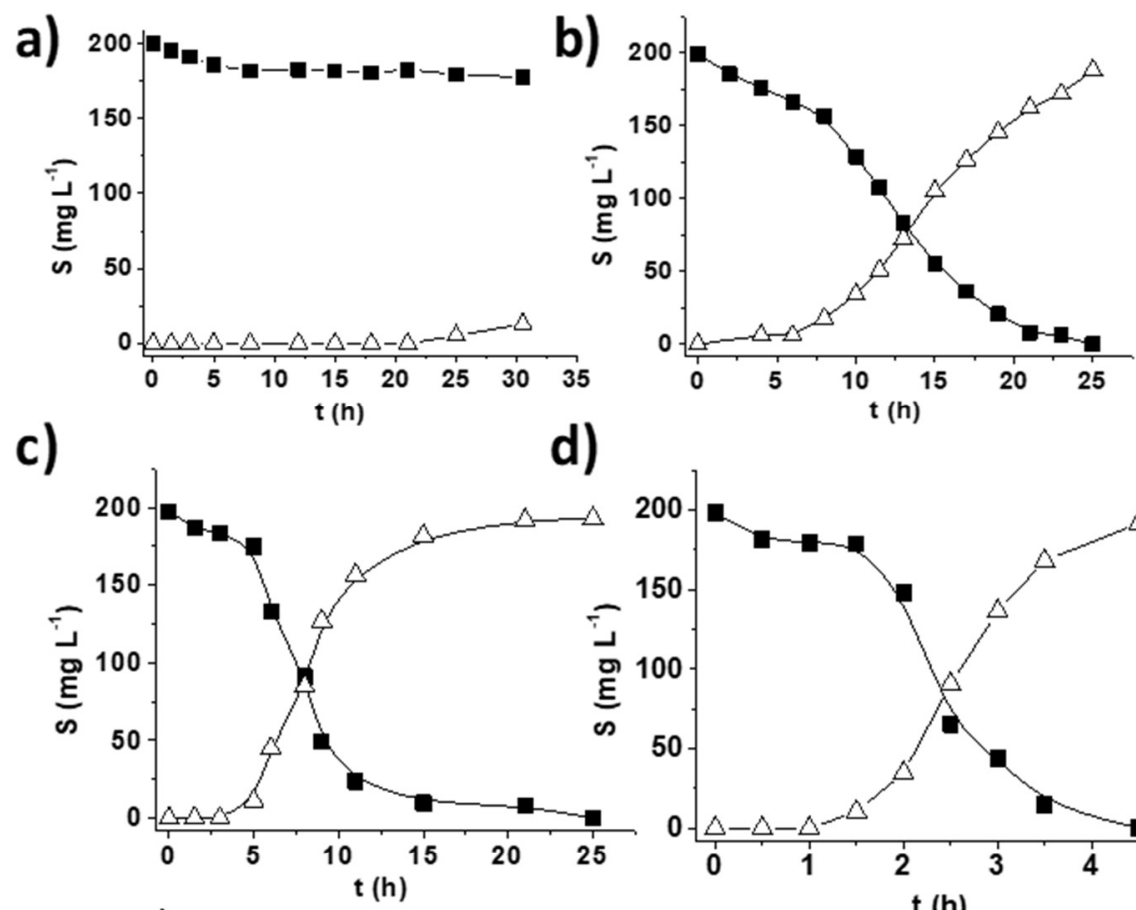

e)
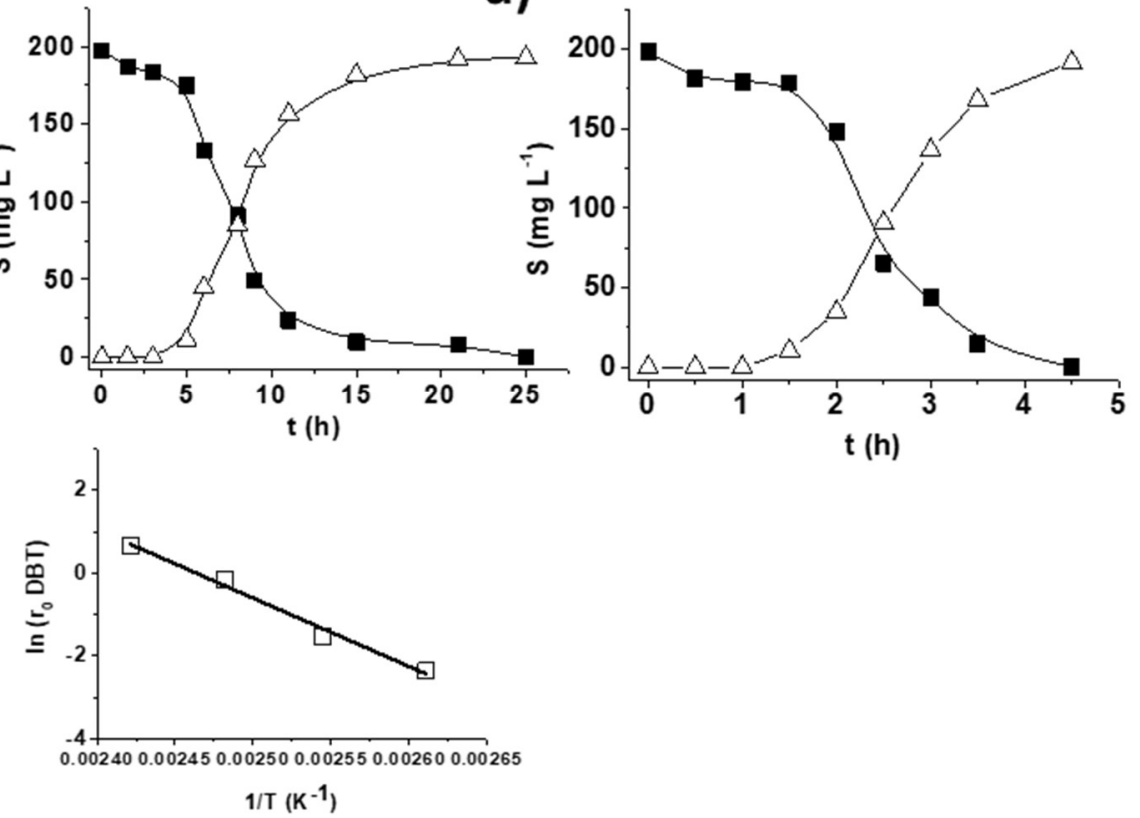

$\mathrm{t}(\mathrm{h})$

Figura 4.6. Influencia de la temperatura de reacción siendo $110^{\circ} \mathrm{C}(\mathrm{a}), 120^{\circ} \mathrm{C}(\mathrm{b}), 130^{\circ} \mathrm{C}(\mathrm{c})$ o $140^{\circ} \mathrm{C}$ (d) y gráfico de Arrhenius (e) en la oxidación aeróbica de DBT (a) a DBT-Sulfona $(\Delta)$ usando MIL$101(\mathrm{Cr})$ como catalizador. Condiciones de reacción: catalizador $\left(500 \mathrm{mg} \mathrm{L}^{-1}\right)$, DBT $\left(1150 \mathrm{mg} \mathrm{L}^{-1}\right) n-$ dodecano $(10 \mathrm{~mL}), \mathrm{O}_{2}(1 \mathrm{~atm})$. 


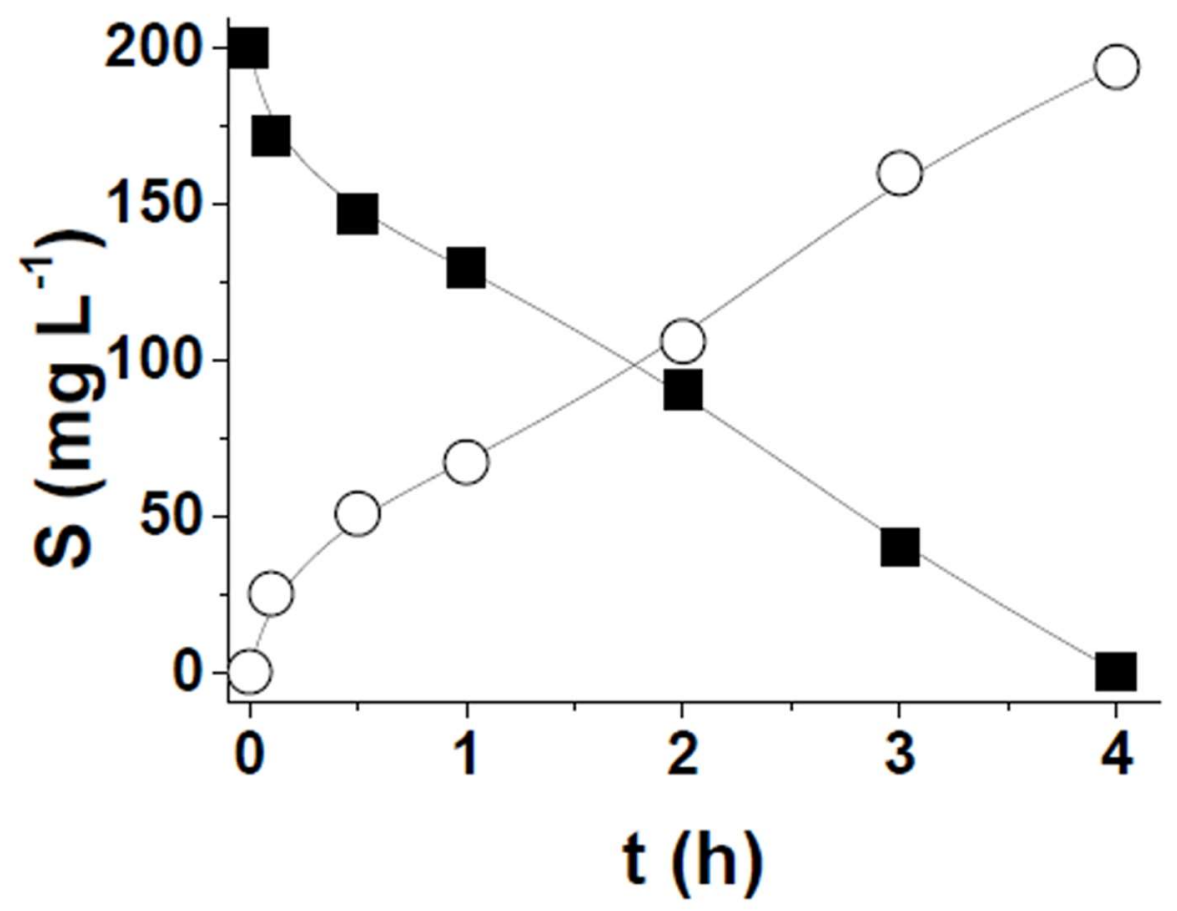

Figura 4.7. Oxidación aeróbica de DBT ( ) a DBT-Sulfona (o) usando MIL-101(Cr) como catalizador. Condiciones de reacción: catalizador $\left(1000 \mathrm{mg} \mathrm{L}^{-1}\right)$, DBT $\left(1150 \mathrm{mg} \mathrm{L}^{-1}\right) n$-dodecano $(10 \mathrm{~mL}), \mathrm{O}_{2}(1$ atm) y $140{ }^{\circ} \mathrm{C}$.

El material MIL-101(Cr) fue estable como catalizador puesto que exhibió la misma actividad catalítica en varios reusos. La figura 4.8 muestra los perfiles temporales de desaparición de DBT y formación de DBT-S en 5 reacciones consecutivas usando la misma muestra de MIL-101(Cr) la cual fue recuperada de la mezcla de reacción por filtración, lavada con agua y reutilizada. Como muestra la figura 4.8, los mismos perfiles temporales se reproducen exactamente en estas 5 reacciones consecutivas, indicando que el catalizador no sufre desactivación en estas condiciones. Este resultado se confirma también por análisis químico de ICP-OES de la fase líquida tras la reacción, lo que indica que el contenido de Cr está por debajo de $0.5 \%$ de la cantidad total de $\mathrm{Cr}$ presente en el catalizador fresco. Experimentos de control usando cantidades de $\mathrm{Cr}^{3+}$ similares a las que lixivian del sólido, pero en ausencia de MIL-101(Cr) indican que la reacción se promueve por MIL-101(Cr) con una actividad despreciable para la cantidad pequeña de $\mathrm{Cr}$ que lixivia del sólido (Figura 4.9). Además, los datos de DRX y ATR-FT-IR del material fresco MIL-101(Cr) y tras 3 y 5 usos fueron igualmente coincidentes, indicando que la estructura cristalina permanece inalterada durante el proceso (Figura 4.10) estos hechos 
sobre la estabilidad del MIL-101 están de acuerdo con los resultados previos que han empleado este material como catalizador donde se observó una notable estabilidad. ${ }^{16,22,23}$

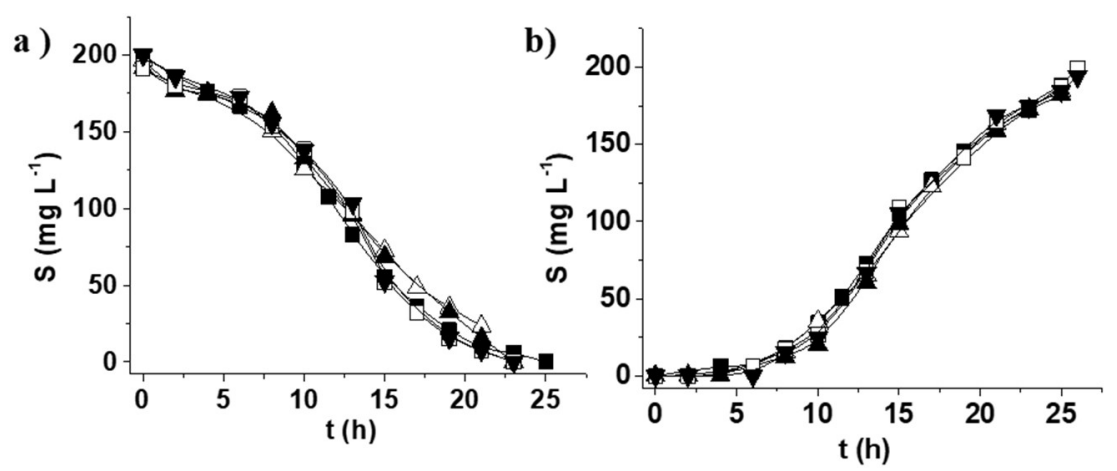

Figura 4.8. Reusabilidad del MIL-101(Cr) en la oxidación aeróbica de DBT (a) a DBT-Sulfona (b). Condiciones de reacción: catalizador $\left(500 \mathrm{mg} \mathrm{L}^{-1}\right)$, DBT $\left(1150 \mathrm{mg} \mathrm{L}^{-1}\right) n$-dodecano $(10 \mathrm{~mL}), \mathrm{O}_{2}(1$ atm), $120^{\circ} \mathrm{C}$. Leyenda: $1^{\circ}$ uso $(\square), 2^{\circ}$ uso $(\Delta), 3^{\circ}$ uso $(\boldsymbol{\Delta}), 4^{\circ}$ uso $(\square)$ y $5^{\circ}$ uso $(\boldsymbol{\nabla})$.

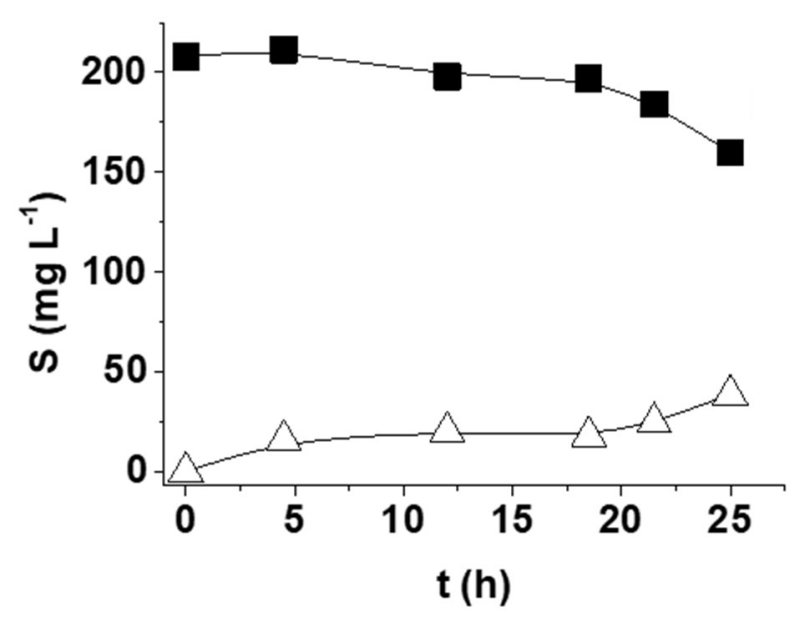

Figura 4.9. Experimento control para la oxidación aeróbica de DBT en homogéneo con $\mathrm{O}_{2}$ en presencia de acetato de cromo (III) como catalizador homogéneo. Condiciones de reacción: cromo (III) acetato hi-

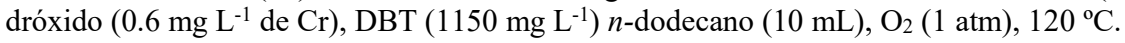


a)

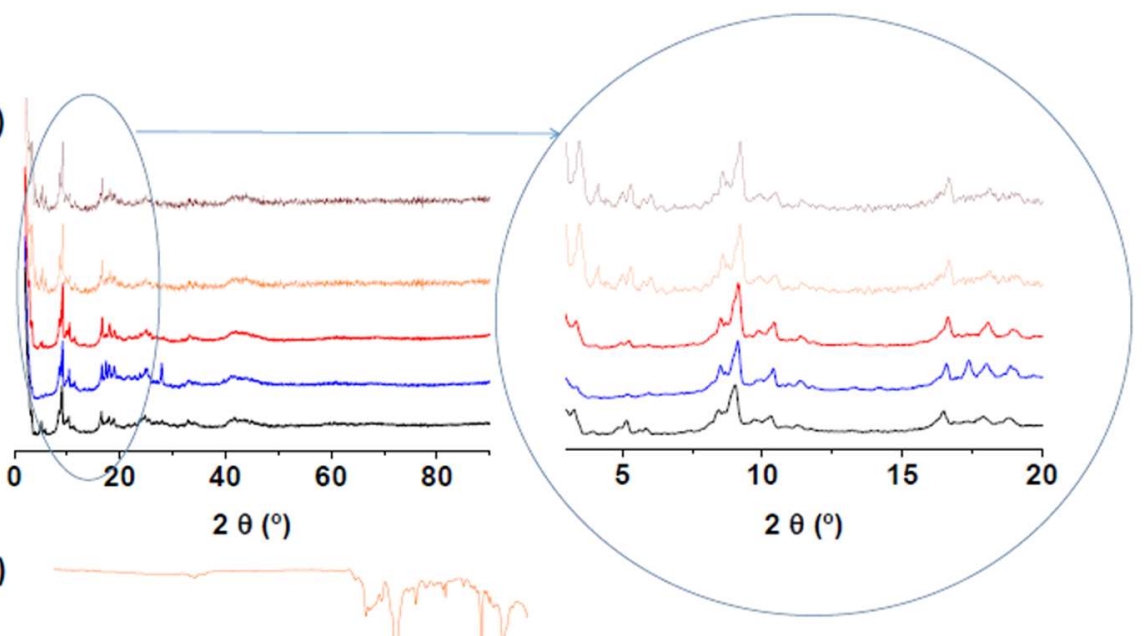

b)

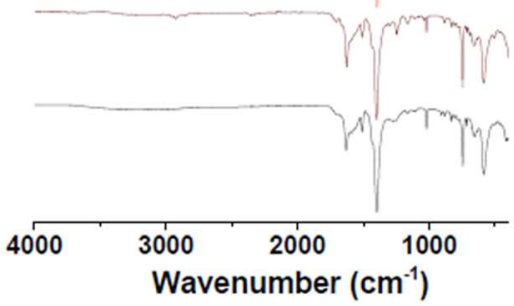

Figura 4.10. DRX (a) y ATR-FT-IR de MIL-101(Cr) fresco y usado. Leyenda para las muestras de MIL-101(Cr): fresco (negro), usado y no lavado (azul), tras un uso (rojo), tras 3 usos (naranja) y tras 5 usos (marrón). Condiciones de reacción para las muestras de MIL-101(Cr) usadas: catalizador $(500 \mathrm{mg}$ $\left.\mathrm{L}^{-1}\right)$, DBT (1150 $\left.\mathrm{mg} \mathrm{L}^{-1}\right) n$-dodecano $(10 \mathrm{~mL}), \mathrm{O}_{2}(1 \mathrm{~atm}), 120^{\circ} \mathrm{C}$.

La estabilidad del catalizador fue apoyada llevando a cabo un test catalítico adicional en el cual se emplean cantidades de DBT 5 veces mayores y llevando a cabo la oxidación usando cantidades de catalizador 50 veces inferiores, llegándose a observar una desaparición casi completa de DBT a períodos de reacción suficientemente largos (Figura 4.11). Se observó, sin embargo, la aparición gradual de un precipitado de DBT-S como un sólido a medida que la reacción progresa. Este hecho es consecuencia de la baja solubilidad de la DBT-S en $n$-dodecano. 


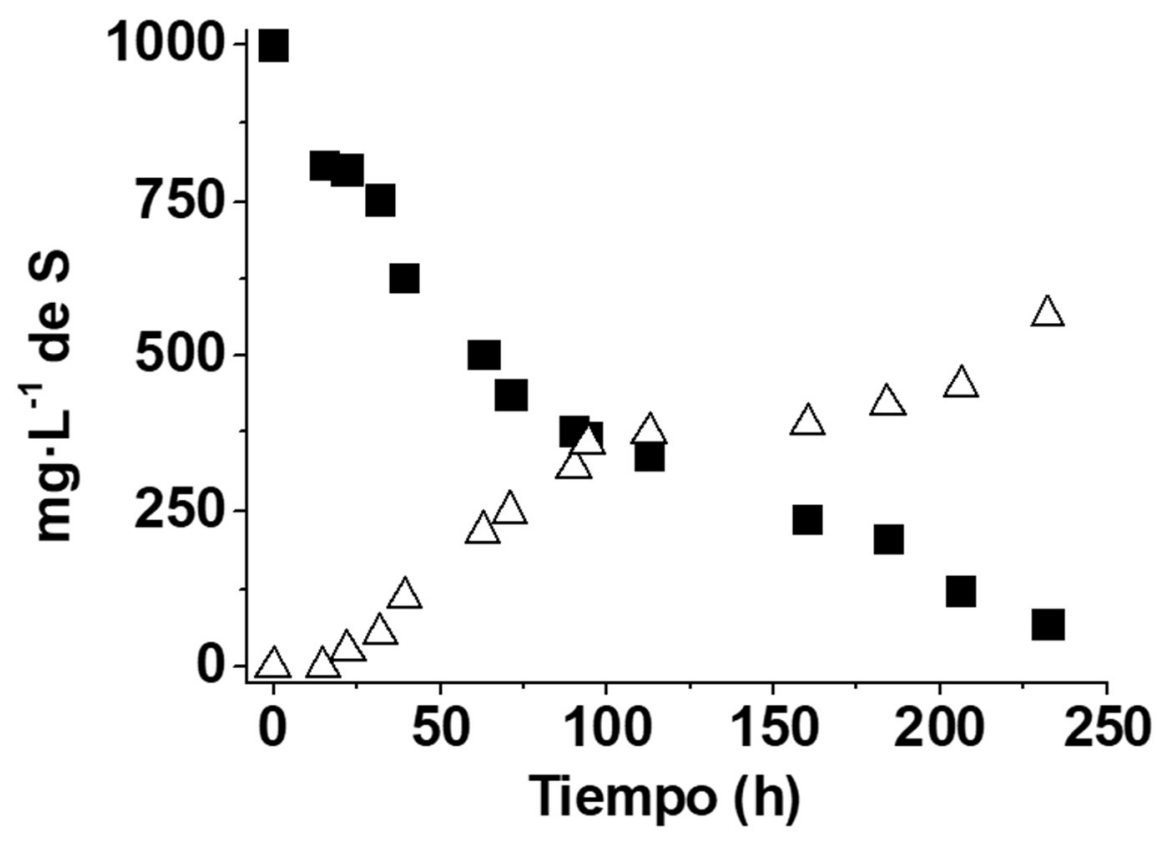

Figura 4.11. Test de productividad para la oxidación aeróbica de DBT (匹) a DBT-Sulfona $(\Delta)$ usando MIL-101(Cr) como catalizado. Condiciones de reacción: catalizador (10 $\left.\mathrm{mg} \mathrm{L}^{-1}\right)$, DBT $\left(5750 \mathrm{mg} \mathrm{L}^{-1}\right)$ $n$-dodecano $(10 \mathrm{~mL}), \mathrm{O}_{2}(1 \mathrm{~atm}), 120^{\circ} \mathrm{C}$.

La heterogeneidad del proceso se estudió llevando a cabo 2 experimentos paralelos y eliminando el catalizador en uno de ellos una vez que se ha superado el período de inducción (10 h) (Figura 4.12). Se observaron exactamente los mismos perfiles temporales para la desaparición del DBT y la formación de la DBT-S en estos 2 experimentos indicando que una vez la reacción ha empezado en presencia de MIL-101(Cr), este sólido ya no es necesario. Este tipo de comportamiento es común en reacciones de autooxidación en cadena en las cuales el papel del iniciador es el de generar radicales libres que a continuación intervienen en ciclos de propagación con oxígeno molecular que ya no requiere de ningún catalizador. ${ }^{23,55,56} \mathrm{~A}$ fin de proporcionar algún apoyo a esta propuesta del mecanismo de autooxidación, se añadió TEMPO como agente inhibidor de radicales, observando que en presencia de este inhibidor de radicales, no tiene lugar la oxidación del DBT en períodos más largos de $30 \mathrm{~h}$. Por otro lado, si la reacción se empieza con MIL-101(Cr) en ausencia de TEMPO y, a continuación, una vez que la reacción progresa, se añade TEMPO, una disminución significativa en la velocidad de reacción es observada (Figura 4.12). 

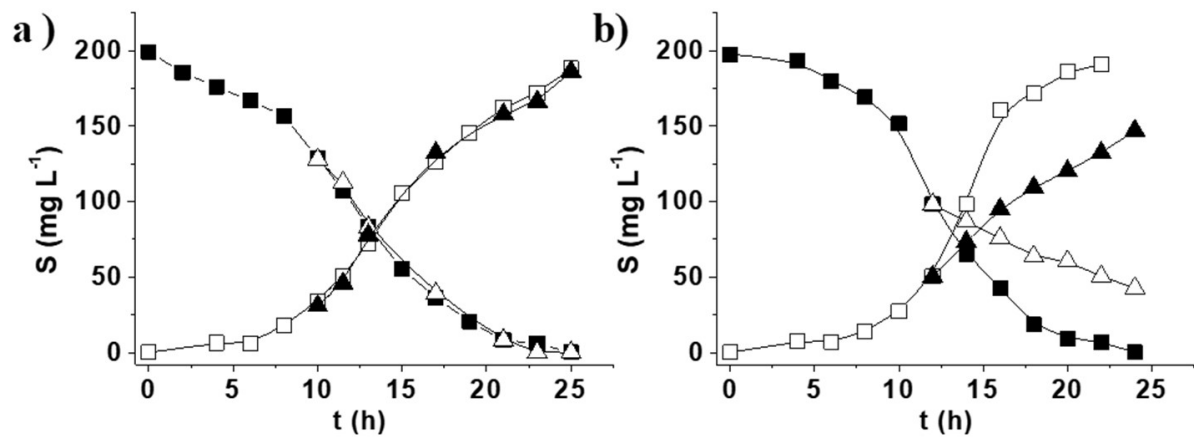

Figura 4.12. (a) Ensayo de filtración en caliente a una conversión del 38\% para la oxidación aeróbica de DBT a DBT-S usando MIL-101(Cr) como catalizador. Condiciones de reacción: catalizador (500 $\left.\mathrm{mg} \mathrm{L}^{-1}\right)$, DBT $\left(1150 \mathrm{mg} \mathrm{L}^{-1}\right) n$-dodecano $(10 \mathrm{~mL}), \mathrm{O}_{2}(1 \mathrm{~atm}), 120^{\circ} \mathrm{C}$. Leyenda: en presencia de catalizador: DBT ( $\bullet$ ) DBT-S ( $\square)$; tras filtración del catalizador DBT $(\Delta)$, DBT-S ( $\mathbf{\Delta})$. (b) Ensayo de filtración en caliente a conversión del $38 \%$ en presencia de TEMPO ( $20 \%$ en moles respecto DBT). Leyenda: en presencia de catalizador: DBT ( $\mathbf{})$ DBT-S ( $\square$ ); tras filtración del catalizador en presencia de TEMPO, $\operatorname{DBT}(\Delta)$, DBT-S $(\boldsymbol{\Delta})$.

INICIACIÓN

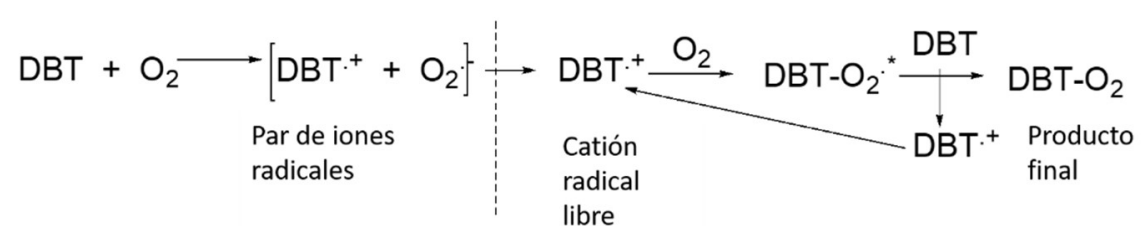

Esquema 4.2. Mecanismo de reacción propuesto para la oxidación aeróbica de DBT con oxígeno molecular en presencia de MIL-101(Cr) como catalizador.

De acuerdo con estos datos se propone el mecanismo de autooxidación indicado en el esquema 4.2. En este mecanismo, tras la iniciación por generación del primer $\mathrm{DBT}^{+}$, ocurre una cadena de propagación por reacción con oxígeno molecular y formación del aducto DBT-O2 ${ }^{+}$y posterior abstracción de un electrón de una molécula neutra de DBT. El primer radical $\mathrm{DBT}^{+}{ }^{+}$sería generado por una especie reactiva de oxígeno formada por interacción con los iones $\mathrm{Cr}^{3+}$ y oxígeno en el catalizado sólido. ${ }^{34,57,58}$

A fin de proporcionar evidencia experimental sobre la generación de especies reactivas de oxígeno, se registraron espectros de EPR usando fenil $\alpha$-tertbutilnitrona (PBN) como agente atrapador de radicales. Como puede verse en la Figura 4.13, mientras que 
MIL-101(Cr) y $\mathrm{O}_{2}$ presentan solo una señal de EPR muy débil cuando se añade PBN la señal de EPR corresponde al aducto del PBN con el radical HOO. Este radical HOO se formaría por protonación del ion superóxido $\mathrm{O}_{2}-$ por la humedad presente en el medio y constituye una evidencia experimental de que especies reactivas de oxígeno son generadas en el medio por acción del sólido MIL-101(Cr) como un iniciador. ${ }^{23}$ Experimentos de inhibición selectiva de radicales usando $p$-benzoquinona ${ }^{59}$ o DMSO $^{60,61}$ como inhibidores de $\mathrm{O}_{2}{ }^{-} / \mathrm{HOO}$ o del radical $\mathrm{HO}$, respectivamente apoyan la generación de $\mathrm{O}_{2}{ }^{-}$ /HOO a partir de $\mathrm{O}_{2}$ molecular. La presencia de $p$-benzoquinona inhibe completamente la reacción (Figura 4.14), apoyando de esta manera la generación de radicales $\mathrm{O}_{2}{ }^{-} / \mathrm{HOO}$. Mientras que la presencia de DMSO (un inhibidor de radicales hidroxilo) no afecta al perfil de reacción de oxidación de DBT a DBT-S. La oxidación a DBT-S por $\mathrm{O}_{2}-/ \mathrm{HOO}$ se apoya además llevando a cabo experimentos adicionales empleando TBHP como oxidante y observando la conversión de DBT a su correspondiente DBT-S (Figura 4.15). En contraste, el uso de peróxidos de benzoilo como agente oxidante no conduce a la oxidación de DBT a DBT-S (Figura 4.15).
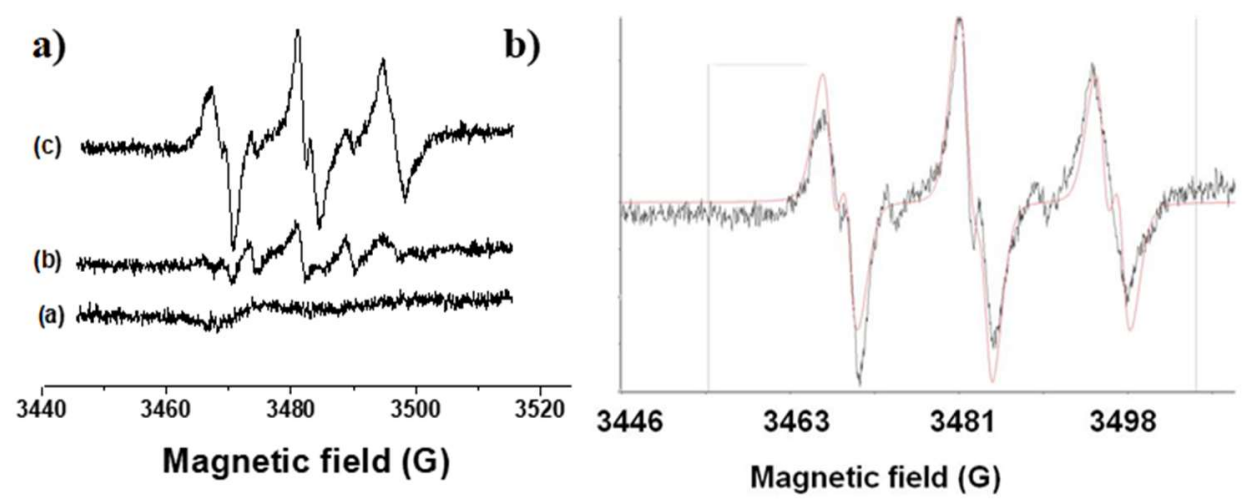

Figura 4.13. (A) Espectro de EPR experimental empleando $n$-dodecano como disolvente a $120^{\circ} \mathrm{C}$ durante 5 h y utilizando (a) MIL-101(Cr) $+\mathrm{O}_{2}$, (b) $\mathrm{PBN}+\mathrm{O}_{2}$ y (c) MIL-101(Cr) $+\mathrm{PBN}+\mathrm{O}_{2}$. (B) Espectro de EPR experimental y simulado de PBN-OOH bajo las condiciones de (c). Las constantes de acoplamiento de $\mathrm{PBN}-\mathrm{OOH}(\sim 90 \%$ área $) \mathrm{AG}_{\mathrm{N}}=14.0$ y $\mathrm{AG}_{\mathrm{H}}=2.05 \mathrm{y}$ tert-butil aminoxyl para el PBN degradado $\mathrm{AG}_{\mathrm{N}}=14.0$ y $\mathrm{AG}_{\mathrm{H}}=14.0$. 

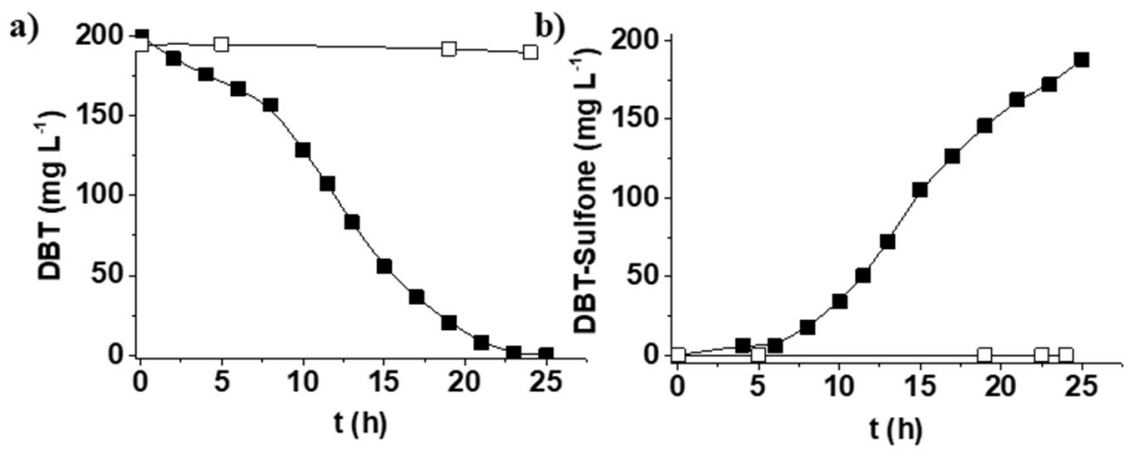

Figura 4.14. Oxidación aeróbica de DBT (a) a DBT-S (b) en ausencia (-) y en presencia de $p$ - benzoquinona ( $\square$ ) como atrapador selectivo de radicales $\mathrm{O}_{2} \cdot / \mathrm{HOO}$ utilizando MIL-101(Cr) como catalizador. Condiciones de reacción: catalizador (500 $\left.\mathrm{mg} \mathrm{L}^{-1}\right)$, DBT (1150 $\left.\mathrm{mg} \mathrm{L}^{-1}\right), p$-benzoquinona $(20 \mathrm{~mol} \%$ con respecto al DBT), $n$-dodecano $(10 \mathrm{~mL}), \mathrm{O}_{2}(1 \mathrm{~atm}), 120^{\circ} \mathrm{C}$.
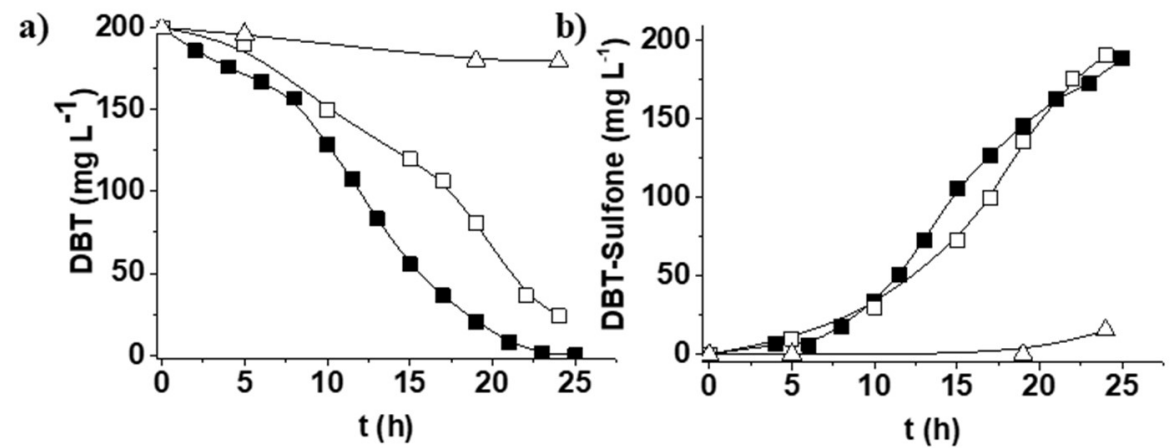

Figura 4.15. Oxidación aeróbica de DBT (a) a DBT-S (b) utilizando MIL-101(Cr) (•) como catalizador heterogéneo o usando TBHP ( $\square$ ) o peróxido de benzoilo $(\Delta)$ como catalizadores homogéneos. Condiciones de reacción: MIL-101(Cr) $\left(500 \mathrm{mg} \mathrm{L}^{-1}\right)$, TBHP o peróxido de benzoilo (20 mol\% con respecto al DBT), DBT (1150 $\left.\mathrm{mg} \mathrm{L}^{-1}\right), n$-dodecano $(10 \mathrm{~mL}), \mathrm{O}_{2}(1 \mathrm{~atm}), 120^{\circ} \mathrm{C}$.

Además de la espectroscopia de EPR, la espectroscopia Raman también proporciona información valiosa que apoya que los radicales $\mathrm{O}_{2}{ }^{-}$son la especie de oxígeno reactivo inicial que ocasiona la autoxidación de DBT.

La activación de oxígeno tanto en MIL-101(Cr) como en MIL-101(Fe) fue estudiada por espectroscopia Raman. ${ }^{62-64}$ Para la muestra MIL-101(Cr) (Figura 4.16 A) se detectaron dos bandas Raman a 998 y $1035 \mathrm{~cm}^{-1}$ cuando la muestra se expone a un flujo de $\mathrm{O}_{2}$ a $120^{\circ} \mathrm{C}$. Estas bandas han sido atribuidas a la formación de especies peroxo y 
superoxo respectivamente. ${ }^{63}$ Hay que notar que la estabilidad de estas bandas es relativamente baja puesto que son fácilmente eliminadas a temperatura ambiente purgado la muestra con una corriente de $\mathrm{N}_{2}$. De manera análoga a la muestra MIL-101(Cr), se observó la activación de oxígeno molecular con formación de peroxo $\left(826 \mathrm{~cm}^{-1}\right)$, superoxo $\left(1161 \mathrm{~cm}^{-1}\right)$ y $_{2}{ }^{\delta-}\left(1313 \mathrm{~cm}^{-1}\right)$ para la muestra de MIL-101(Fe) (Figura 4.16 B) cuando esta se expone a un flujo de $\mathrm{O}_{2}$ a $120{ }^{\circ} \mathrm{C} .{ }^{63,64}$ Estas especies también son fácilmente eliminadas purgando con $\mathrm{N}_{2}$ a temperatura ambiente. La banda de Raman a $1502 \mathrm{~cm}^{-1}$ ha sido atribuida al oxígeno molecular adsorbido ${ }^{62,63}$ la cual disminuye en intensidad purgando con $\mathrm{N}_{2}$. Sin embargo, un comportamiento diferente se observa en la banda de Raman a $1430 \mathrm{~cm}^{-1}$ la cual aumenta su resolución tras tratamiento con $\mathrm{O}_{2}$ a $120{ }^{\circ} \mathrm{C}$. Probablemente esta banda se pueda asignar a alguna modificación estructural en la red del MOF. De hecho, estudios por espectroscopia de IR permiten detectar modificaciones estructurales en la zona de 1650 a $1400 \mathrm{~cm}^{-1}$ con estos tratamientos.
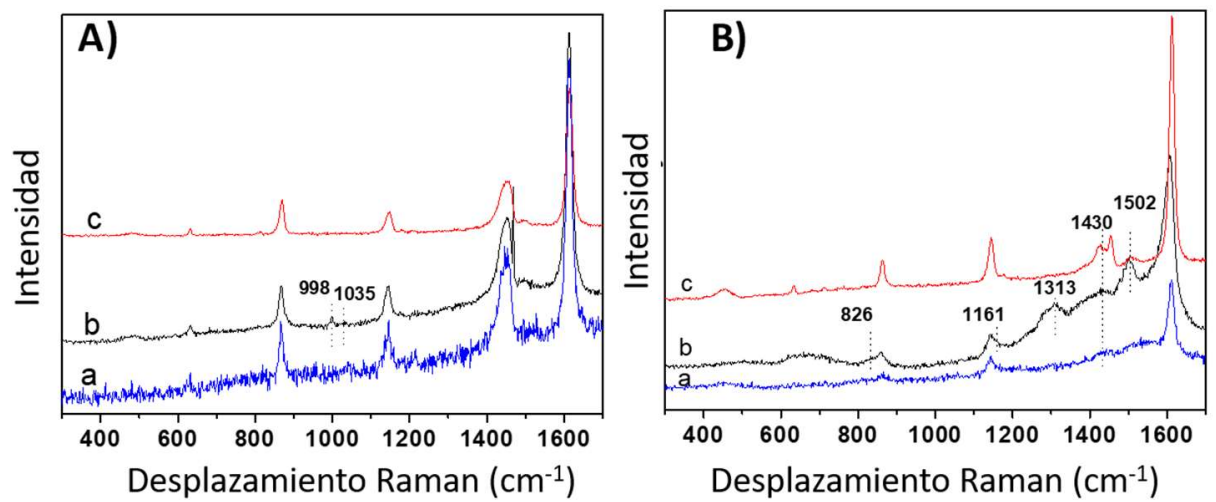

Figura 4.16. Espectro Raman para las muestras de MIL-101(Cr) (A) y MIL-101(Fe) (B) bajo un flujo de $\mathrm{N}_{2}$ a $120^{\circ} \mathrm{C}$ (a), un flujo de $\mathrm{O}_{2}$ a $120^{\circ} \mathrm{C}$ (b) y un flujo de $\mathrm{N}_{2}$ a $25^{\circ} \mathrm{C}$ (c).

De acuerdo con estos resultados, la admisión de oxígeno molecular daría lugar a la generación de especies peroxo y superoxo, las cuales estarían estabilizadas en las estructuras de MIL-101(Cr o Fe). Los picos correspondientes a estas especies de oxígeno reactivas desaparecerían o disminuirían significativamente en espectroscopia Raman si una corriente de nitrógeno circulara en estas muestras, indicando que $\mathrm{O}_{2}-{ }^{-}$pueden difundir fuera de la estructura de MIL-101 una vez formada. Todas estas observaciones están de acuerdo con la detección por espectroscopia de EPR del aducto de PBN con HOO y con la propuesta mecanística indicada en el esquema 4.2.

Más aún, se investigó la posibilidad de que el átomo de azufre de DBT se coordinara con los iones $\mathrm{Cr}^{3+}$ de la muestra MIL-101(Cr), siendo esta asociación un intermedio de reacción y participando en el mecanismo de oxidación. A este fin, se llevó a cabo la 
adsorción de DBT en MIL-101(Cr) a temperatura ambiente y, a continuación, se registraron los espectros de adsorción UV-VIS por reflectancia difusa y el espectro de IR por la técnica de reflectancia total atenuada. La figura 4.17 muestra que no aparece cambio alguno que pueda ser atribuido a la interacción entre los iones $\mathrm{Cr}^{3+}$ del material MIL101(Cr) con DBT. Por consiguiente, la adsorción de DBT en MIL-101(Cr) ocurriría probablemente por interacción $\pi-\pi$ del DBT con los ligandos orgánicos de la estructura de MIL-101.
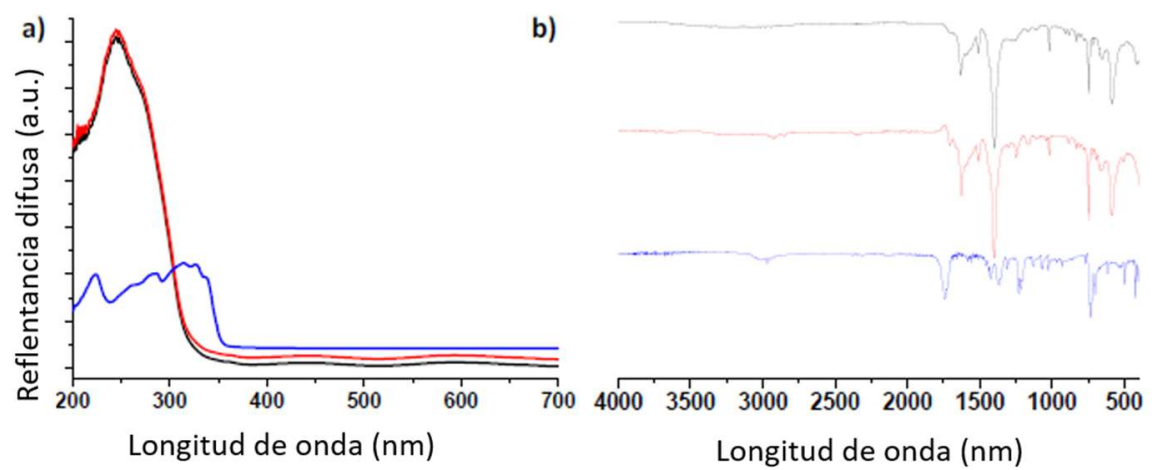

Figura 4.17. Reflectancia difusa de la adsorción UV-vis (a) y espectro ATR-IR (b) para el MIL-101(Cr) (línea negra), DBT (línea azul) y MIL-101(Cr)+DBT adsorbido (línea roja). Condiciones de adsorción: MIL-101(Cr) $(25 \mathrm{mg})$, DBT (1150 $\left.\mathrm{mg} \mathrm{L}^{-1}\right), n$ - dodecano $(10 \mathrm{~mL})$, temperatura ambiente, $24 \mathrm{~h}$.

El rango de sustratos aromáticos conteniendo azufre que pueden ser oxidados empleando MIL-101(Cr) como promotor fue estudiado llevando a cabo en condiciones análogas la oxidación de los derivados 4-metil y 4,6-dimetil del DBT (Figura 4.18). Se observó que estos DBTs metil-sustituidos sufren oxidación a las sulfonas correspondientes siguiendo las mismas características que el DBT sin sustituir, pero reaccionando más rápidamente (Figura 4.18). Este modelo de reactividad sigue el orden que cabría esperar de acuerdo con la influencia de sustituyentes sobre la densidad electrónica de los átomos de azufre tal como se describe en la literatura. ${ }^{65}$ Un comportamiento similar se observó llevando a cabo la oxidación de una solución modelo conteniendo una mezcla de estos compuestos (Figura 4.19). 

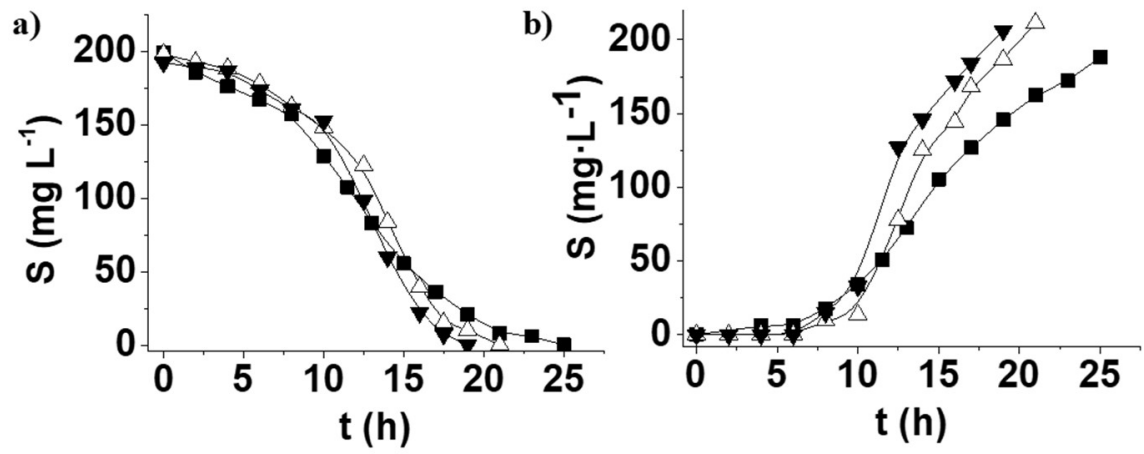

Figura 4.18. Oxidación aeróbica de DBT, 4-metil DBT y 4,6-dimetil DBT a sus correspondientes sulfonas en presencia de MIL-101(Cr) como catalizador. Condiciones de reacción: catalizador $(500 \mathrm{mg} \mathrm{L}$ $\left.{ }^{1}\right)$, sustrato $\left(200 \mathrm{mg} \mathrm{L}^{-1} \mathrm{de} \mathrm{S}\right) n$-dodecano $(10 \mathrm{~mL}), \mathrm{O}_{2}(1 \mathrm{~atm}), 120^{\circ} \mathrm{C}$. Leyenda (a): DBT (a), 4-metil $\operatorname{DBT}(\Delta)$ y 4,6-dimetil DBT $(\boldsymbol{\nabla})$; Leyenda (b): DBT-sulfona $(\boldsymbol{\bullet})$, 4-metil DBT-sulfona $(\Delta)$ y 4,6-dimetil DBT-sulfona $(\boldsymbol{\nabla})$.
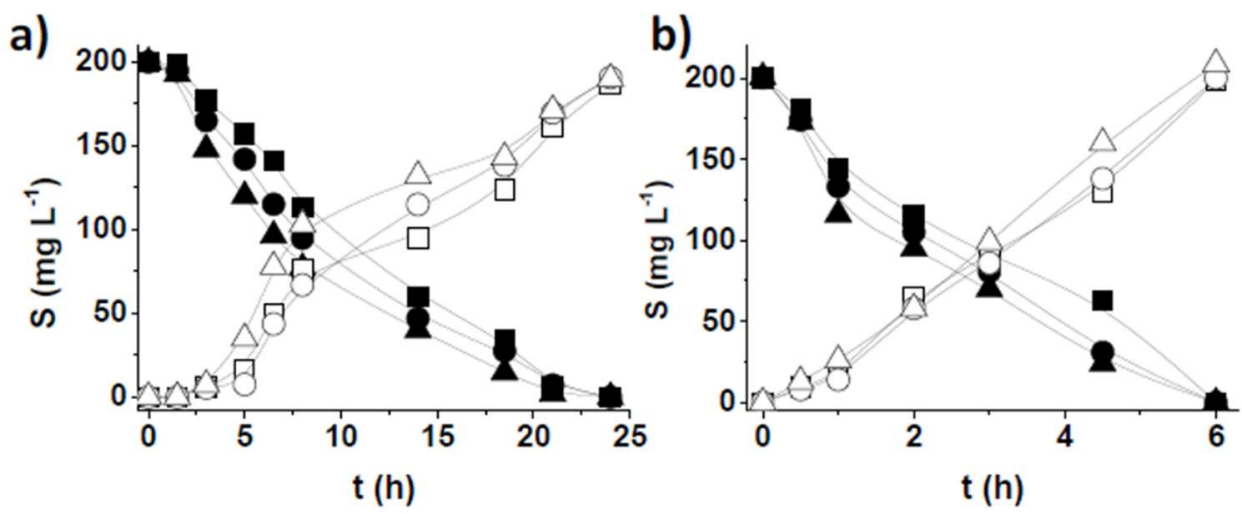

Figura 4.19. Oxidación aeróbica de DBT, 4-metil DBT y 4,6-dimetil DBT en un sistema multicomponente a sus correspondientes sulfonas a $120^{\circ} \mathrm{C}$ (a) o a $140^{\circ} \mathrm{C}$ (b) en presencia de MIL-101(Cr)como catalizador. Condiciones de reacción: catalizador $\left(500 \mathrm{mg} \mathrm{L}^{-1}\right)$, sustrato $\left(200 \mathrm{mg} \mathrm{L}^{-1} \mathrm{de} \mathrm{S}\right.$ de cada componente) $n$-dodecano $(10 \mathrm{~mL}), \mathrm{O}_{2}(1 \mathrm{~atm})$. Leyenda: DBT (•), 4-metil DBT $(\bullet)$ y 4,6-dimetil DBT ( $\left.\mathbf{\Delta}\right)$, DBT-sulfona (口), 4-metil DBT-sulfona (०) y 4,6-dimetil DBT-sulfona $(\Delta)$.

Es importante comentar que la oxidación aeróbica del DBT y de sus derivados 4metil y 4,6-dimetil a las correspondientes sulfonas se pudo conseguir eficientemente también al usar una muestra de diésel comercial (Repsol) en lugar de las disoluciones modelo, aunque en este caso el tiempo de reacción es más largo con respecto a la reacción que emplea $n$-dodecano como disolvente (Figura 4.20). Este hecho puede explicarse considerando la mayor longitud de cadena de los hidrocarburos presentes en la muestra de 
diésel comercial comparados con el $n$-dodecano y/o la presencia de aditivos en la muestra de diésel comercial. Estos aditivos pueden disminuir la adsorción de DBT, desfavoreciendo de esta manera su oxidación promovida por MIL-101.
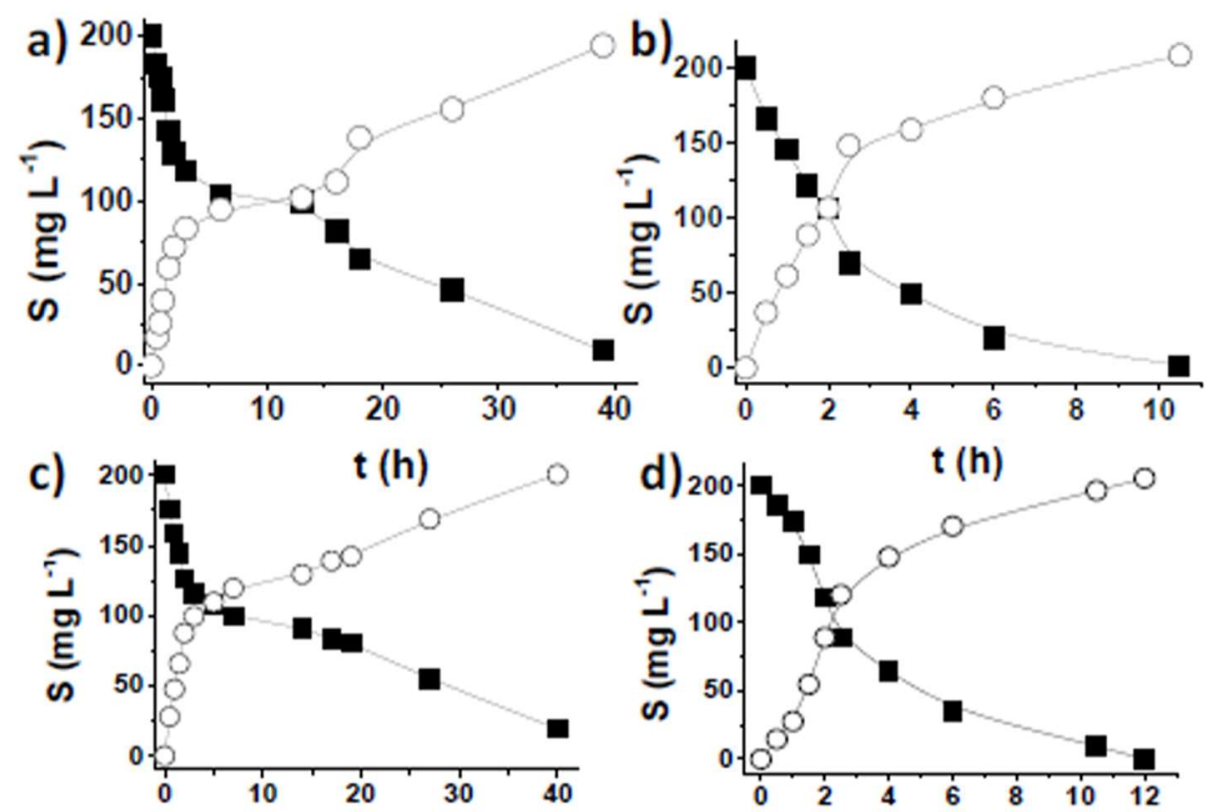

e)
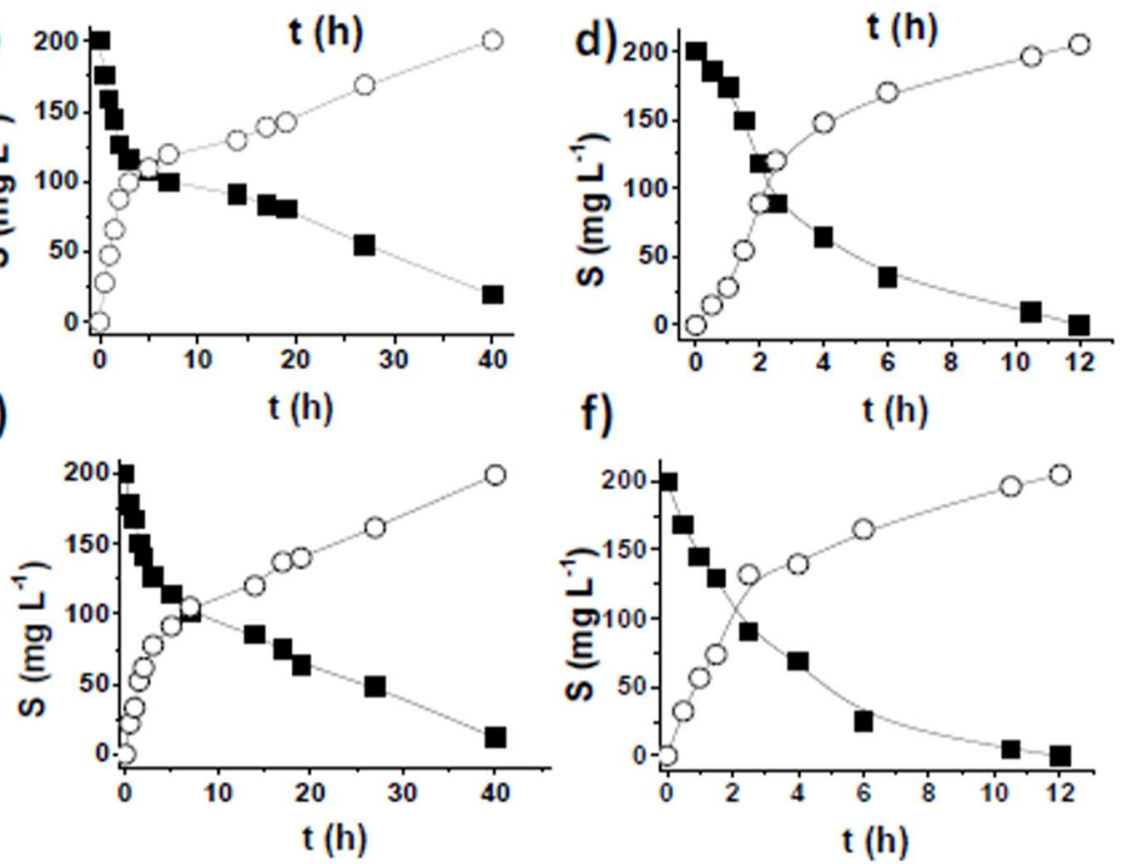

Figura 4.20. Oxidación aeróbica de DBT (a,b), 4-metil DBT (c,d) y 4,6-dimetil DBT (e,f) a sus correspondientes sulfonas a $120^{\circ} \mathrm{C}(\mathrm{a}, \mathrm{c}, \mathrm{e})$ o a $140^{\circ} \mathrm{C}(\mathrm{b}, \mathrm{d}, \mathrm{f})$ en presencia de MIL-101(Cr)como catalizador. Condiciones de reacción: catalizador $\left(500 \mathrm{mg} \mathrm{L}^{-1}\right)$, sustrato $\left(200 \mathrm{mg} \mathrm{L}^{-1} \mathrm{de} \mathrm{S}\right)$ diésel comercial $(10 \mathrm{~mL})$, $\mathrm{O}_{2}(1 \mathrm{~atm})$. 
Capitulo 4.

Finalmente, el proceso de oxidación aeróbica del DBT y de sus derivados metilados usando MIL-101(Cr) como promotor sólido fue seguido de un proceso de extracción líquido-líquido a fin de eliminar los compuestos del azufre. El proceso consiste en la eliminación del catalizador por filtración y posterior extracción de las sulfonas presentes en la fase orgánica con agua. De esta manera el proceso permitió la extracción completa de la DBT-sulfona y de sus derivados resultando una fase orgánica con un contenido en azufre por debajo del límite de detección de nuestro sistema analítico (menor de $4 \mathrm{mg} \mathrm{L}$ ${ }^{1}$ de azufre, aproximadamente menor que $5.3 \mathrm{ppm}$ en peso de azufre). Es digno de mencionar que el contenido máximo de azufre de acuerdo con la legislación, de un combustible debería ser inferior a $10 \mathrm{ppm}$ en peso de azufre..$^{30,31}$

\subsection{Conclusiones.}

El presente capítulo ha mostrado que el material MIL-101 es un promotor eficiente, estable y reusable para llevar a cabo la oxidación aeróbica del DBT y de sus derivados metil-sustituidos presentes en alcanos. La reacción exhibe un período de inducción que está relacionado con la difusión de disolvente y con la formación de la primera especie reactiva de oxígeno que es muy probablemente $\mathrm{O} 2-$ o $\mathrm{HOO}$, los cuales inician un mecanismo radicalario de autooxidación en cadena. Se ha conseguido evidencia experimental de la presencia de estas especies por espectroscopia de EPR detectando la formación del aducto PBN-OOH. También la espectroscopia Raman de una muestra de MIL-101(Cr) expuesta a oxígeno presenta cambios compatibles con la formación de estas especies. Considerando que en la literatura química se ha propuesto que los hidroperóxidos son reactivos que permiten la desulfuración de combustible, los resultados presentes constituyen una alternativa ventajosa que se basa en el empleo de oxígeno molecular como oxidante y de un material sólido poroso que promueve la reacción sin sufrir desactivación alguna. 


\subsection{Referencias}

1. H. Furukawa, K. E. Cordova, M. O'Keeffe y O. M. Yaghi, Science, 2013, 341, 1230444.

2. A. Corma, H. Garcia y F. X. Llabrés i Xamena, Chem. Rev., 2010, 110, 46064655 .

3. Y.-Z. Yang, X.-G. Liu y B.-S. Xu, New Carbon Mater., 2014, 29, 1-14.

4. J. Gascon, A. Corma, F. Kapteijn y F. X. Llabrés i Xamena, ACS Catal., 2014, 4, 361-378.

5. M. Yoon, R. Srirambalaji y K. Kim, Chem. Rev., 2012, 112, 1196-1231.

6. A. Dhakshinamoorthy, M. Alvaro y H. Garcia, Catal. Sci. Technol., 2011, 1, 856867.

7. J. Lee, O. K. Farha, J. Roberts, K. A. Scheidt, S. T. Nguyen y J. T. Hupp, Chem. Soc. Rev., 2009, 38, 1450-1459.

8. S. Kitagawa, R. Kitaura y S.-I. Noro, Angew. Chem. Int. Ed., 2004, 43, 23342237.

9. G. Ferey, C. Mellot-Draznieks, C. Serre, F. Millange, J. Dutour, S. Surble y I. Margiolaki, Science, 2005, 309, 2040-2042.

10. D.-Y. Hong, Y. K. Hwang, C. Serre, G. Férey y J.-S. Chang, Adv. Func. Mater., 2009, 19, 1537-1552.

11. A. Dhakshinamoorthy y H. Garcia, Chem. Soc. Rev., 2012, 41, 5262-5284.

12. T. Devic y C. Serre, Chem.Soc.Rev.,, 2014, 43, 6097-6115.

13. K. Brown, S. Zolezzi, P. Aguirre, D. Venegas-Yazigi, V. Paredes-García, R. Baggio, M. Novak y E. Spodine, Dalton Trans., 2009, 1422-1427.

14. A. Dhakshinamoorthy, M. Alvaro y H. Garcia, J. Catal., 2009, 267, 1-4.

15. L. Hamidipour y F. Farzaneh, Reac. Kinet. Mech. Cat., 2013, 109, 67-75.

16. O. A. Kholdeeva, I. Y. Skobelev, I. D. Ivanchikova, K. A. Kovalenko, V. P. Fedin y A. B. Sorokin, Catal. Today, 2014, 238, 54-61.

17. N. V. Maksimchuk, K. A. Kovalenko, V. P. Fedin y O. A. Kholdeeva, Chem. Comm., 2012, 48, 6812-6814.

18. C. Song, Catal. Today, 2003, 86, 211-263.

19. J. Sun, G. Yu, Q. Huo, Q. Kan y J. Guan, $R S C A d v$., 2014, 4, 38048-38054.

96 
Capítulo 4.

20. Z. Saedi, S. Tangestaninejad, M. Moghadam, V. Mirkhani y I. MohammadpoorBaltork, Catal. Comm., 2012, 17, 18-22.

21. I. Y. Skobelev, K. A. Kovalenko, V. P. Fedin, A. B. Sorokin y O. A. Kholdeeva, Kinet. Catal., 2013, 54, 607-614.

22. I. Y. Skobelev, A. B. Sorokin, K. A. Kovalenko, V. P. Fedin y O. A. Kholdeeva, J. Catal., 2013, 298, 61-69.

23. A. Santiago-Portillo, S. Navalon, F. Cirujano, F. Llabrés i Xamena, M. Alvaro y H. Garcia, ACS Catal. (DOI: 10.1021/acscatal.5b00411), 2015.

24. A. Dhakshinamoorthy, M. Alvaro, P. Concepcion y H. Garcia, Catal. Comm., 2011, 12, 1018-1021.

25. A. Dhakshinamoorthy, M. Alvaro y H. Garcia, J. Catal., 2012, 289, 259-265.

26. A. Dhakshinamoorthy, M. Alvaro y H. Garcia, ChemCatChem, 2010, 2, 14381443.

27. A. Dhakshinamoorthy, M. Alvaro y H. Garcia, ACS Catal., 2011, 1, 836-840.

28. A. Dhakshinamoorthy, M. Alvaro y H. Garcia, ACS Catal., 2011, 1, 48-53.

29. O. A. Kholdeeva, Catal. Sci. Technol., 2014, 4, 1869-1889.

30. V. C. Srivastava, RSC Adv., 2012, 2, 759-783.

31. B. Van de Voorde, B. Bueken, J. Denayer y D. De Vos, Chem. Soc. Rev., 2014, 43, 5766-5788.

32. N. D. McNamara, G. T. Neumann, E. T. Masko, J. A. Urban y J. C. Hicks, J. Catal., 2013, 305, 217-226.

33. D. Wang, E. W. Qian, H. Amano, K. Okata, A. Ishihara y T. Kabe, Appl. Catal. A: Ge, 2003, 253, 91-99.

34. K.-B. Cho, H. Kang, J. Woo, J. Y. Park, M. S. Seo, J. Cho y W. Nam, Inorg. Chem., 2014, 53, 645-652.

35. D. P. Serrano, R. Sanz, P. Pizarro, I. Moreno y S. Medina, App. Catal. B-Environ., 2014, 146, 35-42.

36. Y. Liu, S. Liu, S. Liu, D. Liang, S. Li, Q. Tang, X. Wang, J. Miao, Z. Shi y Z. Zheng, Chemcatchem, 2013, 5, 3086-3091.

37. O. González-García y L. Cedeño-Caero, Catal. Today, 2012, 148, 42-48.

38. V. Chandra Srivastava, RSC Adv., 2012, 2, 759-783.

39. M. Yu, N. Zhang, L. Fan, C. Zhang, X. He, M. Zheng y Z. Li, Rev. Chem. Eng., $2015,31,27-43$. 
40. A. Samokhvalov y B. J. Tatarchuk, Catal. Rev. Sci. Eng.,2010, 52, 381-410.

41. S. Mikhail, T. Zaki y L. Khailil, Appl. Catal., A., 2002, 227, 265-278.

42. Y.C. Zhang, X. W. Yang, D. Li y P. Na, Adv. Mater. Res., 2014,237-241.

43. Y. Zhang, A. Chen, C. Li, M. Luo y Z. Xu, Adsorpt. Sci. Techno., 2011, 29, 197209.

44. S. G. McKinley y R. J. Angelici, Chem. Commun., 2003, 9.

45. K. A. Cychosz, A. G. Wong-Foy y A. J. Matzge, J. Am. Chem. Soc., 2008, 130, 6938-6939.

46. K. M. L. Taylor-Pashow, J. D. Della Rocca, Z. Xie, S. Tran y W. Lin, J. Am. Chem. Soc., 2009, 009, 14261-14263.

47. L. Helm y A. Merbach, E., Chem. Rev., 2005, 105, 1923-1959.

48. P. Horcajada, H. Chevreau, D. Heurtaux, F. Benyettou, F. Salles, T. Devic, A. Garcia-Marquez, C. Yu, H. Lavrard, C. L. Dutson, E. Magnier, G. Maurin, E. Elkaïmd y C. Serre, Chem. Commun., 2014, 50, 6872-6874.

49. A. Vimont, F. Thibault-Starzyk y M. Daturi, Chem. Soc. Rev., 2010, 39, 49284950.

50. P. Valvekens, F. Vermoortele y D. De Vos, Catal. Sci. Technol., 2013, 3, 14351445.

51. H. V. Leclerc, A.; Lavalley, J. C.; Daturi, M.; Wiersum, A. D.; Llewellyn, P. L.; Horcajada, P.; Ferey, G.; Serre, C., Phys. Chem. Phys. C 2011, 13, 11748-11756.

52. A. Vimont, F. Thibault-Starzyk y M. Datur, Chem. Soc. Rev., 2010, 39, 49284950.

53. J. W. Yoon, Y.-K. Seo, Y. K. Hwang, J.-S. Chang, H. Leclerc, S. Wuttke, P. Bazin, A. Vimont, M. Daturi, E. Bloch, P. L. Llewellyn, C. Serre, P. Horcajada, J.M. Grenche, A. E. Rodrigues y G. Férey, Angew. Chem. Int. Ed., 2010, 49, 59495952.

54. T. K. Trung, N. A. Ramsahye, P. Trens, N. Tanchoux, C. Serre, F. Fajula y G. Férey, Micropor. Mesopor. Mat., 2010, 134, 134-140.

55. J. Kim, S. Bhattacharjee, K.-E. Jeong, S.-Y. Jeong y W. S. Ahn, Chem. Commun., 2009, 3904-3906.

56. F. X. Llabrés i Xamena, O. Casanova, R. Galiasso Tailleur, H. Garcia y A. Corma, J. Catal., 2008, 255, 220-227.

57. A. Ansari, P. Jayapal y G. Rajaraman, Angew. Chem. Int. Ed., 2015, 54, 564 568. 
58. J. Cho, J. Woo y W. Nam, J. Am. Chem. Soc., 2010, 132, 5958-5959.

59. A. Dhakshinamoorthy, S. Navalon, M. Alvaro y H. Garcia, ChemSusChem, 2012, 5, 46-64.

60. M. J. Burkitt y R. P. Mason, Proc. Natl. Acad. Sci. USA, 1991, 88, 8440-8444.

61. R. Martin, S. Navalon, J. J. Delgado, J. J. Calvino, M. Alvaro y H. Garcia, Chem. Eur. J., 2011, 17, 9494-9502.

62. Z. Y. Diao, L. L. Han, Z. X. Wang y C. C. Dong, Phys. chem. B., 2005, 109, 5739-5745.

63. J. Guzman, S. Carrettin y A. Corma, J. Am. Chem. Soc., 2005, 127, 3286-3287.

64. R. Q. Long, Y. P. Huang y H. L. J. Wan, Raman Spectrosc., 1997, 28, 29-32.

65. S. Otsuki, T. Nonaka, N. Takashima, W. Qian, A. Ishihara, T. Imai y T. Kabe, Energ. Fuel., 2000, 14, 1232-1239. 
Actividad catalítica del MIL-101 para la desulfuración oxidativa de dibenzotiofenos. 


\section{Capítulo 5 \\ Influencia de los \\ sustituyentes en el ligando \\ del MIL-101(Cr) en la \\ oxidación aeróbica de \\ bencilaminas a iminas.}


Influencia de los sustituyentes en el ligando del MIL-101(Cr) en la oxidación aeróbica de bencilamina a iminas. 


\subsection{Introducción.}

Como se ha comentado en el capítulo de introducción, los MOFs se han convertido en catalizadores sólidos ampliamente empleados para promover reacciones en fase líquida. ${ }^{1-8}$ Entre estos materiales uno de los que ha sido más ampliamente usado en catálisis es el MIL-101, el cual ya ha sido empleado en los capítulos anteriores. La estructura del MIL-101 contiene nodos de 3 átomos de un metal trivalente con coordinación octaédrica compartiendo un átomo de oxígeno con enlace $\mu_{3}$. Cada unidad trimérica está coordinada a seis ligandos tereftalatos. Cuatro nodos metálicos y seis ligandos tereftalato unidos a ellos definen un supertetraedro que al conectarse con otros doce tereftalatos (3 por cada nodo metálico) definen una estructura tridimensional que presenta dos tipos de cajas con ventanas hexagonales $(3.4 \mathrm{~nm})$ y pentagonales $(2.9 \mathrm{~nm})$ y dimensiones de diámetro de 1.6 y $1.2 \mathrm{~nm}$, respectivamente (Figura 5.1). ${ }^{10,12-16}$ Cada ion metálico posee una posición de coordinación adicional que es intercambiable sin comprometer la estructura del material. Dos de los tres iones metálicos de cada unidad trimérica están típicamente ocupados por DMF o por agua dependiendo de las condiciones de síntesis y de los pretratamientos. ${ }^{14,17}$ Mediante un procedimiento de activación adecuado, los ligandos que ocupan posiciones intercambiables sobre la unidad trimérica pueden ser eliminados, generando sitios de coordinación que son capaces de interaccionar con sustratos o reactivos. ${ }^{18-20}$ Una de las características principales del material MIL-101 es su notable estabilidad estructural y la robustez de su red cristalina en un amplio rango de condiciones. ${ }^{18,19,21-24}$

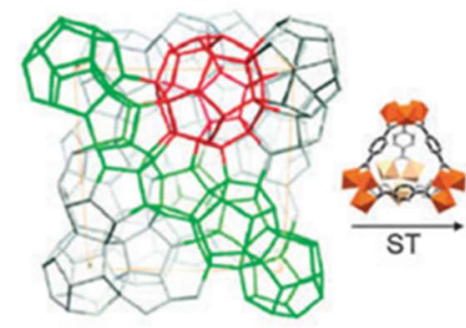

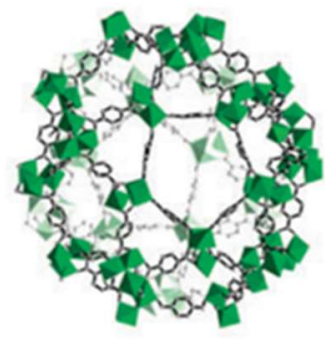

$(\varnothing \sim 29 \AA, 12 \AA)$

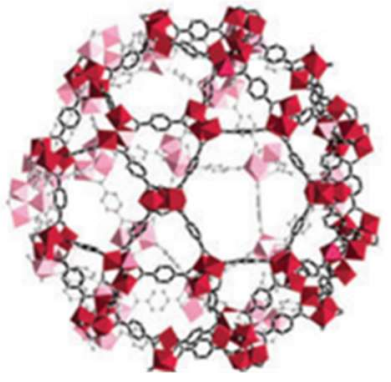

$(\varnothing \sim 34 \AA, 16 \AA)$

Figura 5.1. Representación esquemática de la estructura de MIL-101 constituida por cajas más pequeñas (en verde) y más grandes (en rojo) conectadas a través de supertetraedros (ST). La ilustración muestra en la izquierda la unión de los dos tipos de cajas, las cuales se muestran separadas en la parte derecha.

Como se viene también comentando, un tipo de reacción que está atrayendo actualmente gran interés usando MOFs como catalizadores sólidos es la oxidación aeróbica. ${ }^{25,26} \mathrm{El}$ interés de este tipo de reacciones deriva de las ventajas que supone el uso de 
oxígeno molecular como oxidante y la actividad de los metales de transición en general para catalizar este tipo de reacción. 3,19,24,27,28

En este contexto, hace algunos años, nuestro grupo de investigación ya estudió la actividad catalítica que la $N$-Hidroxiftalimida (NHPI de sus siglas en inglés) adsorbida en muestras comerciales de basolite F300 como un iniciador de radicales que promueve la oxidación aeróbica de bencilaminas a sus correspondiente $N$-benciliden bencilamina mediante acoplamiento oxidativo (Esquema 5.1). ${ }^{29}$ Aunque el uso del material basolite F300 puede ser ventajoso debido a su disponibilidad, uno de los inconvenientes principales del proceso descrito es que el material basolite F300 posee una estructura aún desconocida, lo que hace difícil la racionalización del mecanismo de reacción y el avanzar hacia el desarrollo de catalizadores más eficientes. ${ }^{30}$

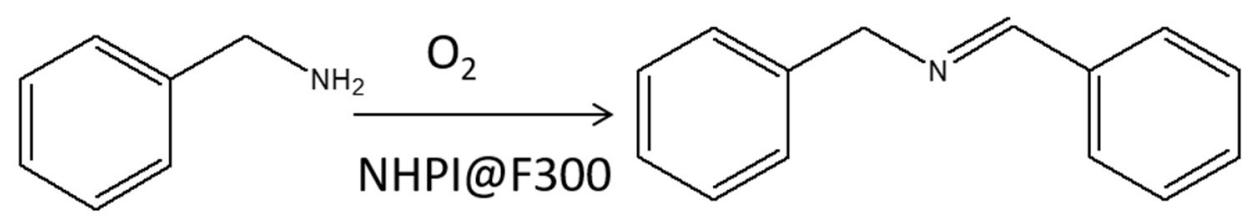

Esquema 5.1. Procesos de oxidación de la bencilamina $N$-benciliden bencilamina usando NHPI@F300 como catalizador. ${ }^{25}$

Continuando con esta línea de investigación, es importante estudiar el acoplamiento oxidativo de bencilamina en presencia de otros MOFs con estructura cristalina bien definida. En este contexto, una característica importante de los MOFs que hace que estos materiales sean prometedores para promover reacciones en fase líquida es la versatilidad de sus síntesis que permite un grado considerable de variaciones a fin de adaptar las propiedades de los sólidos, incluyendo la actividad catalítica de los mismos..$^{2-5,31-36} \mathrm{De}$ esta manera, una estrategia que podría incrementar la actividad de un tipo de MOFs y, específicamente, la actividad del material MIL-101(Cr), sería el uso de ácidos tereftálicos sustituidos como componentes del material, resultando de esta manera la formación de sólidos MIL-101(Cr)-X isoestructurales con el material MIL-101(Cr). ${ }^{37}$ Empleando tereftalatos sustituidos por grupos electrón-atrayentes o electrón-donantes sobre el anillo aromático, sería posible influir en la densidad electrónica alrededor de los iones metálicos que actúan como centros activos, lo que podría permitir un cierto control sobre la fuerza de estos centros activos como ácidos de Lewis y como centros redox. ${ }^{31}$ En este contexto, la síntesis de materiales MIL-101(Cr) con una serie de tereftalatos sustituidos ha sido ya descrita en la literatura, ${ }^{38-46}$ aunque hasta el momento de la presente tesis doctoral, estos materiales no habían sido ensayados en catálisis como una manera de aumentar la actividad de los mismos. 
En el presente capítulo se ha preparado una serie de 6 materiales MIL-101(Cr)-X $\left(\mathrm{X}=\mathrm{H}, \mathrm{Cl}, \mathrm{SO}_{3} \mathrm{H}, \mathrm{NO}_{2}, \mathrm{CH}_{3}\right.$ y $\mathrm{NH}_{2}$ ) y se ha procedido a evaluar la actividad catalítica de los mismos en la oxidación aeróbica de bencilaminas a $\mathrm{N}$-benciliden bencilaminas (Esquema 5.1). En un trabajo pionero en este campo, Van Speybroeck, de Vos y colaboradores mostraron que la sustitución en el ácido tereftálico puede ejercer una influencia notable en la actividad catalítica como ácido de Lewis del material UiO-66. ${ }^{31}$ Siguiendo este trabajo, en el presente capítulo hemos extendido este estudio a un MOF diferente, como es el caso del MIL-101 y también a un tipo de reacción diferente, oxidaciones aeróbicas en este caso. Se demostrará que la actividad catalítica de los MOFs sustituidos como promotores de oxidaciones varía en función del sustituyente sobre el ligando tereftálico. Esta metodología ilustra las ventajas que los MOFs ofrecen respecto a otros tipos de materiales porosos al permitir aplicar conceptos de química orgánica en la adaptación de las propiedades de los mismos.

\subsection{Resultados y discusión}

La síntesis de la serie de materiales MIL-101(Cr)-X objeto de estudio se llevó a cabo por reacción de una sal de $\mathrm{Cr}^{3+}$ (nitrato o cloruro) y el ácido tereftálico sustituido correspondiente en agua desmineralizada a una temperatura conveniente $\left(180-200{ }^{\circ} \mathrm{C}\right)$, siguiendo procedimientos ya descritos en la bibliografía (Esquema 5.2). ${ }^{10,37}$ En los casos de MIL-101(Cr)-SO $\mathrm{SO}_{3} \mathrm{H}$ y MIL-101(Cr)- $\mathrm{NH}_{2}$, los materiales se obtuvieron a partir de los materiales MIL-101(Cr)-H y MIL-101(Cr)- $\mathrm{NO}_{2}$ previamente obtenidos, por sulfonación y reducción química respectivamente, siguiendo los métodos descritos en la literatura ${ }^{47-}$ ${ }_{48}$ (esquema 5.2). Los análisis químicos indicaron que en el material MIL-101(Cr)- $\mathrm{SO}_{3} \mathrm{H}$, los grupos sulfónicos deben estar presentes en el $30 \%$ de los ligandos tereftalatos.

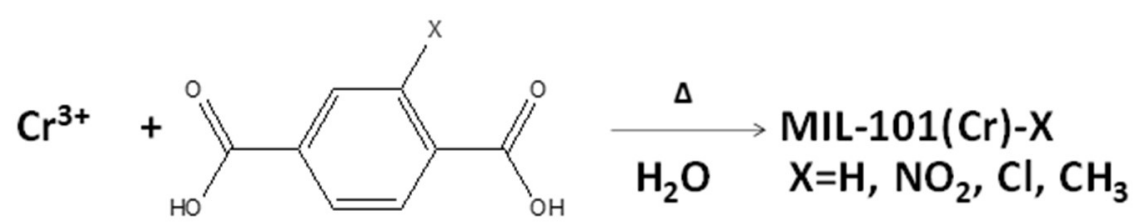

$$
\begin{aligned}
& \mathrm{MIL}-101(\mathrm{Cr})-\mathrm{H}+\mathrm{HSO}_{3} \mathrm{Cl} \longrightarrow \mathrm{MIL}-101(\mathrm{Cr})-\mathrm{SO}_{3} \mathrm{H} \\
& \mathrm{MIL}-101(\mathrm{Cr})-\mathrm{NO}_{2}+\mathrm{SnCl}_{2} \cdot \mathrm{HCl} \underset{\mathrm{EtOH}}{\stackrel{\Delta}{\longrightarrow}} \mathrm{MIL-101}(\mathrm{Cr})-\mathrm{NH}_{2}
\end{aligned}
$$

Esquema 5.2. Esquema de la síntesis de los materiales MIL-101 ( $\mathrm{Cr})-\mathrm{X}\left(\mathrm{X}=\mathrm{H}, \mathrm{Cl}, \mathrm{SO}_{3} \mathrm{H}, \mathrm{NO}_{2}, \mathrm{CH}_{3}\right.$ y $\mathrm{NH}_{2}$ ). 
La difracción de rayos $\mathrm{X}$ en polvo (DRX) de la serie de los seis materiales MIL101(Cr)-X muestran que todos los sólidos son isoestructurales con el material MIL$101(\mathrm{Cr})-\mathrm{H}$ con parámetros de celda unidad coincidentes, como ya estaba descrito en la literatura. ${ }^{37,47,48}$ La figura 5.2 muestra los modelos de DRX de estos materiales. El área superficial BET y volumen de poro de la serie de materiales MIL-101(Cr)-X fue medida por adsorción isoterma de $\mathrm{N}_{2}$, obteniendo valores entre 2735 y $1240 \mathrm{~m}^{2} \mathrm{~g}^{-1}$ y $2.16-1.02$ $\mathrm{cm}^{3} \mathrm{~g}^{-1}$, respectivamente. Estos valores están en el rango de los que han sido descritos en la literatura para estos materiales. ${ }^{19,37}$ Las figuras 5.3-5.8 muestran las gráficas de adsorción isoterma correspondientes a partir de las cuales se han calculado los valores de área superficial y volumen de poro. La tabla 5.1 resume los valores de área superficial BET para cada uno de los materiales. Tal como ha sido descrito, la presencia de sustituyentes en el anillo aromático disminuye los valores de área y volumen de poro con respecto a los que presenta el material MIL-101(Cr)-H sin sustituir. Debido al espacio necesario para acomodar el sustituyente orgánico del anillo. ${ }^{37} \mathrm{La}$ presencia de sustituyentes en el ligando tereftalato se determinó por espectroscopia FTIR. ${ }^{37}$ La figura 5.9 presenta los espectros de FTIR para los materiales MIL-101(Cr)-X usados en el presente capítulo, mientras que la tabla 5.1 incluye también los valores para las bandas de vibración más características que aparecen debido a la presencia de los sustituyentes. Las figuras 5.105.15 muestran los espectros de FTIR para cada uno de los materiales MIL-101(Cr)-H. Los perfiles termogravimétricos de la serie de muestras MIL-101(Cr)-X se determinaron a fin de establecer su estabilidad térmica, el contenido de agua adsorbida y el porcentaje de ligandos orgánicos. Las figuras 5.16-5.21 presentan los perfiles termogravimétricos para cada una de las muestras, mientras que los datos más relevantes de están incluidos en la tabla 5.1. 


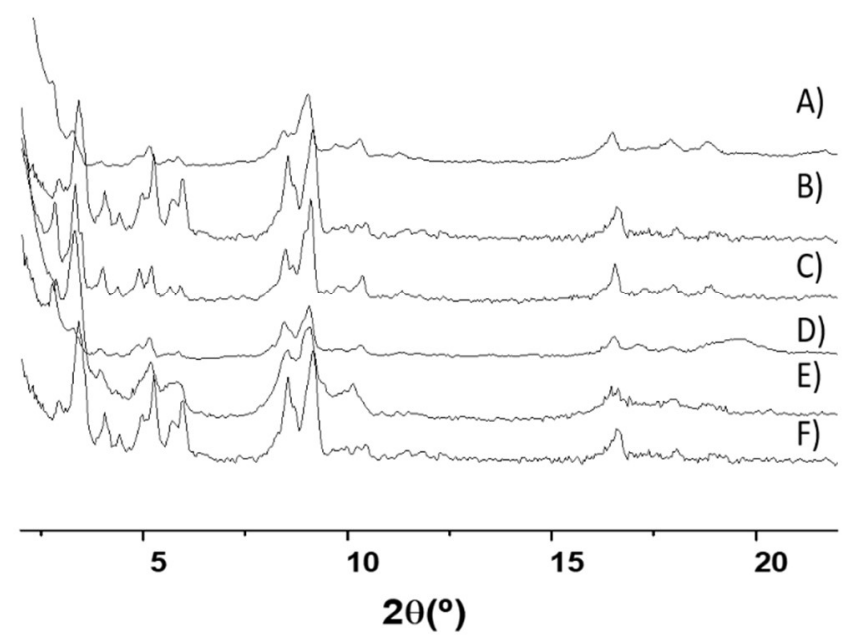

Figura 5.2. Modelo de difracción de rayos $X$ para los materiales MIL-101(Cr)-H (A), MIL-101(Cr)$\mathrm{NO}_{2}$ (B), MIL-101(Cr)-SO 3 H (C), MIL-101(Cr)-Cl (D), MIL-101(Cr)-CH (E), MIL-101(Cr)-NH 2 (F). 
Influencia de los sustituyentes en el ligando del MIL-101(Cr) en la oxidación aeróbica de bencilamina a iminas.

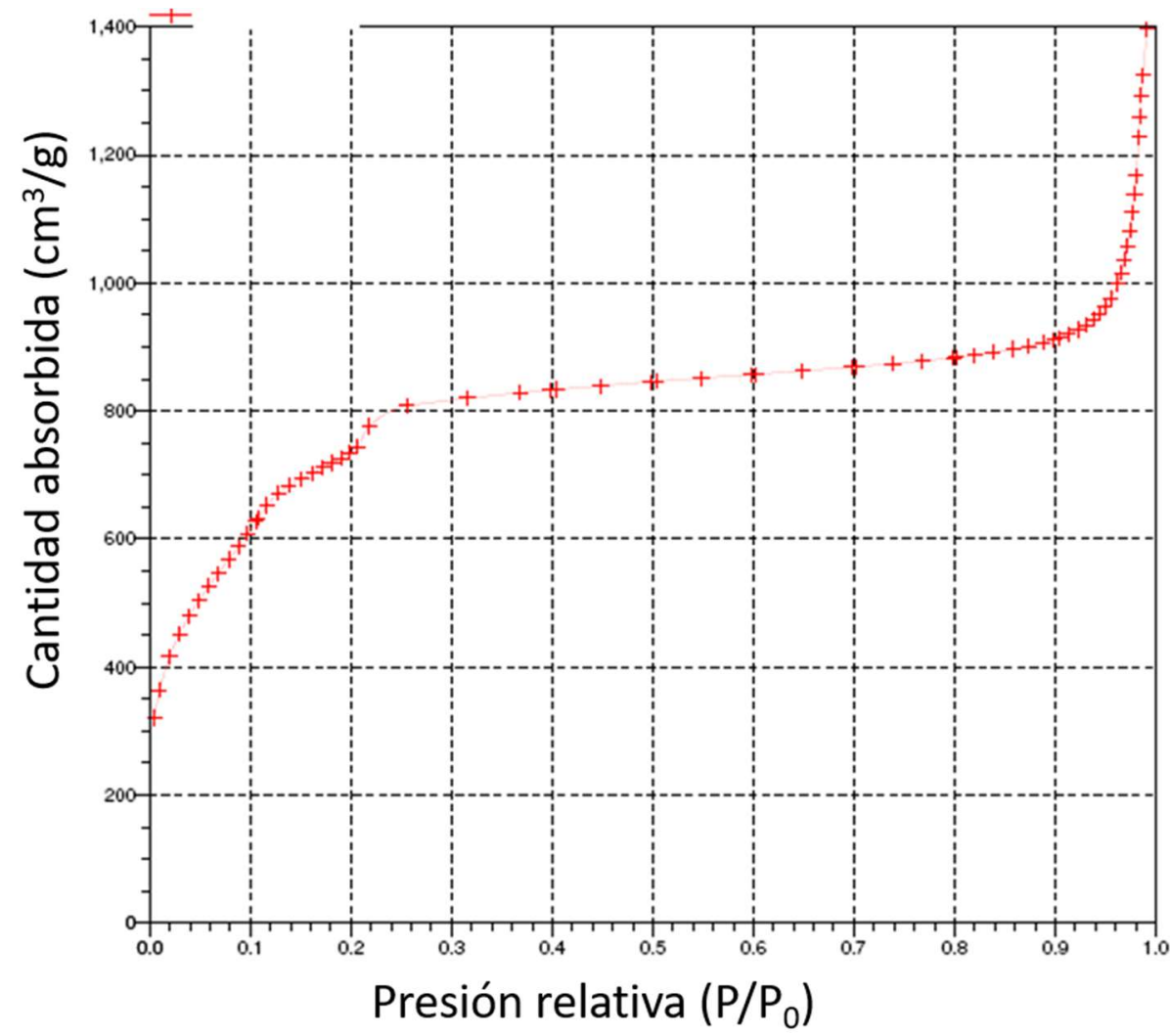

Figura 5.3. Isoterma de adsorción de $\mathrm{N}_{2}$ del MIL-101(Cr)-H. 


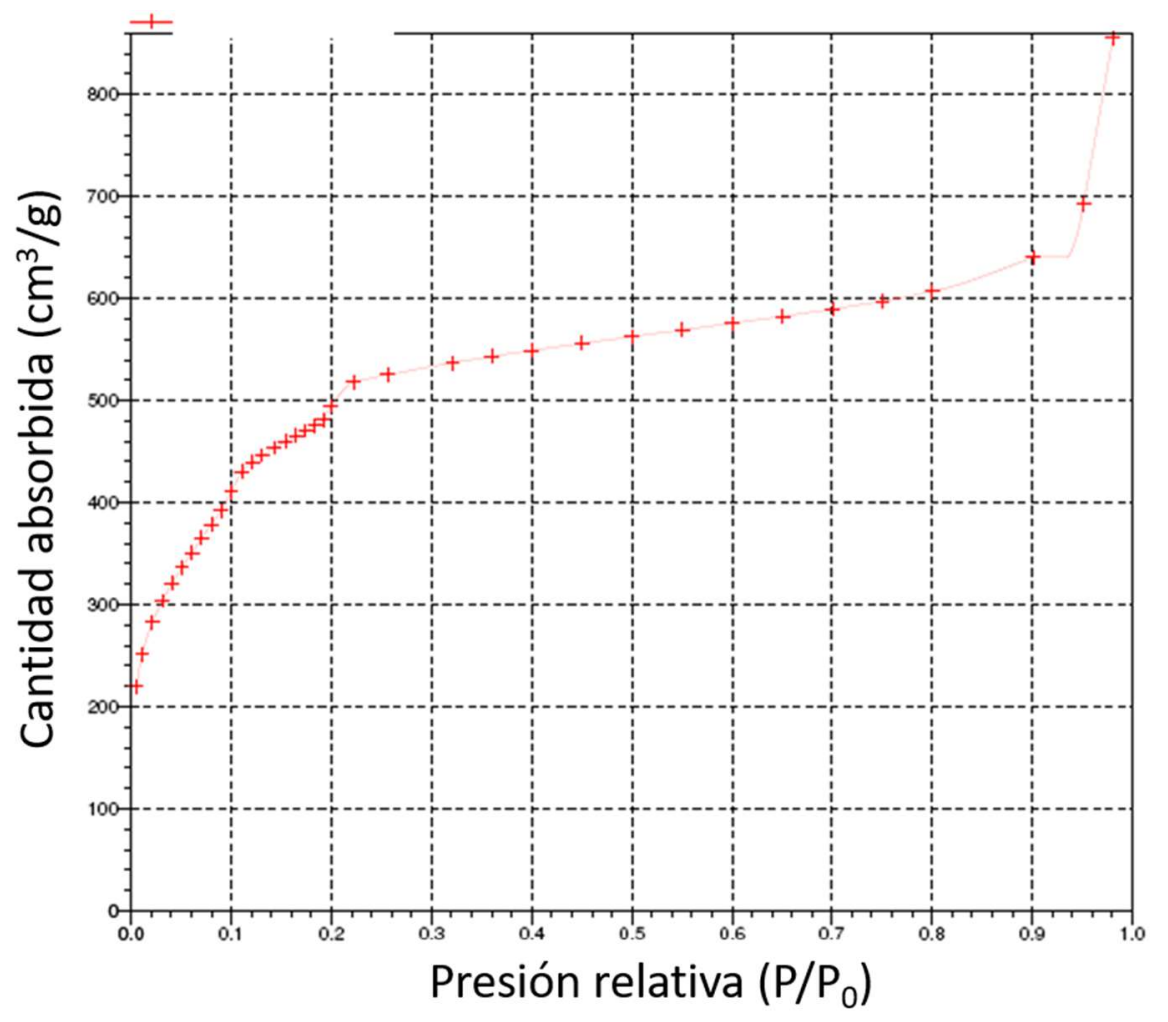

Figura 5.4. Isoterma de adsorción de $\mathrm{N}_{2}$ del MIL-101(Cr)- $\mathrm{NO}_{2}$. 


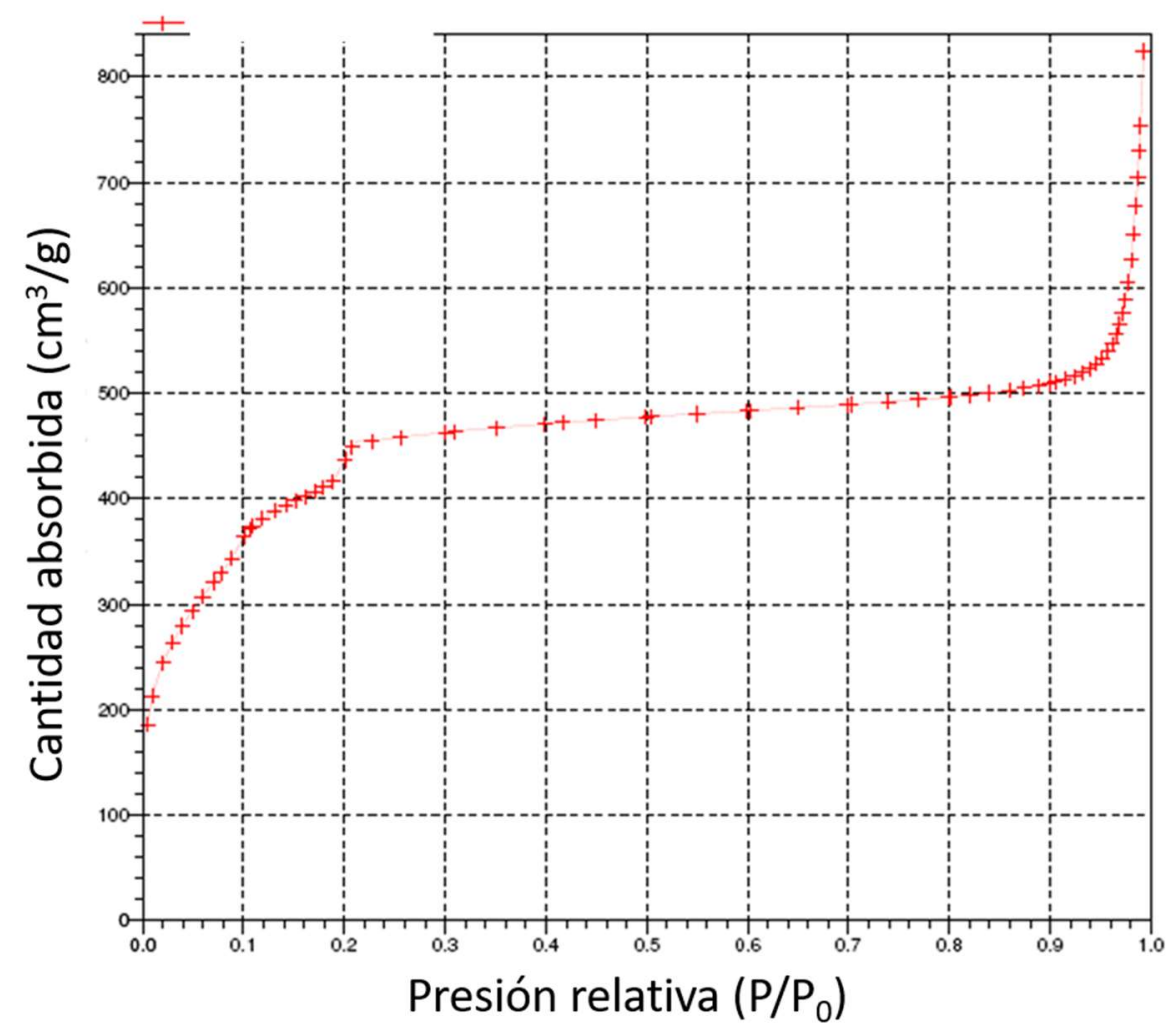

Figura 5.5. Isoterma de adsorción de $\mathrm{N}_{2}$ del MIL-101(Cr)- $\mathrm{SO}_{3} \mathrm{H}$. 


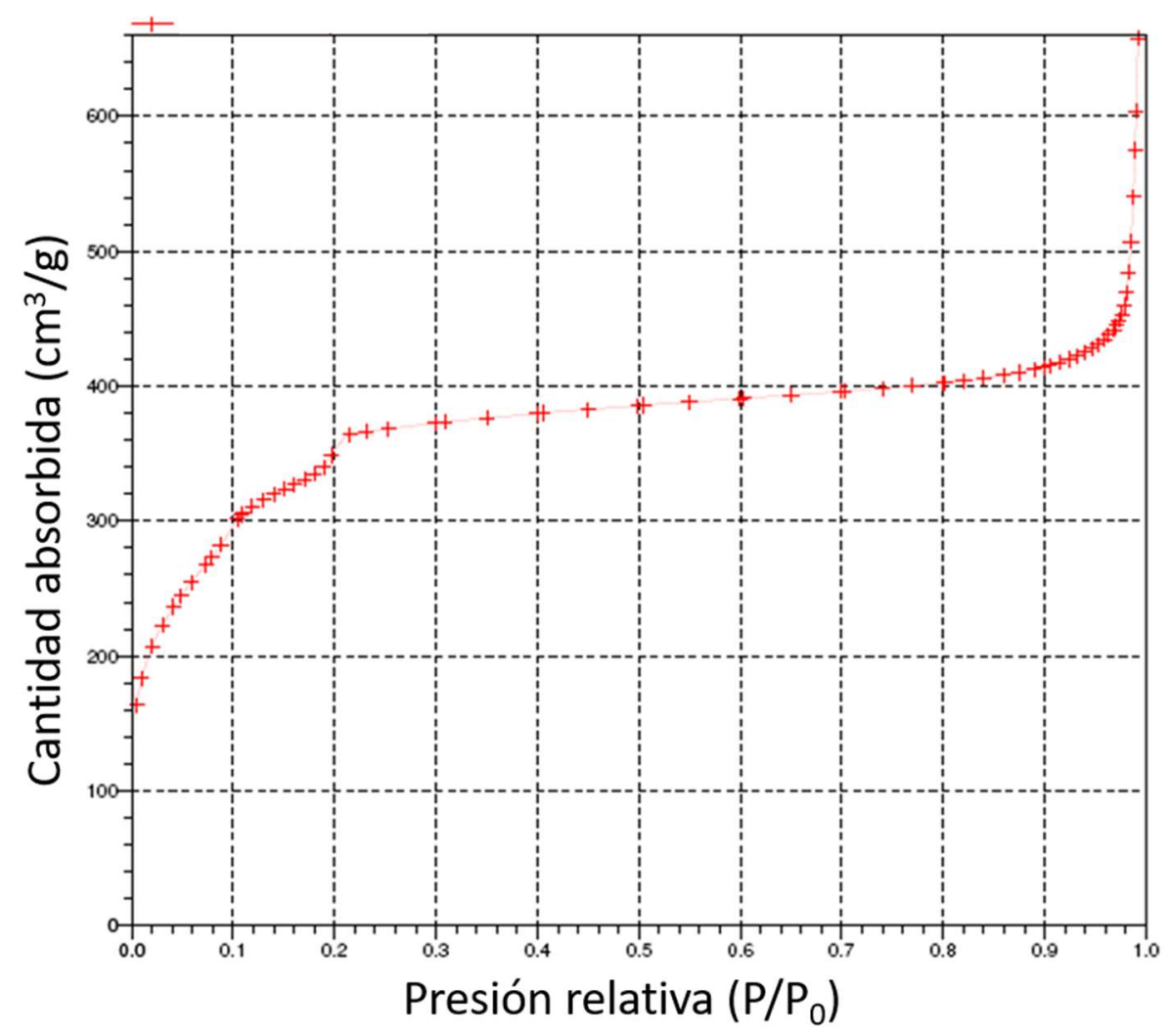

Figura 5.6. Isoterma de adsorción de $\mathrm{N}_{2}$ del MIL-101(Cr)-Cl. 


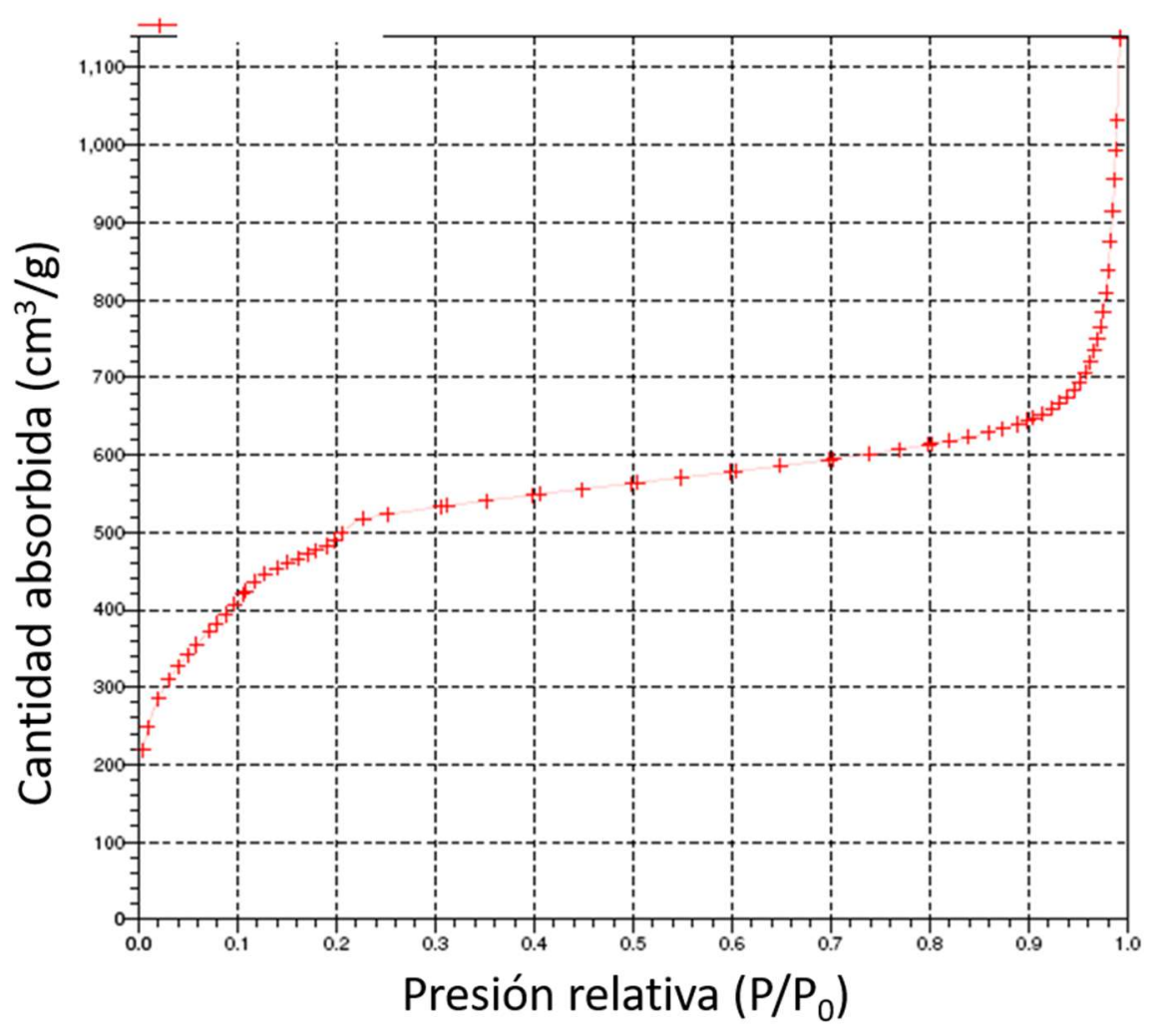

Figura 5.7. Isoterma de adsorción de $\mathrm{N}_{2}$ del MIL-101(Cr)- $\mathrm{CH}_{3}$. 


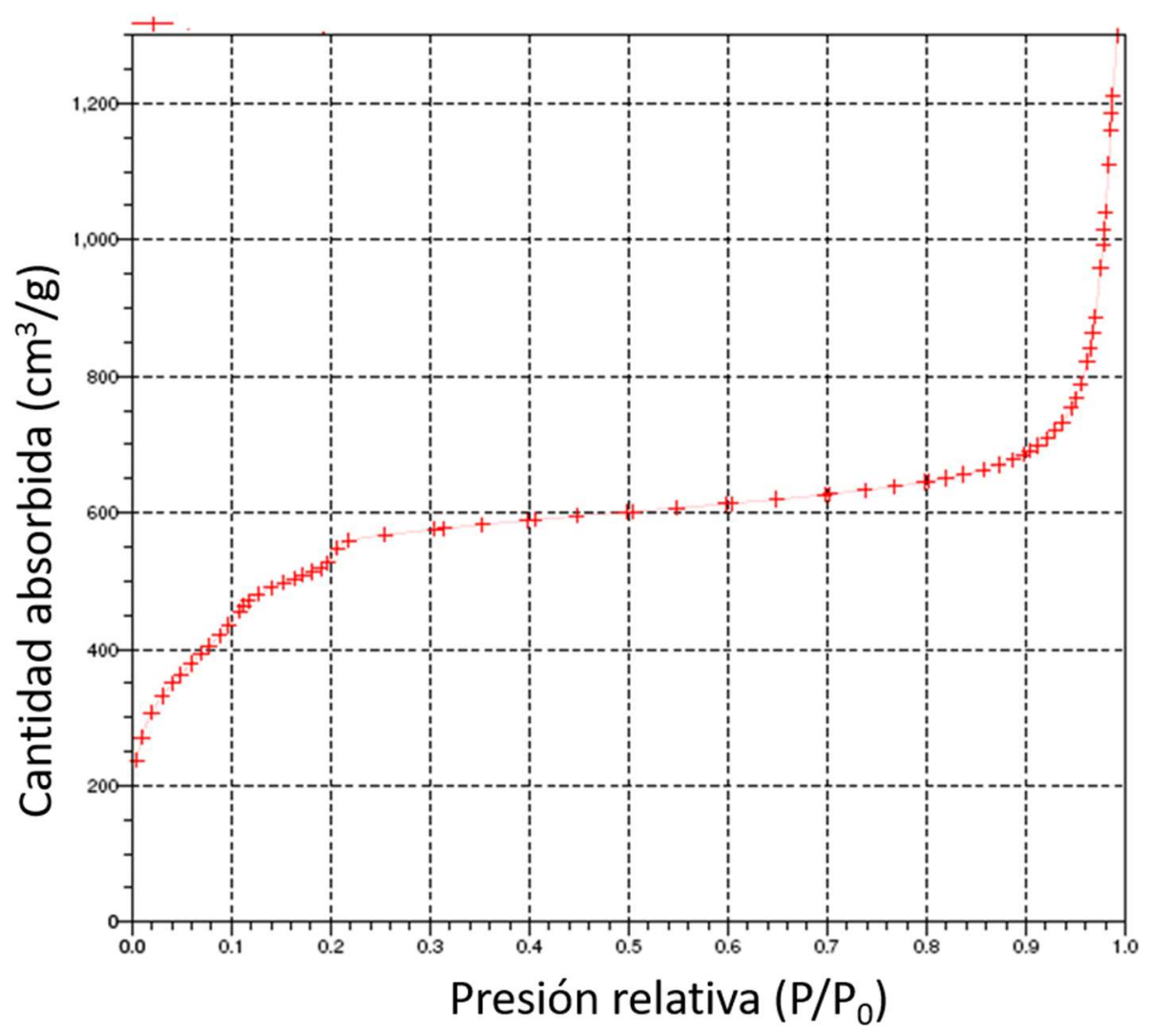

Figura 5.8. Isoterma de adsorción de $\mathrm{N}_{2}$ del MIL-101(Cr)- $\mathrm{NH}_{2}$. 


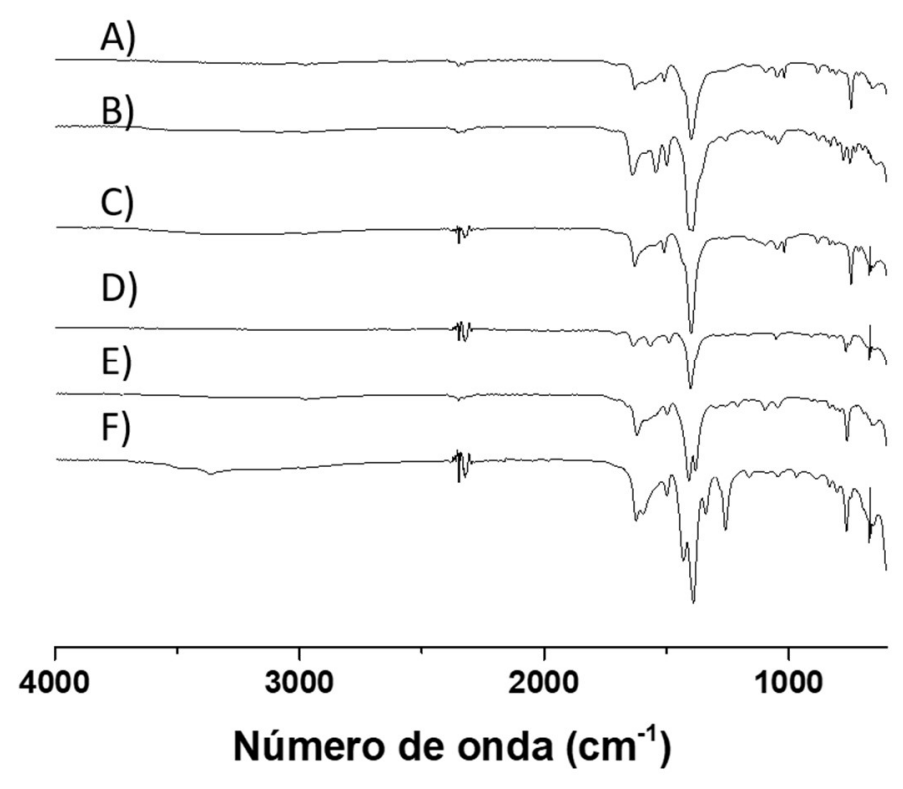

Figura 5.9. Espectros de IR de los materiales MIL-101(Cr)-H (A), MIL-101(Cr)-NO $\mathrm{NO}_{2}$ (B), MIL$101(\mathrm{Cr})-\mathrm{SO}_{3} \mathrm{H}(\mathrm{C}), \mathrm{MIL}-101(\mathrm{Cr})-\mathrm{Cl}(\mathrm{D}), \mathrm{MIL}-101(\mathrm{Cr})-\mathrm{CH}_{3}(\mathrm{E}), \mathrm{MIL}-101(\mathrm{Cr})-\mathrm{NH}_{2}(\mathrm{~F})$.

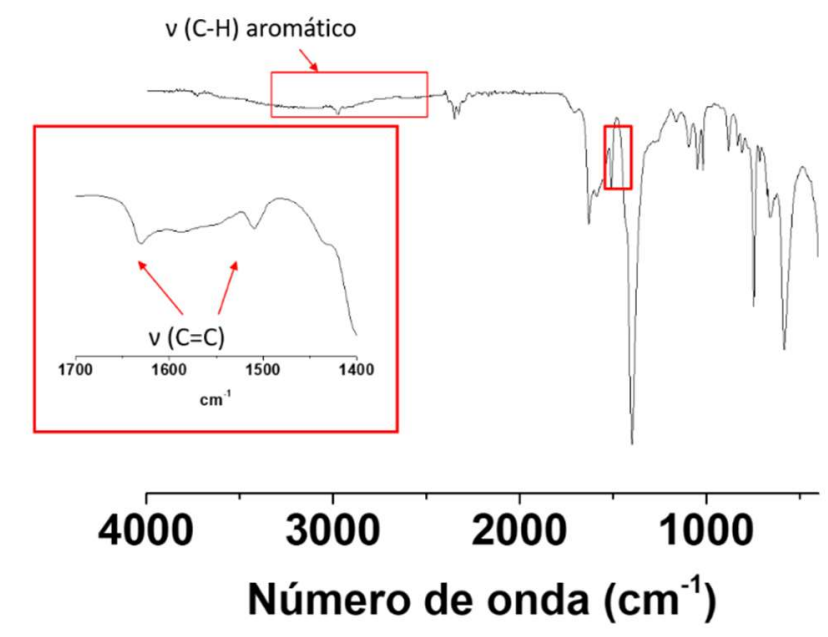

Figura 5.10. Espectro de IR de MIL-101(Cr)-H. El recuadro insertado muestra la expansión de la región desde $1700-1400 \mathrm{~cm}^{-1}$. Las flechas muestran las bandas de vibración características. 


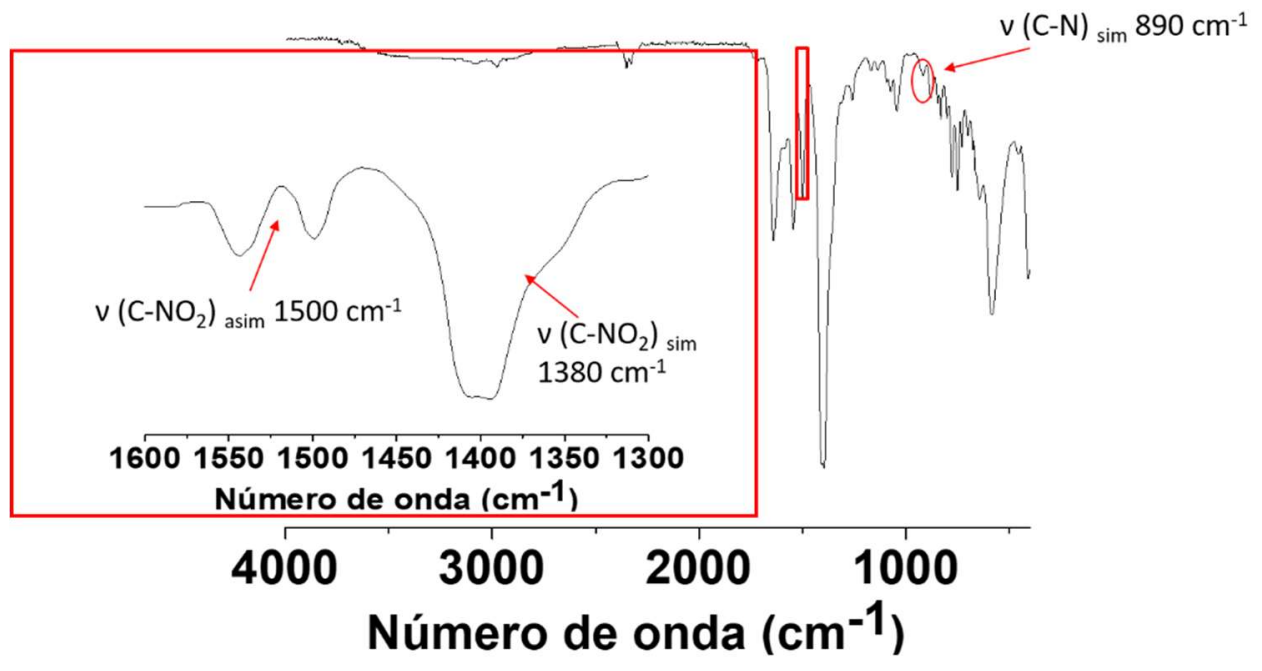

Figura 5.11. Espectro de IR de MIL-101(Cr)-NO $\mathrm{NO}_{2}$. El recuadro insertado muestra la expansión de la región desde 1600-1300 $\mathrm{cm}^{-1}$. Las flechas muestran las bandas de vibración características.

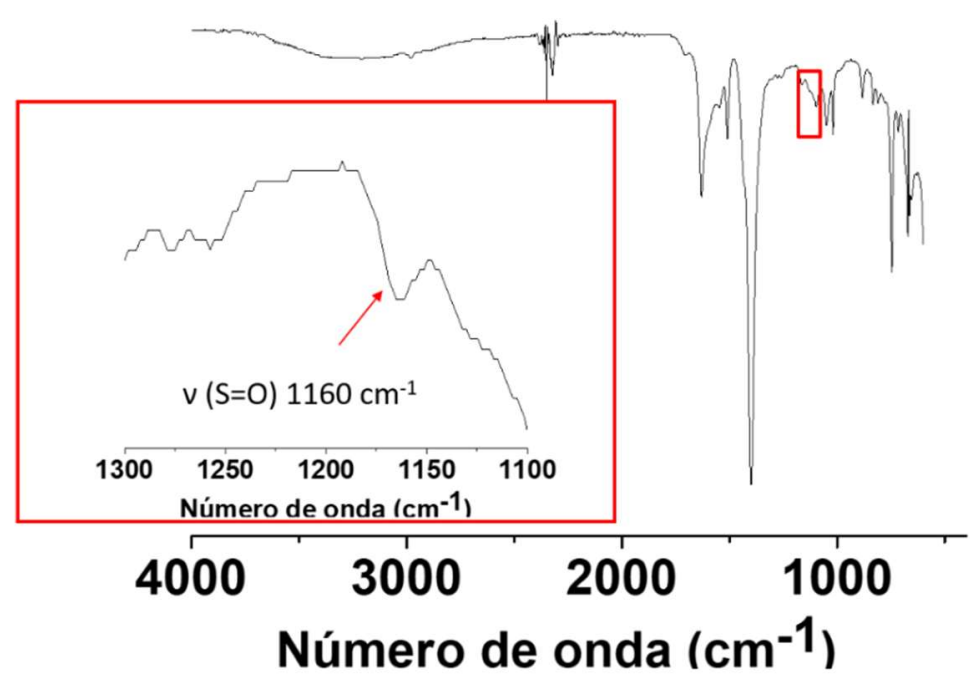

Figura 5.12. Espectro de IR de MIL-101(Cr)- $\mathrm{SO}_{3} \mathrm{H}$. El recuadro insertado muestra la expansión de la región desde 1300-1100 $\mathrm{cm}^{-1}$. Las flechas muestran las bandas de vibración características. 


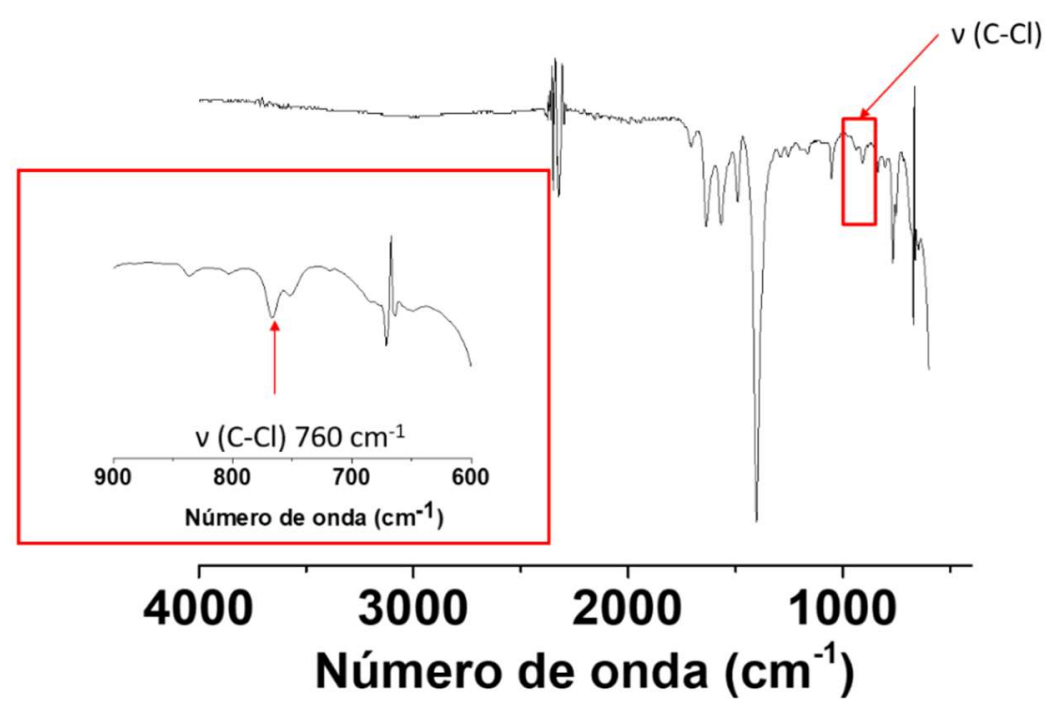

Figura 5.13. Espectro de IR de MIL-101(Cr)-Cl. El recuadro insertado muestra la expansión de la región desde $900-600 \mathrm{~cm}^{-1}$. Las flechas muestran las bandas de vibración características.

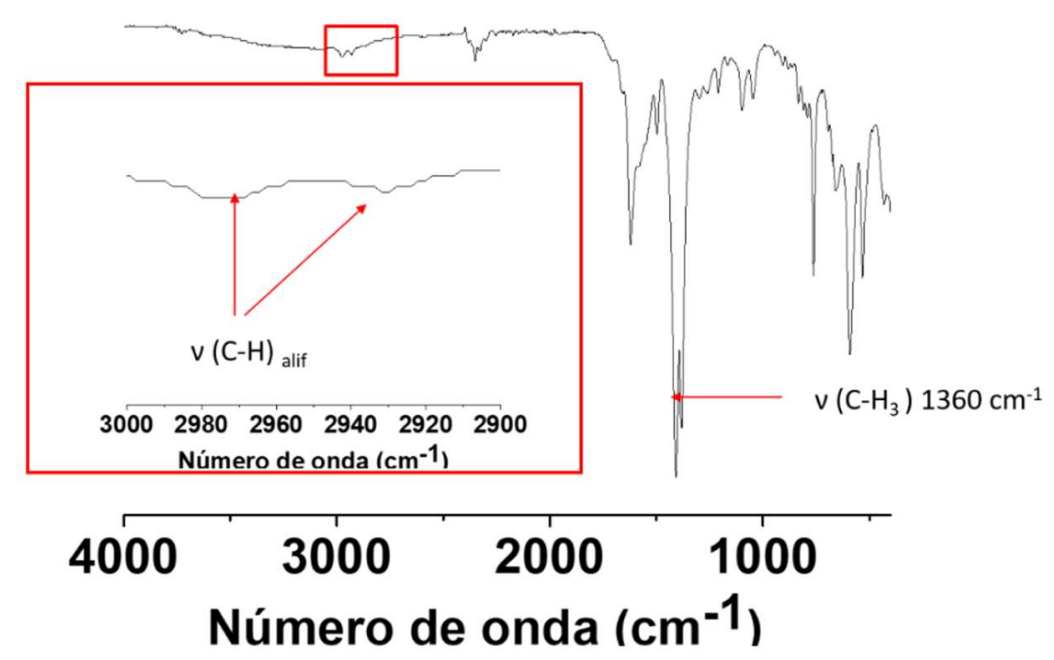

Figura 5.14. Espectro de IR de MIL-101(Cr)- $\mathrm{CH}_{3}$. El recuadro insertado muestra la expansión de la región desde $3000-2900 \mathrm{~cm}^{-1}$. Las flechas muestran las bandas de vibración características. 


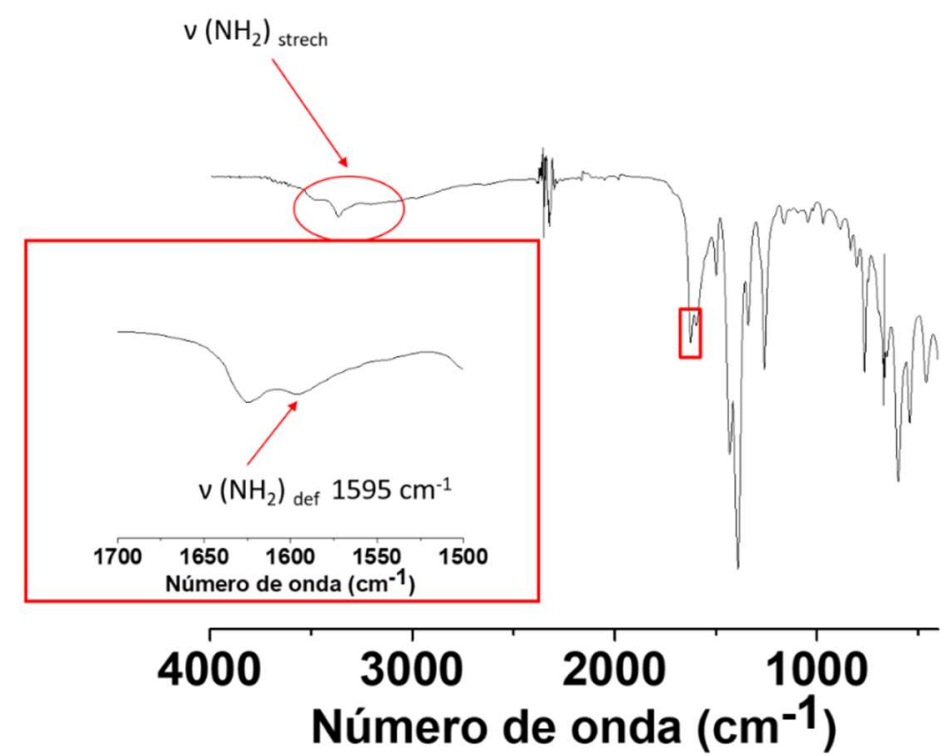

Figura 5.15. Espectro de IR de MIL-101(Cr)- $\mathrm{NH}_{2}$. El recuadro insertado muestra la expansión de la región desde $1700-1500 \mathrm{~cm}^{-1}$. Las flechas muestran las bandas de vibración características.

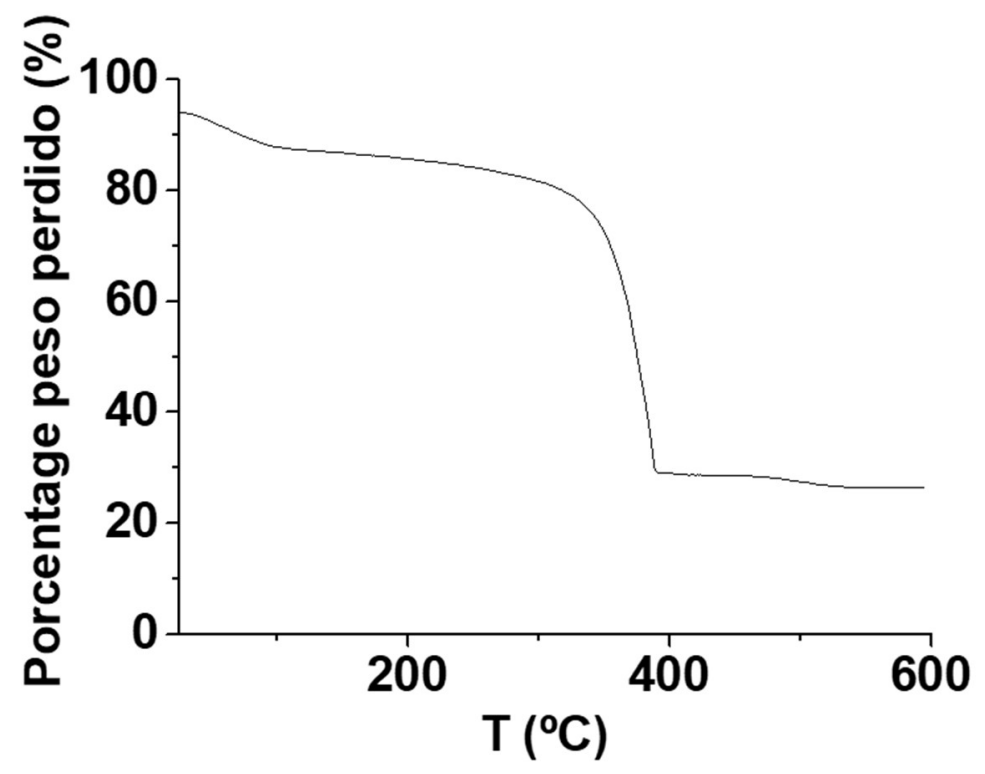

Figura 5.16. Análisis termogravimétrico de MIL-101(Cr)-H. 


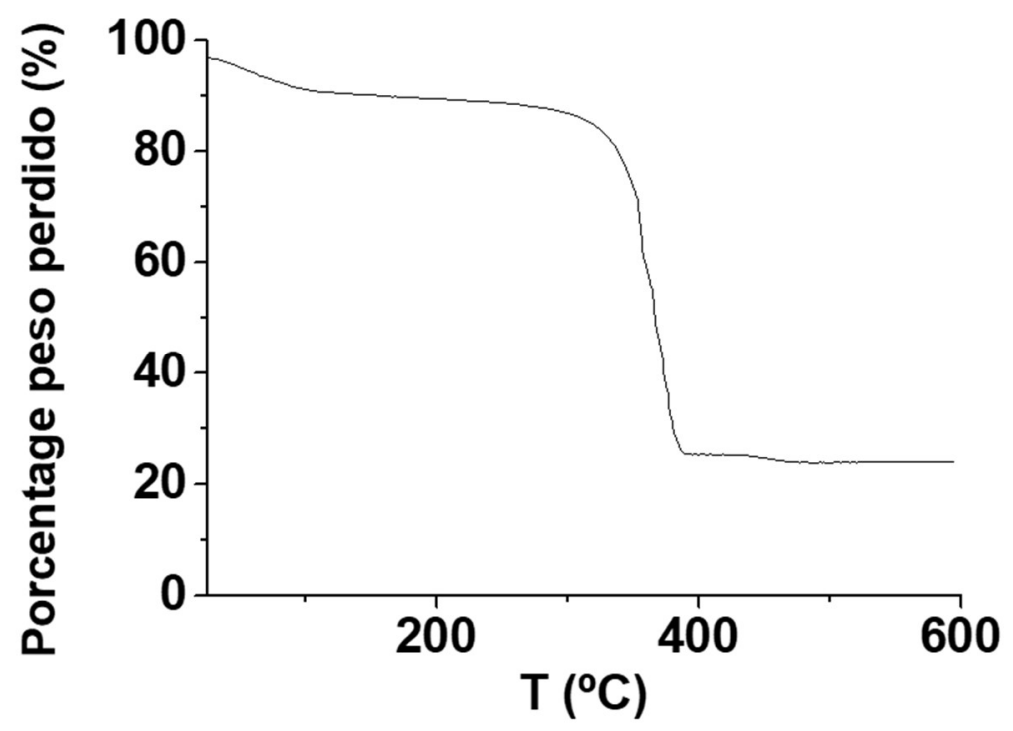

Figura 5.17. Análisis termogravimétrico de MIL-101(Cr)- $\mathrm{NO}_{2}$.

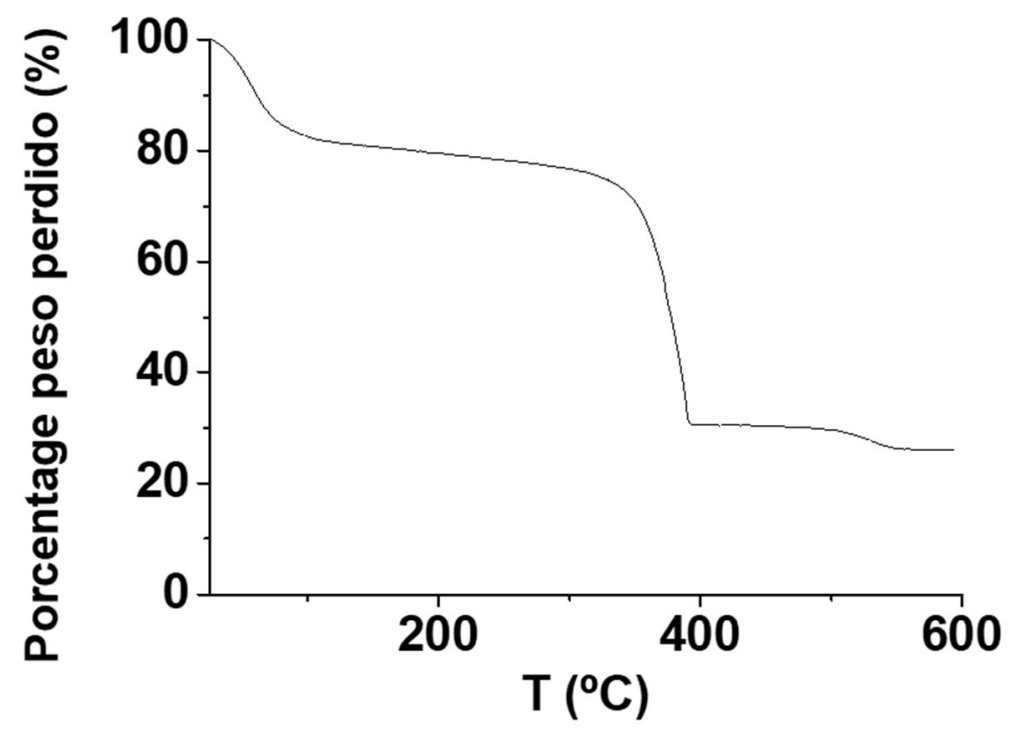

Figura 5.18. Análisis termogravimétrico de MIL-101(Cr)-SO $3{ }_{3} \mathrm{H}$. 


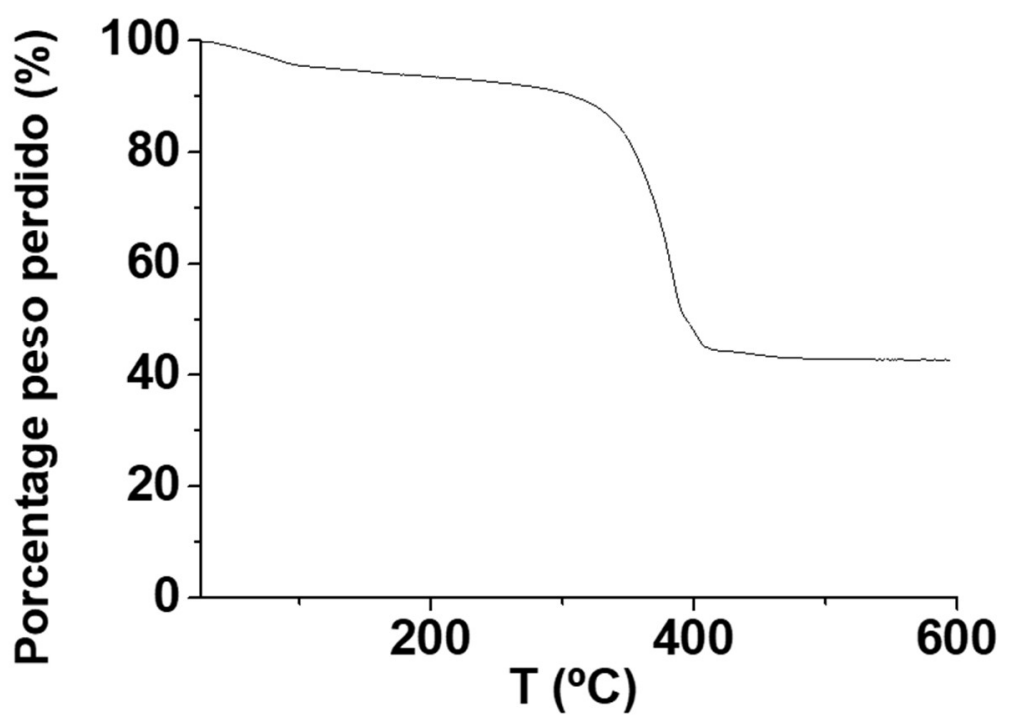

Figura 5.19. Análisis termogravimétrico de MIL-101(Cr)-Cl.

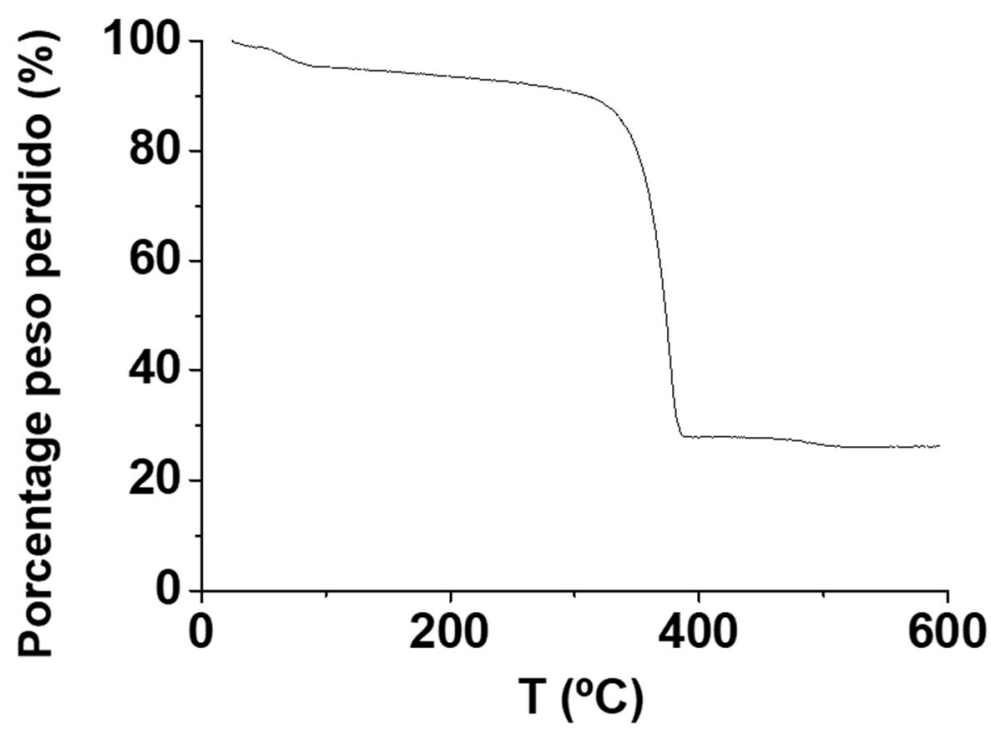

Figura 5.20. Análisis termogravimétrico de MIL-101(Cr)- $\mathrm{CH}_{3}$. 


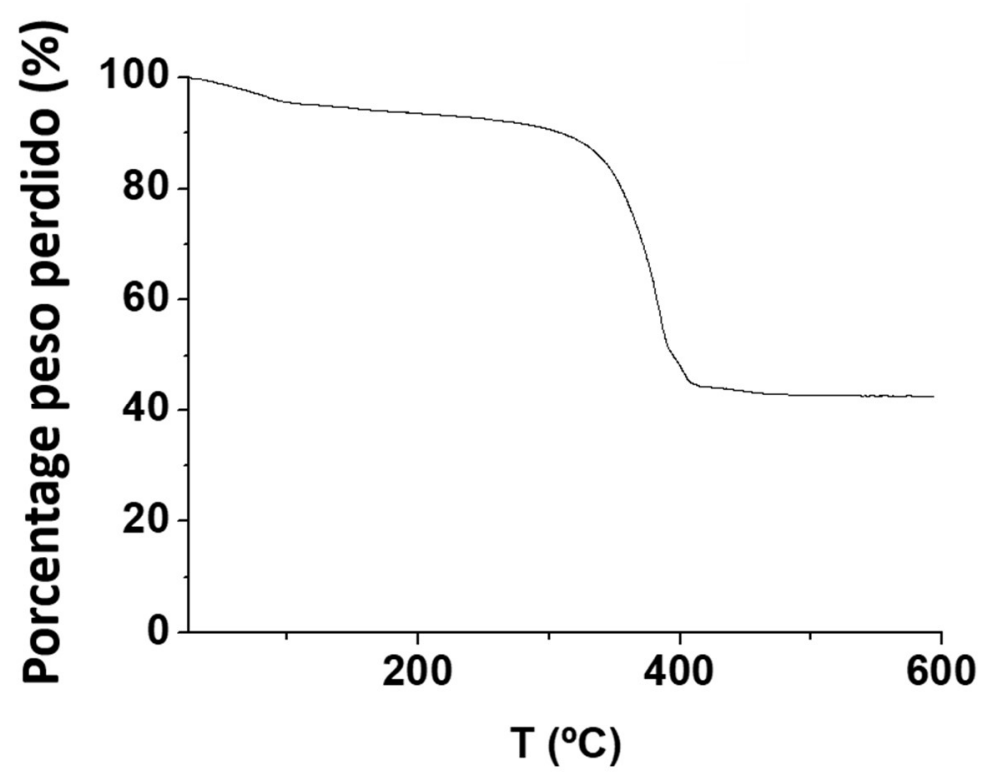

Figura 5.21. Análisis termogravimétrico de $\mathrm{MIL}-101(\mathrm{Cr})-\mathrm{NH}_{2}$.

Tabla 5.1. Lista de catalizadores empleados en el presente capítulo junto con un resumen de sus propiedades texturales, estabilidad y bandas más relevantes en espectroscopia IR.

\begin{tabular}{|c|c|c|c|c|}
\hline Catalizadores & $\begin{array}{l}\text { Área su- } \\
\text { perficial } \\
\text { BET } \\
\left(\mathrm{m}^{2} \mathrm{~g}^{-1}\right)\end{array}$ & $\begin{array}{l}\text { Volumen } \\
\text { de poro } \\
\left(\mathrm{cm}^{3} \mathrm{~g}^{-1}\right)\end{array}$ & $\begin{array}{l}\text { contenido metal } \\
\text { teórico }(\%) \quad / \\
\text { Calculado por } \\
\text { TG }(\%)\end{array}$ & Bandas IR, $v\left(\mathrm{~cm}^{-1}\right)$ \\
\hline MIL-101(Cr)-H & 2,740 & 2.2 & $21.77 / 22.84$ & $\begin{array}{l}3200(\mathrm{OH}), 3050(\mathrm{C}-\mathrm{H} \\
\text { aromático), } 1640 \\
\text { (carboxilato) y } 1515 \\
(\mathrm{C}=\mathrm{C} \text { aromático) }\end{array}$ \\
\hline MIL-101(Cr)-NO ${ }_{2}$ & 1,800 & 1.3 & $17.73 / 18.28$ & 1500 y $1380\left(\mathrm{NO}_{2}\right)$ \\
\hline MIL-101(Cr)-CH & 1,780 & 1.8 & $20.05 / 20.06$ & $\begin{array}{lll}2980-2850 & \left(\mathrm{CH}_{3}\right) & \mathrm{y} \\
1360\left(\mathrm{CH}_{3}\right) & \end{array}$ \\
\hline MIL-101(Cr)-Cl & 1,250 & 1.1 & $18.67 / 20.6$ & $760(\mathrm{C}-\mathrm{Cl})$ \\
\hline MIL-101(Cr)-SO $\mathrm{SO}_{3} \mathrm{H}$ & 1,550 & 1.3 & $16.96 / 17.01$ & $1160\left(\mathrm{SO}_{3} \mathrm{H}\right)$ \\
\hline MIL-101(Cr)-NH ${ }_{2}$ & 1,930 & 2.0 & $20.97 / 21.33$ & $\begin{array}{llll}3450 & \left(\mathrm{NH}_{2}\right) & \text { y } & 1630 \\
\left(\mathrm{NH}_{2}\right) & & \\
\end{array}$ \\
\hline
\end{tabular}


En el caso del MIL-101(Cr)- $\mathrm{SO}_{3} \mathrm{H}$, la cantidad de grupos sulfónicos se determinó por análisis elemental de combustión, dando valores de 24,5 y $1 \%$ para el contenido de $\mathrm{C}, \mathrm{H}$ y S, respectivamente. Este contenido de azufre es similar al que ha sido descrito en la literatura para este material preparado por el mismo procedimiento ${ }^{47} \mathrm{La}$ morfología de las partículas de los materiales de la serie MIL-101(Cr)-X se determinó por SEM, observado tamaños de partículas en el rango entre 100 y $400 \mathrm{~nm}$. (Tabla 5.2) ${ }^{37,49} \mathrm{En}$ el caso de la muestra MIL-101(Cr)- $\mathrm{CH}_{3}$ se observaron cristales mucho mayores de tamaños micrométricos y forma ortogonal junto con las partículas más pequeñas. En conjunto, todos los datos de caracterización indican que se han preparado los materiales MIL$101(\mathrm{Cr})-\mathrm{X}$ de forma exitosa con datos de caracterización coincidentes o muy similares con los previamente descritos. ${ }^{37,47,48}$ Estos materiales nos van a permitir la posibilidad de evaluar la influencia de los sustituyentes en la actividad catalítica de los mismos. 
Influencia de los sustituyentes en el ligando del MIL-101(Cr) en la oxidación aeróbica de bencilamina a iminas.

Tabla 5.2. Imágenes representativas de SEM para los materiales MIL-101(Cr)-X.

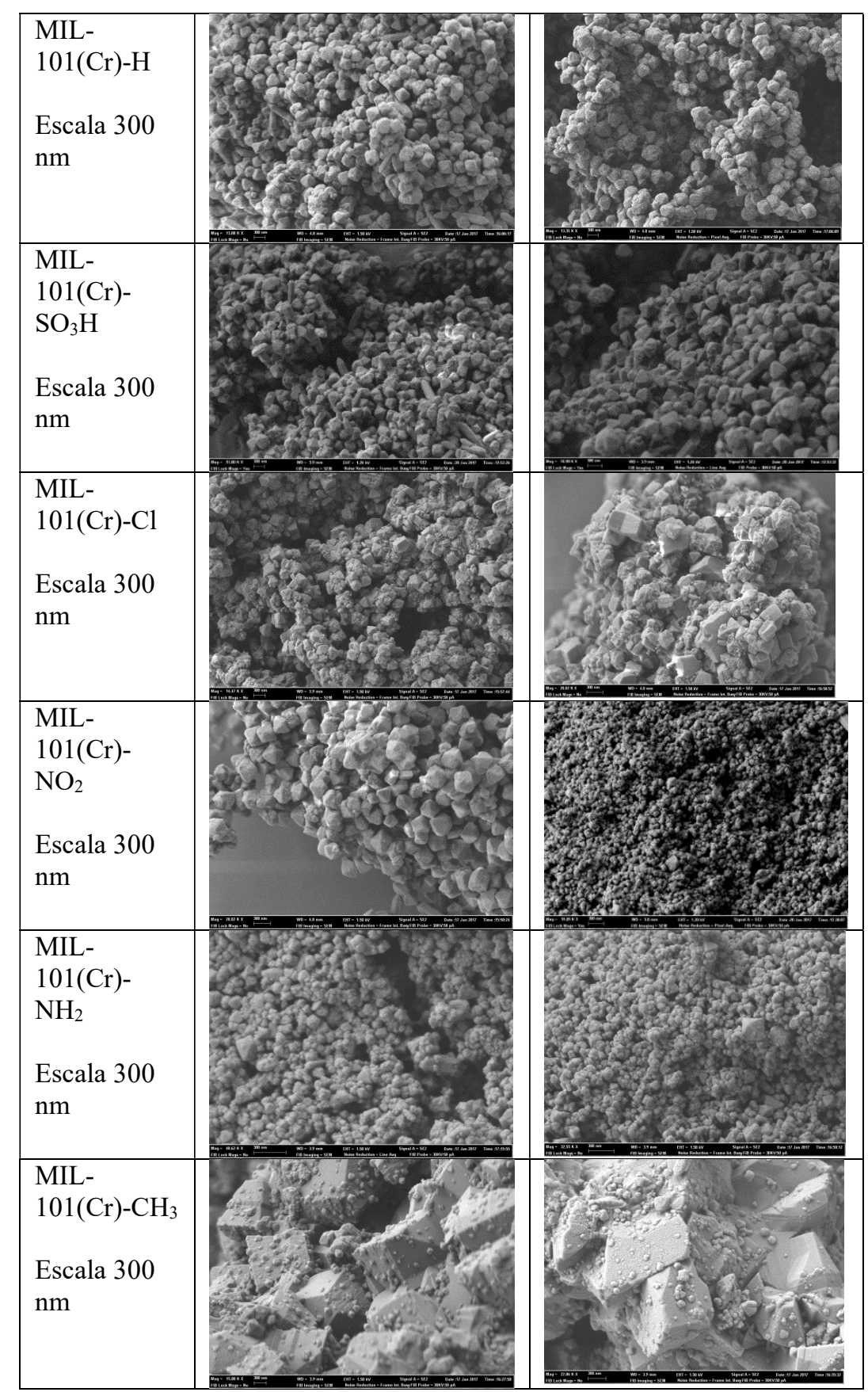


Con el conjunto de muestras MIL-101(Cr)-X preparadas anteriormente se llevó a cabo la oxidación aeróbica de la bencilamina al correspondiente producto de acoplamiento oxidativo. Esta reacción es una de las favoritas ampliamente empleada en la literatura para evaluar la actividad de diferentes catalizadores sólidos incluyendo nanopartículas de metales nobles, tales como el oro. ${ }^{29,50-52}$ Más próximo a los estudios del presente capítulo, nuestro grupo ha descrito que el NHPI absorbido sobre muestras comerciales de $\mathrm{Fe}$ (BTC) (BTC: 1,3,5-bencenotricarboxilico) es un catalizador adecuado para promover este acoplamiento oxidativo. ${ }^{29}$ En el presente estudio, se observó la oxidación de la bencilamina empleando como catalizador cualquiera de las muestras MIL101(Cr)-X. Merece destacarse que la velocidad de reacción inicial y la conversión a tiempo de reacción final dependieron en gran medida del sustituyente presente en el tereftalato. La figura 5.22 presenta los perfiles temporales de conversión de la bencilamina en presencia de cada uno de los catalizadores MIL-101(Cr)-X. Un experimento control llevado a cabo en las mismas condiciones en ausencia de catalizador no presenta conversión alguna de la bencilamina en las condiciones de reacción empleadas. En presencia de catalizador, el único producto observado fue la $N$-benciliden bencilamina con una selectividad mayor del 95\%. La tabla 5.2 resume los valores de velocidad inicial ( $\left.\mathrm{r}_{0}\right)$ y conversiones de bencilamina a tiempo final.

a)

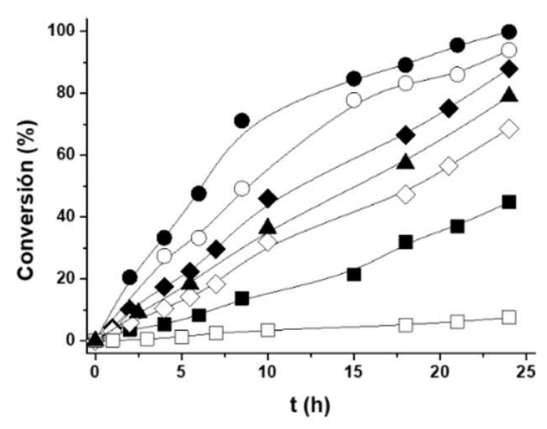

b)

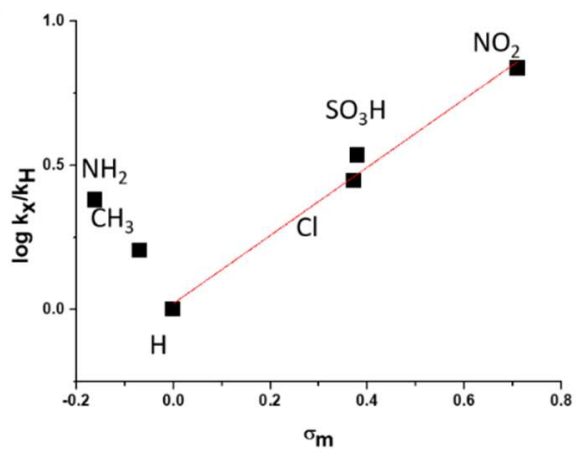

Figura 5.22. a) Curvas de conversión frente a tiempo para la oxidación aeróbica de la bencilamina a $\mathrm{N}$-benciliden bencilamina usando como catalizador las muestras de MIL-101(Cr)-X. Leyenda: MIL101(Cr)-H (•), MIL-101(Cr)-NO 2 (•), MIL-101(Cr)-SO 3 H (०), MIL-101(Cr)-Cl (•), MIL-101(Cr)$\mathrm{CH}_{3}(\diamond), \mathrm{MIL}-101(\mathrm{Cr})-\mathrm{NH}_{2}(\boldsymbol{\Delta})$ y experimentos de control en ausencia de catalizador $(\square)$. Condiciones de reacción: Catalizador $(0.04 \mathrm{mmol}$ de $\mathrm{Cr})$, sustrato $(20 \mathrm{mmol}), 120{ }^{\circ} \mathrm{C}$, atmósfera de $\mathrm{O}_{2}$. (b) Gráfica de Hammett representando la influencia de la constante $\sigma_{\mathrm{m}}$ en el logaritmo de las velocidades relativas de reacción. 
Tabla 5.3. Velocidades iniciales de reacción, conversiones finales y potenciales de oxidación para la serie de MIL-101(Cr)-X en estudio. Condiciones de reacción: Catalizador (0.04 mmol de Cr) sustrato (20 mmol), $120{ }^{\circ} \mathrm{C}$, atmósfera de $\mathrm{O}_{2}$.

\begin{tabular}{|c|c|c|c|}
\hline Catalizadores & $\mathbf{r}_{0}\left(\mathrm{mM} \mathrm{h}^{-1}\right)^{[\mathrm{a}]}$ & $\begin{array}{l}\text { Conv. } \\
\text { (\%) }\end{array}$ & $E_{1 / 2}(V)^{[B]}$ \\
\hline MIL-101(Cr) & 1.82 & 45 & 0.4025 \\
\hline $\begin{array}{l}\mathrm{MIL}-101(\mathrm{Cr})- \\
\mathrm{NO}_{2}\end{array}$ & 12.5 & $>95$ & 0.5135 \\
\hline $\begin{array}{l}\mathrm{MIL}-101(\mathrm{Cr})- \\
\mathrm{SO}_{3} \mathrm{H}\end{array}$ & 6.25 & 94 & 0.4525 \\
\hline MIL-101(Cr)-Cl & 5.1 & 88 & 0.4065 \\
\hline $\begin{array}{l}\mathrm{MIL}-101(\mathrm{Cr})- \\
\mathrm{CH}_{3}\end{array}$ & 2.5 & 68.5 & -- \\
\hline $\begin{array}{l}\text { MIL-101(Cr)- } \\
\mathrm{NH}_{2}\end{array}$ & 3.8 & 78 & -- \\
\hline \multicolumn{4}{|c|}{$\begin{array}{l}{ }^{\mathrm{a}} \text { Determinado a partir de la gráfica de conversión frente a tiempc } \\
\text { midiendo la pendiente de la gráfica de conversión a tiempo } 0\end{array}$} \\
\hline
\end{tabular}

En un intento de racionalizar la influencia de la naturaleza del sustituyente, se representó el logaritmo de las velocidades iniciales relativas en el catalizador MIL$101(\mathrm{Cr})-\mathrm{X}$ respecto a la del catalizador MIL-101(Cr)-H frente a la constante sigma de Hammett para cada sustituyente. De las varias constantes de Hammett posibles, aquella que mejor se ajusta a una relación lineal con los valores experimentales fue la que correspondía a la posición meta, $\sigma_{\mathrm{m}}$. Conviene hacer notar que cada unidad de tereftalato está conectada simultáneamente a dos nodos metálicos y, para uno de ellos, el sustituyente se encuentra en posición meta, mientras que para el otro es una posición orto. Pero como en la ecuación de Hammett sólo se tuvieron en cuenta los sustituyentes del ácido benzoico en meta o en para y no en orto, las constantes de Hammett empleadas en este capítulo son $\sigma_{\mathrm{m}}$. Los resultados de esta representación gráfica se muestran en la figura 5.22. Como puede verse allí, se obtiene una linealidad razonable para cuatro catalizadores, pero no para los casos de los sustituyentes electrón-dadores MIL-101(Cr)- $\mathrm{NH}_{2}$ y MIL-101(Cr)- $\mathrm{CH}_{3}$. Podría ocurrir que, además de influir en la densidad electrónica de los nodos, estos dos sustituyentes tuvieran un papel adicional promoviendo la reacción o estabilizando los intermedios de reacción, o bien exhibiendo una adsorción/desorción preferente, diferente al resto de sustituyentes, para sustratos y productos, mediante, por ejemplo, el ajuste de la hidrofobicidad o el establecimiento de puentes de hidrógeno. ${ }^{54}$ La habilidad del grupo $-\mathrm{NH}_{2}$ para formar puentes de hidrógeno además de como dador 
de electrones y la posibilidad de formar radicales bencílicos en el sustituyente $-\mathrm{CH}_{3}$, podría jugar un papel adicional al simple efecto inductivo sobre los nodos metálicos. Los materiales MIL-101(Cr)- $\mathrm{NH}_{2}$ y MIL-101(Cr)- $\mathrm{CH}_{3}$ exhiben alrededor de cuatro y dos veces mayores velocidades de reacción que las que son esperables de acuerdo con las constantes $\sigma_{\mathrm{m}}$. De acuerdo con la tendencia mostrada en la figura 5.22, parece que la presencia de sustituyentes electrón-aceptores sobre el anillo aromático aumenta la actividad catalítica alrededor de los nodos conteniendo $\mathrm{Cr}^{3+}$, debido probablemente a los efectos inductivos los cuales deben disminuir la densidad electrónica alrededor de los iones $\mathrm{Cr}^{3+} \cdot{ }^{31,53}$ Conviene notar también que en el caso de MIL-101(Cr)-SO ${ }_{3} \mathrm{H}$, aunque la muestra bajo evaluación no posee todos los anillos tereftalato completamente sulfonados, presenta una actividad que está de acuerdo con el valor predicho en base a una relación lineal. Ello podría ser debido a que los iones $\mathrm{Cr}^{3+}$ conectados con los tereftalatos sulfonados contribuyen en mayor medida que el resto a la actividad catalítica que se observa.

Se consiguió evidencia experimental a favor de la influencia de sustituyentes en el anillo aromático del tereftálico sobre los iones $\mathrm{Cr}^{3+}$ mediante medidas de voltametría cíclica. La figura 5.23 muestra la voltametría cíclica del material MIL-101(Cr)-H comparada con la de la muestra MIL-101(Cr)- $\mathrm{NO}_{2}$ mientras que las figuras 5.24-5.27 muestran el resto de voltametrias cíclicas para las otras muestras. Como puede verse en la figura 5.23, la muestra MIL-101(Cr)-H exhibe un pico de oxidación a $0.503 \mathrm{~V}$ en las condiciones estudiadas, apareciendo a un valor de potencial más bajo que para el caso de MIL-101(Cr)- $\mathrm{NO}_{2}$. En este caso, un pico de oxidación quasireversible apareció a $0.577 \mathrm{~V}$. Este desplazamiento en el pico de oxidación de los iones $\mathrm{Cr}^{3+}$ se puede atribuir a la influencia de los grupos $\mathrm{NO}_{2}$ electrón-aceptores que harían la oxidación de los iones $\mathrm{Cr}^{3+}$ más difícil. En apoyo a esta hipótesis, las muestras MIL-101(Cr)-Cl y MIL-101(Cr)$\mathrm{SO}_{3} \mathrm{H}$ también presentan potenciales de oxidación más altos que el de la muestra sin substituir MIL-101(Cr)-H. Los valores de $\mathrm{E}_{1 / 2}$ medidos para los materiales MIL-101(Cr)$\mathrm{X}$ se resumen en la tabla 5.3. 


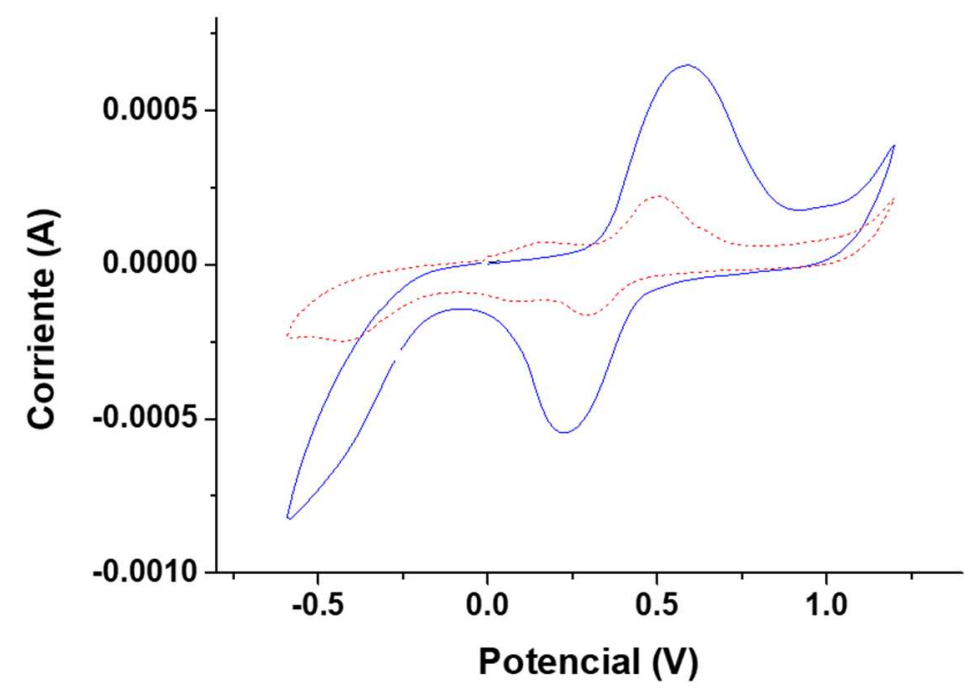

Figura 5.23. Voltametría cíclica (velocidad de barrido $50 \mathrm{mV} \mathrm{s}^{-1}$ ) en el rango entre $+1.2 \mathrm{~V}>\mathrm{E}>-0.6$ V de MIL-101(Cr)- $\mathrm{NO}_{2}$ sobre la superficie de un electrodo de grafito pirolítico, usando una disolución acuosa $0.1 \mathrm{M}$ de ácido acético como electrolito (línea azul continuo) y una voltametría en condiciones idénticas de la muestra MIL-101(Cr)-H (línea roja punteada).

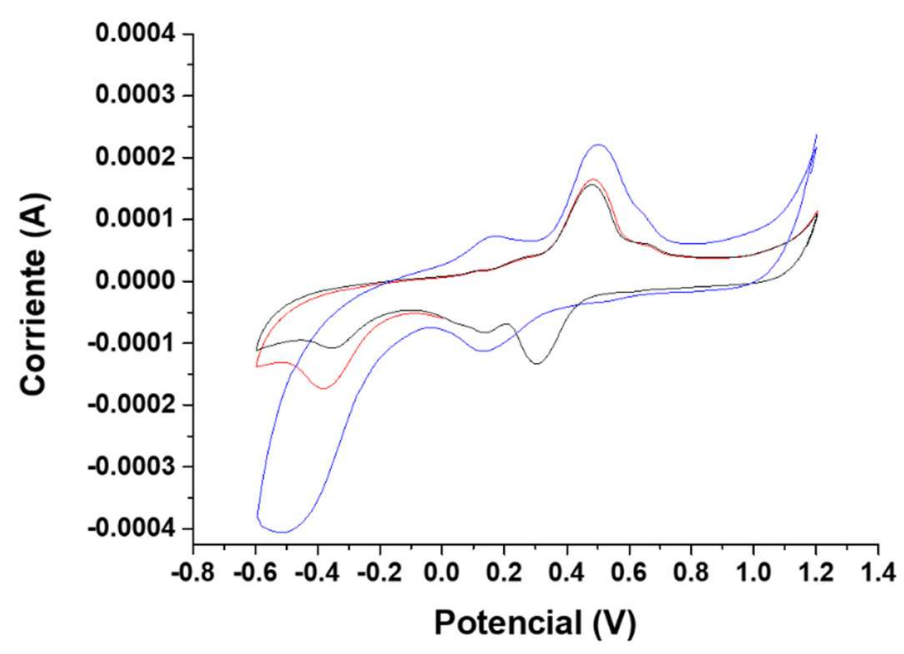

Figura 5.24. Voltametría cíclica de la muestra MIL-101(Cr)-H a 3 velocidades de barrido diferentes: $100 \mathrm{mV} / \mathrm{s}$ (negro), $50 \mathrm{mV} / \mathrm{s}$ (azul) y $30 \mathrm{mV} / \mathrm{s}$ (rojo). 


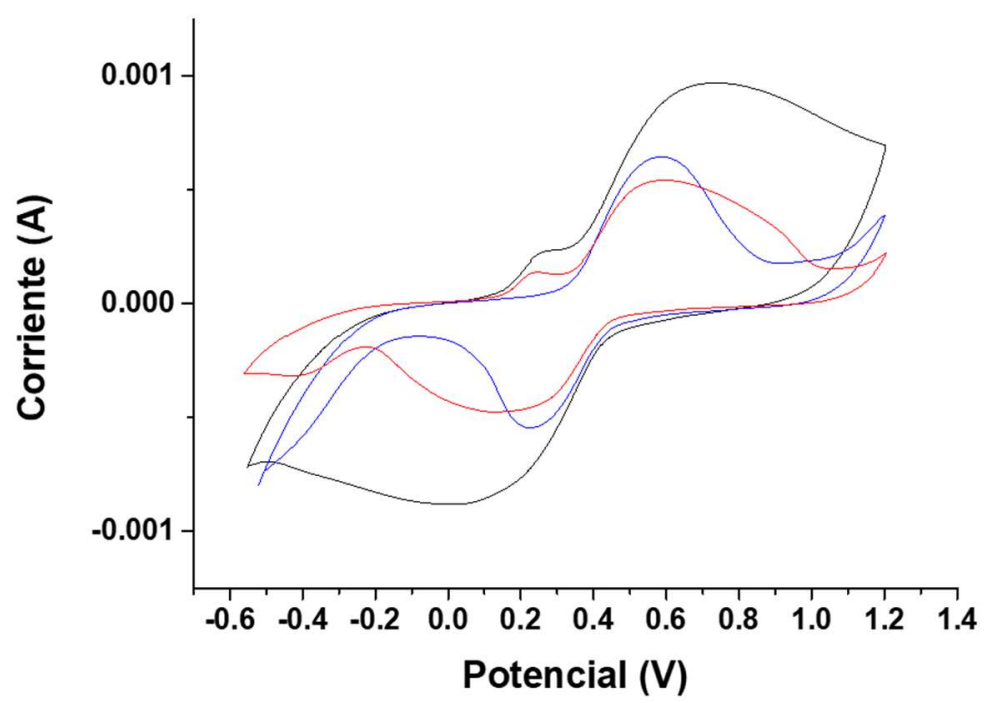

Figura 5.25. Voltametría cíclica de la muestra MIL-101(Cr)- $\mathrm{NO}_{2}$ a 3 velocidades de barrido diferentes: $100 \mathrm{mV} / \mathrm{s}$ (negro), $50 \mathrm{mV} / \mathrm{s}$ (azul) y $30 \mathrm{mV} / \mathrm{s}$ (rojo).

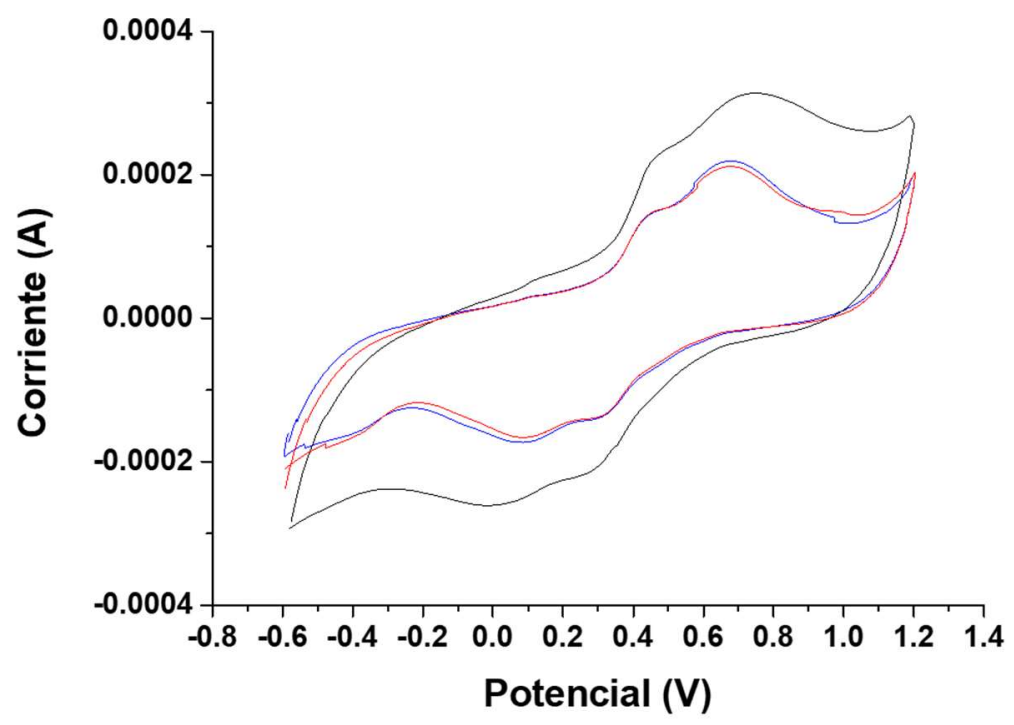

Figura 5.26. Voltametría cíclica de la muestra MIL-101(Cr)- $\mathrm{SO}_{3} \mathrm{H}$ a 3 velocidades de barrido diferentes: $100 \mathrm{mV} / \mathrm{s}$ (negro), $50 \mathrm{mV} / \mathrm{s}$ (azul) y $30 \mathrm{mV} / \mathrm{s}$ (rojo). 


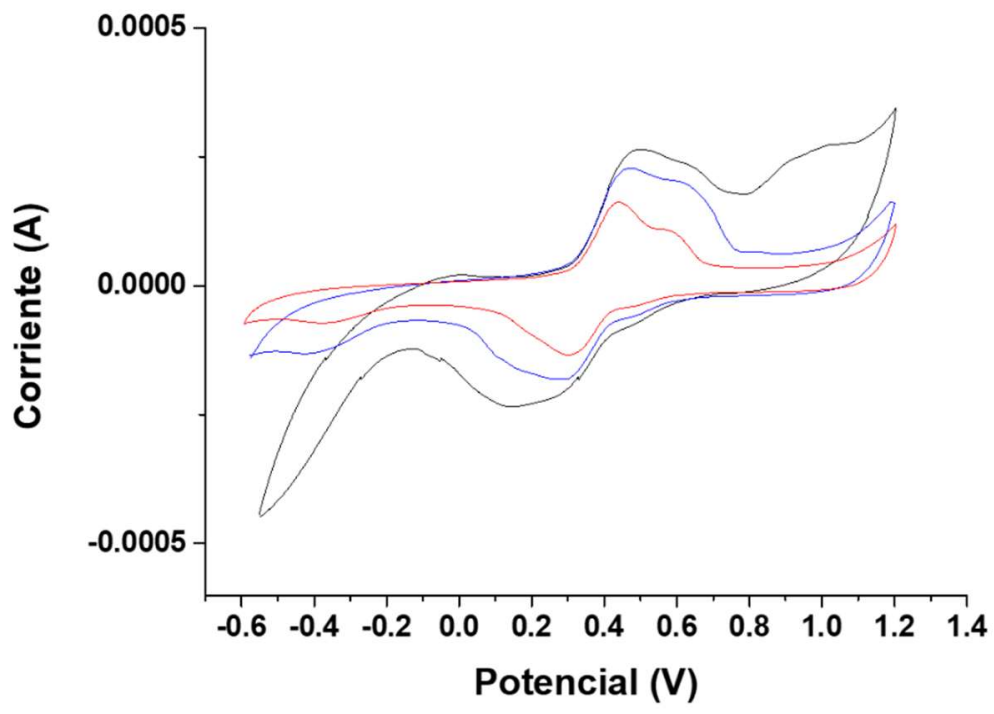

Figura 5.27. Voltametría cíclica de la muestra MIL-101(Cr)-Cl a 3 velocidades de barrido diferentes: $100 \mathrm{mV} / \mathrm{s}$ (negro), $50 \mathrm{mV} / \mathrm{s}$ (azul) y $30 \mathrm{mV} / \mathrm{s}$ (rojo).

Basándonos en los datos experimentales obtenidos por voltametría cíclica para la oxidación de $\mathrm{Cr}^{3+}$ en las muestras MIL-101(Cr)-H en función de la naturaleza del sustituyente, se propone que la mayor actividad catalítica observada para la muestra MIL$101(\mathrm{Cr})-\mathrm{NO}_{2}$ deriva de su habilidad para promover la oxidación inicial de la bencilamina por transferencia electrónica desde la amina aromática rica en electrones al agregado $\mathrm{Cr}_{3}-\mu \mathrm{O}$ como unidad aceptora de electrones, iniciando un mecanismo de autooxidación que implica radicales bencílicos. El esquema 5.3 resume nuestra propuesta mecanística. 

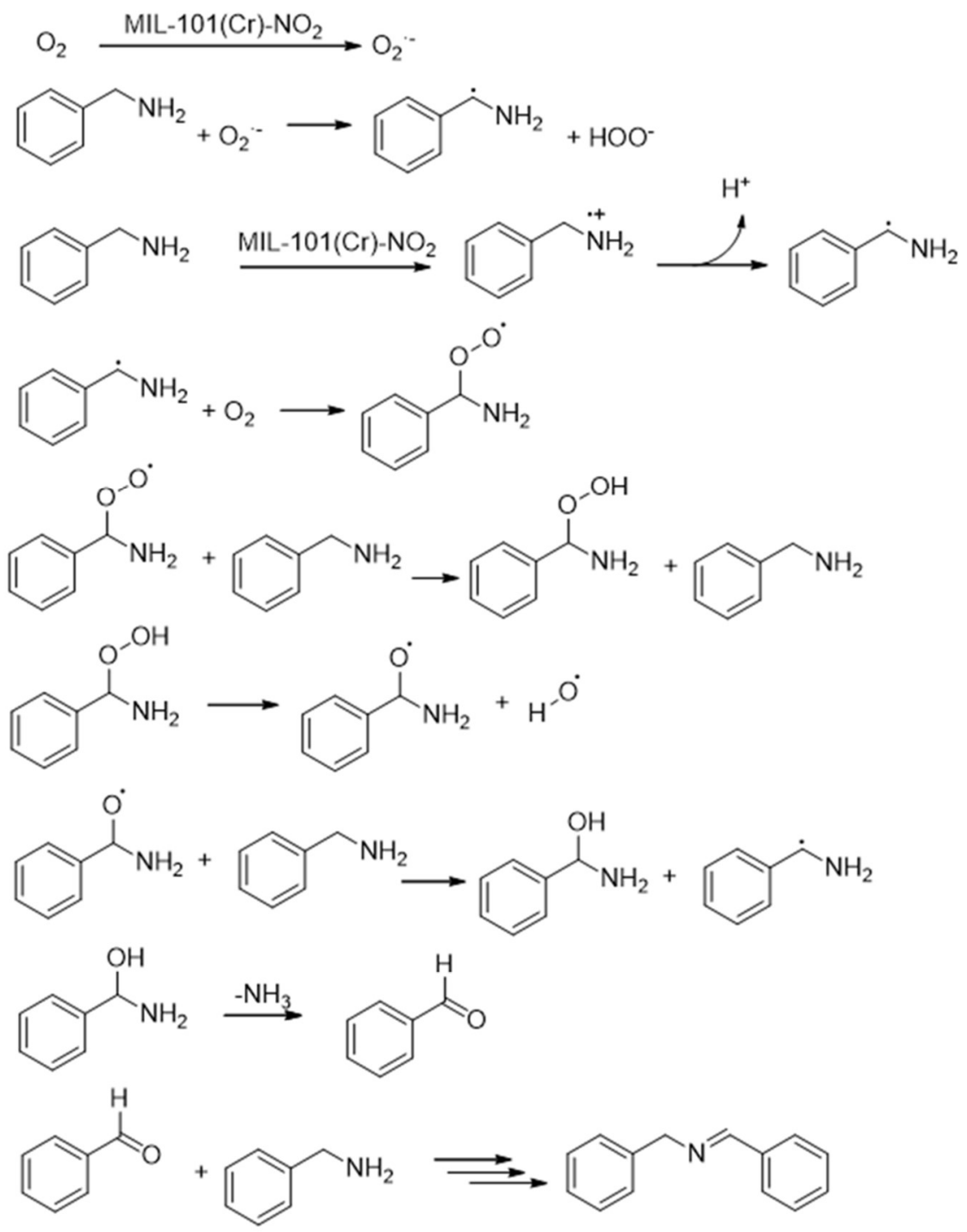

Productos encontrados con menos de $1 \%$ de selectividad<smiles>O=Cc1ccccc1</smiles><smiles>N#Cc1ccccc1</smiles><smiles>ON=Cc1ccccc1</smiles>

Esquema 5.3. Mecanismo propuesto para la oxidación aeróbica de bencilamina usando MIL-101(Cr)$\mathrm{X}$. 
En apoyo de la existencia de un mecanismo de autooxidación radicalaria en cadena, se llevó a cabo un experimento de filtración en caliente para determinar la influencia que la separación del catalizador sólido de la mezcla de la reacción tiene una vez esta se ha iniciado la reacción. La figura 5.28 muestra las gráficas de conversión frente a tiempo para dos reacciones llevadas a cabo simultáneamente en las mismas condiciones, pero donde en una de las cuales se filtró el catalizador en caliente, permitiendo que la fase líquida en ausencia de partículas sólidas continuara la reacción. La otra reacción simultánea se mantuvo en todo momento en contacto con el catalizador. La filtración del sólido se llevó a cabo a las $4 \mathrm{~h}$ de reacción cuando la conversión era entorno al $48 \%$. Como puede verse en la figura 5.28, la presencia o ausencia de catalizador no tiene casi influencia alguna una vez que la reacción se ha iniciado y la conversión alcanzada es entorno a la mitad del valor final. Resultados similares de los ensayos de filtración en caliente han sido observados cuando se usa la muestra MIL-101(Cr)-H como catalizador (Figura 5.29). Habría dos explicaciones alternativas que permitirían entender las razones por las que la reacción en el ensayo de filtración en caliente progresa similarmente en ausencia o en presencia de catalizador en ambas reacciones. La más simple seria que parte del $\mathrm{Cr}$, como centro activo, lixivia del sólido a la disolución y la reacción tendría lugar en fase homogénea. En reacciones de autooxidación radicalaria en cadena es conocido que tan solo pequeñas cantidad de metal en disolución, incluso ppb, pueden activar estas reacciones. ${ }^{55}$ Sin embargo, experimentos de control usando acetato de Cr tanto en la cantidad determinada de $\mathrm{Cr}$ en la fase líquida mediante análisis de ICP como el doble de este valor muestra que estas cantidades ínfimas hacen progresar la reacción en mucho menor grado, alcanzándose solo conversiones del 10\% a tiempo final de reacción (Figura 5.28). 


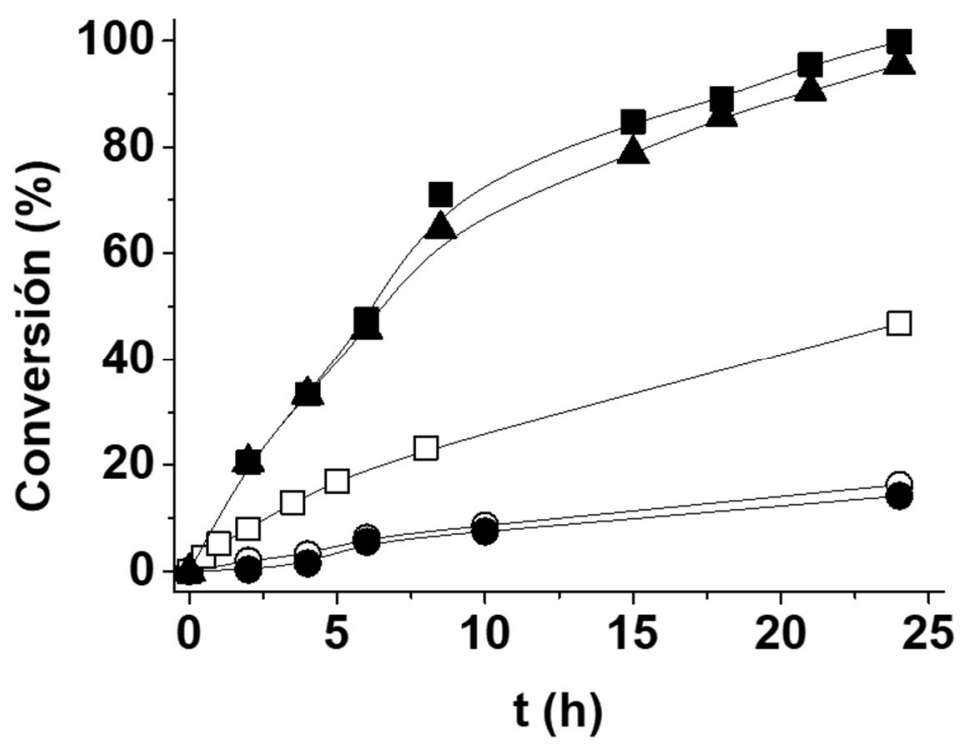

Figura 5.28. Gráfica de conversión frente a tiempo para la oxidación aeróbica de bencilamina a $N$ benciliden bencilamina usando MIL-101(Cr)- $\mathrm{NO}_{2}$ como catalizador, el cual es filtrado a las $4 \mathrm{~h}$ de reacción, o permanece en contacto con el sustrato por todo el tiempo concreto de reacción. Experimentos de control empleando $\mathrm{Cr}(\mathrm{OAc})_{3}$ como catalizador homogéneo han sido también representados. Leyenda: MIL-101(Cr)- $\mathrm{NO}_{2}(\boldsymbol{\square})$ y tras filtración del catalizador a las $4 \mathrm{~h}(\boldsymbol{\Delta})$, acetato de cromo empleando la cantidad de $\mathrm{Cr}$ presente en el MIL-101(Cr)- $\mathrm{NO}_{2}(\square)$, acetato de cromo en la cantidad de cromo lixiviado encontrado cuando se emplean los materiales MIL-101(Cr)- $\mathrm{NO}_{2}(\bullet)$ y acetato de cromo en el doble de cantidad a la determinada para el $\mathrm{Cr}$ lixiviado $(\mathrm{O})$. Condiciones de reacción: catalizador (12 mg de MIL-101(Cr)-NO $\mathrm{NO}_{2}$ equivalente a $0.04 \mathrm{mmol}$ de $\mathrm{Cr}$ ), sustrato $(20 \mathrm{mmol}), 120^{\circ} \mathrm{C}$, atmósfera de $\mathrm{O}_{2}$. 


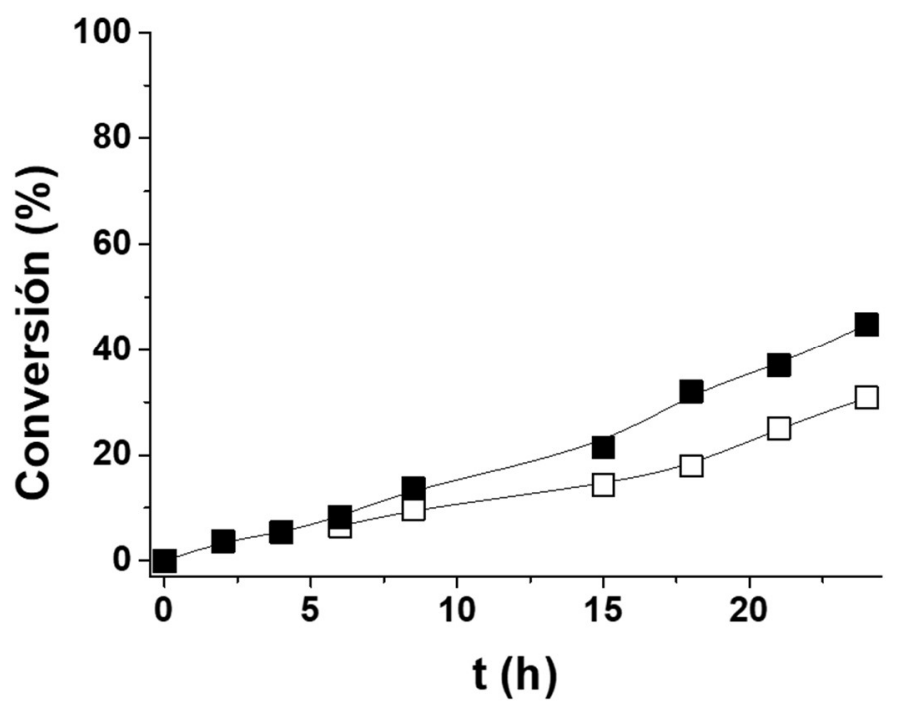

Figura 5.29. Gráfica de conversión frente a tiempo para la oxidación aeróbica de bencilamina a $\mathrm{N}$ benciliden bencilamina usando MIL-101(Cr)-H como catalizador, el cual es filtrado a las $6 \mathrm{~h}$ de reacción $(\square)$, o permanece en contacto con el sustrato por todo el tiempo concreto de reacción (a). Condiciones de reacción: catalizador (12 mg de MIL-101(Cr)- $\mathrm{NO}_{2}$ equivalente a $0.04 \mathrm{mmol} \mathrm{de} \mathrm{Cr}$ ), sustrato (20 mmol), $120^{\circ} \mathrm{C}$, atmósfera de $\mathrm{O}_{2}$.

Una segunda posibilidad alternativa para explicar el progreso de la reacción tras la filtración del sólido en la reacción sería que la muestra de MIL-101(Cr)- $\mathrm{NO}_{2}$ actúa como un iniciador de radicales promoviendo la autooxidación bencílica. En esta segunda explicación, el papel de MIL-101(Cr)-X es más el de iniciador de radicales que el de un verdadero catalizador para esta reacción de oxidación. Debe hacerse notar, sin embargo, que como puede verse en la figura 5.22, un experimento control en ausencia de cualquier catalizador bajo las mismas condiciones de reacción a $120{ }^{\circ} \mathrm{C}$ y $\mathrm{O}_{2}$ no da lugar a una conversión significativa de bencilamina durante $23 \mathrm{~h}$.

Tras haber mostrado la actividad de MIL-101(Cr)-X para la oxidación de la bencilamina, era de interés conseguir información sobre el mecanismo de reacción y, particularmente, como la bencilamina o el oxígeno son activados por los catalizadores MIL101(Cr)-X. Con este fin, se llevaron a cabo estudios de espectroscopía de resonancia paramagnética de electrones (EPR de sus siglas en inglés) sobre la activación de oxígeno molecular por la muestra de MIL-101(Cr)-H comparada con MIL-101(Cr)-NO $\mathrm{NO}_{2}$. Los experimentos se llevaron a cabo usando PBN como agente atrapador de radicales y $n$-dodecano como disolvente en ausencia de bencilamina, con el objetivo de caracterizar espectroscópicamente el aducto de $\mathrm{PBN}$ con cualquier especie reactiva de $\mathrm{O}_{2}$ que pudiera 
generarse debido a la acción catalítica del MOF. Los resultados se presentan en la figura 5.30 y el capítulo 8 , en el que se describe la sección experimental, se encuentran los detalles de estos experimentos. Como puede verse en la figura mencionada, simplemente calentando en ausencia de cualquier catalizador MOF la molécula sonda permite la detección del aducto entre radicales hidroperoxilo (HOO) y el PBN. Bajo las mismas condiciones de reacción, la presencia de MIL-101(Cr)-H aumenta significativamente la concentración de este aducto. Sin embargo, la señal del aducto $\mathrm{PBN}-\mathrm{OOH}$ resulta ser mucho más intensa (alrededor de un orden de magnitud mayor que en el caso de MIL-101(Cr)$\mathrm{H}$ y sobre dos órdenes de magnitud que en el experimento en ausencia de sólido) cuando se emplea MIL-101(Cr)-NO $\mathrm{NO}_{2}$ como iniciador. La figura 5.30 presenta también el espectro de EPR simulado para la estructura del aducto $\mathrm{PBN}-\mathrm{OOH}$ mostrando que aunque no hay una estricta coincidencia en la intensidad esperada como la que predice la teoría, la posición y constantes de acoplamiento del espectro experimental de EPR coincide exactamente con las posiciones y valores del espectro teórico simulado para el aducto PBN$\mathrm{OOH} .{ }^{24}$ Esta coincidencia proporciona un apoyo experimental convincente a la generación de radicales $\mathrm{HOO}$, particularmente, en presencia del sólido MIL-101(Cr)-NO $\mathrm{NO}_{2}$. Es importante hacer notar que algunos autores han descrito la degradación de PBN bajo las condiciones requeridas para los experimentos de atrapamiento de radicales y, por consiguiente, es posible que la cantidad exacta de spines para los aductos $\mathrm{PBN}-\mathrm{OOH}$ no se corresponda con las que se generan en realidad en los experimentos. ${ }^{56,57}$ Aunque las condiciones de las medidas de EPR no garantizan una cuantificación rigurosa de la cantidad de radicales HOO generados, estas medidas proporcionan una clara indicación cualitativa de que el material más eficiente para la activación de oxígeno es el MIL-101(Cr)$\mathrm{NO}_{2}$, mostrando de esta manera la influencia de los sustituyentes en el ligando tereftalato sobre la actividad del material. El esquema 5.3 muestra el conjunto de reacciones que, de acuerdo con la bibliografía, son los procesos más probables que derivan de la actividad de oxígeno molecular. ${ }^{19,24,29}$ 


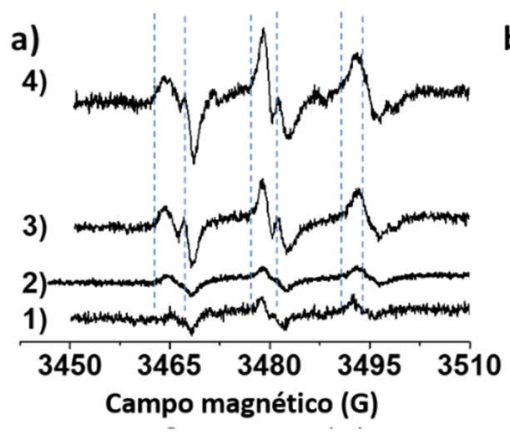

b)

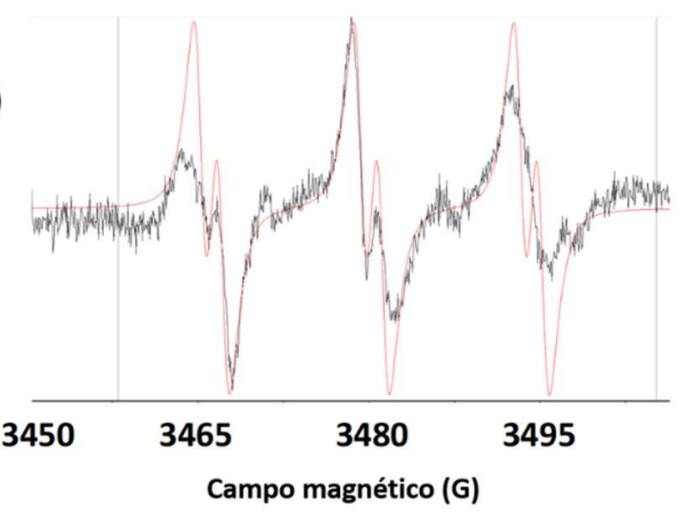

Figura 5.30. (a) Espectros de EPR experimentales usando 1) $\mathrm{PBN}+\mathrm{O}_{2}$, 2) $\mathrm{MIL}-101(\mathrm{Cr})-\mathrm{H}+\mathrm{PBN}+$ $\left.\mathrm{O}_{2}, 3\right) \mathrm{MIL}-101(\mathrm{Cr})-\mathrm{NO}_{2}+\mathrm{PBN}+\mathrm{Ar}$ y 4) MIL-101(Cr)-NO $\mathrm{NO}_{2}+\mathrm{PBN}+\mathrm{O}_{2}$. Los experimentos se llevaron a cabo usando $n$-dodecano a $120^{\circ} \mathrm{C}$ durante $4 \mathrm{~h}$. (b) Espectros de EPR experimental y simulado del aducto formado PBN-OOH bajo las condiciones de reacción (4) en el apartado anterior. Constante de acoplamiento del aducto $\mathrm{PBN}-\mathrm{OOH}$ coinciden con los descritos en la literatura $\left(\mathrm{AG}_{\mathrm{N}}=14.0\right.$ y $\left.\mathrm{AGH}_{\mathrm{H}}=2.05\right)$.

En apoyo de estas ecuaciones sobre los procesos que derivan de la formación de radicales hidroperoxilo, fuimos capaces de detectar la presencia de $\mathrm{H}_{2} \mathrm{O}_{2}$, el producto final más probable de la reducción de $\mathrm{O}_{2}$ a través de $\mathrm{HOO}$, mediante medidas de rutina basadas en colorimetría (ver detalles sobre las medidas en el capítulo 8 sobre los procedimientos experimentales y en la figura 5.31) en una concentración mucho más elevada para el material MIL-101(Cr)-NO $\mathrm{NO}_{2}$ que para el MIL-101(Cr)-H alcanzando una concentración máxima de $110 \mathrm{ppm}(3.25 \mathrm{mM})$ de $\mathrm{H}_{2} \mathrm{O}_{2}$. Conviene hacer notar, sin embargo, que la cantidad de $\mathrm{H}_{2} \mathrm{O}_{2}$ generada a tiempo final de reacción en el experimento fue de 7 $\mu$ moles y que es improbable que esta concentración tenga mucha influencia en la conversión de $20 \mathrm{mmol}$ de bencilamina. Además, como puede verse en la figura 5.31, existe un periodo de inducción en la formación de $\mathrm{H}_{2} \mathrm{O}_{2}$ que podría corresponder con el aumento en la formación de especies reactivas de oxígeno. Otros experimentos adicionales para la oxidación de bencilamina a la imina usando MIL-101(Cr)- $\mathrm{NO}_{2}$ como catalizador muestran que la adicción a propósito de $\mathrm{H}_{2} \mathrm{O}_{2}$ en las mezclas de reacciones iniciales aumenta la velocidad de reacción (Figura 5.32) más aún, una comparación de las velocidades de descomposición de $\mathrm{H}_{2} \mathrm{O}_{2}$ usando diferentes catalizadores MIL-101(Cr)-X muestra que la actividad relativa para este proceso es la misma que la que se observa en la oxidación aeróbica de bencilamina: MIL-101(Cr)- $\mathrm{NO}_{2}>$ MIL-101(Cr) $-\mathrm{SO}_{3} \mathrm{H}>$ MIL$101(\mathrm{Cr})-\mathrm{Cl}>\mathrm{MIL}-101(\mathrm{Cr})-\mathrm{NH}_{2}>\mathrm{MIL}-101(\mathrm{Cr})-\mathrm{CH}_{3}>\mathrm{MIL}-101(\mathrm{Cr})-\mathrm{H}$ (figura 5.33). Estos resultados indican que el $\mathrm{H}_{2} \mathrm{O}_{2}$ generado puede interaccionar a continuación con 
los iones $\mathrm{Cr}^{3+}$ conduciendo a la formación de especies reactivas de oxigeno que podrían contribuir a la oxidación de la bencilamina a la imina correspondiente..$^{58}$
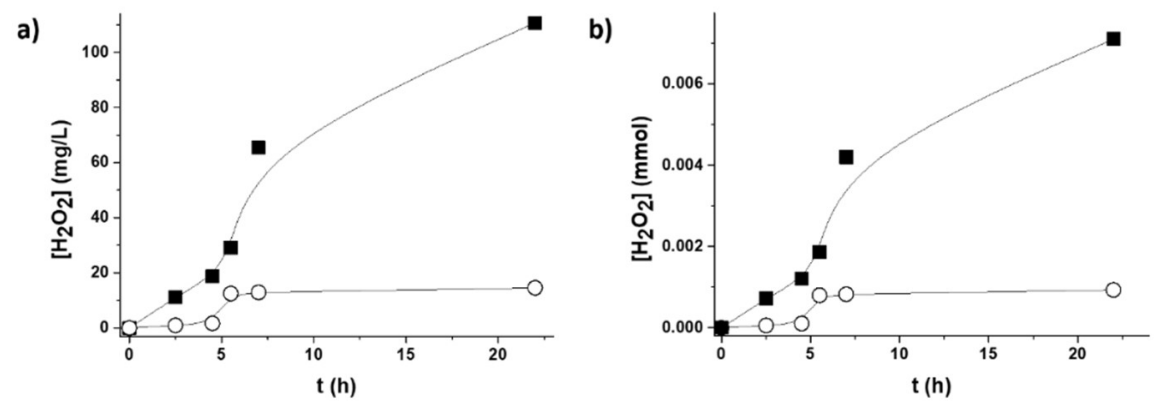

Figura 5.31. Formación de $\mathrm{H}_{2} \mathrm{O}_{2}$ usando MIL-101(Cr)- $\mathrm{NO}_{2}$ (匹) y MIL-101(Cr)-H (o) como catalizador. La gráfica (a) en $\mathrm{mg} / \mathrm{L}$ y la gráfica (b) en mmol. Condiciones de reacción: catalizador $(12 \mathrm{mg}$ de MIL-101(Cr)- $\mathrm{NO}_{2}$ equivalente a $0.04 \mathrm{mmol} \mathrm{de} \mathrm{Cr}$ ), sustrato $(20 \mathrm{mmol}), 120^{\circ} \mathrm{C}$, atmósfera de $\mathrm{O}_{2}$.

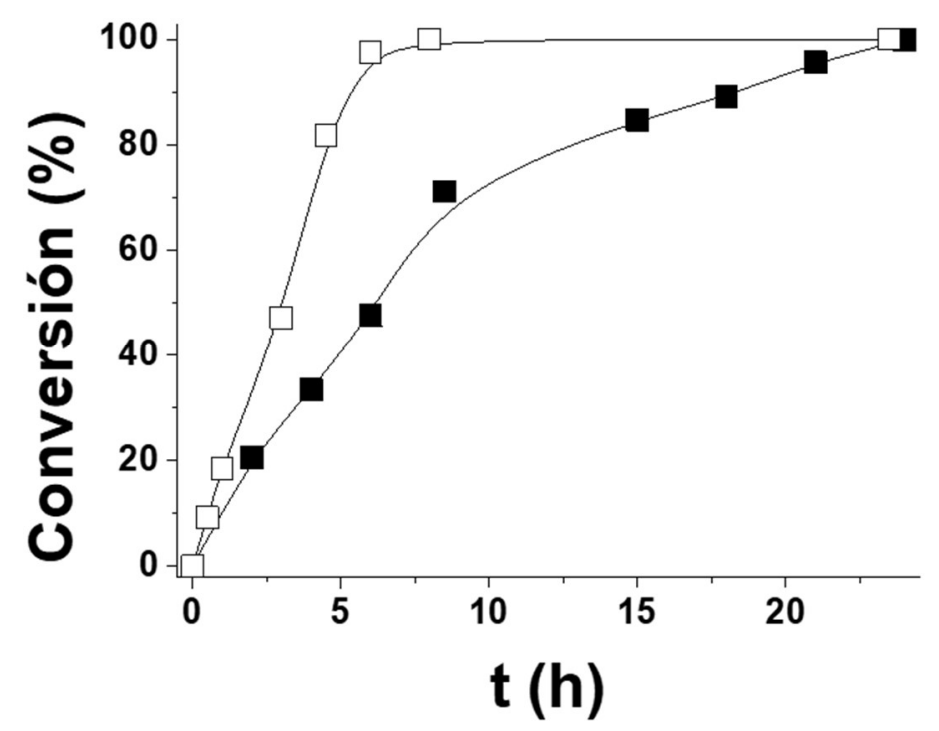

Figura 5.32. Gráfica de conversión frente a tiempo para la oxidación aeróbica de bencilamina a $N$ benciliden bencilamina usando MIL-101(Cr)- $\mathrm{NO}_{2}$ como catalizador en presencia ( $\square$ ) o ausencia de $\mathrm{H}_{2} \mathrm{O}_{2}(\boldsymbol{\varpi})$. Condiciones de reacción: catalizador (12 mg de MIL-101(Cr)- $\mathrm{NO}_{2}$ equivalente a $0.04 \mathrm{mmol}$ de $\mathrm{Cr}$ ), sustrato $(20 \mathrm{mmol}), 120^{\circ} \mathrm{C}$, atmósfera de $\mathrm{O}_{2}, \mathrm{H}_{2} \mathrm{O}_{2}(0.5$ equivalentes $)$. 


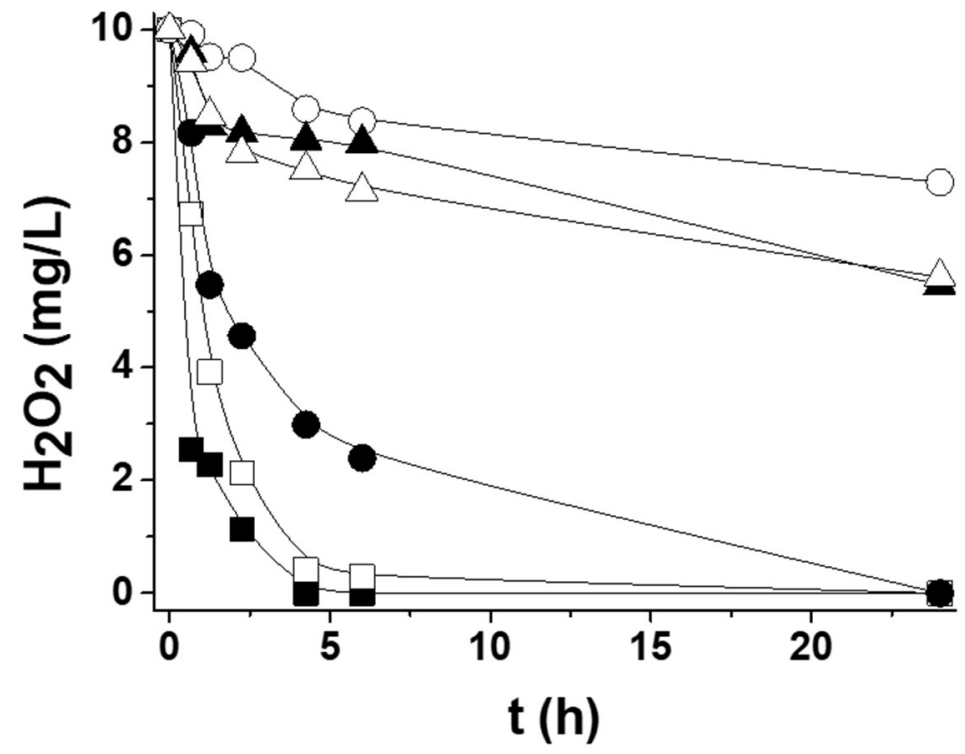

Figura 5.33. Gráfica de descomposición de $\mathrm{H}_{2} \mathrm{O}_{2}$ utilizando los materiales MIL-101(Cr)-X. Leyenda:

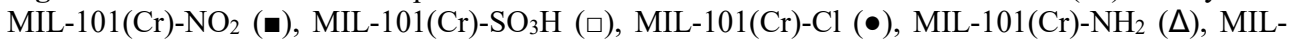
101(Cr)- $\mathrm{CH}_{3}(\boldsymbol{\Delta})$ y MIL-101(Cr)-H (०). Condiciones de reacción: catalizador (0.04 mmol de $\left.\mathrm{Cr}\right), 120$ ${ }^{\circ} \mathrm{C}$, atmósfera de $\mathrm{O}_{2}, \mathrm{H}_{2} \mathrm{O}_{2}(10 \mathrm{mg} / \mathrm{L})$.

El esquema 5.3 muestra varias especies diferentes de oxígeno reactivo que pueden ser responsables del ataque en la posición bencílica de la bencilamina, iniciando el acoplamiento oxidativo que eventualmente llevaría a la $\mathrm{N}$-benciliden bencilamina final. Es posible que todas estas especies reactivas de oxígeno contribuyan en varios grados en la generación del radical de la bencilamina o podría ser que la oxidación de la bencilamina fuera causada por una única especie reactiva de oxígeno. A fin de discutir este punto y ganar información adicional sobre el mecanismo de reacción, se llevaron a cabo una serie de 3 experimentos. En estos experimentos la oxidación de bencilamina en presencia de MIL-101(Cr)- $\mathrm{NO}_{2}$ se llevó a cabo añadiendo DMSO, $p$-benzoquinona, o TEMPO (2,2,6,6-tetrametil-1-piperidiniloxi). Existe abundante literatura mostrando que el DMSO inhibe selectivamente los radicales hidroxilo debido a la formación de ácido metasurfinico. ${ }^{19,24,59,60}$ En contraste, la $p$-benzoquinona es un inhibidor selectivo del anión superóxido $\left(\mathrm{O}_{2}^{-}\right),{ }^{19,24,61}$ mientras que el TEMPO reacciona con radicales bencílicos del carbono. ${ }^{19}$ Los resultados de estos estudios de inhibición se presentan en la figura 5.34 los cuales representan los perfiles temporales de una serie de cuatro reacciones, en tres de las cuales se añadieron los agentes inhibidores a las $5 \mathrm{~h}$ de reacción, mientras que no se añadió ningún agente en el cuarto experimento. Hay que hacer notar que ninguno de 
los inhibidores fue capaz de parar la reacción por completo, un hecho que puede entenderse considerando que la activación en el MIL-101(Cr) ocurre continuadamente tanto en presencia, como en ausencia de inhibidores, dentro de las cavidades del material y, debido a las limitaciones de difusión, una inhibición completa no es esperable en condiciones de generación continuada de especies reactivas de oxígeno. Sin embargo, como puede verse en esa figura 5.34, la presencia de $p$-benzoquinona o TEMPO disminuye considerablemente la conversión de bencilamina, indicando que, como era de esperar, el ion superóxido y los radicales centrales del carbono son los intermedios más importantes que intervienen en la oxidación.

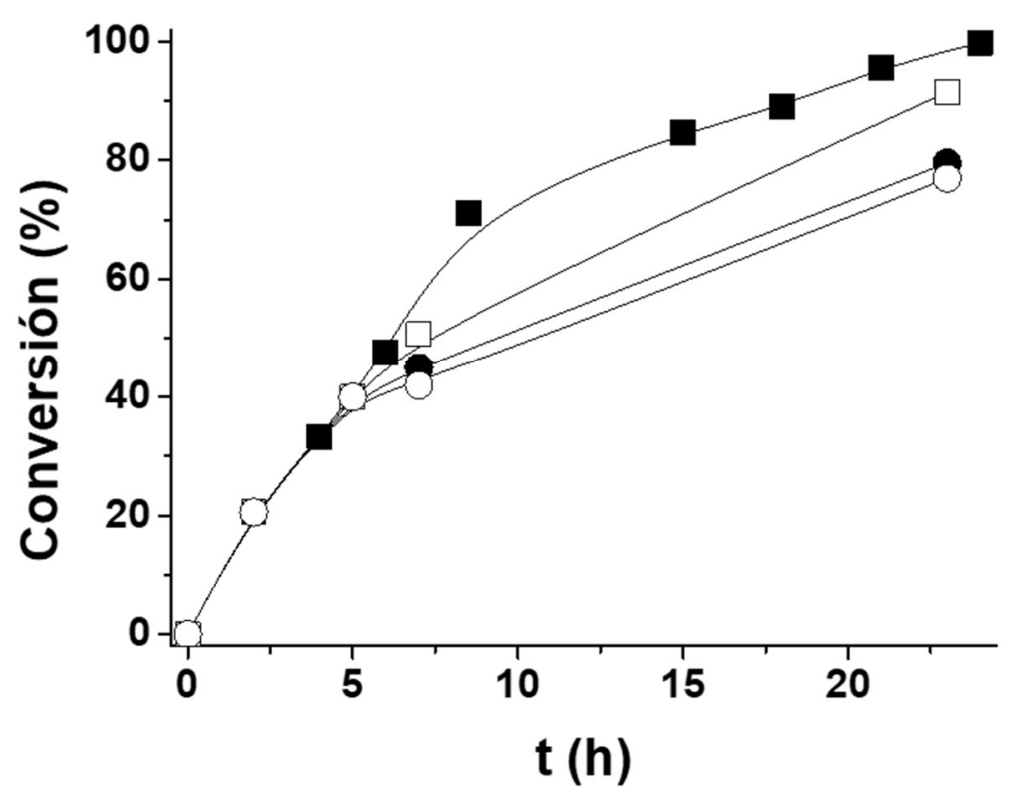

Figura 5.34. Gráficas de conversión frente a tiempo para la oxidación aeróbica de la bencilamina a $N$ benciliden bencilamina usando MIL-101(Cr)- $\mathrm{NO}_{2}$ como catalizador. Leyenda: $\mathrm{MIL}-101(\mathrm{Cr})-\mathrm{NO}_{2}(\mathbf{\square})$, $20 \%$ DMSO ( $\square$ ), $20 \%$ p-benzoquinona $(\bullet)$ y $20 \%$ TEMPO (०). Condiciones de reacción: catalizador (0.04 mmol de $\mathrm{Cr}$ ), $20 \mathrm{mmol}$ de sustrato, $120^{\circ} \mathrm{C}$, atmósfera de $\mathrm{O}_{2}$.

Más sorprendente fue, sin embargo, la influencia de DMSO, puesto que este agente inhibidor es específico para radicales $\mathrm{HO}$ y no es capaz de atrapar radicales hidroperoxilo HOO ${ }^{19,59}$ Como puede verse en la figura 5.34, la presencia de DMSO suprime parcialmente la reacción de oxidación de bencilamina, aunque entorno a la mitad comparada con el efecto de la $p$-benzoquinona. De acuerdo con este resultado, en la formación de especies reactivas de oxígeno y la generación de $\mathrm{H}_{2} \mathrm{O}_{2}$, la muestra MIL-101(Cr)- $\mathrm{NO}_{2}$ es capaz de generar radicales $\mathrm{HO}$ que contribuyen parcialmente a la oxidación de bencilamina. Tras la generación del radical de la bencilamina los pasos siguientes implicarían, 
como se propone en literatura, ${ }^{29}$ la formación de una bencilimina o benzaldehído como especies intermedias, seguido del ataque nucleofílico de bencilamina al benzaldehído o bencilimina y posterior deaminación. (Ver esquema 5.3).

Habiendo determinado que el papel del MIL-101(Cr)- $\mathrm{NO}_{2}$ en la oxidación aeróbica de bencilamina es más el de un iniciador, activando el oxígeno molecular, que el de un catalizador verdadero con ciclos catalíticos, cada uno de los cuales implicarían la participación del centro activo en el MOF, se procedió a optimizar la cantidad de catalizador. La figura 5.35 muestra el perfil temporal de la conversión de la bencilamina en función dela cantidad de MIL-101(Cr)-NO $\mathrm{NO}_{2}$. Se observó que aumentando la cantidad de catalizador aumentaba la velocidad de reacción, pero, había como dos diferentes regímenes. Uno de estos dos estadios se observa para cantidades pequeñas de MIL-101(Cr)- $\mathrm{NO}_{2}$ y está caracterizado por una pendiente elevada en el gráfico de velocidad inicial frente a peso de catalizador presente. El segundo régimen ocurre para cantidades más elevadas de catalizador y está caracterizado por una pendiente más pequeña. La cantidad de catalizador en la cual el régimen cambia está alrededor de $6 \mathrm{mg}$ en nuestras condiciones experimentales. Esto indica que cantidades más pequeñas de catalizador son comparativamente más eficientes para promover la reacción y, con el aumento adicional de peso de catalizador por encima de $6 \mathrm{mg}$, el aumento en la velocidad de reacción se vuelve menos importante. Los dos regímenes podrían estar causados por la concentración de oxígeno en la fase líquida que es prácticamente una constante y la generación más eficiente de radicales hidroperoxilo y otras especies reactivas de oxígeno para pesos más bajos de catalizador. Para cantidades de catalizador más altas, el factor limitante sería entonces la concentración de oxígeno disuelto, haciendo que el proceso fuera menos eficiente por centro activo.
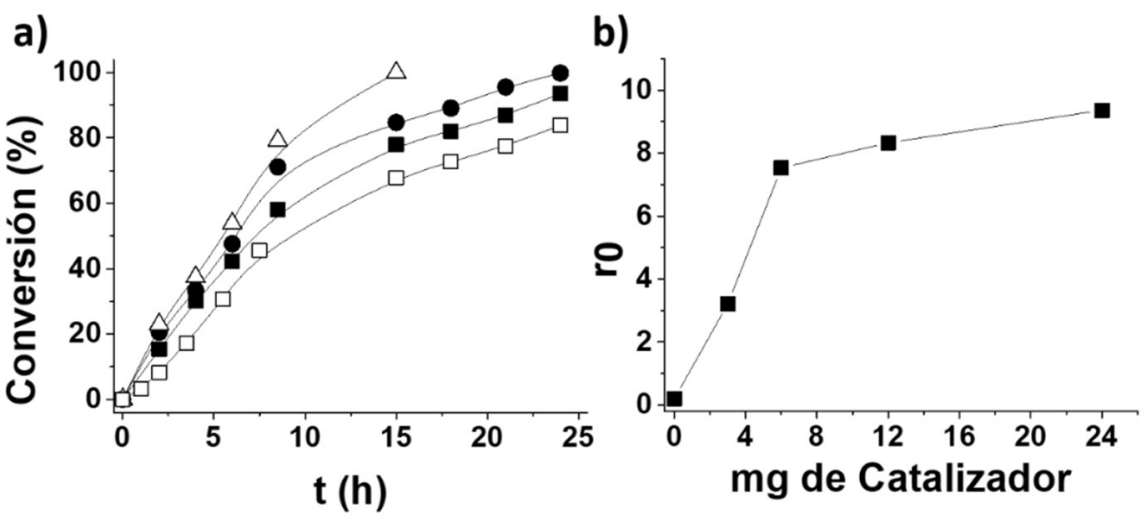

Figura 5.35. (a) gráficas de conversión frente a tiempo para la oxidación aeróbica de bencilamina a $N$ benciliden bencilamina usando diferentes cantidades de MIL-101( $\mathrm{Cr})-\mathrm{NO}_{2}$ como catalizador. Leyenda: $3 \mathrm{mg}$ de MIL-101(Cr)-NO $\mathrm{N}_{2}(\square), 6 \mathrm{mg}$ de MIL-101(Cr)-NO $(\bullet), 12 \mathrm{mg}$ de MIL-101(Cr)-NO $\mathrm{NO}_{2}(\bullet)$ y 24 $\mathrm{mg}$ de MIL-101-(Cr)-NO $2(\Delta)$. (b) Velocidad inicial frente a peso de catalizador. 
A fin de comprobar esta hipótesis, llevamos a cabo tres experimentos adicionales en los cuales la atmósfera fue Ar, aire y oxígeno respectivamente. Los resultados se muestran en la figura 5.36. Como puede verse en esa figura, bajo Ar, la conversión de la bencilamina fue muy baja $(<20 \%)$ a $24 \mathrm{~h}$ del tiempo de la reacción, estando este resultado de acuerdo con la necesidad de un oxidante para conseguir la oxidación estequiométrica de la bencilamina. La baja conversión medida podría ser debido a que el MOF está actuando como reactivo en lugar de como catalizador. Si trascurridas 24h bajo Ar, la atmósfera se cambia a $\mathrm{O}_{2}$, entonces la reacción tiene lugar con un perfil temporal similar al medido cuando la reacción se inicia bajo atmósfera de oxígeno. Cuando la reacción se lleva a cabo con atmósfera de aire, debido a la presión de oxígeno menor en estas condiciones, comparado con la reacción en atmósfera de oxígeno puro, se observa una disminución en la velocidad inicial de reacción, así como, una menor conversión final a $24 \mathrm{~h}$. Este comportamiento está de acuerdo con que la solubilidad de oxígeno en la fase líquida es el factor limitante en la oxidación de la bencilamina. Más aún, la representación de la velocidad inicial de reacción frente a la presión parcial de oxígeno conduce a una línea recta indicando que la reacción es de primer orden con respecto a la concentración de oxígeno (Figura 5.36 b).

a)

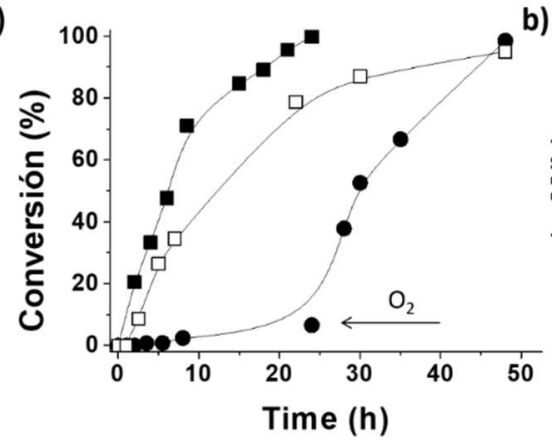

b)

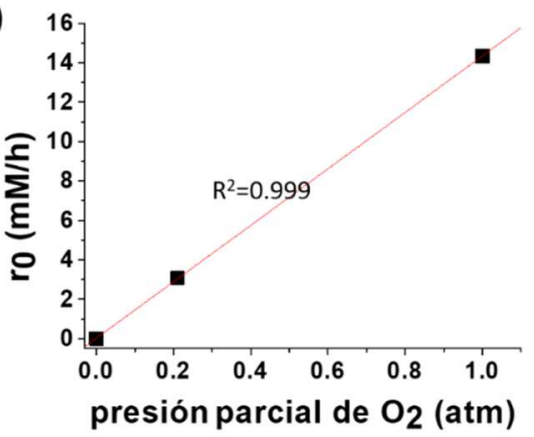

Figura 5.36. a) Influencia de la atmósfera de la reacción en el gráfico de conversión frente a tiempo para la reacción de la bencilamina catalizada por MIL-101(Cr)- $\mathrm{NO}_{2}$. Leyenda: $\mathrm{O}_{2}(\square)$, aire (口), $\mathrm{Ar}$ durante $24 \mathrm{~h}$ y entonces $\mathrm{O}_{2}(\bullet)$. Condiciones de reacción: $12 \mathrm{mg}$ de $\mathrm{MIL}-101(\mathrm{Cr})-\mathrm{NO}_{2}(0.04 \mathrm{mmol}$ de $\mathrm{Cr})$, $20 \mathrm{mmol}$ de sustrato, $120^{\circ} \mathrm{C}$. b) gráfico de velocidad inicial de reacción frente a la presión parcial de oxígeno en la oxidación de bencilamina.

La estabilidad de MIL-101(Cr)-NO 2 como catalizador se confirmó llevando a cabo una serie de usos consecutivos de la misma muestra y representando la evolución temporal de la conversión de la bencilamina para cada reacción. Después de cada reacción, la muestra de MIL-101(Cr)- $\mathrm{NO}_{2}$ fue recuperada de la reacción por filtración, se lavó con etanol y se secó a $60^{\circ} \mathrm{C}$ antes del siguiente uso. Los resultados de este estudio de reusa- 
bilidad se representan en la figura 5.37. Como puede verse en la figura 5.37, el catalizador mantiene la velocidad inicial de reacción constante con el uso, alcanzando a tiempo finales de reacción conversión completa en todos los casos. Estos resultados confirman la estabilidad de la muestra en las condiciones de reacción. Más aún, la cristalinidad del material usado en varias reacciones se confirmó llevando a cabo la difracción de rayos $\mathrm{X}$ de la muestra (ver recuadro insertado en la figura 5.37). Como puede verse en esa figura, no se observaron cambios en el modelo de difracción para la muestra con el uso, indicando que la estructura se mantiene durante la reacción. Además, el análisis químico de la fase líquida muestra que la cantidad de $\mathrm{Cr}$ presente en la disolución es de $0.05 \%$ de la cantidad total de $\mathrm{Cr}$ presente en la muestra fresca de MIL-101(Cr)-NO $\mathrm{NO}_{2}$. Esta estabilidad está de acuerdo con estudios previos usando MIL-101(Cr)-H como catalizador de oxidaciones aeróbicas en fase líquida, indicando que este MOF en particular es robusto bajo condiciones de reacción de oxidación típicas. ${ }^{19,21-24}$

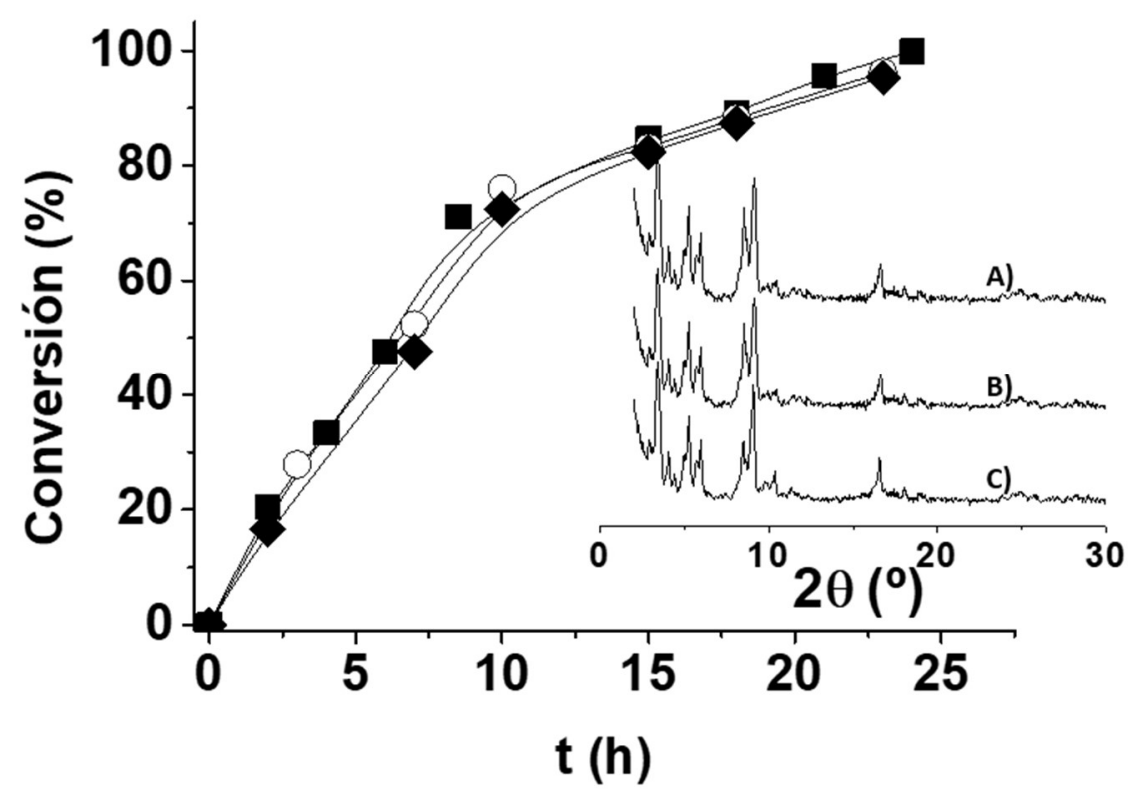

Figura 5.37. Experimentos de reusabilidad empleando como catalizador MIL-101(Cr)- $\mathrm{NO}_{2}$ en la oxidación aeróbica de bencilamina a $\mathrm{N}$-benciliden bencilamina. Condiciones de reacción: catalizador (12 $\mathrm{mg}$ ), sustratos (20 mmol), $120{ }^{\circ} \mathrm{C}$, atmósfera de $\mathrm{O}_{2}$. Leyenda: primer uso (a), tercer uso (०) y quinto uso $(\diamond)$. Los perfiles temporales de los ensayos segundo y cuarto son también coincidentes y no han sido dibujados para que haya más claredad en el gráfico. Insertado: Modelo de difracción de rayos X de la muestra fresca (A), usada tres veces (B) y usada cinco veces(C) para el material MIL-101(Cr)$\mathrm{NO}_{2}$. 
Un experimento alternativo para comprobar la estabilidad del catalizador y su eficiencia es el así llamado "test de productividad" en el cual la oxidación de bencilamina se lleva a cabo con relaciones molares de catalizador frente a sustrato mucho menores. En el presente caso se llevó a cabo un experimento adicional usando $200 \mathrm{mmol}$ de bencilamina ( $21.4 \mathrm{~g}$ ) y una reacción molar Cr/bencilamina del $0.02 \%$, siguiendo la evolución temporal de la conversión de bencilamina hasta alcanzar conversión completa. La figura 5.38 presenta el gráfico de conversión frente a tiempo para este ensayo de productividad, mostrando que incluso cuando se usa una cantidad muy pequeña de catalizador en comparación con la cantidad de sustrato, la reacción progresa alcanzando conversión completa a tiempos de reacción largos. Esto indica que el catalizador no sufre desactivación.

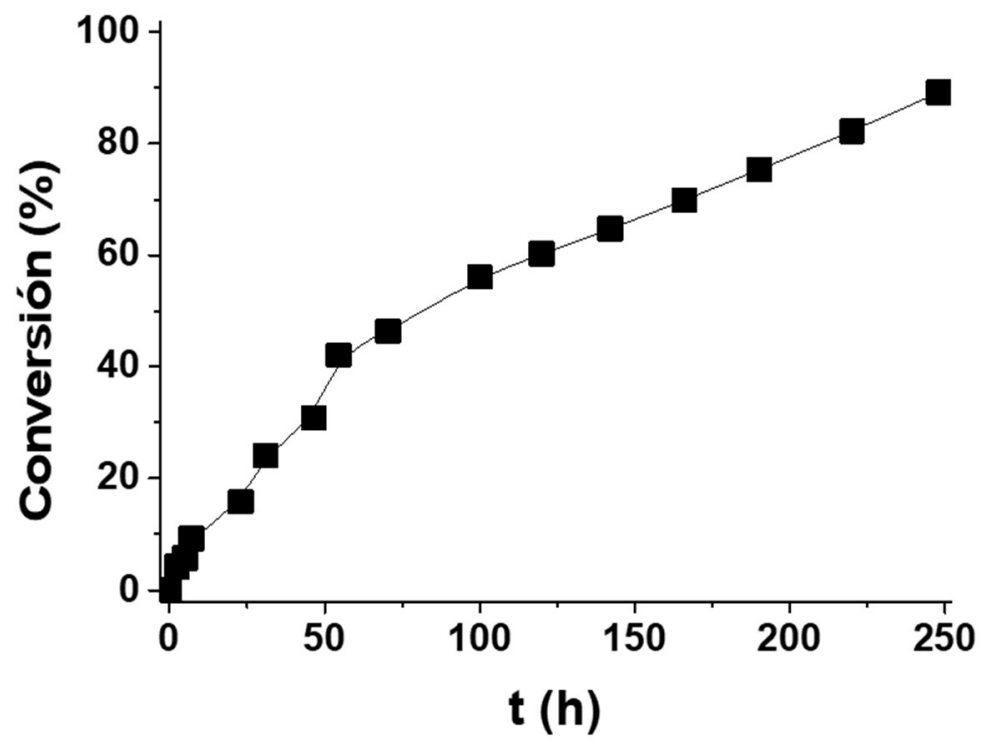

Figura 5.38. Gráfico de conversión frente a tiempo para la oxidación aeróbica de bencilamina a $N$ benciliden bencilamina en condiciones del ensayo de productividad usando una baja relación MIL$101(\mathrm{Cr})-\mathrm{NO}_{2}$ /sustrato. Condiciones de reacción: Catalizador $10 \mathrm{mg}(0.033 \mathrm{mmol} \mathrm{de} \mathrm{Cr})$, sustrato (21.4 g, $200 \mathrm{mmol}), 120^{\circ} \mathrm{C}$, presión atmosférica de $\mathrm{O}_{2}$.

La energía de activación para la oxidación de bencilamina usando MIL-101(Cr)$\mathrm{NO}_{2}$ fue calculada estudiando la influencia de la temperatura de reacción sobre la velocidad inicial de reacción en el rango de 110 y $140^{\circ} \mathrm{C}$ y usando la ecuación de Arrhenius. La figura 5.39 muestra la evolución temporal de la conversión de bencilamina en función de la temperatura de reacción. Se obtuvo una correlación lineal entre el $\ln \left(\mathrm{r}_{0}\right)$ y $1 / \mathrm{T}\left(\mathrm{K}^{-}\right.$ ${ }^{1}$ ), permitiendo de esta manera estimar una energía de activación de $46 \mathrm{~kJ} \mathrm{~mol}^{-1}$ a partir de la pendiente de la línea recta obtenida por ajuste de los puntos experimentales. El 
valor de energía de activación para la oxidación de la bencilamina empleando MIL$101(\mathrm{Cr})-\mathrm{H}$ fue igualmente determinado. Como se podría esperar, la energía de activación para esta reacción usando MIL-101(Cr)-H como catalizador es más elevada $\left(131 \mathrm{~kJ} \mathrm{~mol}^{-}\right.$ $\left.{ }^{1}\right)$ que la obtenida para el catalizador más activo MIL-101(Cr)-NO 2 (Figura 5.40).

a)

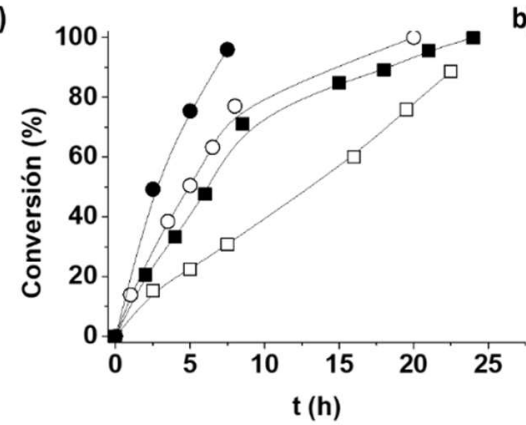

b) 0.8

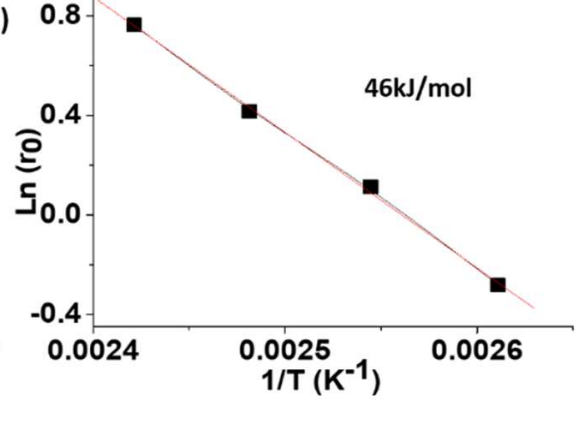

Figura 5.39. a) Gráfica de conversión frente a tiempo para la oxidación aeróbica de bencilamina a $N$ benciliden bencilamina usando como catalizador MIL-101(Cr)- $\mathrm{NO}_{2}$ llevada a cabo a cuatro temperaturas diferentes. b) Gráfica de Arrhenius para la oxidación aeróbica de bencilamina a $N$-benciliden bencilamina basada en las velocidades iniciales de reacción ( $\left.\mathrm{r}_{0}\right)$ obtenidas a partir de las cuervas de conversión frente a tiempo. Leyenda: $110^{\circ} \mathrm{C}(\square), 120^{\circ} \mathrm{C}(\boldsymbol{\bullet}), 130{ }^{\circ} \mathrm{C}(\mathrm{O}), 140{ }^{\circ} \mathrm{C}(\bullet)$. Condiciones de reacción: catalizador $(12 \mathrm{mg})$, sustrato $(20 \mathrm{mmol})$, atmósfera de $\mathrm{O}_{2}$.

a)

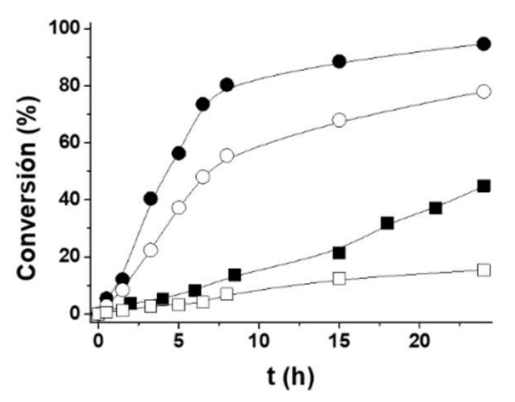

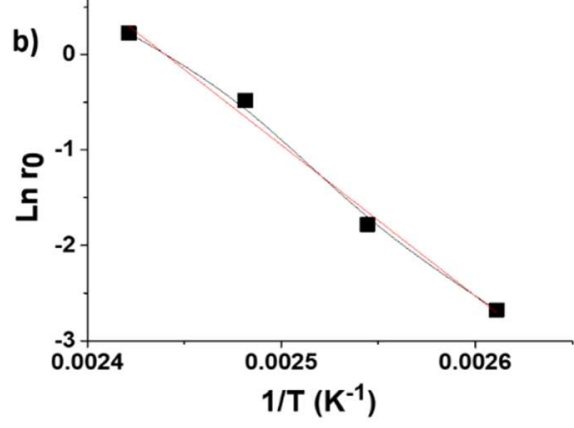

Figura 5.40. a) Gráfica de conversión frente a tiempo para la oxidación aeróbica de bencilamina a $N$ benciliden bencilamina usando como catalizador MIL-101(Cr)-H llevada a cabo a cuatro temperaturas diferentes. b) gráfica de Arrhenius para la oxidación aeróbica de bencilamina a $N$-benciliden bencilamina basada en las velocidades iniciales de reacción ( $\mathrm{r}_{0}$ ) obtenidas a partir de las cuervas de conversión frente a tiempo. Leyenda: $110^{\circ} \mathrm{C}(\square), 120^{\circ} \mathrm{C}(\bullet), 130{ }^{\circ} \mathrm{C}(\circ), 140{ }^{\circ} \mathrm{C}(\bullet)$. Condiciones de reacción: catalizador (12 mg), sustrato $(20 \mathrm{mmol})$, atmósfera de $\mathrm{O}_{2}$.

A fin de mostrar que el sustituyente en el anillo del tereftalato influye en la actividad en la oxidación de bencilaminas en general y que el orden de reactividad de los sólidos 
no está determinado por el sustrato, se llevó a cabo también la oxidación de la 4-chlorobencilamina usando la serie de los 6 materiales MIL-101(Cr)-X (Figura 5.41). Se observó que la 4-clorobencilamina reacciona en general más rápidamente que la bencilamina, debido a la influencia del átomo de - $\mathrm{Cl}$ como aceptor de electrones sobre el anillo aromático. También para el caso de la 4-clorobencilamina la serie de materiales MIL$101(\mathrm{Cr})-\mathrm{X}$ exhibe actividades catalíticas diferentes, siguiendo el mismo orden relativo que el previamente indicado para la bencilamina sin sustituir. Más aún, el gráfico del ln $\mathrm{r}_{0}$ frente a $\sigma_{\mathrm{m}}$ sigue la misma tendencia que ha sido anteriormente presentada para la bencilamina sin sustituir. De forma similar a la bencilamina, el material MIL-101(Cr)$\mathrm{CH}_{3}$ fue 5 veces más activo de lo esperado de acuerdo con el parámetro de Hammett $\sigma_{\mathrm{m}}$. Este comportamiento para la 4-clorobencilamina muestra que la influencia del sustituyente del tereftalato sobre el MIL-101(Cr)-H es un efecto general, aunque debe hacerse notar que el aumento en la velocidad de reacción relativa con grupo $-\mathrm{NO}_{2}$ frente $-\mathrm{H}$ es de alrededor 2.5 veces más bajo para la 4-clorobencilamina como sustrato comparado con la bencilamina sin sustituir. Así, la naturaleza del sustrato también juega un papel en la velocidad inicial de reacción y los valores cuantitativos del efecto del sustituyente sobre el anillo aromático del ligando. Esta influencia del sustrato se refleja también en las diferentes energías de activación estimadas a partir de la gráfica de Arrhenius (Figura 5.42) para 4-clorobencilamina $\left(\mathrm{E}_{\mathrm{a}}=28.62 \mathrm{~kJ} \mathrm{~mol}^{-1}\right)$ comparado con el de la bencilamina $\left(\mathrm{E}_{\mathrm{a}}=46 \mathrm{~kJ} \mathrm{~mol}^{-1}\right)$.

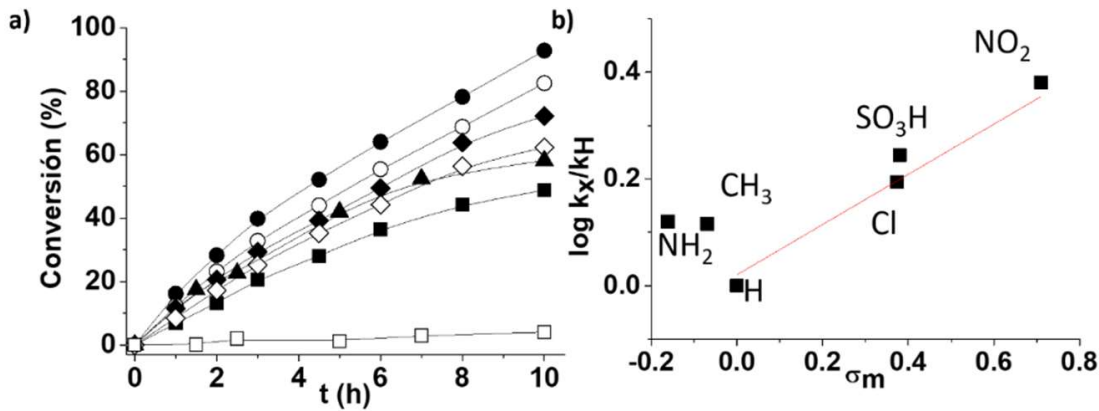

Figura 5.41. Gráfico de conversión frente a tiempo para la oxidación aeróbica de 4-clorobencilamina a la correspondiente $N$-benciliden bencilamina usando como catalizador MIL-101(Cr)-X. Leyenda:

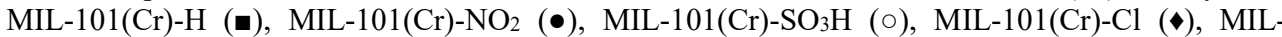
101(Cr)- $\mathrm{CH}_{3}(\diamond), \mathrm{MIL}-101(\mathrm{Cr})-\mathrm{NH}_{2}(\boldsymbol{\Delta})$ y experimento de control sin catalizador $(\square)$. Condiciones de reacción: catalizador $(0.04 \mathrm{mmol}$ de $\mathrm{Cr}), 20 \mathrm{mmol}$ sustrato, $120^{\circ} \mathrm{C}$, atmósfera de $\mathrm{O}_{2}$. b) Gráfico del logaritmo de la velocidad inicial relativa frente a la constante de Hammett $\sigma_{\mathrm{m}}$. 
a)

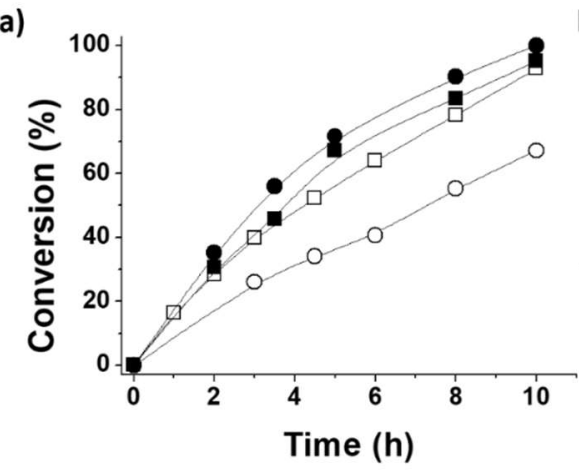

b)

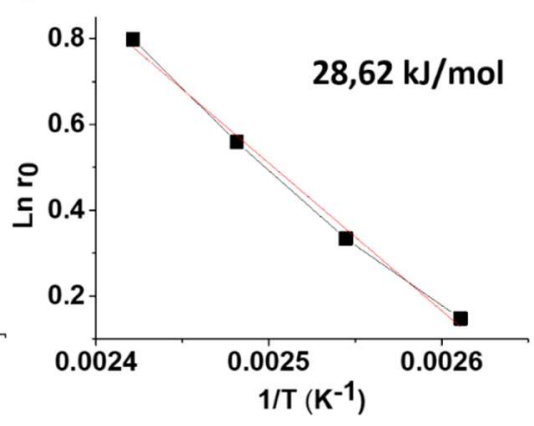

Figura 5.42. a) Gráfico de conversión frente a tiempo para la oxidación de 4-clorobencilamina al correspondiente $\mathrm{N}$-benciliden bencilamina usando MIL-101(Cr)- $\mathrm{NO}_{2}$, llevada a cabo a 4 temperaturas diferentes. b) Gráfica de Arrhenius para la oxidación aeróbica de bencilamina a $N$-benciliden bencilamina basada en las velocidades iniciales de reacción $\left(\mathrm{r}_{0}\right)$ obtenidas a partir de las cuervas de conversión frente a tiempo. Leyenda: $110{ }^{\circ} \mathrm{C}(\circ), 120^{\circ} \mathrm{C}(\square), 130{ }^{\circ} \mathrm{C}(\bullet)$ y $140{ }^{\circ} \mathrm{C}(\bullet)$. Condiciones de reacción: catalizador (12 mg) sustrato $(20 \mathrm{mmol})$, atmósfera de $\mathrm{O}_{2}$.

El rango de sustratos capaces de ser oxidados usando MIL-101(Cr)-NO $\mathrm{NO}_{2}$ como catalizador se ha evaluado llevando a cabo la reacción con otras 5 bencilaminas, además de la bencilamina no sustituida y dos bencilaminas para-sustituidas. A saber, 4-cloro y 4-metilbencilamina y una bencilamina heterocíclica, 2-picolil amina, y una dibencilamina secundaria y una tribencilamina terciaria como sustratos. Los resultados se resumen en la tabla 5.4.

Aunque se consiguieron conversiones completas para las bencilaminas sustituidas en para hacia los correspondientes $N$-benciliden bencilaminas sustituidas, se observó que la presencia de un sustituyente influye en la velocidad de reacción, siendo la 4-clorobencilaina considerablemente más reactiva que la bencilamina sin sustituir o la 4-metilbencilamina, que fue el sustrato que reaccionaba más lento. La influencia del sustituyente en la bencilamina fue analizada cuantitativamente representando la velocidad inicial de reacción frente la constante de Hammett $\left(\sigma_{\mathrm{m}}\right)$ de los sustituyentes (Figura 5.43). A partir de la relación lineal entre ambos, se puede concluir que la naturaleza del estado de transición exhibe algún carácter aniónico, por lo que sustituyentes electrón-aceptores tales como el -Cl deben aumentar la velocidad al estabilizar la carga parcial negativa que se genera en la posición bencílica. De acuerdo con esta propuesta para la naturaleza del estado de transición la 2-picolilamina teniendo un heterociclo de piridina electrón deficiente también reaccionó rápidamente bajo las condiciones de reacción, aunque en este caso la 2-picolilamida fue el producto principal observado. Para la dibencilamina y tribencilamina, se observó la formación de la $\mathrm{N}$-benciliden bencilamina como único producto en el caso de dibencilamina o acompañado por la formación de algo de dibencilamina en el caso de la tribencilamina. La característica más importante para las bi y 
tribencilamina fue, sin embargo, que su velocidad de reacción era considerablemente más lenta que para el caso de bencilamina, indicando que la velocidad de la reacción decrece cuando el tamaño de la bencilamina crece. De hecho, en el caso de la tribencilamina la reacción a $120^{\circ} \mathrm{C}$ fue casi despreciable y la reacción se tuvo que llevar a cabo a $140{ }^{\circ} \mathrm{C}$ obteniendo una conversión del $20 \%$ a las $32 \mathrm{~h}$ de reacción. Este orden de reactividad relativo se puede explicar fácilmente asumiendo que la reacción tiene lugar dentro de los poros del MIL-101(Cr)- $\mathrm{NO}_{2}$ y considerando que los coeficientes de difusión relativos disminuyen a medida que aumentan las dimensiones. ${ }^{19,24}$ Por consiguiente, a medida que el sustrato es más grande la reacción es más lenta debido a la difusión más difícil del sustrato por el interior de los cristales del MOF.

Tabla 5.4. Oxidación aeróbica de derivados de bencilamina usando MIL-101(Cr)- $\mathrm{NO}_{2}$ como catalizador.

\begin{tabular}{|l|l|l|l|}
\hline & $\begin{array}{l}\text { Conversión } \\
(\%)\end{array}$ & Productos de reacción & $\begin{array}{l}\text { Selectivi- } \\
\text { dad }(\%)\end{array}$ \\
\hline $\begin{array}{l}\text { 4-Clorobencila- } \\
\text { mine }\end{array}$ & 100 & $\begin{array}{l}\text { 4-chlorobenciliden } \\
\text { bencilamina }\end{array}$ & $>99$ \\
\hline $\begin{array}{l}\text { 4-Metilbencila- } \\
\text { mine }\end{array}$ & 100 & $\begin{array}{l}\text { 4-methylbenciiden } \\
\text { bencilamina }\end{array}$ & $>99$ \\
\hline 2-Picolilamina & 85 & Di-(2-picolil)amina & 67 \\
\hline Dibencilamine & 55 & N-benciliden bencilamina & $>99$ \\
\hline Tribencilamine ${ }^{[\mathrm{b}]}$ & 20 & N-benciliden bencilamina & 75.8 \\
\cline { 2 - 4 } & Dibencilamine & 24.2 \\
\hline
\end{tabular}

a Condiciones de reacción: Catalizador $(12 \mathrm{mg})$, sustrato $(20 \mathrm{mmol})$, atmósfera de $\mathrm{O}_{2}, 120^{\circ} \mathrm{C}, 24 \mathrm{~h}$ para todos los sustratos excepto para el 4-clorobencilamine $(8 \mathrm{~h}) .{ }^{\mathrm{b}}$ Temperatura de reacción $140^{\circ} \mathrm{C}$. 


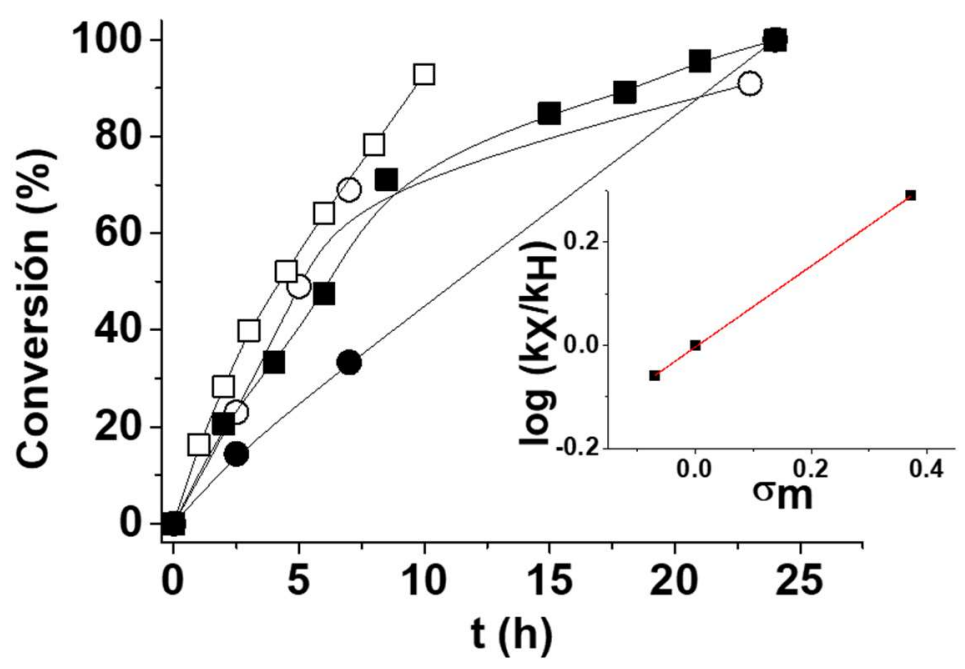

Figura 5.43. Gráfica de conversión frente a tiempo para la oxidación aeróbica de bencilamina ( $\square)$, 4clorobencilamina ( $\square$ ), 2-picolilamina (O) y 4-metilbencilamina $(\bullet)$ a las $N$-benciliden bencilamina correspondientes usando MIL-101(Cr)-NO $\mathrm{NO}_{2}$ como catalizador. El recuadro muestra el grafico de la velocidad inicial de reaccionó en escala logarítmica frente a la constante de Hammett $\sigma_{\mathrm{m}}$. Condiciones de reacción: catalizador $(12 \mathrm{mg})$ sustrato $(20 \mathrm{mmol}), 120^{\circ} \mathrm{C}$, atmósfera de $\mathrm{O}_{2}$.

\subsection{Concusiones.}

Yendo más allá del estado del arte que ha mostrado la influencia de los sustituyentes en el anillo aromático en el material UiO-66 para reacciones catalizadas como ácido de Lewis. En el presente capítulo, hemos mostrado que esta influencia también existe en oxidaciones aeróbicas, donde la naturaleza del sustituyente sobre el ligando juega un papel en la actividad de diferentes MOFs como promotores en reacciones de oxidación. Este hallazgo es particularmente notable puesto que los datos mecanísticos disponibles indican que el papel del MIL-101 en este tipo de reacciones no es realmente catalítico, sino más bien el de un promotor generando especies reactivas de oxígeno. Además, los datos electroquímicos han demostrado que la presencia de sustituyentes en el anillo del tereftalato modifican los potenciales redox de los iones $\mathrm{Cr}^{3+}$ en el nodo y que esto puede ser beneficioso para promover la oxidación aeróbica cuando están presentes grupos electrón-atrayentes sobre el ligando. Se ha demostrado que el material MIL-101(Cr)- $\mathrm{NO}_{2}$ no sufre desactivación en las condiciones de reacción y que puede ser aplicado para la oxidación de un amplio rango de bencilaminas cuya reactividad aumenta con la presencia de sustituyentes electrón-aceptores. A partir del orden de reactividad relativa que está 
básicamente controlada por el tamaño de la molécula, se propone que la reacción tiene lugar predominantemente en el interior de las partículas de los cristales del MOF.

Por consiguiente, los datos del presente capítulo muestran la flexibilidad que los materiales tipo MOF ofrecen para mejorar la actividad catalítica introduciendo sustituyentes apropiados en el ligando orgánico que modulan la densidad electrónica alrededor de los nodos metálicos que actúan como centros activos. 


\subsection{Referencias.}

1. A. Corma, H. Garcia y F. X. Llabrés i Xamena, Chem. Rev., 2010, 110, 46064655 .

2. A. Dhakshinamoorthy, M. Opanasenko, J. Čejka y H. Garcia, Catal. Sci. Technol., 2013, 3, 2509-2540.

3. A. Dhakshinamoorthy, M. Alvaro y H. Garcia, Catal. Sci. Technol., 2011, 1, 856867.

4. J. Gascon, A. Corma, F. Kapteijn y F. X. Llabrés i Xamena, ACS Catal., 2014, 4, 361-378.

5. M. Yoon, R. Srirambalaji y K. Kim, Chem. Rev., 2012, 112, 1196-1231.

6. H. Furukawa, K. E. Cordova, M. O'Keeffe y O. M. Yaghi, Science, 2013, 341, 1230444.

7. A. H. Chughtai, N. Ahmad, H. A. Younus, A. Laypkov y F. Verpoort, Chem. Soc. Rev., 2015, 44, 6804-6849.

8. O. A. Kholdeeva, Catal. Today, 2016, 278, 22-29.

9. T. Devic y C. Serre, Chem.Soc.Rev.,, 2014, 43, 6097-6115.

10. G. Ferey, C. Mellot-Draznieks, C. Serre, F. Millange, J. Dutour, S. Surble y I. Margiolaki, Science, 2005, 309, 2040-2042.

11. S. Kitagawa, R. Kitaura y S.-I. Noro, Angew. Chem., Int. Ed., 2004, 43, 23342237.

12. Y. F. Chen, R. Babarao, S. I. Sandler y J. W. Jiang, Langmuir, 2010, 26, 87438750.

13. S. H. Jhung, J.-H. Lee, J. W. Yoon, C. Serre, G. Férey y J.-S. Chang, Adv. Mater., 2007, 19, 121-124.

14. N. V. Maksimchuk, O. V. Zalomaeva, I. Y. Skobelev, K. A. Kovalenko, V. P. Fedin y O. A. Kholdeeva, Proc. R. Soc. A, 2012, 468, 2017-2034.

15. G. Férey, Chem. Soc. Rev., 2008, 37, 191-214.

16. O.I. Lebedev, F. Millange, C. Serre, G. Van Tendeloo y G. Ferey, Chem. Mater., 2005, 17, 6525-6527.

17. A. Demessence, P. Patricia Horcajada, C. Christian Serre, C. C. Boissière, D. Grosso, C. Sanchez y G. Férey, Chem. Commun., 2009, 14, 7149-7151.

18. N. V. Maksimchuk, K. A. Kovalenko, V. P. Fedin y O. A. Kholdeeva, Chem. Comm., 2012, 48, 6812-6814. 
19. A. Santiago-Portillo, S. Navalon, F. Cirujano, F. Llabrés i Xamena, M. Alvaro y H. Garcia, ACS Catal., 2015, 5, 3216-3224.

20. Y. K. Hwang, D.-Y. Hong, J.-S. Chang, H. Seo, M. Yoon, J. Kim, S. H. Jhung, C. Serre y G. Férey, Appl. Catal., A., 2009, 358, 249-253.

21. O. A. Kholdeeva, I. Y. Skobelev, I. D. Ivanchikova, K. A. Kovalenko, V. P. Fedin y A. B. Sorokin, Catal. Today, 2014, 238, 54-61.

22. I. Y. Skobelev, K. A. Kovalenko, V. P. Fedin, A. B. Sorokin y O. A. Kholdeeva, Kinet. Catal., 2013, 54, 607-614.

23. I. Y. Skobelev, A. B. Sorokin, K. A. Kovalenko, V. P. Fedin y O. A. Kholdeeva, J. Catal., 2013, 298, 61-69.

24. A. Gómez-Paricio, A. Santiago-Portillo, S. Navalón, P. Concepción, M. Alvaro y H. Garcia, Green Chem., 2016, 18, 508-515.

25. R. Guo, J. Bai, H. Zhang, Y. Xie y J. Li, Prog. Chem., 2016, 28, 232-243.

26. A. Dhakshinamoorthy, A. M. Asiri y H. Garcia, Chem. Eur. J., 2016, 22, $8012-$ 8024.

27. F. X. Llabrés i Xamena, O. Casanova, R. Galiasso Tailleur, H. Garcia y A. Corma, J. Catal., 2008, 255, 220-227.

28. I. Luz, A. León, M. Boronat, F. X. Llabrés i Xamena y A. Corma, Catal. Sci. Technol., 2013, 3, 371-379.

29. A. Dhakshinamoorthy, M. Alvaro y H. Garcia, Chem CatChem, 2010, 2, 14381443.

30. A. Dhakshinamoorthy, M. Alvaro, P. Horcajada, E. Gibson, M. Vishnuvarthan, A. Vimont, J.-M. Grenèche, C. Serre, M. Daturi y H. Garcia, ACS Catal., 2012, 2, 2060-2065.

31. F. Vermoortele, M. Vandichel, B. V. de Voorde, R. Ameloot, M. Waroquier, V. Van Speybroeck y D. E. De Vos, Angew. Chem. Int. Ed., 2012, 51, 4887-4890.

32. S. M. Cohen, Chem. Rev., 2012, 112, 970-1000.

33. K. K. Tanabe y S. M. Cohen, Chem. Soc. Rev., 2011, 40, 498-519.

34. M. Ranocchiari, Bokhoven, J.A.V., Phys. Chem. Chem. Phys., 2011, 13, 63886396.

35. C. Wang, Zheng, M., Lin, W., J. Phys. Chem. Lett., 2011, 2, 1701-1709.

36. J. Liu, L. Chen, H. Cui, J. Zhang, L. Zhang y C.-Y. Su, Chem. Soc. Rev., 2014, 43, 6011-6061. 
37. M. Lammert, S. Bernt, F. Vermoortele, D. E. De Vos y N. Stock, Inorg. Chem., 2013, 52, 8521-8528.

38. M. Saikia y L. Saikia, RSC Adv., 2016, 6, 15846-15853.

39. Y. Luan, Y. Qi, H. Gao, R. S. Andriamitantsoa, N. Zheng y G. Wang, J. Mater. Chem. A, 2015, 3, 17320-17331.

40. B. Li, K. Leng, Y. Zhang, J. J. Dynes, J. Wang, Y. Hu, D. Ma, Z. Shi, L. Zhu, D. Zhang, Y. Sun, M. Chrzanowski y S. Ma, J. Am. Chem. Soc., 2015, 137, 42434248 .

41. D. Wang y Z. Li, Catal. Sci. Technol., 2015, 5, 1623-1628.

42. Y. X. Zhou, Y. Z. Chen, Y. Hu, G. Huang, S. H. Yu y H. L. Jiang, Chem. Eur. $J ., 2014,20,14976-14980$.

43. Z. Hasan, J. W. Jun y S. H. Jhung, Chem. Eng. J., 2015, 278, 265-271.

44. Y. Jin, J. Shi, F. Zhang, Y. Zhong y W. Zhu, J. Mol. Catal. A.-Chem., 2014, 383384, 167-171.

45. Y. Zang, J. Shi, F. Zhang, Y. Zhong y W. Zhu, Catal. Sci. Technol., 2013, 3, 2044-2049.

46. M. Hartmann y M. Fischer, Micropor. Mesopor. Mater., 2012, 164, 38-43.

47. B. Li, Y. Zhang, D. Ma, L. Li, G. Li, G. Li, Z. Shi y S. Feng, Chem. Commun., 2012, 48, 6151-6153.

48. S. Bernt, V. Guillerm, C. Serre y N. Stock, Chem. Commun., 2011, 47, 28382840 .

49. D.-Y. Hong, Y. K. Hwang, C. Serre, G. Férey y J.-S. Chang, Adv. Funct. Mater., 2009, 19, 1537-1552.

50. A. Grirrane, A. Corma y H. Garcia, J. Catal., 2009, 264, 138-144.

51. S. Navalon, A. Dhakshinamoorthy, M. Alvaro y H. Garcia, Chemical Reviews, 114, 6179-6212.

52. C. Su, M. Acik, K. Takai, J. Lu, S.-J. Hao, Y. Zheng, P. Wu, Q. Bao, T. Enoki, Y. J. Chabal y K. P. Loh, Nat. Commun., 2012, 3, 2315.

53. P. Valvekens, F. Vermoortele y D. de Vos, Catal. Sci. Technol., 2013, 3, 14351445.

54. G. Akiyama, R. Matsuda, H. Sato, A. Hori, T. Takata y S. Kitagawa, Microporous Mesoporous Mater., 2012, 157, 89-93.

55. N. A. Milas, Chem. Rev., 1932, 10, 295-364. 
56. E. G. Janzen, Y. Kotake y H. Randall D., Free Radical Bio. Med., 1992, 12, 169173.

57. E. G. Janzen, R. D. Hinton y Y. Kotake, Tetrahedron Lett., 1992, 33, 1257-1260.

58. O. A. Kholdeeva, M. N. Timofeeva, G. M. Maksimov, R. I. Maksimovskaya, W. A. Neiwert y C. L. Hill, Inorg. Chem., 2005, 44, 666-672.

59. M. J. Burkitt y R. P. Mason, Proc. Natl. Acad. Sci. USA, 1991, 88, 8440-8444.

60. R. Martin, S. Navalon, J. J. Delgado, J. J. Calvino, M. Alvaro y H. Garcia, Chem. - Eur. J. , 2011, 17, 9494-9502.

61. A. Dhakshinamoorthy, S. Navalon, M. Alvaro y H. Garcia, ChemSusChem, 2012, 5, 46-64.

62. Y. Wang, Y. Xie, H. Sun, J. Xiao, H. Cao y S. Wang, ACS Appl. Mater. Interfaces, 2016, 8, 9710-9720. 
Influencia de los sustituyentes en el ligando del MIL-101(Cr) en la oxidación aeróbica de bencilamina a iminas. 


\section{Capítulo 6 \\ Influencia de los \\ sustituyentes en el ligando del MIL-101(Cr) en tres reacciones características \\ de ácidos de Lewis.}


Influencia de los sustituyentes en el ligando del MIL-101(Cr) en tres reacciones características de ácidos de Lewis 


\subsection{Introducción}

Como se ha venido comentando en capítulos anteriores y principalmente en el capítulo de introducción, como resultado del alto porcentaje de metal de transición que tiene frecuentemente una posición de coordinación intercambiable además de la alta porosidad y accesibilidad de los vacíos intracristalinos, los materiales reticulares metalorgánicos se han convertido en catalizadores heterogéneos preferentes para llevar a cabo reacciones en fase líquida. ${ }^{1-3}$ Aunque los centros activos pueden estar localizados en los ligandos o bien hospedados en los espacios vacíos de los MOFs, ${ }^{4}$ el caso más frecuente en el uso de MOFs como catalizadores heterogéneos es el de los nodos metálicos actuando como ácidos de Lewis. ${ }^{2,5-7}$

En un estudio pionero, de Vos y colaboradores demostraron para el material UiO66 que la actividad catalítica del mismo podría ser modulada y aumentarse por sustitución en el anillo aromático del ligando tereftalato. ${ }^{5}$ Se demostró que la habilidad de los sustituyentes de donar o aceptar electrones al anillo aromático influye en la densidad electrónica de los nodos metálicos a través de efectos inductivos y de esta manera en la actividad de estos centros como ácido de Lewis. ${ }^{5}$ Considerando el interés de los MOFs como catalizadores sólidos, parece necesario expandir el estudio inicial a otros MOFs, particularmente a aquellos que han exhibido una mayor estabilidad y actividad, a fin de determinar en qué medida y para que tipos de reacción esta metodología basada en el uso de ligando tereftalatos sustituidos puede ser útil en catálisis. ${ }^{2}$

En este contexto, en este capítulo se ha seleccionado el material MIL-101(Cr) y se procederá a estudiar la influencia de la presencia de sustituyentes en el ligando tereftalato para 3 tipos diferentes de reacciones orgánicas catalizadas por ácidos de Lewis. El material MIL-101 está constituido por nodos $\mathrm{Cr}_{3}-\mu_{3} \mathrm{O}$ donde 3 iones $\mathrm{Cr}^{3+}$ se encuentran unidos a un oxígeno central y coordinados octaédricamente con dos grupos tereftálicos siendo la sexta posición ocupada bien por un anión de compensación en un tercio de los casos o bien por una molécula de disolvente. Estas unidades $\mathrm{Cr}_{3}-\mu_{3} \mathrm{O}$ actúan como nodos conectados a 6 ligandos tereftalato. ${ }^{8-10}$ La estructura de MIL-101(Cr) se ilustra en la figura 6.1 los nodos y los ligandos definen una unidad denominada supertetraedro cuya ordenación espacial da lugar a dos tipos de cavidades de 1.6 y $1.2 \mathrm{~nm} .{ }^{10} \mathrm{La}$ primera de las cuales se accede a partir de aperturas hexagonales $(0.86 \mathrm{~nm})$ mientras que en el segundo caso las aberturas son pentagonales de una menor dimensión $(0.55 \mathrm{~nm}) .{ }^{10}$ 


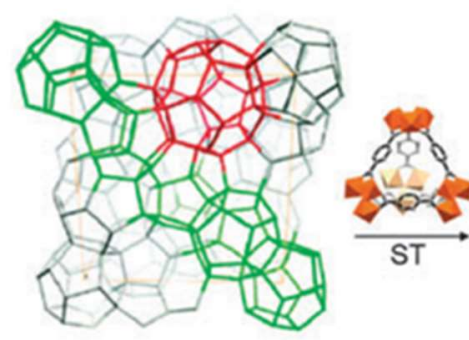

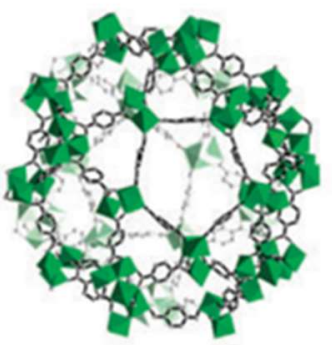

$(\varnothing \sim 29 \AA, 12 \AA)$

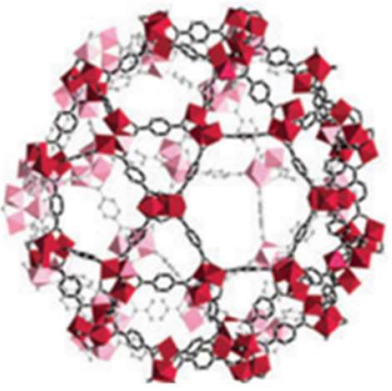

$(\varnothing \sim 34 \AA, 16 \AA)$

Figura 6.1. Estructura de MIL-101 mostrando que está constituida por cajas más pequeñas (verdes) y más grandes(rojo) constituidas por supertetraedros (ST). Izquierda: estructura formada por la unión de los dos tipos de cajas, pequeñas y grandes. Derecha: estructura de los dos tipos de cajas y de la cavidad que contienen de forma aislada.

El material MIL-101 posee una elevada área superficial y un volumen de poro también elevado de $2700 \mathrm{~m}^{2} \mathrm{~g}^{-1}$ y $2.1 \mathrm{~cm}^{3} \mathrm{~g}^{-1}$, respectivamente. ${ }^{9}, 10$ Una de las características más importantes del material MIL-101 es la reproducibilidad en el procedimiento de preparación y la alta cristalinidad de las muestras que se obtienen. ${ }^{9,10}$ Esta situación contrasta con la del material UiO-66, que fue el material inicial para el cual se describió la influencia de los sustituyentes. ${ }^{11,12}$ Es conocido que el material UiO-66 puede presentar una elevada proporción de defectos en su estructura, dependiendo del protocolo de síntesis empleado. La presencia de defectos que impliquen iones metálicos con posiciones de coordinación insaturadas se solaparía con la posible influencia de sustituyentes sobre el anillo aromático al determinar la actividad catalítica de estos materiales defectuosos. Este hecho hace difícil determinar la influencia exacta de la sustitución en el ligando tereftálico sobre la actividad catalítica. ${ }^{12}$ En contraste, seleccionando el material MIL101 , el cual es conocido que posee menos defectos estructurales, es posible confirmar de una forma más segura la importancia que lo efectos inductivos de los sustituyentes ejercen sobre la fuerza ácida de los nodos metálicos. ${ }^{9,13}$ Además, el material MIL-101(Cr) posee una alta estabilidad estructural frente a los agentes físicos y químicos, lo que hace que este sólido se encuentre entre los MOFs más robustos y estables, lo cual es un requisito para su uso como catalizadores heterogéneos. , $^{3,14,15}$ 


\subsection{Resultados y discusión}

En el presente capítulo se prepararon 6 materiales MIL-101 $(\mathrm{Cr})-\mathrm{X}(\mathrm{X}=\mathrm{H}, \mathrm{Cl}$, $\mathrm{SO}_{3} \mathrm{H}, \mathrm{NO}_{2}, \mathrm{CH}_{3}$ y $\mathrm{NH}_{2}$ ) que poseen diferentes sustituyentes sobre el ligando tereftálico. La preparación de cada una de las muestras empleadas en el estudio se resume en el capítulo 8 (parte experimental). El esquema 6.1 ilustra el procedimiento seguido para la preparación de cada una de estas muestras y el capítulo 8 contiene las cantidades de cada uno de los reactivos, las temperaturas de reacción y los tiempos de tratamiento hidrotermal empleados en la preparación de cada uno de los materiales. Cuatro de estos materiales incluyendo el material sin sustituir MIL-101(Cr)-H, se obtuvieron directamente por reacción de sales de $\mathrm{Cr}$ (III) con los tereftalatos correspondientes en condiciones de síntesis hidrotermal, siguiendo recetas disponibles en la bibliográfica. ${ }^{9}{ }^{16-18} \mathrm{El}$ material MIL-101(Cr)-SO ${ }_{3} \mathrm{H}$ se obtuvo por reacción del sólido MIL-101(Cr)- $\mathrm{H}$ con $\mathrm{HSO}_{3} \mathrm{Cl}_{1}{ }^{18}$ y el material MIL-101(Cr)- $\mathrm{NH}_{2}$ se preparó por reducción química de los grupos nitro del MIL-101(Cr)- $\mathrm{NO}_{2}$ con $\mathrm{SnCl}_{2}$ como agente reductor en medio ácido. ${ }^{16} \mathrm{La}$ serie de materiales MIL-101(Cr)-X usada en el presente estudio ha sido descrita previamente en la literatura y también en el capítulo anterior. ${ }^{9,16-18}$ Tal como se ha indicado en el capítulo precedente, los modelos de difracción de rayos $\mathrm{X}$ en polvo para las muestras son muy similares, indicando que todos estos materiales son isoestructurales. Los valores de área específica obtenidos por medidas de adsorción isoterma de nitrógeno son también los indicados en el capítulo anterior. Tal como se ha comentado, el área BET del material MIL-101(Cr)-H es la mayor de entre toda la serie y esta área disminuye como consecuencia de la presencia de sustituyentes. 
<smiles>[X]c1cc(C(=O)O)ccc1C(=O)O</smiles>

\section{$\Delta$ $\underset{\mathrm{H}_{2} \mathrm{O}}{\longrightarrow} \mathrm{MlL}-101(\mathrm{Cr})-\mathrm{X}$ \\ $\mathrm{X}: \mathrm{H}, \mathrm{NO}_{2}, \mathrm{Cl}, \mathrm{CH}_{3}$}

$$
\mathrm{MIL}-101(\mathrm{Cr})-\mathrm{NO}_{2} \frac{\mathrm{SnCl}_{2} \cdot \mathrm{HCl}}{\Delta, \mathrm{EtOH}} \mathrm{MIL}-101(\mathrm{Cr})-\mathrm{NH}_{2}
$$

$$
\mathrm{MIL}-101(\mathrm{Cr})-\mathrm{H} \stackrel{\mathrm{HSO}_{3} \mathrm{Cl}}{\longrightarrow} \mathrm{MIL}-101(\mathrm{Cr})-\mathrm{SO}_{3} \mathrm{H}
$$

Esquema 6.1. Preparación de los materiales MIL-101(Cr)-X (X $=\mathrm{H}, \mathrm{NO}_{2}, \mathrm{Cl}, \mathrm{CH}_{3}, \mathrm{NH}_{2}$ y SO $\left.3 \mathrm{H}\right)$.

La naturaleza del sustituyente se determina mediante espectroscopía de infrarrojo donde se registraron las vibraciones especificas esperadas para cada uno de los mismos. Estos espectros de infrarrojo se han mostrado en el capítulo precedente. Los resultados del análisis termogravimétrico en aire de los materiales MIL-101(Cr)-X están de acuerdo con su alta estabilidad, no observándose descomposición alguna hasta temperaturas en torno a $300^{\circ} \mathrm{C}$. Se determinó la relación esperada entre el contenido de $\mathrm{Cr}$ teórico, según la formula estructural para cada uno de los materiales MIL-101(Cr)-X, y los valores experimentales. En el caso de MIL-101(Cr)-Cl se observó un contenido en metal ligeramente más alto $(1.5 \%)$ respecto al valor teórico esperable, lo que indicaría de algún óxido de $\mathrm{Cr}$ en el interior de las cavidades del material. Este hecho estaría de acuerdo con su menor área superficial respecto a los otros materiales MIL-101(Cr)-X con otros sustituyentes. De esta manera, la menor área superficial del material MIL-101(Cr)-Cl podría ser bien debido a la presencia de óxidos de cromo o bien a la presencia de ácido tereftálico libre en el interior de las cavidades. 
El propósito del estudio del presente capítulo es establecer la influencia de la naturaleza de los sustituyentes sobre el ligando en el material MIL-101(Cr)-X para 3 reacciones diferentes catalizadas por ácido (Esquema 6.2). Con este propósito, se llevó a cabo la reacción de apertura de epóxido por metanol (Figura 6.2), la reacción de acetalización de benzaldehído por metanol (Figura 6.3) y la reacción de Prins de acoplamiento del $\beta$-pineno y formaldehido (Figura 6.4) en presencia de los materiales MIL-101(Cr)-X como catalizadores heterogéneos.

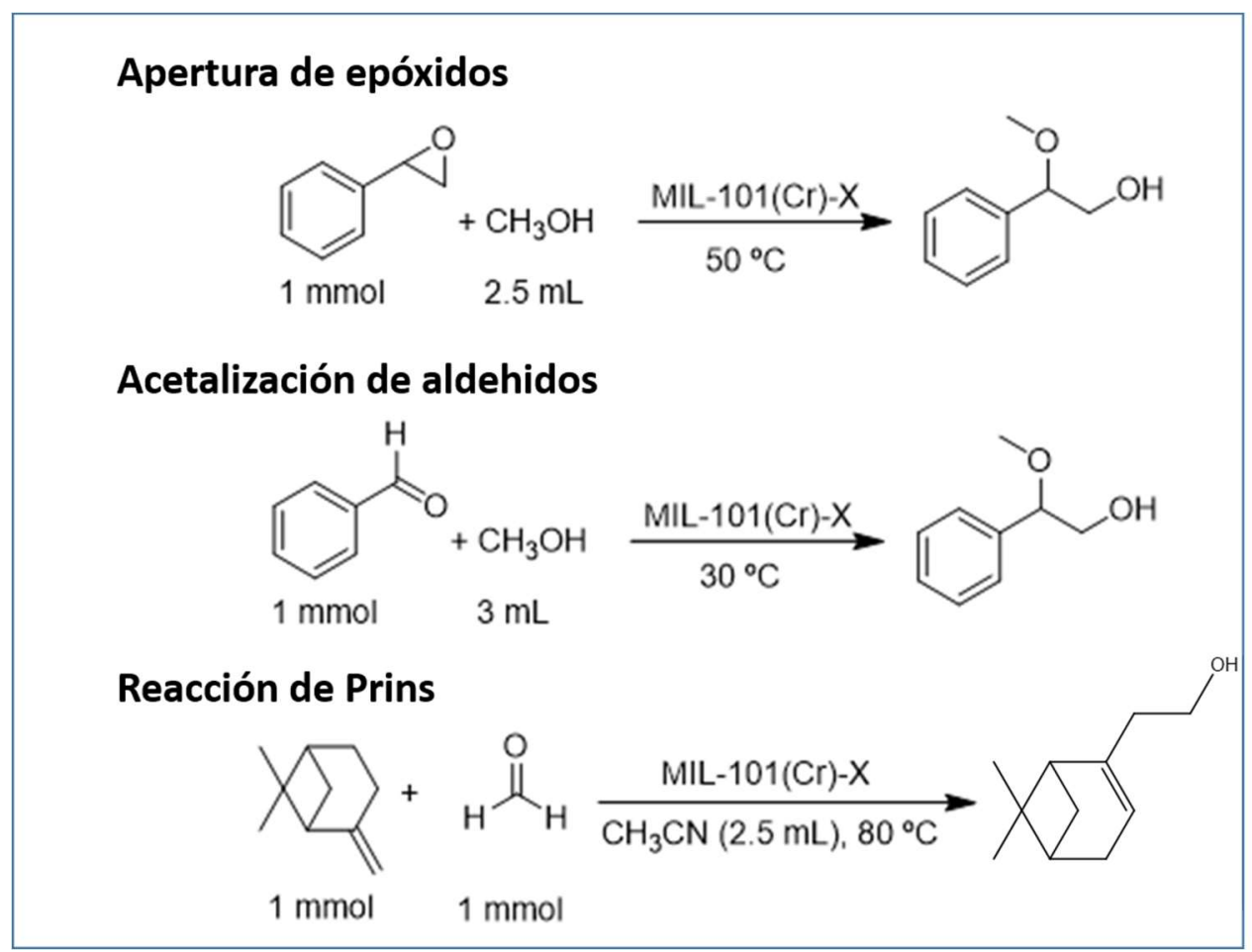

Esquema 6.2. Tres reacciones catalizadas por ácido que son el objeto de estudio en el presente capítulo usando los materiales MIL-101(Cr)-X como catalizadores heterogéneos. Se observó que los tres tipos de reacciones siguen el mismo orden relativo de actividad para el conjunto de catalizadores, siendo la muestra MIL-101(Cr)-NO $\mathrm{NO}_{2}$ la más activa que el resto de muestras. 

ácidos de Lewis
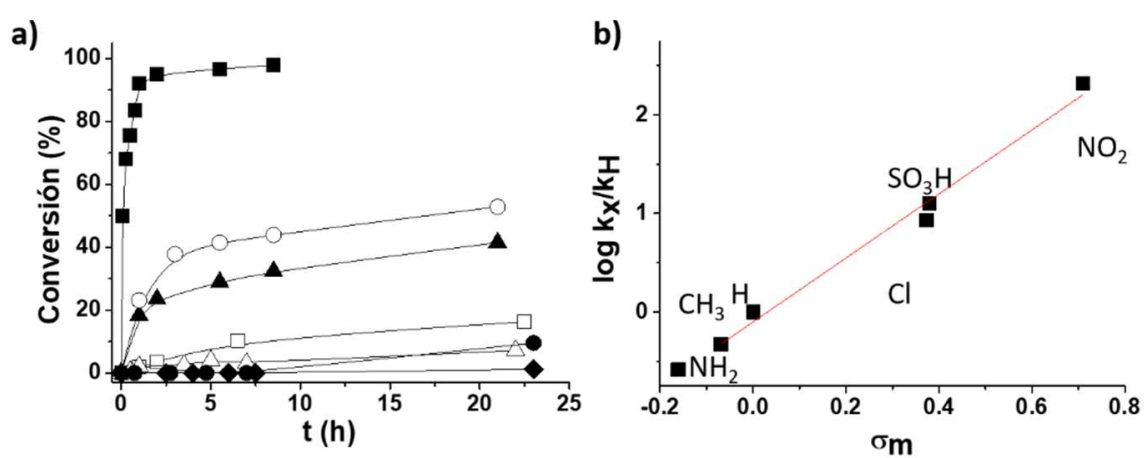

Figura 6.2. a) Gráfico de conversión frente a tiempo para la apertura de anillo del óxido de estireno por metanol catalizada por MIL-101(Cr)-X. Leyenda: MIL-101(Cr)-H (口), MIL-101(Cr)-NO 2 (ם), MIL$101(\mathrm{Cr})-\mathrm{SO}_{3} \mathrm{H}(\circ), \mathrm{MIL}-101(\mathrm{Cr})-\mathrm{Cl}(\boldsymbol{\Delta}), \mathrm{MIL}-101(\mathrm{Cr})-\mathrm{CH}_{3}(\Delta), \mathrm{MIL}-101(\mathrm{Cr})-\mathrm{NH}_{2}(\bullet)$ y experimento en blanco sin catalizador $(\diamond)$. b) Gráfico del logaritmo de las velocidades iniciales de reacción relativas frente a la constante de Hammett $\sigma_{\mathrm{m}}$ de cada sustituyente presente en el anillo de tereftálico. Condiciones de reacción: Catalizador (12 mg de MIL-101(Cr)- $\mathrm{NO}_{2}$ lo que equivale a $0.04 \mathrm{mmol}$ de $\mathrm{Cr}$ ), óxido de estireno ( $1 \mathrm{mmol}), 2.5 \mathrm{~mL}$ metanol, $50{ }^{\circ} \mathrm{C}$.

a)

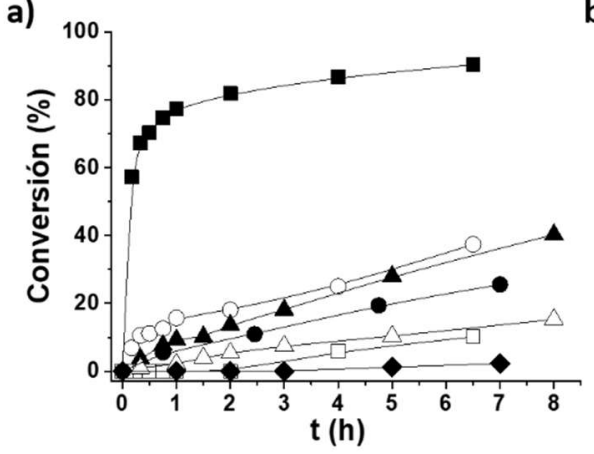

b)

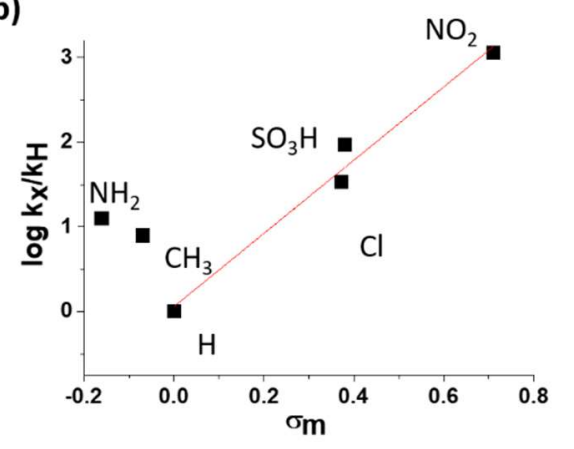

Figura 6.3. a) Gráfico de conversión frente a tiempo para la reacción de acetalización de benzaldehido por metanol catalizada por los materiales MIL-101(Cr)-X. Leyenda: MIL-101(Cr)-H (口), MIL$101(\mathrm{Cr})-\mathrm{NO}_{2}(\boldsymbol{\bullet}), \mathrm{MIL}-101(\mathrm{Cr})-\mathrm{SO}_{3} \mathrm{H}(\circ), \mathrm{MIL}-101(\mathrm{Cr})-\mathrm{Cl}(\boldsymbol{\Delta}), \mathrm{MIL}-101(\mathrm{Cr})-\mathrm{CH}_{3}(\Delta)$, MIL$101(\mathrm{Cr})-\mathrm{NH}_{2}(\bullet)$ y experimento en blanco sin catalizador $(\bullet)$. b) Gráfico del logaritmo de las velocidades iniciales de reacción relativas frente a la constante de Hammett $\sigma_{\mathrm{m}}$ de cada sustituyente presente en el anillo de tereftálico. Condiciones de reacción: Catalizador (12 mg de MIL-101(Cr)- $\mathrm{NO}_{2}$ lo que equivale a $0.04 \mathrm{mmol}$ de $\mathrm{Cr}$ ), benzaldehido $(1 \mathrm{mmol}), 3 \mathrm{~mL}$ metanol, $30^{\circ} \mathrm{C}$. 
a)

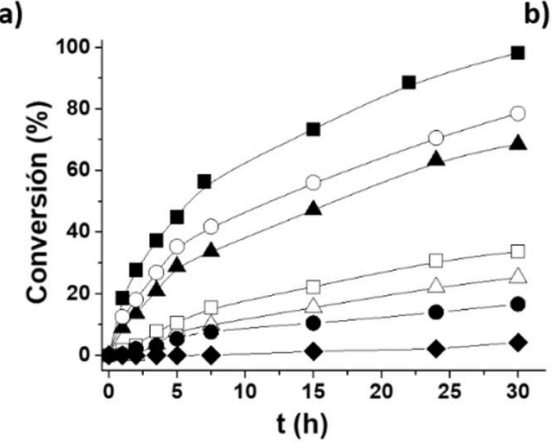

b)

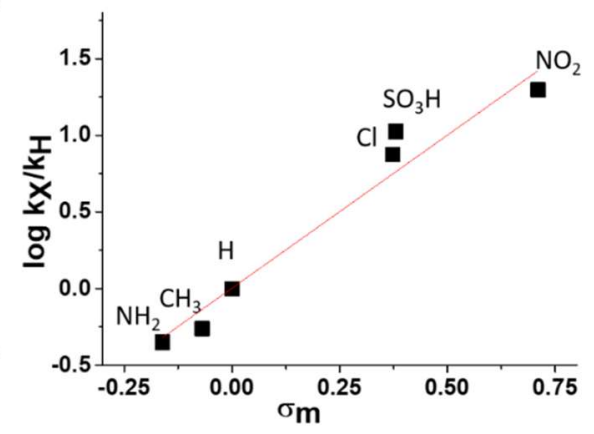

Figura 6.4. a) Gráfico de conversión frente a tiempo para la reacción de Prins de acoplamiento del $\beta$ pineno con formaldehido catalizada por los materiales MIL-101(Cr)-X. Leyenda: MIL-101(Cr)-H ( $\square$ ),

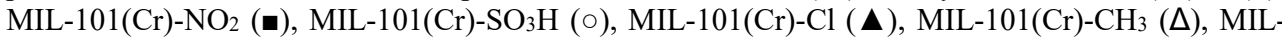
$101(\mathrm{Cr})-\mathrm{NH}_{2}(\bullet)$ y experimento en blanco sin catalizador $(\bullet)$. b) Gráfico del logaritmo de las velocidades iniciales de reacción relativas frente a la constante de Hammett $\sigma_{\mathrm{m}}$ de cada sustituyente presente en el anillo de tereftálico. Condiciones de reacción: Catalizador (24 mg de MIL-101(Cr)- $\mathrm{NO}_{2}$ lo que equivale a $0.08 \mathrm{mmol} \mathrm{de} \mathrm{Cr}), \beta$-pineno $(1 \mathrm{mmol})$, formaldehido $(1 \mathrm{mmol}), 2.5 \mathrm{~mL}$ acetonitrilo, $80^{\circ} \mathrm{C}$.

Previamente, ${ }^{5}$ se seleccionó la constante de Hammett para sustituyentes en posición meta del anillo aromático, $\sigma_{\mathrm{m}}$, como el parámetro más adecuado para correlacionar la velocidad de reacción inicial relativa con el sustituyente, puesto que de esta manera se obtiene una mejor linealidad. Por consiguiente, al igual que en el capítulo anterior, también en el presente estudio se seleccionó $\sigma_{\mathrm{m}}$ para establecer la correlación entre actividad y sustituyentes. La apertura del anillo de epóxido (Figura 6.2) y la reacción de acoplamiento de Prins (Figura 6.4) siguen una relación con una buena linealidad entre la actividad catalítica del material y la constante de Hammett $\sigma_{\mathrm{m}}$, mientras que en el caso de acetalización de benzaldehído, los materiales MIL-101(Cr)-X con sustituyentes electrón dadores $\left(\mathrm{CH}_{3}\right.$ y NH $\left.\mathrm{NH}_{2}\right)$ exhiben una actividad catalítica más elevada de lo esperable de acuerdo con los valores de $\sigma_{\mathrm{m}}$ (Figura 6.3).

En el caso de la apertura del anillo de epóxido, la velocidad de reacción inicial cambia 4 órdenes de magnitud desde el sustituyente $-\mathrm{NH}_{2}$, el catalizador menos activo; $\left.\mathrm{r}_{0} 0.00058 \mathrm{mmol} \mathrm{h}^{-1}\right)$ al del grupo $-\mathrm{NO}_{2}$ como sustituyentes $\left(\mathrm{r}_{0} 5.49 \mathrm{mmol} \mathrm{h}^{-1}\right)$, y la actividad catalítica del material conteniendo el grupo nitro es más de 300 veces mayor que la actividad de la muestra MIL-101(Cr)-H donde los grupos tereftalato no están sustitui$\operatorname{dos}\left(\mathrm{r}_{0} 0.018 \mathrm{mmol} \mathrm{h}^{-1}\right)$. Aunque una tendencia similar se observa también en la reacción de Prins, en este caso la influencia de los sustituyentes no es tan notable. Así, la velocidad de reacción inicial relativa aumente desde el catalizador con grupos - $\mathrm{NH}_{2}\left(\mathrm{r}_{0} 0.00078\right.$ mmol h$\left.{ }^{-1}\right)$ al del grupo $-\mathrm{NO}_{2}\left(\mathrm{r}_{0} 0.116 \mathrm{mmol} \mathrm{h}^{-1}\right)$ por un factor de 200 veces y el sólido funcionalizado con grupos $-\mathrm{NO}_{2}$ es aproximadamente 8 veces más activo que el material sin sustituir MIL-101(Cr)-H ( $\left.\mathrm{r}_{0} 0.021 \mathrm{mmol} \mathrm{h}^{-1}\right)$. 
Influencia de los sustituyentes en el ligando del MIL-101(Cr) en tres reacciones características de ácidos de Lewis

A fin de poner estos valores en contexto, particularmente en el caso de UiO-66-X substituidos descritos anteriormente, la actividad catalítica para la ciclación del citronela se aumentó por un factor de 56.

En el caso de la acetalización del benzaldehído, se consiguió aumentar la actividad catalítica del material mediante la introducción de grupos nitro hasta 3 órdenes de magnitud (3.105 $\left.\mathrm{mmol} \mathrm{h}^{-1}\right)$ con respecto al MOF sin sustituir MIL-101(Cr)-H (0.0113 mmol $\mathrm{h}^{-1}$ ), aunque, como se ha comentado anteriormente, el material sustituido por grupos $\mathrm{NH}_{2}$ fue más eficiente (aproximadamente 2 órdenes de magnitud) de lo esperado si solo se tiene en cuenta los valores de la constante de Hammett $\sigma_{\mathrm{m}}$. Como en las dos reacciones previas, se observó una buena linealidad y parece improbable que esta desviación de la linealidad en el caso de la presencia de grupos $\mathrm{NH}_{2}$ pueda ser debida a defectos en la estructura del MOF o a algún otro factor estructural que no sea directamente la presencia de grupos amino. ${ }^{5,7}$ Además de centros metálicos con densidad electrónica que pueden ser influidos por los ligandos tereftalatos, se sugiere que la actividad del material MIL$101(\mathrm{Cr})-\mathrm{NH}_{2}$ mayor de la esperada debe reflejar la existencia de un mecanismo alternativo de reacción en el cual los grupos amino juegan también un papel activo y probablemente interaccionan con el grupo carbonilo del benzaldehído, abriendo nuevos caminos para la acetalización, que probablemente implican una amina. ${ }^{7,19}$ También es posible que otros factores tales como la capacidad de adsorción puedan contribuir a la desviación de la linealidad que se observa.

A fin de correlacionar la actividad catalítica observada con la acidez de Lewis de la muestra, se llevaron a cabo medidas de adsorción de CO mediante espectroscopia IR para llevar a cabo la valoración de la acidez Lewis (Figura 6.5). ${ }^{20}$ 


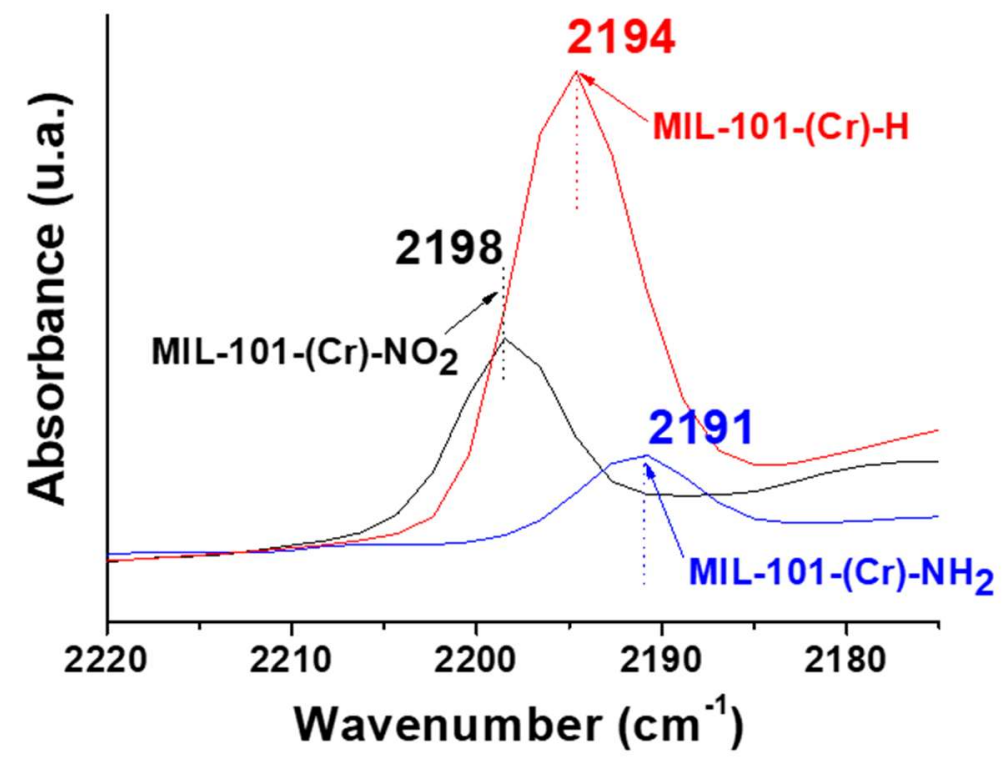

Figura 6.5. Espectros de IR para el CO adsorbido a 6 mbar y $-176{ }^{\circ} \mathrm{C}$ sobre $\mathrm{MIL}-101(\mathrm{Cr})-\mathrm{NO}_{2}$, MIL101(Cr)-NH2, MIL-101(Cr)-H.

Los espectros de IR de CO adsorbido sobre MIL-101(Cr)-NO $\mathrm{NO}_{2}$, MIL-101(Cr)-NH $\mathrm{NH}_{2}$ MIL-101(Cr)-H se muestran en la figura 6.5, observándose un desplazamiento en el valor de la frecuencia $v(\mathrm{CO})$ que aparece a $v=2198 \mathrm{~cm}^{-1}$ para el catalizador más activo, MIL$101(\mathrm{Cr})-\mathrm{NO}_{2}, v=2194 \mathrm{~cm}^{-1}$ para la muestra del material MIL-101(Cr)-H y $v=2191 \mathrm{~cm}^{-}$ ${ }^{1}$ para la muestra menos activa de MIL-101(Cr)- $\mathrm{NH}_{2}$. Los valores de frecuencia de $\mathrm{CO}$ observados para estas muestras son causados por la interacción de $\mathrm{CO}$ con iones $\mathrm{Cr}^{3+},{ }^{21}$ y un desplazamiento a valores de frecuencia más altos corresponden a una mayor acidez de Lewis de los iones $\mathrm{Cr}^{3+}$. De acuerdo con estas medidas, se puede establecer una escala cuantitativa de acidez Lewis para las muestras que sigue el orden: MIL-101(Cr)- $\mathrm{NO}_{2}>$ MIL-101(Cr)-H > MIL-101(Cr)- $\mathrm{NH}_{2}$ lo cual se correlaciona con la actividad catalítica de las muestras.

La mayor actividad catalítica de la muestra MIL-101(Cr)- $\mathrm{NO}_{2}$ con respecto a MIL$101(\mathrm{Cr})-\mathrm{NH}_{2}$ es atribuida principalmente a los efectos inductivos, los cuales aumentarían la acidez Lewis del material sólido a medida que el efecto inductivo del sustituyente en el anillo aromático aumenta.

El MIL-101(Cr)- $\mathrm{NH}_{2}$ fue obtenido por reducción química de MIL-101(Cr)-NO $\mathrm{NO}_{2}$. Esta reacción química no altera aparentemente la morfología de las partículas de MOF y 
Influencia de los sustituyentes en el ligando del MIL-101(Cr) en tres reacciones características de ácidos de Lewis

las imágenes de SEM revelan que la forma y distribución de tamaño de partículas son casi coincidentes para los materiales MIL-101(Cr)-NH $\mathrm{NH}_{2}$ y ML-101(Cr)- $\mathrm{NO}_{2}$ (Figura 6.6). Estos datos de caracterización apoyan que el aumento en la actividad catalítica de los materiales MIL-101(Cr)-X evaluados en este trabajo para estas 3 reacciones de catálisis acida pueden ser atribuidos a la mayor acidez Lewis inducida por la presencia de grupos electrón aceptores.
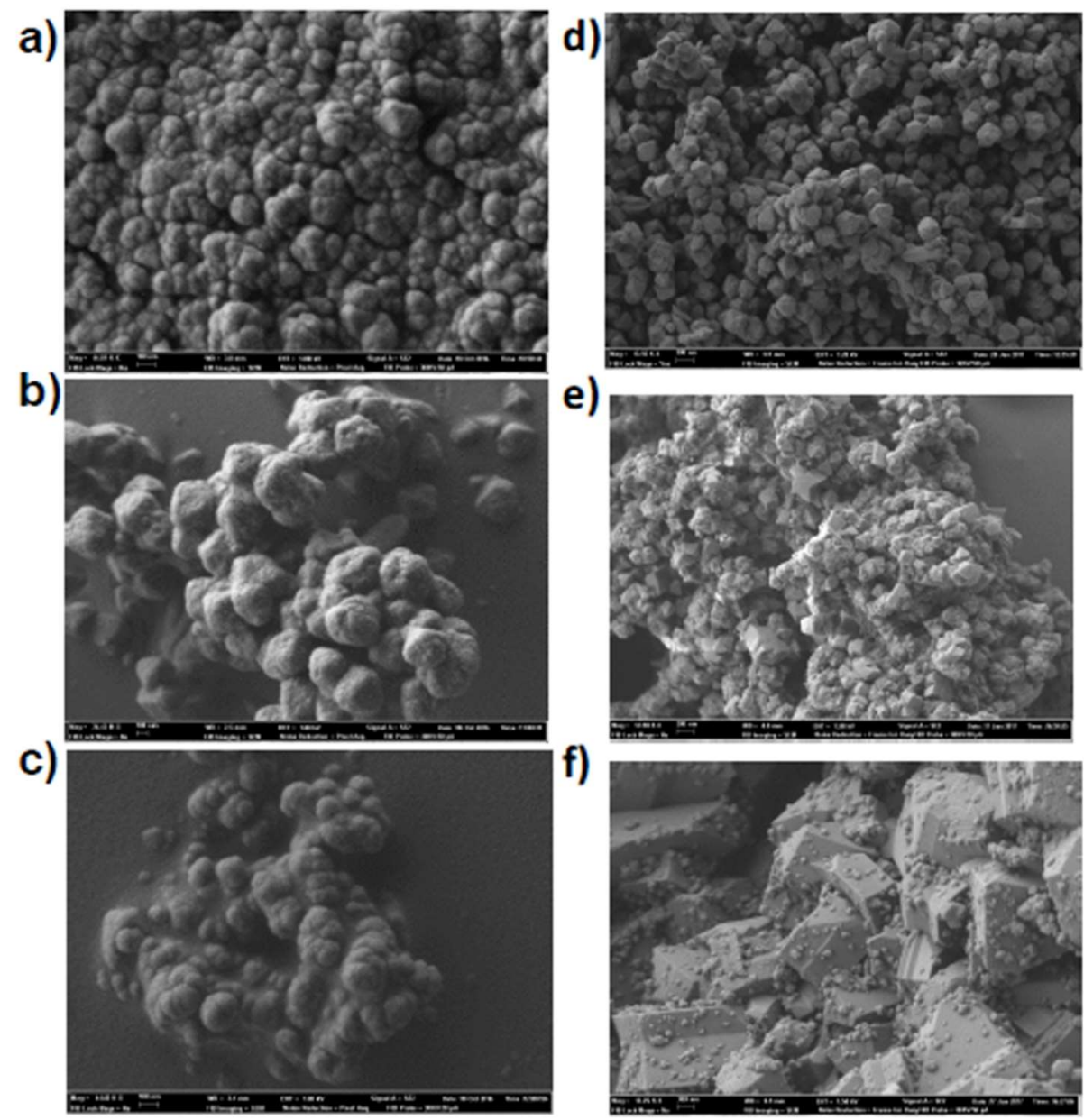

Figura 6.6. Imágenes representativas de SEM de los materiales MIL-101(Cr)-NO $\mathrm{NO}_{2}$ (a), MIL-101(Cr)$\mathrm{H}$ (b), MIL-101(Cr)-NH $\mathrm{NH}_{2}$ (c), MIL-101(Cr)-SO $3 \mathrm{H}(\mathrm{d}), \mathrm{MIL}-101(\mathrm{Cr})-\mathrm{Cl}(\mathrm{e})$ y MIL-101(Cr)-CH $(\mathrm{f})$. Escala: $300 \mathrm{~nm}$. 
La ausencia de lixiviado de especies metálicas y el hecho de que la catálisis sea verdaderamente heterogénea se demostró para la muestra MIL-101(Cr)- $\mathrm{NO}_{2}$ mediante análisis químico de la fase líquida tras la reacción y mediante los tests de filtración en caliente (Figuras 6.7-6.9). Los análisis químicos mostraron que la cantidad de $\mathrm{Cr}$ al final de las reacciones en la disolución eran menores que el $0.5 \%$ de la cantidad total de $\mathrm{Cr}$ presente en el catalizador sólido. Experimentos de control bajo las mismas condiciones usando la cantidad de $\mathrm{Cr}$ determinada por análisis químico no presentan actividad para las reacciones en las condiciones de reacción empleadas en el estudio (Figura 6.10). En el caso del ensayo de filtración en caliente, el catalizador sólido se elimina a la temperatura de reacción una vez que la reacción se ha iniciado y la conversión alcanza aproximadamente el $50 \%$, observándose que las reacciones se detienen una vez que el catalizador sólido se elimina del medio de reacción (Figuras 6.7-6.9)

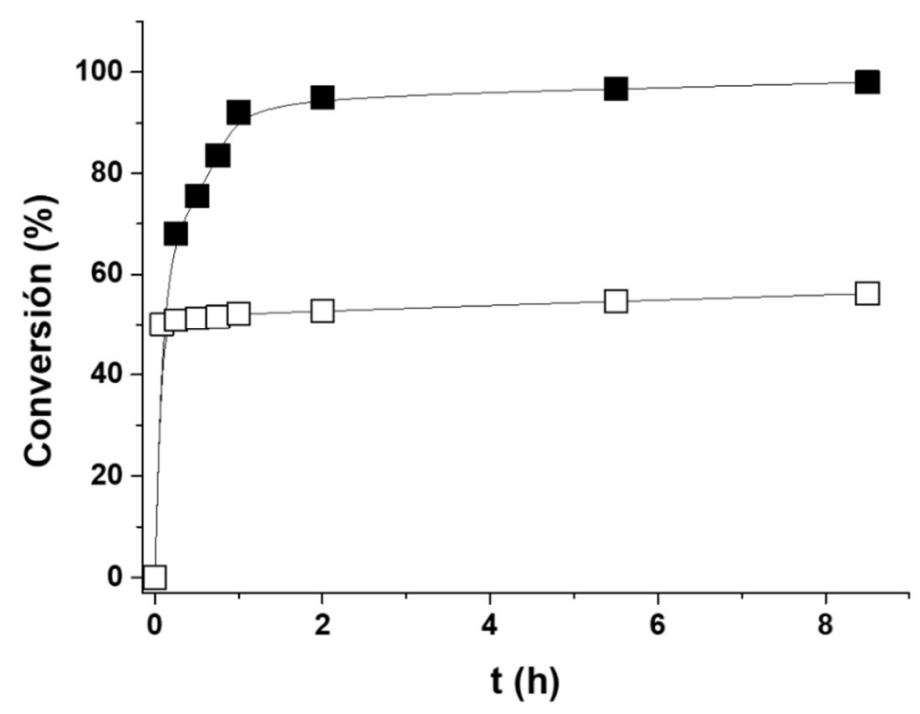

Figura 6.7. Gráfico de conversión frente a tiempo para la apertura del anillo del óxido de estireno con metanol usando MIL-101(Cr)- $\mathrm{NO}_{2}$ como catalizador, el cual es filtrado a los $30 \mathrm{~min}$ ( $\square$ ) o permanece en contacto con el sustrato durante todo el tiempo de reacción ( $\mathbf{a})$. Condiciones de reacción: Catalizador $\left(12 \mathrm{mg}\right.$ de MIL-101(Cr)- $\mathrm{NO}_{2}$ lo que equivale a $0.04 \mathrm{mmol}$ de $\mathrm{Cr}$ ), óxido de estireno $(1 \mathrm{mmol}), 2.5 \mathrm{~mL}$ metanol, $50{ }^{\circ} \mathrm{C}$. 
Influencia de los sustituyentes en el ligando del MIL-101(Cr) en tres reacciones características de ácidos de Lewis

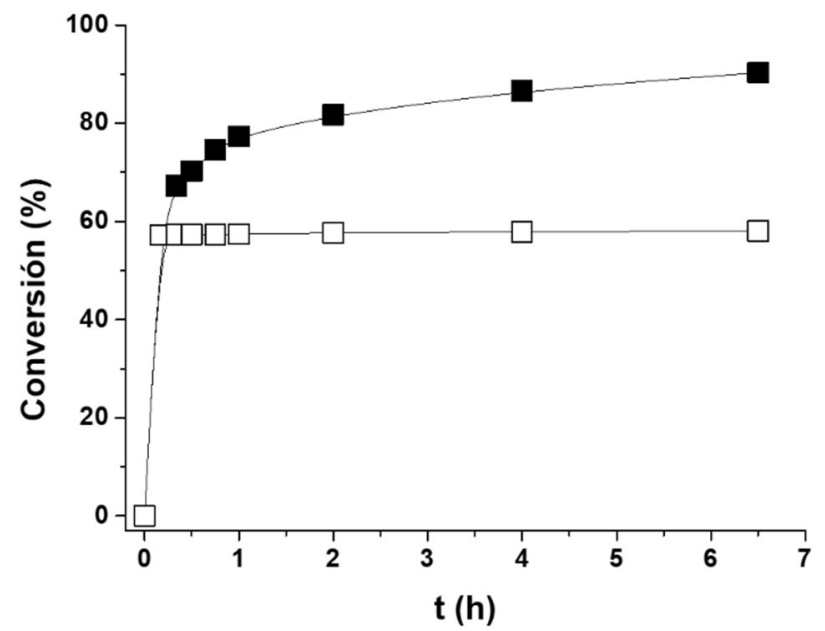

Figura 6.8. Gráfico de conversión frente a tiempo para la acetalización de benzaldehido con metanol usando MIL-101(Cr)-NO $\mathrm{NO}_{2}$ como catalizador, el cual es filtrado a los $30 \mathrm{~min}$ ( $\square$ ) o permanece en contacto con el sustrato durante todo el tiempo de reacción ( $\mathbf{(})$. Condiciones de reacción: Catalizador (12 $\mathrm{mg}$ de MIL-101(Cr)- $\mathrm{NO}_{2}$ lo que equivale a $0.04 \mathrm{mmol}$ de $\left.\mathrm{Cr}\right)$, benzaldehido $(1 \mathrm{mmol}), 3 \mathrm{~mL}$ metanol, $30^{\circ} \mathrm{C}$.

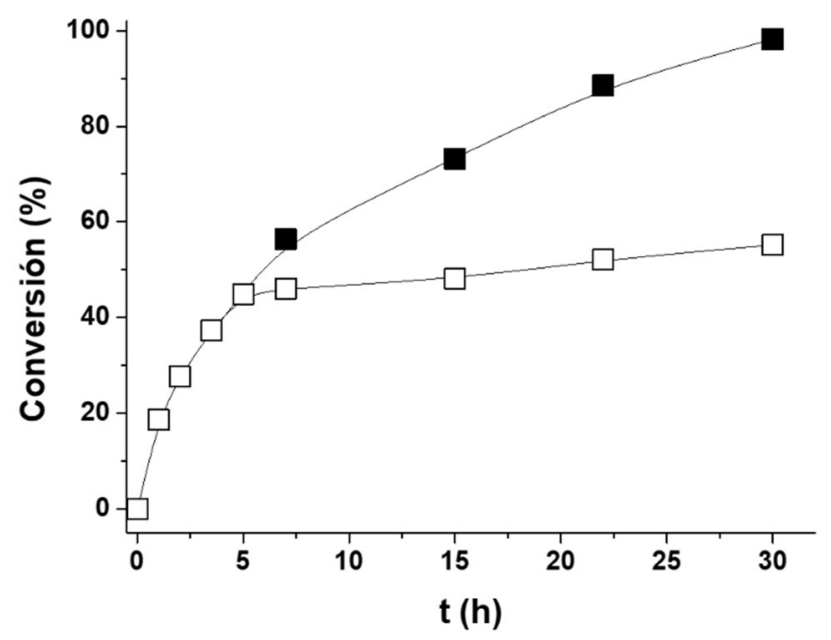

Figura 6.9. Gráfico de conversión frente a tiempo para la reacción de acoplamiento de Prins de $\beta$ pineno usando MIL-101(Cr)- $\mathrm{NO}_{2}$ como catalizador, el cual es filtrado a las $6 \mathrm{~h}(\square)$ o permanece en contacto con el sustrato durante todo el tiempo de reacción ( $\mathbf{})$. Condiciones de reacción: Catalizador (24 mg de MIL-101(Cr)- $\mathrm{NO}_{2}$ lo que equivale a $0.08 \mathrm{mmol}$ de $\mathrm{Cr}$ ), $\beta$-pineno $(1 \mathrm{mmol})$, formaldehido (1 mmol), $2.5 \mathrm{~mL}$ acetonitrilo, $80^{\circ} \mathrm{C}$. 
a)

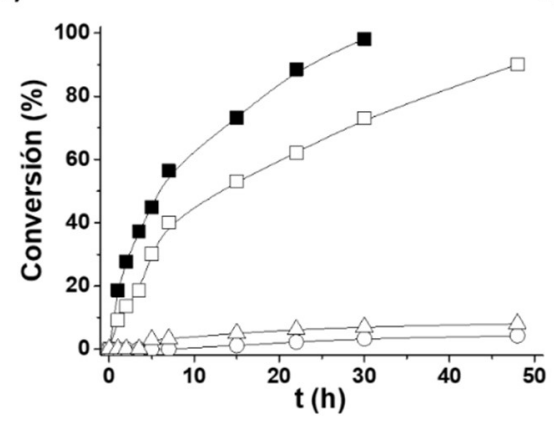

b)

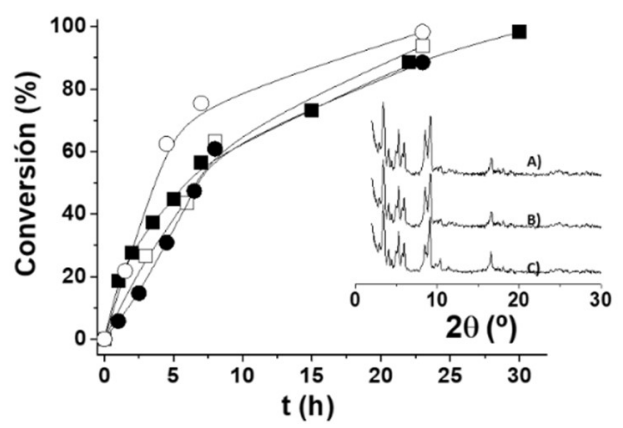

Figura 6.10. a) Gráfico de conversión frente a tiempo para el acoplamiento de Prins del betapineno catalizada por MIL-101(Cr)-NO $\mathrm{NO}_{2}$ acetato de Cr. Leyenda: MIL-101(Cr)-NO $\mathrm{NO}_{2}(\boldsymbol{\bullet})$, acetato de cromo en la misma cantidad de $\mathrm{Cr}$ que MIL-101(Cr)-NO $\mathrm{NO}_{2}(\square)$, acetato de cromo en la misma cantidad de $\mathrm{Cr}$ lixiviado del material MIL-101(Cr)- $-\mathrm{NO}_{2}(\mathrm{O})$ y acetato de cromo al doble de la cantidad que lixivia de la muestra de MIL-101(Cr)- $\mathrm{NO}_{2}(\Delta)$. Condiciones de reacción: Catalizador (24 mg de MIL-101(Cr)$\mathrm{NO}_{2}$ lo que equivale a $\left.0.08 \mathrm{mmol} \mathrm{de} \mathrm{Cr}\right), \beta$-pineno $(1 \mathrm{mmol})$, formaldehido $(1 \mathrm{mmol}), 2.5 \mathrm{~mL}$ acetonitrilo, $80^{\circ} \mathrm{C}$. b) Test de reusabilidad del MIL-101(Cr)- $\mathrm{NO}_{2}$ en las mismas condiciones que a) y durante cinco usos. El recuadro insertado en la figura $\mathrm{b}$ muestra los modelos de difracción de rayos $\mathrm{X}$ para $\mathrm{A}$ ) muestra fresca de MIL-101(Cr)-NO 2 , B) MIL-101(Cr)-NO $\mathrm{NO}_{2}$ usada tres veces y C) MIL-101(Cr)-NO usada cuatro veces.

En el caso del material MIL-101(Cr)- $\mathrm{NO}_{2}$, su reusabilidad se confirmó llevando a cabo una serie de reacciones consecutivas usando la misma muestra para la reacción de Prins (Figura 6.10b). Al final de cada reacción el catalizador se separó por filtración y se secó antes de su próximo uso. La actividad catalítica y la cristalinidad del material sólido se mantienen con el uso (Figura 6.10b).

Finalmente, la actividad catalítica del material MIL-101(Cr)-NO $\mathrm{NO}_{2}$ se comparó con la actividad del acetato de $\mathrm{Cr}$ como catalizador homogéneo en las mismas condiciones (Figura 6.10). El acetato de $\mathrm{Cr}$ es igualmente activo para promover el acoplamiento de Prins, pero el sólido MIL-101(Cr)- $\mathrm{NO}_{2}$ exhibe una mayor velocidad inicial, una conversión más alta y una conversión a tiempo final de $48 \mathrm{~h}$ más elevada que la de la sal soluble de $\mathrm{Cr}$, lo que muestra la ventaja de la introducción de un sustituyente adecuado para aumentar la actividad catalítica de los centros activos. Si se comparan los catalizadores homogéneos y heterogéneos se observa generalmente que la inmovilización de los centros activos en el sólido disminuye su actividad debido a las restricciones en la difusión de los sustratos y reactivos para alcanzar el centro catalítico los cuales son menos accesibles cuando están en el sólido que cuando están disueltos en la fase líquida. Aunque este sería también el caso en el presente capítulo, la comparación de la actividad catalítica del acetato de $\mathrm{Cr}$ disuelto en acetato de $\mathrm{Cr}$ con la del material MIL-101(Cr)-H, hace 
Influencia de los sustituyentes en el ligando del MIL-101(Cr) en tres reacciones características de ácidos de Lewis

posible la introducción de sustituyentes electrón-atrayentes sobre los ligandos del tereftalato lo que convierte al catalizador sólido en mucho más activo que la sal de $\mathrm{Cr}^{3+}$ homogénea, contrarrestando de esta manera los efectos negativos de la difusión.

\subsection{Conclusiones.}

De acuerdo con estudios previos y los capítulos precedentes, el presente capítulo ha demostrado que la actividad catalítica de los materiales reticulares metal-orgánico como ácido de Lewis sólidos puede aumentarse por la presencia de sustituyentes electrón-aceptores en el ligando orgánico. Estos sustituyentes aumentan la deficiencia electrónica sobre los iones metálicos del nodo, los cuales son los centros catalíticos en este tipo de reacción, por efecto inductivo. Así, en el presente capítulo se ha encontrado un aumento de hasta 3 órdenes de magnitud al comparar la actividad de materiales MIL-101(Cr)-X con grupos amino y sustituidos con grupos nitro. Con respecto a los estudios existentes en la bibliografía, los datos del presente capítulo son relevantes por usar el material MIL101, el cual es conocido por ser una de las estructuras reticulares metal-orgánico cristalinas más estables y con una menor tendencia a presentar defectos estructurales. Los datos aquí presentados proporcionan una evidencia experimental firme en apoyo de la influencia de los sustituyentes en la actividad catalítica de las reacciones estudiadas, apertura de epóxido y Prins exhiben una buena linealidad entre las velocidades iniciales relativas en escala logarítmica y la constante de Hammett sigma meta, lo cual sugiere que en estos casos no existen otros factores a parte de la acidez influyendo en el mecanismo de reacción. 


\subsection{Referencias.}

1. a) H. Chughtai, N. Ahmad, H. A. Younus, A. Laypkov y F. Verpoort, Chem. Soc. Rev. 2015, 44, 6804-6849; b) A. Dhakshinamoorthy, M. Alvaro y H. Garcia, Catal. Sci. Technol. 2011, 1, 856-867; c) H. Furukawa, K. E. Cordova, M. O'Keeffe y O. M. Yaghi, Science 2013, 341, 1230444; d) J. Gascon, A. Corma, F. Kapteijn y F. X. Llabrés i Xamena, ACS Catal. 2014, 4, 361-378; e) O. A. Kholdeeva, Catal. Today 2016, 278, 2229; f) M. Yoon, R. Srirambalaji y K. Kim, Chem. Rev. 2012, 112, 1196-1231.

2. A. Corma, H. Garcia y F. X. Llabrés i Xamena, Chem. Rev. 2010, 110, 4606-4655.

3. A. Dhakshinamoorthy, M. Opanasenko, J. Čejka y H. Garcia, Catal. Sci. Technol. 2013, 3, 2509-2540.

4. Y.-X. Zhou, Y.-Z. Chen, Y. Hu, G. Huang, S.-H. Yu y H.-L. Jiang, Chem. Eur. J., 2014, 20, 14976-14980.

5. F. Vermoortele, M. Vandichel, B. V. de Voorde, R. Ameloot, M. Waroquier, V. Van Speybroeck y D. E. de Vos, Angew. Chem. Int. Ed. 2012, 51, 4887-4890.

6. a) B. Li, K. Leng, Y. Zhang, J. J. Dynes, J. Wang, Y. Hu, D. Ma, Z. Shi, L. Zhu, D. Zhang, Y. Sun, M. Chrzanowski y S. Ma, J. Am. Chem. Soc. 2015, 137, 4243-4248; b) A. Herbst, A. Khutia y C. Janiak, Inorg. Chem. 2014, 53, 7319-7333; c) C. K. Brozek y M. Dincă, J. Am. Chem. Soc. 2013, 135, 12886-12891.

7. J. F. Blandez, A. Santiago-Portillo, S. Navalón, M. Giménez-Marqués, M. Álvaro, P. Horcajada y H. García, J. Mol. Cata. A.-Chem. 2016, 425, 332-339.

8. a) Y. F. Chen, R. Babarao, S. I. Sandler y J. W. Jiang, Langmuir 2010, 26, 8743-8750;

b) N. V. Maksimchuk, O. V. Zalomaeva, I. Y. Skobelev, K. A. Kovalenko, V. P. Fedin y O. A. Kholdeeva, Proc. R. Soc. A 2012, 468, 2017-2034.

9. G. Ferey, C. Mellot-Draznieks, C. Serre, F. Millange, J. Dutour, S. Surble y I. Margiolaki, Science 2005, 309, 2040-2042.

10. A. Demessence, P. Patricia Horcajada, C. Christian Serre, C. C. Boissière, D. Grosso, C. Sanchez y G. Férey, Chem. Commun. 2009, 14, 7149-7151.

11. H. Wu, Y. S. Chua, V. Krungleviciute, M. Tyagi, P. Chen, T. Yildirim y W. Zhou, J. Am. Chem. Soc. 2013, 135, 10525-10532.

12. Z. Fang, B. Bueken, D. E. de Vos y R. A. Fischer, Ang. Chem. Int. Ed 2015, 54, 7234-7254.

13. D.-Y. Hong, Y. K. Hwang, C. Serre, G. Férey y J.-S. Chang, Adv. Funct. Mater. 2009, 19, 1537-1552.

14. a) A. Dhakshinamoorthy y H. Garcia, Chem. Soc. Rev. 2012, 41, 5262-5284 y A. Gómez-Paricio, A. Santiago-Portillo, S. Navalón, P. Concepción, M. Alvaro y H. Garcia, Green Chem. 2016, 18, 508-515. 
Influencia de los sustituyentes en el ligando del MIL-101(Cr) en tres reacciones características de ácidos de Lewis

15. A. Santiago-Portillo, S. Navalon, F. Cirujano, F. Llabrés i Xamena, M. Alvaro y H. Garcia, ACS Catal. 2015, 5, 3216-3224.

16. S. Bernt, V. Guillerm, C. Serre y N. Stock, Chem. Commun. 2011, 47, 2838-2840.

17. M. Lammert, S. Bernt, F. Vermoortele, D. E. de Vos y N. Stock, Inorg. Chem. 2013, 52, 8521-8528.

18. B. Li, Y. Zhang, D. Ma, L. Li, G. Li, G. Li, Z. Shi y S. Feng, Chem. Commun. 2012, 48, 6151-6153.

19. M. Hartmann y M. Fischer, Micropor. Mesopor. Mater. 2012, 164, 38-43.

20. M. I. Zaki y H. Knözinger, Spectrochim. Acta 1987, 43, 1455- 1459.

21. K. Hadjiivanov y G. N. Vayssilov Adv. Catal. 2002, 47, 307-511. 


\section{Capítulo 7 \\ Oxidación de alquenos empleando UiO-66 con intercambio combinado de átomos de titanio $y$ sustitución en los ligandos}


Oxidación de alquenos empleando UiO-66 con intercambio combinado de átomos de titanio y sustitución en los ligandos. 


\subsection{Introducción}

Como se ha venido comentando en la introducción, los metales de transición poseen en general actividad catalítica para promover oxidaciones aeróbicas de hidrocarburos a través de diferentes mecanismos, algunos de los cuales implican especies reactivas de oxígeno. ${ }^{1-3}$ Mientras que el uso de oxígeno como oxidante en lugar de peróxidos u otros reactivos oxidantes es muy atractivo debido a la disponibilidad de este agente químico, la benignidad de su uso y la sostenibilidad del proceso, la falta de selectividad que es observada generalmente en los productos formados limita enormemente su aplicación en síntesis o en la industria química. ${ }^{3-9}$

Ya se ha comentado, en la introducción, la estructura de los MOFs y el porqué de su uso como catalizadores heterogéneos, principalmente en reacciones en fase líquida. ${ }^{10-}$ ${ }^{25}$ Como catalizadores sólidos, los MOFs ofrecen diferentes posibilidades para introducir centros activos, incluyendo el cambio en el elemento metálico ${ }^{26-29}$ y también la optimización en los sustituyentes que están presentes en los ligandos orgánicos. ${ }^{30-32}$ Los capítulos 5 y 6 ya han presentado ejemplos mostrando la influencia de los sustituyentes en los ligandos tereftalatos sobre la actividad catalítica de los centros metálicos. Continuando con esta línea de investigación dirigida a optimizar la actividad catalítica de los MOFs, sería de interés demostrar el concepto de generación de centros activos en MOFs que de otra manera son inactivos como catalizadores mediante el intercambio iónico de los metales de los nodos, combinando esta estrategia con la optimización de la actividad catalítica por sustitución en el ligando tereftalato. ${ }^{36-38}$ En este contexto, Li y colaboradores han demostrado que es posible reemplazar en el material UiO-66(Zr) un porcentaje de hasta el $30 \%$ de iones $\mathrm{Zr}^{4+}$ por iones $\mathrm{Ti}^{4+}$ por tratamiento post-síntesis del material precursor UiO-66(Zr) con $\mathrm{TiCl}_{4}(\mathrm{THF})_{2}$ por intercambio iónico. ${ }^{39}$ Esta estrategia ha sido usada, por ejemplo, para aumentar la actividad fotocatalítica del material base UiO$66(\mathrm{Zr})$ para la reducción de $\mathrm{CO}_{2}$ al introducir iones $\mathrm{Ti}^{4+}$ que actúan favoreciendo la transferencia electrónica entre el ligando tereftalato fotoexcitado y los iones $\mathrm{Zr}^{4+} .40$

A fin de confirmar este concepto y considerando la actividad descrita en la literatura para los iones aislados $\mathrm{Ti}^{4+}$ anclados covalentemente sobre sílices y zeolitas como catalizadores de oxidación, particularmente en presencia de peróxidos como agentes oxidantes, pero también usando oxígeno como oxidante, ${ }^{41-47}$ en el presente capítulo se describe la reactividad de alquenos, particularmente cicloalquenos, para formar el epóxido correspondiente o mezclas ol/ona en posiciones alílicas. Como se va a describir a continuación, mientras el material UiO-66(Zr) no posee una actividad catalítica en la oxidación aeróbica de cicloalcanos, el intercambio iónico de $\mathrm{Zr}^{4+}$ por $\mathrm{Ti}^{4+}$ introduce centros activos para promover esta oxidación aeróbica. Más aún, la actividad catalítica de UiO-66( $\mathrm{Zr}$, Ti) puede ser incrementada por sustitución con grupos nitro sobre el ligando tereftalato. En el área de catalizadores de titanio anclados sobre materiales micro y mesoporosos, se ha encontrado que átomos de titanio aislados actúan como centros activos en reacciones 
Oxidación de alquenos empleando UiO-66 con intercambio combinado de átomos de titanio y sustitución en los ligandos.

de epoxidación ${ }^{45,48-50}$ y similares centros de $\mathrm{Ti}^{4+}$ aislados pueden ser obtenidos fácilmente en $\mathrm{UiO}-66(\mathrm{Zr})$ a través de un intercambio parcial de iones $\mathrm{Zr}^{4+}$ por $\mathrm{Ti}^{4+}$ mediante tratamiento post-sintético.

\subsection{Resultados y discusión}

La lista de catalizadores preparados en el presente capítulo, sus propiedades más relevantes y algunos datos analíticos se resumen en la tabla 7.1. Como puede verse en esa tabla, se prepararon tres series de materiales UiO-66 isoestructurales teniendo sobre el ligando tereftalato grupos nitro, amino o sin sustituir. Cada una de estas tres series, presentan cuatro niveles de intercambio de $\mathrm{Zr}^{4+}$ por $\mathrm{Ti}^{4+}$. La preparación de los materiales isoestructurales UiO-66- $\mathrm{H}$, UiO-66- $\mathrm{NO}_{2}$ y UiO-66- $\mathrm{NH}_{2}$ se llevó a cabo siguiendo los procedimientos descritos en la bibliografía química. ${ }^{34}$ De manera más específica y breve, los tres materiales UiO-66(Zr) se prepararon por cristalización solvatotérmica de $\mathrm{ZrCl}_{4}$ y tereftálico, 2-nitrotereftálico o 2-aminotereftálico como ligando en DMF. Las condiciones de síntesis y las masas exactas de los componentes se indican en el capítulo 8 que contiene los procedimientos experimentales. Los tres materiales UiO-66-X $\left(\mathrm{X}: \mathrm{H}, \mathrm{NO}_{2}\right.$, $\mathrm{NH}_{2}$ ) se sometieron a intercambio iónico de $\mathrm{Zr}^{4+}$ por $\mathrm{Ti}^{4+}$ en DMF a $120^{\circ} \mathrm{C}$ a tres concentraciones diferentes del complejo $\mathrm{TiCl}_{4}(\mathrm{THF})_{2}$ a fin de obtener para cada serie del material UiO-66-X muestras con diferente contenido de Ti entre 0 y $10 \% .{ }^{51,54}$ 
Tabla 7.1. Lista de catalizadores empleados en el presente capítulo con los datos de área superficial BET, volumen de poro, contenido metálico y velocidad inicial de reacción para la epoxidación aeróbica catalítica de cicloocteno.

\begin{tabular}{|c|c|c|c|c|c|}
\hline Catalizador & $\begin{array}{l}\text { Área su- } \\
\text { perficial } \\
\text { BET } \\
\left(\mathrm{m}^{2} \mathrm{~g}^{-1}\right)\end{array}$ & $\begin{array}{l}\text { Volumen } \\
\text { de poro } \\
\left(\mathrm{cm}^{3} \mathrm{~g}^{-1}\right)\end{array}$ & $\begin{array}{l}\text { ICP Zr } \\
(\%)\end{array}$ & $\begin{array}{ll} & \text { ICP } \\
\text { Ti } \\
(\%)\end{array}$ & $\mathrm{r}_{0}\left(\mathrm{mM} \mathrm{h}^{-1}\right)$ \\
\hline $\mathrm{UiO}-66(\mathrm{Zr})-\mathrm{NO}_{2}$ & 600 & 0.60 & 100.00 & - & 2.02 \\
\hline UiO-66 $\left(\mathrm{Zr}_{5.97} \mathrm{Ti}_{0.03}\right)-\mathrm{NO}_{2}$ & 520 & 0.46 & 99.49 & 0.51 & 6.34 \\
\hline $\mathrm{UiO}-66\left(\mathrm{Zr}_{5.94} \mathrm{Ti}_{0.06}\right)-\mathrm{NO}_{2}$ & 580 & 0.52 & 98.40 & 1.60 & 7.01 \\
\hline $\mathrm{UiO}-66\left(\mathrm{Zr}_{5.4} \mathrm{Ti}_{0.6}\right)-\mathrm{NO}_{2}$ & 590 & 0.50 & 89.60 & 10.40 & 9.83 \\
\hline UiO-66(Zr)-H & 800 & 0.75 & 100.00 & - & 1.25 \\
\hline $\mathrm{UiO}-66\left(\mathrm{Zr}_{5.97} \mathrm{Ti}_{0.03}\right)-\mathrm{H}$ & 770 & 0.78 & 99.42 & 0.58 & 3.83 \\
\hline $\mathrm{UiO}-66\left(\mathrm{Zr}_{5.94} \mathrm{Ti}_{0.06}\right)-\mathrm{H}$ & 740 & 0.68 & 98.80 & 1.20 & 4.98 \\
\hline UiO-66( $\left.\mathrm{Zr}_{5.4} \mathrm{Ti}_{0.6}\right)-\mathrm{H}$ & 740 & 0.77 & 89.40 & 10.60 & 6.94 \\
\hline $\mathrm{UiO}-66(\mathrm{Zr})-\mathrm{NH}_{2}$ & 780 & 0.85 & 100.00 & - & 1.20 \\
\hline UiO-66 $\left(\mathrm{Zr}_{5.97} \mathrm{Ti}_{0.03}\right)-\mathrm{NH}_{2}$ & 720 & 0.50 & 99.40 & 0.60 & 2.38 \\
\hline UiO-66 $\left(\mathrm{Zr}_{5.94} \mathrm{Ti}_{0.06}\right)-\mathrm{NH}_{2}$ & 730 & 0.52 & 98.50 & 1.50 & 3.97 \\
\hline $\mathrm{UiO}-66\left(\mathrm{Zr}_{5.4} \mathrm{Ti}_{0.6}\right)-\mathrm{NH}_{2}$ & 770 & 0.51 & 89.60 & 10.40 & 6.09 \\
\hline \multicolumn{6}{|c|}{$\begin{array}{l}\text { a Catalizador }\left(0.016 \mathrm{mmol} \text { de metal), sustrato }(2 \mathrm{mmol}), \mathrm{CH}_{3} \mathrm{CN}(2 \mathrm{~mL}), 120^{\circ} \mathrm{C} \text { y }\right. \\
\mathrm{O}_{2}(5 \mathrm{~atm}) \text {. }\end{array}$} \\
\hline
\end{tabular}

Como puede verse en las figuras 7.1-7.3, los difractogramas de rayos $\mathrm{X}$ para todas las muestras de UiO-66-X $\left(\mathrm{Zr}_{6-\mathrm{x}} \mathrm{Ti}_{\mathrm{x}}\right)$ exhiben modelos coincidentes correspondiendo a un material altamente cristalino. Como era de esperar en vista de los datos descritos, la presencia de $\mathrm{Ti}^{4+}$ en el material, causa un desplazamiento gradual del pico de difracción más intenso (111) desde el valor de $2 \theta$ inicial $7.39^{\circ}$ al siguiente punto hacia ángulos de difracción más altos, alcanzando valores de $2 \theta$ de $7.43^{\circ}$. Este efecto del desplazamiento gradual en la posición de los picos de difracción ha sido descrito previamente en la literatura y ha sido racionalizado como consecuencia del tamaño algo más pequeño de la 
Oxidación de alquenos empleando UiO-66 con intercambio combinado de átomos de titanio y sustitución en los ligandos.

celda unidad para las muestras conteniendo $\mathrm{Ti}^{4+}$ debido a la contracción causada por el menor radio iónico de $\mathrm{Ti}^{4+}$ comparado con el del $\mathrm{Zr}^{4+}$. ${ }^{39,54}$ Por consiguiente, de acuerdo con la bibliografía, el desplazamiento gradual de la posición del pico de difracción (111) observado para cada una de las series UiO-66(Zr Ti)-X $\left(\mathrm{X}: \mathrm{H}, \mathrm{NO}_{2}, \mathrm{NH}_{2}\right)$ se considera como una evidencia del éxito de la sustitución parcial en la red de $\mathrm{Zr}^{4+}$ por $\mathrm{Ti}^{4+} .39,54$

1)

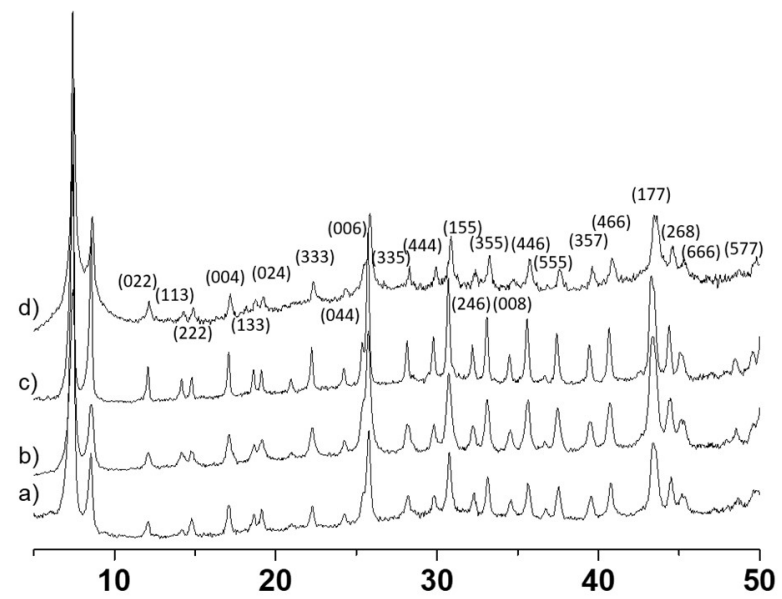

2)

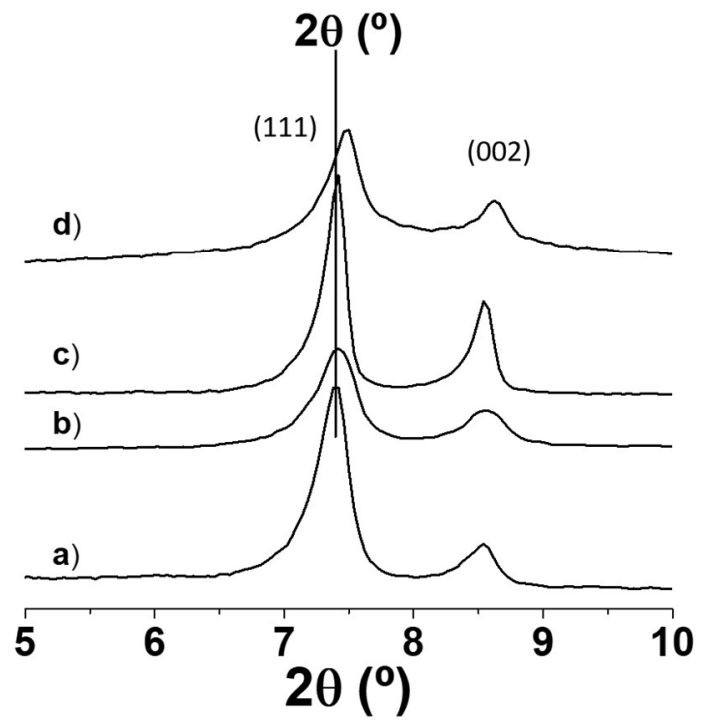

Figura 7.1. 1) Modelos de difracción de rayos Z para UiO-66(Zr)-H (a), UiO-66( $\left.\mathrm{Zr}_{5.97} \mathrm{Ti}_{0.03}\right)-\mathrm{H}$ (b) y $\mathrm{UiO}-66\left(\mathrm{Zr}_{5.94} \mathrm{Ti}_{0.06}\right)-\mathrm{H}$ (c) y UiO-66( $\left.\mathrm{Zr}_{5.4} \mathrm{Ti}_{0.6}\right)-\mathrm{H}$ (d). 2) Expansión de la zona correspondiente al pico de difracción (111). 
1)

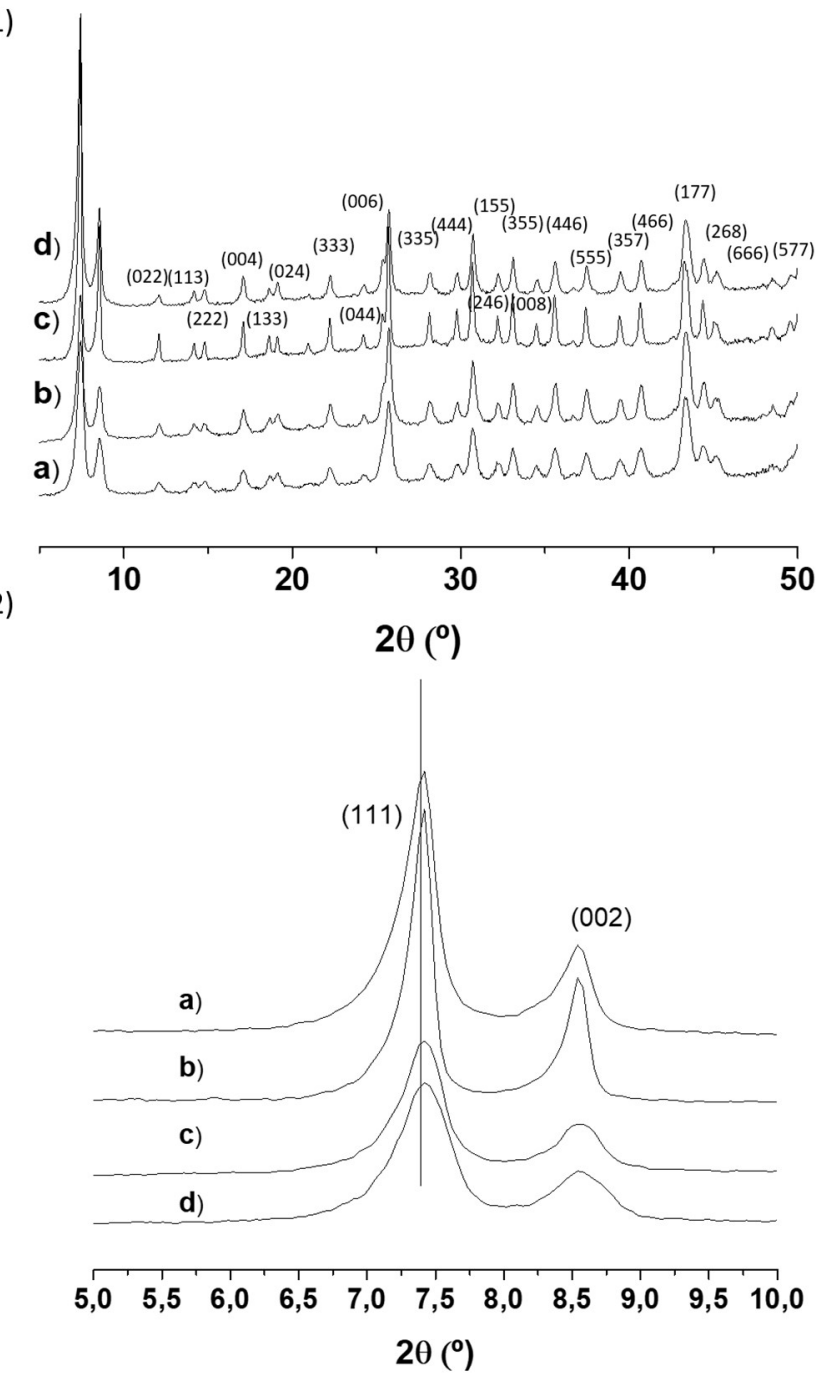

Figura 7.2. 1) Modelos de difracción de rayos $\mathrm{Z}$ para UiO-66(Zr)- $\mathrm{NO}_{2}(\mathrm{a}), \mathrm{UiO}-66\left(\mathrm{Zr}_{5.97} \mathrm{Ti}_{0.03}\right)-\mathrm{NO}_{2}$ (b) y UiO-66( $\mathrm{Zr}_{5} .94 \mathrm{Ti}$ io.06)-NO $\mathrm{NO}_{2}$ (c) y UiO-66( $\mathrm{Zr}_{5.4} \mathrm{Ti}$ 0.6)- $\mathrm{NO}_{2}$ (d). 2) Expansión de la zona correspondiente al pico de difracción (111). 
Oxidación de alquenos empleando UiO-66 con intercambio combinado de átomos de titanio y sustitución en los ligandos.

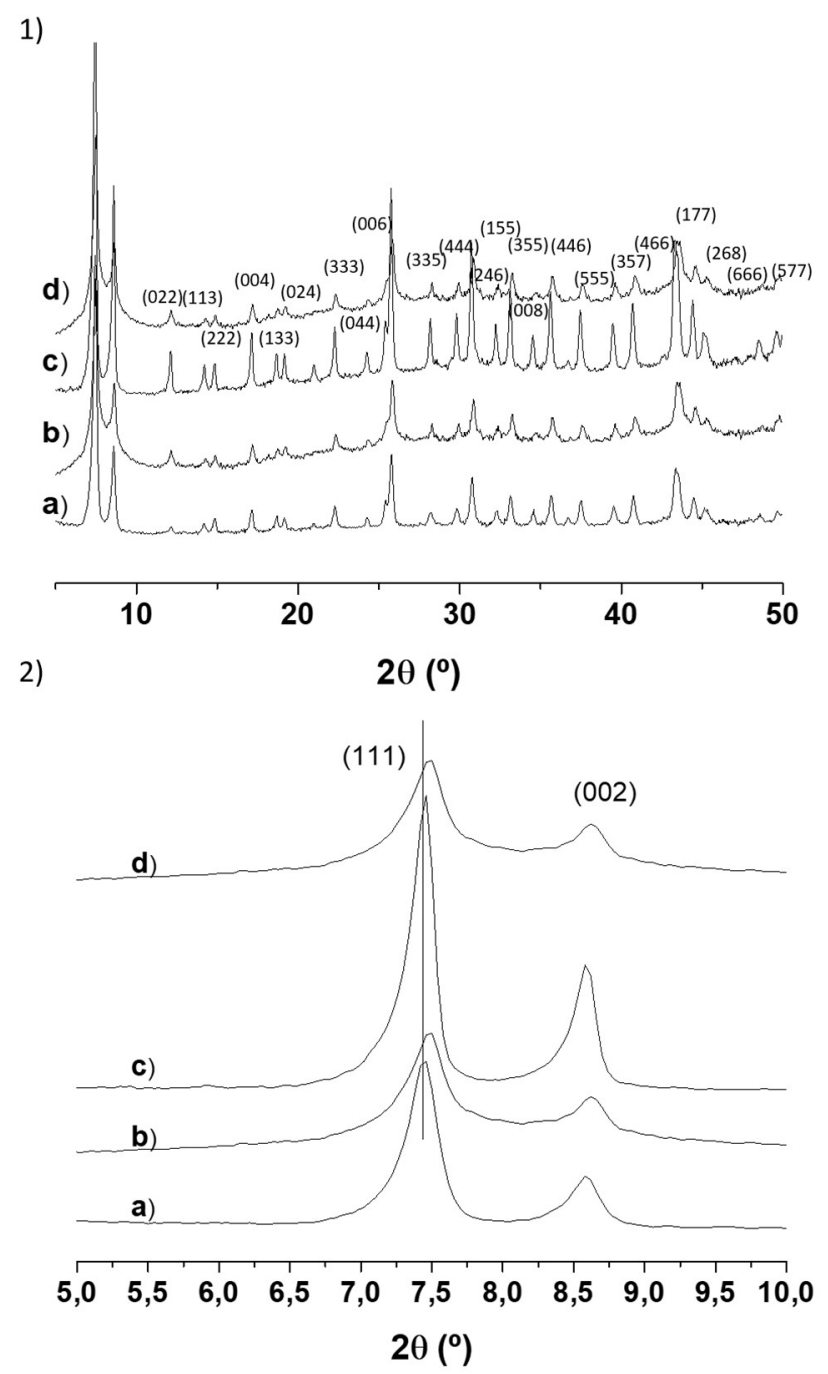

Figura 7.3. 1) Modelos de difracción de rayos $\mathrm{Z}$ para UiO-66(Zr)- $\mathrm{NH}_{2}$ (a), UiO-66( $\left.\mathrm{Zr}_{5.97} \mathrm{Ti}_{0.03}\right)-\mathrm{NH}_{2}$ (b) y UiO-66(Zr5.94 Tio.06)-NH2 (c) y UiO-66(Zr5.4 Tio.6)-NH2 (d). 2) Expansión de la zona correspondiente al pico de difracción (111). 
La diferente sustitución en el ligando tereftalato se confirma por espectroscopía de infrarrojo de los sólidos donde se observan los picos característicos de vibración asociados a $\mathrm{NO}_{2}\left(1500\right.$ y $\left.1380 \mathrm{~cm}^{-1}\right)$ y NH $2\left(3350\right.$ y $\left.959 \mathrm{~cm}^{-1}\right)$ (Figuras 7.4-7.6). En contraste, la sustitución parcial de $\mathrm{Zr}^{4+}$ por $\mathrm{Ti}^{4+}$ en los materiales UiO-66( $\mathrm{Zr}$ Ti)- $\mathrm{NO}_{2}$ no causa cambios significativos en los espectros de IR (Figura 7.5)

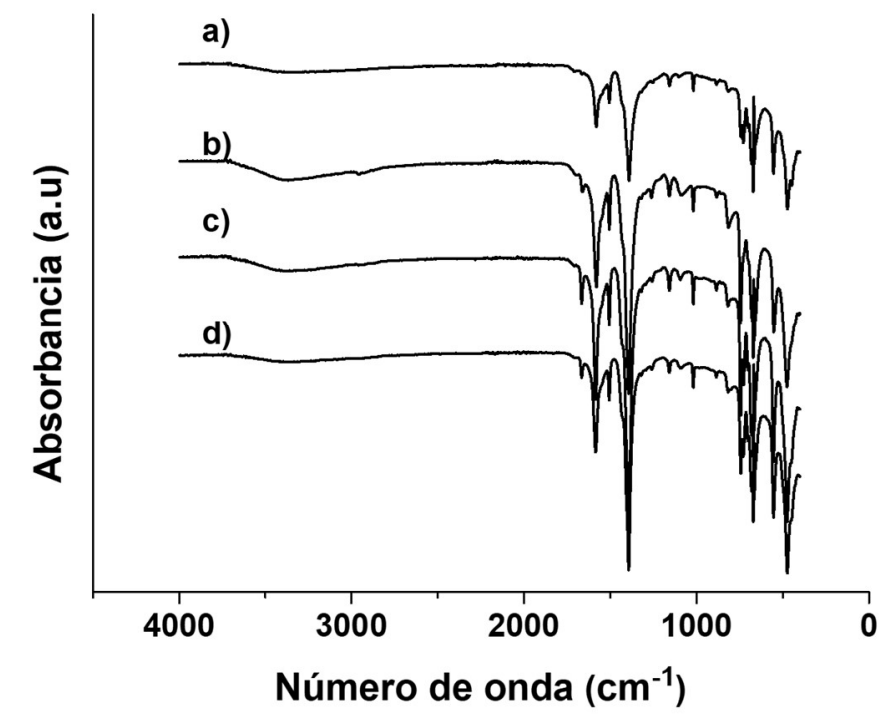

Figura 7.4. Espectros de FT-IR para UiO-66(Zr)-H (a), UiO-66(Zr $\left.r_{5.97} \mathrm{Ti}_{0.03}\right)-\mathrm{H}$ (b) y UiO-66( $\mathrm{Zr}_{5.94}$ Tio.06)-H (c) y UiO-66(Zr5.4 Ti0.6)-H (d). 


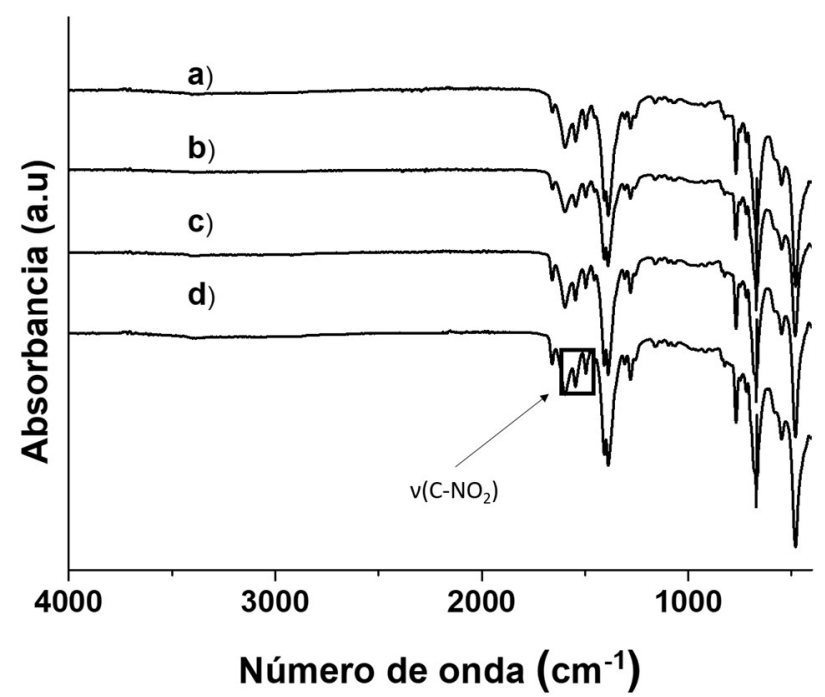

Figura 7.5. Espectros de FT-IR para UiO-66(Zr)-NO2 (a), UiO-66(Zr5.97 Ti0.03)-NO2 $\mathrm{NO}_{2}$ (b) y UiO-66(Zr5.94 Tio.06)-NO 2 (c) y UiO-66( $\left.\mathrm{Zr}_{5.4} \mathrm{Ti}_{0.6}\right)-\mathrm{NO}_{2}(\mathrm{~d})$.

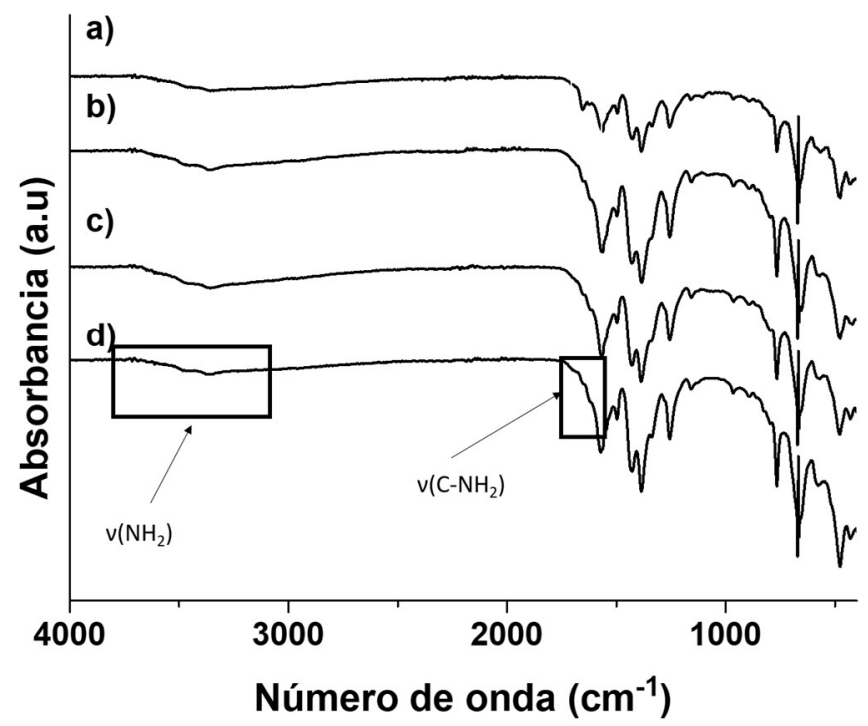

Figura 7.6. Espectros de FT-IR para UiO-66(Zr)-NH $\mathrm{NH}_{2}$ (a), UiO-66( $\left.\mathrm{Zr}_{5.97} \mathrm{Ti}_{0.03}\right)-\mathrm{NH}_{2}$ (b) y UiO-66(Zr $\mathrm{Zr}_{5.94}$ $\left.\mathrm{Ti}_{0.06}\right)-\mathrm{NH}_{2}(\mathrm{c})$ y UiO-66( $\left.\mathrm{Zr}_{5.4} \mathrm{Ti}_{0.6}\right)-\mathrm{NH}_{2}(\mathrm{~d})$. 
Las medidas de adsorción isoterma de nitrógeno indican que el área superficial específica y los volúmenes de poro para las muestras UiO-66-X estudiadas varían entre 800 y $520 \mathrm{~m}^{2} \mathrm{~g}^{-1}$ y entre 0.75 y $0.46 \mathrm{~cm}^{3} \mathrm{~g}^{-1}$, respectivamente (tabla 7.1 ). Estos valores y la tendencia general observada donde el área superficial de cada serie UiO-66-X (X: $\mathrm{H}$, $\mathrm{NO}_{2} \circ \mathrm{NH}_{2}$ ), aunque similar, disminuye con el grado de intercambio iónico, estando este hecho de acuerdo con los datos de la literatura. ${ }^{54,61}$

Tabla 7.1. Lista de catalizadores empleados en el presente estudio con sus correspondientes áreas específicas (BET), volumen de poro, contenido de metal y velocidad inicial de reacción para la epoxidación aeróbica de cicloocteno. ${ }^{\mathrm{a}}$

\begin{tabular}{|c|c|c|c|c|c|}
\hline Catalizadores & $\begin{array}{l}\text { Área } \\
\text { especí- } \\
\text { fica } \\
\text { BET } \\
\left(\mathrm{m}^{2} \mathrm{~g}^{-1}\right)\end{array}$ & $\begin{array}{l}\text { Volumen } \\
\text { de poro } \\
\left(\mathrm{cm}^{3} \mathrm{~g}^{-1}\right)\end{array}$ & $\begin{array}{l}\text { ICP Zr } \\
(\%)\end{array}$ & $\begin{array}{ll}\text { ICP } & \text { Ti } \\
(\%)\end{array}$ & $\begin{array}{l}\mathrm{r}_{0}(\mathrm{mM} \\
\left.\mathrm{h}^{-1}\right)\end{array}$ \\
\hline UiO-66(Zr)-NO ${ }_{2}$ & 600 & 0.60 & 100.00 & - & 2.02 \\
\hline UiO-66 $\left(\mathrm{Zr}_{5.97} \mathrm{Ti}_{0.03}\right)-\mathrm{NO}_{2}$ & 520 & 0.46 & 99.49 & 0.51 & 6.34 \\
\hline UiO-66 $\left(\mathrm{Zr}_{5.94} \mathrm{Ti}_{0.06}\right)-\mathrm{NO}_{2}$ & 580 & 0.52 & 98.40 & 1.60 & 7.01 \\
\hline UiO-66 $\left(\mathrm{Zr}_{5.4} \mathrm{Ti}_{0.6}\right)-\mathrm{NO}_{2}$ & 590 & 0.50 & 89.60 & 10.40 & 9.83 \\
\hline UiO-66(Zr)-H & 800 & 0.75 & 100.00 & - & 1.25 \\
\hline UiO-66( $\left.\mathrm{Zr}_{5.97} \mathrm{Ti}_{0.03}\right)-\mathrm{H}$ & 770 & 0.78 & 99.42 & 0.58 & 3.83 \\
\hline $\mathrm{UiO}-66\left(\mathrm{Zr}_{5.94} \mathrm{Ti}_{0.06}\right)-\mathrm{H}$ & 740 & 0.68 & 98.80 & 1.20 & 4.98 \\
\hline $\mathrm{UiO}-66\left(\mathrm{Zr}_{5.4} \mathrm{Ti}_{0.6}\right)-\mathrm{H}$ & 740 & 0.77 & 89.40 & 10.60 & 6.94 \\
\hline $\mathrm{UiO}-66(\mathrm{Zr})-\mathrm{NH}_{2}$ & 780 & 0.85 & 100.00 & - & 1.20 \\
\hline UiO-66 $\left(\mathrm{Zr}_{5.97} \mathrm{Ti}_{0.03}\right)-\mathrm{NH}_{2}$ & 720 & 0.50 & 99.40 & 0.60 & 2.38 \\
\hline UiO-66 $\left(\mathrm{Zr}_{5.94} \mathrm{Ti}_{0.06}\right)-\mathrm{NH}_{2}$ & 730 & 0.52 & 98.50 & 1.50 & 3.97 \\
\hline $\mathrm{UiO}-66\left(\mathrm{Zr}_{5.4} \mathrm{Ti}_{0.6}\right)-\mathrm{NH}_{2}$ & 770 & 0.51 & 89.60 & 10.40 & 6.09 \\
\hline
\end{tabular}



ción en los ligandos.

La termogravimetría en presencia de aire proporciona una información importante respecto a la presencia de defectos en el material, al comparar los pesos experimentales tras la combustión completa de los componentes orgánicos con el valor teórico correspondiente al residuo $\mathrm{Zr}_{6-\mathrm{x}} \mathrm{Ti}_{\mathrm{x}} \mathrm{O}_{2}$ en base a la fórmula estructural de la muestra. ${ }^{30,31} \mathrm{Los}$ perfiles termogravimétricos (Figuras 7.7-7.9) exhiben una pérdida de peso inicial desde temperatura ambiente hasta $150^{\circ} \mathrm{C}$ que corresponde con la desorción del agua y/o moléculas de disolvente adsorbidas. Tras esta etapa, se observa una pérdida de peso exotérmica atribuible a la combustión del ligando orgánico que tiene lugar en todas las muestras estudiadas entre 250 y $400{ }^{\circ} \mathrm{C}$. La diferencia entre el peso experimental del residuo determinado mediante el perfil termogravimétrico a $800^{\circ} \mathrm{C}$ con el que se calcula en base a la fórmula molecular, bien sea positivo o negativo, indica el exceso o defecto en la cantidad de óxido metálico presente en el material respecto al valor teórico de acuerdo con la fórmula. En el presente estudio, el exceso de peso del residuo en termogravimetría indica bien un exceso de contenido en metal ( $\mathrm{Zr}$ y Ti) o la existencia de vacantes de ligando en el sólido. Los resultados de estos estudios termogravimétricos se presentan en la tabla 7.2. Es conocido en el estado del arte que el material UiO-66(Zr) puede presentar una gran densidad de defectos, los cuales pueden cuantificarse de una manera conveniente en base a la diferencia entre el análisis químico teórico y experimental. ${ }^{62}$ Conviene mencionar aquí el error experimental asociado con las medidas de termogravimetría, los cuales no permiten determinar diferencias en el peso residual para aquellas muestras con el nivel de intercambio de Ti más bajo. Un resumen de los datos termogravimétricos experimentales más relevantes y su comparación con los valores teóricos se presenta en la tabla 7.2. Como puede verse allí, las muestras precursoras UiO-66(Zr)-X (X: $\mathrm{H}, \mathrm{NO}_{2} \circ \mathrm{NH}_{2}$ ) antes del intercambio iónico con Ti exhiben porcentajes de $\mathrm{Zr}$ más elevados (aproximadamente 1\% en peso) con respecto a los calculados de acuerdo con la fórmula de la celda ideal que varían entre 0.3 para UiO-66( $\mathrm{Zr})-\mathrm{NH}_{2}$ a $0.9 \%$ para UiO$66(\mathrm{Zr})-\mathrm{NO}_{2}$ indicando que los materiales contienen defectos asociados a una cantidad de $\mathrm{Zr}$ mayor que la que corresponde a la fórmula ideal. Estos defectos pueden ser, por ejemplo, vacantes de tereftalato o la presencia de agregados amorfos de óxido de zirconio en el material. Para poner en contexto los datos presentados en la tabla 7.2 mostrando solo una densidad de defectos relativamente baja debido al contenido de zirconio algo menor del esperado en comparación con otros precedentes descritos en la literatura, se ha llegado a describir excesos de $\mathrm{Zr}$ superiores al $10 \%{ }^{34,63}$ 
Table 2. Lista de catalizadores empleados en el presente estudio con sus correspondientes porcentajes de metal calculados teóricamente de acuerdo a la fórmula o medido experimentalmente por TG.

\begin{tabular}{|c|c|c|c|c|}
\hline \multirow[t]{2}{*}{ Fórmula teórica de los MOFs } & \multicolumn{2}{|l|}{$\operatorname{Zr}(\%)$} & \multicolumn{2}{|l|}{$\operatorname{Ti}(\%)$} \\
\hline & $\begin{array}{l}\text { Calcu- } \\
\text { lado }\end{array}$ & Medido & $\begin{array}{l}\text { Calcu- } \\
\text { lado }\end{array}$ & Medido \\
\hline $\begin{array}{l}\mathrm{UiO}-66(\mathrm{Zr})-\mathrm{NO}_{2} \\
\mathrm{Zr}_{6} \mathrm{O}_{4}(\mathrm{OH})_{4}\left(\mathrm{OOC}-\mathrm{C}_{6} \mathrm{H}_{3} \mathrm{NO}_{2}-\mathrm{COO}\right)_{6}\end{array}$ & 28.3 & 29.2 & - & - \\
\hline $\begin{array}{l}\mathrm{UiO}-66\left(\mathrm{Zr}_{5.97} \mathrm{Ti}_{0.03}\right)-\mathrm{NO}_{2} \\
\mathrm{Zr}_{5.97} \mathrm{Ti}_{0.03} \mathrm{O}_{4}(\mathrm{OH})_{4}\left(\mathrm{OOC}-\mathrm{C}_{6} \mathrm{H}_{3} \mathrm{NO}_{2}-\mathrm{COO}\right)_{6}\end{array}$ & 28.2 & 27.6 & 0.1 & 0.1 \\
\hline $\begin{array}{l}\mathrm{UiO}-66\left(\mathrm{Zr}_{5.94} \mathrm{Ti}_{0.06}\right)-\mathrm{NO}_{2} \\
\mathrm{Zr}_{5.94} \mathrm{Ti}_{0.06} \mathrm{O}_{4}(\mathrm{OH})_{4}\left(\mathrm{OOC}-\mathrm{C}_{6} \mathrm{H}_{3} \mathrm{NO}_{2}-\mathrm{COO}\right)_{6}\end{array}$ & 28.1 & 27.7 & 0.2 & 0.2 \\
\hline $\begin{array}{l}\mathrm{UiO}-66\left(\mathrm{Zr}_{5.4} \mathrm{Ti}_{0.6}\right)-\mathrm{NO}_{2} \\
\mathrm{Zr}_{5.4} \mathrm{Ti}_{0.6} \mathrm{O}_{4}(\mathrm{OH})_{4}\left(\mathrm{OOC}-\mathrm{C}_{6} \mathrm{H}_{3} \mathrm{NO}_{2}-\mathrm{COO}\right)_{6}\end{array}$ & 25.9 & 27.3 & 1.5 & 1.3 \\
\hline $\begin{array}{l}\mathrm{UiO}-66(\mathrm{Zr})-\mathrm{H} \\
\mathrm{Zr}_{6} \mathrm{O}_{4}(\mathrm{OH})_{4}\left(\mathrm{OOC}-\mathrm{C}_{6} \mathrm{H}_{4}-\mathrm{COO}\right)_{6}\end{array}$ & 32.9 & 33.3 & - & - \\
\hline $\begin{array}{l}\mathrm{UiO}-66\left(\mathrm{Zr}_{5.97} \mathrm{Ti}_{0.03}\right)-\mathrm{H} \\
\mathrm{Zr}_{5.97} \mathrm{Ti}_{0.03} \mathrm{O}_{4}(\mathrm{OH})_{4}\left(\mathrm{OOC}-\mathrm{C}_{6} \mathrm{H}_{4}-\mathrm{COO}\right)_{6}\end{array}$ & 32.8 & 33.1 & 0.2 & 0.2 \\
\hline $\begin{array}{l}\mathrm{UiO}-66\left(\mathrm{Zr}_{5.94} \mathrm{Ti}_{0.06}\right)-\mathrm{H} \\
\mathrm{Zr}_{5.94} \mathrm{Ti}_{0.06} \mathrm{O}_{4}(\mathrm{OH})_{4}\left(\mathrm{OOC}-\mathrm{C}_{6} \mathrm{H}_{4}-\mathrm{COO}\right)_{6}\end{array}$ & 32.7 & 33.1 & 0.3 & 0.3 \\
\hline $\begin{array}{l}\mathrm{UiO}-66\left(\mathrm{Zr}_{5.4} \mathrm{Ti}_{0.6}\right)-\mathrm{H} \\
\mathrm{Zr}_{5.4} \mathrm{Ti}_{0.6} \mathrm{O}_{4}(\mathrm{OH})_{4}\left(\mathrm{OOC}-\mathrm{C}_{6} \mathrm{H}_{4}-\mathrm{COO}\right)_{6}\end{array}$ & 30.1 & 31.3 & 1.8 & 1.5 \\
\hline $\begin{array}{l}\mathrm{UiO}-66(\mathrm{Zr})-\mathrm{NH}_{2} \\
\mathrm{Zr}_{6} \mathrm{O}_{4}(\mathrm{OH})_{4}\left(\mathrm{OOC}-\mathrm{C}_{6} \mathrm{H}_{3} \mathrm{NH}_{2}-\mathrm{COO}\right)_{6}\end{array}$ & 31.2 & 31.5 & - & - \\
\hline $\begin{array}{l}\text { UiO-66 }\left(\mathrm{Zr}_{5.97} \mathrm{Ti}_{0.03}\right)-\mathrm{NH}_{2} \\
\mathrm{Zr}_{5.97} \mathrm{Ti}_{0.03} \mathrm{O}_{4}(\mathrm{OH})_{4}\left(\mathrm{OOC}-\mathrm{C}_{6} \mathrm{H}_{3} \mathrm{NH}_{2}-\mathrm{COO}\right)_{6}\end{array}$ & 31.1 & 31.2 & 0.2 & 0.2 \\
\hline $\begin{array}{l}\mathrm{UiO}-66\left(\mathrm{Zr}_{5.94} \mathrm{Ti}_{0.06}\right)-\mathrm{NH}_{2} \\
\mathrm{Zr}_{5.94} \mathrm{Ti}_{0.06} \mathrm{O}_{4}(\mathrm{OH})_{4}\left(\mathrm{OOC}-\mathrm{C}_{6} \mathrm{H}_{3} \mathrm{NH}_{2}-\mathrm{COO}\right)_{6}\end{array}$ & 30.9 & 31.0 & 0.3 & 0.3 \\
\hline $\begin{array}{l}\mathrm{UiO}-66\left(\mathrm{Zr}_{5.4} \mathrm{Ti}_{0.6}\right)-\mathrm{NH}_{2} \\
\mathrm{Zr}_{5.4} \mathrm{Ti}_{0.6} \mathrm{O}_{4}(\mathrm{OH})_{4}\left(\mathrm{OOC}-\mathrm{C}_{6} \mathrm{H}_{3} \mathrm{NH}_{2}-\mathrm{COO}\right)_{6}\end{array}$ & 28.5 & 29.2 & 1.7 & 1.4 \\
\hline
\end{tabular}


Oxidación de alquenos empleando UiO-66 con intercambio combinado de átomos de titanio y sustitución en los ligandos.
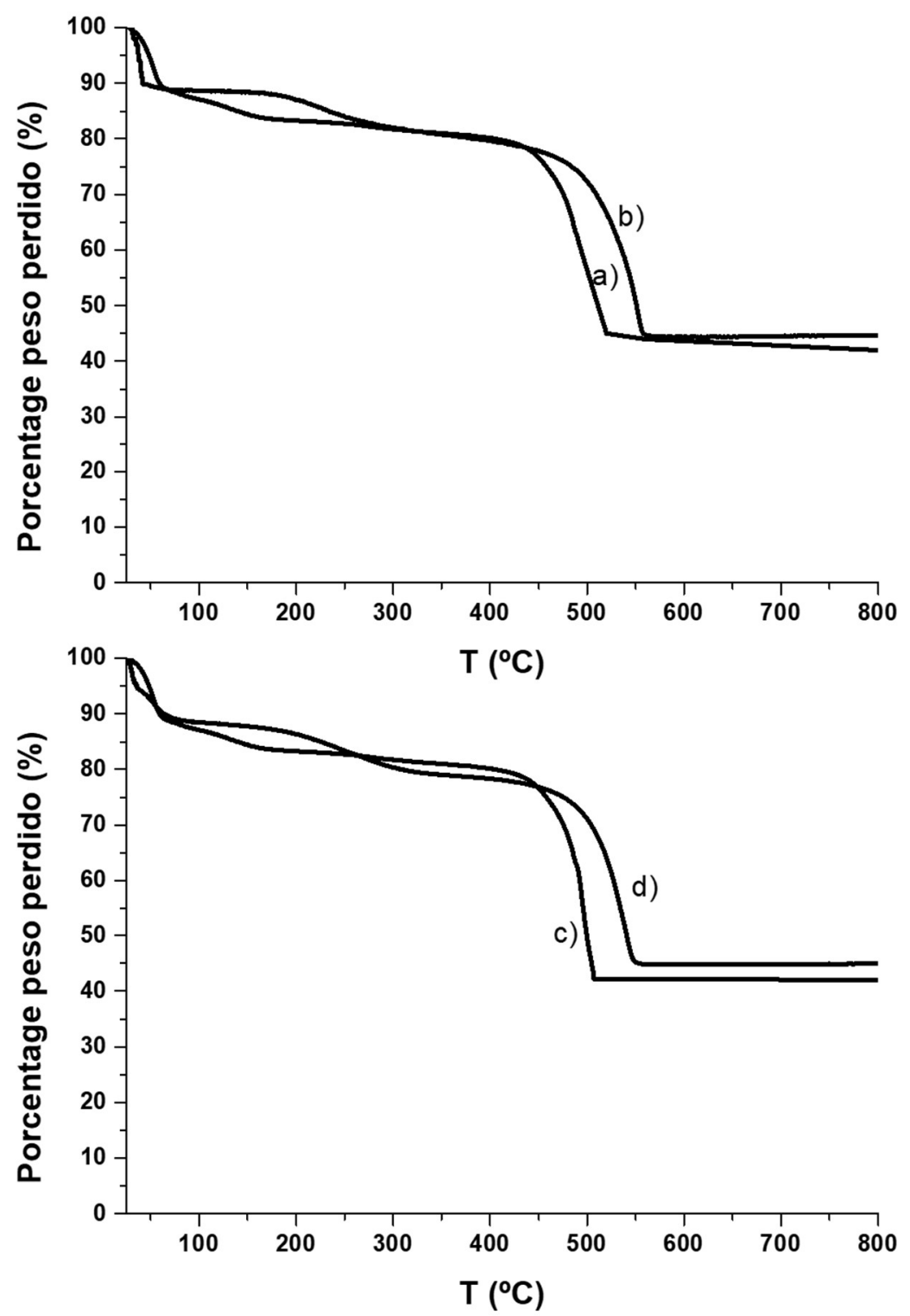

Figura 7.7. Análisis termogravimétrico para UiO-66(Zr)-H (a), UiO-66( $\left.\mathrm{Zr}_{5.97} \mathrm{Ti}_{0.03}\right)-\mathrm{H}$ (b) y UiO66( $\left.\mathrm{Zr}_{5.94} \mathrm{Ti}_{0.06}\right)-\mathrm{H}$ (c) y UiO-66( $\left.\mathrm{Zr}_{5.4} \mathrm{Ti}_{0.6}\right)-\mathrm{H}(\mathrm{d})$. 

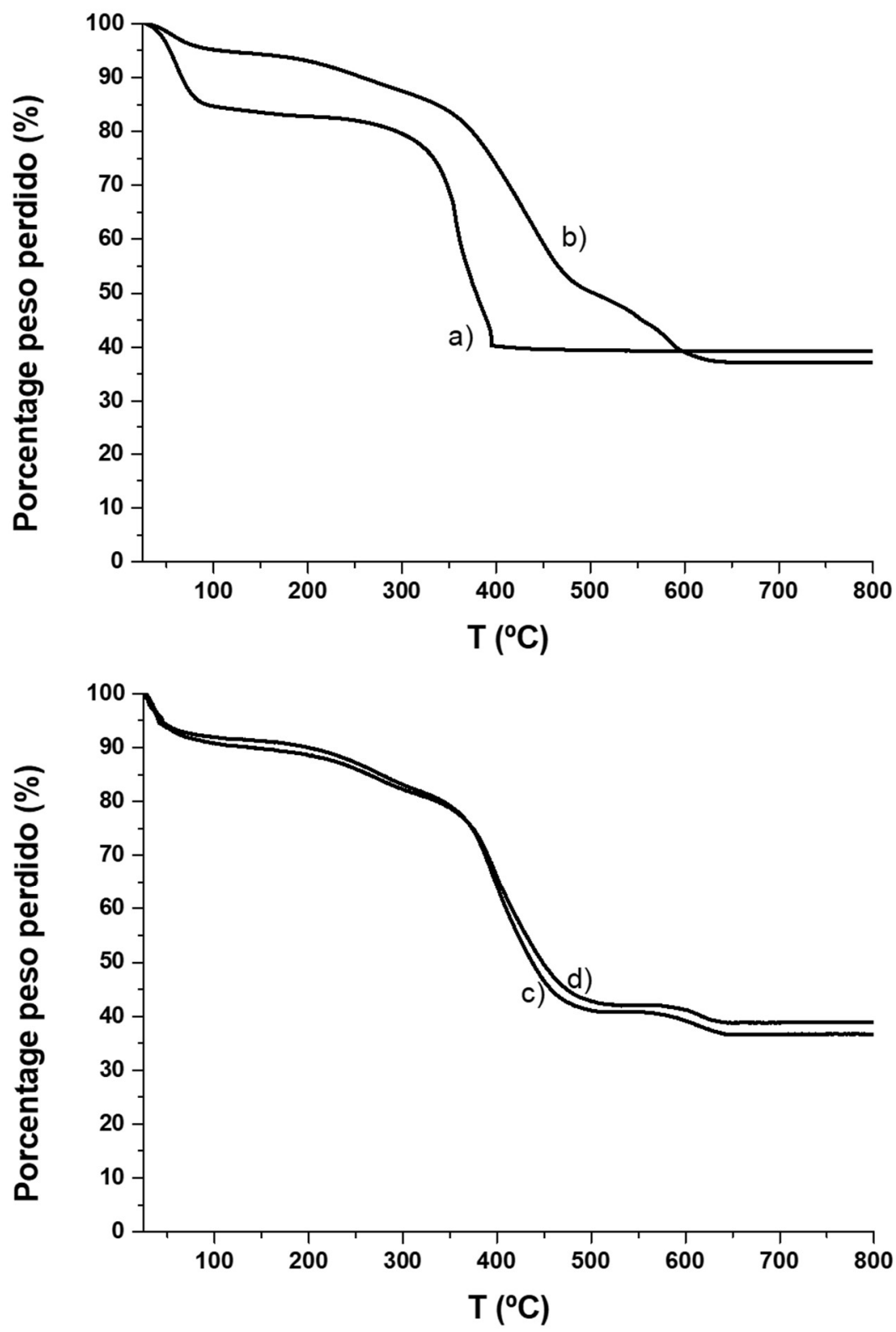

Figura 7.8. Análisis termogravimétrico para UiO-66( $\mathrm{Zr})-\mathrm{NO}_{2}$ (a), $\mathrm{UiO}-66\left(\mathrm{Zr}_{5.97} \mathrm{Ti} 0_{0.03}\right)-\mathrm{NO}_{2}$ (b) y UiO66( $\mathrm{Zr} 5.94$ Tio.06) $-\mathrm{NO}_{2}$ (c) y UiO-66(Zr5.4 $\left.\mathrm{Ti}_{0.6}\right)-\mathrm{NO}_{2}(\mathrm{~d})$. 

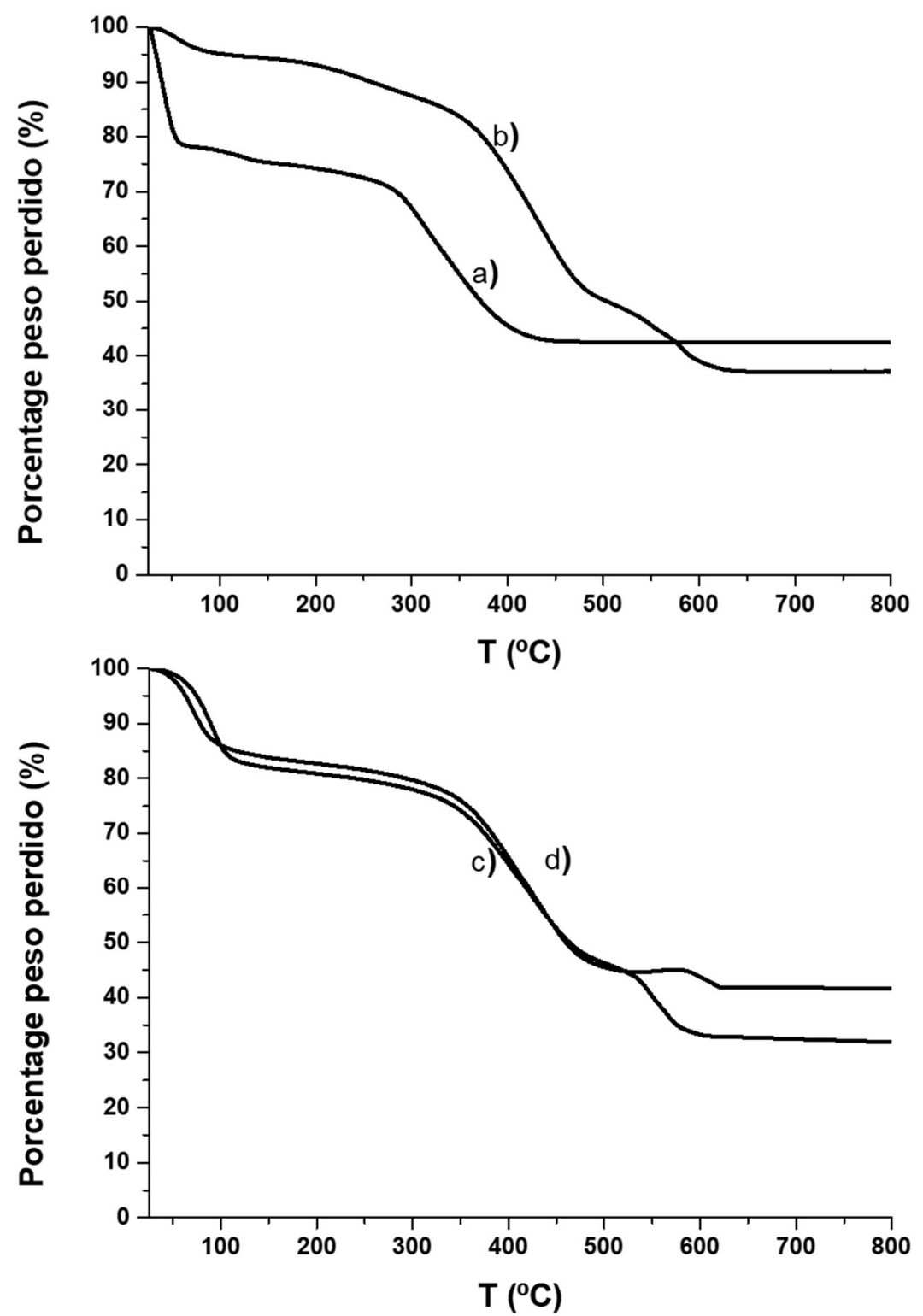

Figura 7.9. Análisis termogravimétrico para UiO-66(Zr)-NH $(\mathrm{a}), \mathrm{UiO}-66\left(\mathrm{Zr}_{5.97} \mathrm{Ti}_{0.03}\right)-\mathrm{NH}_{2}$ (b) y UiO$66\left(\mathrm{Zr}_{5.94} \mathrm{Ti}_{0.06}\right)-\mathrm{NH}_{2}$ (c) y UiO-66( $\left.\mathrm{Zr}_{5.4} \mathrm{Ti}_{0.6}\right)-\mathrm{NH}_{2}(\mathrm{~d})$. 
Cuando se sometieron las muestras de UiO-66(Zr)-X a intercambio por Ti en la concentración más elevada se observó un cambio en el peso residual del material debido a la menor masa atómica de $\mathrm{Ti}$ (47.9 unidad atómica de masa) respecto a $\mathrm{Zr}$ (91.2 unidad atómica de masa), de acuerdo con la fórmula de la celda unidad. Específicamente, la disminución en el peso residual debido al intercambio de $\mathrm{Zr}$ por Ti debería ser teóricamente entre el $2.4 \%$ en peso en el caso de UiO-66 $\left(\mathrm{Zr}_{5.4} \mathrm{Ti}_{0.6}\right)-\mathrm{NO}_{2}$ al 2.2 en peso para el material UiO-66 $\left(\mathrm{Zr}_{5.4} \mathrm{Ti}_{0.6}\right)$-H. Como se ve en la tabla 7.2, se observó esta disminución en el porcentaje del peso residual menor que el $3 \%$ en la masa residual medida por TG. Medidas experimentales de la disminución de la masa residual varían entre -1.9 y -2.3 $\%$ para las muestras $\mathrm{UiO}-66(\mathrm{Zr})-\mathrm{NO}_{2}$ y UiO-66(Zr)-NH $\mathrm{NH}_{2}$, respectivamente. Estos datos analíticos están de acuerdo con el éxito del intercambio de un metal más pesado como el zirconio por otro más ligero como el titanio en un grado medible.

Los análisis de XPS de las muestras UiO-66 (Zr Ti)-X (X: $\mathrm{H}, \mathrm{NO}_{2}, \mathrm{NH}_{2}$ ) establecen también la presencia de titanio en todas las muestras sometidas a intercambio iónico. En el caso particular de la serie UiO-66( $\mathrm{Zr}$ Ti)- $\mathrm{NO}_{2}$ la relación atómica $\mathrm{Ti} / \mathrm{Zr}$ aumenta en todos los casos con el porcentaje de ion intercambiado y fue siempre más elevado que los valores interpretados por otras técnicas analítica (Figura 7.10). Este hecho es probablemente debido a que la técnica de XPS es específica para la medida de superficies y, por consiguiente, los datos parecen indicar un posible gradiente en el contenido de titanio que debería ser más elevado en la superficie externa de las partículas de MOF, disminuyendo esta relación atómica $\mathrm{Ti} / \mathrm{Zr}$ hacia el interior de las partículas $\mathrm{UiO}-66(\mathrm{Zr} \mathrm{Ti})-\mathrm{NO}_{2}$. La figura 7.10 muestra los espectros generales de XPS que indican la presencia de los diferentes elementos en el material $\mathrm{UiO}-66(\mathrm{Zr})-\mathrm{NO}_{2}$, así como la sustitución parcial de $\mathrm{Zr}^{4+}$ por $\mathrm{Ti}^{4+}$ (Figuras 7.11-7.14). Como se esperaba, la relación atómica Ti/Zr aumenta en todos los casos con el porcentaje de intercambio iónico, lo que está de acuerdo con el éxito de la incorporación de $\mathrm{Ti}^{4+}$ en el material sólido. La figura $7.10 \mathrm{~b}$-d muestra también un desplazamiento en los valores de energía de enlace para los picos $\mathrm{Zr} 3 \mathrm{~d}$, Ti2p y $\mathrm{O} 1 \mathrm{~s}$ a medida que aumenta el contenido en $\mathrm{Ti}^{4+}$. Existen precedentes en la literatura que sugieren que estos desplazamientos en la energía de enlace en los picos de XPS reflejan la menor electronegatividad que experimentan los elementos a medida que los iones de $\mathrm{Zr}^{4+}$ se intercambian por iones $\mathrm{Ti}^{4+}$ y la misma explicación sirve para el presente estudio. ${ }^{51,61,64-66}$ 
Oxidación de alquenos empleando UiO-66 con intercambio combinado de átomos de titanio y sustitución en los ligandos.
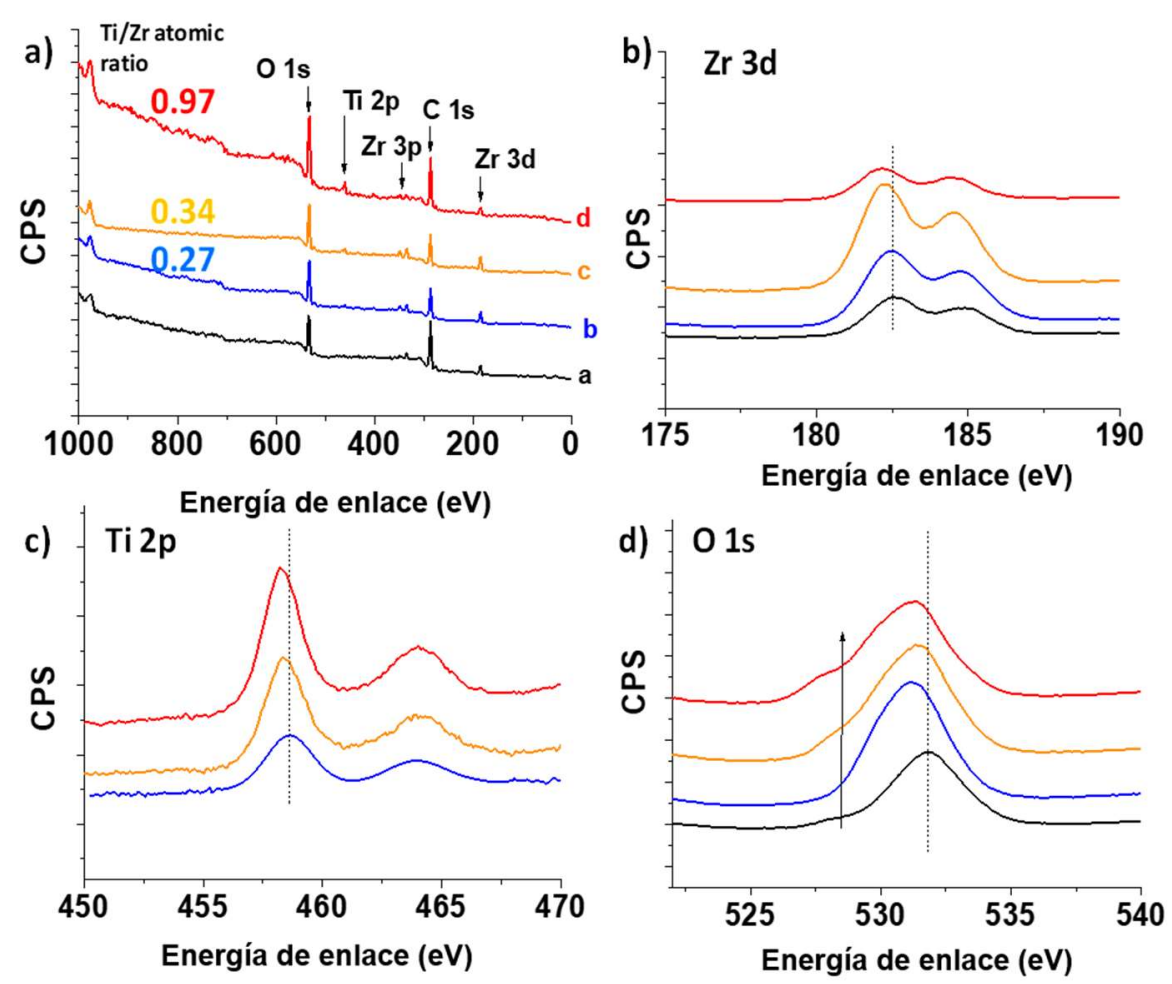

Figura 7.10. Espectros generales de XPS (a) y picos en alta resolución para $\mathrm{Zr} 3 \mathrm{~d}$ (b), Ti 2p (c) y O 1s (d) para las muestras $\mathrm{UiO}-66(\mathrm{Zr} \mathrm{Ti})-\mathrm{H}$. 

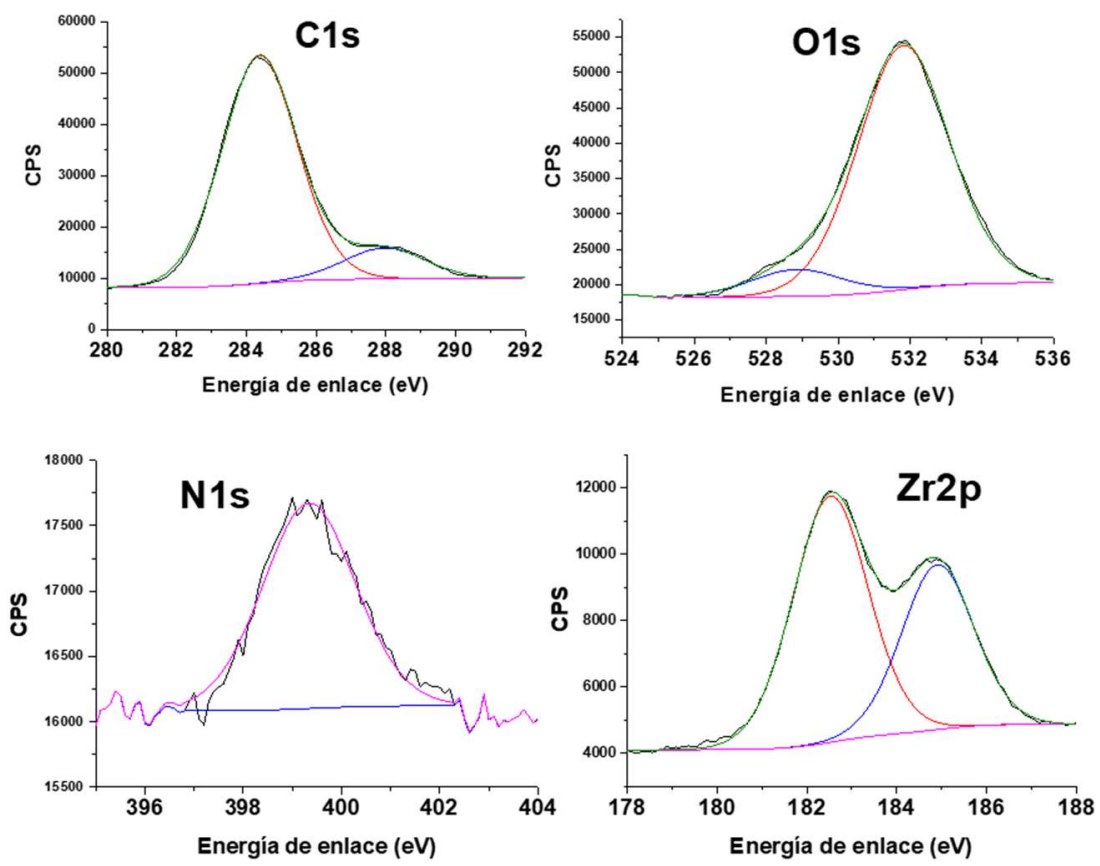

Figura 7.11. XPS de alta resolución para la muestra $\mathrm{UiO}-66(\mathrm{Zr})-\mathrm{NO}_{2}$. 
Oxidación de alquenos empleando UiO-66 con intercambio combinado de átomos de titanio y sustitución en los ligandos.
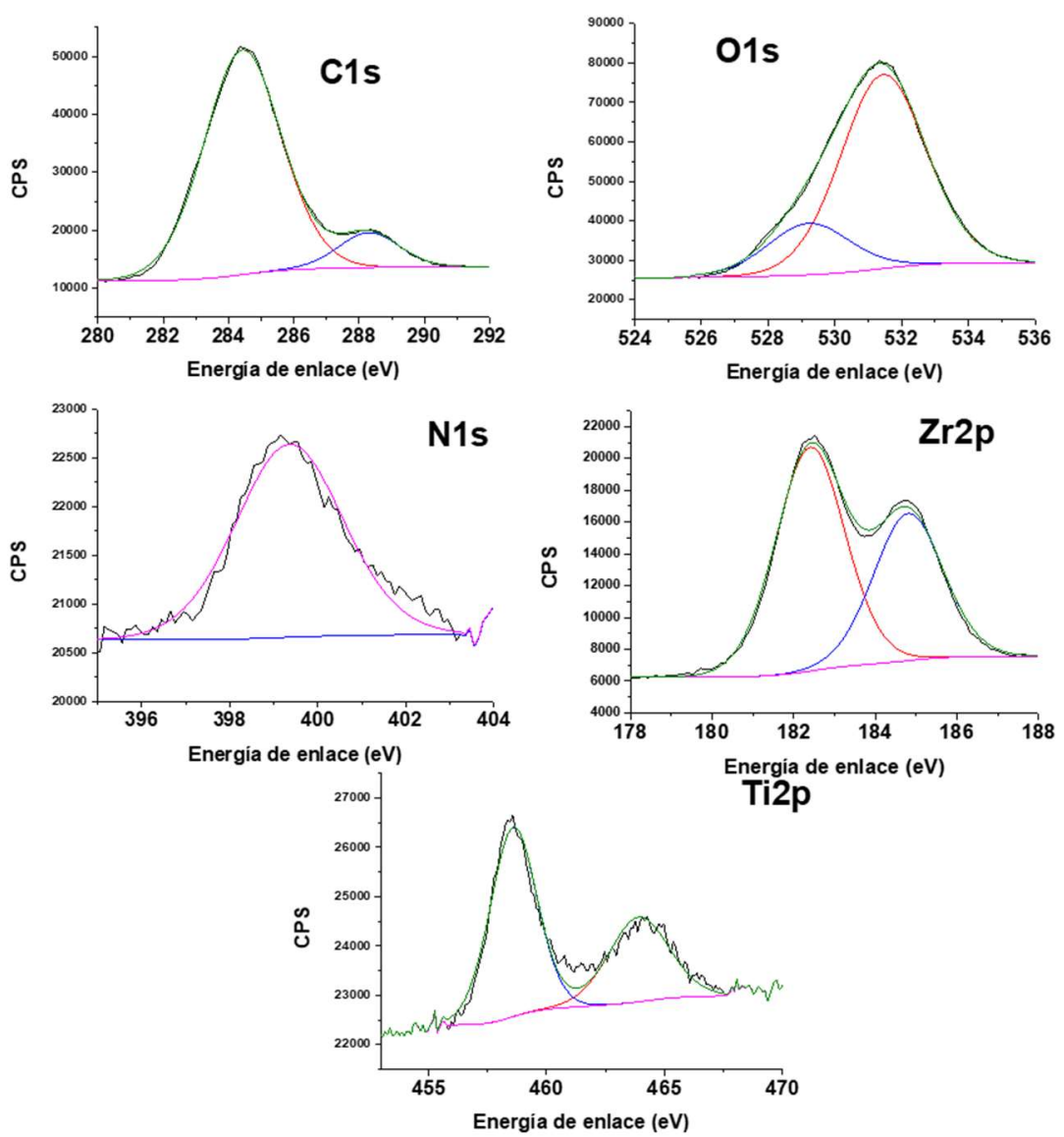

Figura 7.12. XPS de alta resolución para la muestra UiO-66 $\left(\mathrm{Zr}_{5.97} \mathrm{Ti}_{0.03}\right)-\mathrm{NO}_{2}$. 

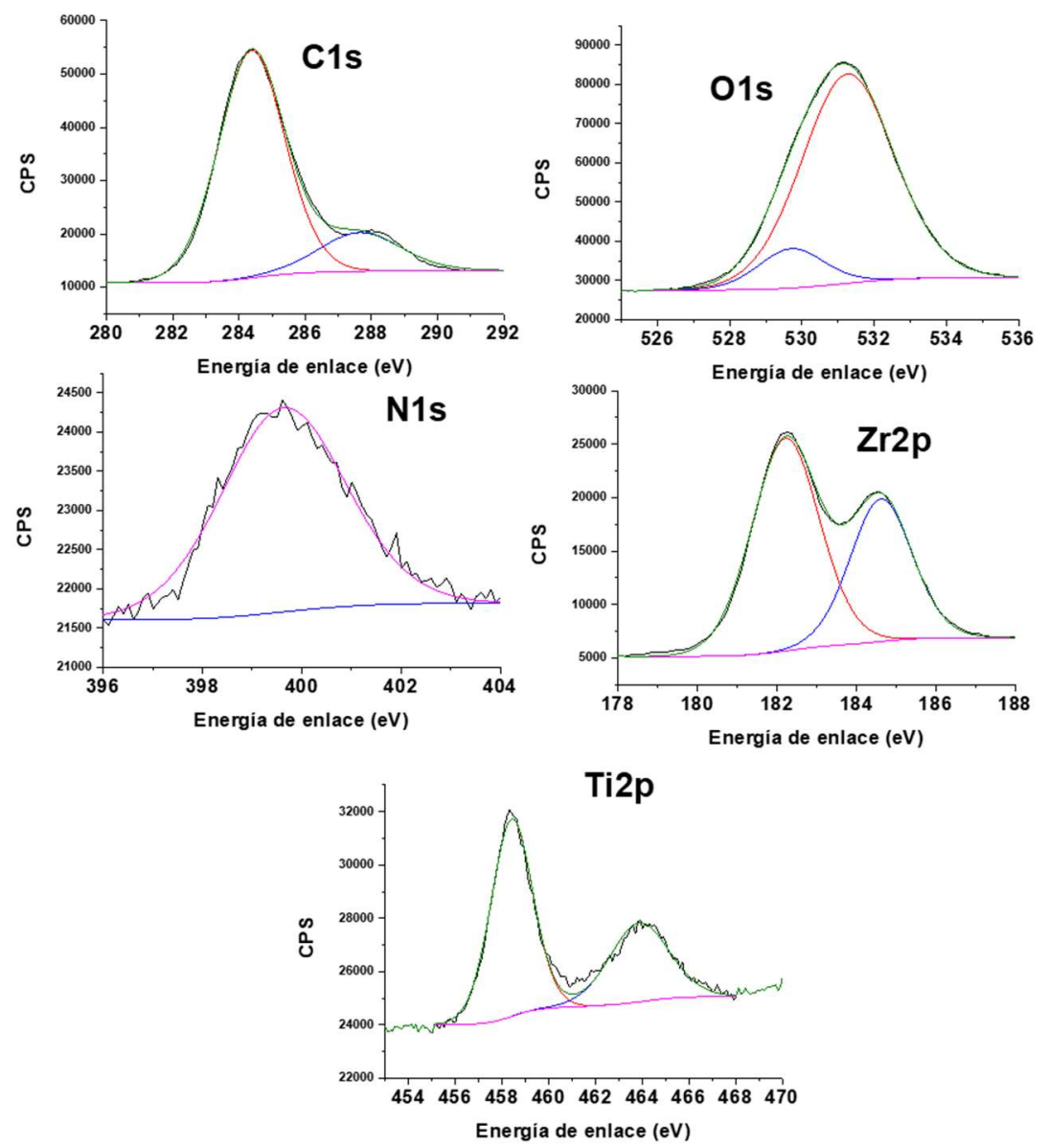

Figura 7.13. XPS de alta resolución para la muestra UiO-66( $\left.\mathrm{Zr}_{5.94} \mathrm{Ti} \mathbf{T i}_{0.06}\right)-\mathrm{NO}_{2}$. 

ción en los ligandos.
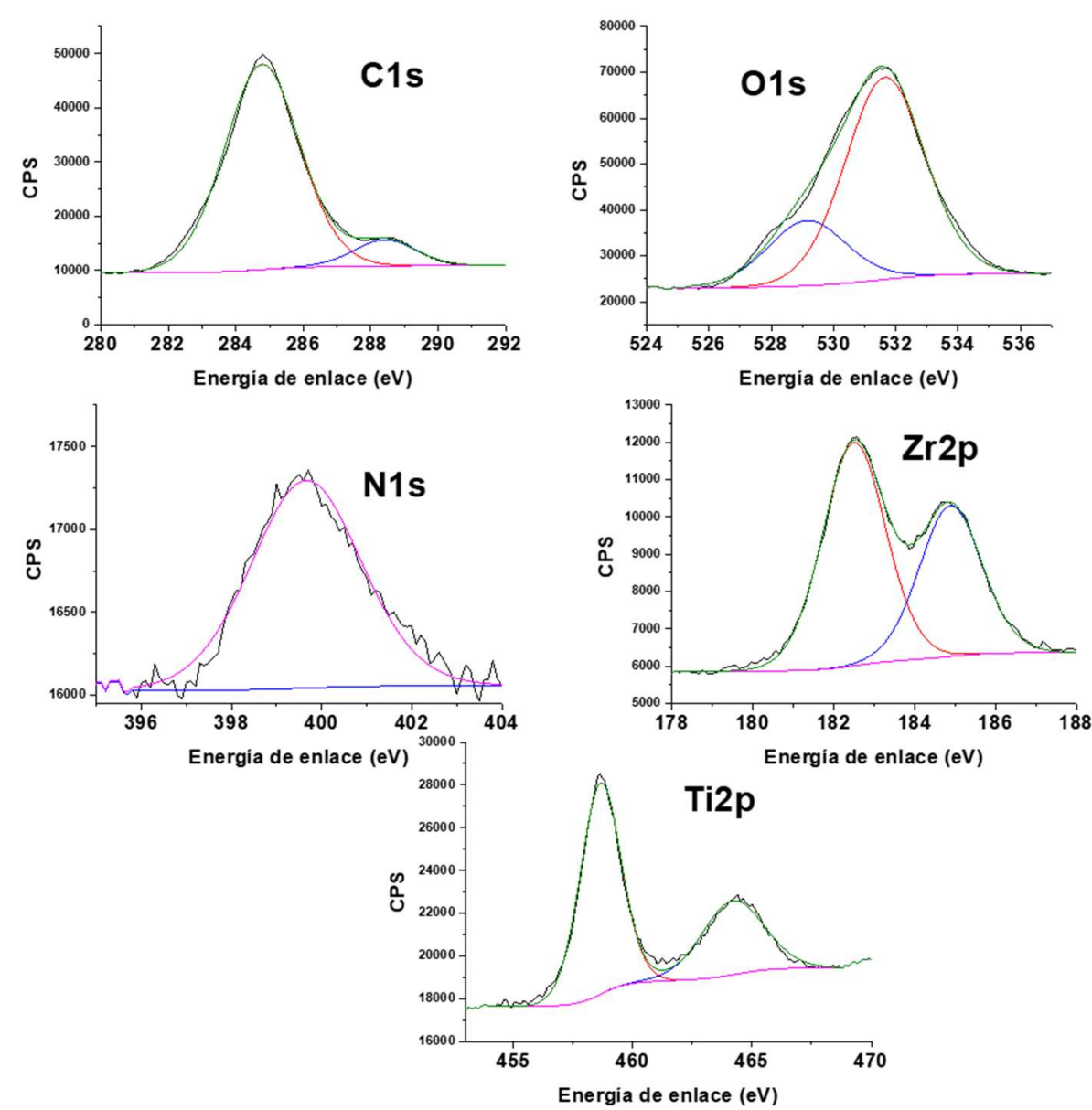

Figura 7.14. XPS de alta resolución para la muestra $\mathrm{UiO}-66\left(\mathrm{Zr}_{5.4} \mathrm{Ti} \mathbf{1}_{0.6}\right)-\mathrm{NO}_{2}$.

Los espectros de reflectancia difusa para la serie de materiales UiO-66-X fueron también medidos (Figuras 7.15-7.17). Como ha sido descrito en la bibliografía, ${ }^{29,34}$ se observa un desplazamiento batocrómico en el inicio de la adsorción, dando lugar a un ensanchamiento de la adsorción con la sustitución parcial de $\mathrm{Zr}^{4+}$ por $\mathrm{Ti}^{4+}$ con respecto al material precursor UiO-66(Zr)-X $\left(\mathrm{X}: \mathrm{H}, \mathrm{NO}_{2} \circ \mathrm{NH}_{2}\right)$ hacia longitudes de onda más largas. ${ }^{54,61}$ 


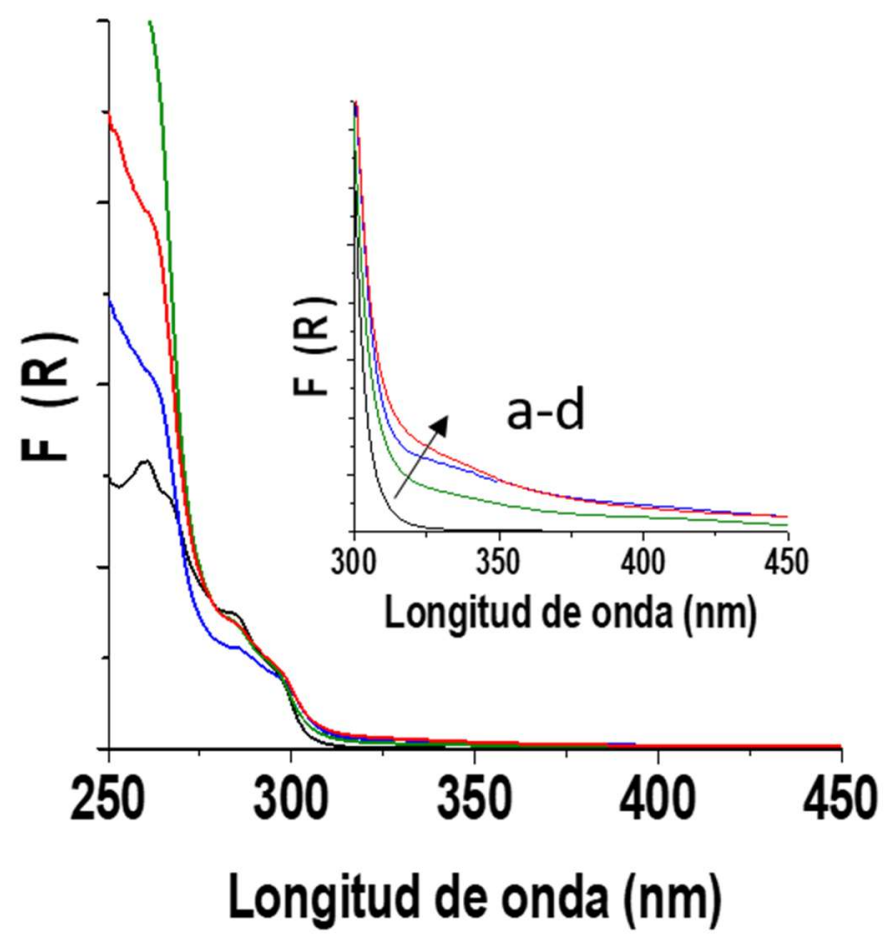

Figura 7.15. Espectros UV-Vis por reflectancia difusa para las muestras UiO-66(Zr)-H (a) UiO66( $\left.\mathrm{Zr}_{5.97} \mathrm{Ti}_{0.03}\right)-\mathrm{H}$ (b), UiO-66( $\left.\mathrm{Zr}_{5.94} \mathrm{Ti}_{0.06}\right)-\mathrm{H}$ (c) y UiO-66 ( $\left.\mathrm{Zr}_{5.4} \mathrm{Ti}_{0.6}\right)-\mathrm{H}$ (d). 


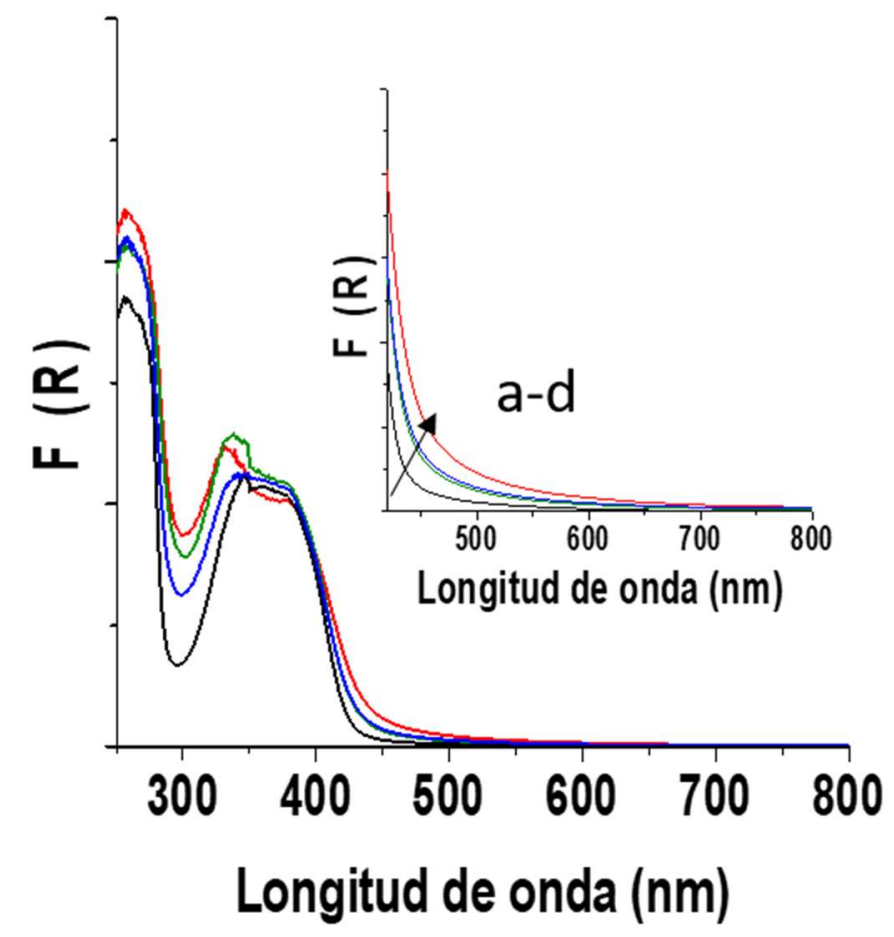

Figura 7.16. Espectros UV-Vis por reflectancia difusa para las muestras UiO-66(Zr)- $\mathrm{NH}_{2}$ (a) UiO66 $\left(\mathrm{Zr}_{5.97} \mathrm{Ti}_{0.03}\right)-\mathrm{NH}_{2}$ (b), UiO-66 $\left(\mathrm{Zr}_{5.94} \mathrm{Ti}_{0.06}\right)-\mathrm{NH}_{2}$ (c) y UiO-66 $\left(\mathrm{Zr}_{5.4} \mathrm{Ti}_{0.6}\right)-\mathrm{NH}_{2}(\mathrm{~d})$. 


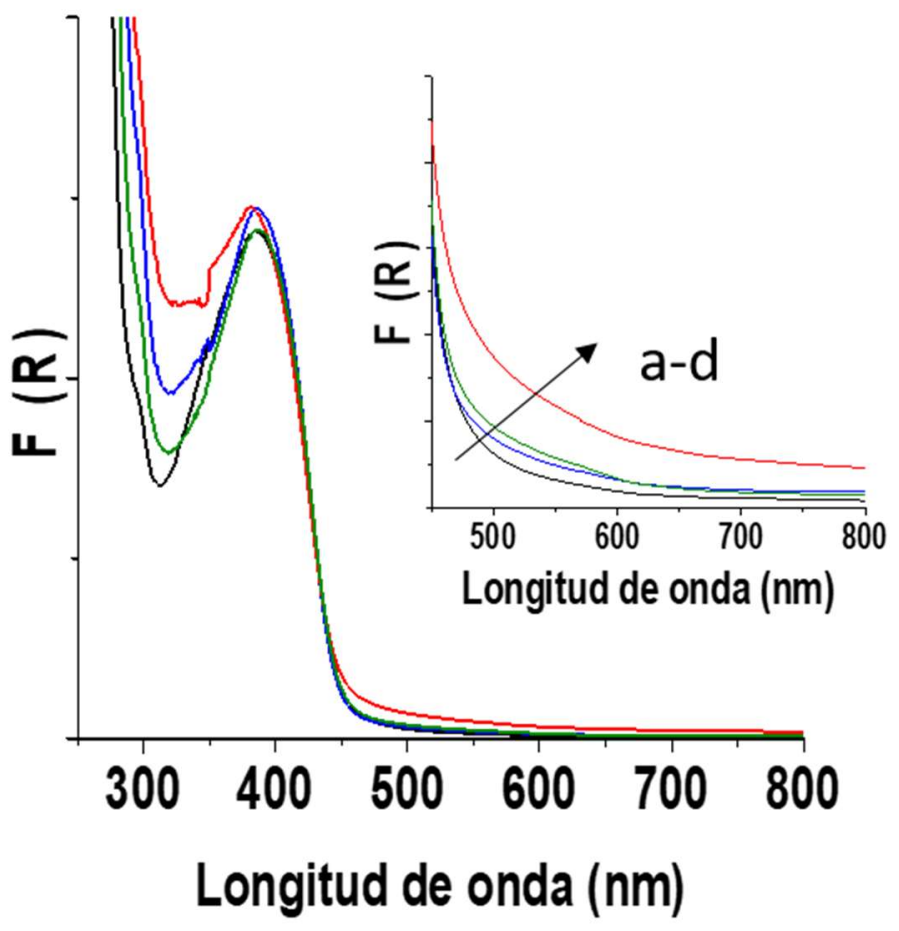

Figura 7.17. Espectros UV-Vis por reflectancia difusa para las muestras $\mathrm{UiO}-66(\mathrm{Zr})-\mathrm{NO}_{2}$ (a) $\mathrm{UiO}-$ $66\left(\mathrm{Zr}_{5.97} \mathrm{Ti}_{0.03}\right)-\mathrm{NO}_{2}$ (b), UiO-66 $\left(\mathrm{Zr}_{5.94} \mathrm{Ti}_{0.06}\right)-\mathrm{NO}_{2}$ (c) y UiO-66 $\left(\mathrm{Zr}_{5.4} \mathrm{Ti}_{0.6}\right)-\mathrm{NO}_{2}$ (d).

La morfología de las partículas de las muestras UiO-66(Zr)-H se determinó mediante imágenes de SEM (Figura 7.18 y Tablas 7.3-7.5). Las imágenes de SEM para las muestras UiO-66(Zr)-X antes del intercambio por Ti muestran que el material está constituido por cristales con forma definida en el rango de los micrómetros que están acompañados por partículas mucho más pequeñas. Los mapas por EDS de las partículas individuales muestras la distribución homogénea de elementos de acuerdo con la fórmula de la celda unidad. Es digno de comentar que la morfología de las partículas cambia algo durante el procedimiento de intercambio iónico, siendo el cambio más característico la disminución en la población de los cristales de mayor tamaño y un aumento en consonancia de las partículas mucho más pequeñas en el rango de nm. Este cambio morfológico sugiere que hay una rotura de las partículas grandes durante el intercambio iónico. Los mapas de distribución de elementos a resolución submicrométrica mediante EDS (Espectrometría de dispersión de energía de rayos X) muestra que el titanio esta homogéneamente distribuido en la partícula (Figura 7.19-7.29). Especialmente a altos porcentajes de intercambio de Ti para los cuales las imágenes de Ti K $\alpha 1$ están más definidas, 
Oxidación de alquenos empleando UiO-66 con intercambio combinado de átomos de titanio y sustitución en los ligandos.

se observa una buena coincidencia en la distribución de $\mathrm{Zr}$ y Ti, conformando que el Ti está presente en las mismas posiciones que $\mathrm{Zr}$, a resolución submicrométrica. La figura 7.18 muestra una selección de imágenes para ilustrar la información obtenida por SEM, a saber, el aumento en la proporción de partículas pequeñas frente a las grandes con el aumento en el porcentaje de Ti y la coincidencia entre la distribución de Zr y Ti en las figuras.
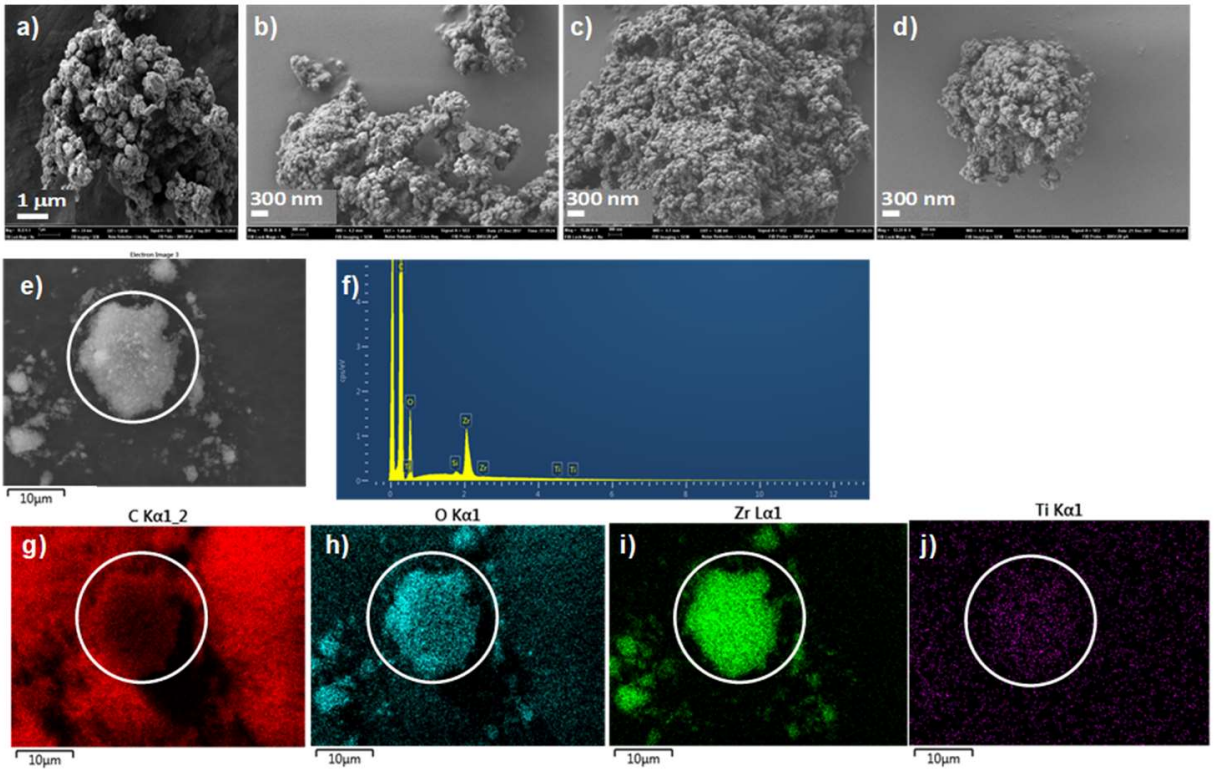

Figuras 7.18. Imágenes de SEM para las muestras UiO-66(Zr)-H (a) UiO-66 ( $\left.\mathrm{Zr}_{5.97} \mathrm{Ti}_{0.03}\right)-\mathrm{H}$ (b), UiO$66\left(\mathrm{Zr}_{5.94} \mathrm{Ti}_{0.06}\right)-\mathrm{H}$ (c) y UiO-66 $\left(\mathrm{Zr}_{5.4} \mathrm{Ti}_{0.6}\right)-\mathrm{H}(\mathrm{d})$. Mapas y espectro de la imagen (e) con una circulo para la muestra UiO-66 (Zr5.94 Ti0.06)-H (f-j). 
Tabla 7.3. Imágenes SEM para las muestras UiO-66-H.

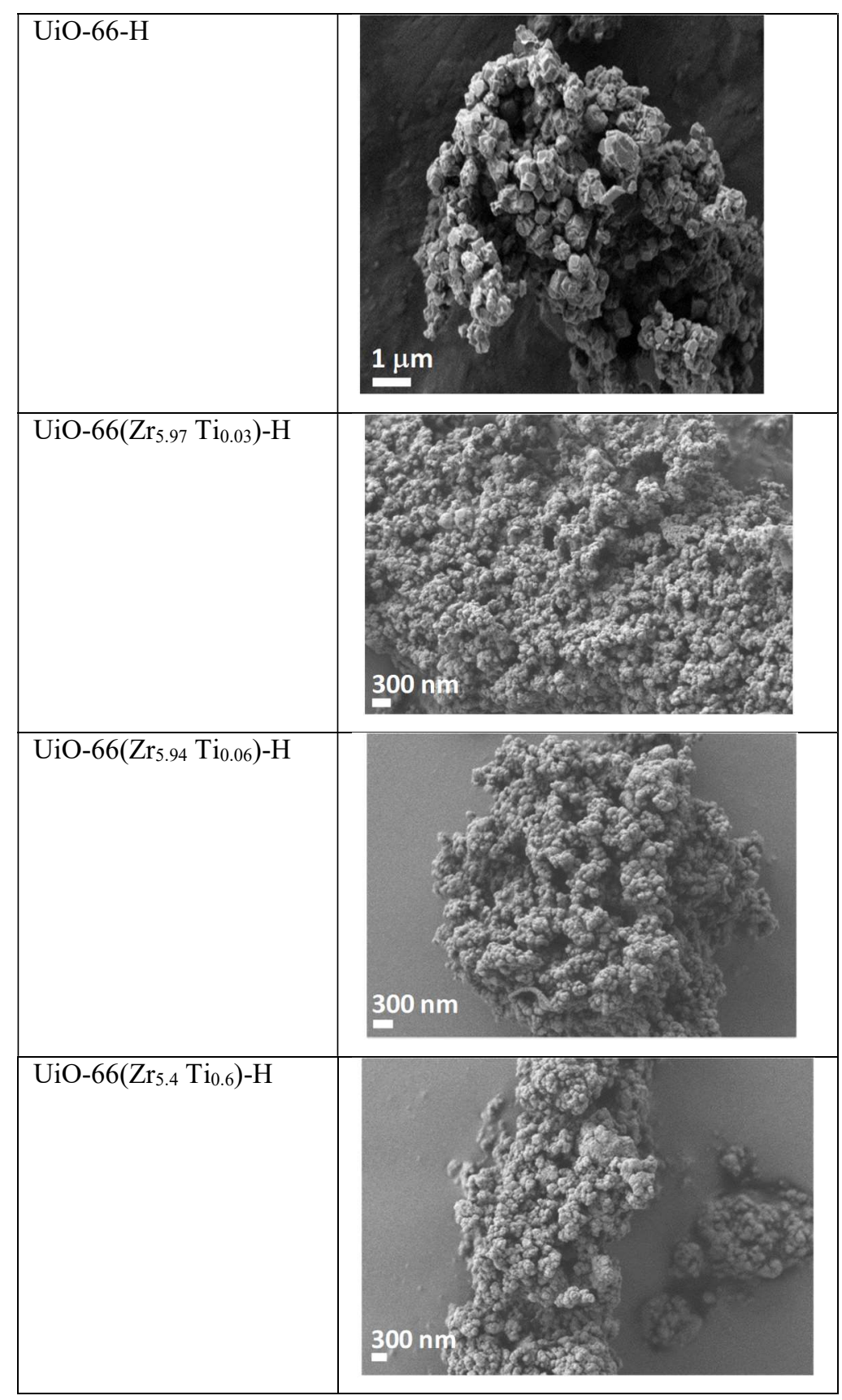


Oxidación de alquenos empleando UiO-66 con intercambio combinado de átomos de titanio y sustitución en los ligandos.

Tabla 7.4. Imágenes SEM para las muestras UiO-66-NO2.

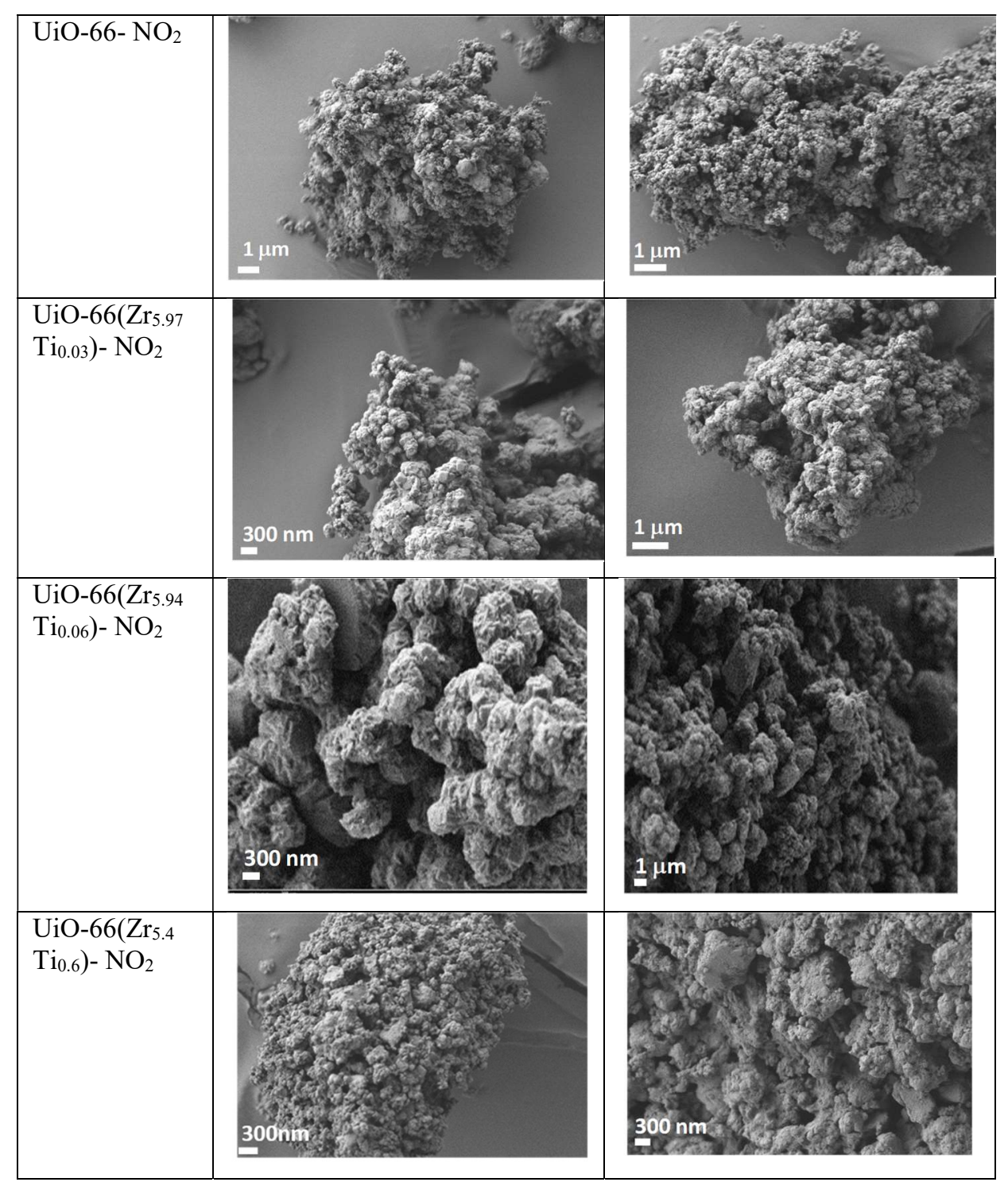


Tabla 7.5. Imágenes SEM para las muestras UiO-66- $\mathrm{NH}_{2}$.

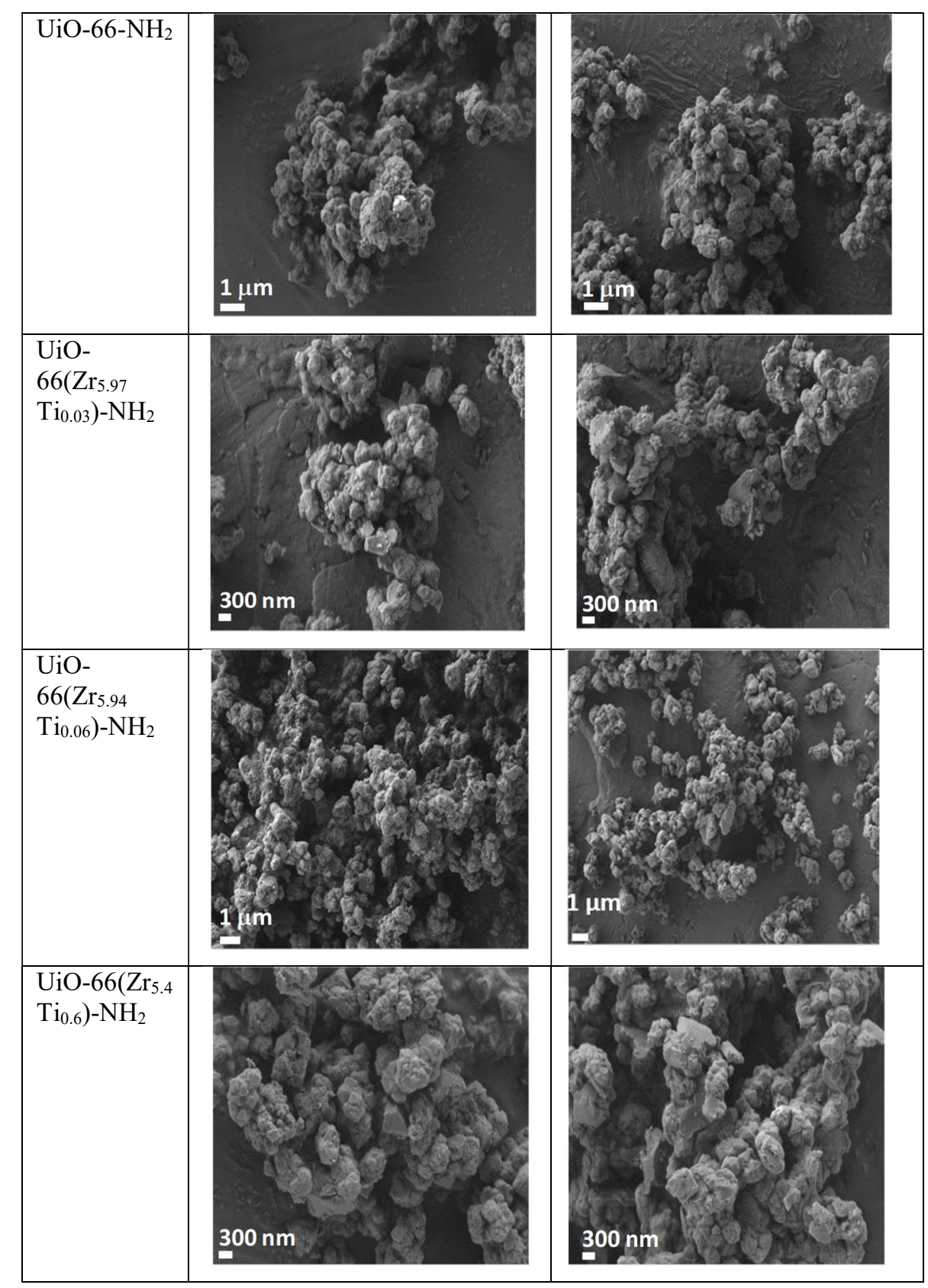


Oxidación de alquenos empleando UiO-66 con intercambio combinado de átomos de titanio y sustitución en los ligandos.

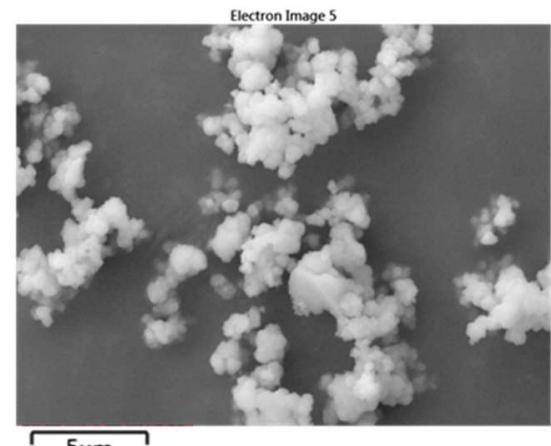

C K $\alpha 12$
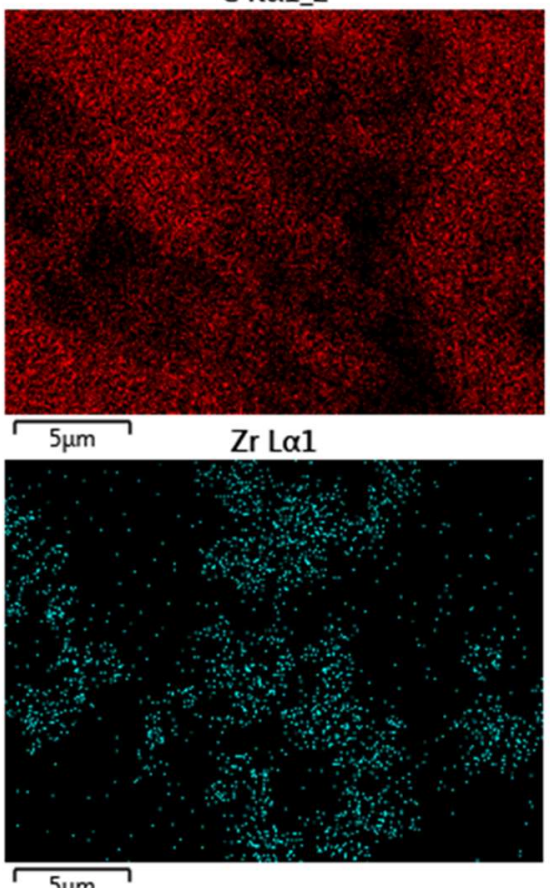

$5 \mu \mathrm{m}$

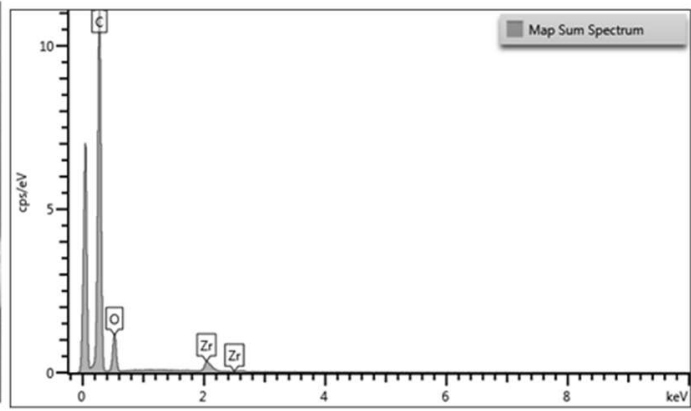

$\mathrm{O} K \alpha 1$

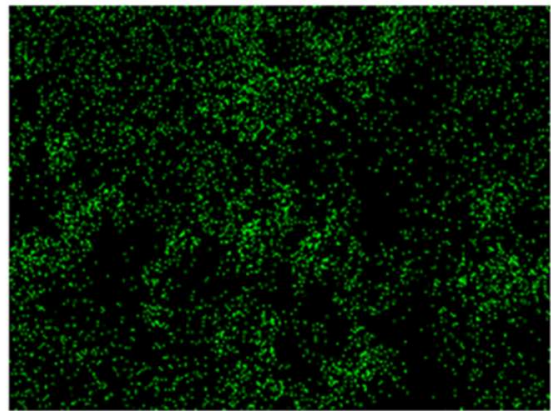

N Ka1_2

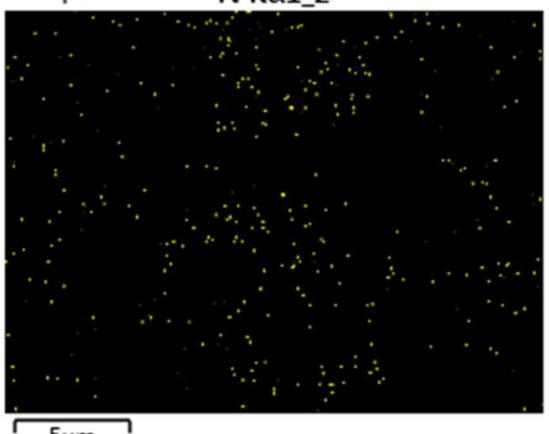

$5 \mu \mathrm{m}$

Figuras 7.19. Imágenes de SEM, mapa de los elementos y análisis obtenido usando un detector EDX para el UiO-66(Zr)-NH 


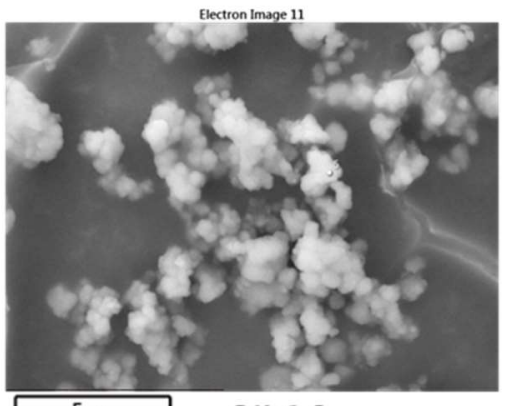

C K $\alpha 1$
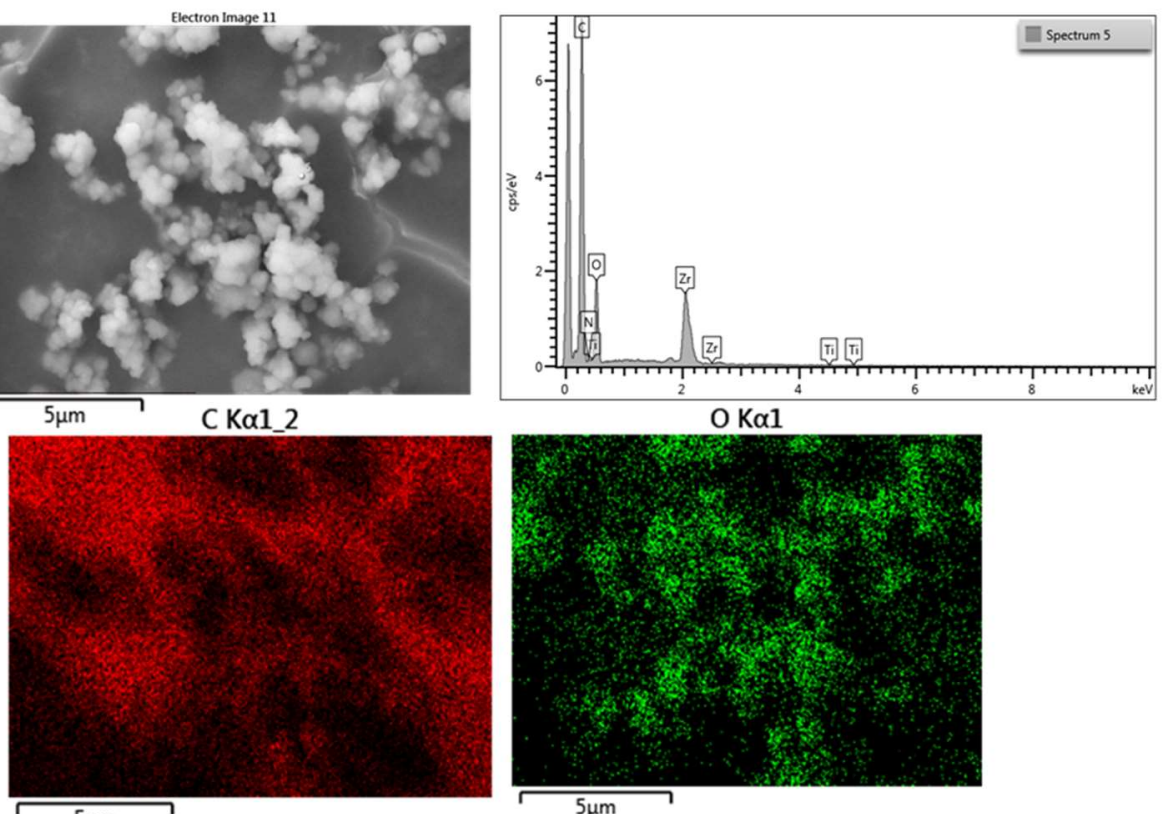

$5 \mu \mathrm{m}$

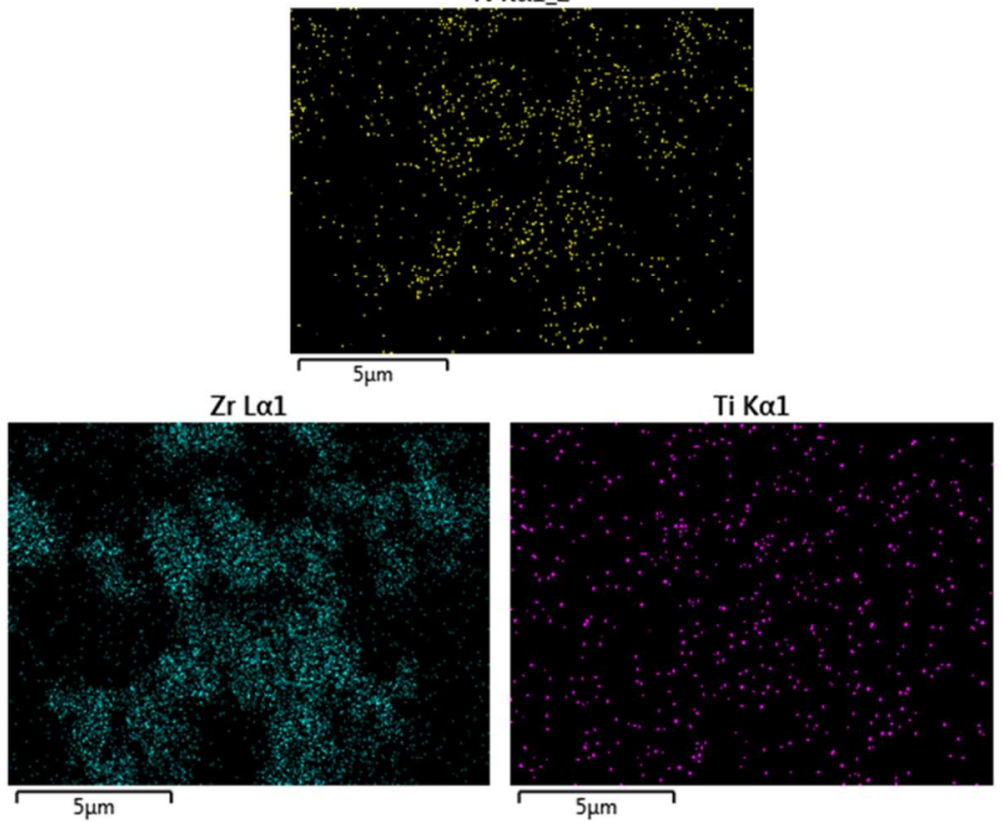

Figuras 7.20. Imágenes de SEM, mapa de los elementos y análisis obtenido usando un detector EDX para el UiO-66(Zr $\left.\mathrm{Zr}_{5.97} \mathrm{Ti}_{0.03}\right)-\mathrm{NH}_{2}$. 
Oxidación de alquenos empleando UiO-66 con intercambio combinado de átomos de titanio y sustitución en los ligandos.

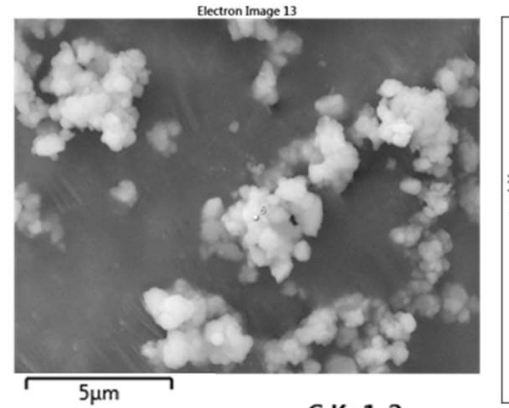

$\mathrm{C} K \alpha 1_{2} 2$

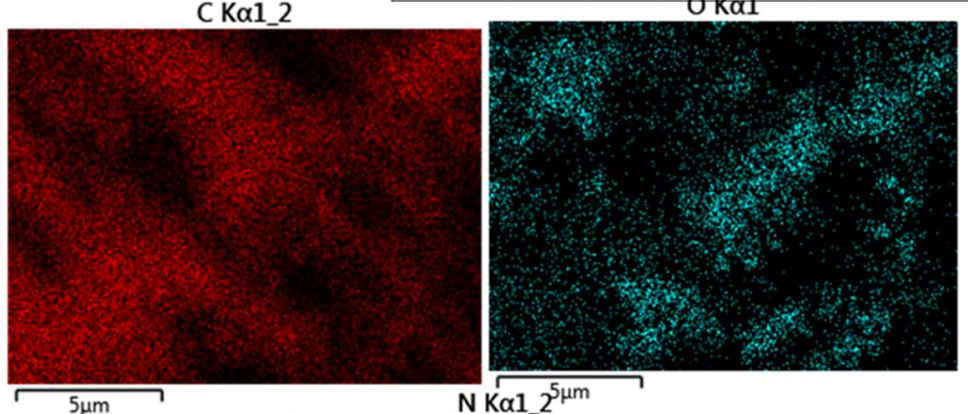

$\mathrm{N}$ Ka1 $2^{5 \mu m}$

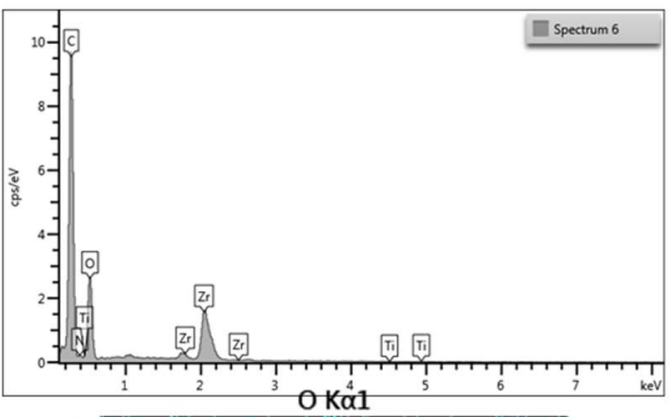

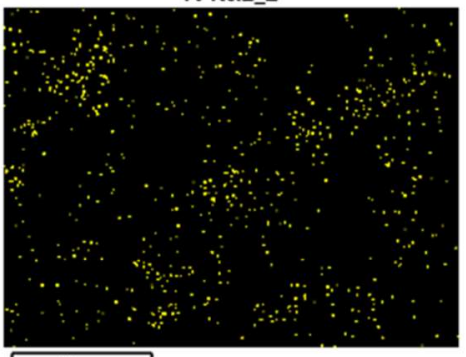

$\operatorname{ZrL} \alpha 1$

$\mathrm{Ti} \mathrm{K} \alpha 1$
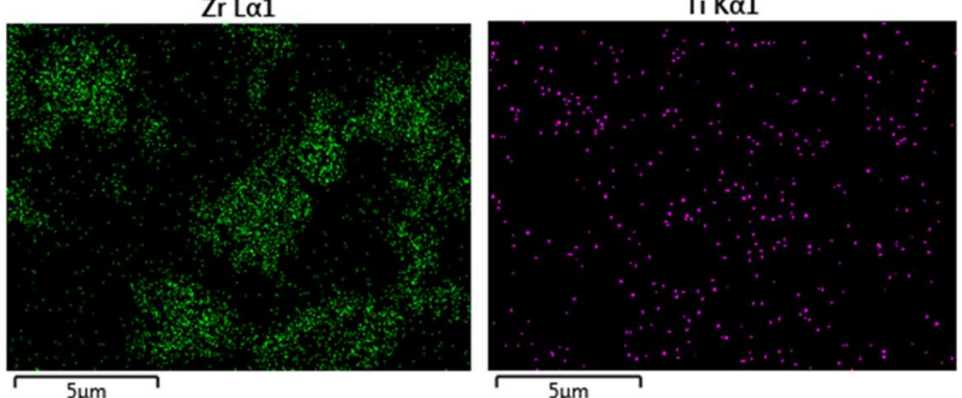

Figuras 7.21. Imágenes de SEM, mapa de los elementos y análisis obtenido usando un detector EDX para el UiO-66 $\left(\mathrm{Zr}_{5.94} \mathrm{Ti}_{0.06}\right)-\mathrm{NH}_{2}$. 

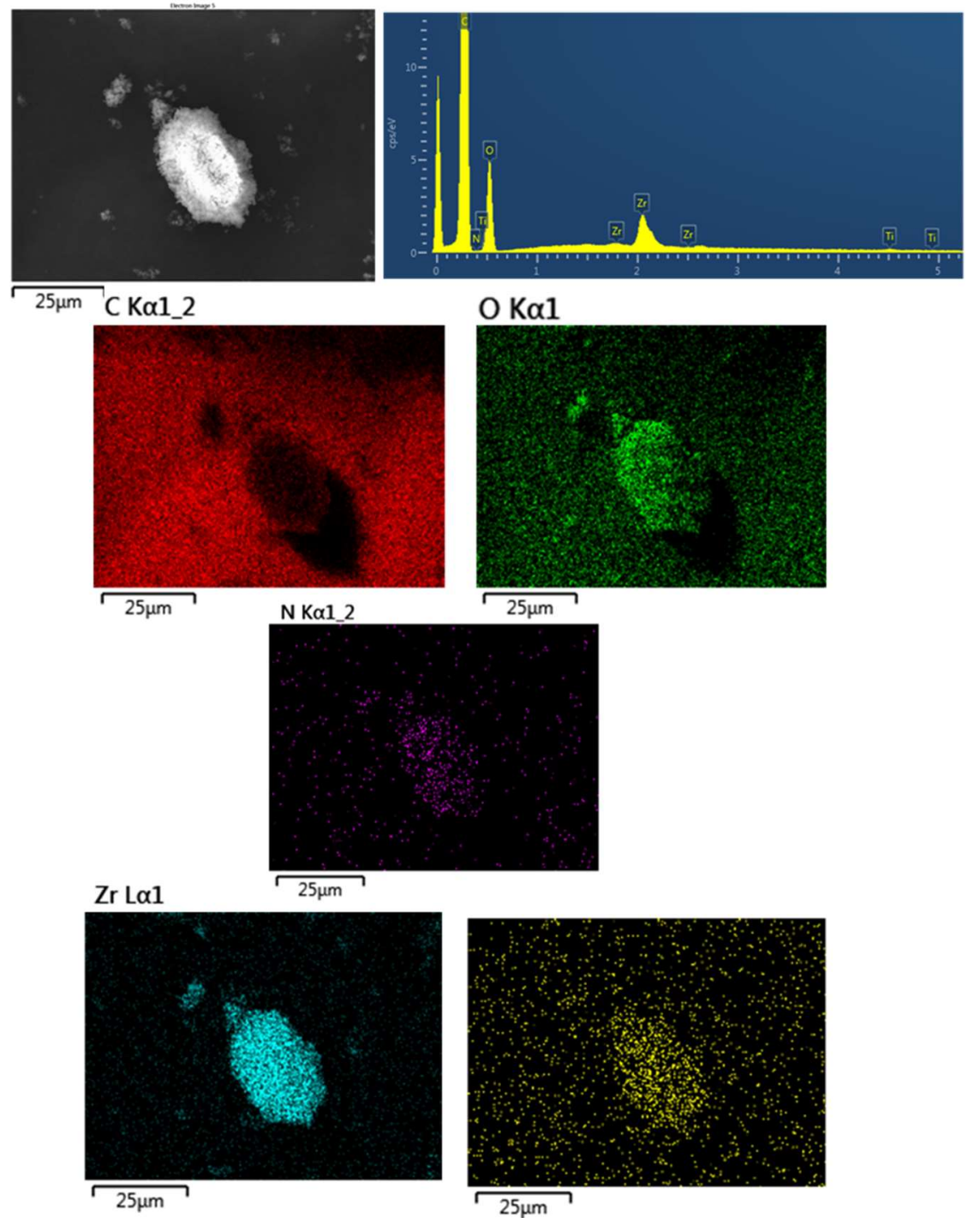

Figuras 7.22. Imágenes de SEM, mapa de los elementos y análisis obtenido usando un detector EDX para el UiO-66( $\left.\mathrm{Zr}_{5.6} \mathrm{Ti}_{0.4}\right)-\mathrm{NH}_{2}$. 
Oxidación de alquenos empleando UiO-66 con intercambio combinado de átomos de titanio y sustitución en los ligandos.

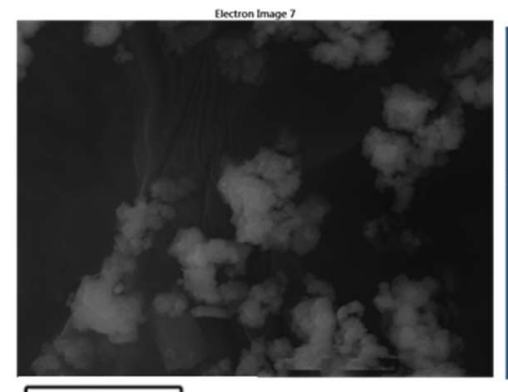

$\longdiv { 5 \mu \mathrm { m } }$

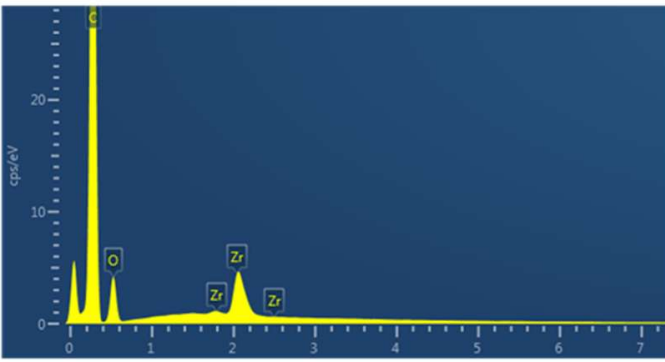

$\mathrm{O} K \alpha 1$
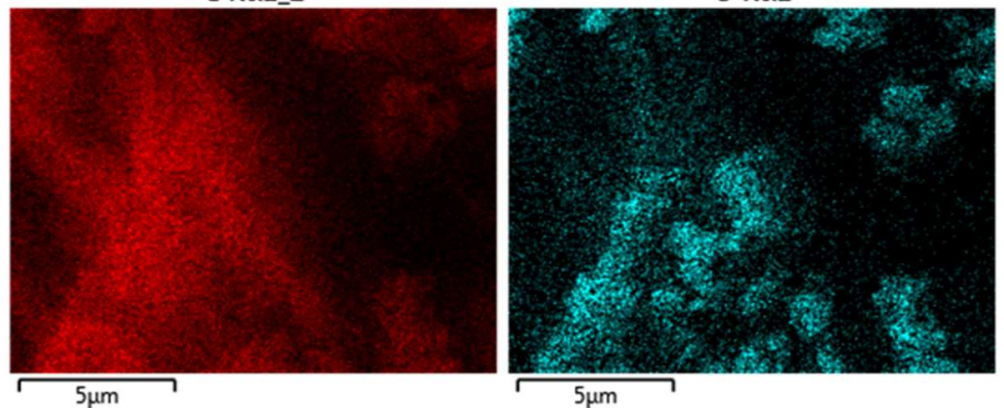

$\operatorname{Zr} \operatorname{La1}$

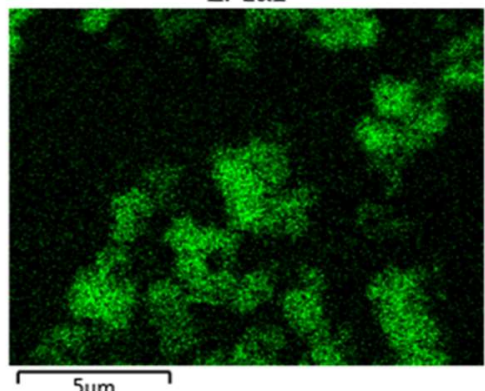

$5 \mu \mathrm{m}$

Figuras 7.23. Imágenes de SEM, mapa de los elementos y análisis obtenido usando un detector EDX para el UiO-66(Zr)-H. 


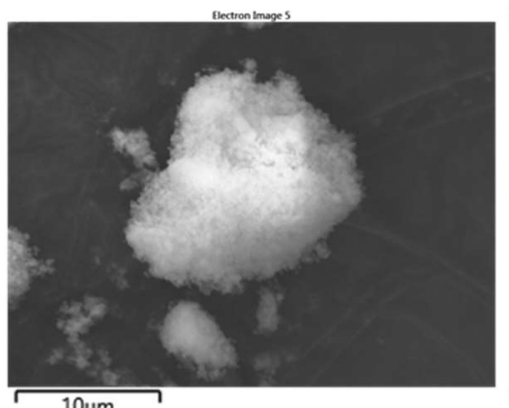

C Ka1_2

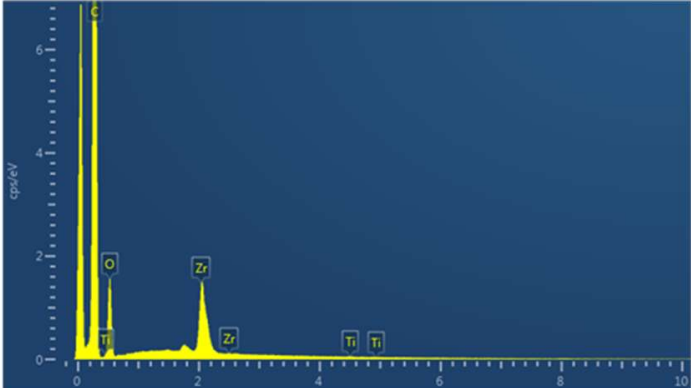

$\mathrm{O} K \alpha 1$

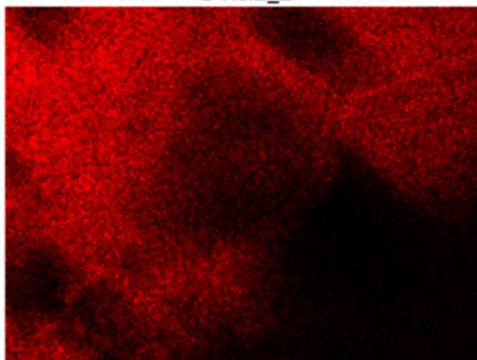

$10 \mu \mathrm{m} \quad \mathrm{Zr} \operatorname{L} \alpha 1$

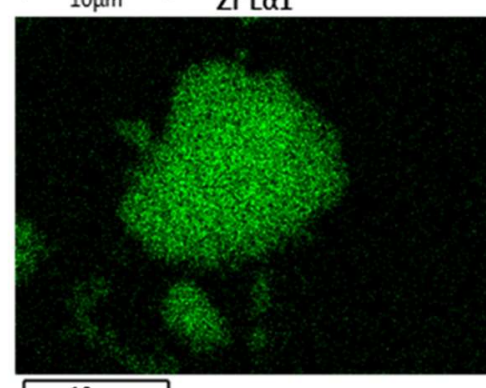

$10 \mu \mathrm{m}$

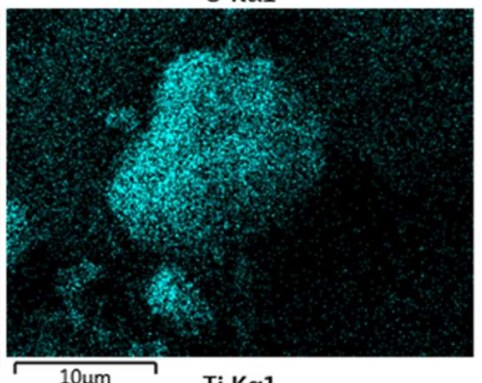

Ti Kal

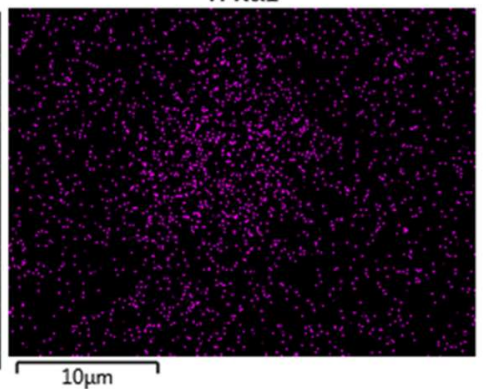

Figuras 7.24. Imágenes de SEM, mapa de los elementos y análisis obtenido usando un detector EDX para el UiO-66(Zr $\left.5.97 \mathrm{Ti}_{0.03}\right)-\mathrm{H}$. 
Oxidación de alquenos empleando UiO-66 con intercambio combinado de átomos de titanio y sustitución en los ligandos.
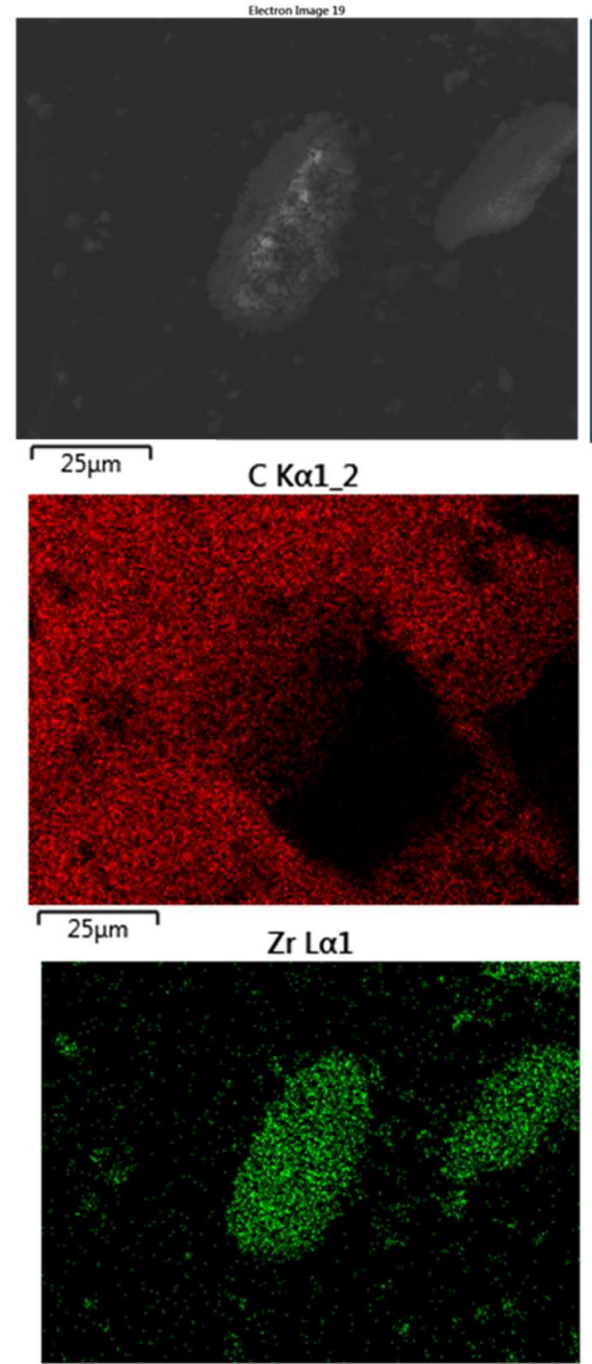

$\longdiv { 2 5 \mu \mathrm { m } }$

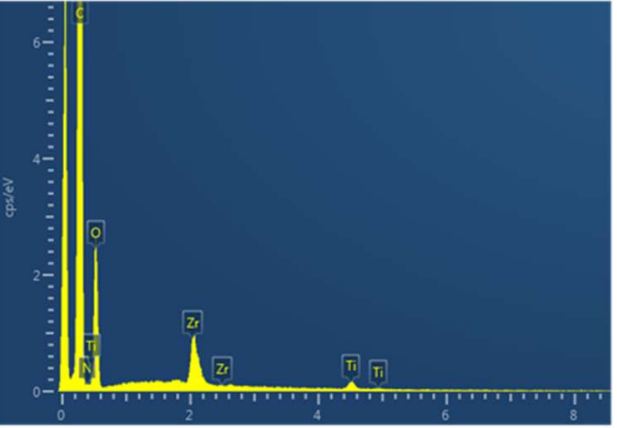

$\mathrm{O} K \alpha 1$

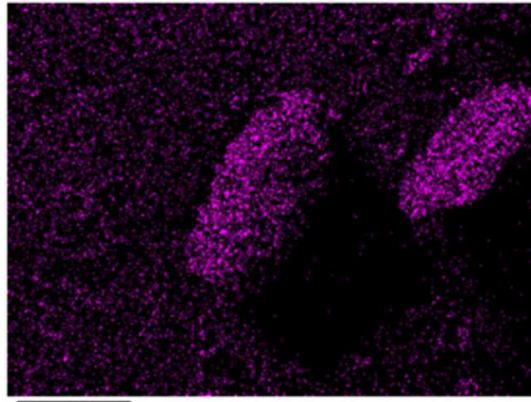

Ti K $\alpha 1$

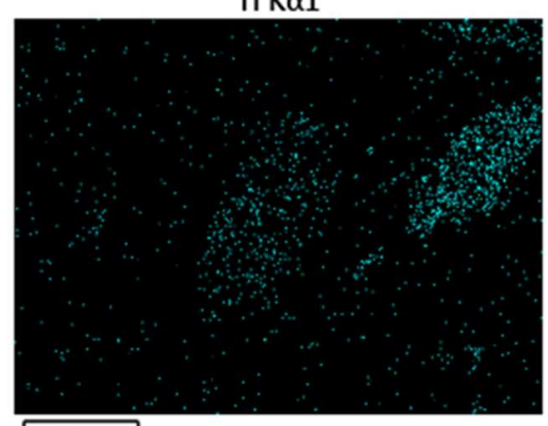

$25 \mu \mathrm{m}$

Figuras 7.25. Imágenes de SEM, mapa de los elementos y análisis obtenido usando un detector EDX para el UiO-66(Zr5.94 Ti0.06)-H. 


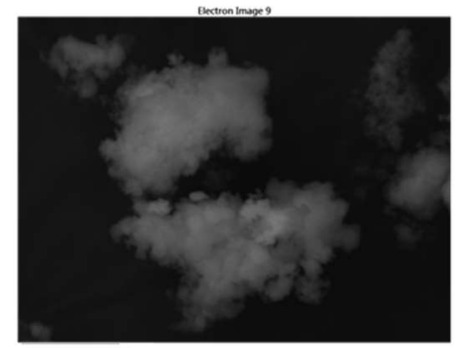

$\longdiv { 5 \text { um } }$

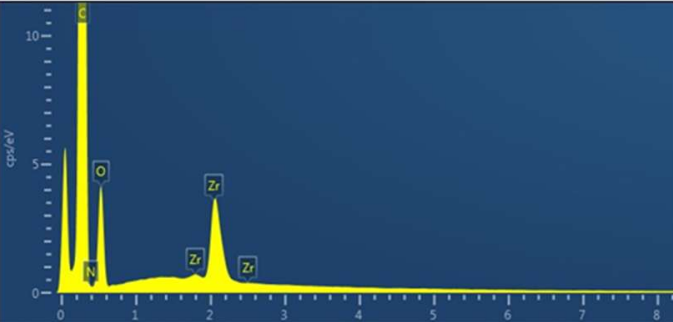

$\mathrm{OK} \alpha 1$

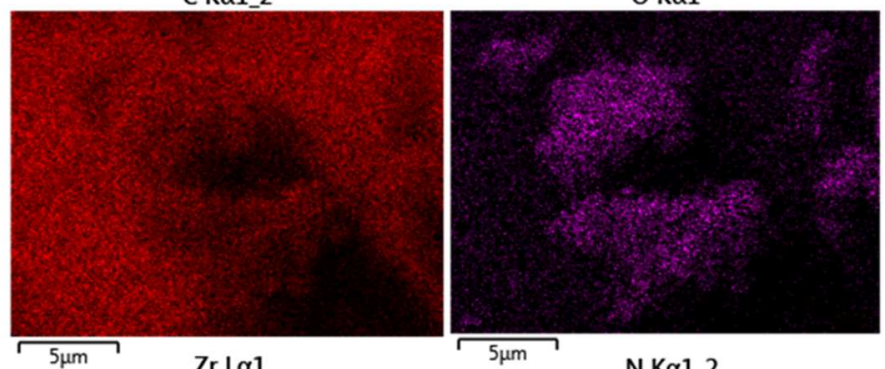

N Ka1_2
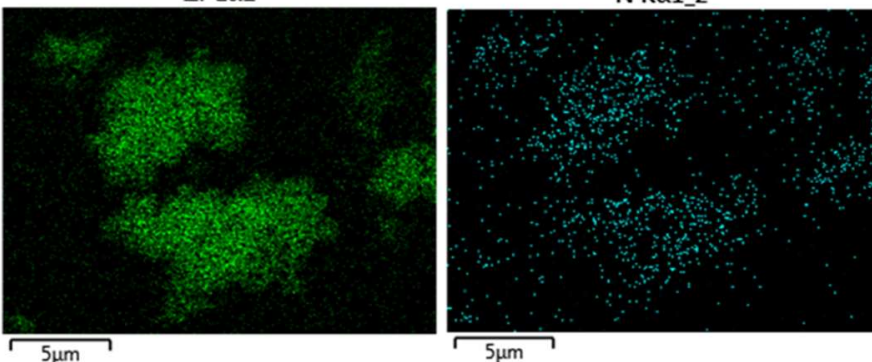

$5 \mu \mathrm{m}$

Figuras 7.26. Imágenes de SEM, mapa de los elementos y análisis obtenido usando un detector EDX para el UiO-66(Zr)-NO $\mathrm{NO}_{2}$. 
Oxidación de alquenos empleando UiO-66 con intercambio combinado de átomos de titanio y sustitución en los ligandos.
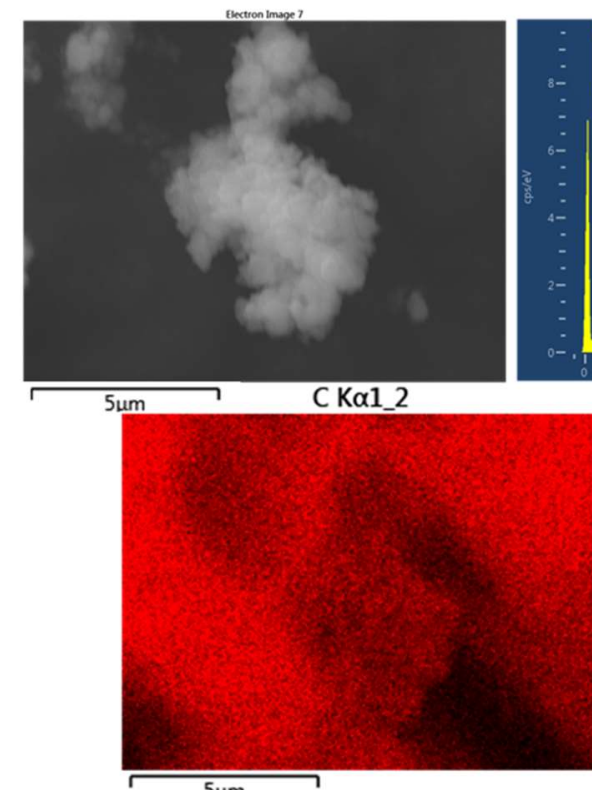

$5 \mu \mathrm{m}$

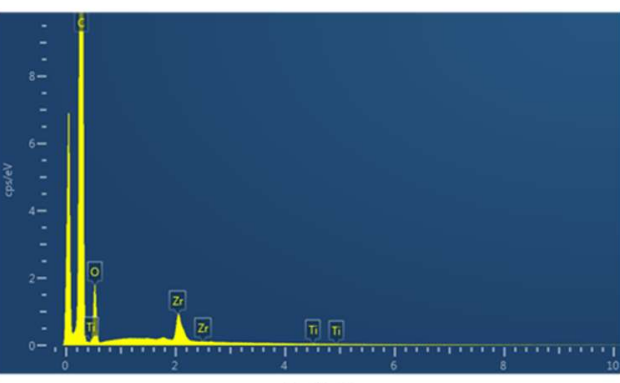

$\mathrm{O} K \alpha 1$

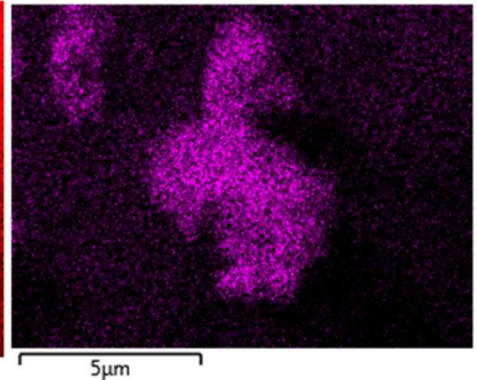

$\mathrm{N} \mathrm{K \alpha 12}$

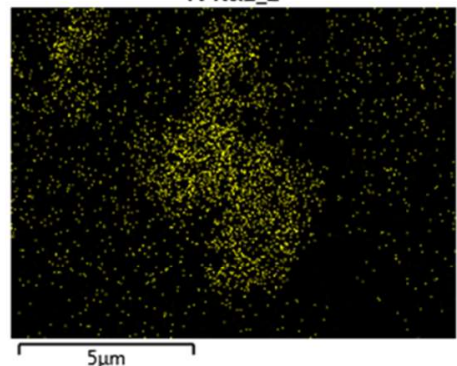

$\mathrm{Ti} \mathrm{K} \alpha 1$
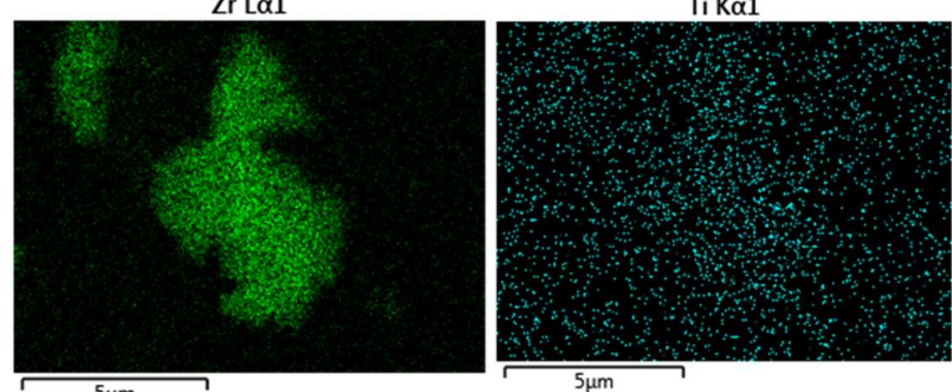

$5 \mu \mathrm{m}$

Figuras 7.27. Imágenes de SEM, mapa de los elementos y análisis obtenido usando un detector EDX para el UiO-66( $\left.\mathrm{Zr}_{5.97} \mathrm{Ti}_{0.03}\right)-\mathrm{NO}_{2}$. 
Capítulo 7.
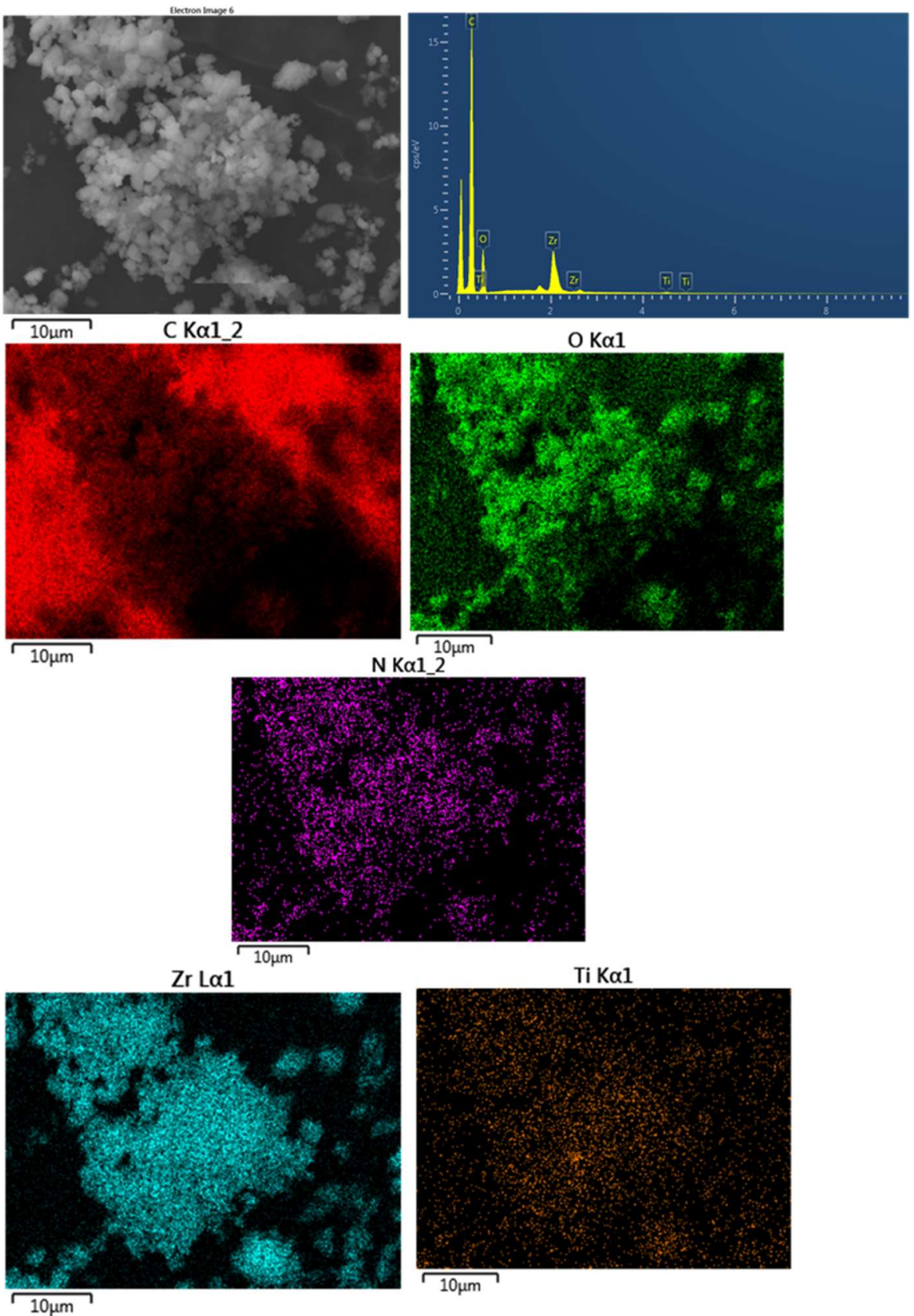

Figuras 7.28. Imágenes de SEM, mapa de los elementos y análisis obtenido usando un detector EDX para el UiO-66( $\left.\mathrm{Zr}_{5.94} \mathrm{Ti}_{0.06}\right)-\mathrm{NO}_{2}$. 
Oxidación de alquenos empleando UiO-66 con intercambio combinado de átomos de titanio y sustitución en los ligandos.
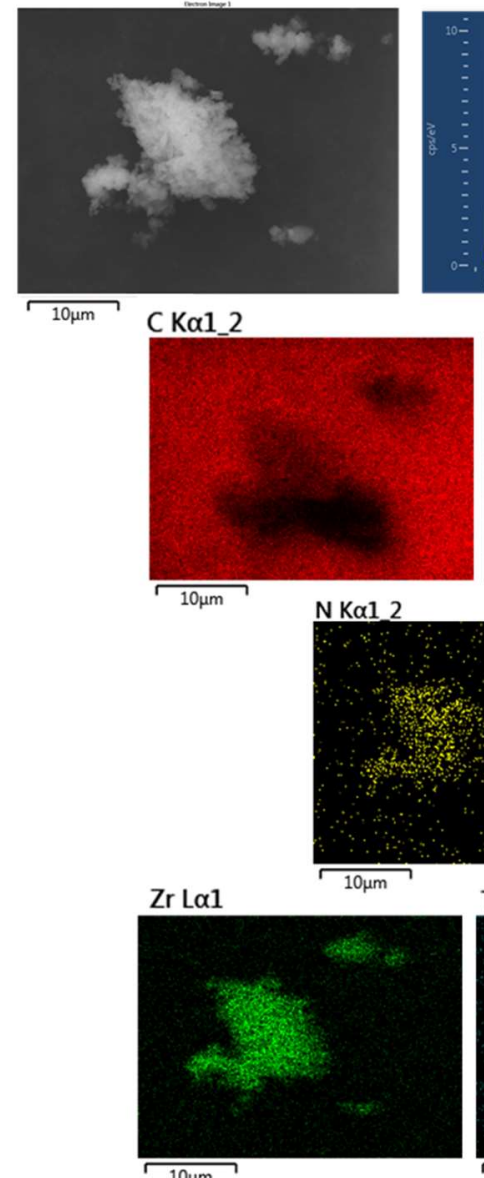

$10 \mu \mathrm{m}$

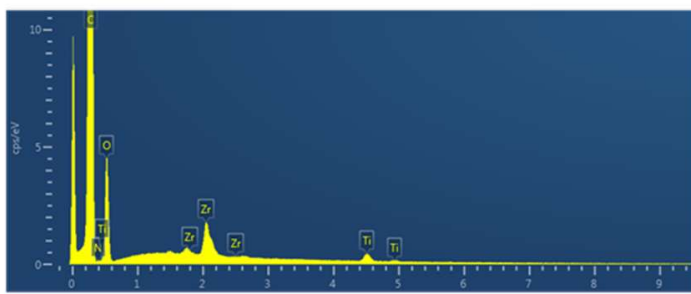

$\mathrm{O} K \alpha 1$

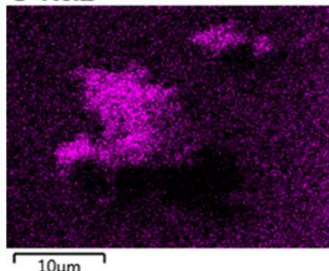

$\longdiv { 1 0 \mu \mathrm { m } }$

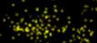

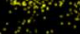
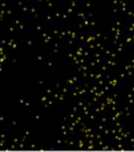

$\mathrm{Ti} \mathrm{K} \alpha 1$

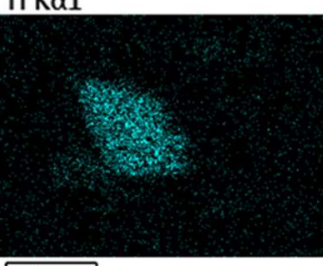

Figuras 7.29. Imágenes de SEM, mapa de los elementos y análisis obtenido usando un detector EDX para el UiO-66( $\left.\mathrm{Zr}_{5.4} \mathrm{Ti}_{0.6}\right)-\mathrm{NO}_{2}$.

Como se ha comentado anteriormente, la evaluación de la actividad catalítica para las muestras UiO-66 $\left(\mathrm{Zr}_{5.4} \mathrm{Ti}_{0.6}\right)$-X se llevó a cabo inicialmente para la oxidación aeróbica de cicloocteno en $\mathrm{CH}_{3} \mathrm{CN}$, el único producto observado en todos los casos fue el correspondiente a la oxidación de cicloocteno (Figura 7.30) y con un balance de masas completo. Se observó que la presencia de UiO-66(Zr)-H (0.08 mol\%) no introduce ninguna actividad catalítica respecto al experimento control (Figura 7.31-7.33). En contraste, se observó que la actividad catalítica para la serie de materiales con los tres ligandos tereftalatos diferentemente sustituidos aumenta consistentemente con el porcentaje de intercambio de $\mathrm{Zr}^{4+}$ por $\mathrm{Ti}^{4+}$, siendo mayor para la muestra sustituida con grupos $\mathrm{NO}_{2}$ (Figura 7.30). A continuación, sin sustituir (Figura 7.32) y finalmente sustituido por 
grupos $\mathrm{NH}_{2}$ (Figura 7.33). La actividad de la serie de muestras UiO-66(Zr Ti)-X se evaluó cuantitativamente comparando las velocidades de reacción iniciales que fueron determinadas a partir de la pendiente de las gráficas a periodos cortos, estos valores se resumen en la tabla 7.1.

a)

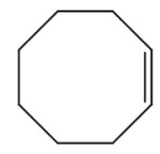

$\mathrm{UiO}-66$

$(0.0016 \mathrm{mmol}$ metal $)$

$\mathrm{CH}_{3} \mathrm{CN}(2 \mathrm{~mL})$

$\mathrm{O}_{2}(5 \mathrm{~atm}), 120^{\circ} \mathrm{C}$
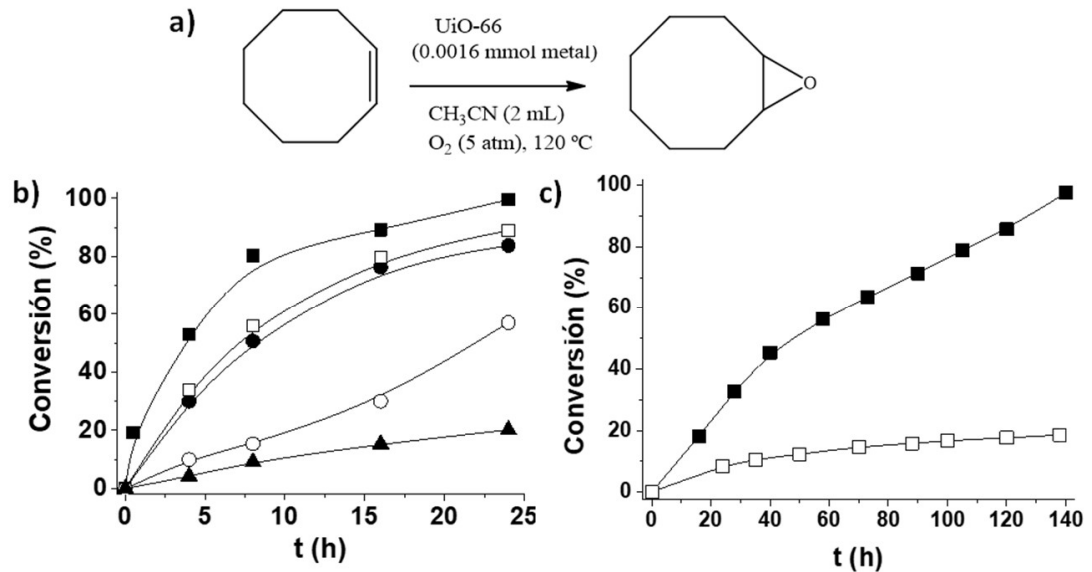

Figura 7.30. a) Oxidación aeróbica de cicloocteno utilizando como catalizadores materiales UiO-66; b) gráficas de conversión frente a tiempo para la oxidación aeróbica de cicloocteno a óxido de cicloocteno usando como catalizador UiO-66(Zr)-NO $\mathrm{NO}_{2}$. Leyenda: UiO-66( $\left.\mathrm{Zr}_{5.4} \mathrm{Ti}_{0.6}\right)-\mathrm{NO}_{2}(\boldsymbol{\bullet}), \mathrm{UiO}-66\left(\mathrm{Zr}_{5.94}\right.$ $\left.\mathrm{Ti}_{0.06}\right)-\mathrm{NO}_{2}(\square), \mathrm{UiO}-66\left(\mathrm{Zr}_{5.97} \mathrm{Ti}_{0.03}\right)-\mathrm{NO}_{2}(\bullet)$ UiO-66(Zr)-NO $\mathrm{NO}_{2}(\circ)$ y reacción en blanco, en ausencia de catalizador $(\boldsymbol{\Delta})$. Condiciones de reacción: catalizador $(0.016 \mathrm{mmol}$ de metal) sustrato $(2 \mathrm{mmol})$, $\mathrm{CH}_{3} \mathrm{CN}(2 \mathrm{~mL}), 120^{\circ} \mathrm{C}$ y $\mathrm{O}_{2}(5 \mathrm{~atm})$. c) Gráficas de conversión frente a tiempo para la oxidación aeróbica de cicloocteno a óxido de cicloocteno en condiciones de ensayo de productividad usando una cantidad baja de UiO-66 $\left(\mathrm{Zr}_{5.4} \mathrm{Ti}_{0.6}\right)-\mathrm{NO}_{2}$. Leyenda: UiO-66 $\left(\mathrm{Zr}_{5.4} \mathrm{Ti}_{0.6}\right)-\mathrm{NO}_{2}(\boldsymbol{\bullet})$ y prueba en blanco en ausencia de catalizador $(\square)$. Condiciones de reacción: catalizador $(0.016 \mathrm{mmol}$ de metal), sustrato (10 $\mathrm{mmol}), \mathrm{CH}_{3} \mathrm{CN}(3 \mathrm{ml}), 120^{\circ} \mathrm{C}$ y $\mathrm{O}_{2}(5 \mathrm{~atm})$. 

ción en los ligandos.
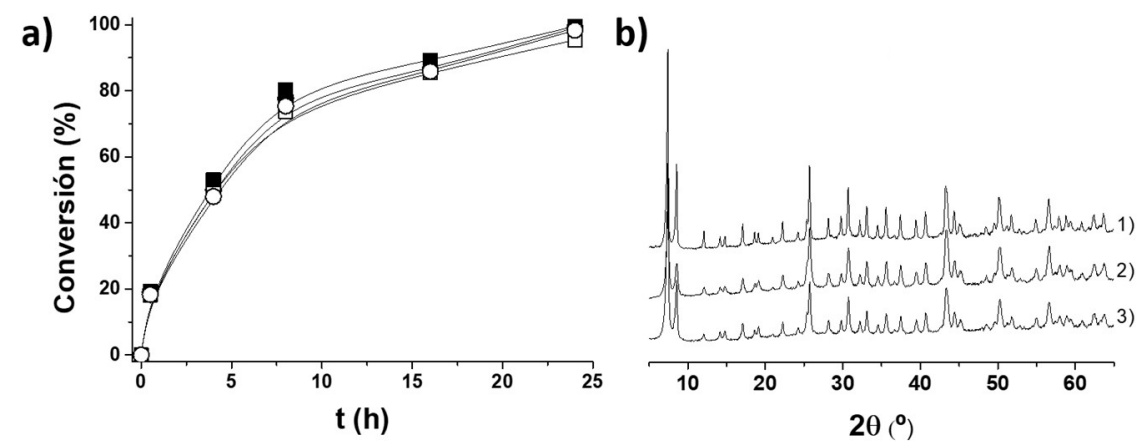

Figura 7.31. a) Experimentos de reusabilidad empleando UiO-66 $\left(\mathrm{Zr}_{5.4} \mathrm{Ti}_{0.6}\right)-\mathrm{NO}_{2}$ como catalizador en la oxidación aeróbica de cicloocteno a óxido de cicloocteno. Leyenda: primer uso (๘), segundo uso ( $\square$ ), cuarto uso (•) y sexto uso (०). b) difractograma de rayos X de la muestra fresca (1), tras tres usos (2) y tras seis usos (3) para el catalizador UiO-66 $\left(\mathrm{Zr}_{5.4} \mathrm{Ti}_{0.6}\right)-\mathrm{NO}_{2}$. Condiciones de reacción: catalizador (0.016 mmol de metal), sustrato $(2 \mathrm{mmol}), \mathrm{CH}_{3} \mathrm{CN}(2 \mathrm{~mL}), 120{ }^{\circ} \mathrm{C}$ y $\mathrm{O}_{2}(5 \mathrm{~atm})$.

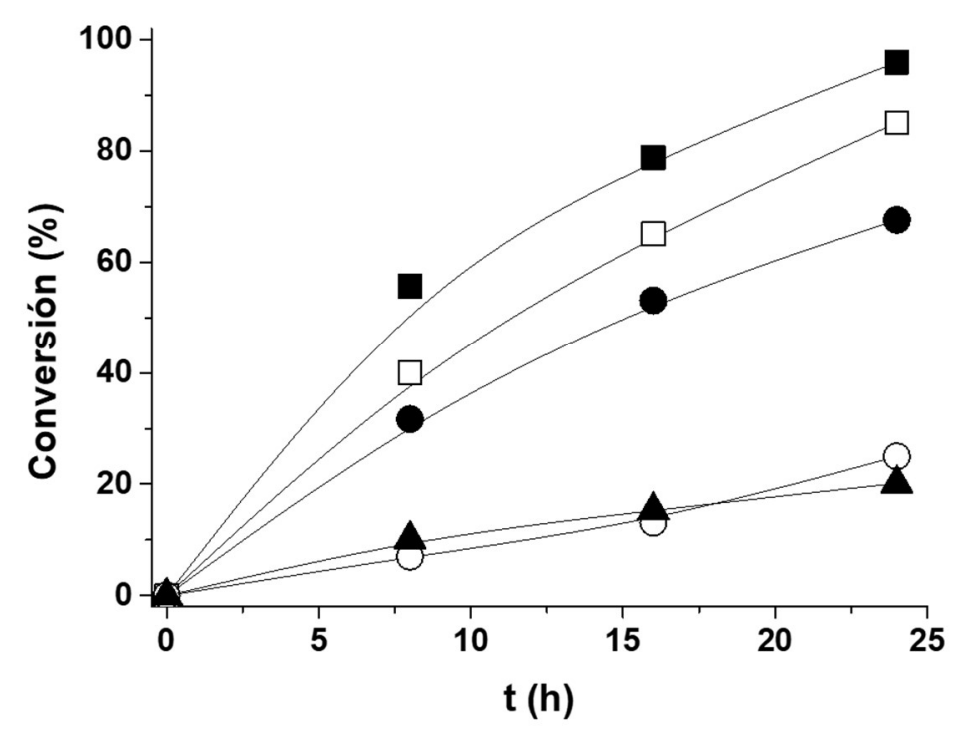

Figura 7.32. Gráficas de conversión frente a tiempo para la oxidación aeróbica de cicloocteno a óxido de cicloocteno usando como catalizador UiO-66( $\mathrm{Zr})-\mathrm{H}$. Leyenda: UiO-66( $\left.\mathrm{Zr}_{5.4} \mathrm{Ti}_{0.6}\right)-\mathrm{H}$ (ロ), UiO66( $\left.\mathrm{Zr}_{5.94} \mathrm{Ti}_{0.06}\right)-\mathrm{H}(\square), \mathrm{UiO}-66\left(\mathrm{Zr}_{5.97} \mathrm{Ti}_{0.03}\right)-\mathrm{H}(\bullet) \mathrm{UiO}-66(\mathrm{Zr})-\mathrm{H}(\mathrm{\circ})$ y reacción en blanco, en ausencia de catalizador $(\boldsymbol{\Delta})$.Condiciones de reacción: catalizador $(0.016 \mathrm{mmol}$ de metal $)$ sustrato $(2 \mathrm{mmol})$, $\mathrm{CH}_{3} \mathrm{CN}(2 \mathrm{~mL}), 120^{\circ} \mathrm{C}$ y $\mathrm{O}_{2}(5 \mathrm{~atm})$. 


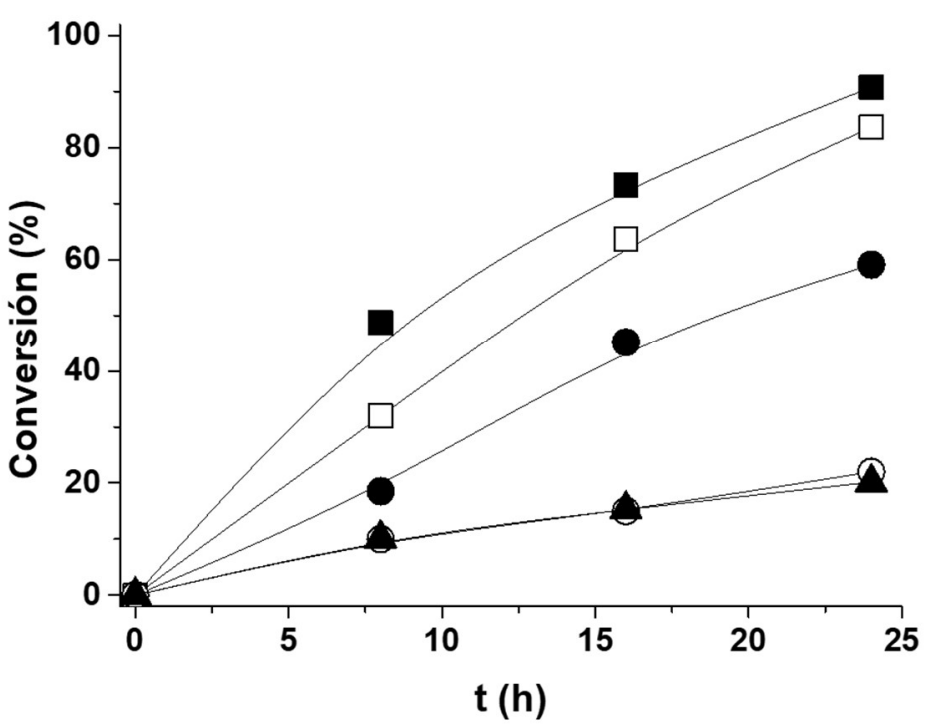

Figura 7.33. Gráficas de conversión frente a tiempo para la oxidación aeróbica de cicloocteno a óxido de cicloocteno usando como catalizador UiO-66( $\mathrm{Zr})-\mathrm{NH}_{2}$. Leyenda: UiO-66( $\left.\mathrm{Zr}_{5.4} \mathrm{Ti}_{0.6}\right)-\mathrm{NH}_{2}(\mathbf{m}), \mathrm{UiO}-$ $66\left(\mathrm{Zr}_{5.94} \mathrm{Ti} 0_{0.06}\right)-\mathrm{NH}_{2}(\square), \mathrm{UiO}-66\left(\mathrm{Zr}_{5.97} \mathrm{Ti}_{0.03}\right)-\mathrm{NH}_{2}(\bullet) \mathrm{UiO}-66(\mathrm{Zr})-\mathrm{NH}_{2}(\circ)$ y reacción en blanco, en ausencia de catalizador $(\boldsymbol{\Lambda})$. Condiciones de reacción: catalizador $(0.016 \mathrm{mmol}$ de metal) sustrato (2 $\mathrm{mmol}), \mathrm{CH}_{3} \mathrm{CN}(2 \mathrm{~mL}), 120^{\circ} \mathrm{C}$ y $\mathrm{O}_{2}(5 \mathrm{~atm})$.

Por consiguiente, de acuerdo con esta tabla el material más activo fue UiO-66 $\left(\mathrm{Zr}_{5.4}\right.$ $\left.\mathrm{Ti}_{0.6}\right)-\mathrm{NO}_{2}$ en donde se combina la influencia positiva de la presencia de iones $\mathrm{Ti}^{4+}$ generando grupos activos y los grupos nitro sustituyendo al tereftalato optimizando el proceso de intercambio combinado. Con respecto a los centros activos y el papel de los iones $\mathrm{Ti}^{4+}$, debe hacerse notar que como se ve claramente en las figuras 7.32 y 7.33 , la actividad catalítica de UiO-66(Zr)-H y UiO-66(Zr)- $\mathrm{NH}_{2}$ son coincidentes con las de la prueba en blanco en ausencia de cualquier catalizador. Esto indica que en ausencia de Ti los materiales $\mathrm{UiO}-66(\mathrm{Zr})-\mathrm{H}$ y UiO-66(Zr)-NH $\mathrm{N}_{2}$ no exhiben ninguna actividad catalítica, por consiguiente, se propone que los iones $\mathrm{Ti}^{4+}$ son los centros activos en esta oxidación aeróbica. Más aun, como puede verse en la tabla 7.1 y en las figuras 7.31-7.33, la velocidad inicial de reacción aumenta casi linealmente con el contenido en Ti hasta un cierto valor de intercambio $\mathrm{Ti} / \mathrm{Zr}$ a partir del cual el aumento de la velocidad de reacción inicial con el contenido en $\mathrm{Ti}^{4+}$ es menor, apoyando la propuesta de que es el $\mathrm{Ti}^{4+}$ el centro que promueve la oxidación (Figura 7.34). Puesto que de acuerdo con la tabla 7.2, la densidad de defectos, aunque baja, también aumenta con el porcentaje de intercambio de Ti, no se puede descartar la posibilidad de que los defectos generados en el proceso de intercambio iónico sean verdaderamente los centros activos en lugar de los iones $\mathrm{Ti}^{4+}$ o que estén 

ción en los ligandos.

asociados con ellos. Sin embargo, si los defectos de cualquier otra naturaleza no relacionados con la presencia de $\mathrm{Ti}^{4+}$ fueran responsables de la actividad catalítica no sería razonable esperar una relación directa entre la actividad catalítica y el $\%$ de $\mathrm{Ti}^{4+}$. Por consiguiente, los resultados obtenidos apoyan el papel de los iones $\mathrm{Ti}^{4+}$ como sitios activos.

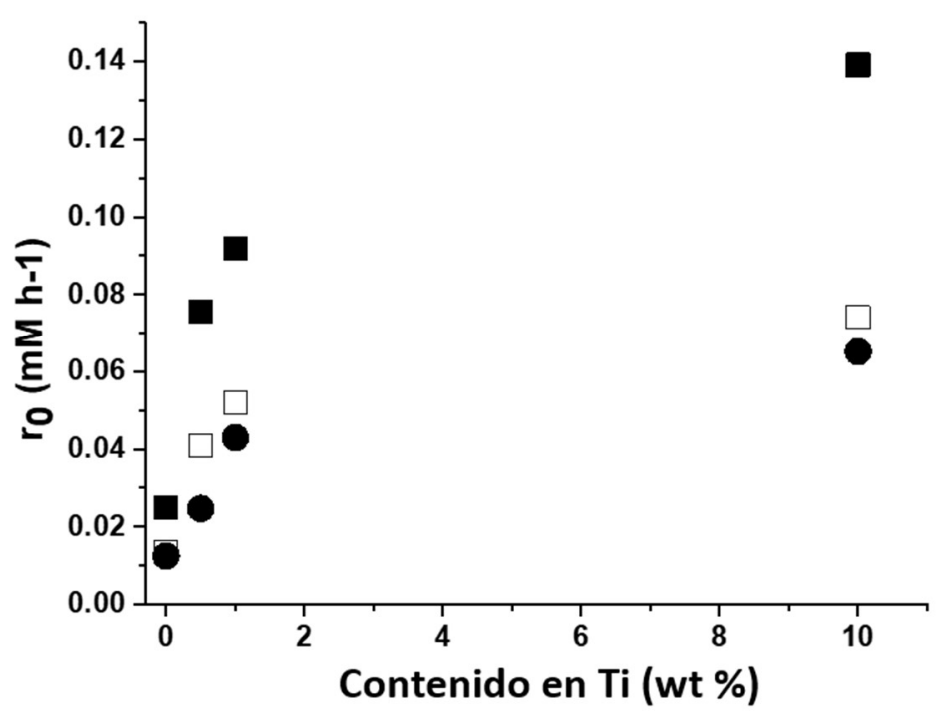

Figura 7.34. Influencia del contenido en titanio en la velocidad inicial ( $\mathrm{r}_{0}$ ) para la oxidación aeróbica de cicloocteno a óxido de cicloocteno utilizando como catalizadores UiO-66(Zr6-y Tiy $)$-X (X: $\mathrm{H}_{1} \mathrm{NO}_{2}$, $\left.\mathrm{NH}_{2}\right)$. Leyenda: UiO-66 $\left(\mathrm{Zr}_{6-\mathrm{y}} \mathrm{Ti}_{\mathrm{y}}\right)-\mathrm{NO}_{2}(\boldsymbol{\bullet})$, UiO-66 $\left(\mathrm{Zr}_{6-\mathrm{y}} \mathrm{Ti}\right.$ ) $)-\mathrm{H}(\square), \mathrm{UiO}-66\left(\mathrm{Zr}_{6-\mathrm{y}} \mathrm{Ti}_{\mathrm{y}}\right)-\mathrm{NH}_{2}(\bullet)$. Condiciones de reacción: catalizador $\left(0.016 \mathrm{mmol}\right.$ de metal) sustrato $(2 \mathrm{mmol}), \mathrm{CH}_{3} \mathrm{CN}(2 \mathrm{~mL}), 120^{\circ} \mathrm{C} \mathrm{y}$ $\mathrm{O}_{2}(5 \mathrm{~atm})$.

Usando el material más activo UiO-66 $\left(\mathrm{Zr}_{5.4} \mathrm{Ti}_{0.6}\right)-\mathrm{NO}_{2}$, se llevó a cabo un test de productividad, así como se sometió la misma muestra a reusos consecutivos. El propósito fue determinar la estabilidad del material UiO-66 $\left(\mathrm{Zr}_{5.4} \mathrm{Ti}_{0.6}\right)-\mathrm{NO}_{2}$ en condiciones catalíticas usando en un caso un gran exceso de sustrato con respecto a la cantidad de catalizador (Ensayo de productividad) y en el otro establecer la variación temporal de la evolución con el reuso del material. Para el ensayo de productividad (Figura 7.30), conversiones de ciclooctano completas con una selectividad total hacia el óxido de cicloocteno se consiguieron en 6 días de reacción. De esta manera se determinó un número de ciclos por centro (TON) de 1660 considerando la cantidad total de metal como centro activo o 16600 si solo se considera el contenido de titanio. Este valor de TON compara 
favorablemente con los medidos en otros estudios para la oxidación aeróbica bajo catálisis homogénea utilizando heteropoliácidos (valor de TON de 10000) para $\gamma$ $\mathrm{SiW}_{10}\left\{\mathrm{Fe}^{3+}\left(\mathrm{OH}_{2}\right)\right\}_{2} \mathrm{O}_{38}{ }^{6-},{ }^{67} \mathrm{e}$ incluso otros con catalizadores heterogéneos donde se lleva a cabo la oxidación de cicloalquenos con $\mathrm{H}_{2} \mathrm{O}_{2}$ empleando $\mathrm{CH}_{3} \mathrm{ReO}_{3}$ TON 20000, ${ }^{68}$ $\mathrm{Ta}_{2} \mathrm{O}_{5} / \mathrm{SiO}_{2}$ (TON 150$)^{69} \mathrm{e}$ incluso un catalizador basado en UiO-66(Zr) donde se calculó un TON de $50 .{ }^{70}$

Se observaron perfiles temporales de desaparición de cicloocteno casi coincidentes para seis reusos consecutivos del material UiO-66 $\left(\mathrm{Zr}_{5.4} \mathrm{Ti}_{0.6}\right)-\mathrm{NO}_{2}$ (Figura 7.31) los cambios menores en las velocidades de reacción iniciales en los ensayos de reusos se deben probablemente a la recuperación incompleta del sólido durante el filtrado del catalizador tras la finalización de la reacción. A fin de confirmar la estabilidad del material UiO$66\left(\mathrm{Zr}_{5.4} \mathrm{Ti}_{0.6}\right)-\mathrm{NO}_{2}$ se llevó a cabo el análisis químico de la fase líquida tras la reacción a fin de determinar la ausencia de $\mathrm{Zr}$ y Ti. Los datos experimentales indican que la cantidad de $\mathrm{Zr}$ y Ti lixiviada es inferior al $0.05 \%$ respecto al contenido de metales del material empleando como catalizador. Más aún, se confirmó la cristalinidad del material UiO-66 $\left(\mathrm{Zr}_{5.4} \mathrm{Ti}_{0.6}\right)-\mathrm{NO}_{2}$ tras su uso como catalizador mediante el difractograma de rayos $\mathrm{X}$ donde no se observaron cambios significativos en la cristalinidad del material. Por consiguiente, todos los datos disponibles, la pequeña cantidad de $\mathrm{Zr}$ y Ti lixiviado, la coincidencia de los perfiles temporales con los reusos, la ausencia de cambios en la difracción de rayos $\mathrm{X}$, todos indican la estabilidad del material en condiciones de reacción.

Se llevaron a cabo experimentos de control adicionales usando el porcentaje de $\mathrm{ZrO}_{2}$ y TiO 2 contenidos en UiO-66 $\left(\mathrm{Zr}_{5.4} \mathrm{Ti}_{0.6}\right)-\mathrm{NO}_{2}$ o empleando solo la cantidad medida en el lixiviado. Los resultados se presentan en la figura 7.35 que muestra que la actividad catalítica de UiO-66 $\left(\mathrm{Zr}_{5.4} \mathrm{Ti}_{0.6}\right)-\mathrm{NO}_{2}$ es mucho mayor en términos de velocidad inicial de reacción o conversión final que cualquiera de los cuatro experimentos de control. Además, la actividad catalítica de UiO-66 $\left(\mathrm{Zr}_{5.4} \mathrm{Ti}_{0.6}\right)-\mathrm{NO}_{2}$ conteniendo los dos metales fue notablemente mayor que la del material MIL-125(Ti). Este resultado muestra las ventajas de una elevada porosidad y una distribución de Ti en UiO-66 $\left(\mathrm{Zr}_{5.4} \mathrm{Ti}_{0.6}\right)-\mathrm{NO}_{2}$ respecto al material MIL-125(Ti). La comparación entre la actividad de UiO-66 $\left(\mathrm{Zr}_{5.4}\right.$ $\mathrm{Ti}_{0.6}$ ) $-\mathrm{NO}_{2}$ y MIL-125(Ti) muestra la importancia que el aislamiento de los átomos de titanio en los nodos de $\mathrm{Zr}_{5} \mathrm{Ti}(\mathrm{O})_{4}(\mathrm{OH})_{4}$ y las mayores dimensiones de los poros del material UiO-66. 


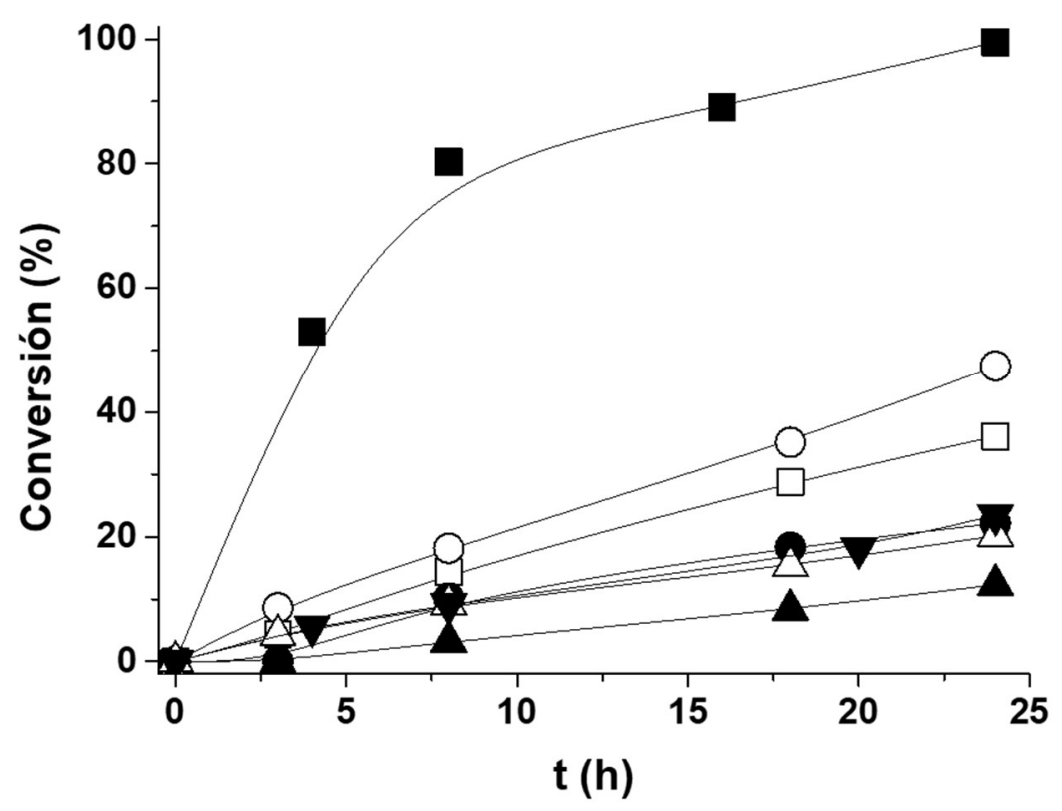

Figura 7.35. Gráfica de conversión frente a tiempo para la oxidación aeróbica de cicloocteno a óxido de cicloocteno empleando diferentes catalizadores. Leyenda: $\mathrm{UiO}-66\left(\mathrm{Zr}_{5.4} \mathrm{Ti}_{0.6}\right)-\mathrm{NO}_{2}(\boldsymbol{\bullet}), \mathrm{MIL}-125(\mathrm{Ti})$ $(\square), \mathrm{ZrO}_{2}(\bullet), \mathrm{TiO}_{2}(\circ), \mathrm{ZrO}_{2}$ en cantidades iguales a las del lixiviados $(\boldsymbol{\Delta})$ y $\mathrm{TiO}_{2}$ en cantidades iguales a las que lixivian durante la reacción $(\Delta)$. Condiciones de reacción: catalizador $(0.016 \mathrm{mmol}$ de metal $)$, sustrato $(2 \mathrm{mmol}), \mathrm{CH}_{3} \mathrm{CN}(2 \mathrm{~mL}), 120^{\circ} \mathrm{C}$ y $\mathrm{O}_{2}(5 \mathrm{~atm})$.

A fin de entender el papel de UiO-66( $\left.\mathrm{Zr}_{5.4} \mathrm{Ti} \mathrm{Ti}_{0.6}\right)$-X como catalizador en esta oxidación aeróbica así como establecer la heterogeneidad del proceso se llevó a cabo un ensayo de filtración en caliente en el cual se comparan los perfiles temporales de dos reacciones llevadas a cabo en el mismo tiempo, una de ellas en presencia continuada de catalizador y otra que se inicia con catalizador sólido y, entonces, eliminando el sólido a la temperatura de reacción permitiendo que la disolución en ausencia de sólido continúe la reacción. Los resultados obtenidos se muestran en la figura 7.36. Como puede verse allí, en una de las dos reacciones paralelas, el catalizador se filtró a 0.5 horas de reacción, donde la conversión del cicloocteno era de alrededor del $20 \%$. Las comparaciones de las dos gráficas de conversión frente a tiempo muestran que, aunque la reacción en ausencia de catalizador continúa progresando en torno a un $50 \%$ menos que en presencia de catalizador sólido, hay una conversión significativa de cicloocteno a óxido de cicloocteno en la disolución tras la eliminación del catalizador sólido. Conviene comentar aquí que, de acuerdo con la figura 7.30, en las mismas condiciones de reacción, ocurre un cierto por- 
centaje de autooxidación del cicloocteno en ausencia de cualquier catalizador que se estima en un $30 \%$. Sin embargo, en el presente caso, tras filtración del catalizador, la conversión del cicloocteno aumenta desde 20 al $50 \%$, lo cual es significativamente mayor que lo esperable de acuerdo con el experimento control para una reacción no catalizada (entorno al 20\% para el mismo tiempo de reacción, Figura 7.30). En conjunto, los datos catalíticos indican que tras la iniciación de la oxidación por parte de UiO-66 $\left(\mathrm{Zr}_{5.4} \mathrm{Ti}_{0.6}\right)$ $\mathrm{NO}_{2}$ algunas especies reactivas de oxígeno o algunas especies del catalizador migran a la fase líquida contribuyendo en parte (alrededor del $30 \%$ ) a la conversión total que se observa en un experimento catalítico cuando el sólido está presente en el experimento. Por otra parte, si al filtrar el catalizador se filtra a las $0.5 \mathrm{~h}$ y se añade un $20 \mathrm{~mol} \% \mathrm{de}$ TEMPO se observa que la reacción para por completo lo que significa que los radicales de centros $\mathrm{C}$ derivados del cicloocteno son los intermedios de reacción responsables del progreso de la reacción después del filtrado del catalizador y además estos radicales centros $\mathrm{C}$ sobreviven durante horas en el medio de reacción después de la filtración del catalizador.

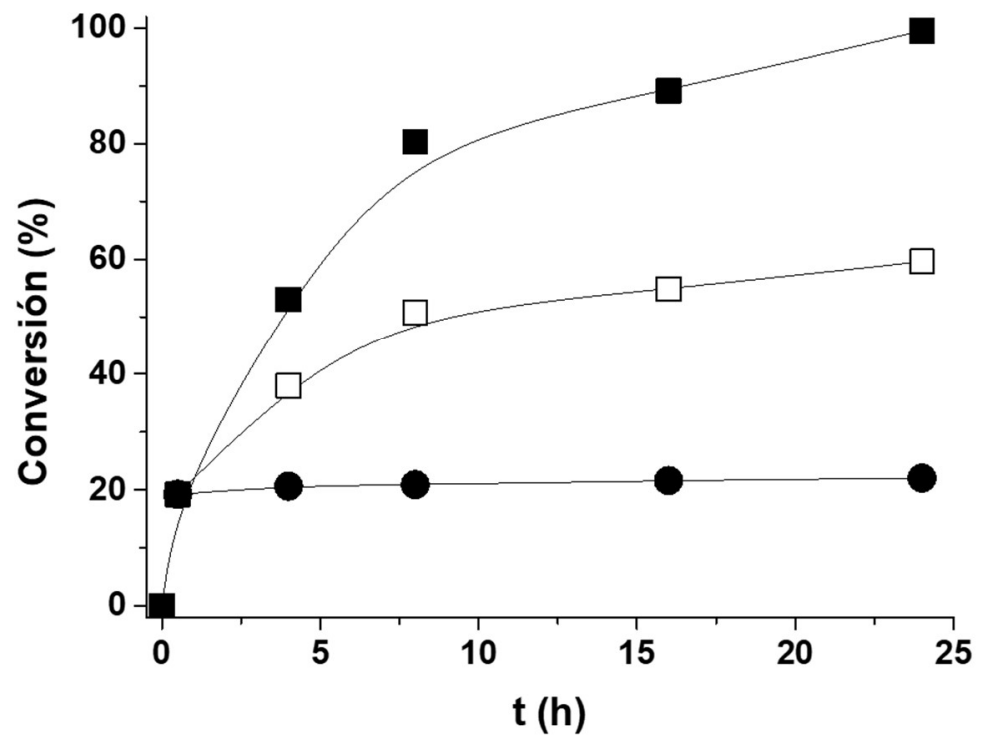

Figura 7.36. Gráficas de conversión frente a tiempo para la oxidación aeróbica de cicloocteno a óxido de cicloocteno utilizando UiO-66 $\left(\mathrm{Zr}_{5.4} \mathrm{Ti}_{0.6}\right)-\mathrm{NO}_{2}$ como catalizador, el cual es filtrado a las 0.5 horas de reacción o permanece en contacto con el sustrato durante todo el tiempo de reacción. Leyenda: UiO$66\left(\mathrm{Zr}_{5.4} \mathrm{Ti}\right.$ i.6) $-\mathrm{NO}_{2}(\square)$ y en ausencia de catalizador a partir de las $0.5 \mathrm{~h}(\square)$ y en ausencia de catalizador a partir de las $0.5 \mathrm{~h}$ y añadiendo un $20 \mathrm{~mol} \%$ de TEMPO cuando se filtra el catalizador. Condiciones de reacción: catalizador $\left(0.016 \mathrm{mmol}\right.$ de metal), sustrato $(2 \mathrm{mmol}), \mathrm{CH}_{3} \mathrm{CN}(2 \mathrm{~mL}), 120^{\circ} \mathrm{C} \mathrm{y} \mathrm{O}_{2}(5 \mathrm{~atm})$. 

ción en los ligandos.

Posibles especies presentes en la fase líquida que pueden contribuir al progreso de la reacción tras la eliminación del catalizador pueden incluir $\mathrm{H}_{2} \mathrm{O}_{2}$, hidroperóxidos y peróxidos orgánicos, así como nanopartículas coloidales de $\mathrm{ZrO}_{\mathrm{x}}$ o $\mathrm{TiO}_{\mathrm{x}}$. Puesto que la cantidad de $\mathrm{O}_{2}$ consumida en la reacción, determinada por la disminución de la presión del reactor, es estequiométrica con respecto a la conversión del ciclooctano en los límites de error (cantidad de $\mathrm{O}_{2}$ total consumida $0.975 \mathrm{mmol} / \mathrm{mmol}$ sustrato), se puede deducir que el porcentaje de estas especies oxigenadas que serían posibles intermedios de reacción (incluyendo cualquier reacción de oxidación del disolvente) debe ser bajo, en el límite de detección.

A fin de discutir el origen de la conversión en la reacción de oxidación del cicloocteno en el experimento de filtración en caliente, se llevaron a cabo análisis de contenido en $\mathrm{Zr}$ y Ti en la fase líquida tras filtración del catalizador en caliente a $0.5 \mathrm{~h}$. Los resultados muestran que tras la filtración del catalizador el líquido contiene una cantidad despreciable de $\mathrm{Zr}$ y Ti que equivalen al $0.5 \%$ del contenido de metal presente en el catalizador. Conviene comentar que, aunque la cantidad de $\mathrm{Zr}$ y Ti lixiviados a la fase líquida era muy pequeña, existen precedentes en la literatura en donde se ha encontrado que pequeñas cantidades de metales de transición en el rango de los ppm pueden ser suficientes para acelerar las reacciones de autooxidación en una extensión medible. ${ }^{59}$ Por consiguiente, no se puede descartar que las especies metálicas lixiviadas contribuyan en alguna medida al avance de la reacción en ausencia de catalizador.

Para discutir la posible contribución de las especies de $\mathrm{Zr}$ y Ti lixiviadas, se procedió a llevar a cabo experimentos de control como los ya comentados en la figura 7.35 en donde la oxidación aeróbica del cicloocteno se llevó a cabo usando $\mathrm{ZrO}_{2}$ y TiO en ambos la concentración determinada en el análisis elemental para el líquido tras la filtración del catalizador, así como la concentración correspondiente a la cantidad total de $\mathrm{Zr}$ y Ti presente en $\mathrm{UiO}-66\left(\mathrm{Zr}_{5.4} \mathrm{Ti}_{0.6}\right)-\mathrm{NO}_{2}$. En ambos casos, se observó que, aunque particularmente el $\mathrm{TiO}_{2}$ exhibe alguna actividad catalítica, la actividad observada es mucho menor que cuando se utiliza UiO-66 $\left(\mathrm{Zr}_{5.4} \mathrm{Ti}_{0.6}\right)-\mathrm{NO}_{2}$. Estos experimentos de control sugieren alguna actividad pequeña debido a las posibles especies de $\mathrm{Zr}$ y Ti lixiviadas. Pero lejos de la actividad que se mide en presencia de $\mathrm{UiO}-66\left(\mathrm{Zr}_{5.4} \mathrm{Ti}_{0.6}\right)-\mathrm{NO}_{2}$. Por otra parte, es también conocido que la autooxidación ocurre a través de un mecanismo en cadena, en donde las etapas de propagación pueden dar lugar a la formación de un gran número de moléculas de producto con tan solo un evento de propagación. ${ }^{59}$ Normalmente, la longitud de este ciclo de propagación no es larga cuando los radicales se generan en los vacíos de materiales porosos debido a las restricciones, a la difusión de los intermedios de reacción que ocurre en estos casos. ${ }^{59}$ Sin embargo, cuando se filtra el catalizador estos radicales libres presentes en la fase líquida podrían exhibir longitudes de propagación mucho más largas y de esta manera podrían contribuir a la conversión de cicloocteno. En precedentes relacionados descritos en la literatura se ha observado que la filtración en caliente no para las oxidaciones aeróbicas de hidrocarburos bencílicos y se propone que el papel del material sólido es el de un iniciador de radicales de carbono sólido en vez de un catalizador en donde los centros activos presentes en el material 
llevan a cabo cada ciclo de conversión de una molécula de sustrato en otra de producto. De forma análoga, aquí podría ocurrir que, aunque no completamente, el material UiO$66\left(\mathrm{Zr}_{5.4} \mathrm{Ti}_{0.6}\right)-\mathrm{NO}_{2}$ se comportara parcialmente como un iniciador sólido. ${ }^{30} \mathrm{En}$ el caso presente para el material UiO-66 $\left(\mathrm{Zr}_{5.4} \mathrm{Ti}_{0.6}\right)-\mathrm{NO}_{2}$ se estima una contribución superior al $65 \%$ de la conversión total como correspondiente a un proceso catalítico verdadero.

A fin de conseguir la mayor comprensión sobre el mecanismo de reacción y, específicamente, obtener alguna evidencia sobre la naturaleza de posibles especies reactivas de oxígeno implicadas en la oxidación del cicloocteno, se llevaron a cabo experimentos de inhibición usando $p$-benzoquinona y DMSO. La $p$-benzoquinona es un inhibidor selectivo para las especies hidroperóxido/superóxidos..$^{56,57,59,60}$ Mientras que el DMSO inhibe selectivamente los radicales hidroxilo. ${ }^{56-59}$ Así, una comparación de los perfiles de la reacción de oxidación de cicloocteno en presencia de inhibidores (en una proporción molar respecto a sustrato del $20 \%$ ) podría proporcionar una información valiosa sobre la naturaleza de las especies activas de oxígeno responsables de la reacción. Los resultados de los test de inhibición se muestran en la figura 7.37. Se debe hacer notar que estos inhibidores se añaden a las $0.5 \mathrm{~h}$ de reacción, cuando la conversión del cicloocteno ya es entorno al $20 \%$ y los posibles intermedios de reacción ya se han generado. También, la cantidad de inhibidor empleado se encuentra en una proporción subestequiométrica respecto a la del sustrato. La figura 7.37 muestra que la reacción para casi completamente con la adición de $p$-benzoquinona, indicando que las especies hidroperóxido/superóxido están implicas en el proceso. Sin embargo, más sorprendente fueron los resultados obtenidos con el DMSO, que es un inhibidor selectivo de los radicales hidroxilo, con el cual también disminuye considerablemente la conversión de cicloocteno, aunque no para completamente la reacción. Por consiguiente, la información de los datos cinéticos mostrados en la figura 7.37 puede ser entendida considerando que el superóxido es la especie radicalaria de oxígeno primaria y, por consiguiente, está implicado de alguna manera en la formación de todo el producto de reacción. Además, los radicales hidroxilo más agresivos estarían también implicados, pero estos radicales hidroxilo no serían la única especie reactiva de oxígeno implicada puesto que esta especie no corresponde con la formación de todo el producto. Más aun, los radicales hidroxilo se formarían como intermedios secundarios a partir del superóxido. La figura $7.37 \mathrm{~b}$ propone varias rutas por las que se podrían generar radicales hidroxilo. De acuerdo con esta figura, parece que el principal papel del sólido UiO-66 $\left(\mathrm{Zr}_{5.4} \mathrm{Ti}_{0.6}\right)-\mathrm{NO}_{2}$ sería el de abrir rutas adicionales para la activación de oxígeno y generar especies de oxígeno reactivas. Las medidas de EPR usando el material UiO-66 $\left(\mathrm{Zr}_{5.4} \mathrm{Ti}_{0.6}\right)-\mathrm{NO}_{2}$ como catalizador confirman la formación de radicales hidroperoxilo al detectarse el aducto con PBN (Figura 7.33d). 

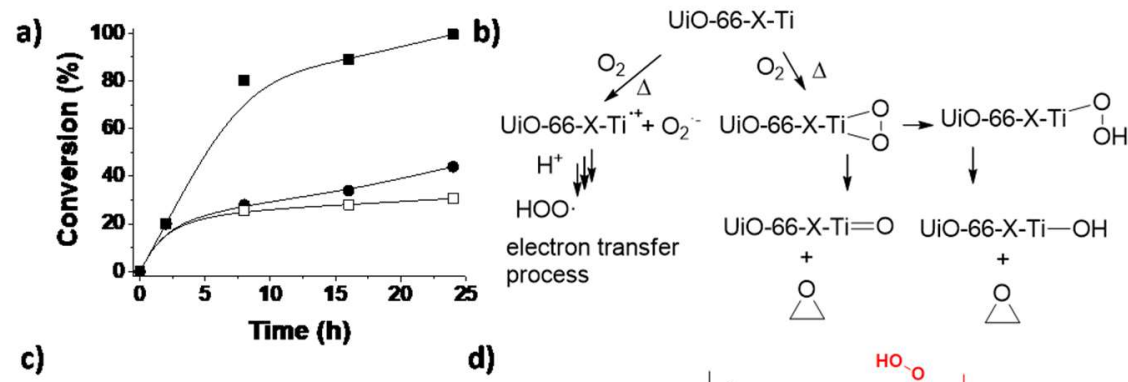

c)

d)

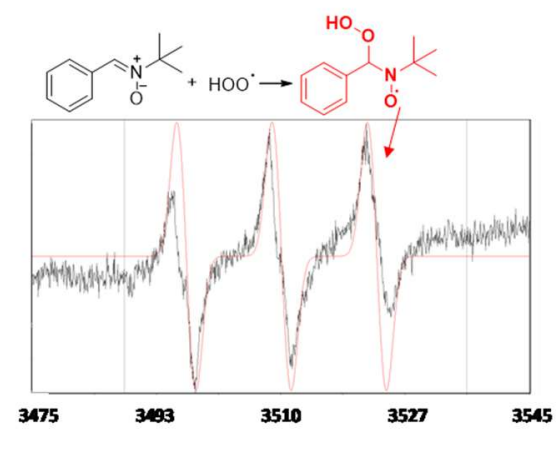

Figura 7.37. a) Gráficas de conversión frente a tiempo para la oxidación aeróbica de cicloocteno a óxido de cicloocteno usando UiO-66 $\left(\mathrm{Zr}_{5.4} \mathrm{Ti}_{0.6}\right)-\mathrm{NO}_{2}$ como catalizador. Leyenda: en ausencia de cualquier inhibidor (匹), tras la adicción del $20 \%$ de DMSO (•) y tras la adicción de $p$-benzoquinona al $20 \%$ (). Condiciones de reacción: catalizador $\left(0.016 \mathrm{mmol}\right.$ de metal), sustrato $(2 \mathrm{mmol}) \mathrm{CH}_{3} \mathrm{CN}(2 \mathrm{~mL})$, $120{ }^{\circ} \mathrm{C}$ y $\mathrm{O}_{2}(5 \mathrm{~atm})$. La adición de inhibidor se lleva a cabo cuando se alcanza una conversión de cicloocteno del $20 \%$. b) Mecanismo propuesto para la activación de oxígeno en la oxidación de alquenos usando UiO-66( $\left.\mathrm{Zr}_{5.4} \mathrm{Ti}_{0.6}\right)-\mathrm{NO}_{2}$ como catalizador. c) espectros experimentales de EPR obtenidos usando $\mathrm{PBN}+\mathrm{O}_{2}(1)$ y UiO-66 $\left(\mathrm{Zr}_{5.4} \mathrm{Ti}_{0.6}\right)-\mathrm{NO}_{2}+\mathrm{PBN}+\mathrm{O}_{2}$ (2) en $n$-dodecano como disolvente a 120 ${ }^{\circ} \mathrm{C}$ durando 4 h. d) Espectros de EPR experimental (línea negra) y simulado (línea roja) para el aducto PBN-OOH cuando se usa UiO-66 $\left(\mathrm{Zr}_{5.4} \mathrm{Ti}_{0.6}\right)-\mathrm{NO}_{2}+\mathrm{PBN}+\mathrm{O}_{2}$ en $n$-dodecano como disolvente a $120^{\circ} \mathrm{C}$ durante $4 \mathrm{~h}$. Las constantes de acoplamiento hiperfinas experimentales para $\mathrm{PBN}-\mathrm{OOH}$ coinciden con las descritas en la literatura $\mathrm{AG}_{\mathrm{N}}=14.4$ y $\mathrm{AG}_{\mathrm{H}}=2.05 .30,71,72$

El papel del oxígeno molecular en la actividad catalítica se confirmó también al observar una relación lineal entre la presión de oxígeno y la velocidad inicial de reacción para la epoxidación del cicloocteno (Figura 7.38a). Esta observación está de acuerdo con el mecanismo radicalario propuesto en el cual el $\mathrm{O}_{2}$ molecular reacciona con radicales del carbono para formar radicales hidroperoxilo como la etapa determinante de la velocidad cuando se usa como catalizador UiO-66 $\left(\mathrm{Zr}_{5.4} \mathrm{Ti}_{0.6}\right)-\mathrm{NO}_{2}$. La energía de activación aparente para la oxidación aeróbica del cicloocteno se estimó llevando a cabo una serie de reacciones en el rango de temperaturas entre 110 y $140{ }^{\circ} \mathrm{C}$ (Figura 7.38b). A partir de la gráfica de Arrhenius del logaritmo neperiano de la velocidad inicial de reacción relativa $\left(\mathrm{r}_{0}\right)$ frente a la inversa del valor de la temperatura absoluta, se determina una energía de activación de $36 \mathrm{~kJ} \mathrm{~mol}^{-1}$. Este valor de energía de activación, es similar, pero algo 
menor, que otros valores para la oxidación aeróbica de hidrocarburos aromáticos usando MOFs como catalizadores o promotores. ${ }^{59}$
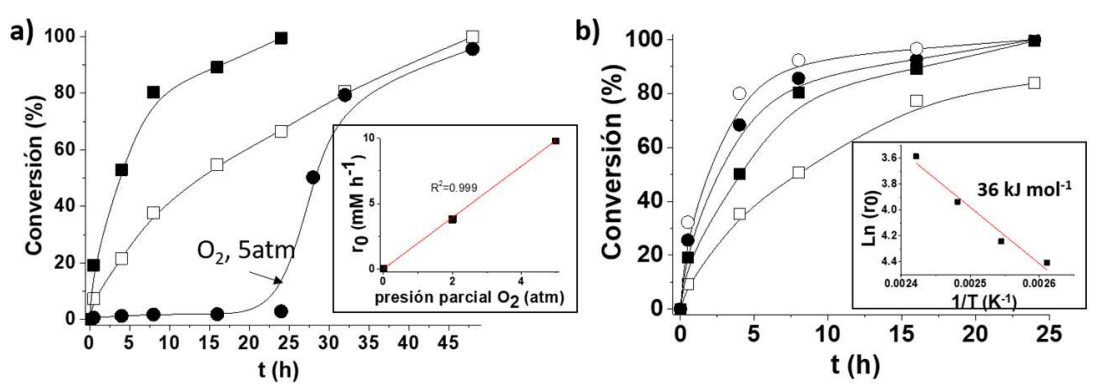

Figura 7.38. a) Influencia de la presión parcial de oxígeno en la actividad catalítica de UiO-66( $\mathrm{Zr}_{5.4}$ $\mathrm{Ti}_{0.6)}-\mathrm{NO}_{2}$ para la oxidación del cicloocteno. El recuadro insertado muestra la relación lineal entre las velocidades de reacción iniciales para la oxidación de cicloocteno frente a la presión parcial de $\mathrm{O}_{2}$. Leyenda: $\mathrm{O}_{2}(\bullet)$, aire ( $\left.\square\right)$, Ar inicialmente y tras $45 \mathrm{~h}(\bullet)$. b) curvas de conversión frente a tiempo para la oxidación aeróbica de cicloocteno a óxido de cicloocteno usando como catalizador $\mathrm{UiO}-66\left(\mathrm{Zr}_{5.4}\right.$ Tio.6)- $\mathrm{NO}_{2}$ llevada a cabo a 4 temperaturas diferentes. El recuadro insertado muestra el diagrama de Arrhenius para la oxidación aeróbica de cicloocteno a óxido cicloocteno basado en las velocidades iniciales de reacción $\left(\mathrm{r}_{0}\right)$ obtenidas a partir de las gráficas de conversión frente a tiempo. Leyenda: 110 ${ }^{\circ} \mathrm{C}(\square), 120^{\circ} \mathrm{C}(\bullet), 130^{\circ} \mathrm{C}(\bullet), 140{ }^{\circ} \mathrm{C}(\circ)$. Condiciones de reacción: catalizador $(0.016 \mathrm{mmol}$ de metal $)$, sustrato $(2 \mathrm{mmol}) \mathrm{CH}_{3} \mathrm{CN}(2 \mathrm{~mL}), 120^{\circ} \mathrm{C}$ y $\mathrm{O}_{2}(5 \mathrm{~atm})$.

Como se ha comentado anteriormente, la actividad catalítica de UiO-66 $\left(\mathrm{Zr}_{5.4} \mathrm{Ti}_{0.6}\right)$ $\mathrm{NO}_{2}$ aumenta tanto con el intercambio parcial de $\mathrm{Zr}^{4+}$ por $\mathrm{Ti}^{4+}$ como por la presencia de grupos $\mathrm{NO}_{2}$ en el ligando orgánico. El catalizador más activo para la oxidación de olefinas es el UiO-66 $\left(\mathrm{Zr}_{5.4} \mathrm{Ti}_{0.6}\right)-\mathrm{NO}_{2}$ (Figura 7.30a). En la sección de introducción de este capítulo se ha indicado que los iones aislados $\mathrm{Ti}^{4+}$ en una red de zeolita han sido previamente descritos como los centros activos para promover reacciones de oxidación actuando como ácidos de Lewis. ${ }^{41,43}$ En el presente caso, especulamos que la acidez de Lewis del material UiO-66 $\left(\mathrm{Zr}_{5.4} \mathrm{Ti}_{0.6}\right)$-H debería aumentar o disminuir debido a la presencia de grupos electrón dadores o aceptores tales como $\mathrm{NO}_{2} \mathrm{o} \mathrm{NH}_{2} \cdot{ }^{31}$ De hecho, se ha encontrado en el presente capítulo una relación lineal entre la constante de Hammett en posición meta $\left(\sigma_{\mathrm{m}}\right)$ y el logaritmo de $\mathrm{r}_{0}$ (Figura $7.39 \mathrm{~b}$ ). A fin de obtener información adicional sobre la influencia de la sustitución del grupo $\mathrm{NO}_{2}$ en la actividad del MOF, se llevó a cabo un estudio de adsorción de CO seguido por espectroscopia de FT-IR para la serie de materiales UiO-66( $\mathrm{Zr} \mathrm{Ti}$ )-X. Se observó que la sustitución parcial de $\mathrm{Zr}$ por átomos de $\mathrm{Ti}$ en el material UiO-66 $\left(\mathrm{Zr}_{5.4} \mathrm{Ti}_{0.6}\right)-\mathrm{NO}_{2}$ no cambia en número de onda de la interacción de $\mathrm{Zr}^{4+}$ con $\mathrm{CO}$. Este hecho no es totalmente inesperado considerando la acidez de Lewis similar del $\mathrm{Zr}^{4+}$ y el ion $\mathrm{Ti}^{4+}$. Por otra parte, la presencia de grupos 
Oxidación de alquenos empleando UiO-66 con intercambio combinado de átomos de titanio y sustitución en los ligandos.

donadores o aceptores de electrones tales como $\mathrm{NH}_{2}$ o $\mathrm{NO}_{2}$ causan un notable desplazamiento en la frecuencia de la banda metal-CO hacia valores más altos o más bajos dependiendo del sustituyente. Esta observación se correlaciona bien con la propuesta de disminución o aumento de la acidez Lewis de los centros metálicos del material UiO-66 ( $\mathrm{Zr} \mathrm{Ti}$ )-X cuando llevan grupos $-\mathrm{NH}_{2}$ o $-\mathrm{NO}_{2}$ respectivamente. Se propone que un aumento de acidez de Lewis es beneficioso para la activación de HOO una vez formado a partir del $\mathrm{O}_{2}$ molecular, y entonces las velocidades de epoxidación aumentan debido a la polarización de los enlaces peroxi O-O.
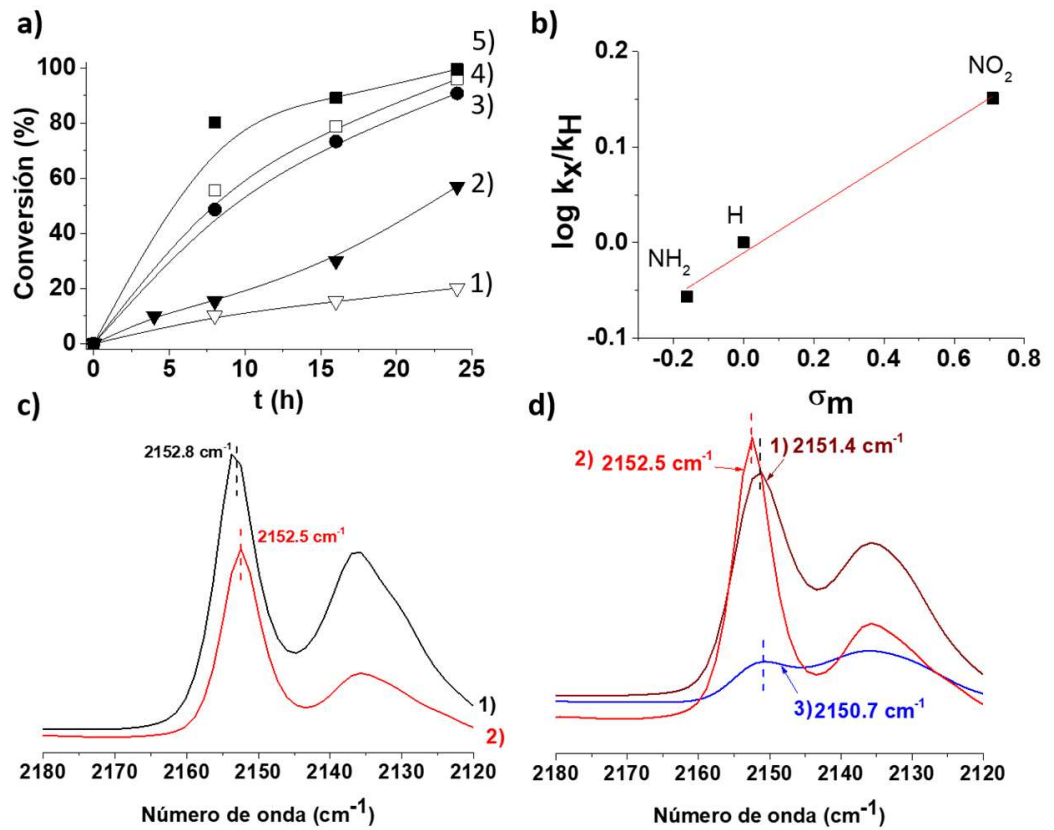

Figura 7.39. a) Perfiles de conversión frente a tiempo para la epoxidación de cicloocteno catalizada por una serie de materiales UiO-66 ( $\mathrm{Zr}$ Ti)-X. Leyenda: ausencia de catalizador (1), UiO-66( $\mathrm{Zr})-\mathrm{NO}_{2}(2)$, UiO-66( $\left.\mathrm{Zr}_{5.4} \mathrm{Ti}_{0.6}\right)-\mathrm{NH}_{2}$ (3), UiO-66( $\left.\mathrm{Zr}_{5.4} \mathrm{Ti}_{0.6}\right)-\mathrm{H}(4)$ y UiO-66 $\left(\mathrm{Zr}_{5.4} \mathrm{Ti}_{0.6}\right)-\mathrm{NO}_{2}$ (5). Condiciones de reacción: catalizador $\left(0.016 \mathrm{mmol}\right.$ de metal), sustrato $(2 \mathrm{mmol}) \mathrm{CH}_{3} \mathrm{CN}(2 \mathrm{~mL}), 120{ }^{\circ} \mathrm{C}_{\text {y }} \mathrm{O}_{2}(5 \mathrm{~atm})$. b) Gráfica del logaritmo de las constantes de velocidad relativas en función de la constante meta de Hammett $\left(\sigma_{\mathrm{m}}\right)$ del sustituyente presente en el ligando tereftalato. c) Espectros de FT-IR de adsorción de $\mathrm{CO}$ a 6 mbar y $-176{ }^{\circ} \mathrm{C}$ sobre UiO-66 (Zr)-NO 2 (1) y UiO-66 ( $\left.\mathrm{Zr}_{5.4} \mathrm{Ti}_{0.6}\right)-\mathrm{NO}_{2}$ (2). d) Espectros de FT-IR tras la adsorción de CO a una presión de 6 mbar y $-176^{\circ} \mathrm{C}$ sobre UiO-66 ( $\mathrm{Zr}_{5.4}$ Tio.6)-H (1) y UiO-66 (Zr5.4 Tio.6)-NO2 (2) y UiO-66 ( $\mathrm{Zr}_{5.4}$ Tio.6)-NH2. 
El presente estudio sobre la oxidación aeróbica de cicloocteno se extendió determinando el rango de productos que pueden sufrir una oxidación análoga empleando UiO$66\left(\mathrm{Zr}_{5.4} \mathrm{Ti}_{0.6}\right)-\mathrm{NO}_{2}$ como catalizador. Es conocido en la literatura que el tamaño del anillo de cicloalqueno tiene una gran influencia en la distribución de productos, particularmente, en la relación entre epoxidación del doble enlace frente a la oxidación alílica que disminuye desde el cicloocteno a medida que el tamaño de anillo disminuye. ${ }^{56,57,74}$ Una tendencia similar se observa en el presente caso (Figura 7.40). Así, mientras que para el cicloocteno el único producto observado fue el correspondiente epóxido con una selectividad prácticamente completa, en el caso del ciclohepteno la formación del correspondiente epóxido va acompañado con la aparición de la 2-cicloheptanona con una selectividad que cambia en función de la conversión. La figura 7.40 muestra los perfiles temporales de conversión y el gráfico de selectividad frente a conversión para la oxidación del ciclohepteno usando $\mathrm{UiO}-66\left(\mathrm{Zr}_{5.4} \mathrm{Ti}_{0.6}\right)-\mathrm{NO}_{2}$ como catalizador. Como cabía esperar, en el caso del ciclohexeno, la selectividad hacia el óxido de ciclohexeno fue muy baja, siendo la oxidación alílica hacia la mezcla ol/ona correspondiente el principal producto con un valor de selectividad a tiempos de reacción finales entorno al $85 \%$. (Figura 7.40). Un hecho específico del ciclohexeno es la longitud de cadena corta en la etapa de propagación del proceso de autooxidación comparado con el caso del cicloocteno. Esto se refleja en el hecho de que el ensayo de filtración en caliente para el ciclohexeno tras eliminación del material UiO-66 $\left(\mathrm{Zr}_{5.4} \mathrm{Ti}_{0.6}\right)-\mathrm{NO}_{2}$ resulta en un progreso de conversión mucho menor (15\%) comparado con el caso análogo para el cicloocteno (35\%). También, debido a la cadena de propagación más corta y a la menor concentración de especies activas fuera del material, en el caso del ciclohexeno, los experimentos de inhibición por $p$-benzoquinona y DMSO no fueron positivos, indicando que la reacción de oxidación del ciclohexeno tiene lugar predominantemente dentro de los poros del material UiO-66 $\left(\mathrm{Zr}_{5.4} \mathrm{Ti}_{0.6}\right)-\mathrm{NO}_{2}$ cerca de los centros activos. La contribución debida a procesos de oxidación de radicales libres fuera de los poros de UiO-66 $\left(\mathrm{Zr}_{5.4} \mathrm{Ti}_{0.6}\right)-\mathrm{NO}_{2}$ en disolución es en este caso despreciable (Figura 7.40). 

ción en los ligandos.

a)
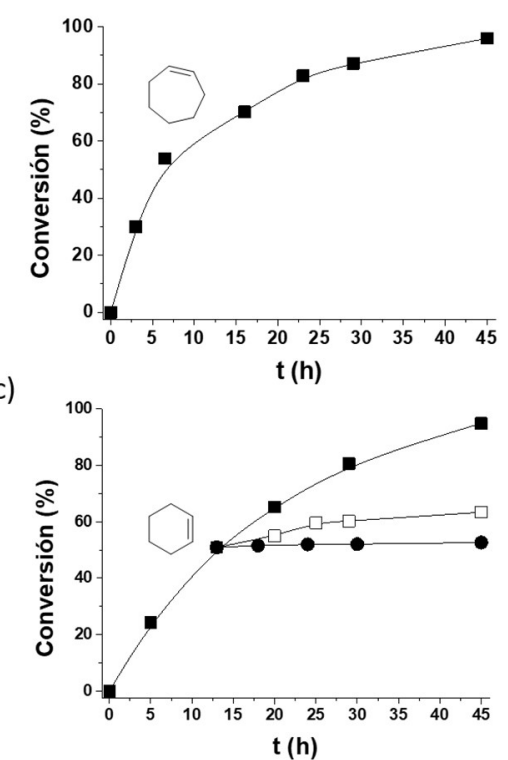

b)

d)
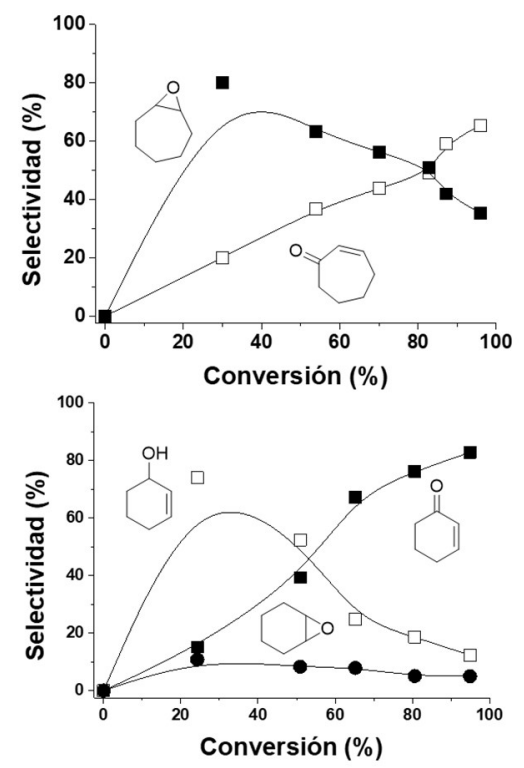

Figura 7.40. Gráficas de conversión frente a tiempo para las oxidaciones aeróbicas de cicloheptene (a) o ciclohexeno (c) usando UiO-66 $\left(\mathrm{Zr}_{5.4} \mathrm{Ti}_{0.6}\right)-\mathrm{NO}_{2}$ como catalizador. Los gráficos de conversión frente a selectividad de cicloheptene (b) o ciclohexene (d) a los correspondientes productos de reacción que se indican en las gráficas. Leyenda c: UiO-6 $\left(\mathrm{Zr}_{5.4} \mathrm{Ti}_{0.6}\right)-\mathrm{NO}_{2}(\mathbf{\square})$ y tras filtrar el catalizador a las $13 \mathrm{~h}$ ( $\square$ ). Condiciones de reacción: catalizador ( $0.016 \mathrm{mmol}$ de metal), sustrato $(2 \mathrm{mmol}) \mathrm{CH}_{3} \mathrm{CN}(2 \mathrm{~mL})$, $120^{\circ} \mathrm{Cy} \mathrm{O}_{2}(5 \mathrm{~atm})$.

El material UiO-66 $\left(\mathrm{Zr}_{5.4} \mathrm{Ti}_{0.6}\right)-\mathrm{NO}_{2}$ fue también capaz de promover la epoxidación aeróbica de alquenos terminales lineales tales como el 1-octene. En este caso, la cinética es más lenta que la de los correspondientes compuestos cíclicos. Esto puede ser fácilmente racionalizado considerando que la difusión de alquenos lineales en materiales porosos es siempre más lenta que la de los correspondientes análogos cíclicos y/o alternativamente que la actividad intrínseca de alquenos terminales monosustituidos es más baja que la de compuestos cíclicos disustituidos. Lo que es notable en todo caso es la alta selectividad de catalizador $\mathrm{UiO}-66\left(\mathrm{Zr}_{5.4} \mathrm{Ti}_{0.6}\right)-\mathrm{NO}_{2}$ para la epoxidación aeróbica lo que da lugar a la formación del óxido de 1-octeno con una selectividad casi completa como puede verse en la Figura 7.41. 


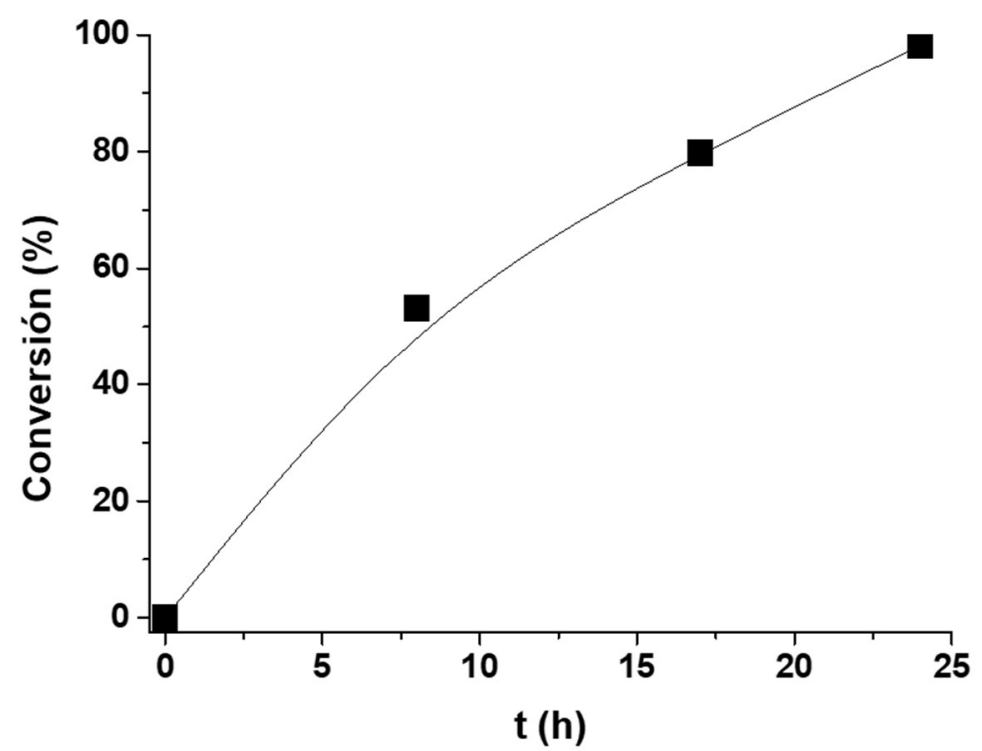

Figura 7.41. Gráfica de conversión frente a tiempo para la oxidación aeróbica de 1-octeno usando UiO$66\left(\mathrm{Zr}_{5.4} \mathrm{Ti}_{0.6}\right)-\mathrm{NO}_{2}$ como catalizador. Condiciones de reacción: catalizador $(0.016 \mathrm{mmol}$ de metal), sustrato $(2 \mathrm{mmol}) \mathrm{CH}_{3} \mathrm{CN}(2 \mathrm{~mL}), 120{ }^{\circ} \mathrm{C}$ y $\mathrm{O}_{2}(5 \mathrm{~atm})$.

El rango de aplicación del material UiO-66 $\left(\mathrm{Zr}_{5.4} \mathrm{Ti}_{0.6}\right)$-X para promover oxidaciones aeróbicas de alquenos se extendió a alquenos conjugados con grupos alilo, estudiando la reacción de estireno y estilbeno. En el caso del estireno, la oxidación da lugar a una mezcla en la que la selectividad cambia con la conversión, el producto principal a conversión final es el benzaldehído con una selectividad del $40 \%$, acompañado de fenilacetaldehido (15\%), acetofenona (15\%) y cantidades menores de óxido de estireno (8 $\%$ y ácido benzoico (8\%) (Figura 7.42) La formación de todos estos productos se puede explicar fácilmente como derivados de dos rutas competitivas. Por un lado, la ruptura oxidativa del enlace $\mathrm{C}=\mathrm{C}$ da lugar inicialmente a benzaldehído que, posteriormente sufriría una oxidación adicional a ácido benzoico. El segundo camino seria la epoxidación del doble enlace dando inicialmente óxido de estireno que sufriría una trasposición al isómero carbonílico terminal (fenilacetaldehido) o interno (acetofenona). 

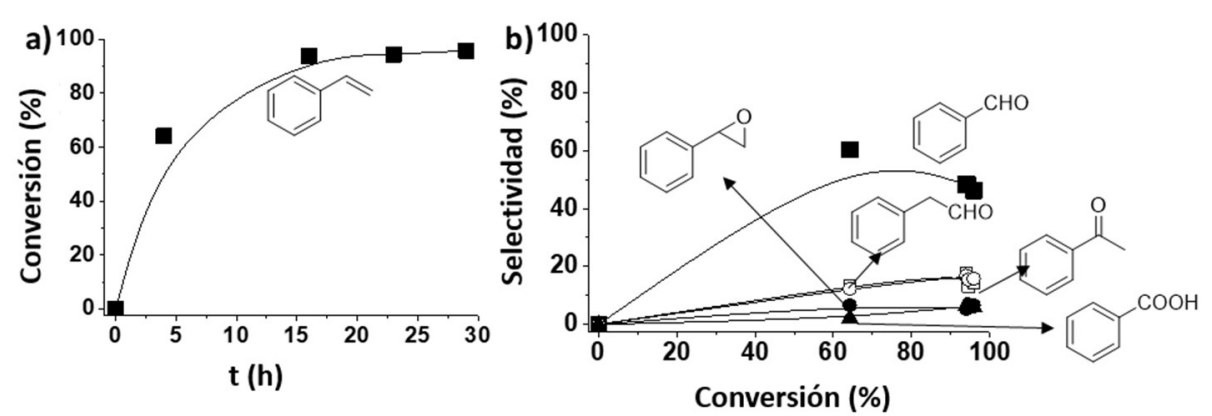

Figura 7.42. Gráfica de conversión frente a tiempo (a) y selectividad frente a conversión (b) para la oxidación aeróbica de estireno usando UiO-66( $\mathrm{Zr}_{5.4} \mathrm{Ti}$ i.6) $)-\mathrm{NO}_{2}$ como catalizador. Condiciones de reacción: catalizador $\left(0.016 \mathrm{mmol}\right.$ de metal), sustrato $(2 \mathrm{mmol}) \mathrm{CH}_{3} \mathrm{CN}(2 \mathrm{~mL}), 120{ }^{\circ} \mathrm{C}_{\text {y }} \mathrm{O}_{2}(5 \mathrm{~atm})$.

En el caso del trans-estilbeno las dos rutas competitivas tendrían lugar conduciendo a benzaldehído (ruptura del enlace $\mathrm{C}=\mathrm{C}$ ) con baja selectividad ( $25 \%$ ) a tiempos finales de reacción y óxido de trans-estilbeno (epoxidación del $\mathrm{C}=\mathrm{C}$ ) que es el producto principal a tiempos de reacciones finales con una selectividad del $75 \%$ (Figura 7.43). En contraste al trans-estilbeno, el cis-estilbeno fue inerte en las mismas condiciones no observándose producto de oxidación alguno en presencia de UiO-66 $\left(\mathrm{Zr}_{5.4} \mathrm{Ti}_{0.6}\right)-\mathrm{NO}_{2}$ en idénticas condiciones. De nuevo, la falta de reactividad del isómero cis comparada con la reactividad del trans-estilbeno sería un típico caso de catálisis con selectividad de forma. ${ }^{75}$ Esta selectividad deriva del hecho de que en los alquenos conjugados la reacción tendría lugar predominantemente dentro de los poros donde la difusión del isómero cis está impedida respecto al trans-estilbeno debido a las menores dimensiones de este último. Alternativamente, la posibilidad de que el isómero cis exhiba una reactividad menor respecto al isómetro trans no puede ser descartada. Así, en contraste al caso del cicloocteno donde algún grado de conversión ocurre en fase líquida, la falta de reactividad del cis-estilbeno indica que, para alquenos conjugados, la contribución a la reacción en la fase líquida fuera de los poros sería despreciable. Esta observación está de acuerdo con el conocimiento básico en química orgánica donde la influencia de la estructura del sustrato orgánico en la reactividad es bien conocida. 

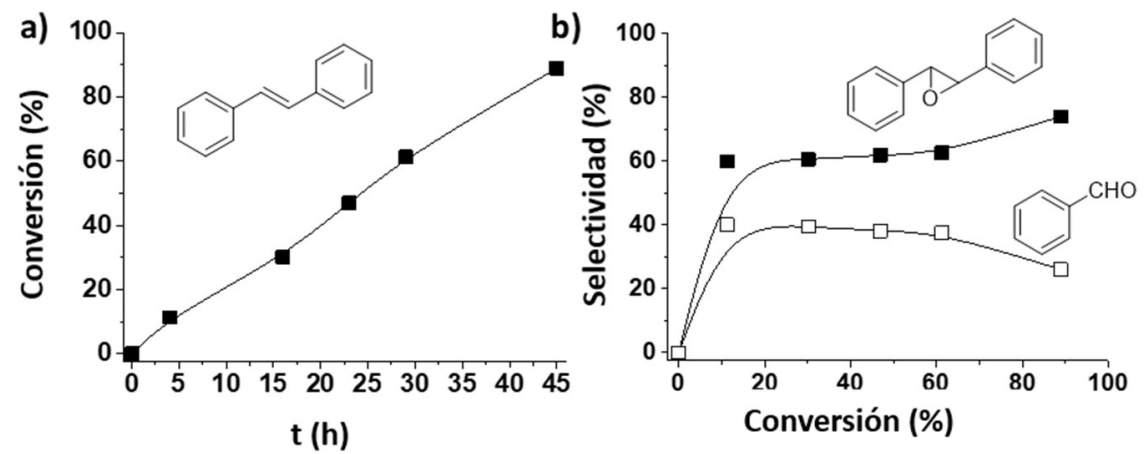

Figura 7.43. Gráfica de conversión frente a tiempo (a) y selectividad frente a conversión (b) para la oxidación aeróbica de trans-estilbeno usando UiO-66 $\left(\mathrm{Zr}_{5.4} \mathrm{Ti}_{0.6}\right)-\mathrm{NO}_{2}$ como catalizador. Condiciones de reacción: catalizador $\left(0.016 \mathrm{mmol}\right.$ de metal), sustrato $(2 \mathrm{mmol}) \mathrm{CH}_{3} \mathrm{CN}(2 \mathrm{~mL}), 120{ }^{\circ} \mathrm{C}_{\text {y }} \mathrm{O}_{2}(5 \mathrm{~atm})$.

\subsection{Conclusiones}

El presente capítulo ha establecido que mientras el material de referencia UiO-66 (Zr) no posee actividad catalítica para la activación de oxígeno molecular el intercambio de iones $\mathrm{Zr}^{4+}$ por $\mathrm{Ti}^{4+}$ introducen actividad catalítica para la oxidación aeróbica de cicloocteno. La actividad del UiO-66 conteniendo $\mathrm{Ti}^{4+}$ puede ser aumentada aún más mediante la presencia de grupos electrón aceptores en el ligando orgánico. De esta manera, la velocidad inicial de reacción para la conversión del cicloocteno al epóxido correspondiente puede ser óptima para el UiO-66 $\left(\mathrm{Zr}_{5.4} \mathrm{Ti}_{0.6}\right)-\mathrm{NO}_{2}$ comparada con la del material inactivo de referencia UiO-66(Zr)-H alcanzando valores de número de ciclos que son más elevados que los que se miden para la mayoría de catalizadores homogéneos. La muestra más activa de la serie es también capaz de promover la epoxidación de otros cicloalquenos así como alquenos lineales y aromáticos, siguiendo la reactividad esperada de acuerdo con la reactividad de cada sustrato.

En definitiva, puesto que los MOFs están constituidos por nodos metálicos y ligandos orgánicos, el presente capítulo ilustra la estrategia para crear centros activos por intercambio iónico de ambos componentes, los cuales pueden ser simultáneamente ajustados para aumentar y optimizar la actividad catalítica de cada MOF para una reacción en particular. Así, el presente capítulo ilustra la estrategia de creación de centros activos por intercambio iónico y que la actividad de estos centros puede ser a la vez optimizada por la introducción de grupos nitro. Se propone que esta estrategia de combinar sustituciones en el ligando orgánico con la modificación post-sintética del nodo metálico puede ser útil para muchas reacciones orgánicas implicando centros Lewis. 
Oxidación de alquenos empleando UiO-66 con intercambio combinado de átomos de titanio y sustitución en los ligandos.

\section{4 Referencias}

1. Y. Ishii, S. Sakaguchi y T. Iwahama, Adv. Synth. Catal., 2001, 343, 393-427.

2. R. A. F. Tomás, J. C. M. Bordado y J. F. P. Gomes, Chem. Rev., 2013, 113, 74217469.

3. T. Punniyamurthy, S. Velusamy y J. Iqbal, Chem. Rev., 2005, 105, 2329-2363.

4. S. E. Allen, R. R. Walvoord, R. Padilla-Salinas y M. C. Kozlowski, Chem. Rev., 2013, 113, 6234-6458.

5. A. Dhakshinamoorthy, M. Alvaro y H. Garcia, Catal. Sci. Technol., 2011, 1, 856867.

6. C. N. Cornell y M. S. Sigman, Inorg. Chem., 2007, 46, 1903-1909

7. A. Dhakshinamoorthy, A. M. Asiri y H. Garcia, ACS Catal., 2017, 7, 2896-2919.

8. N. Gunasekaran, Adv. Synth. Catal., 2015, 357, 1990-2010.

9. A. E. Wendlandt, A. M. Suess y S. S. Stahl, Angew. Chem. Int. Ed, 2011, 50, 1106211087.

10. T. Devic y C. Serre, Chem. Soc. Rev., 2014, 43, 6097-6115.

11. G. Férey, Chem. Soc. Rev., 2008, 37, 191-214.

12. S. Kitagawa, R. Kitaura y S. -I. Noro, Angew. Chem., Int. Ed., 2004, 43, 2334-2237.

13. H. Furukawa, K. E. Cordova, M. O'Keeffe y O. M. Yaghi, Science 2013, 341, 1230444.

14. O. M. Yaghi, M. O'Keeffe, N. W. Ockwig, H. K. Chae, M. Eddaoudi y J. Kim, Nature 2003, 423, 705-714.

15. A. H. Chughtai, N. Ahmad, H. A. Younus, A. Laypkov y F. Verpoort, Chem. Soc. Rev., 2015, 44, 6804-6849.

16. A. Corma, H. Garcia y F. X. Llabrés i Xamena, Chem. Rev., 2010, 110, 4606-4655.

17. D. Farrusseng, S. Aguado y C. Pinel, Angew. Chem. Int. Ed., 2009, 48, 7502-7513.

18. J. Gascon, A. Corma, F. Kapteijn y F. X. Llabrés i Xamena, ACS Catal., 2014, 4, 361-378.

19. M. Yoon, R. Srirambalaji y K. Kim, Chem. Rev., 2012, 112, 1196-1231.

20. A. Dhakshinamoorthy, A. Santiago-Portillo, P. Concepcion, J. R. Herance, S. Navalon, M. Alvaro y H. Garcia, Catal. Sci. Technol., 2017, 7, 2445-2449.

21. Y. -B. Huang, J. Liang, X. -S. Wang y R. Cao, Chem. Soc. Rev., 2017, 46, 126-157.

22. J. Liang, Z. Liang, R. Zou y Y. Zhao, Adv. Mater. 2017, 29, 1701139. 
23. S. M. J. Rogge, A. Bavykina, J. Hajek, H. Garcia, A. I. Olivos-Suarez, A. SepúlvedaEscribano, A. Vimont, G. Clet, P. Bazin, F. Kapteijn, M. Daturi, E. V. Ramos-Fernandez, F. X. Llabrés i Xamena, V. Van Speybroeck, J. Gascon, Chem. Soc. Rev., 2017, 46, 31343184 .

24. C.-D. Wu y M. Zhao, Adv. Mater., 2017, 29, 1605446.

25.L. Zhu, X. -Q. Liu, H. -L. Jiang y L. -B. Sun, Chem. Rev., 2017, 117, 8129-8176.

26. G. Gómez-Pozuelo, C. P. Cabello, M. Opanasenko, M. Horáček y J. Čejka, ChemPlusChem, 2017, 82, 152-159.

27. L. Mitchell, P. Williamson, B. Ehrlichov, A. E. Anderson, V. R. Seymour, S. E. Ashbrook, N. Acerbi, L. M. Daniels, R. I. Walton, M. L. Clarke y P. Wright, Chem. Eur. $J ., 2014,20,17185-17197$.

28. Q. Sun, M. Liu, K. Li, Y. Han, Y. Zuo, F. Chai, C. Song, G. Zhang y X. Guo, Inorg. Chem. Front., 2017, 4, 144-153.

29. R. Zou, P. -Z. Li, Y. -F. Zeng, J. Liu, R. Zhao, H. Duan, Z. Luo, J. -G. Wang, R. Zou y Y. Zhao, Small, 2016, 12, 2334-2343.

30. A. Santiago-Portillo, J. F. Blandez, S. Navalón, M. Álvaro y H. García, Catal. Sci. Technol., 2017, 7, 1351-1362.

31. A. Santiago-Portillo, S. Navalón, P. Concepción, M. Álvaro y H. García, ChemCatChem, 2017, 9, 2506-2511.

32. F. Vermoortele, M. Vandichel, B. V. de Voorde, R. Ameloot, M. Waroquier, V. Van Speybroeck y D. E. de Vos, Angew. Chem. Int. Ed., 2012, 51, 4887-4890.

33. A. Herbst, A. Khutia y C. Janiak, Inorg. Chem., 2014, 53, 7319-7333.

34. J. F. Blandez, A. Santiago-Portillo, S. Navalon, M. Gimenez-Marques, M. Alvaro, P. Horcajada y H. Garcia, J. Mol. Catal. A Chem., 2016, 425, 332-339.

35. M. N. Timofeeva, V. N. Panchenko, J. W. Jun, Z. Hasan, M. M. Matrosova y S. H. Jhung, Appl. Catal. A-Gen., 2014, 471, 91-97.

36. S. M. Cohen, Chem. Sci., 2010, 1, 32-36.

37. S. M. Cohen, Chem. Rev., 2012, 112, 970-1000.

38. K. K. Tanabe, S. M. Cohen, Chem. Soc. Rev., 2011, 40, 498-519.

39. D. Sun, W. Liu, M. Qiu, Y. Zhang y Z. Li, Chem.Commun., 2015, 51, 2056-2059.

40. Y. Lee, S. Kim, J. K. Kang y S. M. Cohen, Chem.Commun., 2015, 51, 5735-5738.

41. A. Corma y H. García, Chem. Rev., 2002, 102, 3837-3892. 
Oxidación de alquenos empleando UiO-66 con intercambio combinado de átomos de titanio y sustitución en los ligandos.

42. T. De Baerdemaeker, B. Steenackers y D. E. de Vos, Chem. Commun., 2013, 49, 7474-7476.

43. D. E. De Vos, B. F. Sels y P. A. Jacobs, Adv. Synth. Catal., 2003, 345, 457-473.

44. P. Ratnasamy, D. Srinivas y H. Knözinger, Adv. Catal., 2004, 48, 161-169.

45. M. G. Clerici, G. Bellussi y U. Romano, J. Catal. 1991, 129, 159-167.

46. G. J. Hutchings, D. F. Lee y A. R. Minihan, Catal. Lett., 1996, 39, 83-90.

47. Q. Wang, Z. Mi, Y. Wang y L. Wang, J. Mol. Catal. A Chem., 2005, 229, 71-75.

48. W. Adam, A. Corma, A. Martinez, C. M. Mitchell, T. I. Reddy, M. Renz y A. Smerz, J. Mol. Catal. A Chem., 1997, 117, 357-366.

49. W. Adam, A. Corma, T. I. Reddy y M. Renz, J. Org. Chem., 1997, 62, 3631-3637.

50. D. Tantanak, M. A. Vincent y I. H. Hillier, Chem. Commun., 1998, 0, 1031-1032.

51. D. Sun, W. Liu, M. Qiu, Y. Zhang y Z. Li, Chem. Commun., 2015, 51, 2056-2059.

52. J. H. Cavka, S. Jakobsen, U. Olsbye, N. Guillou, C. Lamberti, C.Bordiga y K. P. Lillerud, J. Am. Chem. Soc., 2008, 130, 13850-13851.

53. M. Kandiah, M. H. Nilsen, S. Usseglio, S. Jakobsen, U. Olsbye, M. Tilset, C. Larabi, E. A. Quadrelli y F. Bonino, Chem. Mater., 2010, 22, 6632-6640.

54. A.Santiago Portillo, H. G. Baldoví, M. T. García Fernandez, S. Navalón, P. Atienzar, B. Ferrer, M. Alvaro, H. Garcia y Z. Li, J. Phys. Chem. C, 2017, 121, 7015-7024.

55. D. Sempere, S. Navalon, M. Dančíková, M. Alvaro y H. Garcia, Appl. Catal. BEnviron, 2013, 142, 259-267.

56. J. F. Blandez, S. Navalon, M. Alvaro y H. Garcia, ChemCatChem, 2018, 10, 198205.

57. P. Cancino, A. Vega, A. Santiago-Portillo, S.Navalon, M. Alvaro, P. Aguirre, E. Spodine y H. García, Catal. Sci. Technol., 2016, 6, 3727-3736.

58. J. C. Espinosa, S. Navalón, M. Álvaroy H. García, ChemCatChem, 2016, 8, $2642-$ 2648.

59. A. Santiago-Portillo, S. Navalon, F. Cirujano, F. X. Llabrés i Xamena, M. Alvaro y H. Garcia, ACS Catal., 2015, 5, 3216-3224.

60. A. Gómez-Paricio, A. Santiago-Portillo, S. Navalón, P. Concepción, M. Alvaro y H. Garcia, Green Chem., 2016, 18, 508-515.

61. A. Wang, Y. Zhou, Z. Wang, M. Chen, L. Sun y X. Liu, RSC Adv., 2016, 6, 36713679 . 
62. Z. Fang, B. Bueken, D. E. de Vos y R. Fischer, 2015, 54, 7234-7254. Angew. Chem. Int. Ed.,

63. G. C. Shearer, S. Chavan, S. Bordiga, S. Svelle, U. Olsbye y K. P. Lillerud, Chem. Mater., 2016, 28, 3749-3761.

64. J. H. Cavka, S. Jakobsen, U. Olsbye, N. Guillou, C. Lamberti, S. Bordiga y K. P. Lillerud, J. Am. Chem. Soc., 2008, 130, 13850-13851.

65. M. Hino y K. Arata, Chem. Commun., 1988, 18, 1259-1260.

66. M. Kandiah, M. H. Nilsen, S. Usseglio, S. Jakobsen, U. Olsbye, M. Tilset, C. Larabi, E. A. Quadrelli, F. Bonino y K. P. Lillerud, Chem. Mater., 2010, 22, 6632-6640.

67. Y. Nishiyama, Y. Nakagawa y N. Mizuno, Angew. Chem. Int. Ed., 2001, 40, 36393641.

68. S. Yamazaki, Org. biomolec. chem., 2007, 5, 2109-2113.

69. N. Morlanes y J. M. Notestein, Appl. Catal. A: Gen., 2010, 387, 45-54.

70. H. G. T. Nguyen, L. Mao, A. W. Peters, C. O. Audu, Z. J. Brown, O. K. Farha, J. T. Hupp y S. T. Nguyen, Catal. Sci. Technol., 2015, 5, 4444-4451.

71. G. R. Buettner, Free Radic Biol Med., 1987, 3, 259-303.

73. K. A. Joergensen, Chem. Rev., 1989, 89, 431-458.

74. A. Dhakshinamoorthy, M. Alvaro y H. Garcia, J. Catal., 2012, 289, 259-265. 
Oxidación de alquenos empleando UiO-66 con intercambio combinado de átomos de titanio y sustitución en los ligandos. 
Capítulo 8

\section{Parte experimental.}


En el presente capítulo se va a proceder a explicar toda la parte experimental que se ha llevado a cabo para obtener los resultados presentados en los Capítulos 3, 4, 5, 6 y 7. En concreto, la síntesis de los materiales MOFs, las técnicas de caracterización y los procedimientos seguidos para llevar a cabo las reacciones catalizadas por MOFs y su análisis.

Además, cabe destacar que todos los reactivos comerciales empleados se obtuvieron de Sigma-Aldrich.

\subsection{Síntesis de MOFs.}

\subsubsection{Síntesis del MIL-101(Cr).}

El material MIL-101(Cr) fue preparado siguiendo el procedimiento descrito por Ferey ${ }^{1}$. Inicialmente, el ácido tereftálico $(250 \mathrm{mg})$ y $\mathrm{Cr}\left(\mathrm{NO}_{3}\right)_{3} \cdot 9 \mathrm{H}_{2} \mathrm{O}(400 \mathrm{mg})$ se añaden a un autoclave de teflón de $30 \mathrm{~mL}$ conteniendo $8 \mathrm{~mL}$ de agua desmineralizada y $10 \mu \mathrm{L}$ de HF. El autoclave se calienta a $200{ }^{\circ} \mathrm{C}$ durante $8 \mathrm{~h}$. Después de enfriar a temperatura ambiente, el precipitado resultante se lava 2 veces con DMF a $120^{\circ} \mathrm{C}$ durante la noche, después se filtra y se lava con etanol 2 veces a $80^{\circ} \mathrm{C}$. Por último, se vuelve a añadir el sólido verde al autoclave con etanol y se calienta a $100^{\circ} \mathrm{C}$ durante $2 \mathrm{~h}$.

\subsubsection{Síntesis del MIL-101(Fe).}

En cuanto al MIL-101(Fe), este material fue sintetizado de forma parecida al material isoestructural de $\mathrm{Cr}$. En este caso, el ácido tereftálico $(206 \mathrm{mg})$ y el $\mathrm{FeCl}_{3} \cdot 6 \mathrm{H}_{2} \mathrm{O}(675$ $\mathrm{mg}$ ) se añaden a un autoclave de teflón que contiene $15 \mathrm{~mL}$ de DMF y se calienta a 135 ${ }^{\circ} \mathrm{C}$ durante $8 \mathrm{~h}$. Después de este tiempo, el sistema se enfría a temperatura ambiente y el sólido se filtra y se lava 2 veces con etanol a $80^{\circ} \mathrm{C}$ durante una noche.

Cabe destacar, en cuanto al MIL-101(Fe), que debido a su inestabilidad y a su facilidad a cambiar de estructura pasando a la fase del MIL-88(Fe), el sólido obtenido se guarda con etanol.

\subsubsection{Síntesis de los materiales $\mathrm{MIL}-101(\mathrm{Cr})-\mathrm{X}, \mathrm{X}: \mathrm{NO}_{2}, \mathrm{CH}_{3}, \mathrm{Cl}$.}

La serie de materiales MIL-101(Cr)-X se prepararon según bibliografía. ${ }^{2}$ Es decir, en estos casos el correspondiente ácido tereftálico $(1.5 \mathrm{mmol})$, que en el caso del $-\mathrm{CH}_{3}$ y del -Cl se sintetizan previamente, ya que no se venden comercialmente, se mezcla con $\mathrm{CrCl}_{3}(1 \mathrm{mmol})$ en un autoclave de $30 \mathrm{~mL}$ que contiene $8 \mathrm{~mL}$ de agua desmineralizada. La temperatura y el tiempo de la síntesis de los materiales varía según el MOF, como se puede observar en la tabla 8.1 . 
Tabla 8.1. Valores de temperatura y tiempo empleados en la síntesis del MIL-101(Cr)-X. X: $\mathrm{NO}_{2}, \mathrm{CH}_{3}$, $\mathrm{Cl}$.

\begin{tabular}{|l|l|l|}
\hline & Temperatura $\left({ }^{\circ} \mathrm{C}\right)$ & Tiempo $(\mathrm{h})$ \\
\hline MIL-101(Cr)-H & 200 & 8 \\
\hline MIL-101(Cr)-NO ${ }_{2}$ & 180 & 120 \\
\hline MIL-101(Cr)-Cl & 180 & 96 \\
\hline MIL-101(Cr)-CH $\mathrm{CH}_{3}$ & 180 & 120 \\
\hline
\end{tabular}

Además, después de enfriar a temperatura ambiente, los materiales se lavan varias veces con DMF caliente y con etanol, tal como se ha explicado en el punto 8.1.1 de este mismo capítulo.

\subsubsection{Síntesis del MIL-101(Cr)-NH}

El material MIL-101(Cr)- $\mathrm{NH}_{2}$ se sintetiza por reducción del material MIL$101(\mathrm{Cr})-\mathrm{NO}_{2}$ con $\mathrm{SnCl}_{2}$ como se define en la bibliografía. ${ }^{3}$ Más concretamente, $100 \mathrm{mg}$ de MIL-101(Cr)- $\mathrm{NO}_{2}$ y $3.6 \mathrm{~g}$ de $\mathrm{SnCl}_{2} \cdot 2 \mathrm{H}_{2} \mathrm{O}$ se suspenden en $20 \mathrm{~mL}$ de etanol y se calientan a $70{ }^{\circ} \mathrm{C}$ durante seis horas. Pasado este tiempo, el material se centrifuga y se lava con $20 \mathrm{~mL}$ de $\mathrm{HCl}$ concentrado, después se centrifuga 3 veces con $15 \mathrm{~mL}$ de agua y por último con etanol. Finalmente, el material se seca a $70^{\circ} \mathrm{C}$ durante $12 \mathrm{~h}$.

\subsubsection{Sintesis del MIL-101(Cr)-SO $\mathrm{S}_{3} \mathrm{H}$.}

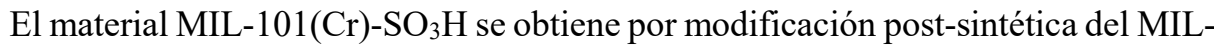
101(Cr), por sulfonación con el ácido clorosulfónico. ${ }^{4}$ Más concretamente, $200 \mathrm{mg}$ de MIL-101(Cr) se activan a vacío a $120{ }^{\circ} \mathrm{C}$ durante una noche. Después se añaden $15 \mathrm{~mL}$ de cloroformo y se agita a $20^{\circ} \mathrm{C}$ durante 10 minutos. Después se añade gota a gota una disolución de $\mathrm{ClSO}_{3} \mathrm{H}(2.8 \mathrm{mmol})$ en $5 \mathrm{~mL}$ de $\mathrm{CHCl}_{3}$ y se deja agita la mezcla a $20{ }^{\circ} \mathrm{C}$ durante 10 minutos más. Pasado este tiempo, el sólido se recoge por filtración y se lava varias veces con $\mathrm{CHCl}_{3}$ y por último con $100 \mathrm{~mL}$ de $\mathrm{H}_{2} \mathrm{O}$ y se deja secar. 


\subsubsection{Síntesis de los materiales UiO-66-X, $\mathrm{X}: \mathrm{H}, \mathrm{NO}_{2}, \mathrm{NH}_{2}$.}

Los tres materiales UiO-66-X se sintetizaron siguiendo procedimientos ya publicados. ${ }^{5}$ En este caso, el correspondiente ácido tereftálico $(1 \mathrm{mmol})$ se mezcla con $\mathrm{ZrCl}_{4}$ en un autoclave de $30 \mathrm{~mL}$ que contiene $3 \mathrm{~mL}$ de DMF. El sistema se calienta a la temperatura y el tiempo que se indica en la tabla 8.2. Después de la síntesis, los sólidos se lavan en la centrífuga con DMF ( 3 veces) y con metanol (3 veces). Finalmente, el material se lava en un Soxhlet con metanol durante $8 \mathrm{~h}$ y se seca a $100{ }^{\circ} \mathrm{C}$ durante $24 \mathrm{~h}$.

Tabla 8.2. Condiciones de síntesis para los materiales UiO-66-X.

\begin{tabular}{|c|l|l|}
\hline $\mathrm{X}$ & Temperatura $\left({ }^{\circ} \mathrm{C}\right)$ & Tiempo de reacción $(\mathrm{h})$ \\
\hline $\mathrm{NH}_{2}$ & 100 & 24 \\
\hline $\mathrm{H}$ & 220 & 12 \\
\hline $\mathrm{NO}_{2}$ & 220 & 24 \\
\hline
\end{tabular}

\subsubsection{Intercambio post-sintético de $\mathrm{Zr}^{4+}$ por $\mathrm{Ti}^{4+}$ en la estructura de los UiO-66-X.}

El intercambio post-sintético de $\mathrm{Zr}^{4+}$ por $\mathrm{Ti}^{4+}$ en la estructura de los materiales UiO66-X se realiza siguiendo un procedimiento ya reportado. ${ }^{6}$ En este caso, $200 \mathrm{mg}$ de UiO66-X se suspenden en $5 \mathrm{~mL}$ de DMF anhidro en un Schlenk. Por otra parte, se pesan en condiciones inertes la cantidad de $\mathrm{TiCl}_{4}(\mathrm{THF})_{2}$ requerida para cada intercambio. Finalmente, y en condiciones inertes, se mezcla la suspensión del MOF en DMF con la cantidad requerida del complejo de Ti y se deja agitando a $120{ }^{\circ} \mathrm{C}$ durante 4 días en atmósfera de nitrógeno.

\subsection{Técnicas de caracterización.}

\subsubsection{Difracción de rayos $X(X R D)$.}

La difracción de rayos X (DRX) se empleó de forma sistemática para identificar las fases cristalinas de los diferentes materiales sintetizados, así como para determinar el grado de cristalinidad de los mismos.

La DRX se puede utilizar también para determinar expansiones y contracciones de la red del sólido a partir de la medida de la posición de picos seleccionados, como se ha observado en el capítulo anterior. 
Los análisis de rayos $\mathrm{X}$ se obtuvieron utilizando un difractómetro Cubix-Pro de PANalytical, equipado con un detector PANalytical X'Celerator.

Se emplea una radiación monocromática de rayos $\mathrm{X}$ de $\mathrm{CuK} \alpha\left(\kappa_{1}=1.5406 \AA, \kappa_{2}=\right.$ $1.5444 \AA, \mathrm{I}_{2} / \mathrm{I}=0.5$ ) y un voltaje e intensidad de tubo de $45 \mathrm{kV}$ y $40 \mathrm{~mA}$, respectivamente. Además, se utiliza una rendija variable con un área de muestra irradiada de $5 \mathrm{~mm}$ y la longitud del brazo del goniómetro es de $200 \mathrm{~mm}$.

Los difractogramas se obtuvieron a temperatura ambiente en el rango de ángulo $2 \theta$ entre 2 y $90^{\circ}$, con un incremento de $0.02^{\circ}(2 \theta)$.

\subsubsection{Espectroscopía de infrarrojo por transformada de Fourier (FTIR).}

La técnica de Espectroscopía de Infrarrojo permite la identificación de los grupos funcionales de un compuesto. Esto debido a que cuando una molécula absorbe radiación infrarroja, la vibración intramolecular con frecuencia igual a la de la radiación, aumenta en intensidad, lo que genera señales con frecuencias que corresponden a la vibración de un enlace específico.

La absorción en el infrarrojo se produce por interacción de la radiación incidente con los niveles vibracionales de las moléculas. La intensidad de la absorción depende de las variaciones que produce la oscilación en el momento dipolar. Los espectros FTIR fueron registrados a temperatura ambiente en un espectrofotómetro Bruker Tensor 27 secando previamente la muestra en un horno a $100^{\circ} \mathrm{C}$.

\subsubsection{Termogravimetría (TGA).}

Los análisis de termogravimetría (TGA) estudian los procesos de descomposición térmica de los compuestos orgánicos, en este caso permite saber la cantidad de agua que tienen los materiales, la cantidad de ligando y de metal total, así como su estabilidad en función de la temperatura.

Los análisis se llevaron a cabo con un aparato Mettler Toledo TGA/SDTA 851e en el rango de temperaturas de 20 a $800{ }^{\circ} \mathrm{C}$ a una velocidad de $10{ }^{\circ} \mathrm{C} \mathrm{min}-1$ y un flujo de aire de $20 \mathrm{~mL} \mathrm{~min} \mathrm{~m}^{-1}$.

\subsubsection{Adsorción de nitrógeno.}

Esta medida se realiza para obtener los valores de área específica, para lo cual se utiliza el modelo BET, en nuestros casos, y también para saber el volumen de poro de los MOFs. 
Para llevar a cabo estos tipos de análisis, se dispone de dos equipos automáticos MICROMERITICS: ASAP 2020 (convertible en ASAP 2020C) y Autopore IV. Se trata de instrumentos de última generación, dotados de todo el equipamiento auxiliar y el software más avanzado en tareas para el estudio físico de la porosimetría.

Durante la medida, se obtienen isotermas de adsorción-desorción de $\mathrm{N}_{2}$ a $77 \mathrm{~K}$, que se desarrollan variando la presión relativa $(\mathrm{P} / \mathrm{Po})$ del gas a una temperatura constante $\mathrm{y}$ registrando el volumen de gas adsorbido en la superficie del sólido. Las muestras se activan a $150^{\circ} \mathrm{C}$ durante una noche.

\subsubsection{Espectroscopía emisión de plasma de acoplamiento inductivo (ICP-OES).}

El ICP-OES es una técnica de análisis inorgánico que es capaz de determinar y cuantificar la mayoría de los elementos de la tabla periódica en un rango dinámico lineal de 8 órdenes de magnitud $(\mathrm{ng} / \mathrm{l}-\mathrm{mg} / \mathrm{l})$. Por tanto, permite la determinación de la composición y la cuantificación de los metales presentes en un material.

Su principal ventaja son sus bajos límites de detección para la mayoría de los elementos detectando unas pocas ppb - ppt lo que la hace ideal para el análisis de elementos traza.

La técnica se basa en la excitación de los átomos de la disolución que se nebuliza en un plasma de alta temperatura, los átomos excitados caen al estado fundamental emitiendo un fotón de energía característica para cada átomo. La intensidad de dicha emisión es proporcional a la cantidad de metal presente en la muestra, así que de esta manera se puede cuantificar la cantidad presente de metal, relacionando los resultados adquiridos con los estándares obtenidos a partir de las rectas de calibrado de los patrones comerciales del metal a analizar.

Las muestras se han analizado en un equipo Varian 715-ES ICP-Optical Emission Spectrometer. Para la determinación de la cantidad de metal presente en un catalizador, éste se suspende en agua y nítrico durante unas horas para facilitar el lixiviado del metal a la disolución. Posteriormente, la muestra se filtra y se analiza para determinar la cantidad de metal presente en el catalizador. Por otro lado, también se puede analizar la fase líquida obtenida después de cada reacción, para averiguar la cantidad de metal que puede lixiviar del metal durante la reacción.

\subsubsection{Espectroscopía Raman.}

La espectroscopía Raman en este caso se ha empleado para analizar la activación de oxígeno con el material, es decir, comprobar si durante medidas de Raman "in situ" con oxígeno los metales del material son capaces de formar superóxido o peróxidos. 
Consiste en el análisis de la dispersión de la luz que provoca un material al incidir sobre él un haz de luz monocromático. Los análisis se llevaron a cabo por medio de un instrumento Renishaw in Via Raman Microscope a temperatura ambiente con un láser de ion Ar de $514 \mathrm{~nm}$ como fuente de excitación acoplado a un microscopio óptico Lyca que permite determinar la zona de la muestra expuesta al haz láser que posee una superficie de $1 \mu \mathrm{m}^{2}$.

Se registraron los espectros en la región de desplazamiento Raman de 0 a $3500 \mathrm{~cm}^{-}$ ${ }^{1}$, con una resolución inferior a $4 \mathrm{~cm}^{-1}$, pudiendo realizar hasta 10 barridos en un tiempo total de acumulación de $100 \mathrm{~s}$. Para un correcto análisis es necesaria la comparación de los espectros obtenidos en diferentes puntos de la muestra.

Las muestras se midieron en atmósfera de nitrógeno también para comparar como varía el espectro Raman cuando se introduce oxígeno.

\subsubsection{Resonancia paramagnética de electrones (EPR).}

El método de resonancia paramagnética de electrones en este caso es usado para ver si se forman en disolución radicales hidroperoxilo al poner en contacto oxígeno en una suspensión del MOF con $n$-dodecano y añadiendo un "spin trap", en nuestro caso PBN.

Las medidas se emplean en un equipo Bruker EMX con los siguientes parámetros: frecuencia $9.803 \mathrm{GHz}$ con una anchura de barrido de $3489.9 \mathrm{G}$ a un tiempo constante de $40.95 \mathrm{~ms}$ y una frecuencia de modulación $100 \mathrm{kHz}$ con una anchura de modulación de 1 $\mathrm{G}$ y una potencia de microondas de $19.92 \mathrm{~mW}$.

\subsubsection{Análisis elemental por combustión (AE)}

El análisis elemental por combustión permite la determinación de la composición de un material en base a los elementos $\mathrm{C}, \mathrm{H}, \mathrm{S}$ y N presentes en su estructura, dando a conocer los porcentajes de cada elemento presentes en la muestra.

La muestra se somete a combustión térmica desde 166 a $1800{ }^{\circ} \mathrm{C}$, en atmósfera de $\mathrm{O}_{2}$, cuantificando la transformación total de los componentes: $\mathrm{C}$ a $\mathrm{CO}_{2}, \mathrm{H}$ a $\mathrm{H}_{2} \mathrm{O}, \mathrm{N}$ a $\mathrm{N}_{2}, \mathrm{~S}$ a SO $\mathrm{SO}_{2}$. Estos gases, después de ser separados con distintas técnicas (columna cromatográfica, infrarrojos) según el equipo utilizado, son medidos y procesados teniendo en consideración el peso de la muestra y los datos proporcionados por una muestra patrón obteniéndose de este modo el contenido porcentual de cada elemento en la muestra.

El equipo utilizado para este tipo de análisis es un analizador Euro EA3000 Elemental Analyzer (EuroVector), empleando la sulfanilamida como patrón de referencia. 
Capitulo 8.

\subsubsection{Espectroscopía de infrarrojo por transformada de Fourier de adsorción de CO (CO-FTIR).}

Esta técnica de caracterización se ha empleado para estudiar la acidez Lewis de los materiales.

Para ello los espectros de CO-FTIR se midieron usando un espectrofotómetro Nexus 8700 FTIR con una celda de IR que permite tratamientos "in situ" controlando la temperatura desde los 176 hasta los $500^{\circ} \mathrm{C}$ y conectado a un sistema de alto vacío.

En estas medidas, las muestras se pretrataron a vacío $\left(10^{-6} \mathrm{mbar}\right)$ a $150^{\circ} \mathrm{C}$ durante $5 \mathrm{~h}$. Una vez activada la muestra, se enfría a $-176^{\circ} \mathrm{C}$ y se dosifica $\mathrm{CO}$ con un aumento de presión (0.4 - 6 mbar) midiendo espectros de IR en cada dosificación.

Todos los espectros de IR fueron normalizados según el peso de la muestra.

\subsubsection{Microscopía electrónica de barrido (SEM)}

Se empleó esta técnica para analizar el tamaño de los cristales de los MOFs y ver si son iguales en toda la serie de materiales MIL-101(Cr)-X y UiO-66-X.

Las imágenes de microscopía electrónica de barrido (SEM) se obtuvieron con un microscopio JEOL JSM-5410. Los análisis elementales por espectroscopía de rayos X de energía dispersiva (EDX) se realizaron con un detector de Oxford Instruments acoplado a estos microscopios.

\subsubsection{Espectrofotometría fotoelectrónica de rayos $X$ (XPS)}

La espectroscopía fotoelectrónica de rayos X (XPS) es una técnica de caracterización para el análisis de superficies que permite la estimación de la estequiometría, el estado químico y la estructura electrónica de los elementos presentes en un material.

El espectro de XPS se obtiene por irradiación con rayos X, generalmente provenientes de un ánodo de $\mathrm{Al}$ o $\mathrm{Mg}$, midiendo la energía cinética y el número de electrones que escapan de la superficie de la muestra de análisis. Los XPS se obtuvieron mediante un espectrofotómetro SPECS equipado con un detector Phoibos 150-9MCD, que utiliza una fuente monocromática de rayos $\mathrm{X}$ de $\mathrm{Al} \mathrm{K} \alpha(1483.6 \mathrm{eV})$ operando a $50 \mathrm{~W}$.

Las muestras se sometieron a un vacío previo en una precámara del equipo a $10^{-9}$ mbar. El tratamiento de los espectros, así como su cuantificación, se llevó a cabo utilizando el software CASA, y la corrección de carga de los espectros se realiza en base a la señal del carbono C1s, que posee una energía de enlace conocida de $284.5 \mathrm{eV}$. 


\subsection{Procedimientos de reacción.}

\subsubsection{Procedimiento general para la oxidación aeróbica de compuestos bencílicos.}

Inicialmente en el capítulo 3, antes de emplear los compuestos bencílicos como sustratos en las reacciones, estos se destilaron para comparar los resultados obtenidos con los sustratos destilados o sin destilar.

Generalmente, la cantidad de catalizador requerida $(75 \mathrm{mg})$ se añaden a un matraz de fondo redondo de 2 bocas $(25 \mathrm{~mL})$. Si las muestras se someten a activación, estos sólidos se dejan a vacío, a $120^{\circ} \mathrm{C}$ durante $6 \mathrm{~h}$. Una vez activado el catalizador, se añade el sustrato requerido en cada reacción $(20 \mathrm{mmol})$ y se purga con oxígeno (si se estudia la atmósfera de la reacción se utiliza aire o Ar) y se sonica durante 15 min. Una vez sonicada, la reacción se calienta a $120^{\circ} \mathrm{C}$ mientras permanece bajo agitación.

\subsubsection{Procedimiento general para la oxidación desulfurativa de dibenzotiofenos.}

La reacción de oxidación de dibenzotiofenos se lleva a cabo en un matraz de 2 bocas de $25 \mathrm{~mL}$ en el que se añade MIL-101(Cr o Fe $)(0.02 \mathrm{mmol}$ de metal $)$ y se activa a $150^{\circ} \mathrm{C}$ durante una noche, posteriormente se añade el sustrato (200 ppm de S) disuelto en $n$ dodecano o diésel $(10 \mathrm{~mL})$ y se purga con oxígeno y se sonica durante $15 \mathrm{~min}$. Pasado este tiempo se pone en una placa calefactora a $120^{\circ} \mathrm{C}$ bajo agitación constante.

\subsubsection{Procedimiento de extracción líquido-líquido para eliminar completamente la sulfona del medio de reacción.}

Una vez finalizada la reacción, se eliminar el catalizador por medio de filtración con un filtro de nylon de $0.2 \mu \mathrm{m}$. Luego la fase orgánica $(10 \mathrm{~mL})$ se extrae con agua destilada $(3 \times 10 \mathrm{~mL})$ usando un embudo de decantación.

Este proceso resulta eficiente para eliminar la sulfona de la fase orgánica a la fase acuosa ya que, si se recoge la fase orgánica y se analiza por cromatografía de gases, la sulfona deja de aparecer, es decir, se sabe que la cantidad de sulfona es menor a 4 ppmw de $\mathrm{S}$, cuando la legislación pide que sea menor que $10 \mathrm{ppmw}$ de $\mathrm{S}$.

\subsubsection{Procedimiento general para la oxidación de bencilaminas a iminas.}

Cómo se ha visto anteriormente, primero se procede a activar el material MIL$101(\mathrm{Cr})-\mathrm{X}\left(0.04 \mathrm{mmol}\right.$ de metal) a $150^{\circ} \mathrm{C}$ durante una noche en un matraz de dos bocas de $25 \mathrm{~mL}$. Una vez activado el catalizador, se añade la bencilamina $(20 \mathrm{mmol})$, se purga la reacción con oxígeno y se sónica durante $15 \mathrm{~min}$. Después, se calienta la mezcla de reacción a $120^{\circ} \mathrm{C}$ bajo agitación. 


\subsubsection{Procedimiento para la reacción de Prins.}

En este caso la cantidad de MIL-101(Cr)-X que se activa es mayor (0.08 mmol de $\mathrm{Cr})$, una vez activado el MOF, se añaden $\beta$-pineno $(1 \mathrm{mmol})$ y formaldehido $(1 \mathrm{mmol})$ disueltos en acetonitrilo $(2.5 \mathrm{~mL})$ y se sonica durante $15 \mathrm{~min}$. Una vez se homogeniza toda la mezcla de reacción, se calienta a $80^{\circ} \mathrm{C}$ bajo agitación.

\subsubsection{Procedimiento para la reacción de apertura de epóxidos.}

La reacción de apertura de epóxidos se prepara de igual manera que la Prins, pero en este caso la cantidad de MIL-101(Cr)-X empleada son $0.04 \mathrm{mmol}$ de $\mathrm{Cr}$, el disolvente empleado es el propio metanol, uno de los sustratos de la reacción $(2.5 \mathrm{~mL})$ y el otro sustrato empleado es el epóxido $(1 \mathrm{mmol})$.

Además, en este caso la temperatura de la reacción son $50{ }^{\circ} \mathrm{C}$.

\subsubsection{Procedimiento para la acetalización de benzaldehído.}

Esta reacción se lleva a cabo de forma similar a la apertura de epóxido, en este caso la cantidad de metanol empleada son $3 \mathrm{~mL}$ y el otro sustrato empleado es benzaldehído (1 mmol)

Esta reacción se lleva a cabo a $30^{\circ} \mathrm{C}$.

\subsubsection{Procedimiento para la epoxidación de cicloalquenos.}

En este tipo de reacción se ha utilizado el material UiO-66(Zr Ti)-X $(0.016 \mathrm{mmol}$ de metal). El catalizador se introduce en un reactor vessel $(5 \mathrm{~mL})$ y se añade la olefina $(2 \mathrm{mmol})$ disuelta en $\mathrm{CH}_{3} \mathrm{CN}(2.5 \mathrm{~mL})$. El sistema se presuriza con la cantidad de $\mathrm{O}_{2}$ requerida (normalmente $5 \mathrm{~atm}$ ) a temperatura ambiente.

La reacción se lleva a cabo a $120^{\circ} \mathrm{C}$ y bajo agitación constante.

\subsubsection{Reacciones para estudiar la energía de activación de la reacción.}

En todos los casos, se llevó a cabo la reacción a cuatro temperaturas diferentes y mediante la gráfica de Arrhenius del logaritmo de la velocidad inicial de las cuatro reacciones con la inversa de la temperatura se obtiene la pendiente, que será el valor de energía de activación de la reacción. 


\subsubsection{Experimentos de inhibición.}

En este caso, en todos los capítulos se ha procedido de la misma manera, se lleva a cabo la reacción correspondiente, pero una vez ya iniciada se añade un $20 \mathrm{~mol} \%$ del inhibidor de radicales, ya sea de DMSO (HO), $p$-benzoquinona $\left(\mathrm{O}^{\circ} / \mathrm{HOO}\right) \mathrm{o}$ TEMPO (inhibidor de radicales de C).

\subsubsection{Experimentos de adsorción.}

Para calcular la adsorción de los MOFs en los sustratos, en un matraz de fondo redondo de 2 bocas con $1 \mathrm{mmol}$ de los sustratos a estudiar y $p$-xileno $(3 \mathrm{~mL})$. Luego se añade el MOF $(75 \mathrm{mg})$ y se deja a temperatura ambiente $\left(20^{\circ} \mathrm{C}\right)$ agitando.

Para cuantificar la adsorción del catalizador en el sustrato a estudiar, se van tomando muestras de la reacción a diferentes tiempos y se analizan por cromatografía de gases empleando nitrobenceno como patrón externo.

\subsubsection{Experimentos de medida de lixiviado.}

Para medir si existe lixiviado del metal a la reacción, una vez finalizada, se filtra el catalizador usando un filtro de nylon de $0.2 \mu \mathrm{m}$ y luego la fase orgánica se pone en contacto con $30 \mathrm{~mL}$ de una disolución acuosa de $\mathrm{HNO}_{3}(3 \mathrm{M})$ y se analiza la fase acuosa por ICP-OES.

\subsubsection{Experimentos de reusabilidad del material.}

En este tipo de experimentos, se lleva a cabo la reacción como ya se ha indicado, una vez finalizada se filtra el MOF en un sistema de filtración a vacío, el líquido se recoge para prepararlo para analizar el lixiviado del material y el sólido se lava con el disolvente que se ha empleado en cada caso, se pasa también etanol y se recoge para proceder a su lavado en caliente con etanol $\left(80^{\circ} \mathrm{C}\right.$ y $\left.2 \mathrm{~h}\right)$. Una vez en caliente se vuelve a filtrar el catalizador a vacío y se pasa etanol. Este procedimiento se repite 2 veces más.

Una vez lavado el material, se deja secar en una estufa a $100^{\circ} \mathrm{C}$ y posteriormente se vuelve a activar para volver a ser utilizado en un nuevo ciclo. 


\subsection{Procedimiento de análisis de las muestras de reacción.}

\subsubsection{Análisis de las muestras por cromatografía de gases (GC)}

Para analizar los resultados obtenidos en las reacciones que se han llevado a cabo, se cogen alícuotas de la reacción a diferentes tiempos. Estas alícuotas se disuelven en tolueno (en el caso de la oxidación de compuestos bencílicos y bencilaminas), en anisol (en el caso de la oxidación de dibenzotiofeno), en metanol (en el caso de la reacción de apertura de epóxidos o la acetalización) o en acetonitrilo (en el caso de la reacción de Prins o en el caso de la epoxidación de cicloalquenos) con una cantidad conocida de nitrobenceno, el cual se usa como patrón externo.

Las alícuotas se filtran con un filtro de jeringa de nylon de $0.2 \mu \mathrm{m}$ y se analizan por cromatografía de gases, empleando un detector por ionización de llama (FID).

La columna utilizada para la separación de los productos fue una capilar $(\% 5 \mathrm{de}$ metilfenilsilicona), HP-5 de 25 m de longitud.

Las condiciones de operación del cromatógrafo fueron las siguientes:

- Gas portador: He

- Presión de He en cabeza de columna: 9 psi.

- Relación de split: 50

- Temperatura del inyector: $250^{\circ} \mathrm{C}$

- Temperatura del detector: $300^{\circ} \mathrm{C}$

- Flujo de aire (FID): $300 \mathrm{ml} / \mathrm{min}$.

- Flujo de hidrógeno (FID): $30 \mathrm{ml} / \mathrm{min}$.

- Flujo de He adicional en el detector ("make-up"): $30 \mathrm{ml} / \mathrm{min}$.

Los productos se identificaron por espectrometría de masas (GC-MS), comparándose los espectros obtenidos con los de los compuestos puros.

La cuantificación se lleva a cabo usando curvas de calibración con los reactivos y productos utilizados y usando nitrobenceno como patrón. $95 \%$

Cabe destacar que los balances de masas en todos los casos han sido superiores al 


\subsubsection{Análisis de la cantidad de agua oxigenada formada.}

Esta técnica ha sido utilizada en el capítulo 5 en donde una vez filtrada la alícuota $(0.5 \mathrm{~mL})$ se disuelven en agua destilada $(4.5 \mathrm{~mL})$ y se añade una disolución de oxalato de titanio $\left(\mathrm{K}_{2}(\mathrm{TiO})\left(\mathrm{C}_{2} \mathrm{O}_{4}\right)_{2}\right.$ en $\left.\mathrm{H}_{2} \mathrm{SO}_{4} / \mathrm{HNO}_{3} ; 0.5 \mathrm{~mL}\right)$ como agente colorimetrante y se deja reaccionar durante $10 \mathrm{~min}$.

La intensidad de aparición del color amarillo en las muestras se monitoriza por un espectrómetro de UV-Vis a $\lambda=420 \mathrm{~nm}$. 
Capitulo 8.

\subsection{Referencias.}

1. G. Ferey, C. Mellot-Draznieks, C. Serre, F. Millange, J. Dutour, S. Surble y I. Margiolaki, Science, 2005, 309, 2040-2042.

2. M. Lammert, S. Bernt, F. Vermoortele, D. E. De Vos y N. Stock, Inorg. Chem., 2013, 52, 8521-8528.

3. S. Bernt, V. Guillerm, C. Serre y N. Stock, Chem. Commun., 2011, 47, 2838-2840.

4. B. Li, Y. Zhang, D. Ma, L. Li, G. Li, G. Li, Z. Shi y S. Feng, Chem. Commun., 2012, 48, 6151-6153.

5. J. F. Blandez, A. Santiago-Portillo, S. Navalon, M. Gimenez-Marques, M. Alvaro, P. Horcajada y H. Garcia, J. Mol. Catal. A Chem., 2016, 425, 332-339.

6. D. Sun, W. Liu, M. Qiu, Y. Zhang y Z. Li, Chem. Commun., 2015, 51, 2056-2059. 


\section{Capítulo 9 \\ Conclusiones}


A la vista de los resultados obtenidos se puede concluir que los MOFs son catalizadores y promotores de reacciones de oxidación aeróbica que trascurren a través de especies reactivas de oxígeno como fundamentalmente hidroperóxido e hidroxilo sin sufrir degradación o descomposición. Además, se ha observado que la presencia de sustituyentes fuertemente aceptores de electrones aumentan la actividad catalítica de estos materiales para reacciones que implican los átomos metálicos, bien sea ácido-base o reacciones de oxidación aeróbica. Más específicamente, las conclusiones de cada capítulo son la siguientes:

(I) Se ha demostrado que el material MIL-101(Cr o Fe) es un promotor adecuado para las reacciones de oxidación aeróbica de hidrocarburos bencílicos. Se han observado diferencias en función de la naturaleza del metal, así como la preactivación del material. De entre las condiciones ensayadas, el empleo de MIL-101(Cr) sin preactivación térmica parece la mejor opción para llevar a cabo la oxidación aeróbica de hidrocarburos bencílicos y cíclicos sin que el promotor sufra desactivación y a través de un mecanismo que implica que el radical hidroperóxido e hidroxilo como especie activa.

(II) Se ha demostrado que el material MIL-101(Cr) es un promotor adecuado para llevar a cabo la oxidación de DBT a la correspondiente sulfona. El proceso presenta un período de inducción que ha sido atribuido al tiempo necesario para que las cadenas de disolvente difundan entre los poros del material. El material MIL-101(Cr) es estable en las condiciones de reacción y no sufre una desactivación notable con el reuso. La reacción se puede llevar a cabo utilizando combustibles comerciales como disolventes, demostrando de esta manera, que es posible eliminar los compuestos orgánicos azufrados que típicamente se encuentran presentes en combustibles comerciales antes de su tratamiento para eliminar este tipo de compuestos.

(III) Se ha demostrado que el sustituyente presente sobre los ligandos tereftalato ejercen una influencia sobre la actividad catalítica de estos materiales que se correlaciona con la constante de Hammett sigma meta del sustituyente.

(IV) De forma análoga se ha demostrado que los sustituyentes electrón-aceptores aumentan la actividad catalítica del material MIL-101(Cr)-X para reacciones que requieren centros ácidos de Lewis. Se ha encontrado una relación lineal entre la constante de Hammet $\sigma_{\mathrm{m}}$ del sustituyente y la velocidad inicial de reacción para el caso de la reacción de Prins entre el $\beta$-pineno y el 
formaldehido. En otros casos se ha propuesto que la desviación de esta linealidad para sustituyentes que poseen grupos dadores $y$, particularmente, el grupo amino indica la existencia de un mecanismo de reacción alternativo que ocurre simultáneamente con el mecanismo general.

(V) Se ha demostrado que partiendo de un material UiO-66( $\mathrm{Zr})-\mathrm{H}$ que no posee actividad catalítica para la reacción de epoxidación de cicloocteno es posible generar centros activos tras la síntesis del material mediante el empleo de reacciones postsintéticas de intercambio iónico reemplazando un cierto porcentaje de iones $\mathrm{Zr}^{4+}$ por $\mathrm{Ti}^{4+}$ y/o por introducción en los grupos tereftalato de sustituyentes electrón-aceptores que favorezcan la reacción de oxidación.

En el contexto del empleo de materiales MOFs como catalizadores, la presente tesis doctoral ha hecho contribuciones relevantes respecto a la oxidación de dibenzotiofenos, en pequeño porcentaje presentes en medios hidrocarbonados de cadena larga, y sobre la influencia de la presencia de sustituyentes tanto en reacciones de oxidación aeróbica como en reacciones ácido de Lewis para materiales MOFs diferentes del estudio inicial referido al MOF UiO-66(Zr). Igualmente se ha demostrado la posibilidad de combinar ambas estrategias, es decir, la influencia del sustituyente y la introducción de centros activos sobre los nodos metálicos. 
Resúmenes de la tesis 


\section{Resumen}

En la presente tesis doctoral se ha estudiado la aplicación de los MOFs de las familias MIL-101 y UiO-66 como catalizadores heterogéneos y su facilidad para ser modificados tanto sintéticamente como post-sintéticamente, bien sea intercambiando un porcentaje de metal del nodo, como modificando el ligando introduciendo grupos electrodadores o electroaceptores, demostrando además la posibilidad de combinar ambas estrategias.

En particular, la tesis se centra en la aplicación de los MOFs como catalizadores heterogéneos para reacciones de oxidación aeróbica, como la oxidación de compuestos bencílicos, de dibenzotiofenos, de bencilaminas o de alquenos, y reacciones de catálisis ácido de Lewis como la reacción de Prins, la apertura de epóxidos o la acetalización.

A la vista de los resultados obtenidos se ha demostrado que los MOFs son catalizadores y promotores de reacciones de oxidación aeróbica que trascurren a través de especies reactivas de oxígeno como fundamentalmente hidroperóxido e hidroxilo sin sufrir degradación o descomposición. También, se ha demostrado, que estos materiales en las condiciones de reacción empleadas no sufren desactivación con los reusos, ya que no se produce prácticamente lixiviado de metal a la fase líquida durante las reacciones y además mantienen la cristalinidad después de varios cíclos catalíticos.

Además, se ha observado que la presencia de sustituyentes fuertemente aceptores de electrones aumentan la actividad catalítica de estos materiales para reacciones que implican los átomos metálicos, bien sea ácido-base o reacciones de oxidación aeróbica. 


\section{Resum}

En la present tesis doctoral se ha estudiat l'aplicació dels MOFs de les famílies MIL-101 y UiO-66 com a catalitzadors heterogenis y la seua facilitat per a ser modificats tant sintèticament como post-sintèticament, be siga intercanviant un percentatge de metall del node, como modificant el lligand introduint grups electrodadors o electroaceptors, demostrant a més la possibilitat de combinar ambdues estratègies.

En particular, la tesis es centra en la aplicació dels MOFs como a catalitzadors heterogenis per a reaccions d'oxidació aeròbica, como l'oxidació de compostos bencílics, de dibenzotiofens, de bencilamines o d'alquens, y reaccions de catàlisis d'àcid de Lewis com la reacció de Prins, la apertura de epòxids o la acetalització.

En vista dels resultats obtinguts s'ha demostrat que els MOFs son catalitzadors y promotors de reaccions d'oxidació aeròbica que tenen lloc a través d'espècies reactives d'oxigen com fonamentalment hidroperòxid e hidroxil sense sofrir degradació o descomposició. També, s'ha demostrat, que estos materials en les condicions de reacció empleades no experimenten desactivació amb els reusos, ja que no es produeix pràcticament lixiviat de metall a la fase líquida durant les reaccions i a més, mantenen la cristalinitat després de diversos cicles catalítics.

A més, s'ha observat que la presència de substituents fortament acceptors d'electrons augmenten l'activitat catalítica d'estos materials per a reaccions que impliquen els àtoms metàl·lics, be siga àcid-base o reaccions d'oxidació aeròbica. 


\section{Summary}

In the present doctoral thesis, we study the application of the MOFs MIL-101 and UiO-66 families as heterogeneous catalysts and their ease to be modified both synthetically and post-synthetically, either by exchanging a percentage of the metal of the node, as modifying the ligand introducing electron donors or electron acceptors groups, demonstrating also the possibility of combining both strategies.

Particularly, the thesis focuses on the application of MOFs as heterogeneous catalysts for aerobic oxidation reactions, such as the oxidation of benzylic compounds, dibenzothiophenes, benzylamines or alkenes, and Lewis acid catalysis reactions such as Prins reaction, ring opening of epoxies or acetalization of benzaldehyde.

In view of the results obtained, it has been demonstrated that MOFs are catalysts and promoters of aerobic oxidation reactions that pass through reactive oxygen species such as hydroperoxide and hydroxyl without suffering degradation or decomposition. Also, it has been demonstrated that these materials under the reaction conditions used do not undergo deactivation with reuse, since there is practically no leaching of metal to the liquid phase during the reactions and they also maintain the crystallinity after several catalytic cycles.

In addition, it has been observed that the presence of strongly electron-accepting substituents increases the catalytic activity of these materials for reactions involving the metal atoms, either acid-base or aerobic oxidation reactions. 


\section{Lista de publicaciones}




\section{Lista de publicaciones.}

Las publicaciones que se han obtenido durante estos años de tesis doctoral son las siguientes:

1. MIL-101 as Reusable Solid Catalyst for Autoxidation of Benzylic Hydrocarbons in the Absence of Additional Oxidizing Reagents.

Andrea Santiago Portillo, Sergio Navalón Oltra, Francisco García Cirujano, Francesc X Llabrés Xamena, Mercedes Álvaro Rodríguez, Hermenegildo García Gómez.

ACS Catalysis, 2015, 5, 3216 - 3224.

2. MIL-101 promotes the efficient aerobic oxidative desulfurization of dibenzothiophenes.

Adrián Gómez Paricio, Andrea Santiago Portillo, Sergio Navalón Oltra, Patricia Concepción, Mercedes Álvaro Rodríguez, Hermenegildo García Gómez.

Green Chemistry, 2016, 18, 508 - 515.

3. A novel copper(II)-lanthanum(III) metal organic framework as a selective catalyst for the aerobic oxidation of benzylic hydrocarbons and cycloalkenes.

Patricio Cancino, Andrés Vega, Andrea Santiago Portillo, Sergio Navalón Oltra, Mercedes Álvaro Rodriguez, Pedro Aguirre, Evgenia Spodine, Hermenegildo García Gómez.

Catalysis Science and Technology, 2016, 6, 3727 - 3736.

4. Influence of functionalization of terephthalate linker on the catalyticactivity of UiO-66 for epoxide ring opening.

Juan Francisco Blandez Barradas, Andrea Santiago Portillo, Sergio Navalón Oltra, Mónica Giménez Marqués, Mercedes Álvaro Rodriguez, Patricia Horcajada, Hermenegildo García Gómez.

Journal of Molecular Catalysis A: Chemical, 2016, 425, 332 - 339.

5. Influence of Terephthalic Acid Substituents on the Catalytic Activity of MIL-101(Cr) in Three Lewis Acid Catalyzed Reactions.

Andrea Santiago Portillo, Sergio Navalón Oltra, Patricia Concepción, Mercedes Álvaro Rodriguez, Hermenegildo García Gómez.

ChemCatChem, 2017, 9, 1 - 7 . 
6. Influence of the organic linker substituent on the catalytic activity of MIL101(Cr) for the oxidative coupling of benzylamines to imines.

Andrea Santiago Portillo, Juan Francisco Blandez Barradas, Sergio Navalón O1tra, Mercedes Álvaro Rodriguez, Hermenegildo García Gómez.

Catalysis Science and Technology, 2017, 7, 1351 - 1362.

7. $\mathrm{Ti}$ as Mediator in the Photoinduced Electron Transfer of Mixed-Metal NH2-UiO-66(Zr/Ti): Transient Absorption Spectroscopy Study and Application in Photovoltaic Cell.

Andrea Santiago Portillo, Hermenegildo García Baldoví, María Teresa García Fernández, Sergio Navalón Oltra, Pedro Atienzar, Belen Ferrer Ribera, Mercedes Álvaro Rodriguez, Hermenegildo García Gómez, Zhaohui Li.

The Journal of Physical Chemistry C, 2017, 121, 7015 - 7024.

8. Room temperature silylation of alcohols catalyzed by metal organic frameworks.

Amarajothi Dhakshinamoorthy, Andrea Santiago Portillo, Patricia Concepción, José Raul Herance, Sergio Navalón Oltra, Mercedes Álvaro Rodriguez, Hermenegildo García Gómez.

Catalysis Science and Technology, 2017, 7, 2445 - 2449.

9. Adaptability of the metal (III, IV) 1,2,3-trioxobenzene rod secondary building unit for the production of chemically stable and catalytically active MOFs.

Georges Mouchaham, Brian Abeykoon, Mónica Giménez Marqués, Sergio Navalón Oltra, Andrea Santiago Portillo, Maame Affran, Nathalie Guillou, Charlotte Martineau, Hermenegildo García Gómez, Alexandra Fateeva, Thomas Devic.

Chemical Communication, 2017, 53, 7661 - 7664.

10. A Highly Stable and Hierarchical Tetrathiafulvalene-based Metal-Organic Framework with Improved Performance as Solid Catalyst.

Manuel Souto, Andrea Santiago Portillo, Miguel Palomino, Ínigo J. Vitórica Yrzebal, Bruno J.C Vieira, Joao Carlos Waerenborgh, Susana Valencia, Sergio Navalón Oltra, Fernando Rey, Hermenegildo García Gómez, Guillermo Mínguez Espallargas.

Chemical Science, 2018, 9, 2413 - 2418. 
11. Generating and optimizing the catalytic activity in UiO-66 for aerobic oxidation of alkenes by post-synthetic exchange $\mathrm{Ti}$ atoms combined with ligand substitution.

Andrea Santiago Portillo, Sergio Navalón Oltra, Mercedes Álvaro Rodriguez, Hermenegildo García Gómez.

Journal of Catalysis, 2018, 365, 450 - 463.

12. $\mathrm{Cu}(\mathrm{II})-\mathrm{Schiff}$ base covalently anchored to $\mathrm{MIL}-125(\mathrm{Ti})-\mathrm{NH}_{2}$ as heterogeneous catalyst for oxidation reactions.

Andrea Santiago Portillo, Saba Daliran, Sergio Navalón Oltra, Ali Reza Oveisi, Mercedes Álvaro Rodriguez, Ramin Ghorbani Vaghei, Davood Azarifar, Hermenegildo García Gómez.

Journal of Colloid and Interfaces Science, 2018, 532, 700 - 710.

13. Ruthenium(II) Tris (2,2'-bipyridyl) Complex incorporated in UiO-67 as Photoredox Catalyst.

Andrea Santiago-Portillo, Herme G. Baldoví, Esther Carbonell, Sergio Navalón, Belén Ferrer, Mercedes Álvaro, Hermenegildo García.

Journal of Physical Chemistry C

Además, de 3 papers que se encuentran bajo revisión

14. Highly conductive nanostructured PEDOT polymer confined into the mesoporous MIL-100(Fe).

Andrea Santiago Portillo, Pablo Salcedo Abraira, Pedro Atienzar, Pierre Bordet, Fabrice Salles, Nathalie Guillou, Erik Elkaim, Hermenegildo García, Sergio Navalón, Patricia Horcajada

Journal of Materials Chemistry C

15. Long-term photostability in Metal-Organic Frameworks

Diego Mateo, Andrea Santiago Portillo, Josep Albero, Sergio Navalón, Mercedes Álvaro, Hermenegildo García

Angewandte Chemie

16. Engineering UiO-66 Metal Organic Framework for Heterogeneous Catalysis. Amarajothi Dhakshinamoorthy, Andrea Santiago Portillo, Abdullah M. Asiri, Hermenegildo García

ChemCatChem 
